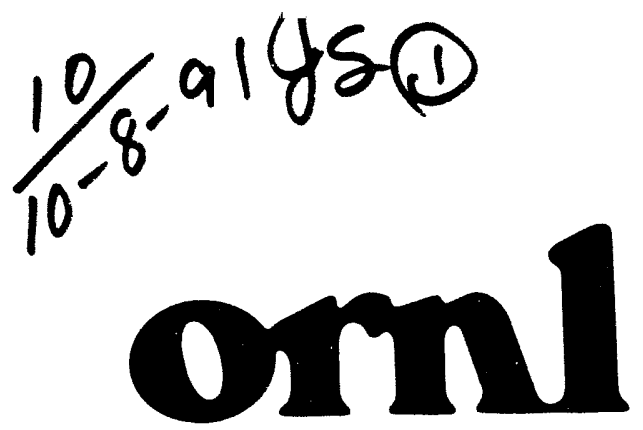

OAK RIDGE NATIONAL LABORATORY

\title{
Energy Division Annual Progress Report for Period Ending September 30, 1990
}

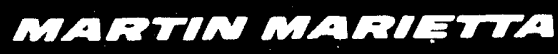


This report has been reproduced directly from the best available copy.

Available to DOE and DOE contractors from the Office of Scientific and Technical Information, P.O. Box 62, Oak Ridge, TN 37831; prices available from (615) 576-8401, FTS 626-8401.

Available to the public from the National Technical Information Service, U.S. Depertment of Commerce, 5285 Port Royal Rd., Springfield, VA 22161.

This report was prepared as an account of work sponsored by an agency of the United States Government. Neither the United States Government nor any agency thereof, nor any of their employees, makes any warranty, express or implied, or assumes any legal liability or responsibility for the accuracy, completeness, or usefulness of any information, apparatus, product, or process disclosed, or represents that its use would not infringe privately owned rights. Reference herein to any specific commercial product, process, or service by trade name, trademark, manufacturer, or otherwise, does not necessarily constitute or imply its endorsement, recommendation, or favoring by the United States Government or any agency thereof. The views and opinions of authors expressed herein do not necessarily state or reflect those of the United States Government or any agency thereof. 
ORNL- -6661

DE92 000414

\title{
ENERGY DIVISION ANNUAL PROGRESS REPORT for Period Ending September 30, 1990
}

\author{
R. B. Shelton, Director \\ M. A. Kuliasha, Associate Director \\ K. H. Zimmerman, Technical Assistant
}

M. S. Bronzini, Director, Center for Transportation Analysis

J. B. Cannon, Section Head, Integrated Analysis and Assessment Section

G. E. Courville, Section Head, Efficiency and Renewables Research Section C. R. Kerley, Section Head, Energy and Economic Analysis Section

T. J. Wilbanks, Senior Planner, Planning and Coordination

Date Published-June 1991

R. H. Selden, Editor

L. A. Daniel, Electronic Publisher

Prepared by the

OAK RIDGE NATIONAL LABORATORY

Oak Ridge, Tennessee 37831

managed by

MARTIN MARIETTA ENERGY SYSTEMS, INC.

for the

U.S. DEPARTMENT OF ENERGY

under Contract No. DE-AC05-84OR21400 


\section{LOUTILLIE W. RICKERT September 1927-April 1991}

Tillie was bom in Sanford, Florida. She received a B. S. in chemistry from the University of Kentucky at Lexington in 1948. Tillie began her career as a librarian at Michigan State University in East Lansing, Michigan. After her marriage, she worked as a librarian at Dow Chemical Company in Midland, Michigan. When her husband took a new job, the family moved to Knoxville, and Tillie worked in the family business, TRANS-CHEM, Inc., as a translator of chemical information.

In 1975, Tillie became an information center analyst at ORNL in the Information Division. She joined the Energy Division in 1984 and worked in the Integrated Analysis and Assessment Section collecting data and analyzing social impacts and institutional issues associated with various energy

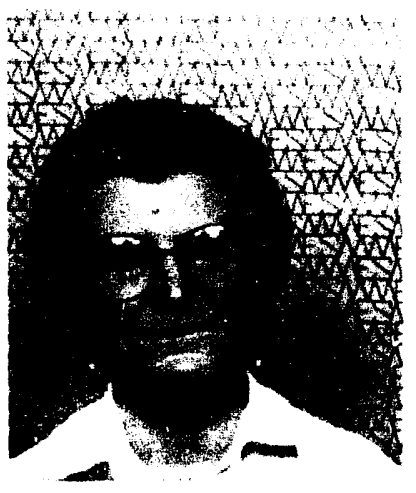
technologies. Tillie contributed in the preparation of numerous environmental assessments and environmental impact statements. Recently, Tillie worked on a project involving the relicensing of nuclear power plants in the United States. She identified and procured hundreds of documents that aided staff in the analysis of impacts of past operation of nuclear plants.

Over the years, Tillie's office became a "library of information" that she used to find ready answers to a multiplicity of reference questions. The fact that many people in the division depended upon her gift for finding the answers to complex questions is revealed by the fact that in the past year she was involved in 29 separate projects.

Tillie was well-known at the Laboratory and appreciated for her thoughtfulness, wit, and pleasant demeanor. Her wide knowledge of languages (she could translate ten languages), chemistry, and information resources coupled with her desire and ability to share these talents made her a much loved person and a highly regarded employee. She will be greatly missed.

Tillie is survived by four daughters, Barbara Rickert, Patricia Dehaven Drackett, Jane Ellis, and Maria Rickert; and two sons, Herbert and Karl Rickert. 


\section{TABLE OF CONTENTS}

Page

1. INTRODUCTION AND EXECUTIVE SUMMARY . . . . . . . . . . . . . 1-1

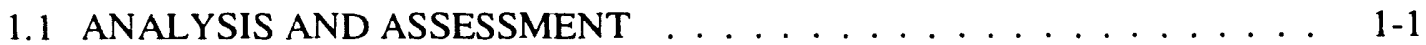

1.1.1 Energy and Resource Analysis . . . . . . . . . . . . . . . . . 1-2

1.1.2 Environmental Assessments . . . . . . . . . . . . . . . . . 1 1-4

1.1.3 Emergency Preparedness . . . . . . . . . . . . . . . . . . . . . . 1-4

1.1.4 Developing Country Analysis . . . . . . . . . . . . . . . . 1-4

1.1.5 Transportation Analysis . . . . . . . . . . . . . . . . 1-5

1.2 ENERGY CONSERVATION TECHNOLOGIES . . . . . . . . . . . 1-5

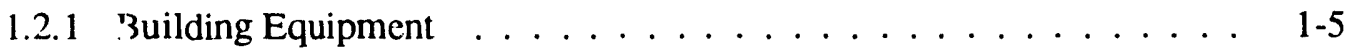

1.2 .2 Building Envelopes $\ldots \ldots \ldots \ldots$. . . . . . . . . . . . . . . . . .

1.2 .3 Existing Buildings Research . . . . . . . . . . . . . 1-6

1.2 .4 Electric Power Systems . . . . . . . . . . . . . . . . . . 1-6

1.3 MILITARY TRANSPORTATION . . . . . . . . . . . . . . . 1-6

1.3.1 Military Transportation . . . . . . . . . . . . . . . 1-6

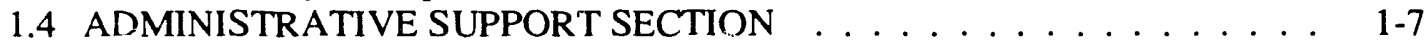

2. INTEGRATED ANAL YSIS AND ASSESSMENT SECTION

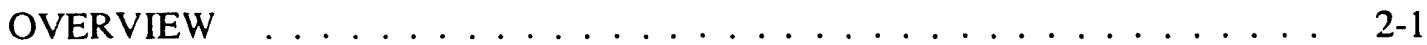

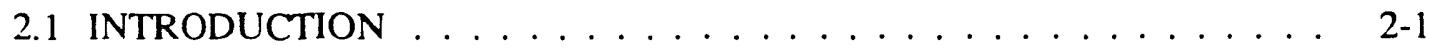

2.2 NEPA PROJECTS . . . . . . . . . . . . . . . . . . . 2-1

2.2.1 Generic Environmental Impact Statement for the Nuclear

Regulatory Commissions . . . . . . . . . . . . . . . . 2-3

2.3 EMERGENCY PREPAREDNESS . . . . . . . . . . . . . . 2-6

2.3.1 Chemical Stockpile Emergency Preparedness Program . . . . . . . . . 2-6

2.3.1.1 Computer-Based Decision Support Systems . . . . . . . . . 2-6

2.3.1.2 Transferring Results of Technology . . . . . . . . . . . 2-6

2.3.1.3 Emergency Upgrades at CSEPP Sites . . . . . . . . . . 2-6

2.4 APPLIED PHYSICAL SCIENCES . . . . . . . . . . . . . . . . 2-8

2.4.1 Performance Assessment for Solid Waste Storage Area 6

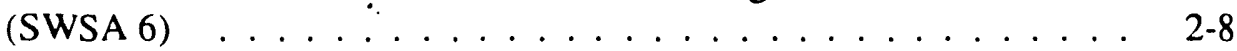

2.4.2 Air Quality Impacts of Low-Level Flying Operations . . . . . . . 2 2-8

2.5 TECHNOLOGY AND SOCIAL SYSTEMS . . . . . . . . . . . . . 2-14

2.6 ENERGY AND ENVIRONMENTAL ANALYSES . . . . . . . . . . . . 2-15

2.6.1 Effects of Clean Air Legislation on Electric Utilities . . . . . . . . . . 2-15

2.6.2 Extemal Costs of Fuel Cycles . . . . . . . . . . . . . . . . . . 2-16

2.7 REFERENCES . . . . . . . . . . . . . . . . . . . 2-16

3. ENERGY AND ECONOMIC ANALYSIS SECTION OVERVIEW . . . . . . . 3-1

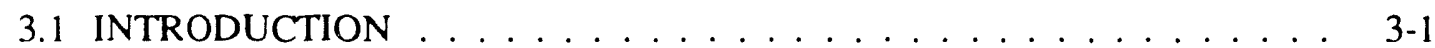

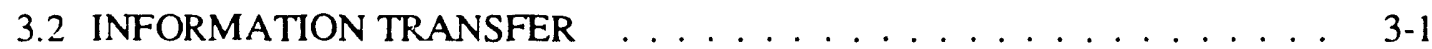

3.3 RESEARCH PROGRAM . . . . . . . . . . . . . . . . . . . 3 3-4

3.3.1 Productivity and Energy Security . . . . . . . . . . . . . . . 3-4

3.3.2 Energy and Environment . . . . . . . . . . . . . . . . . . 3-5

3.3 .3 Modeling and Technology . . . . . . . . . . . . . . 3- 3-10

3.3.4 Emergency Management and Risk Acceptance . . . . . . . . . . . . . 3-12

3.4 RESEARCH UTILIZATION . . . . . . . . . . . . . . . . . . . 3-13 
4. CENTER FOR TRANSPORTATION ANALYSIS OVERVIEW . . . . . . . . . 4-1

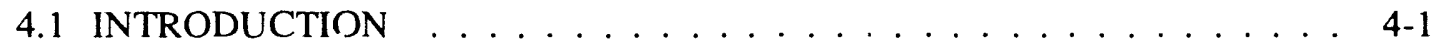

4.2 POLICY ANALYSIS AND ENERGY CONSERVATION . . . . . . . . . . 4-1

4.2.1 Evaluating Strategies for Transportation Energy Conservation . . . . . 4-1

4.2.2 Transportation Planning . . . . . . . . . . . . . . . . . 4-3

4.2.3 Navy Mobility Fucls Forecasting System . . . . . . . . . . . . 4 4-3

4.2.4 Evacuation Planning and Analysis . . . . . . . . . . . . . 4 4-4

4.3 ENVIRONMENT . . . . . . . . . . . . . . . . . . 4 4 4 . .

4.3.1 Transportation and Global Warming . . . . . . . . . . . . . 4-5

4.3.2 Linking Highway System Development to the Ecological

Impacts of Deforestation . . . . . . . . . . . . . . . . 4-5

4.3.3 Transportation and Clean-Up of Hazardous Waste . . . . . . . . 4-5

4.4 METHODS AND DATA . . . . . . . . . . . . . . . . . . . 4-6

4.4.1 National Transportation and Energy Related Databases . . . . . . . . 4-6

4.4.1.1 Transportation Energy Data Book . . . . . . . . . . . . . . 4-6

4.4.1.2 National Multimodal Network Databases and Their

Applications ................. . . 4-6

4.4.2 Traffic and Transportation Operations Research . . . . . . . . . . . 4-8

4.4.2.1 Intra-Urban and Corridor Traffic Analyses . . . . . . . . . . . 4-8

4.4.2.2 Planning and Scheduling Algorithms . . . . . . . . . . 4-8

4.4 .3 Artificial Intelligence . . . . . . . . . . . . . . . . . 4 4-8

4.4.3.1 Communications Alarm Processor (CAP) _ . . . . . . . . . 4-8

4.5 PLANNING AND SCHEDULING SYSTEMS . . . . . . . . . . . . . . . 4-11

4.5.1 Flow and Analysis System for Transcom (FAST) . . . . . . . . . . 4-11

4.5.2 World-Wide Household Goods Shipment Information

System for Transportation Modemization (WHIST-MOD) . . . . . . . 4-12

4.6 INTERACTIONS WITH THE WIDER SCIENTIFIC COMMUNITY . . . . . 4-12

4.6.1 Advanced Computing for the Social Sciences Conference . . . . . . . 4-12

4.6.2 ADANS - Generated Activities on Improved Vehicle Routing and Scheduling Techniques . . . . . . . . . . . . . 4-12

4.7 REFERENCES . . . . . . . . . . . . . . . . . . . . . 4-12

5. EFFICIENCY AND RENEWABLES RESEARCH SECTION OVERVIEW . . . . 5-1

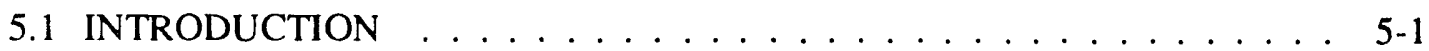

5.2 BUILDING EQUIPMENT RESEARCH PROGRAM . . . . . . . . . 5 5-1

5.2.1 Thermally Activated Heat Pumps . . . . . . . . . . . . . . 5-1

5.2 .2 Novel Cycles . . . . . . . . . . . . . . . . . . . . . 5-3

5.2 .3 Refrigeration Systems . . . . . . . . . . . . . . . . 5 5-3

5.2.4 Work for Others for the BER Program . . . . . . . . . . . . . . 5-8

5.2.4.1 Advanced Surfaces for Vertical-Tube Absorbers . . . . . . . . . 5-8

5.2.4.2 EPRI CFC Alternatives for Centrifugal Chillers . . . . . . . 5-8

5.3 ENVIRONMENTAL CONTROL TECHNOLOGY . . . . . . . . . . . . . 5-8

5.3.1 Work for Others for Environmental Control Technology . . . . . . . . 5-9

5.4 BUILDING THERMAL ENVELOPE SYSTEMS AND MATERIALS . . . . 5-9

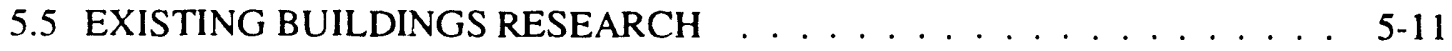

5.6 ENERGY PROGRAM PLANNING AND EVALUATION . . . . . . . . 5-13

5.7 INTEGRA'TED RESOURCE PLANNING FOR ELECTRIC UTILITIES . . . 5-15

5.7.1 Work for Others for Integrated Resource Planning for Electric

Utilities . . . . . . . . . . . . . . . . . . . . . 5-17

5.8 TECHNOLOGY TRANSFER AND COMMUNITY SYSTEMS $\ldots \ldots \ldots$. . 5-17

5.9 POWER SYSTEMS TECHNOLOGY . . . . . . . . . . . . . . . $5-17$

5.9 .1 Power Systems Transients . . . . . . . . . . . . . . . . 5-18

5.9.2 Materials and Components . . . . . . . . . . . . . . . . . . 5-19

5.9 .3 Energy for Developing Countries . . . . . . . . . . . . . . . . . . . . 5-19

5.9.4 Work for Others for Power Systems Technology . . . . . . . . . 5-21 
6. PLANN!NG AND COORDINATION OVERVIEW $\ldots \ldots \ldots \ldots \ldots$. . . . . .

6.1 INTRODUCTION ...................... 6 . . .

6.2 DEVELOPING COUNTRY PROGRAMS . . . . . . . . . . . . . 6- 6-1

6.2.1 Energy Strategy Development . . . . . . . . . . . . . . . . . 6-1

6.2.2 Energy Efficiency Improvement . . . . . . . . . . . . . . . . . 6-1

6.2 .3 Environmental Management . . . . . . . . . . . . . . 6 6-3

6.2.3.1 A.I.D. Climate Change Study . . . . . . . . . . . . . . 6 6-3

6.2 .3 .2 Africa $\mathrm{CO}_{2} \ldots \ldots \ldots \ldots \ldots$. . . . . . . . . . . . . . . .

6.2.3.3 Initiatives in Developing Countries . . . . . . . . . . . . . . 6-4

6.2.4 Renewable Energy Options and Rural Area Energy Systems . . . . . . 6-5

6.2 .5 Energy R\&D Applications . . . . . . . . . . . . . . . . . . . 6-5

6.2.6 Energy Technology Transfer . . . . . . . . . . . . . . . 6 6-5

6.3 OTHER ACTIVITIES . . . . . . . . . . . . . . . . 6-6

6.4 REFERENCES . . . . . . . . . . . . . . . . . . . . 6-6

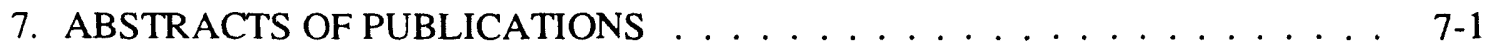

7.1 ABSTRACTS OF INTEGRATED ANALYSIS AND

ASSESSMENT SECTION . . . . . . . . . . . . . . . . 7-1

7.2 ABSTRACTS OF ENERGY AND ECONOMIC ANALYSIS

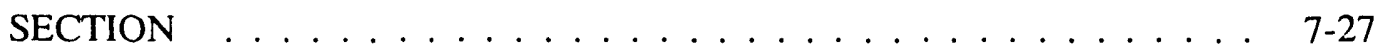

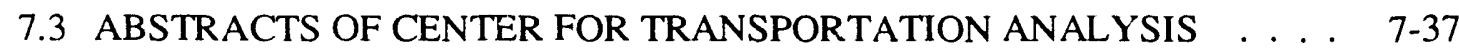

7.4 ABSTRACTS OF EFFICIENCY AND RENEWABLES RESEARCH

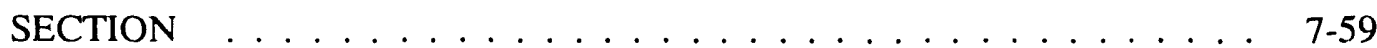

8. PUBLICATIONS AND PROFESSIONAL ACTIVITIES . . . . . . . . . . . . 8-1

8.1 ENERGY DI $Y I S I O N$ ADVISORY COMMITTEE . . . . . . . . . . . . . 8-1

8.2 ENERGY DIVISION PERSONNEL BY DISCIPLINE . . . . . . . . . . . 8-2

8.3 ENERGY DIVISION PROFESSIONAL HONORS AND AWARDS

FY $1990 \ldots \ldots \ldots \ldots \ldots \ldots . \ldots \ldots \ldots$. . . . . . . . . . . . . . . . .

8.4 ENERGY DIVISION PROFESSIONAL ACTIVITIES FY $1990 \ldots \ldots$

8.5 ENERGY DIVISION PUBLICATIONS FY $1990 \ldots \ldots \ldots$

8.6 ENVIRONMENTAL ASSESSMENTS AND ENVIRONMENTAL IMPACT STATEMENTS . . . . . . . . . . . . . . . . . 8 8-25

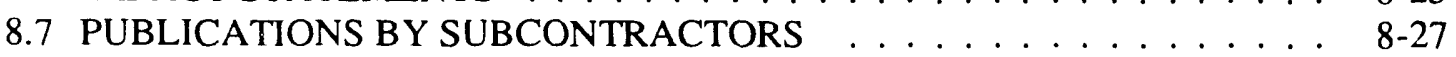

8.8 ENERGY DIVISION CONSULTANTS AND SUBCONTRACTORS . . . $\quad 8-30$

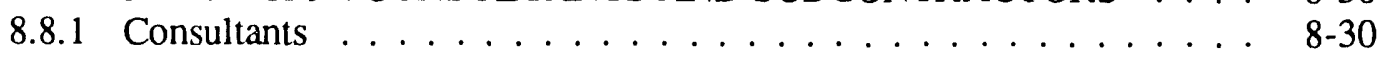

8.8.2 Subcontractors by Company . . . . . . . . . . . . . . . 8-31

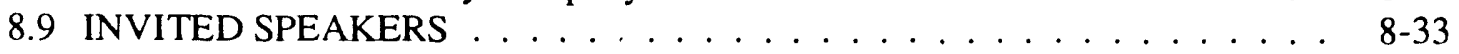

8.10 WORKSHOPS AND SYMPOSIA ORGANIZED BY ENERGY

DIVISION STAFF . . . . . . . . . . . . . . . . . . . . 8-36

8.11 ENERGY DIVISION PATENT INITORMATION . . . . . . . . . . . . 8-37

8.12 ENERGY DIVISION SPONSORS, EXPENDITURES, AND
COMMITMENTS OF SCIENTIFIC STAFF FOR FY $1990 \ldots \ldots$. . . . . . . 8 8-38

ORGANIZATIONAL CHART

INTERNAL DISTRIBUTION

EXTERNAL DISTRIBUTION 


\title{
ACRONYMS
}

\author{
A.I.D. \\ ADANS \\ ADSS \\ AEO \\ AFB \\ AFGD \\ AHAM \\ ANAD \\ APG \\ AREFG \\ ARNG \\ ASHRAE \\ ASTM \\ A.TC \\ BER \\ BMW \\ BOM \\ BTESM \\ Btu \\ CADDET \\ CAFE \\ CAP \\ CARES \\ CCTDP \\ CCTP \\ $\mathrm{CF}$ \\ CFC \\ CFR \\ CHP \\ $\mathrm{CNG}$ \\ $\mathrm{CO}_{2}$ \\ CONUS \\ CORA \\ CRADA \\ CSDP \\ CSEPP \\ dBA \\ DELTA \\ DIS-SPR \\ DOD \\ DOE \\ DOT \\ DSM \\ DW \\ EA \\ EEAS \\ EIA \\ EIS \\ EMP \\ EPA \\ EPPE \\ EPRI \\ ERIP \\ FAST \\ FEMA \\ Agency for International Development \\ Airlift Analysis Deployment Sysiem \\ automated decision-support system \\ Annual Energy Outlook \\ Air Force Base \\ advanced flue gas desulfurization \\ Association of Home Appliance Manufacturers \\ Anniston Army Depot \\ Aberdeen Proving Ground \\ air refueling group \\ Army National Guard \\ American Society of Heating, Refrigerating, and Air Conditioning Engineers \\ American Society for Testing and Materials \\ air training command \\ Building Equipment Research \\ bombardment wing \\ U.S. Bureau of Mines \\ Building Thermal Envelope Systems and Materials \\ British thermal unit \\ Center for the Analysis and Dissemination of Demonstrated Technologies \\ Corporate Average Fuel Economy \\ Communications Alarm Processor \\ Central American Rural Electrification Support \\ Clean Coal Technology Demonstration Program \\ Clean Coal Technology Program \\ Citizens' Forum \\ chlorofluorocarbon \\ Code of Federal Regulations \\ chemical heat pump \\ Canadian Natural Gas \\ carbon dioxide \\ continental United States \\ Cost of Remedial Action \\ Cooperative Research and Development Agreement \\ Chemical Stockpile Disposal Program \\ Chemical Stockpile Emergency Preparedness Program \\ decibels on an A-weighted scale \\ Dynamic Ecological Land Tenure Analysis \\ Interagency Working Group Midcap Result model \\ U.S. Department of Defense \\ U.S. Department of Energy \\ U.S. Department of Transportation \\ demand-side management \\ defense waste \\ environmental assessment \\ Energy and Economic Analysis Section \\ Energy Information Administration \\ environmental impact statement \\ electromagnetic pulse \\ U.S. Environmental Protection Agency \\ Energy Program Planning and Evaluation \\ Electric Power Research Institute \\ Energy-Related Inventions Program \\ Flow and Analysis System for USTRANSCOM \\ Federal Emergency Management Agency
}




\begin{tabular}{|c|c|}
\hline FERC & Federal Energy Regulatory Commission \\
\hline FHW A & Federal Highway Administration \\
\hline FPEIS & final programmatic environmental in pact statement \\
\hline FRERP & Federal Radiological Emergency Response Plan \\
\hline FTW & flying training wing \\
\hline FY & fiscal year \\
\hline GDT & geophysical diffraction tomography \\
\hline GEEI & Global Energy Efficiency Initiative \\
\hline GEIS & Generic Environmental Impact Statement \\
\hline GRI & Gas Research Institute \\
\hline HAZMAT & hazardous material \\
\hline $\mathrm{HCFC}$ & hydrochlorofluorocarbon \\
\hline HMIMS & Hazardous Materials Incident Management System \\
\hline $\mathrm{HX}$ & heat exchanger \\
\hline IAAS & Integrated Analysis and Assessment Section \\
\hline IC & internal combustion \\
\hline IRM & information resource management \\
\hline IRP & integrated resource planning \\
\hline JACADS & Johnston Atoll Chemical Agent Disposal System \\
\hline LBL & Lawrence Berkeley Laboratory \\
\hline LEPC & local emergency planning committec \\
\hline LKP & Lee-Kesler-Plöcker \\
\hline LSCS & Large Scale Climate Simulator \\
\hline MAC & Military Airlift Command \\
\hline MAILS & Multiple-Aircraft Instantaneous Line Source \\
\hline MHD & magnetohydrodynamic \\
\hline MLE & maximum likelihood estimator \\
\hline MOA & military operations areas \\
\hline MOS & military occupational specialist \\
\hline MSW & municipal solid waste \\
\hline MTI & Mechanical Technology, Inc. \\
\hline MTMC & Military Traffic Management Command \\
\hline MTR & military training routes \\
\hline NAAQS & National Ambient Air Quality Standards \\
\hline NARM & nonazeotropic refrigerated mixture \\
\hline NEPA & National Environmental Policy Act of 1969 \\
\hline NES & National Energy Strategy \\
\hline NIIS/FDAM & $\begin{array}{l}\text { ational Infrastructure Information System Facility Damage } \\
\text { Assessment Module }\end{array}$ \\
\hline $\mathrm{NO}_{x}$ & nitrogen oxides \\
\hline NRC & Nuclear Regulatory Commission \\
\hline NRECA & National Rural Electric Cooperative Association \\
\hline NSF & National Science Foundation \\
\hline NTACS & Nationwide Truck Activities anu Commodity Survey \\
\hline NTP & National Transportation Policy \\
\hline NTU & number of transfer units \\
\hline OBT & Office of Building Technologies \\
\hline ORNL & Oak Ridge National Laboratory \\
\hline ORR & Oak Ridge Reservation \\
\hline PACER & Program for the Acceleration of Commerical Energy Rescarch \\
\hline PBA & Pine Bluff Arsenal \\
\hline PEIS & programmatic environmental impact statement \\
\hline PGM & Precision Guided Munition \\
\hline PSD & Prevention of Significant Deterioration Arcas \\
\hline$R \& D$ & research and development \\
\hline i & restricted areas \\
\hline RCCPDS & Reserve Components Common Personnel Data System \\
\hline REAT & Renewable Energy Applications and Training \\
\hline RF & refrigerator/freezer \\
\hline RFF & Resources for the Future \\
\hline
\end{tabular}


RFP

RPPR

RTI

RTMAS

SAIL

SAILS

SEH

SEIS

$\mathrm{SO}_{2}$

SPR

SRC

SSD

SSEIS

SWAT

SWMU

SWSA 6

TIUS

USAF

USTRANSCOM

UT

vs

WAP

WAPA request for proposal

Refined Petroleum Product Reserve

Research Triangle Institute

Real-Time Traffic Monitoring and Analysis System

Scheduling Algorithm to Improve Lift

Single-Aircraft Instantaneous Line Source

Safety, Environment, and Health

supplemental environmental impact statement

sulfur dioxide

Strategic Petroleum Reserve

Stirling refrigeration cycle

superconductive magnetic energy storage device

second supplemental environmental impact statement short wave adaptive technology

solid waste management units

Solid Waste Storage Area 6

Truck Inventory and Use Survey

U.S. Air Force

U.S. Transportation Command

The University of Tennessee

variable speed

Weatherization Assistance Program

Virgin Islands Water and Power Authority 


\section{ABSTRACT}

The Energy Division is one of 17 research divisions at Oak Ridge National Laboratory. The goals and accomplishments of the Energy Division are described in this annual progress report for FY 1990. The Energy Division is a multidisciplinary research organization committed to (1) increasing the knowledge and understanding of how societies make choices in energy use; (2) improving society's understanding of the environmental, social, and economic implications of technological change; (3) developing and transferring energy efficient technologies; and (4) developing improved transportation planning and policy.

The division's total expenditures in FY 1990 were $\$ 42.5$ milli $\mathrm{n}$. The work is supported by the U.S. Department of Energy, U.S. Department of Defense, many other federal agencies, and some private organizations. Disciplines of the 129 staff members include engineering, social sciences, physical and life sciences, and mathematics and statistics.

The Energy Division's programmatic activities focus on three major areas: (1) analysis and assessment, (2) energy conservation technologies, and (3) military transportation systems. Analysis and assessment activities cover energy and resource analysis, the prepazation of environmental assessments and impact statements, research on waste management, analysis of emergency preparedness for natural and technological disasters, analysis of the energy and environmental needs of developing countries, technology transfer, and analysis of civilian transportation. Energy conservation technologies include building equipment (thermally activated heat pumps, chemical heat pumps, refrigeration systems, novel cycles), building envelopes (walls, foundations, roofs, attics, and materials), retrofits for existing buildings, and electric power systems. Military transportation systems concentrate on research for sponsors within the U.S. military on improving the efficiency of military deployment, scheduling, and transportation coordination.

Much of the information produced from the division's research is valuable to other organizations as well as to the sponsors. Dissemination of this information was accomplished by the staff's being involved in professional and trade organizations; holding workshops; engaging private sector firms and universities in the research; interfacing with statie and local govermments; presenting the work at conferences; and publishing the results of the research in joumals, reports, and conference proceedings. 


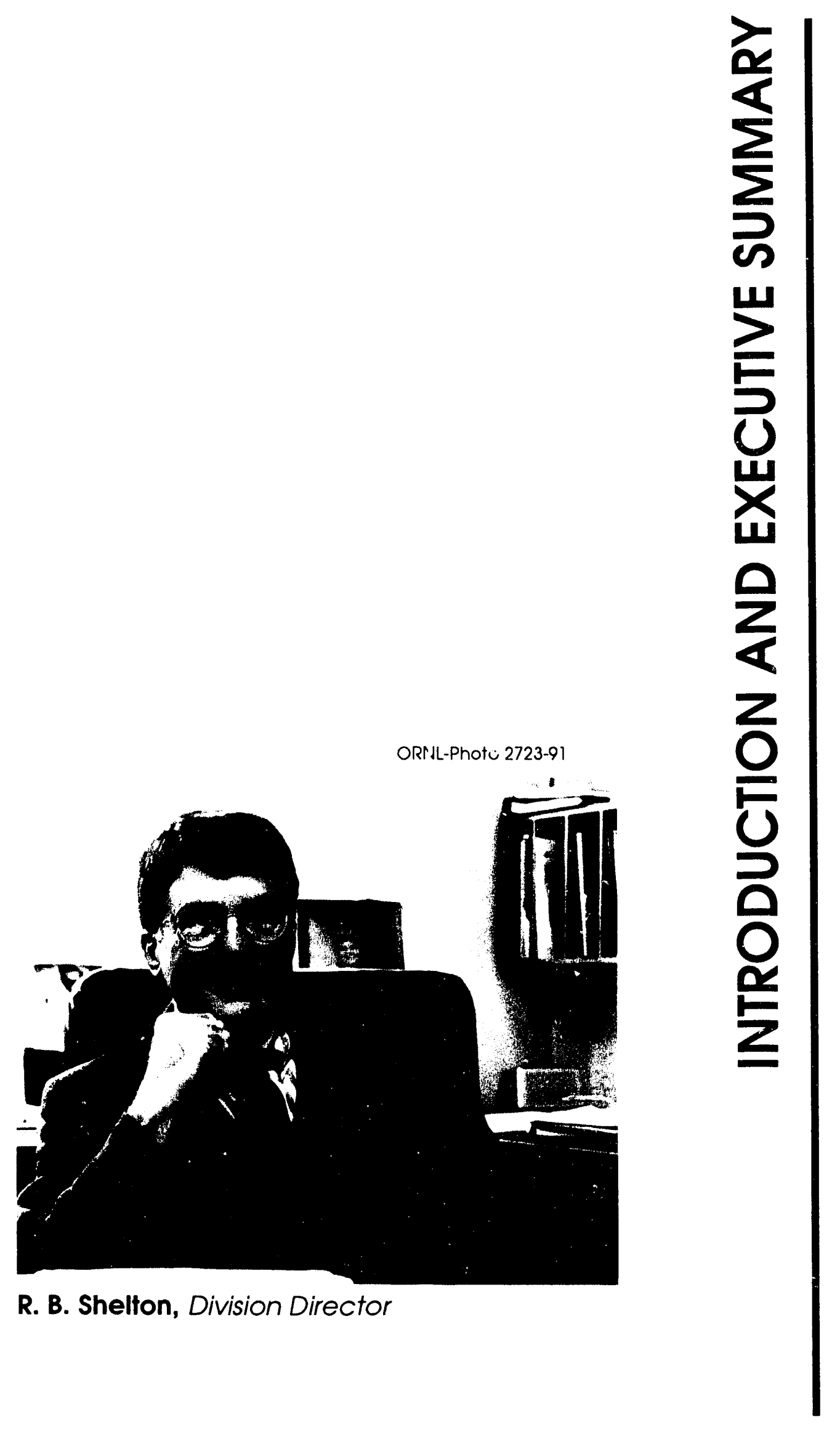




\section{INTRODUCTION AND EXECUTIVE SUMMARY}

Thc Energy Division is one of 17 research divisions at Oak Ridge National Laboratory (ORNL). The division was established in 1974 to bring together work on environmental, technological, and regional assessments related to energy development and to perform research on improving the efficiency of energy use and conversion. The Energy Division is one of the most diverse divisions in terms of its sponsorship, research activities, and range of staff expertise. This diversity is reflected in the division's FY 1990 activities, summarized in the following pages.

A wide range of researich and expertise is necessary to fulfill the Energy Division's four major goals.

- increasing the knowledge and understanding of how societies make choices in energy use;

- improving society's understanding of the envirunmental, social, and economic implications of techrological change;

- developing and transterring energy efficient technologies; and

- developing improved transportation policy and planning.

To help give strategic shape and direction to the myriad of research activities of the Energy Division, the division conceives of its work as apnertaining to one of three major themes. The first theme. analysis and assessment, includes such i. sues as energy and resource analysis, environmental assessments. emergency preparedness, analysis of developing countries, technology transfer, and analysis of civilian transportation. The second theme, energy conservation technologies, embraces conservation sssues involving building equipment, building envelopes, electric power systems and existing buildings. The third theme includes extensive work on research and development of planning models for military transportation systems.

The total Energy Division expenditures in FY 1990 were \$42.5 million (see Fig. 1.1). The U. S. Department of Energy (DOE) and the Department of Defense each represented slightly less than half of the division's expenditures with the remaining funding from other government agencies and some private industries. In terms of expenditures by research area (see Fig. 1.2), analysis and assessment activities accounted for almost half of the budget, with the remaining portion split almost evenly between energy conservation technologies and military transportation. There were

187.5 full-time-equivalent (FTE) staff in the division and 134 guests working onl-site during FY 1990. The staff consisted of 129 technical personnel (see Fig. 1.3) and 58.5 administrative and technical support personnel. About one-third of the technical staff are enginecrs, one-third are social scientists, and the remaining are physical and life scientists and data systems personnel. Approximately $90 \%$ of the technical staff have advanced degrees (see Fig. 1.4). Over half of the staff have doctorate degrees, over one-third have masters degrees, and the remaining $10 \%$ have bachelors degrees.

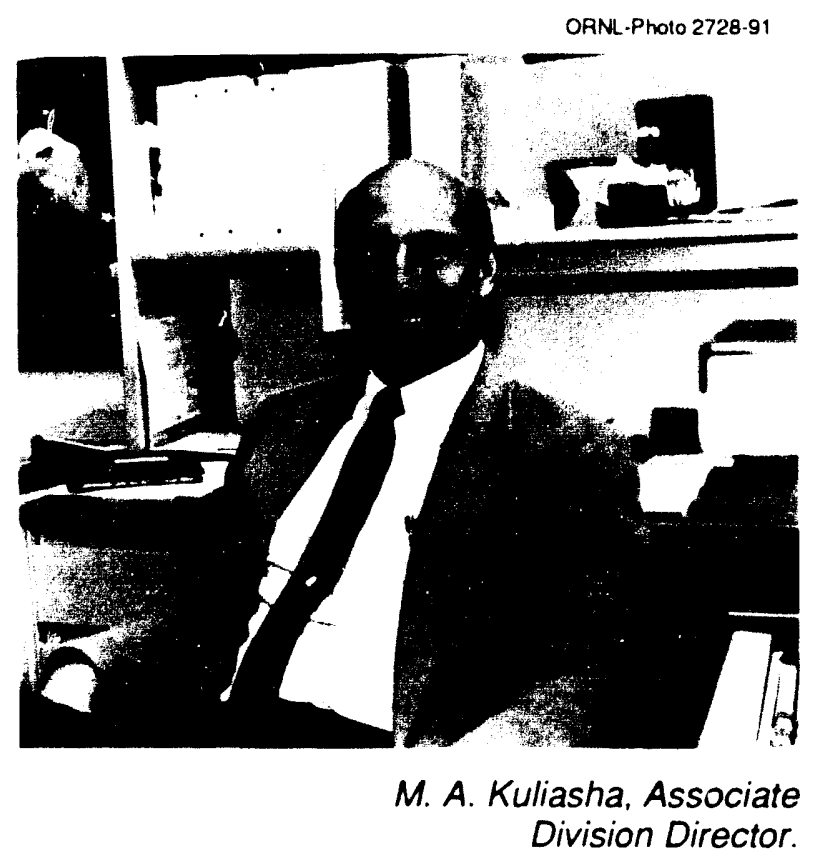

\subsection{ANALYSIS AND ASSESSMENT}

Analysis and assessment activities include (1) energy and resource analysis. (2) environmental assessments. (3) emergency preparedness, (4) deve!oping country analysis, and (5) transportation analysis. Energy and resource analysis is found in every section of the division and covers a wide 


\section{Energy Division \\ Total \$42.5 Million}

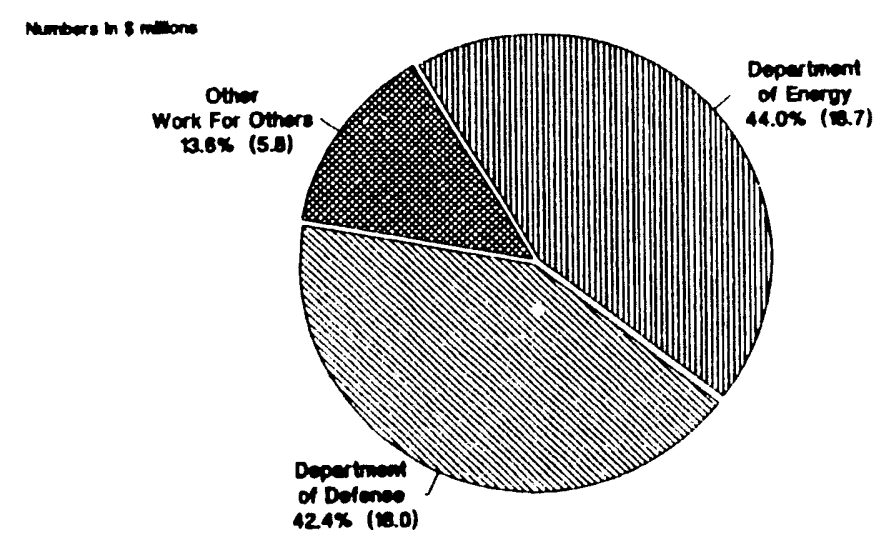

Fig. 1.1. Expenditures during FY 1990 by sponsor. runge of topics from energy security to utility resource planning. Work on environmental assessments includes (1) preparing environmental assessments and environmental impact statements (EISs) for various sponsors to comply with the National Environmental Policy Act of 1969 and (2) research on waste management. Emergency preparedness research is concerned with improving society's ability to cope with natural and technological disasters. Developing country analysis is directed toward their energy and environmental needs. Transportation analysis covers civilian sector research on the development of data and analytical methods useful to conduct policy

studies for DOE and other agencies concemed with transportation. Some highlights from the year's work are presented in the following sections.

\subsubsection{Energy and Resource Analysis}

Researchers developed a PC-based model (CHESHIRE) for the Bureau of Mines to estimate changes in emissions, technology choices, and the costs of electricity as utilities respond to legislation that limits emissions, prices, or mixes in fuels. The effects of five Clean Air bills on costs for 11 major suppliers of electricity to aluminum smelters were examined (see Sect. 2.6.1).

Division staff studied the issue of whether part of the U.S. petroleum stockpile should be stored regionally. as a refined petroleum product, rather than centrally stored as crude oil. The study identified two events for which a refined petroleum product reserve may be suited: product market

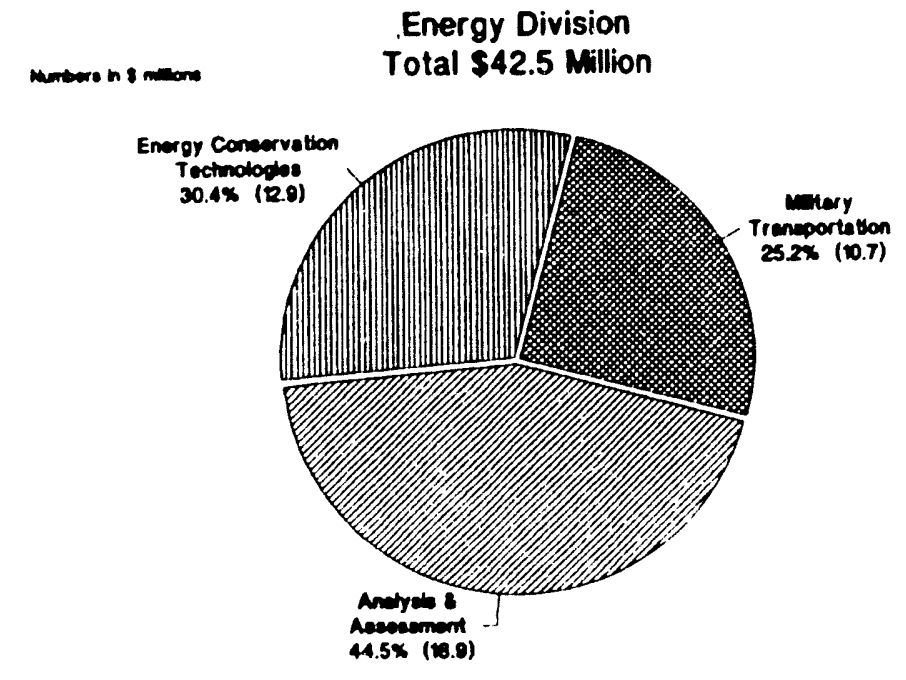

Fig. 1.2. Expenditures during FY 1990 by research area. disruptions such as extremely cold winters or major refinery accidents; or crude oil supply disruptions accompanied by significant lags and constraints in the crude oil refining and distribution system (sec Sect. 3.3.1).

A team led by a division staff member examined advanced energy management concepts through life cycle costing analysis and cost-benefit techniques to find energy technology applications that are superior to existing operations on two Air Force bases. Results indicated that clean coal technologies can meet environmental standards and produce an economic benefit to cost ratio of 1.10 to 1.5 when compared to existing operations (see Sect. 3.3.1). 
Division staff conducted a study of the $\mathrm{CO}_{2}$ emissions from the production of ethanol from com. They concluded that ethanol produced from corn results in $\mathrm{CO}_{2}$ emissions that are $79 \%$ of those from an equivalent amount of gasoline (see Sect. 3.3.2). Further study on emissions led to research performed on the nature of auction mechanisms for air emission permits. The results suggested that mandatory auctions improved efficiency relative to a no-trade alternative (see Sect. 3.3.2 and Sect. 3 highlights for "Auction Mechanisms for Air Emission Permits").

In a time when great interest is being shown in and emphasis placed on conservation and recycling of resources, division researchers used an econometric model to forecast the possible amount of energy derived from biomass in the United States. The projection showed a potential increase in biomass from 3.21 quads in 1990 to 13.56 quads in the year 2030 (see Sect. 3 highlights for "Econometric Model for Forecasting Biomass Energy").

A researcher conducted an assessment of the economic feasibility of integrating super conductive magnetic energy storage devices with conventional electrical substations along electric power rail transit lines. Interim results showed that the benefiu/cost ratios were less than 1.0 for all of the existing systems analyzed (see Sect. 3.3.3).

The first Advanced Users

Workshop for the Regional Recruiting Potential Model was held in July 1990. The model was developed to help the Army National Guard assess the potential supportability of units placed in specific geographic locations (see

Energy Division Total 129.0 FTE

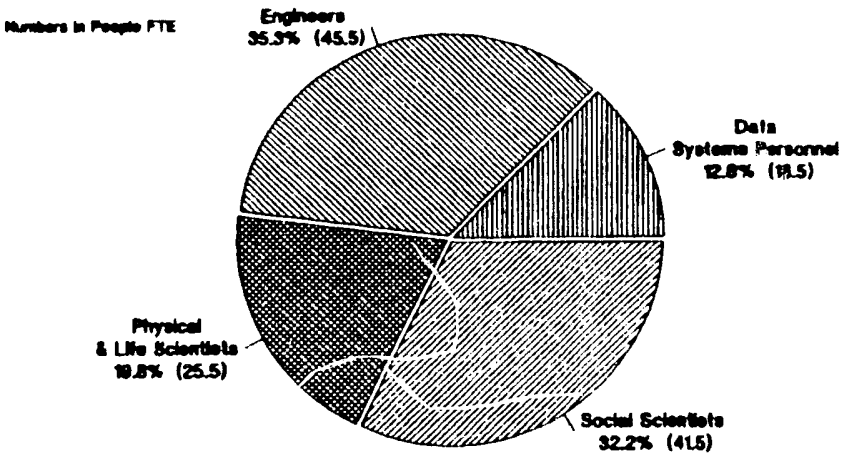

Fig. 1.3. Technical staff for FY 1990.

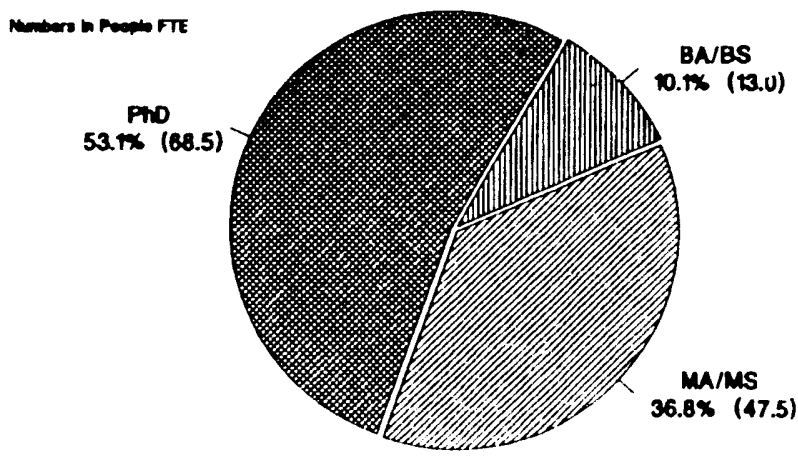

Fig. 1.4. Technical staff for FY 1990. Sect. 3.3.3).

Further research for the military involved the Navy Mobility Fuels Forecasting System, which forecasts the availability. cost, and quality of military and civilian fuels for diffe ent peacetime and wartime scenarios. The System indicated that a severe military disruption could cause substantial degradations in the quality of Navy diesel fuel produced in the Pacific basin and in southern Europe (see Sect. 4.2.3).

During FY 1990 a 3-year. multimillion dollar evaluation of the impact and potential of DOE's low-income Weatherization Assistance Program (WAP) was initiated. The evaluation plan calls for assessing the energy savings. cost effectiveness, and nonenergy impacts of WAP (see Sect. 5.5). 
Researchers collected and reviewed long-term resource plans from about 30 utilities throughout the country. They also interviewed staff from some of these utilities and conducted site visits of others. On the basis of these reviews. guidelines for the preparation and review of plans were developed (see Sect. 5.7).

\subsubsection{Environmental Assessments}

Researchers are preparing a generic environmental impact statement (GEIS) for license renewal of nuclear power plants to support a rulemaking to change the Nuclear Regulatory Commission (NRC) environmental protection rule in 10 CFR 51 regarding requirements for relicensing nuclear power plants. To date, the analyses performed for the GEIS have identified and evaluated 103 issues related to license renewal of nuclear power plants under NRC's environmental protection regulations (see Sect. 2.2.1).

Staff completed a draft supplemental EIS for the United States Antarctic Program. They concluded that under the proposed alternative (complete the Safety, Environment, and Health Initiative and streamline U. S. Antarctic Program activities) the National Science Foundation would be able to continue its research activities at current or increased levels and minimize risks to the environment (see Sect. 2 highlights for "U.S. Antarctic Research Program").

Over the past few years, ORNL has developed and refined a quantitative technique for high-resolution subsurface imaging known as geophysical diffraction tomography (GDT). In a recent development, the maximum likelihood estimator and GDT formalisms have been integrated into a new procedure. A data acquisition system has been designed and individual system components fabricated and bench tested for this new procedure (see Sect. 2 highlights for "Geophysical Diffraction Tomography").

Researchers developed a performance assessment for current and future operations in Solid Waste Storage Area 6 (SWSA 6) to demonstrate compliance with DOE Order 5820.2A. The results of the analyses indicated that SWSA 6 is not in compliance with the performance objectives of DOE Order 5820.2A (see Sect. 2.4.1).

Division staff developed computer-based tools for assessing the air quality impacts of low-level flying operations. The stidy showed that air pollutant emissions from aircraft in low-altitude airspaces are a potential concern only when the airspace overlies or is very near a Prevention of Significant Deterioration Class I area (see Sect. 2.4.2).

\subsubsection{Emergency Preparedness}

A simulation model was developed to assess alternative protection actions under different accident scenarios of releasing chemical agents. Thousands of scenarios were generated and evaluated using the model (see Sect. 2 highlights for "Emergency Preparedness and Simulation Model for Assessment of Alternative Protection Areas").

A User Training Workshop for the Facility Damage Assessment Module of the National Infrastructure Information System was held in September 1990. This system is a component of a regional input-output model that enables planners at the Federal Emergency Management Agency to evaluate the impacts of a variety of disasters on regional and national economies (see Sect. 3.3.4).

\subsubsection{Developing Country Analysis}

Division staff collaborated with others to organize a Global Energy Efficiency Initiative (GEEI), a major program intended to identify and promote energy efficiency projects in developing countries. Region-specific forecasts indicated that a realistic, implementable program to promote world- vide efficiency could be expected to reduce global energy consumption by $25 \%$ without reducing economic development (see Sect. 6 highlights for "Global Energy Efficiency Initiative"). A related achievement consisted of an analysis in Costa Rica of the potential for power sector efficiency improvements that concluded that Costa Rica is approaching the efficiency standards of industrialized countries in some parts of its power sector (see Sect. 6 highlights for "Power Sector Efficiency Improvements in Costa Rica").

Activities related to environmental management in developing countries expanded to include a major effort to assess relationships hetween the programs of A.I.D. related to the global climate change issue, an assessment of the roles of Africa in the overall picture of global environmental change, and a new relationship with A.I.D./Guatemala to provide technical assistance with a variety of environmental projects (see Sect. 6.2.3). 


\subsubsection{Transportation Analysis}

Researchers assessed the importance of the Corporate Average Fuel Economy (CAFE) standards for improving fuel mileage performance of new automobiles. An analysis indicated that CAFE standards were more effective tha' higher fuel prices in influencing carmaker decisions to produce more fuel efficient automobiles (sec Sect. 4 highlights for "Energy Policy Studies").

A statistical relationship was developed between the demand for travel and the effects of restricted highway supply upon this demand, within cities of different sizes. The procedure was linked to Federal Highway Administration software to project future lane mile expenditures under a variety of traffic growth scenarios (see Sect. 4.2.2).

The first stage of the Dynamic Ecological-Land Tenure Analysis (DELTA) modeling system was developed. DELTA integrates land development and ecological impact models to estimate patterns and rates of deforestation under different immigration policies, land tenure practices, and road development scenarios (see Sect. 4.3.2).

The Transportation Energy Data Book reached an external distribution of almost 1000 copies. This publication is recognized internationally as the source for transportation energy data. Data contained in this pulilication are invaluable to the development of DOE's National Eneigy Strategy (see Sect. 4.4.1.1).

Researchers $d r$ vcloped a prototype dynamic traffic routing procedure that better icflects congestion levels on complex urban highway networks than does the static approach currently f:mployed by many of the nation's transportation planning agencies (ice Sect. 4 highlights for "Toward Real-Time Travel Demand Management").

\subsection{ENERGY CONSERVATION TECHNOLOGIES}

Energy conservation technologies cover (1) building equipment, (2) building envelopes, (3) existing buildings, and (4) electric power systems. Work in the building equipment area includes thermally activated heat pumps for residential and commercial applications, novel cycles, refrigeration systems, and chemical heat pumps for industrial applications. Research on building envelopes focuses on the areas of walls, foundations, roofs, and building materials. Research on existing buildings looks into the technical and implementation issues for improving the energy efficiency of existing buildings. Electric power systems research concentrates on electric transmission and distribution syster $s$ with emphasis placed on automation of control, electromagnetic pulse effects, high-voltage transinission technologies, and new material applications. The following is a summary of the major activities.

\subsubsection{Building Equipment}

Good progress was made on the development of a magnetically coupled free-piston Stirling engine driven refrigeration compressor for use in gas-fired residential and light commercial heat pump systems. The engine section hardware met performance objectives and the compressor section performed well in component tests (see Sect. 5.2.1).

An advanced refrigerator/freezer cycle featuring separate evaporators for the fresh food and freezer sections and using a nonazeotropic refrigerant mixture (NARM) is being analyzed. Analytical screening of candidate NARMs in this cycle showed that over $20 \%$ performance improvement may be possible (see Sect. 5.2.3).

Research continued on improving heat exchanger effectiveness with NARMs. Tests using NARMs and pure refrigerants in heat exchangers with enhanced surface and smooth surface showed definite evidence that NARMs take better advantage of surface enhancement than pure refrigerants (see Sect. 5.2.3).

A high-efficiency subcompact air conditioner and an innovative space heater, self-powered by thermoelectrics, were developed and tested. The subcompact unit developed is smaller, lighter, and nearly $10 \%$ more energy efficient than originally specified (see Sect. 5.3).

A two-parameter model was developed that predicts the thermodynamic properties of single or mixed salt solutions and the crystalline phases in single salt solutions using sparse data. Three patent applications have been filed on the analytical technique (see Sect. 5 highlights for "Industrial Chemical Heat Pumps"). 


\subsubsection{Building Envelopes}

The Envelope Systems Research Apparatus facility was constructed this year. It will be used for field testing large flat roof areas and basement wall insulation systems (see Sect. 5.4).

The aging phenomena of roof insulation made with chlorofluorocarbon- (CFC-) 11 and hydrochlorofluorocarbon (HCFC) alternates was analyzed in field tests and accelerated aging laboratory experiments. After the first year of the 3-year study, there has been no indication that the thermal performance differences are serious enough to exclude any of the HCFC altemative blowing agents from being technically viable in polyisocyanurate roof insulation (see Sect. 5.4).

The thermal performance of one brand of loose-fill insulation in a residential attic tested under simulated winter conditions declined by a factor of two as the temperature difference across the insulation increased. This decline in thermal performance is attributed to the initiation of convection through the insulation as the temperature difference increased (see Sect. 5 highlights for "Assessing Conductive Heat Loss in Attics").

\subsubsection{Existing Buildings Research}

Field tests of the advanced single-family energy audit in cold climates have shown dramatic improvements in heating energy savings . . . .
The cost effectiveness of a refined audit system for a single-family, low-income weatherization program was field tested. Results showed that a significant cost-effective level of energy savings resulted, and space-heating energy savings and total installation costs were predicted with reasonable accuracy (see Sect. 5.5).

Field tests of the advanced single-family energy audit in cold climates have shown dramatic improvements in heating energy savings and program cost effectiveness (see Sect. 5 highlights for "Advanced Single Family Energy Audit").

\subsubsection{Electric Power Systems}

A study of electromagnetic pulse effects of electric power systems was conducted. It was found that a single high-altitude burst could cause significant load and generation loss, hut permanent damage would be isolated (see Sect. 5.9.1).

An experiment was conducted to measure the effects of dc currents on distribution transformers. It was found that relative small dc current levels of a few amperes can cause $75 \mathrm{kVA}$ transformers to be driven into saturation and cause significant harmonic distortion of the ac waveform (see Sect. 5.9.1).

A study was conducted to review, analyze, and document the experience of the electric utility industry with geomagnetic disturbances. It was found that elcctric power systems are susceptible to geomagnetically induced earth surface potential gradients as small as about $10 \mathrm{~V} / \mathrm{km}$ (see Sect. 5.9.4).

\subsection{MILITARY TRANSPORTATION}

Research and development on military transportation deals with conceptualizing new approaches to planning and executing strategic deployment of personnel and materiel. Some highlights from this year's work are summarized in Sect. 1.3.1.

\subsubsection{Military Transportation}

Researchers have been developing a prototype set of analysis tools [the Flow and Analysis System for the U.S. Transportation Command (FAST)] for military deployments during deliberate planning, exercises and real-world contingencies. An initial prototype of FAST that was delivered in July 1990 was accelerated into use for Operation Desert Shield (see Sect. 4.5.1).

The Airlift Deployment Analysis System (ADANS) was selected as the exclisive airlift planning and scheduling tool for the Operation Desert Shield deployment of U. S. military personnel and materiel to Saudi Arabia. Division staff worked with the crisis action team at Military Airlift Command headquarters to assist in the implementation of ADANS to support Operation Desert Shield and Operation Desert Storm [see Sect. 4 highlights for "Airlift Deployment Analysis System (ADANS)"]. 


\subsection{ADMINISTRATIVE SUPPORT SECTION}

The Administrative Support Section of the division office provides information, technical, and operational support for the research and development activities of the Energy Division.

The Management Services Group organized an informative training session for all new clerical staff in the division, which has led to improved efficiency and procedure awareness. Continued diligence led to the acquisition of an old chemical storage room which underwent office renovations for the future home of the Applied Physical Sciences Group.

The Financial Services Group automated the tracking of all subcontracts, engineering service orders, and purchase requisitions. Continued individual personal service was provided to all staff members.

Significant progress was made with the newly acquired computer equipment in the Energy Division Publications Office. The acquisition of hardware and software with new capabilities enabled the rapid movement to desktop publishing services provided to all sections of the division. The group continued its editing of a variety of documents including the annual progress report, which for the second year won an award in the Society for Technical Communication competition.

The safety activities within the Energy Division focused on the heightened awareness of environmental, safety, and health issues because of the DOE Tiger Team's visit to ORNL in the summer. In addition to the normal quarterly safety inspections and meetings for all personnel, pre-Tiger Team safety and Occupational Safety and Health Administration inspections were held to ensure the division's readiness. The Tiger Team reported no negative findings for any of Energy Division's facilities.

Training was given to selected division personnel in the areas of respirator use, hazardous waste site activities, asbestos awareness, safe storage of chemicals, environmental laws and regulations, and general employee training. An upgrade of the emergency preparedness status was completed for all locations within ORNL facilities containing Energy Division staff. A program to identify and correct an asbestos release from noor tiles in some division offices was successfully completed. 


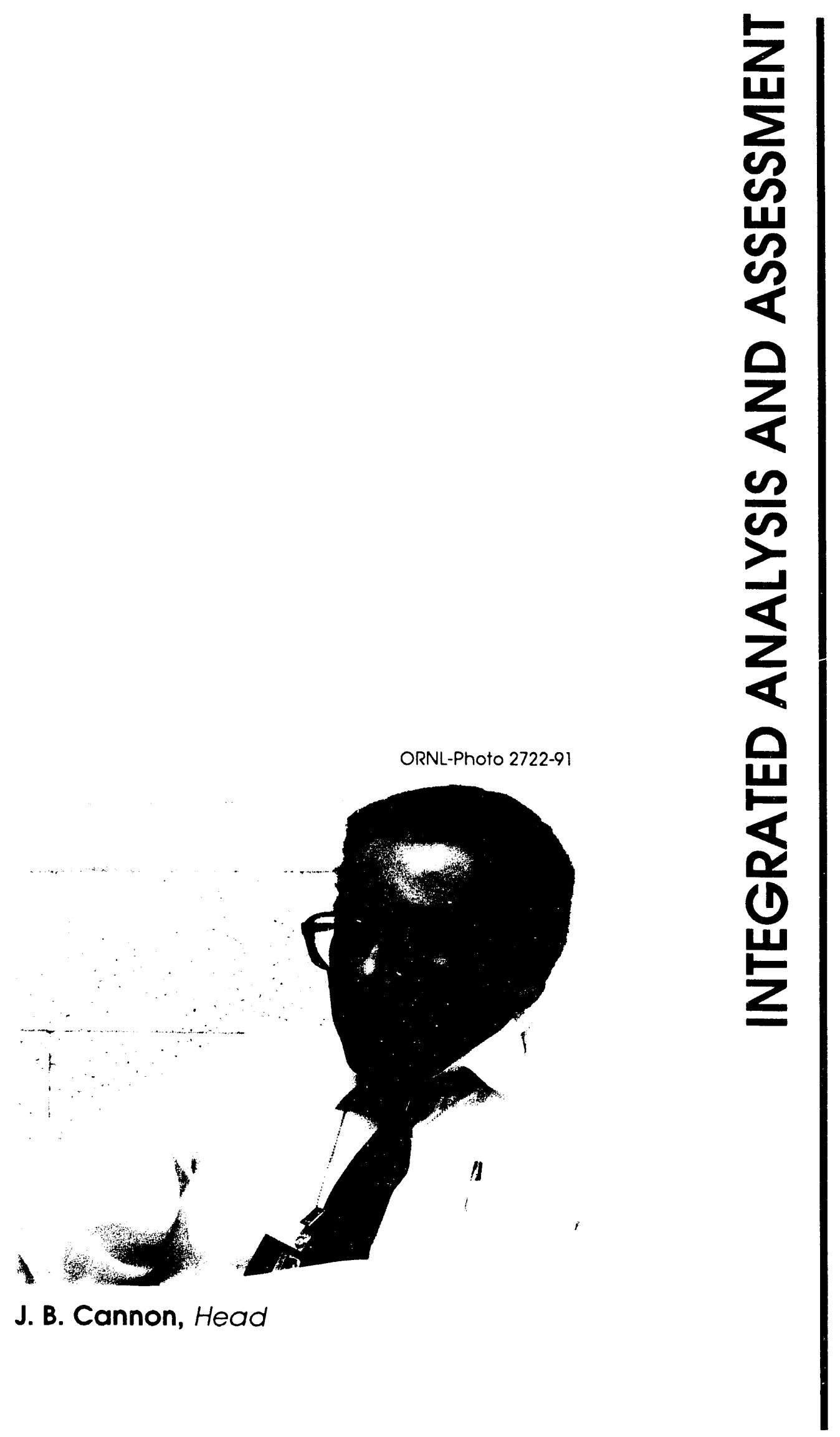




\section{INTEGRATED ANALYSIS AND ASSESSMENT SECTION OVERVIEW}

\subsection{INTRODUCTION}

The Integrated Analysis and Assessment Section (IAAS) is a specialized unit that conducts research in the physical and social sciences and prepares environmental assessments (EAs) and environmental impact statements (EISs) for various federal agencies to comply with the National Environmental Policy Act (NEPA) of 1969. We have expertise in areas such as emergency preparedness, radioactive waste management, siting and characterizing geohydrologic systems for waste disposal facilities, contaminant transport modeling in atmospheric and aqueous systems, public response to hazardous technologies, institutional mechanisms for managing complex technologies, socioeconomic impacts of technological change on communities, and global environmental decision making. We perform research and applied work in these and related areas, both independently and in collaboration with researchers from other divisions at Oak Ridge National Laboratory (ORNL). Much of this work is interdisciplinary.

In areas related to NEPA, we have management responsibility for all EAs and EISs prepared by ORNL for the U.S. Department of Energy (DOE) and for other federal agencies. This work covers a broad spectrum of technologies and issues and is accomplished by dedicated interdisciplinary research and assessment teams assembled from the IAAS, other sections in Energy Division, and other research divisions at ORNL (particularly Environmental Sciences, Health and Safety Research, Chemical Technology, Engineering Technology, and Research Reactors). The NEPA activity constitutes a large fraction of our work load.

\subsection{NEPA PROJECTS}

The section's NEPA work continues to be diverse and consists largely of projects initiated in previous years. A partial listing of projects by sponsor is provided in Table 2.1. Dominant projects include development of a generic EIS (GEIS) for the Nuclear Regulatory Commission (NRC) that addresses the potential environmental impacts associated with extending the operating licenses of commercial nuclear power plants from 40 years to 60 years, and development of a programmatic EIS for research and logistic activities by the United States in Antarctica. The latter work is sponsored by the National Science Foundation (NSF). We continued to provide major NEPA support to the Army's Chemical Stockpile Disposal Program, which is charged with destruction of lethal unitary chemical agents and munitions stockpiled in the continental United Siates and on Johnston Island in the Pacific Ocean. We completed a Final Programmatic EIS in 1988 and are now preparing site-specific EISs for each of the eight sites in the continental United States where stockpiles are stored. In addition, we continued to support the DOE Clean Coal Technology Program (CCTP). Specifically, in 1988-89, we prepared both a programmatic EIS for the CCTP and several project-specific NEPA documents. During FY 1990, we worked on five EAs (Fig. 2.1) and started the discuss plans for a visit to one of the eight proposed disposal sites in the continental United States.

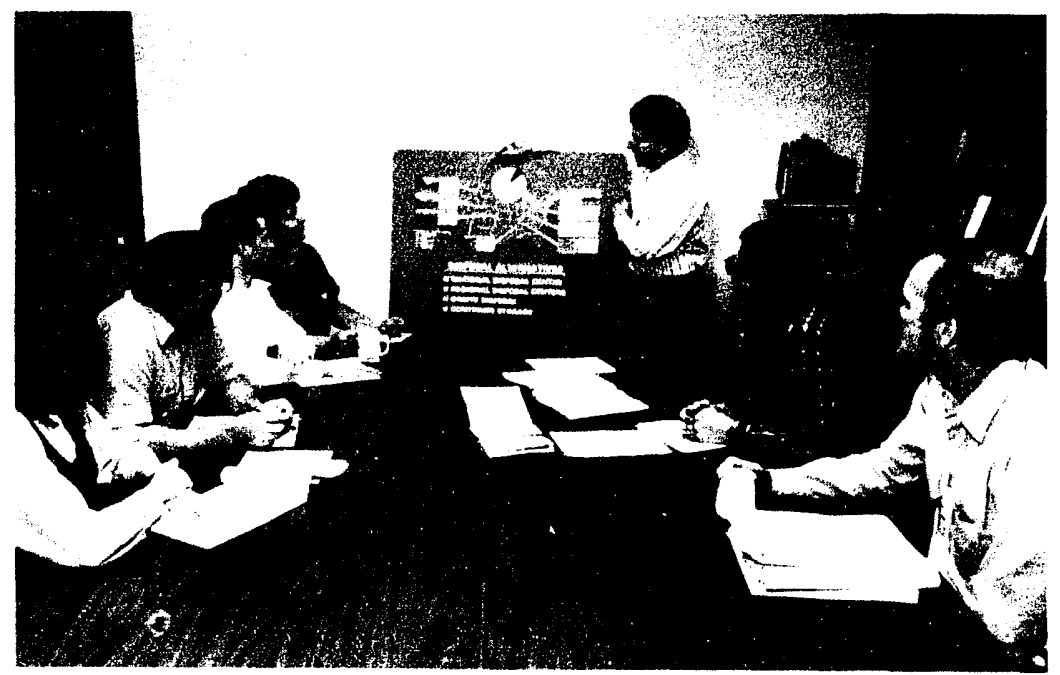

The Chemical Stockpile Disposal Program team meets to 
Table 2.1. Partial listing of FY 1990 NEPA projects

\begin{tabular}{ccc}
\hline Proposed action/task & Document & Principal issue(s) \\
\hline U.S. Department of Energy &
\end{tabular}

\section{U.S. Department of Energy}

Renovation of production facilities and cleanup of contaminated areas at the Feed Materials Production Center, Fernald, Ohio

Decontamination and decommissioning of Bldg. 371 at the Rocky Flats Plant near Boulder, Colorado

Plutonium Recovery Modification Project at the Rocky Flats Plant near Boulder, Colorado

Reduction of polychlorinated biphenyl contamination in ventilation ducts at Portsmouth and Paducah Gaseous Diffusion Plants in Ohio and Kentucky

Clean Coal Technology Demonstrations located in Porter County, Indiana; Springfield, Illinois; Cassville, Wisconsin; Rosebud County, Montana; and Healy, Alaska

\section{Nuclear Regulatory Commission}

Rulemaking on extending the operating license of nuclear power plants from 40 to 60 years
Environmental Radioactive waste management; Impact groundwater contamination; exposure Statement of workers and general public to (EIS) radioactive materials

Environmental Management of low-level waste, assessment transuranic waste, and radioactive (EA) waste mixed with hazardous chemicals

EIS

EA

EAs and EIS Emissions of criteria air pollutants $\left(\mathrm{SO}_{2}\right.$ and $\left.\mathrm{NO}_{\mathbf{x}}\right)$ and water quality

\section{National Science Foundation}

Assessment of current and anticipated environmental impacts associated with the U.S. Antarctic Program
EIS

\section{U.S. Department of Defense-Army}

Disposal of lethal unitary chemical (nerve and blister) agents stored in various configurations at Anniston Army Depot (Alabama), Umatilla Army Depot (Oregon), Pine Bluff Army Depot (Arkansas), and Pueblo Depot Activity (Colorado)

Disposal of the U.S. European chemical munitions stockpile at the Johuston Atoll Chemical Agent Disposal System, Johnston Island

EIS

EIS

Risk assessment, public perceptions of risk, maturity of disposal technology

\section{U.S. Department of Defense-Air Force}

Development of procedures for assessing environmental impacts of Air Force low-altitude flying operations in the continent: ' United States

Strategic Defense Initiative experiments involving laser tests at remote locations (Ascension Island, Antigua, Wake Island, and Maui)

Closure of Mather Air Force Base (AFB), California

Proposed launches at Vandenberg AFB, California, and Cape Canaveral AFB, Florida, for the Titan IV/Solid Rocket Motor Upgrade Program

Realignment of Beale AFB to house the 323rd Flying Training Wing from Mather AFB, California
EIS

A
Risk assessment, public perceptions of risk, maturity of disposal technology

\section{IS}

A

Wetlands (vernal pools),
Public concem regarding low-level flying, wilderness, and parks impacts

Potential impacts of misdirected laser beams on humans and wildlife, archaeological impacts (on Antigua)

Hazardous waste cleanup, noise, and continued protection of threatened and endangered species

Wetlands and threatened and endangered species (Cape Canaveral) socioeconomics 


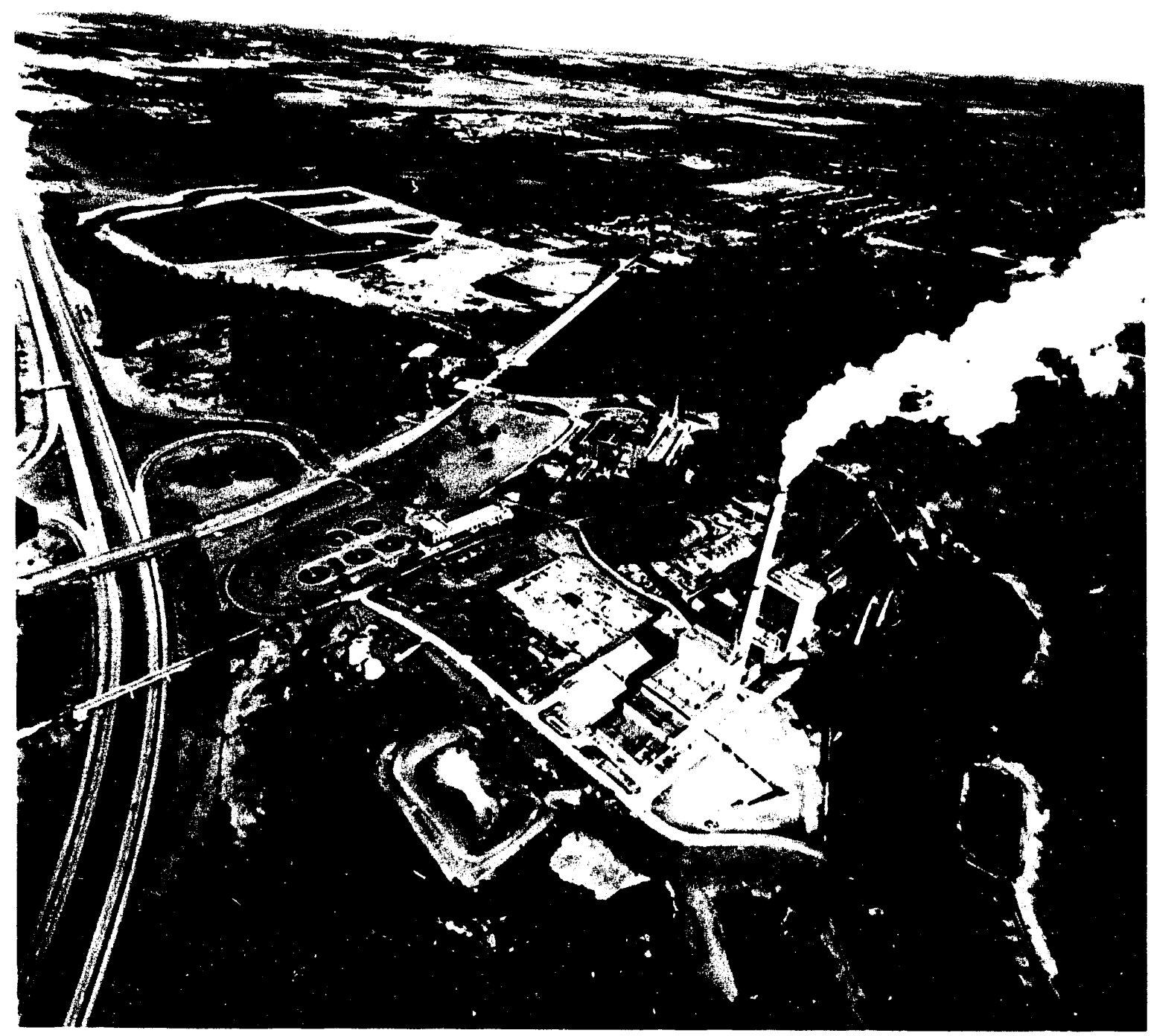

Fig. 2.1. Aerial view of the Lakeside Plant operated by City Water Light and Power in Springfield, Illinois. Unit I of this coal-fired electric generating facility is being repowered with an integrated gasification combined cycle system to reduce $\mathrm{SO}_{2}$ emissions.

first site-specific EIS ever prepared in the $\$ 5$ billion program. The Alaska Industrial Development and Export Authority has proposed a new 50-MW coal-fired power generating facility to be collocated with an existing 25-MW conventional pulverized coal unit in Healy, Alaska. The new facility will feature integration of advanced combustion and flue gas cleanup technologies to reduce emissions of $\mathrm{SO}_{2}$ and $\mathrm{NO}_{x}$. (For the section's work on an EIS for the U.S. Antarctic research program, see "U.S. Antarctic Research Program" highlights.)

\subsubsection{Generic Environmental Impact Statement for the Nuclear Regulatory Commission}

The GEIS for license renewal of nuclear power plants is being prepared to support a rulemaking to change the NRC environmental protection rules in 10 CFR 51 regarding requirements for relicensing nuclear power plants. Significant cost savings could result if the life of nuclear power plants were extended rather than if they were replaced with new facilities powered by nuclear, coal, or some other energy source. NRC has issued a proposed rule (10 CFR 54) that establishes the requirements a nuclear power plant must meet to ensure that its continued operation during the license renewal term will not endanger public safety and the environment.

The analyses in the GEIS encompass all operating light-water power reactors, currently 118 units located at 74 sites. For each type of environmental impact, the GEIS attempts to establish generic findings covering as many plants as possible. The overall approach taken in this GEIS is to assess 


\section{U.S. Antarctic Research Program}

Our pioneering work for the National Science Foundation (NSF) on a programmatic Environmental Impact Statement (EIS) for the U.S. Antarctic research program resulted in some interesting and useful conclusions. NSF currently operates three year-round Antarctic research stations: McMurdo Station on the Ross Sea, the Amundsen-Scott South Pole Station at the geographic South Pole, and Palmer Station on the Antarctic Peninsula (Fig. 2.2). These stations support numerous field research projects at various places on the continent and in the adjacent marine environment. The thrust of our work was to supplement a programmatic EIS that was issued in 1980. Environmental issues identified during the public scoping process centered around concerns that the pristine Antarctic environment be preserved for scientific study. Potential environmental impacts of particular concern include those that could result from solid waste disposal, import of materials into Antarctica, disposal of wastewater in the ocean and in snow or ice pits, handling and storage of fuel, and energy use and conservation.

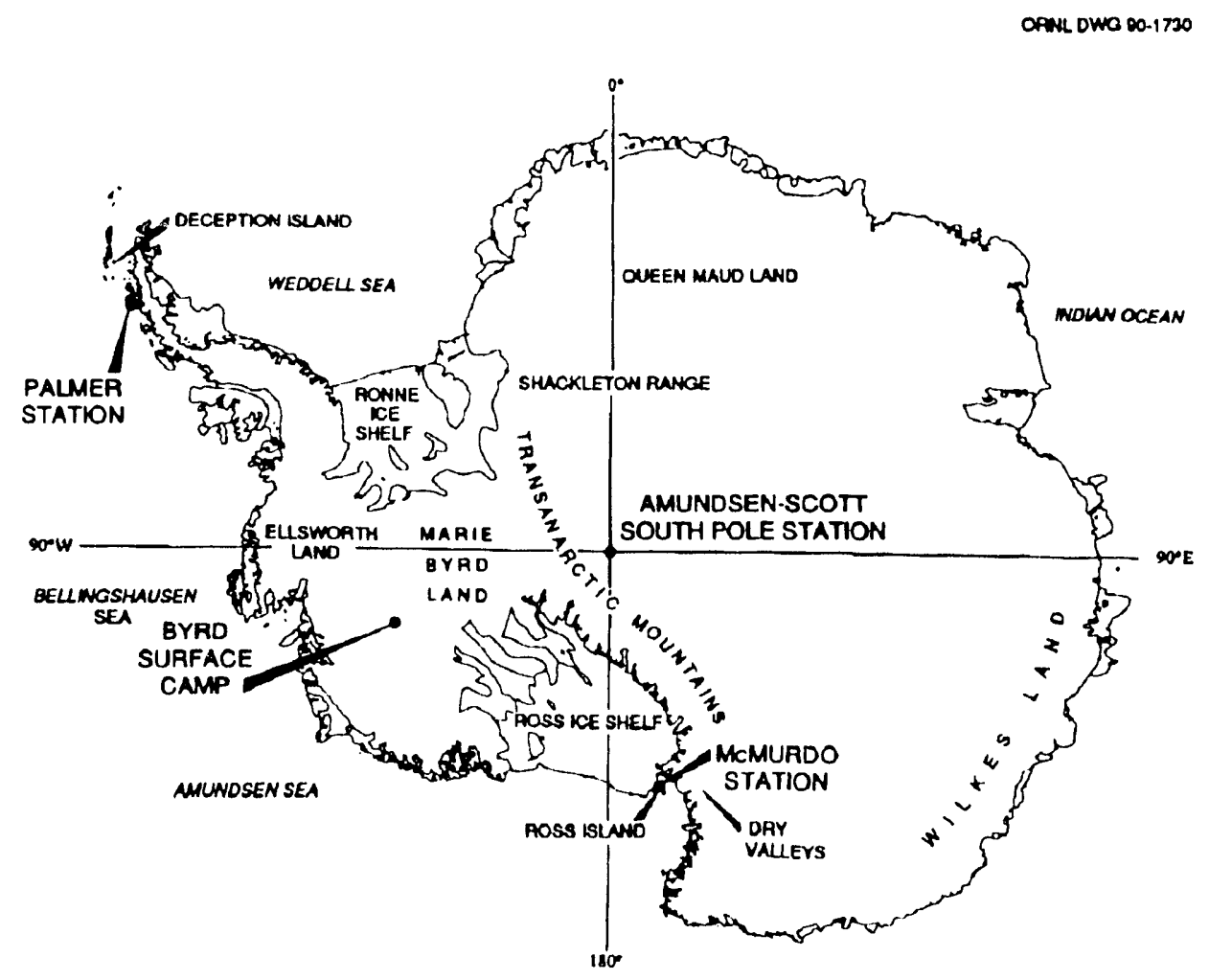

Fig. 2.2. Location of U.S. Antarctic Program stations on the Antarctic continent. 


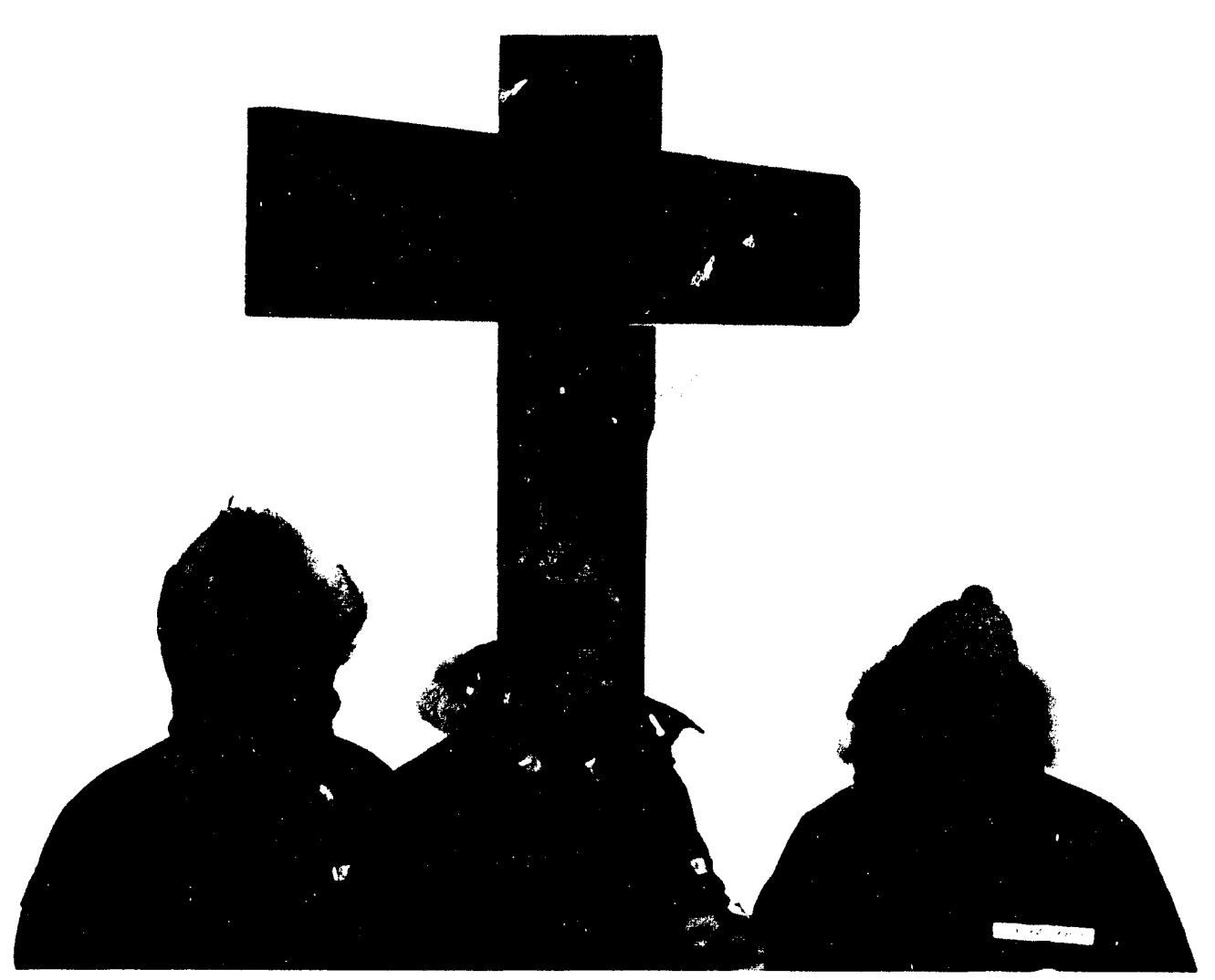

ORNL researchers arrive at the peak of Observation Hill, McMurdo Station.

For protecting the Antarctic environment the following alternatives were considered, differing primarily in the proportion of resources (personnel, equipment, and funds) devoted to environmental protection: (1) no further action beyond that applied prior to implementation of the Safety, Environment, and Health (SEH) Initiative; (2) completion of the SEH Initiative; (3) completion of the SEH Initiative and streamlining of the U.S. Antarctic Program activities (the proposed alternative); and (4) increased environmental protection measures beyond those in the SEH Initiative. Our analysis ${ }^{1}$ showed that current environmental impacts of U.S. activities and facilities in Antarctica are localized. The steps that have been initiated will further mitigate safety, environmental, and health impacts. Implementation of the proposed alternative to reduce the number of support personnel on the continent would also reduce impacts because fewer materials would be needed, less solid waste and wastewater would be generated, and smaller amounts of fuel would be required. We concluded that under the proposed alternative, NSF would be able to continue its research activities at current or increased levels and minimize risks to the environment. 
(1) the environmental impacts of implementing changes required by 10 CFR 54 to plants (i.e., refurbishments and modifications) and their operations; (2) the potential environmental impacts of operating the plants for an additional 20 years, considering changes to plant operating parameters, existing operating experience, and past and possible future changes in the environment; and (3) the potential environmental impacts of no action (no license renewai) with regard to plant shutdown, decommissioning, and replacement energy technologies. To date, the analyses performed for the GEIS have identified and evaluated 103 issues relevant to license renewal of nuclear power plants under NRC's environmental protection regulations. The draft GEIS is expected to be issued in August 1991. The findings will be codified in 10 CFR 51 so that they may be applied to limit requirements for further analysis in future environmental reviews for license renewals at individual plants.

\subsection{EMERGENCY PREPAREDNESS}

IAAS coordinates the division's research in emergency preparedness, which is directed at improving society's ability to cope with natural and technological hazards and large-scale technological disasters such as nuclear war. Our work was focused on enhancement of emergency preparedness at the eight continental United States sites where unitary chemical (nerve and blister) agents are stored. This work was funded by the U.S. Army's Chemical Stockpile Emergency Preparedness Program (CSEPP) and the U.S. Federal Emergency Management Agency (FEMA). We also continued to provide assistance to DOE's Office of Safety Policy and Standards by assisting in planning and conducting two prelaunch exercises for the shuttle launch carrying the plutonium-powered Galileo spacecraft and as part of the federal response group deployed for the launch. We prepared a draft manual to assist DOE regional offices in conducting radiological response workshops, distributed a draft exercise planning guide for DOE-wide con 'ment, and reviewed several documents.

\subsubsection{Chemical Stockpile Emergency Preparedness Program}

ORNL's involvement in CSEPP, as in past years, included research tasks, technology transfer to state and local govemment, and program management support. Research included work on an accident assessment methodology for recognizing and classifying plant accidents, ${ }^{2}$ assessing the role of atmospheric dispersion modeling and metcorological monitoring for emergency planning and response, ${ }^{3}$ reviewing research on risk communications, studying reentry issues after a release, analyzing the effectiveness of protective equipment for emergency workers, and conducting quantitative estimates of evacuation times.

\subsubsection{Computer-Based Decision Support Systems}

Our involvement in computer automation expanded in FY 1990. We published a report that reviewed issues in the adoption of computer-based decision support systems. ${ }^{4}$ The analysis of current efforts and software suggested that no existing system would adequately meet program needs, particularly to ensure coordination between on-post and civilian officials. This finding led to work on prototyping an electronic emergency planning concept that reflected the needs of officers at the eight chemical weapons storage sites. This prototype was demonstrated to state and local participants in the program at the program's national meeting held in Bend, Oregon, in May 1990. Further work will be conducted to define the requirements of the automation system.

\subsubsection{Transferring Results of Technology}

A subcontract was established with SE Technologies, a company that specializes in helping local governments develop emergency plans, to help transfer the results of the ORNL research. Staff of SE Technologies worked extensively with state and local emergency planners to improve their ability to respond to an accident. With support from The University of Tennessee (UT) and SE Technologies, we developed a document to guide the preparation of state and local emergency plans. ${ }^{5}$

\subsubsection{Emergency Upgrades at CSEPP Sites}

We also provided support to Army and FEMA program officials. An ORNL subcontractor assessed the need for improved warning and communication systems at the eight sites where unitary chemical munitions and agents are stored. A report was prepared to provide information about strategies to fund the acquisition of equipment needed to upgrade waming and communication 


\section{Emergency Preparedn'sss and Simulation Model for Assessment of Alternałive Protection Actions}

Work progressed on analyzing the effectiveness of different methods of protecting the pubiic from an accidental release of chemical agent. ${ }^{6}$ A simulation model was developed to assess dose reduction from implementing alternative actions under different accident scenarios. The model allows the user to specify the time, the nature and size of th: release, and the meteorological conditions. The "ser then makes assumptions aboui how much time officials need to make a decision about alerting the public; what type of warning system will be used; how rapidly the public will react; and the type of protection that would ie most effective, such as evacuation, in-place sheltering, or respiratory protection. The computer model then calculates, for a chosen downwind distance, the reduction in doses provided for that action under the chosen scenario. Thousands of scenarios were generated and assessed using the model. The results of that analysis are summarized in Fig. 2.3.

ORNL DWG. $912-7909$
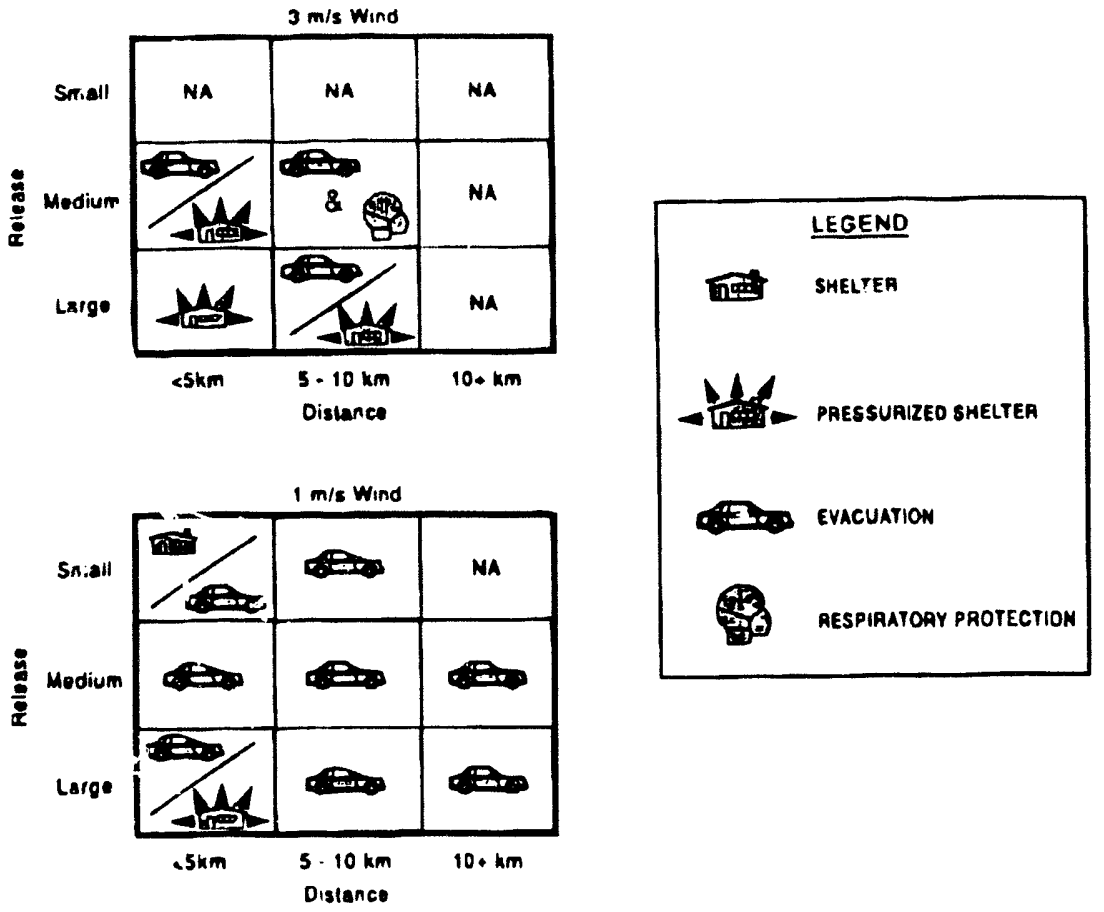

Fig. 2.3. Protective action findings in the Chemical Stockpile Emergency Preparedness Program. 
systems. $^{7}$ We began work on a plan for FEMA to use in developing the emergency exercise program. With assistance from UT personnel, we also began work on preparing detailed planning standards that will be used by FEMA to provide funds to upgrade emergency systems at the eight sites.

\subsection{APPLIED PHYSICAL SCIENCES}

The section continued to support radioactive waste management and environmental restoration activities on the Oak Ridge Reservation. The principal thrust of our efforts in these areas was development of a performance assessment for ORNL's active waste disposal facility (see Sect. 2.4.1). We also initiated a major hydrologic and geohydrologic modeling effort for the Gaseous Diffusion Plant Safety Analysis Report Upgrade Program aimed at assessing (1) the flooding potential of major rivers near the plants and (2) the effect of accidental releases of hazardous materials on surface- and groundwater systems. This work is expected to span several years. As reported in "Geophysical Diffraction Tomography" highlights, development of geophysical diffraction tomography for high-resolution subsurface imaging continues.

The section also performs research directed at understanding the potential air quality consequences of proposed federal actions, assessing the air quality impacts of existing activities, and studying the role of meteorology in the behavior of substances emitted to the air under conditions of normal operations or in the case of accidental releases. The highlights of such work in FY 1990 for the Air Force are provided in Sect. 2.4.2.

\subsubsection{Performance Assessment for Solid Waste Storage Area 6 (SWSA 6)}

The primary emphasis of liie section's activities in the waste management area was development of a performance assessment for current and future operations in SWSA 6 to demonstrate compliance with DOE Order 5820.2A. SWSA 6 is located on a 27.5-ha (68-acre) tract of land near ORNL that currently is used to dispose of 14 is-2265 $\mathrm{m}^{3}\left(50,000-80,000 \mathrm{ft}^{3}\right)$ of wastes each year in subsurface concrete silos (Fig. 2.6), tumuli, double-walled pipe wells, lined auger holes, and unlined trenches. These disposal units were analyzed to assess the radiological implications of leachate that escapes the disposal units and contamirates both surface water and groundwater. Also considered were scenarios involving individuals that may inadvertently intrude into the disposal units at some future date and suffer exposure to radioactive materials. DOE Order $5820.2 \mathrm{~A}$ performance objectives require that off-site exposures to individuals must result in doses less than $25 \mathrm{mrem} / \mathrm{year}$ and doses to inadvertent intruders of $<100 \mathrm{mrem} /$ year for chronic exposures and $<500 \mathrm{mrem} /$ year for acute exposures.

The results of the analyses indicated that SWSA 6 is not in compliance with the performance objectives of DOE Order 5820.2A. Each type of disposal unit was analyzed separately, with some types performing better than others. The worst performance was attributed to the double-walled pipe wells (Fig. 2.6), which showed intruder doses of $400,000 \mathrm{mrem} /$ year for chronic exposure and $20,000 \mathrm{mrem} / \mathrm{year}$ for acute exposure. The asbestos silos and biological trenches met all of the performance objectives. Off-site doses were significantly less than the $25 \mathrm{mrem} /$ year performance objective, and groundwater doses were also much less than the performance objective of $4 \mathrm{mrem} / \mathrm{year}$. Considerable uncertainty is associated with these findings as a result of questionable records of the waste inventory and the leaching characteristics of the waste forms.

The performance assessment for SWSA 6 is a first attempt to establish a comprehensive understanding of the performance of a waste disposal facility on the Oak Ridge Reservation. The technical difficulties associated with establishing a reasonably defensible analysis of site performance are complicated by the extremely complex geology of the Oak Ridge Reservation and the abundance of precipitation. In spite of these difficulties, significant progress has been made toward defining the potential long-term doses associated with the disposal of low-level radioactive wastes in these environs. Design changes and changes in waste acceptance criteria that would allow SWSA 6 to meet the performance objectives in DOE Order 5820.2A are currently being considered. The performance assessment will be reviewed by a DOE Peer Review Panel for technical accuracy and consistency with other DOE facilities. Work is continuing to reduce the uncertainty in the analyses and to provide a more reasonable representation of the performance of SWSA 6.

\subsubsection{Air Quality Impacts of Low-Level Flying Operations}

At the request of the U.S. Air Force, we developed computer-based tools for assessing the air quality impacts of low-level flying operations. Existing air quality models were surveyed and found to be inadequate $f:$ predicting ground-level concentrations of pollutants emitted by aircraft along 


\section{Geophysical Diffraction Tomography}

Over the past several years, Oak Ridge National Laboratory (ORNL) has developed and refined a quantitative technique for high-resolution subsurface imaging known as geophysical diffraction tomography (GDT). For any imaging procedure, adequate imaging can best be realized in a transmission mode measurement geometry in which waves are propagated from a source/receiver through a region to be imaged. For geophysical applications, however, this requires at least one borehole for instrument placement. This borehole requirement increases the cost of GDT applications.

For many applications of remote sensing, the problem is not one of imaging, but rather detection and location estimation (i.e., determining the existence and position of targets of interest). In shallow geophysics such targets could include tunnels, buried waste forms, or waste disposal units. One means for remotely detecting and locating predetermined targets is by the maximum likelihood estimator (MLE). In MLE, actual measured data are correlated with a library of simulated data (templates) for the target of interest at all possible locations within the study region. As shown in Fig. 2.4, the most probable target location is the one which maximizes the correlation of measured data with simulated data. Although the MLE approach is an accepted means for location estimation, it is computationally prohibitive because it requires simulations of data for all possible target positions. In a recent development, the MLE and GDT formalisms have been integrated into a new procedure. This new approach is computationally quite efficient because it requires data simulation for only a single target position. The procedure yields an image of the target probability distribution.
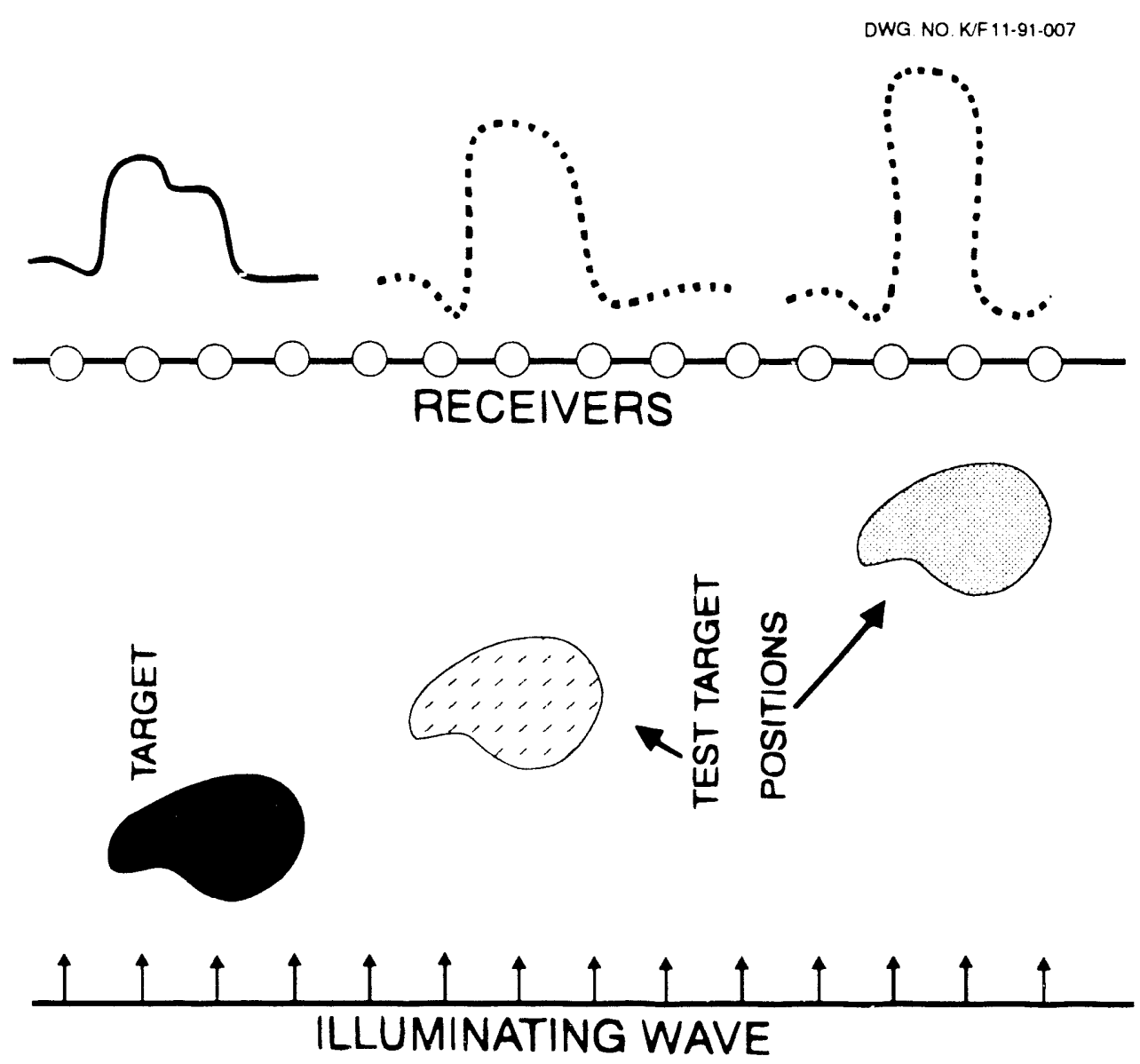

Fig. 2.4. By using the maximum likelihood estimator, researchers are able to locate the target by correlating templates with actual measured data. 
ORNL has been developing a hardware/software system to implement this procedure for the purpose of detecting tunnels based on surface seismic reflection measurements. A data acquisition system has been designed and individual system components fabricated and bench tested. Signal processing algorithms have been developed and tested on simulated data in a reflection mode and actual field data in a transmission. Figure 2.5 is a gray scale image of the tunnel likelihood function derived from field data acquired at a tunnel site. In Fig. 2.5, darker gray levels correspond to increasing probability of tunnel position. The most likely tunnel location is the black area in this figure, which corresponds exactly to the known tunnel location.

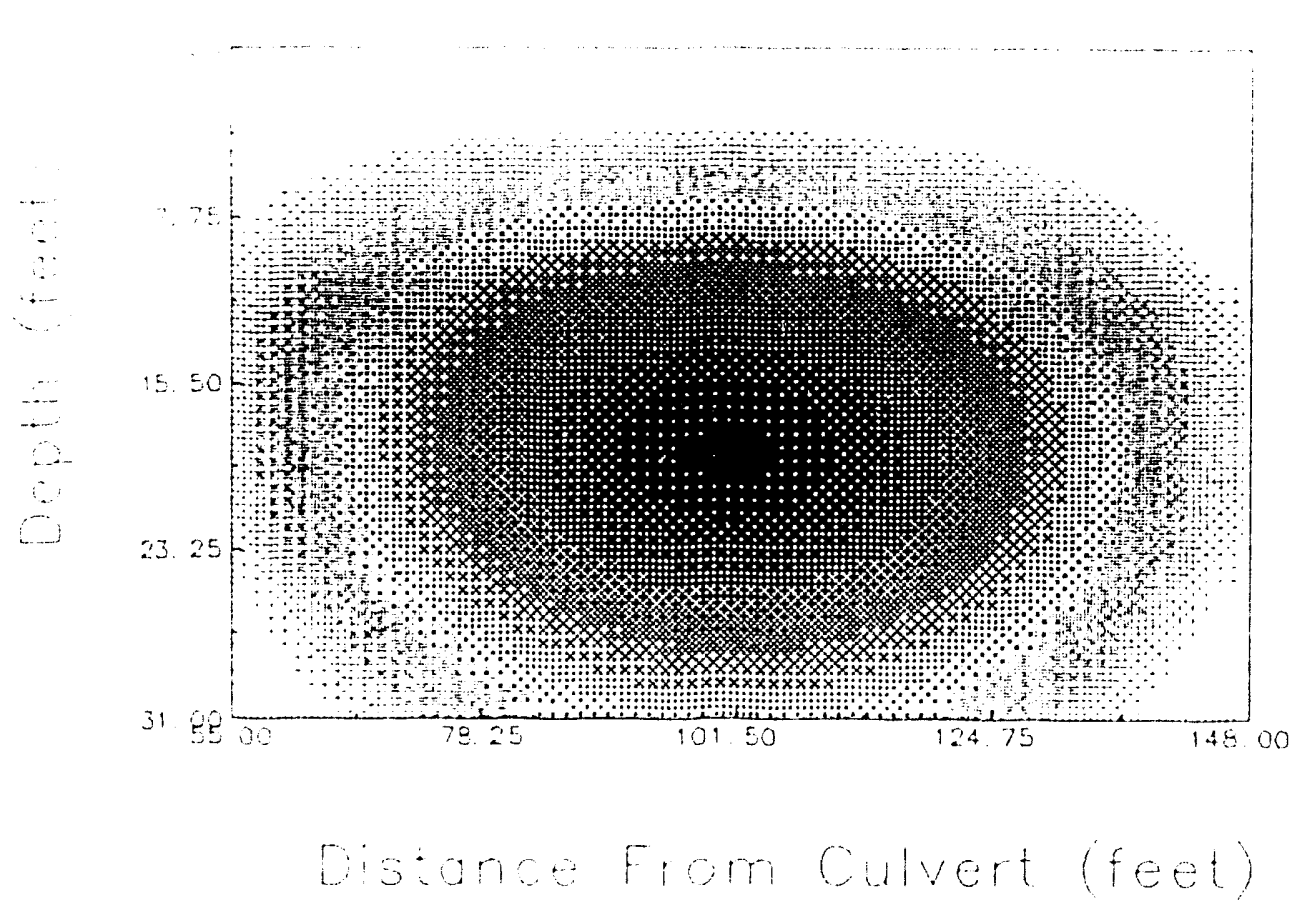

Fig. 2.5. A gray-scale inage of the tunnel likelihood function shows the probability of tunnel location. 


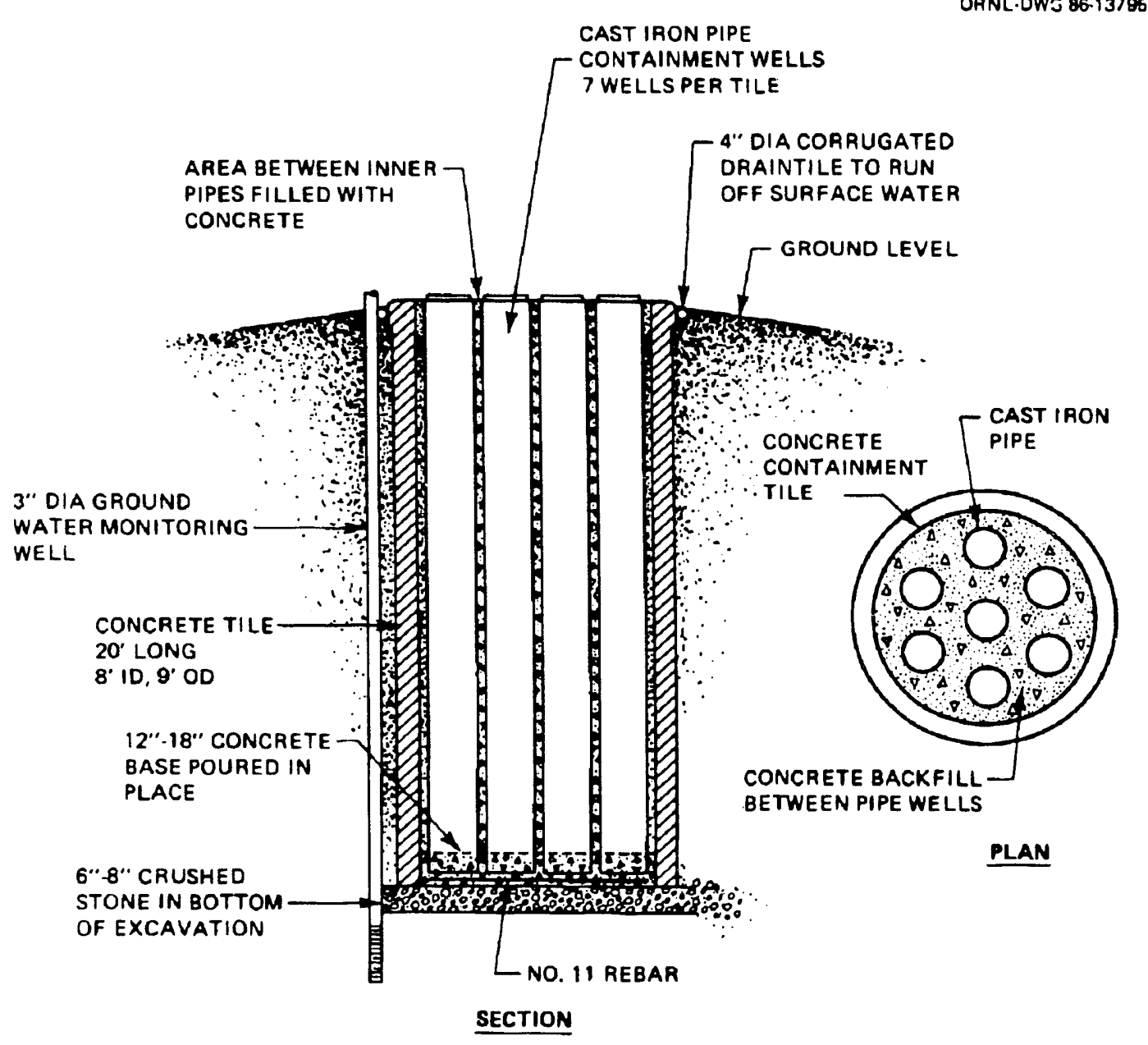

MULTIPLE CONTAINMENT WELLS FOR HIQH ACTIVITY WASTE

Fig. 2.6. Cross-section of concrete silos with containment wells. High-activity low- level radioactive wastes from Oak Ridge National Laboratory are disposed of in these wells.

military training routes (MTRs). The models do not account for the intermittent and essentially instantaneous nature of the emissions, and the size, complexity, or input data requirements of the models make them impractical. Therefore, the Single-Aircraft Instantaneous Line Source (SAILS) model and later the Multiple-Aircraft Instantaneous Line Source (MAILS) model were used to estimate potential impacts along MTRs or MTR-like airspace segments. These models calculate the maximum potential ground-level ambient pollutant concentrations from aircraft flying a linear flight path assumed to be parallel to the wind direction (Fig. 2.7). An existing model, the U.S.

Environmental Protection Agency's (EPA's) Industrial Source Complex Short-Term dispersion model, was chosen to estimate ground-level concentrations from the more widely distributed emissions occurring within military operation areas (MOAs) and restricted areas (RAs). Finally, a protocol was developed and then applied in the field to determine the degree of visibility impairment caused by aircraft engine exhaust plumes. 


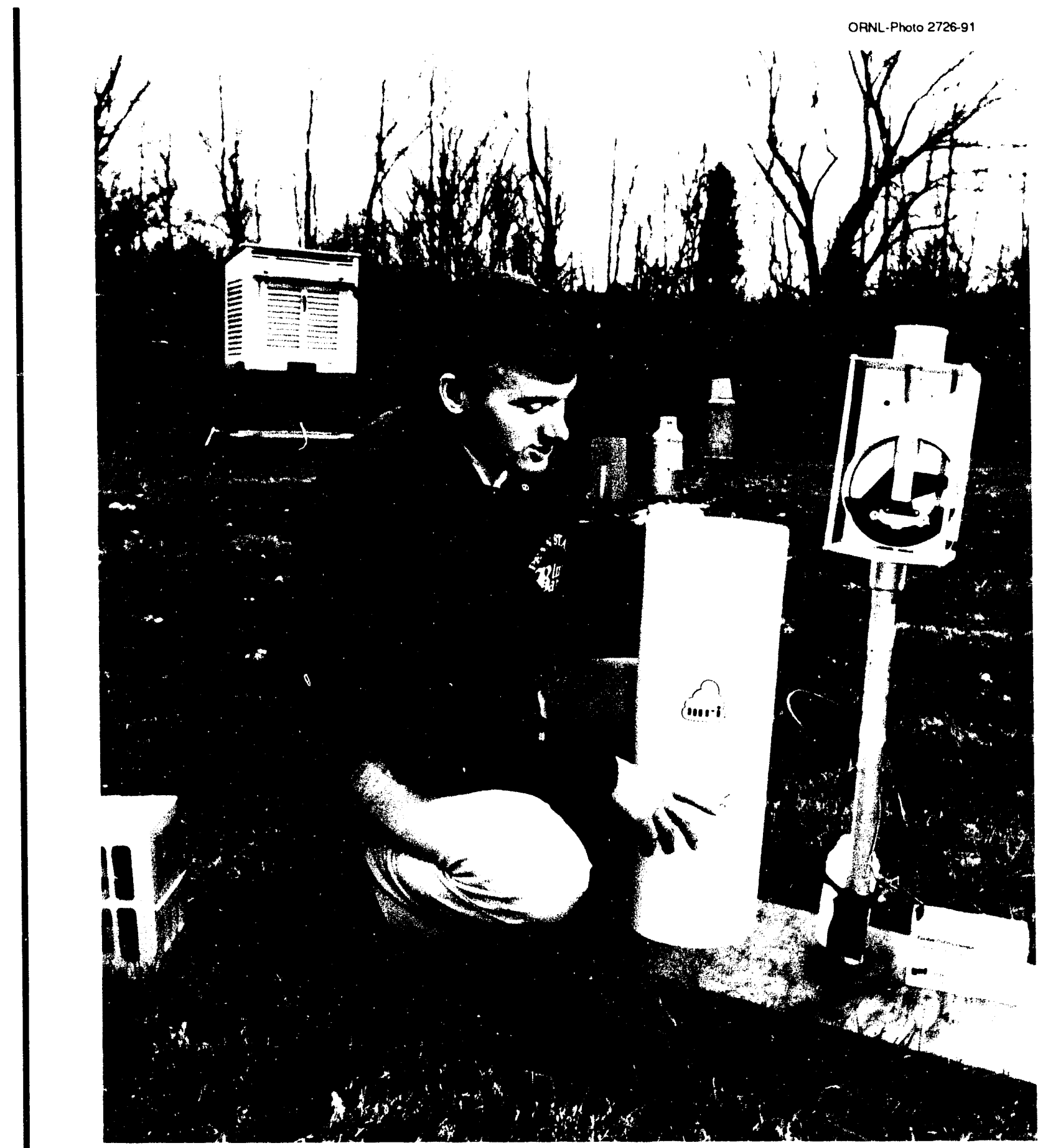

Research with mechanical meteorological instrumentation leads to the development of computer-based tools for air quality modeling. 


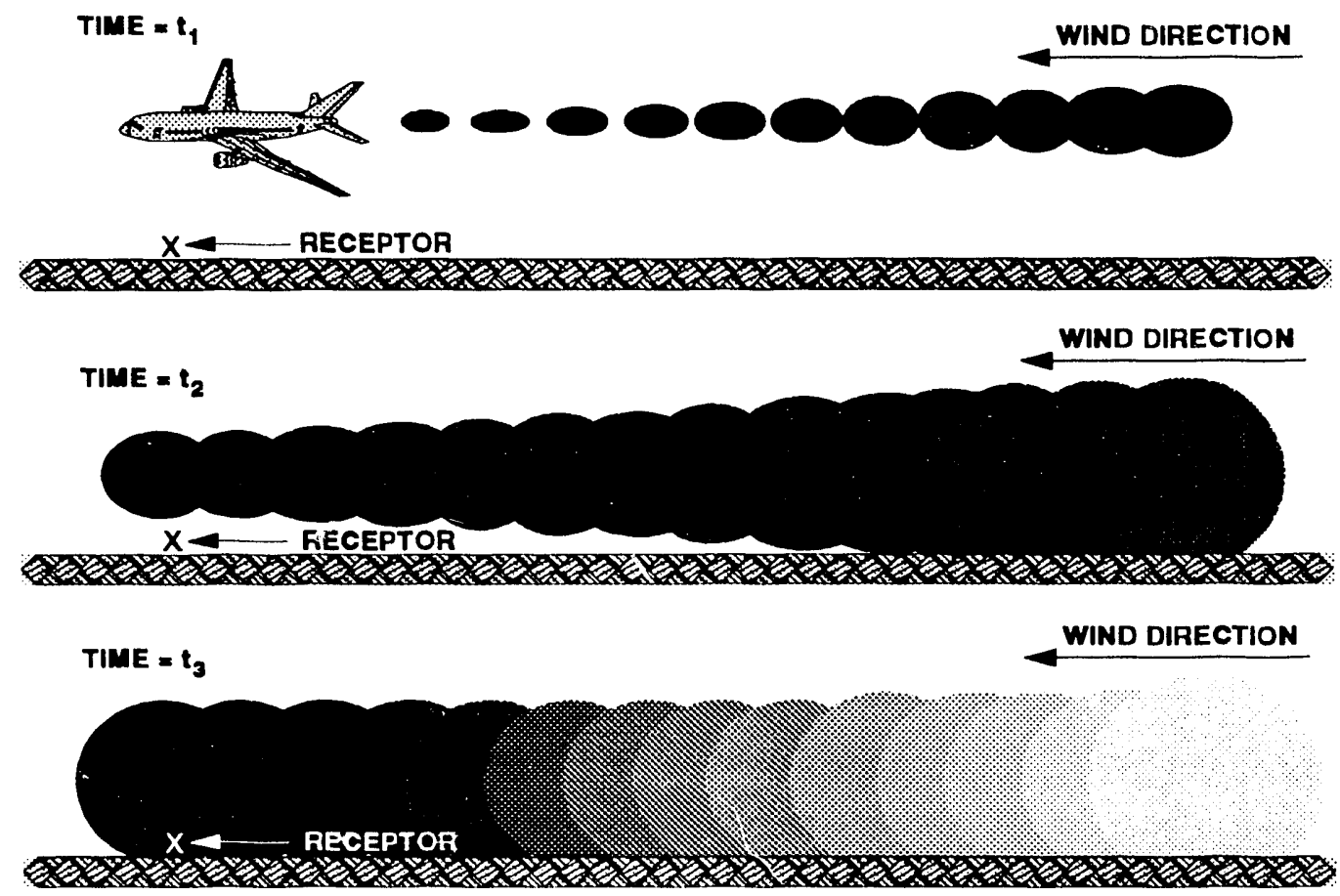

Fig. 2.7. Dispersion modeling concept.

The MAILS model was tested by comparing its results with those from a previously tested, EPA-approved dispersion model configured to provide for a comparison of model performance. The comparison indicated very close agreement between the MAILS model and the EPA model for an MTR scenario. The existing model used for MOAs and RAs was not tested because it has been used widely and is based on generally accepted atmospheric dispersion principles. Testing was not applicable to the visibility impact assessment protocol.

The following results were obtained for the aircraft emissions impact analysis.

- The ground-level air quality impacts of low-flying aircraft in MOAs and RAs are generally insignificant compared with ambient air quality standards.

- The aesthetic impacts on visibility over national parks and wildemess areas are insignificant for exhaust plumes from all types of existing U.S. military aircraft.

- The ground-level air quality impacts of low-flying aircraft along MTRs or MTR-like airspace segments are potentially significant only with respect to the very stringent air quality standards applicable to certain national parks and wilderness areas known as Prevention of Significant Deterioration (PSD) Class I areas.

Based on these findings, the key conclusion from this study is that air pollutant emissions from aircraft in low-altitude airspaces are a potential concern only when the airspace overlies or is within $1 \mathrm{~km}$ of a PSD Class I area. Also, the impacts even over Class I areas generally will be insignificant when the airspace flying operations are widely distributed (as is often the case in MOAs and RAs), as opposed to regularly following a prescribed route or path. Thus, environmental planning and assessment staff can focus the air quality analysis on only those airspaces that intersect PSD Class I areas. 


\subsection{TECHNOLOGY AND SOCIAL SYSTEMS}

Research in the area of technology and social systems is directed at understanding the institutional mechanisms by which society manages technologies. It is critical that we understand the full potential impacts of technology on society so that appropriate institutional responses can be implemenied to guide development of technology. For society, it is vital that those institutions reflect a high level of public trust, operate according to procedures to which socicty has given its consent, and provide for an equitable distribution of cost and risk liabilities in implementing the technology.

To further these objectives, members of IAAS were involved in a number of projects during the year. Work was almost completed on the U.S. Air Force's Generic Environmental Impact Statement for Low Altitude Flying Operations, in which ORNL assisted the Air Force in identifying impacts of low-level flying and developing procedures for assessing and mitigating those impacts. Although not all adverse impacts can be eliminated, it is believed that an assessment process incorporating substantial public participation will help alleviate some concerns that have arisen, such as annoyance to people and interruption of their activities, disturbance of Native American cultural activities, intrusion into wilderness areas, and disturbance to threatened and endangered species.

The Air Force has developed a number of computerized software programs for examining the environmental noise impacts of its flying operations. ORNL assisted the Air Force by developing an implementation plan to establish a center for operating these programs and interpreting their results with respect to the conduct of Air Force flying operations. An important aspect of the study was designing a center that would enhance the quality of environmental noise analyses but could operate effectively within a complex Air Force organizational structure.

We also collaborated with other Energy Division staff in gaining a better understanding of utility decision-making processes, focusing on utility integrated resource planning. The plans and planning processes of 29 utilities and 5 government agencies throughout the United States were examined in detail, and 6 key issues were identified as likely to influence a plan's societal value: (1) the relative emphasis placed on supply- and demand-side management resources throughout the planning process; (2) the breadth of inputs considered during plan preparation from various in-house departments and from nonutility interests; (3) the criteria used to select resource options for the plan; (4) the use of uncertainty analysis techniques to ensure that those options chosen will be appropriate for alternative futures: (5) the relationship between the long-term plan and action plan, or other short-term documents, that specify utility acquisitions; and (6) the relative value attributed to short-and long-term interests during plan development. A follow-up study of 24 utilities used statistical techniques to test a number of hypothesized relationships between selected utility characteristics and the mix of resources for the integrated plan. Utilities that engaged in collaborative planning with nonutility interests and that attributed substantial importance to these interactions were found to select more demand-side resources for their long-term plans than did other utilities.

In regard to the global environmental change program, the section's efforts in policy, energy, and human systems research focused on two issues. First were the opportunities and constraints for a U.S. policy to reduce carbon dioxide emissions from the energy sector. The second focus encompassed the issues of implementing any future agreement for greenhouse gas emissions.

The opportunities and constraints for U.S. carbon dioxide reductions in the energy sector are reported in a forthcoming paper for the British Royal Institute of International Affairs. ${ }^{8}$ The paper concludes that a realistic U.S. contribution to global greenhouse gas reduction would consist of four elements:

1. an aggressive pursuit of energy efficiency throughout all sectors of the economy;

2. an ambitious program of energy $R \& D$ to provide practical supply-side alternatives to fossil fuels;

3. an extensive technology transfer program (perhaps linked to emissions trading) to save developing countries from reliance on fossil fuels in their economic development; and

4. eventual displacement of fossil fuels in the domestic supply side over the long term.

Ensuring that treaties designed to mitigate or prevent global climate change are implementable is an important challenge facing negotiators. The first phase of this study focused on the process of negotiating implementation protocols following a framework convention. 9 The following six factors were identified as optimizing the chances for implementable agreements: 
1. having a sufficient number of relevant participants in negotiations to enhance legitimacy, but not so many as to encumber negotiations with extraneous issues;

2. negotiating issues in an appropriate sequence;

3. relying on confidence-building strategies rather than punitive measures to deter noncompliance:

4. stating signatory obligations as precisely as possible;

5. designing treaties to be renegotiable in the face of new or evolving information; and

6. developing protocols that allow signatory countries the maximum possible flexibility in the instruments they use to implement precisely stated goals.

The second phase concentrated on the types of instruments for implementing climate policy that might be adopted within nation states. ${ }^{10}$ The concept of management frameworks as institutional cultures was explored. Nations and organizations were found to favor one or another of a variety of decision-making styles composed of unique combinations of only three basic types known as hierarchies, markets, and collectives. The decision styles systematically constrain discourse and lead decision makers to frame problems in specific, sometimes incompatible ways. Such constraints affect preferences for different instruments of policy implementation. It was concluded that greater attention to international nongovernmental institutional contacts may provide opportunities to conclude and implement global agreements for environmental management.

The potential roles of state and local governments and nongovernmental organizations (corporations and environmental groups) in implementing global environmental protection policies were explored in a working paper prepared for U.S. DOE's Office of Environmental Analysis. ${ }^{11}$ It was concluded that some initiatives are likely even in the absence of federal government encouragement, while there is a danger that some federal strategies for responding to global issues may need to discourage some local initiatives. The process of local problem solving will require further research.

\subsection{ENERGY AND ENVIRONMENTAL ANALYSES}

The section did extensive work in the areas of energy and the environment that fall outside of our normal range of activities. Two such tasks are highlighted below.

\subsubsection{Effects of Clean Air Legislation on Electric Utilities}

A PC-based model (CHESHIRE) was developed for the Bureau of Mines (BOM) to estimate changes in emissions, technology choices, ard the costs of electricity as utilities respond to legislation that limits emissions, prices, or mixes of i'".ls. Of interest was how different clean air bills, designed to reduce emissions of $\mathrm{SO}_{2}$ and $\mathrm{NO}_{\lambda}$, mit int influence the cost of electricity used by aluminum smelters, ferrosilicon producers, and uther mineral processors. Because electricity is already a significant proportion of production costs in these industries, changes in the cost of electricity are an important issue. BOM's concern was that substantial increases in electricity costs would reduce the ability of U.S. aluminum smelters, for example, to compete in the world market.

The linear programming algorithm is designed to find an emissions technology that will satisfy the target for a unit while minimizing costs. For regions, the model will find the best mix of technologies that minimize costs for the affected units in the region (a single utility, any combinations of utilities, a state or combination of states). Emission technologies currently available in the model are low-sulfur coal (with variable Btu and sulfur content); flue gas desulfurization devices; low $\mathrm{NO}_{\mathbf{x}}$ burners (which can be added to any unit, even those with scrubbers); and clean coal technologies.

The effects of five clean air bills and a trading and no-trading version of the Bush bill on costs for 11 major suppliers of electricity to aluminum smelters were examined. The results are shown in Fig. 2.8. Because the bills have different compliance years, costs were estimated based on the compliance strategies for each bill and then normalized to remove the effect of the different compliance schedules.

Not surprisingly, the estimated costs of compliance differ substantially depending upon whether a utility had a lower or higher base (1985) emission rate. None of the proposed legislation for the cleanest 1985 utilities (Appalachian. Duke Power, and South Carolina Public Service) would increase costs hy more than 3 mills $/ \mathrm{kWh}$, and most bills would increase costs by less than $1 \mathrm{mill} / \mathrm{kWh}$.

A striking result from our calculations is the relatively small effect that the emission allowance trading system in the Administration bill has on electricity costs. Only in the case of Cleveland Electric does trading reduce costs by as much as $1 \mathrm{mill} / \mathrm{kWh}$, compared to the same bill without the 
trading provisions. The increases in electricity costs for some companies are as much as $25 \%$ lower when trading is allowed, but, for most, the savings are smaller, and much smaller than proponents of the trading system have suggested.

\subsubsection{External Costs of Fuel Cycles}

Fuel cycle cost analyses have become a subject of considerable interest in the United States and elsewhere as part of the process of producing, transforming, and using energy. More recently, efforts have been launched in the United States, Canada, Indonesia, and within the United Nations to address the criticism that conventional fuel cycle assessments do not reflect damages to envii onmental and health resources. Many environmental costs associated wiin energy use are not fully reflected in the price consumers pay for energy services. The "uninternalized" costs, or externalities, ultimately impose a burden on society that arguably should be born instead by energy consumers and producers. A number of state regulatory initiatives in the United States have been implemented to address the externalities of energy uses directly; however, resolving extemality issues is confounded by the extremely complex nature of the problem. DOE and the Commission of the European Communities have entered into an agreement to conduct parallel studies in the United States and Europe on the external costs of fuel cycles. ORNL and Resources for the Future (RFF) are the primary U.S. contributors to this multinational research effort.

The ORNL and RFF project seeks to cievelop the best range of estimates of external costs from secondary sources for the following fuels: oil; natural gas; coal; uranium; and renewables, such as solar, biomass, hydroelectric, and wind. Conservation technologies will also be accommodated by the study to the extent that these technologies offer alternatives to increasing capacity. The conservation technology areas to be explored include windows, lighting, appliances, and building shells.

Measuring the extemal costs for a specific energy fuel cycle involves two important components. First is the estimation of the quantities of all resources damaged by producing and consuming the fuel source (most importantly, the nonmarketed resources such as air and water quality). These physical damages represent the loss of resource quantities that fall outside the normal transactions in fuel '.ycle markets. The second component of measuring external costs involves the estimation of the opportunity costs of the used or damaged resource quantities. Opportunity costs reflect the value of goods and services foregone by applying resources to one use rather than another.

Following are the three primary research objectives for the first 18 months of this project:

1. to create a unified conceptual design for quantifying the various external costs associated with the production and consumption of energy from different fuel sources in the U.S.,

2. to demonstrate an accounting framework that can be used to estimate the static measures of a broad range of extemal costs that result from incremental use of different fuel types and to use this information in a comparative analysis of fuel types, and

3. to identify critical methodological issues and information needs that will affect any expanded efforts to develop comprehensive assessments of the social costs of energy use.

\subsection{REFERENCES}

1. National Science Foundation, Draft Supplemental Environmental Impact Statement for the United States Antarctic Program, December 1990.

2. C. Chester, Accident Assessment for the Chemical Stockpile Emergency Preparedness Program, Oak Ridge National Laboratory, ORNL/TM-11354, August 1990. 
3. R. Miller, Atmospheric Dispersion Modeling and Meteorological Monitoring in Support of Emergency Planning and Response for the U.S. Army's Chemical Stockpile Emergency Preparedness Program, Oak Ridge National Laboratory, ORNL/TM-11508, August 1990.

4. D. L. Feldman and J. Dobson, Decision Making Technical Support Study for the U.S. Army's Chemical Stockpile Emergency Preparedness Program, ORNL/TM-11412, Oak Ridge National Laboratory, August 1990.

5. Oak Ridge National Laboratory and Schneider Engineers, Planning Guidance for the Chemical Stockpile Emergency Preparedness Program Final Interim Draft, Department of the Army/FEMA, April 1990.

6. G. Rogers, A. Watson, J. H. Sorensen. R. Sharp, and S. A. Carnes, Evaluating Protective Actions for Chemical Agent Emergencies, Oak Ridge National Laboratory, ORNL-6615, July 1990.

7. D. L. Feldman, Implications of SARA Tille III for Community-Based Emergency Planning in the U.S. Army Chemical Stockpile Disposal Program: The Acquisition of Emergency Equipment, ORNL/TM-11388, Oak Ridge National Laboratory, July 1990.

8. S. Rayner, "Prospects for $\mathrm{CO}_{2}$ Emissions Reduction Policy in the U.S. Energy Sector," to be published in Energy Policies and the Greenhouse Effect, Vol. 2, ed. M. Grubb, RIIA/Dartmouth, Brookfield, $\mathrm{Vt}$.

9. D. L. Feldman, Implementing Global Climate Change Agreements: Compliance, Verification, and Participation in an International Context, ORNL Draft Working Paper, Oak Ridge National Laboratory, 1990.

10. S. Rayner, "A Cultural Perspective on the Structure and Implementation of Global Enviroumental Agreements." Evaluation Review 15(1), 75-102 (February 1991).

11. E. L. Hillsman, Think Locally, Act Globally: Assessing the Potential for Responding to Global Issues by Solving Local Problems, ORNL Draft Working Paper, Oak Ridge National Laboratory, 1991. 
ORNL-Photo 2735-91
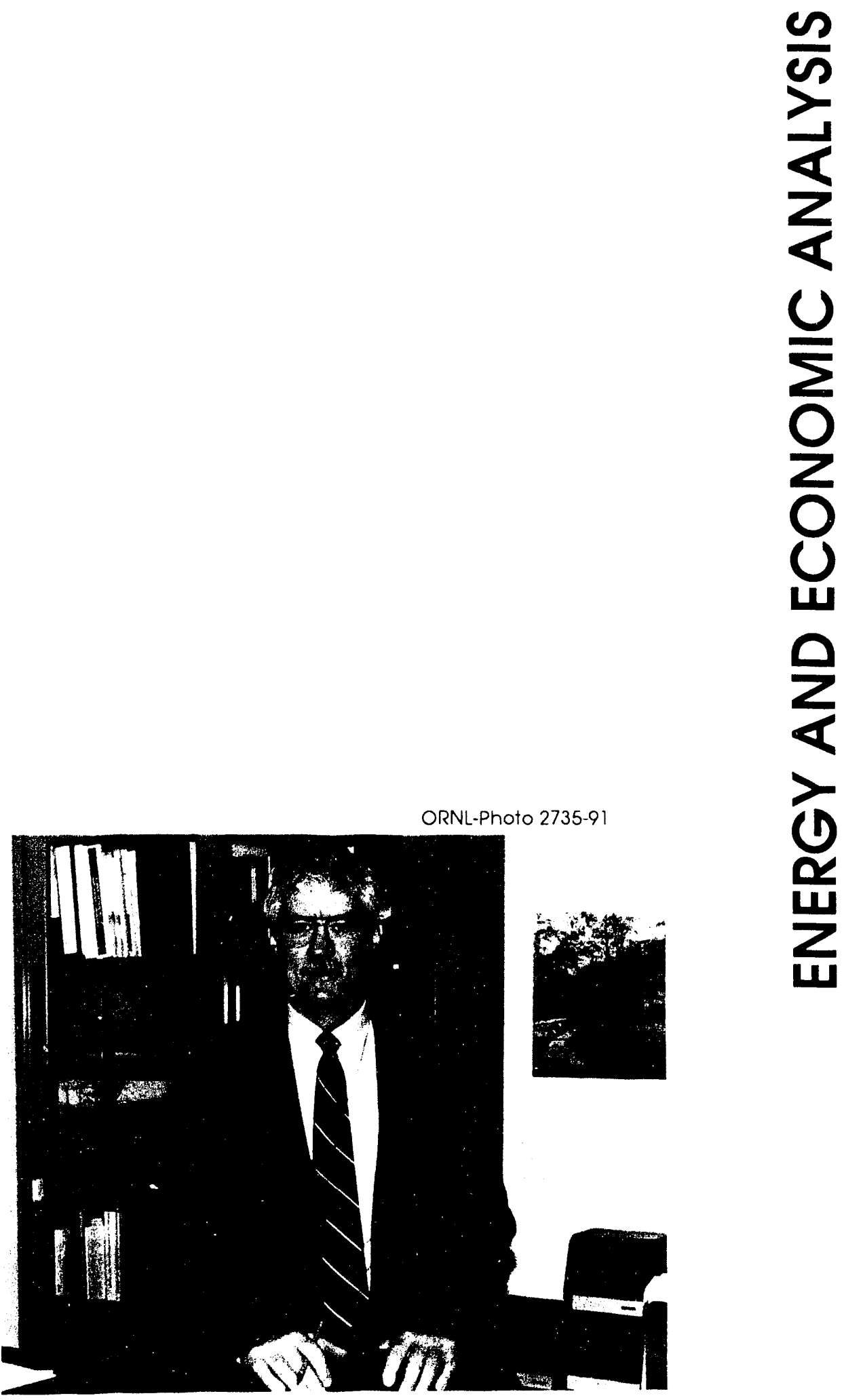

C. R. Kerley, Head 


\section{ENERGY AND ECONOMIC ANALYSIS SECTION OVERVIEW}

\subsection{INTRODUCTION}

The Energy and Economic Analysis Section (EEAS) specializes in economics research. The section is staffed with economists trained in such areas as energy economics, natural resource and environmental economics, public policy studies, applied microeconomic theory, econometrics and mathematical modelling. and economic geography and regional science. Most of the professional staff hold doctoral degrees. EEAS maintains an independent research agenda for the U.S. Department of Energy (DOE) and other sponsoring agencies and supports research projects in other Energy Division sections and Oak Ridge . 'nional Laboratory (ORNL) divisions. Collaborative research with university programs is accomplished through research staff being appointed jointl ' to EEAS and a university. During fiscal year (FY) 1990, two Collaborating Scientists-Milton Russell, former Assistant Administrator for Policy and Planning at the U.S. Environmental Protection Agency (EPA) and a University of Tennessee- (UT-) ORNL appointee, and George Horwich, Purdue University's Burton Morgan Professor for the Study of Private Enterprise-undertook new research initiatives as a result of collaboration with EEAS staff. Russell served as Chairman of the National Acid Precipitation Assessment Program Oversight Committee and undertook a preliminary study on biomass energy utilization opportunities in the Yunnan Province of China, a project jointly sponsored by DOE, the Rockefeller Foundation, and the United Nations Development Program. Horwich continues research at Purdue University on the role

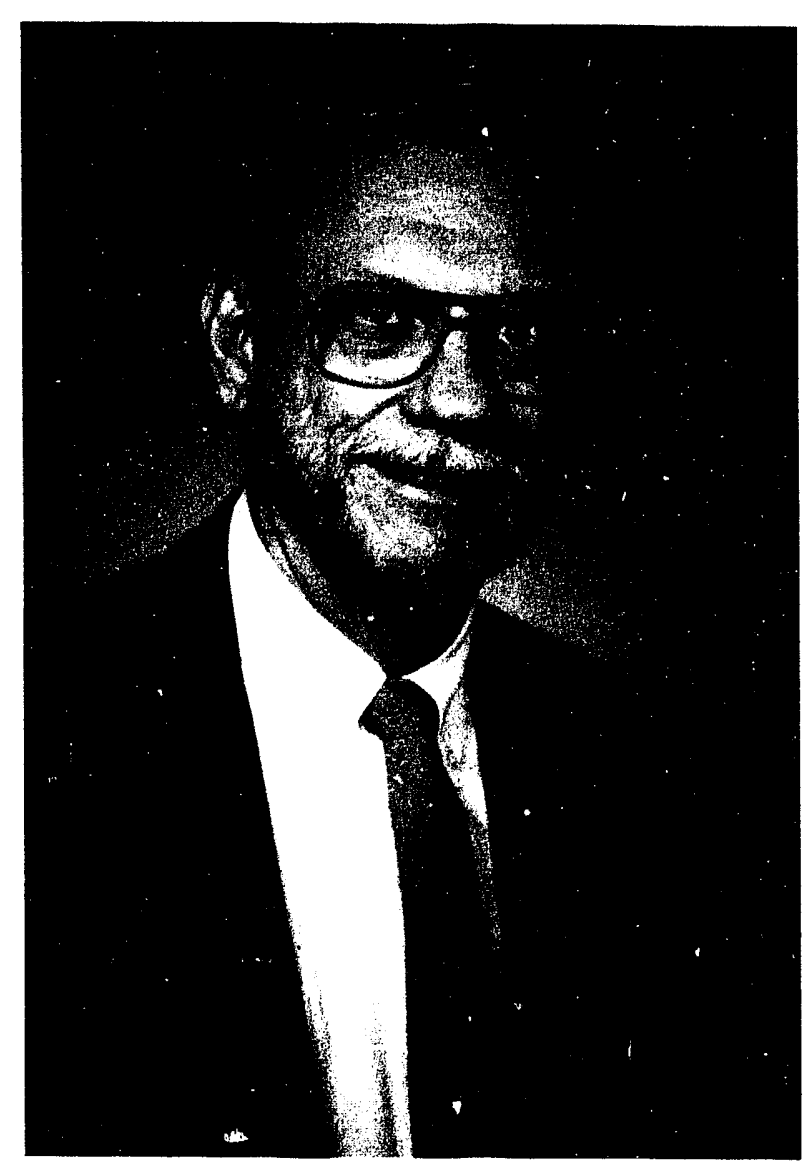

Milton Russell, a Collaborating Scientist in Energy Division. of private sector participation in emergency response, a research project that is important to the EEAS emergency management program. These initiatives with universities are influencing directions of U.S. environmental legislation and emergency management policy.

\subsection{INFURMATION TRANSFER}

An important objective of the EEAS research program is to disseminate research information to DOE, the scientific community, other government agencies, and the public. The EEAS research results are published in refereed journals and ORNL reports. Presentations are made to scientific conferences and workshops, to national advisory boards, and to Congress. In the past, the EEAS has been asked to provide white paper summaries for newly appointed agency administrators to aid in formulating mission plans and programs. 


\section{Modeling for the Strategic Petroleum Reserve}

This year R. Lee and P. N. Leiby led a team that developed and compared models for Strategic Petroleum Reserve (SPR) planning in support of the DOE Office of Planning and Financial Management, Petroleum Reserves. These models assess the economic value of expanding either the size or the drawdown and distribution capability of the U.S. SPR. In. this phase of analysis, the ORNL researchers extensively discussed how to effectively model the SPR size question with members of a federal Interagency Task Force. Existing models, some of which were developed by ORNL researchers, served as a focal point for an Interagency Task Force that developed a new model, Interagency Working Group Midcap Result [Disruption Impact Simulator-(DIS-) SPR]. Issues addressed included alternative characterizations of Organization of Petroleum Exporting Countries, mechanisms to include oil market uncertainty, estimates of the macroeconomic consequences of oil-market disruptions, the need to produce easily interpreted output, and various subtle cost-benefit: accounting considerations. These issues subsequently received attention from other governmental agencies (Office of Technology Assessment and General Accounting Office), and aspects of the modeling problem were ultimately raised in congressional hearings on SPR size. Two of the challenges faced in the modeling of SPR size were (1) presenting the important assumptions and structure of a model to decision makers and (2) explaining how those factors determine the conclusions drawn. In the validation and comparison of altemative models, ORNL sought to reveal explicitly how each of a sequence of changes in model assumptions and structure contributed to diametrically opposed conclusions of two competing models (see Fig. 3.1). In Fig. 3.1, a chart of the estimated incremented benefits from expanding the SPR under various operations assumptions is displayed. In the set of model runs displayed, the lowest benefits are represented by the 1990 DIS-SPR Model, and the highest, by the Energy Modeling Forum parameters for gross national product losses caused by oil price rises. The variation in modeled benefits illustrated the uncertainties associated with model forecasts and assisted the Interagency Task Force in understanding the range of results that have been reported by various researchers and government units working on strategic reserve planning. The two primary conclusions drawn from ORNL's modeling that were ultimately implemented in policies of Congress and the Executive branch were the expansion of the SPR to 1 billion barrels of oil and the immediate drawdown of the reserve at the onset of a disruption or an adverse market adjustment. 
URNL DWG. $91 Z-7907$

!NCREMENTAL EXPANSION BE,IEFITS (\$ BILLION 1988)

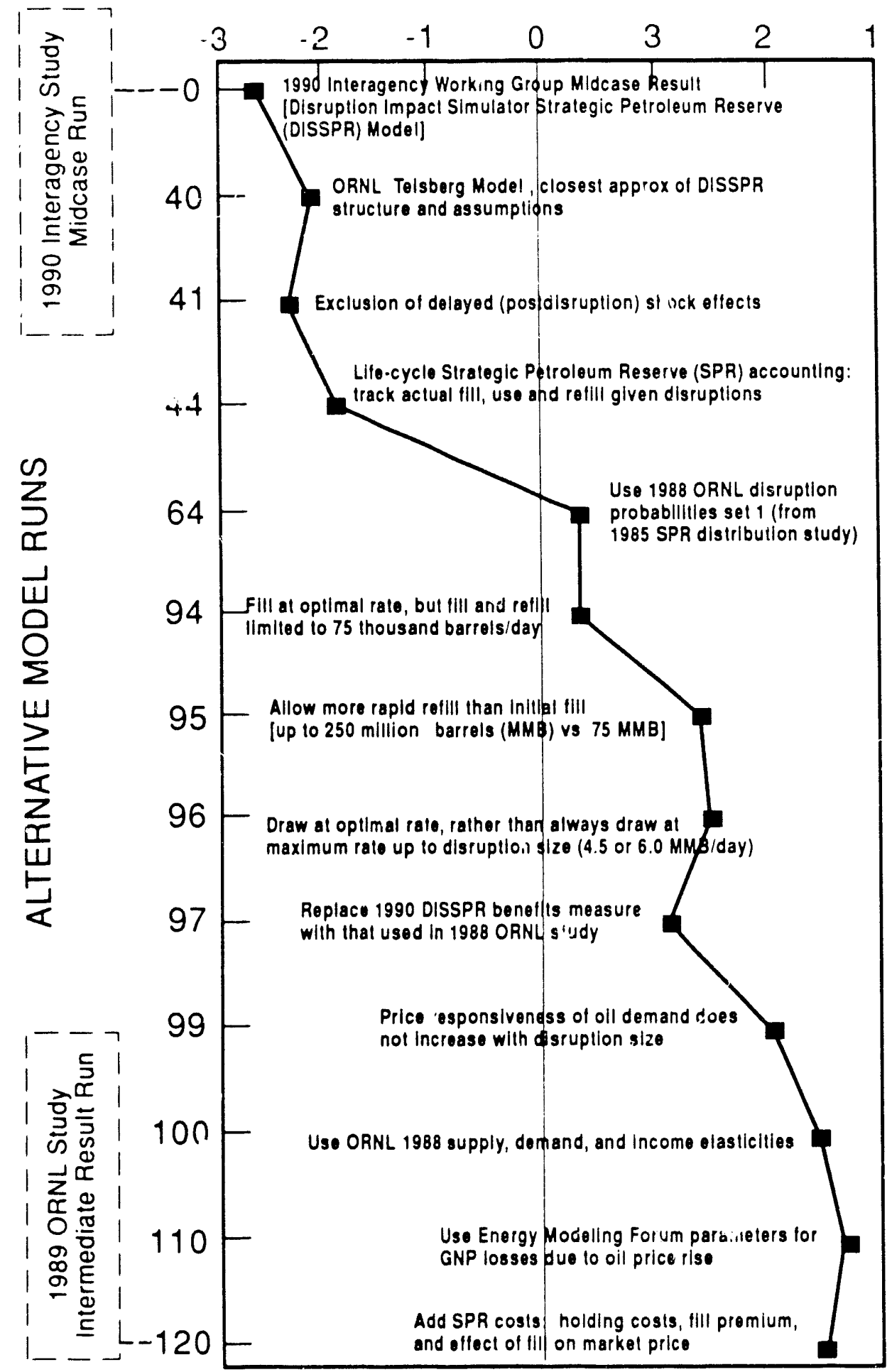

Fig. 3.1. Estimated net benefits as Strategic Petroleum Reserve model structure and assumptions are altered. 


\subsection{RESEARCH PROGRAM}

Our research program consists of four broad categories of projects: productivity and energy security. energy and environment, modeling and technology, and emergency response and risk acceptance. In this report. we highlight a few new activities that were undertaken in FY 1990 by the two groups in the section-the Energy and Environmental Economics Group led by Ditvid J. Bjornstad and the Resource Modeling and Technology Economics Group led by Russell Lee. Throughout. reference will be made to secondary scientific benefits from the work including (1) how other agencies such as the U.S. Department of Defense (DOD) benefit from DOE research and (2) how interdisciplinary teams are being used to find innovative solutions to energy-related issues of national importance.

\subsubsection{Productivity and Energy Security}

The projects conceming productivity and energy security research assist DOE in addressing policy issues related to strategic fuel reserves, reserve drawdown, energy efficiency, fossil energy technology, and energy security.

The Strategic Petroleum Reserve (SPR) research project also began analysis of a separate planning question. whether part of the U.S. petroleum stockpile should be stored regionally, as petroleum products. rather than centrally stored as crude oil. Such a Refined Petroleum Product Reserve (RPPR) would be a part of the SPR system but might be distillate heating oil stored in New England or gasoline stored in California, for example. Previous DOE studies have established that life-cycle costs for refined product storage are significantly higher than those for centralized crude storage. Specifically, product storage facilities (possibly steel tanks rather than abandoned salt mines) would have a higher capital cost, and operating costs may be higher because of the shorter shelf life of refined products. The key to assessing RPPR benefits includes identifying and evaluating the advantages of pre-positioned refined stocks compared with SPR crude. which must be refined and transported to meet the needs of end users. The study identified two classes of events for which an RPPR may be suited: (1) regional or product market disruptions, such as extremely cold winters or maje refinery accidents and (2) crude oil supply disruptions accompanied by significant lags and constraints in the crude oil refining and distribution system. The value of the RPPR is strongly tied to the degree to which a regional product market can become temporarily isolated and suffer extreme costs before additional crude oil can be refined into the needed product mix and transported to market. Historically. the monthly price movements for a particular product (gasoline or heating oil) are tightly linked across U.S. regions, but price movements may vary sharply between products (see Fig. 3.2). A preliminary analysis of potential RPPR benefits also emphasized that many of the costs of a regional product disruption correspond to transfers to U.S. producers and producing regions. The assumed ability of an RPPR to reduce the costs of oil imports is limited by nature of the assumption of an isolated product market.

An important energy security topic related to the SPR rescarch was addressed by a team composed of D. J. Bjornstad and T. R. Curlee of the EEAS and D. R. Bohi of Resources for the Future. They prepared a concept paper on the benefits of energy security. and policies that could alter costs and benefits, for DOE's Office of Energy Emergencies. In this paper, the autioors emphasized prolicies that the government should adhere to for three different aspects of emergency cictizy activities. First. government should condition the decision-making environment by ensuring that adequate information about energy conditions is available and that its own policy position is clear. Next, government should evaluate the preparedness measures undertaken by the private sector by applying two measures: efficiency and equity. Efficiency measures the tradeoffs between current costs and uncertain future henefits if an energy emergency occurred. The equity involves the deternination of whether the burdens of an emergency are distributed fairly.

Several conclusions were reached in considering bew emergency policy intiatives govermment should consider the impacts of its other policy responsibilities, such as environmental degradition, and policy makers should realize that their ability to ameliorate impacts is limited. For individuals, burdens can always be redistributed-tax dollars can ensure that firms or families are not devastatcd. But, on an aggregate basis, emergencies will always impors costs, which can be offset some what by: preparation but are increased by policies that reduce economic efficiency.

The productivity and energy security research has included some research applications for DOD's Coal Conversion Program. A team of economists and engineers led by $C$. R. Kerley of the EEAS and supponted by R. M. Shillings, R. S. Holcomb. F. P. Griffin, ald R. H. Staumton of the Engineering Technolegy Division has used ORNL_s fossil energy technology research fo find solutions 


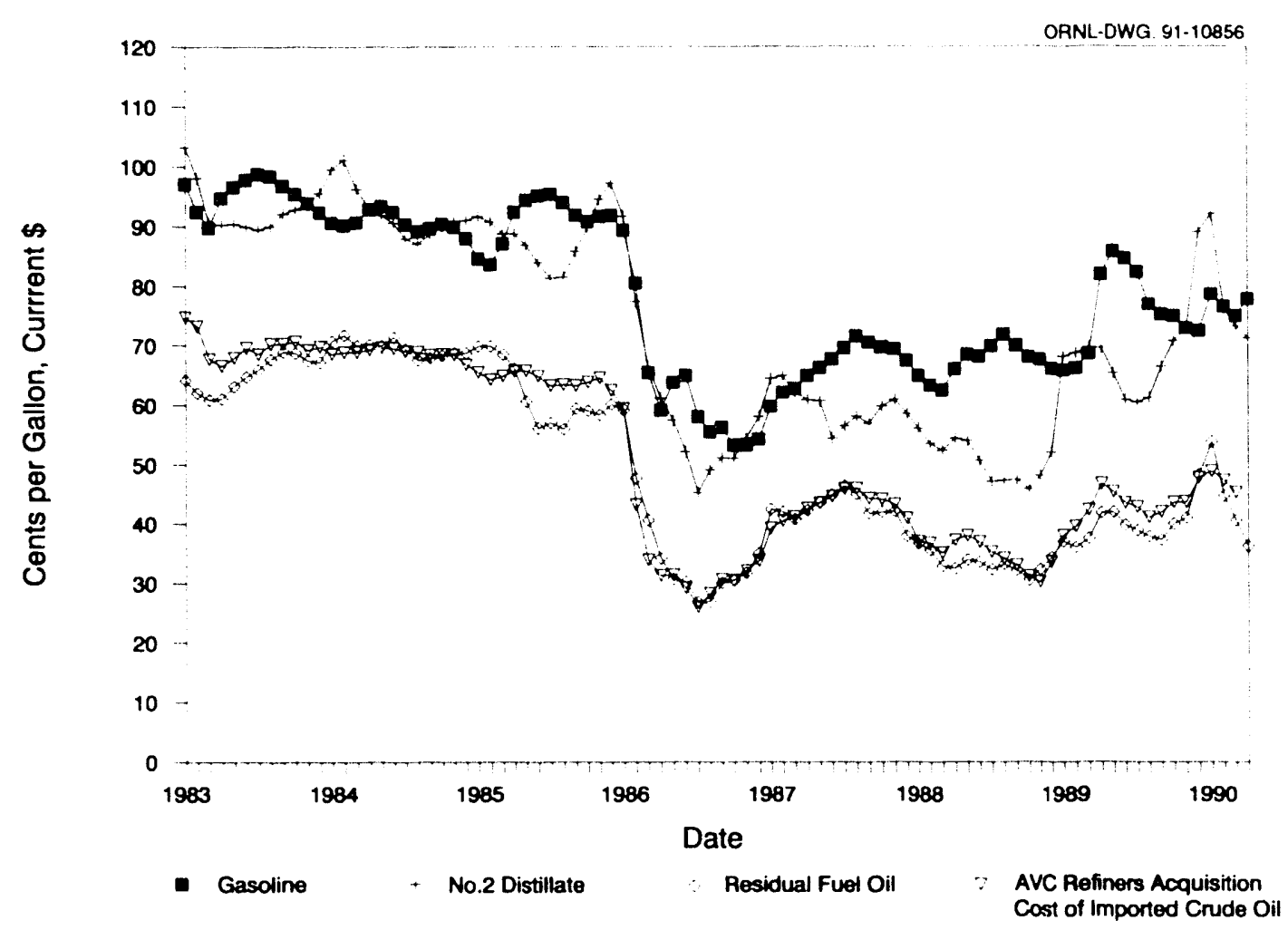

Fig. 3.2. Petroleum product price variation in the United States.

to energy requirements on Air Force bases. Advanced energy management concepts, such as private sector financing and operation, clean coal technology, share energy savings contracting, and demand side management were examined through life cycle costing analyses and cost-benefit techniques to find energy technology applications that are superior to status quo operations on two Air Force bases-Andrews Air Force Base in Maryland and McGuire Air Force Base in New Jersey. Our results indicated that clean coal technologies can meet environmental standards and produce an economic benefit to cost ratio of 1.10 to 1.5 when compared with status quo operations. Government owned cogeneration was not found to be economically viable based on Air Force energy requirements; however, it was determined that privately owned cogeneration plants producing both a larger constant output of electricity for sale to the electric grid and the heating needs of the base would be economical and would provide economic returns sufficient to evoke interest from private developers. We recommended that the Air Force proceed with preparing a request for proposal to invite proposals for private sector development of new energy facilities to meet the base energy requirements. It was recommended that the solicitation permit fuel choice and facility size and type and stipulate only that the proposed option prove to be the most life cycle cost effective for meeting Air Force energy requirements.

\subsubsection{Energy and Environment}

Energy and environment projects include economic analysis of the following: conventional energy use, the substitution of biomass fuels in developing countries, protecting and rebuilding natural environmental systems, agriculture and environment interaction, and ambient air quality.

In our international research, a team composed of R. D. Perlack, Energy Division, J. W. Ranney, Environmental Sciences Division, and M. Russell, Collaborating ORNL-UT Scientist, has found that an indigenous energy supply, biomass, is particularly well suited to small-scale and decentralized energy applications.

Yunnan Province, in the southwest region of China bordering Myanmou (Burma), Laos, and Vietnam, is suffering from a critical shortage of energy. Rural energy problems in Yunnan have resulted in pervasive environmental degradation from biomass fuel collection. The unavailability and unreliability of electric power during the dry season has idled industrial production and has constrained the development of new rural industry. For these commercial energy users, there are shortages and no 
economically viable substitutes. Coal is in limited supply and, if available, is expensive becatuse it must be transported over severely inadequate roads. Considerable hydroclectric potential exists in Yunnan, but low-head projects have highly scasonal output (monsoon conditions), and energy production and irrigation must compete for water.

Our preliminary feasibility study of generating electricity irom biomass energy plantations in Central Yunnan Province identified sites with a resource potential of 24,000 to 45.000 dry tonnes/year. Average annual productivity rates of about 8 dry tonnes/ha were found to be feasible. This level of feedstock production would be sufficient to fuel a $20 \mathrm{MW}$ conversion plant operating with a margin of safety sufficient to cover all but catastrophic failures. Cost of electricity generation was estimated to be about 0.22 yuan $/ \mathrm{kWh}(\$ 0.047 / \mathrm{kWh})$, which may be competitive with generation from coal-fired plants. The ancillary economic development benefits are substantial because of the shortages of electricity, so the value of electricity exceeds its cost of production. In assessing the biomass resource potential, it was concluded that further research (tree crop improvement, site-species trials, and soil stabilization methods) should be conducted before large scale technology deployment is undertiken so that major cost and supply risks can be avoided and so that long-run results will be better.

Nonetheless, a project to demonstrate the concept and to gain information required for scale-up appears sufficiently promising to warrant immediate follow-up and a second stage, detailed investigation. A relatively minor investment in further investigation at this time could open a potentially large market for U.S. technology, the deployment of which would have substantial locial and global environmental benefits as well as improve economic conditions.

A second international program study focused on sub-Saharan Africa. The work was performed by an interdisciplinary team composed of R. D. Perlack. EEAS; D. B. Waddle, Energy Division: and R. Graham, A. Prasod, and J. Ranney of the Environmental Sciences Division. The team studied the potential to reduce greenhouse gas fluxes, principally carbon dioxide. Management of vegetation and fossil fuel trends were and will continue to be evaluated on a yearly hasis from 1985 to 2001. Carbon emissions under different land-use strategies were analyzed by modifying deforestation rates and altering the amount of carbon stored under different lañd-use practices. Threc management options were chosen to address the root causes of deforestation in sub-Saharan Africa: agricultural encroachment, fuel-wood demand, and logging. The land-use options included preservation of existing forests, implementation of agroforestry schemes, and establishment of industrial tree plantations. Of the three land-use options for reducing carbon emissions, aggressive forest protection (total halt of deforestation in conjunction with recovery of degraded forest) yielded the greatest carbon benefit.

Among the findings, our economic analysis suggested that the minimum costs for implementing these options would range from $\$ 25$ to $\$ 115 /$ ha for preservation, $\$ 50$ to $\$ 150 /$ ha for agroforestry, and $\$ 560$ to $\$ 1,060 /$ ha for industrial plantations. These costs are for direct expenses (e.g., seedlings, extension. management) and do not account for institutional constraints (c.g., land tenure arrangements), the need to purchase land, or other location specific factors. Of the three land-use options, industrial reforestation is perhaps the most easily implemented, although the cost per tonne of sequestered carbon is higher for industrial reforestation ( $\$ 11$ to $\$ 22 / t o n n e$ ) than for preservation ( $\$ 3$ to $\$ 15 /$ tonne) and agroforestry (\$2 to $\$ 10 /$ ionne). However, implementing any of these land-use options will depend on population density and rates of population growth (natural growth, migration, or resettlement) as well as other factors such as customs and policies affecting the allocation of land and tenure, access to markets (i.e., infrastructure), foreign debt, government policies designed to generate foreign exchange from cash crops and timber exports, the availability of inputs and local technical skills for intensifying agriculture, and the adequacy of institutions to manage these problems.

Several general land-use policy conclusions were made. First, the Congo basin of Central Africa shelters an enormous pool of carbon in vegetation. The countries of Zaire, Gabon, Central Africal Republic, Cameroon, and Congo contain half the forest carbon of sub-Saharan Africa-about 26,()o) million tonnes of carbon. Due to inaccessibility and fairly low population pressures, this porl is still largely intact. However, it could suffer the fate of the Amazon basin and could be plagued by similar carbon emissions if transportation access improved and governments did not re-cvaluate their overly lenient timber concession policies. Policies that promote the maintenance of this carbon p(x)l, such as controlled logging. reforestation, and reduction of agricultural and fuel-wood pressures, should be pursued. Second, the information base upon which to develop sound specific policies is extremely limited for Central Africa. Development of that information base should take high priority. Finally, as elsewhere in the tropics, deforestation in sub-Saharan Africa is driven hy agriculture, fucl-wood needs. and international wood markets. These issues must be addressed if deforestation is to he successfully 


\section{Auction Mechanisms for Air Emission Permits}

Under the sponsorship of the Energy Information Administration (EIA), D. J. Bjornstad (ORNL) and D. Hale (EIA) researched the nature of auction mechanisms for air emission permits by conducting experiments at the University of Arizona and the University of Colorado. The expcriments sought to analyze the efficiency properties of the auction mechanism under which the marketable permits for controlling $\mathrm{SO}_{2}$ emissions would be traded. Because the project calls for the analysis of market mechanisms that cannot be observed directly, a "laboratory" approach was applied in which analogous, carefully structured markets were created using computerized trading among volunteer subjects who could earn profits by effective trading.

The laboratory experiments sought to address three of the most fundamental questions associated with the auction mechanism.

1. Would a mandatory central auction for some portion of the overall permit allotment promote beneficial exchanges that might not otherwise occur?

2. How do the pricing rules for conducting the central auction affect efficiency?

3. How does the nature of the permit-its life, whether it can be banked for future use, and the availability of sequences of permits (e.g., a 5-year permit)-affect efficiency?

The results of the experiments suggested that mandatory auctions improved efficiency relative to a no-trade alternative. As the share of permits assigned to the central market increased from $10 \%$ to $100 \%$, actual efficiency gains approximated theoretical gains of a competitive market, and prices fell to market clearing levels. This suggests that the price signal given by the mandated market may not be a good estimate of the price that would be generated by a market in which $100 \%$ of emission permits were traded. However, because prices based on marketed shares of less than $100 \%$ overestimate the efficient price, an incentive is provided for additional voluntary trading, which in turn generates further efficiencies.

Other results obtained indicate that a single-price revenue neutral auction-that is, an auction in which all revenues from permit sales are redistributed to original holders-closely approximates the efficiency of a purely competitive market. However, there is a tendency for emitters who initially hold permits to bid higher than efficient prices to "hoard" permits, knowing they will get a revenue rebate to cover their expenditures. This leads to the conclusion that uniform pricing opens the possibilities for inefficiencies resulting from hoarding and that other revenue neutral pricing schemes should be considered. Also, a voluntary market with complex bundling of permits and banking yielded relatively low efficiencies. Therefore, administrative ways of simplifying the auction that would retain the theoretical efficiencies of a competitive market should be considered. 


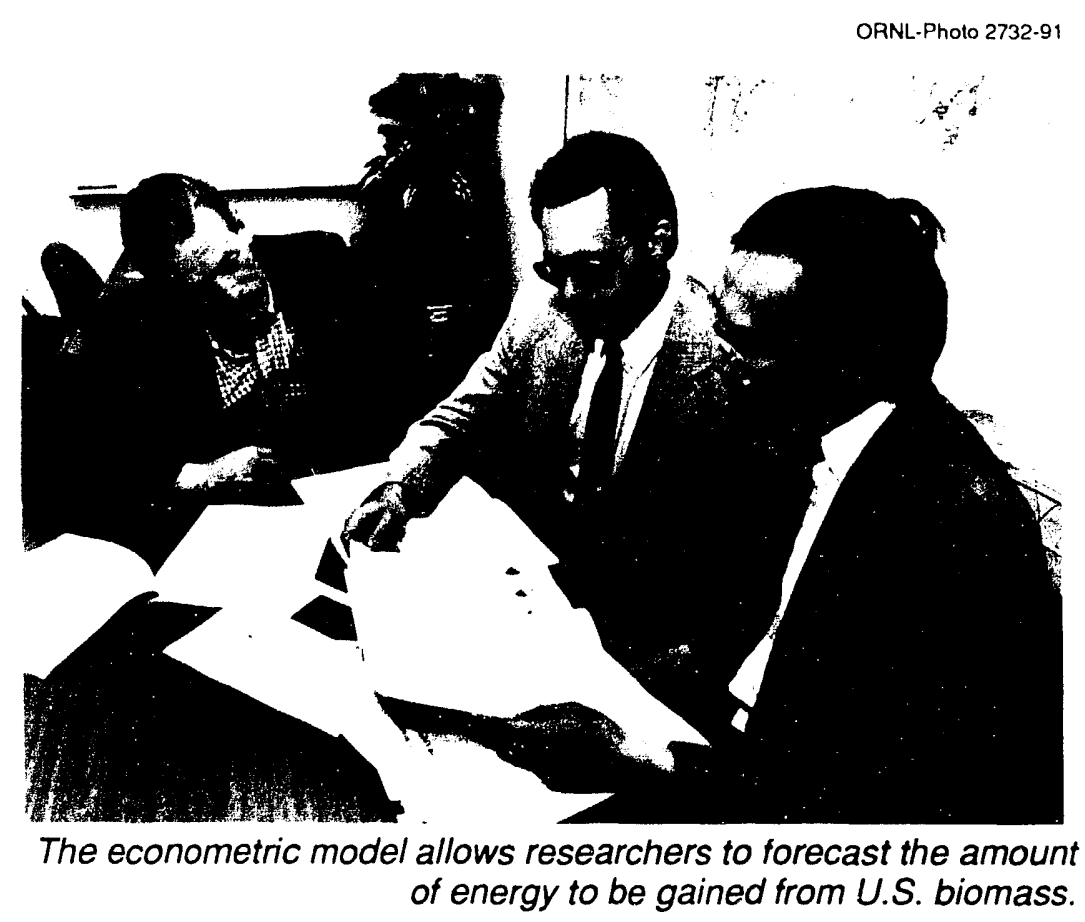

controlled and reforestation or afforestation implemented. The analysis of the energy sector in sub-Saharan Africa indicates that fossil fuel carbon emissions do not and probably will not play a major role in global carbon inventory changes. However, it is apparent that savings could be made in emissions through a variety of energy conservation and fuel substitution programs.

Paralleling the intemational $\mathrm{CO}_{2}$ issues, the section continued related research in support of atmospheric quality issues important to the national economy. This year, the Congressional Research Service requested a study of the $\mathrm{CO}_{2}$ emissions from the production of ethanol from corn. (The study was funded by the Cartonn Dioxide Research Program, Atmospheric and Climate Change Division, Office of Health and Environmental Research, and Office of Energy Research.) The production of ethanol from corn requires the use of fossil-based inputs (e.g., fertilizers, machinery fuel, and steam from coal) to produce the corn and to convert the corn into ethanol. However, the amount of $\mathrm{CO}_{2}$ attributable to the production of ethanol from corn can be highly variable because of (1) geographic variability in corn yield and agricultural practices; (2) temporal variability in com yield, primarily because of weather; and (3) temporal changes in conversion processes and process efficiency. The work conducted by G. Marland, Environmental Science Division, and A. F. Turhollow, EEAS, concluded that, in general, ethanol produced from corn results (on an energy basis) in $\mathrm{CO}_{2}$ emissions that are $79 \%$ of those from an equivalent amount of gasoline. About $75 \%$ of those emissions result from the conversion of corn into ethanol, and $25 \%$ from the production of corn. Production of ethanol in the most and least efficient conversion facilities results in emissions of $67 \%$ and $91 \%$ of those of gasoline, respectively.

A different air quality inquiry was related to the national clean air policy. This study was conducted for the Energy Information Administration. Last summer Congress met as a conference committee to reconcile remaining differences in proposed Amendments to the Clean Air Act. The main task was the definition of a marketable permits scheme to reduce sulphur dioxide emissions from about 16 million tons per year in 1987 to no more than 8.9 million tons per year in 2001 . Under the proposed legislation, permits to generate sulphur dioxide emissions would be distributed to utilities who would "spend" the permits as they emitted sulphur dioxide or trade the permits if they produced emissions that fell below their permit allotments. Thus, the government would control the total amount of sulphur emitted through the number of permits it issued, and the producers would choose the optimal mix of labor, fuel, capital, and permits, based on individual circumstances that would differ considerably from producer to producer. 


\section{Econometric Model for Forecasting Biomass Energy}

Forecasts of the amount of energy from biomass in the United States, principally from wood, energy crops, and municipal solid wastes (MSWs), were projected with the use of an econometric model. Projects of the model indicated that energy from wood in the year 2030 would be 4.7 quads in the industrial sector, 1.7 quads in the residential sector, and 0.1 quad in the commercial and utility sectors-a total of 6.5 quads. This projected quantity is more than double current consumption. Analysis of the use of energy crops gave a projection of 5.5 quads in 2030-although there is considerable uncertainty about the extent and timing of the market penetration of energy crops. For MSWs the estimates accounted for the future volume of wastes per capita, the heat content of the waste stream, and the amount of waste incinerated to produce energy. The projection was an increase in MSW energy from the current level of less than 0.3 quad to 1.6 quads in 2030. Overall, as illustrated in Fig. 3.3, biomass is expected to contribute to a significantly larger share of the nation's energy needs.

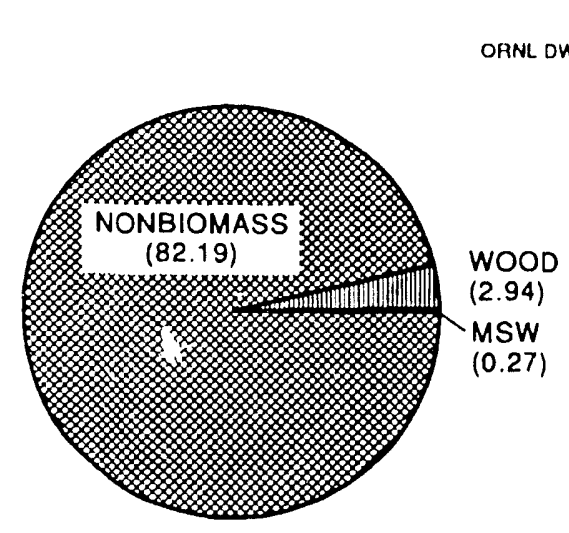

1990

85.4 QUADS TOTAL

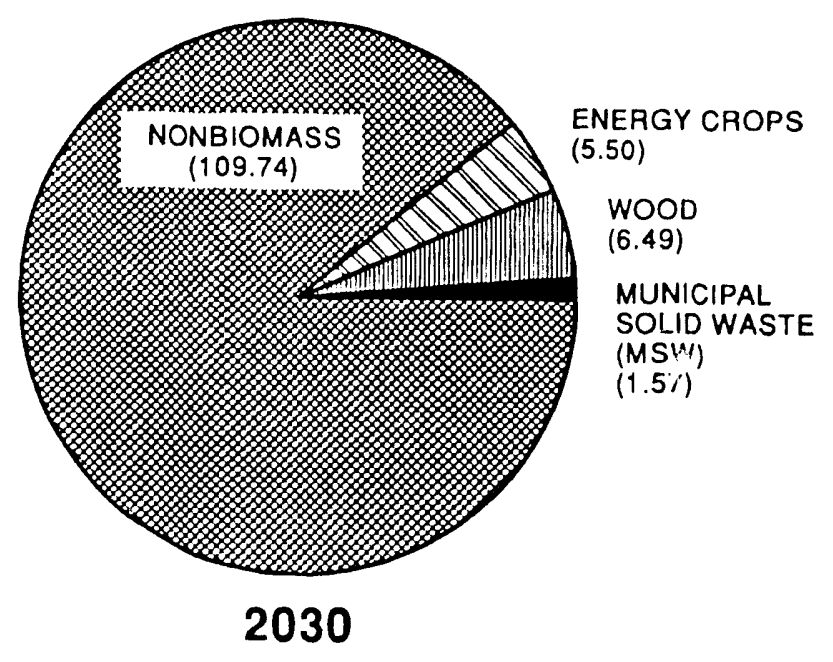

123.3 QUADS TOTAL

Fig. 3.3. The contribution of biomass to the total energy supplied to the U.S. economy (in quads). 


\subsubsection{Modeling and Technology}

Projects and activities in economic modeling and technology research include model development and expert review, manpower studies, and new technology and materials development and transfer. Two important activities this year were (1) continuation of our annual uranium market forecasts and (2) a new biomass energy forecast conducted to support the EIA effort related to the National Energy Strategy (NES) and the Annual Energy Outlook (AEO).

Forecasts of the uranium market were used in DOE's annual report on the viability of the domestic uranium mining and milling industry. The forecasts suggest continued low U.S. uranium production levels of less than 10 million $\mathrm{lb}^{308} \mathrm{U}$. After the year 2000 , worldwide uranium demand is projected to increase moderately, and utilities' excess inventories will have considerably decreased; U.S. producers are expected to participate in this improved market. However, most U.S. production after 2000 is uncertain, being from either new mines and mills or from some that are currently on standby. The projected U.S. uranium supply-demand balance is graphed in Fig. 3.4.

In the technology and materials analysis research, which focuses on municipal solid waste, recycling of plastic, and $m$; rkets for ceramics, two new activities were initiated in FY 1990. S. Cohn conducted an assessment of the economic feasibility of integrating superconductive magnetic energy storage devices (SSDs) with conventional electrical substations along electrically powered rail transit lines. Research and analysis on the project were jointly funded by the SSD manufacturer,

Superconductivity, Inc., and the High Temperature Superconductivity Pilot Center Program. Interim results showed that the benefit-to-cost ratios were less than 1.0 for all of the existing systems analyzed. Somewhat higher benefit-to-cost ratios were calculated for the planned expanded portion of rail systems. The primary reason the SSD units appear to be economically unattractive is because SSD units and their associated equipment cannot be substituted for conventional traction substition equipment. A project teing conducted by the SSD manufacturer and the Bay Area Rapid Transit system authorities is likely to show substantial improvements in the method of determining cost effectiveness for integrating the SSD with rapid transit rail systems.

The second new study, conducted by S. Das, focised on developing recommendations for a comprehensive information database on advanced materials and polymers in support of the Branch of Materials, U.S. Bureau of Mines (BOM).

Table 3.1 summarizes results from the circulation of a questionnaire developed to determine interest in obtaining information for various categories of advanced materials. The likely users of BOM information on advanced material who were questioned expressed greatest interest in obtaining information on the properties of the materials, materials uses, technology, prices, and the costs of

ORNL DWG 912.7906

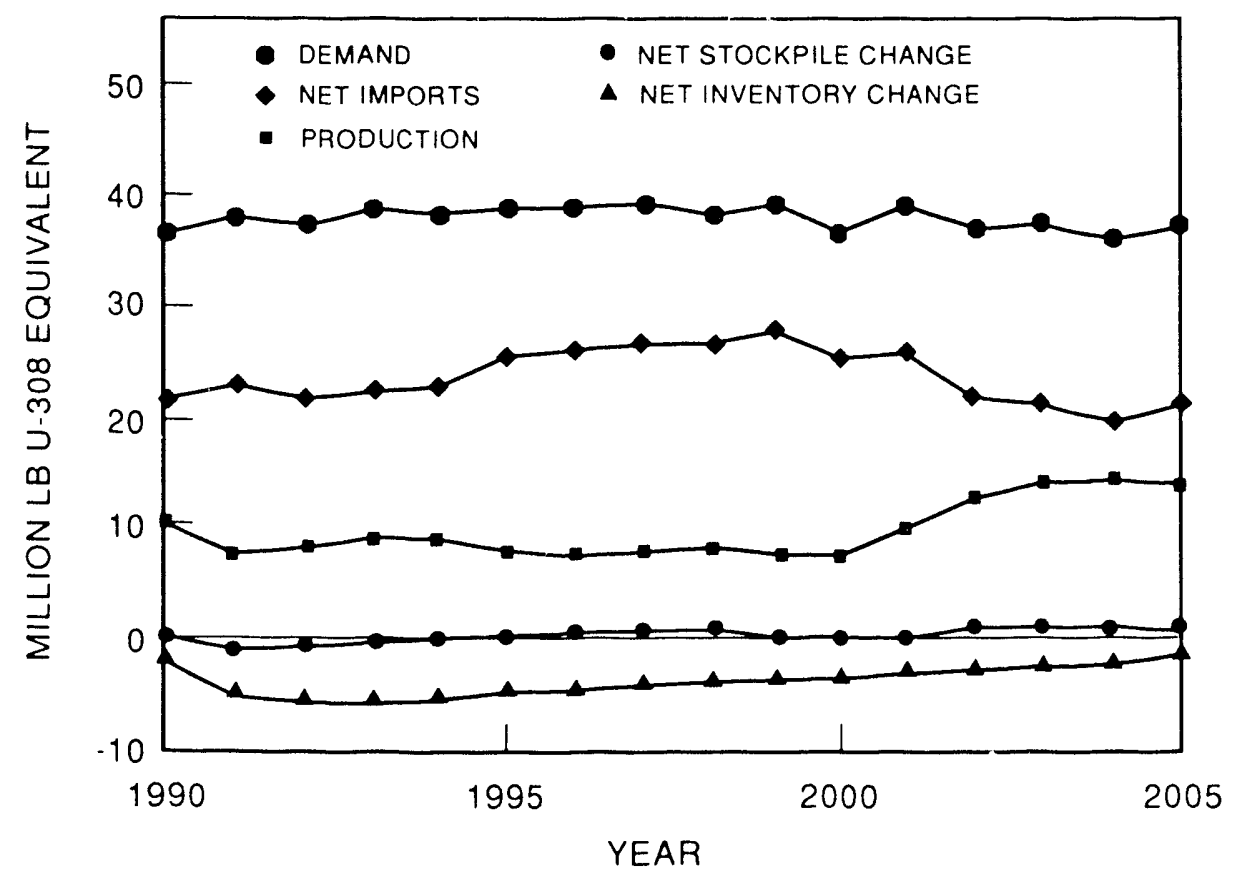

Fig. 3.4. Projected U.S. uranium suippiy andud deninand. 
Table 3.1. Interest in obtaining the types of information for various categories of advanced materials

\begin{tabular}{|c|c|c|c|c|c|c|c|}
\hline Information & $\begin{array}{c}\text { Structural } \\
\text { metals }\end{array}$ & $\begin{array}{c}\text { Composite } \\
\text { metals }\end{array}$ & $\begin{array}{c}\text { Monolithic } \\
\text { structural } \\
\text { ceramics } \\
\end{array}$ & $\begin{array}{l}\text { Composite } \\
\text { structural } \\
\text { ceramics } \\
\end{array}$ & $\begin{array}{l}\text { Structural } \\
\text { engineering } \\
\text { polymers }\end{array}$ & $\begin{array}{l}\text { Composite } \\
\text { engineering } \\
\text { polymers }\end{array}$ & $\begin{array}{c}\text { Electronic } \\
\text { and optical } \\
\text { functional } \\
\text { devices }\end{array}$ \\
\hline $\begin{array}{l}\text { Industry structure (c.g., } \\
\text { size, distribution, } \\
\text { specifications) }\end{array}$ & $\mathrm{A}$ & B & $\mathrm{A}$ & $\mathrm{A}$ & B & A & B \\
\hline Uses of the material & A & A & A & A & A & A & A \\
\hline $\begin{array}{l}\text { Raw materials for } \\
\text { advanced materials }\end{array}$ & B & B & B & B & B & B & B \\
\hline Current technology & A & A & A & A & A & A & A \\
\hline Technology outlook & A & A & A & A & B & A & A \\
\hline $\begin{array}{l}\text { Supply/demand relation- } \\
\text { ships (including } \\
\text { imports, exports, } \\
\text { stocks) }\end{array}$ & A, B & A & B & A & B & B & A \\
\hline Demand forecasts & A, B & A & A & B & A & A & A \\
\hline Supply forecasts & B & A & B & B & B & B & B \\
\hline $\begin{array}{l}\text { Byproducts and } \\
\text { coproducts }\end{array}$ & B & B & B & B & B & B & B \\
\hline Strategic considerations & B & A & $A, B$ & B & B & A & B \\
\hline $\begin{array}{l}\text { Economic factors and } \\
\text { problems (e.g., } \\
\text { prices, costs of } \\
\text { production) }\end{array}$ & A & A & A & A & B & A & A \\
\hline $\begin{array}{l}\text { Operating factors and } \\
\text { problerns (e.g., } \\
\text { toxicity, environ- } \\
\text { mental considerations, } \\
\text { energy requirements) }\end{array}$ & A & A & A & B & $A, B$ & A & B \\
\hline $\begin{array}{l}\text { Legislation and govern- } \\
\text { ment programs }\end{array}$ & B & A & B & A & B & A & A \\
\hline $\begin{array}{l}\text { Properties of the } \\
\text { material }\end{array}$ & A & A & A & A & A & A & A \\
\hline
\end{tabular}

Note: $\mathrm{A}=$ Great Interest. $\mathrm{B}=$ Moderate Interest. $\mathrm{C}=$ No Interest.

production. This interest reflects the economic competitiveness-both at the corporate and at international levels - that may be driving the development of advanced materials and of which advanced materials have become a symbol. Less interest was expressed in information on broader economic and political issues, such as industry structure, supply and demand forecasts, strategic considerations, and legislation and government programs. However, the level of interest was still moderate to great, depending on the material. As one might predict, we determined that greatest interest in obtaining different types of information was associated with advanced materials that have potentially large markets and are further developed as composite metals and composite engineering polymers.

A different set of modeling activities, continuing from previous years, focused on the transfer of two regional economic models to the Army National Guard (ARNG) and the Federal Emergency Management Agency (FEMA).

July 1990 marked the first Advanced Users Workshop for the Regional Recruiting Potential Model (RRPM), a model developed for D. P. Vogt to help the ARNG assess the potential supportability of units placed in specific geographic locations. The model incorporates sophisticated regional economic analysis techniques in a software package that enables users with little computer training and no economics background to generate regional analysis reports. The model's structure also allows advanced users to conduct more complex analyses, such as force structure planning or 
facility location planning. During the workshop EEAS staff introduced the advanced users to basic economic concepts, explained the logic of the RRPM, and identified the most critical information users will need to use the model effectively. Program staff also summarized the results of recent research that addressed ARNG's interest in increasing female membership.

The ARNG research analysis by C. G. Rizy (EEAS) and A. K. Wolfe (Integrated Analysis and Assessment Section) was conducted in five steps using the Reserve Components Common Personnel Data System (RCCPDS) as the primary basis for the analysis. t ine data revealed that almost one-half of the National Guard units are combat units, whereas the remaining units are split fairly evenly between support units and service units. The distribution of male service personnel across unit class closely resembles the distribution of the number of units. The majority of women, $53 \%$, are assigned to service units; $37 \%$ are in support units; and the remaining $10 \%$ are in combat units (the small number of women in combat units is caused, in large part, by the fact that many combat-related positions are closed to women). The top ten military occupational specialists (MOSs) in terms of the number of male personnel, comprise more than $46 \%$ of enlisted male membership in the National Guard. The top ten MOSs for women account for $53 \%$ of female membership. Our analysis indicates that people can be trained to fill a

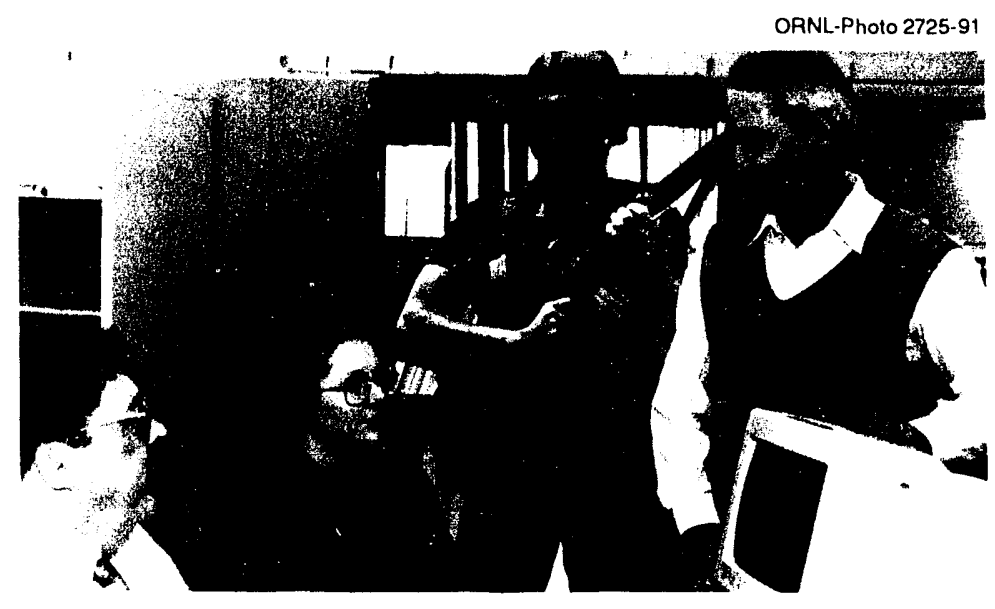
position-they need not have possessed special abilities or skills in their civilian occupations. In the majority of cases, the issue of Researchers work on the Army National Guard Regional Recruiting Potential unit supportability depends on an adequate labor supply from which to recruit in terms of the number of people and does not depend on the availability of a specialized labor force. However, the availability of a labor supply with the skills and abilities associated with broad occupational categories may be useful in siting new guard units. The second model transfer involved improvements in the regional damage assessment modeling system for FEMA and subsequent user training. This work is discussed in the next section.

\subsubsection{Emergency Management and Risk Acceptance}

Projects in the emergency management and risk acceptance category evaluated questions associated with safety and risk, mobilization capabilities, national disasters, and emergencies. In September the Program hosted staff from FEMA at a User Training Workshop for the Facility Damage Assessment Module of the National Infrastructure Information System (NIIS/FDAM). NIIS/FDAM is a component of a regional input-output model that enables planners at FEMA to evaluate the impacts of a variety of disasters on regional and national economies. The workshop provided an overview of the model's capabilities and a demonstration of how to perform a standard analysis, including linkage to the Integrated Emergency Management Information System (IEMIS). FEMA's geographic information system. FEMA and Regional Studies staff are selecting a development strategy to make the model accessible to the Agency's regional offices.

Finally, we followed up on last year's work in support of DOE's assessment of restructuring the energy system of the U.S. Virsin Islands in the wake of Hurricane Hugo. Two recommendations came from our assessment, which was conducted by a six-person team that included four national laboratories and two headquarters DOE staff. One recommendation encouraged establishing a renewable energy center, the other, assessing the efficiency of the Virgin Islands' Water and Power Authority's (WAPA) power delivery system. The assessment will involve a team of professionals organized by ORNL to identify and access economically attractive demand and supply resources for consideration by WAPA management. The assessment will be part of a longer term planning effort to integrate all options into a coherent plan for rebuilding the damaged economy. 


\subsection{RESEARCH UTILIZATION}

Most EEAS research projects contribute directly to planning, policy, and analysis activities of public agencies. The research focuses predominantly on sponsors' needs and normal avenues of use. For example, the petroleum modeling studies are used by DOE to assist in SPR planning activities. Information and analysis developed for EIA support its data and information activities, including the Secretary of Energy's report to Congress on the uranium industry, NES, and AEO. Studies on energy conservation and impacts are used by DOE, the U.S. Department of the Interior, and other agencies to understand energy retrofit decisions. Other agencies that use our research results in program planning and analysis incl-ude FEMA, Bonneville Power Administration, EPA, the U.S. Department of the Air Force, the U.S. Department of the Navy, and the U.S. Agency for International Development.

Though the primary objective of our research is to solve individual sponsors' problems, it is not limited to those purposes. Our mix of economics research projects for DOE and work-for-others sponsors, conducted in an interdisciplinary laboratory environment, provides a forum in which many technical and social aspects of individual problems emerge. These findings ultimately contribute to our understanding of complicated social and economic systems and become incorporated into solutions for general energy related issues of national importance. These include energy, environmental, and emergency problems such as world $\mathrm{CO}_{2}$ increase and stratospheric ozone depletion, infrastructure modemization, energy efficiency, hazardous waste management, energy for development of Third World nations, and public and private resources for emergency response. 


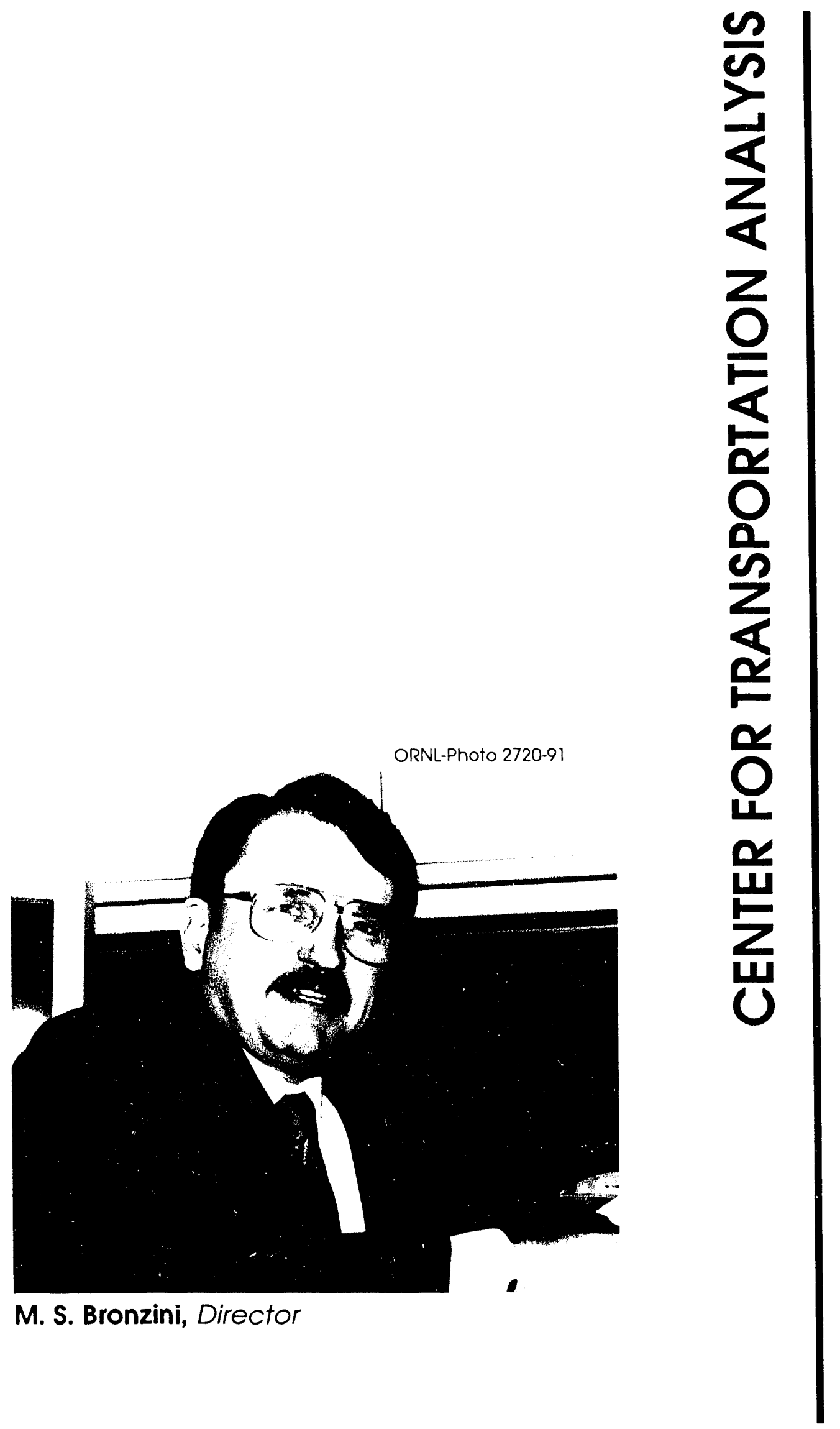




\section{CENTER FOR TRANSPORTATION ANALYSIS OVERVIEW}

\subsection{INTRODUCTION}

During 1990, the Center for Transportation Analysis was established as a new organization within Energy Division. Establishment of the center reflects the increasing importance of transportation research and development to the solution of national and global energy problems. The goal of the new center is to support both civilian and military sectors by performing state-of-the-art analyses and developing systems to increase the efficiency and effectiveness of national and global transportation activities. While the center's main purpose is transportation research, additional activities in studying energy, the environment, artificial intelligence (AI), and analytic methods and data are also significant. Much of the center's research is multidisciplinary in nature and is carried out with staff members from other ORNL divisions and research collaborators outside the laboratory.

The center's research covers both the civilian and military sectors of the transportation field. The civilian sector research can be characterized by the

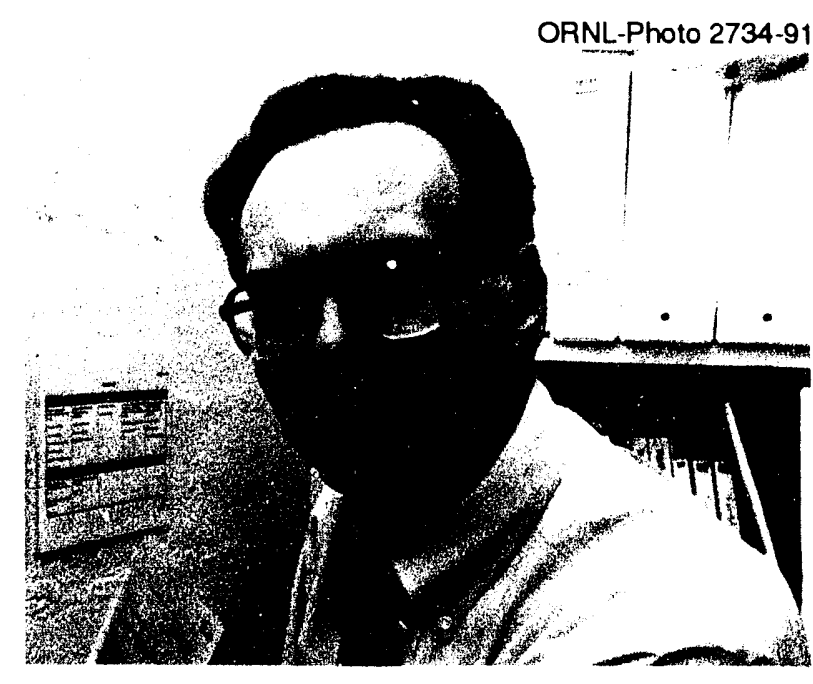

R. G. Edwards, Acting Director of the Center for Transportation Analysis for FY 1990. development of data and analytical methods useful to conduct policy studies for the U.S. Department of Energy (DOE) and other agencies concerned with transportation, such as the U.S. Department of Transportation (DOT), the Federal Emergency Management Agency (FEMA), and the U.S. Environmental Protection Agency. Several of the senior research staff members work closely with these agencies and are in demand for advice on national transportation and energy policy altematives.

Much of the military transportation research and development focuses on new approaches to planning and executing strategic deployment of personnel and materiel. The center staff have developed unique expertise in this research application area and are key contributors to the overall military transportation process. The research products are developed in the form of new concepts of time-sensitive planning, new ways of dealing with information and knowledge, new planning and scheduling algorithms, and the integration of this technology within high performance, networked computer environments.

The rich mix of transportation research activities at the center provides excellent opportunities for a high level of experimentation and prototyping. The center's software products have found their way into immediate use by a variety of federal agencies. Together with the knowledge gained and reported in the open literature, these software products contribute to ORNL's efforts in technology transfer.

\subsection{POLICY ANALYSIS AND ENERGY CONSERVATION}

The center staff members have a long history of commitment to policy analyses in support of national energy conservation programs. The center performs a variety of energy policy analyses in support of DOE. Several of the studies conducted during 1990 have been very timely given the dynamics of world petroleum supplies and renewed concern about energy conservation.

\subsubsection{Evaluating Strategies for Transportation Energy Conservation}

Falling costs associated with recent technological advances in telecommunications suggest a tremendous energy savings potential associated with such travel-reducing strategies as 


\section{Energy Policy Studies}

One center study during 1990 assessed the importance of the Corporate Average Fuel Economy (CAFE) standards on improving fuel mileage performance of new automobiles. An in-depth econometric analysis indicated that higher fuel prices were less effective than CAFE standards in influencing the decisions of automobile manufacturers to produce more fuel efficient automobiles. ${ }^{\prime}$ The real energy savings from meeting new-car mpg standards are large (see Fig. 4.1). ${ }^{2}$ As part of a study for DOE's Office of Policy, Planning, and Analysis, a statistical model was developed to assess the effects of vehicle performance, range, and refueling convenience on consumers' response to alternative and mult fucled vehicles. Using data from the Canadian Natural Gas (CNG) Vehicle Survey, the analysis indicated the importance of each of these factors, in addition to price, in the adoption of CNG fueled automobiles. ${ }^{3}$ Related research estimated that present United States petroleum use is 2 million barrels per day less than it would have been without improvements in automobile fuel economy since 1975, and that by using market-ready technologies, cost-effective fuel economy levels can be increased from the 1987 level of $27 \mathrm{mpg}$ to $31.6 \mathrm{mpg}$ in 1995 and to $34.3 \mathrm{mpg}$ in the year 2000.

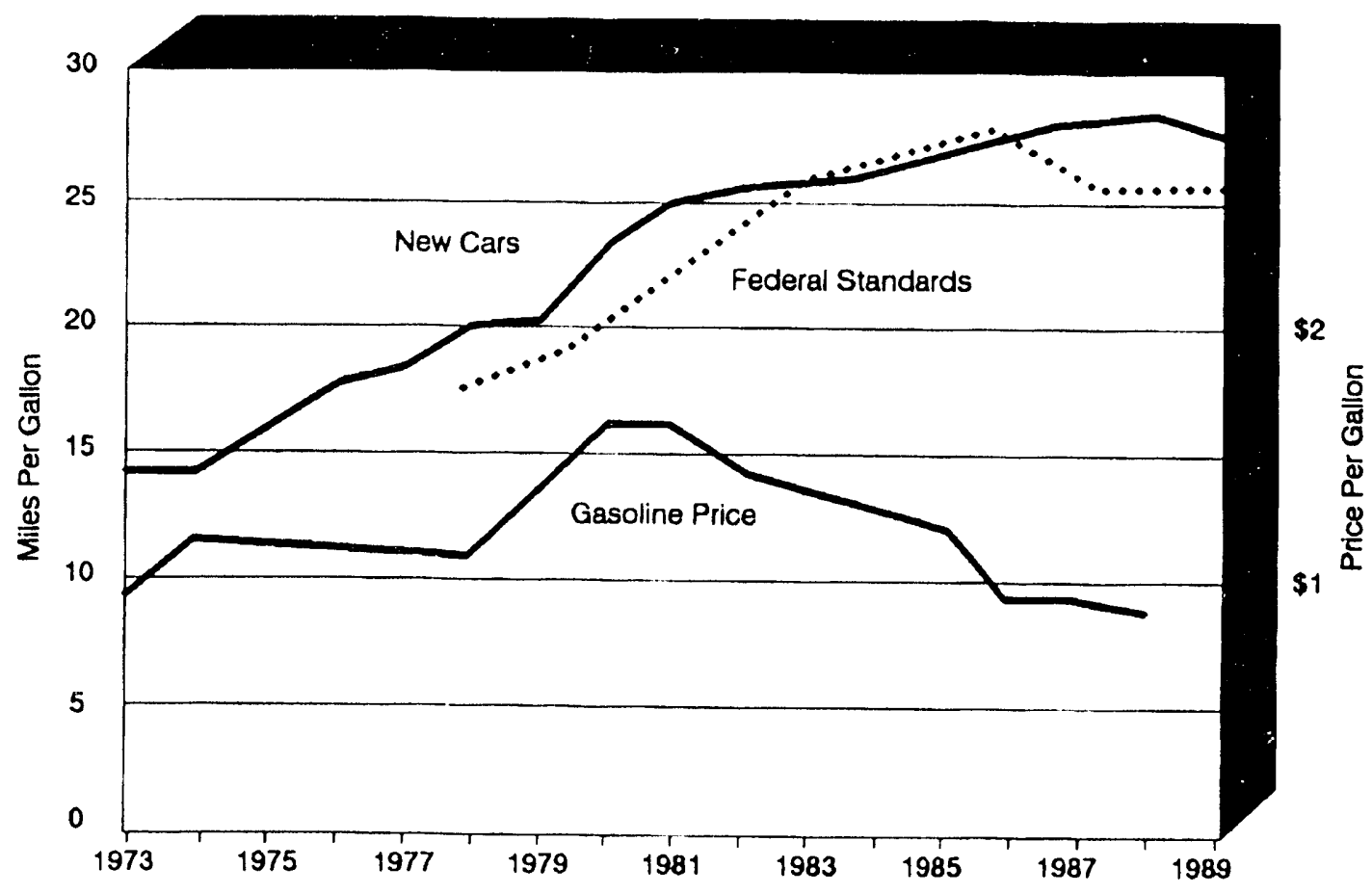

Fig. 4.1. Trends in fuel price and automobile efficiency. 
telecommuting-either out of the home or from near-to-home telework centers. However, little concrete evidence exists at present to verify such claims. For example, how does telecommuting affect a family's total weekly travel activity pattern? In cooperation with the Washington State Energy Office and the University of Washington, the center is providing technical support to the Puget Sound Telecommuting Pilot Project in an effort to involve regional businesses in telecommuting and to evaluate the implications of this new form of "travel-less" wurking arrangement upon, among other things, fuel consumpuion and mobile source emissions.

With the rapid growth of interesi in High Occupancy Vehicle Lanes as a means of reducing traffic congestion, fuel use, and emissions, the center's Network Performance Evaluation Model (NETPEM-PC) was used in California and Washington State. Upgrading of this software to better reflect traffic dynamics (and to reflect the availability of real-time traffic counts) began during 1990.

\subsubsection{Transportation Planning}

Transportation research at the center covers all modes, with a particularly strong record in highway us sportation planning. During 1990, the center's staff assisted the Federal Highway Administration (FHWA) in researching both the demand for and supply of additional highway lane miles. On the demand side, center staff developed an innovative

vehicle-miles-of-travel forecasting procedure from which futuri national highway lane mile needs can be derived. Emphasis was placed upon developing a dynamic model to reflect past and expected trends in travel shifts (both across highw'ay classes and across urban locations), especially shifts toward increased shares of travel within the suburbs and what is currently the urban-rural periphtis. in highly original research, a statistical relationship was developed between the demand for travel and the effects of restricıci highway supply upon this demand within cities of different sizes. The procedure was linked to FHWA software to project future lane mile

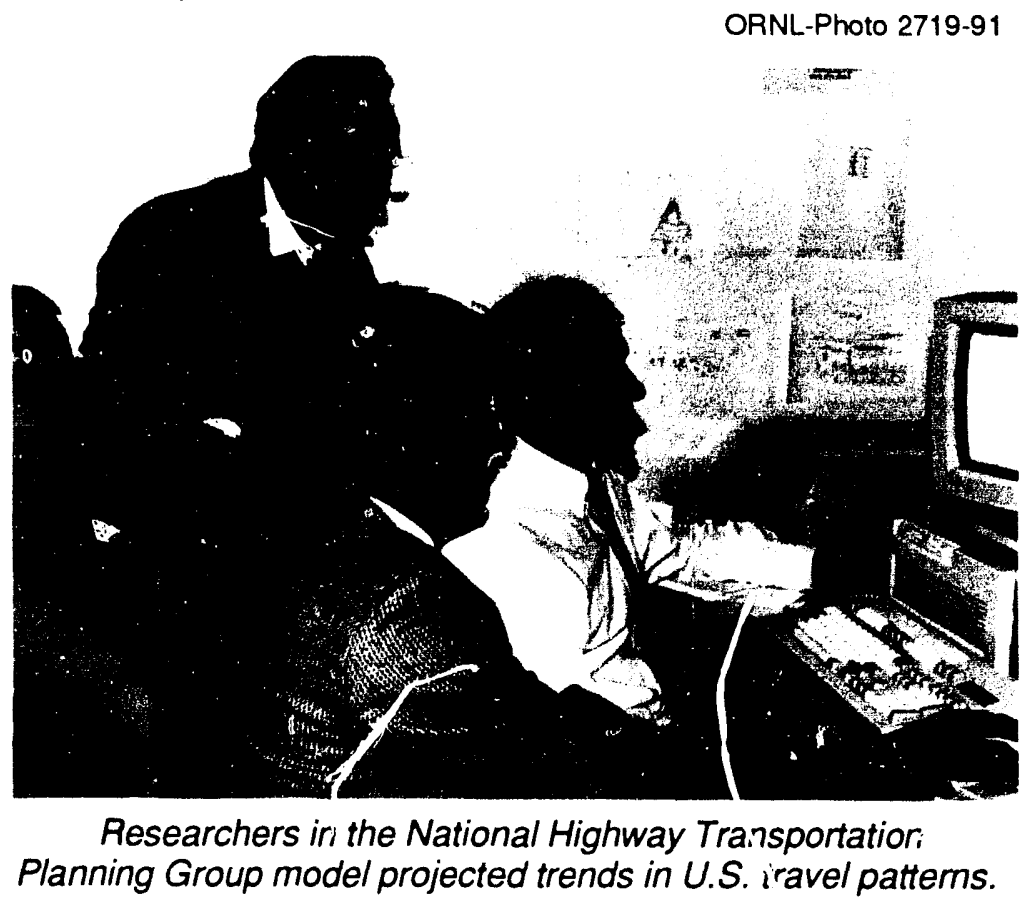
expenditures under a variety of traffic growth scenarios.

The FHWA's Highway Traffic Forecasting System continued to be redesigned by center staff to provide improved forecasts of natior,wide truck freight activity. Multicommodity flow models and truck- vs rail-mode selection models were under development. To support these analytical efforts, and in cooperation with other agencies within DOE, DOT, and the U.S. Department of Defense (DOD), the center contin'sed its leadership role in the development of an extensive national highway network data base. Containing characteristics for some 400,000 miles of highway, this base network saw a number of adaptations and translations, notably into reduced size networks geared toward specific planning studies. Unparalleled opportunities for multimodal (highway/rail/barge/air) transportation network analysis appear imminent at a level of national geographic detail not previously realize 1 .

\subsubsection{Navy Mobility Fuels Forecasting System}

For the Navy's Energy and Natural Reso'srces Office, the center's researchers continued work with the Navy Mobility Fuels Forecasting System, which forecasts the availability, cost, and quality of military and civilian fuels for different p Tretim.s and wartime scenarios (Fig. 4.2). This year's work included analyses of the impacts of a $c$ vere military disruption, including the loss of crude oil and 


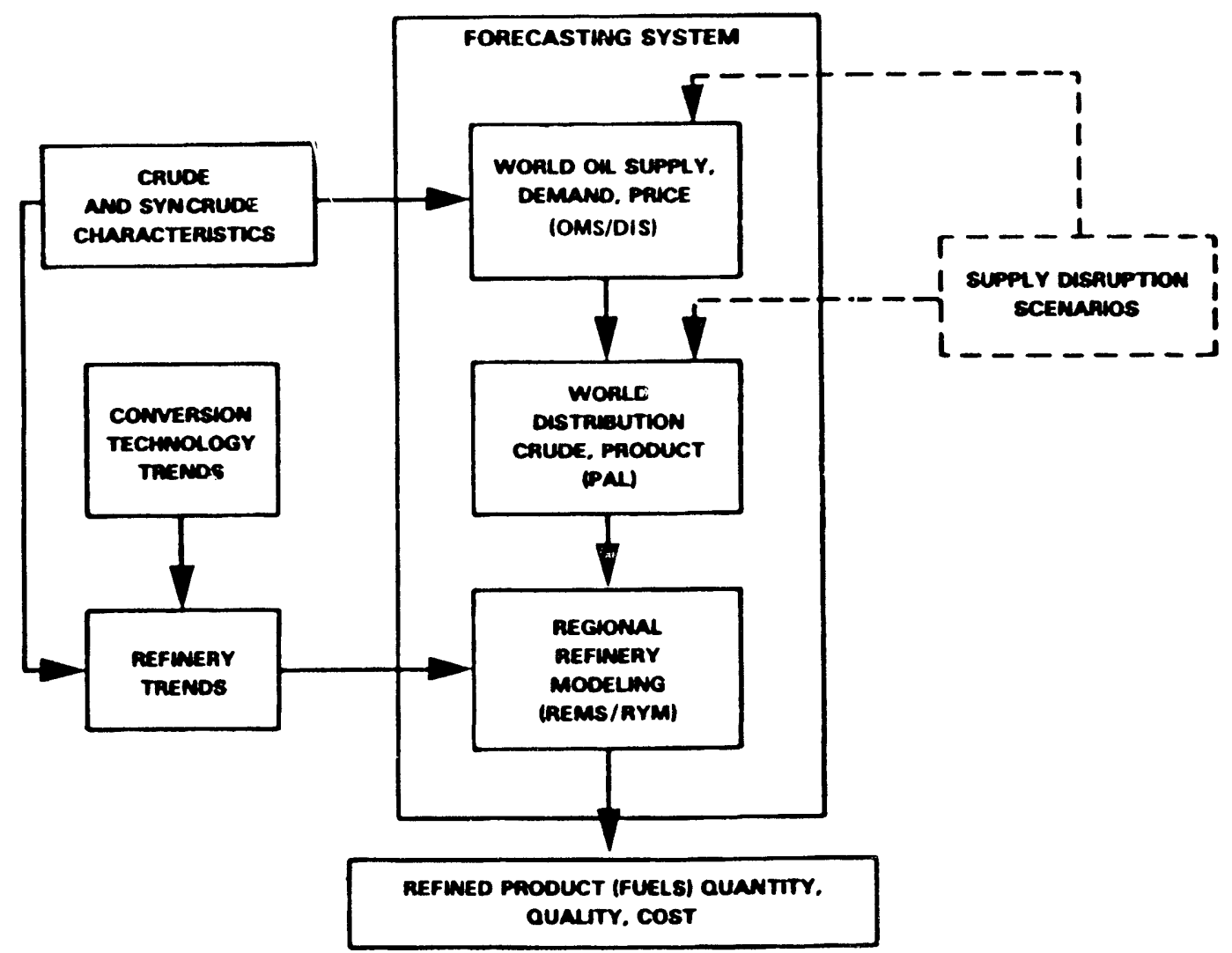

Fig. 4.2. Navy mobility fuels forecasting system.

refined products from the Persian Gulf. The Forecasting System indicated that such a disruption could cause substantial degradations in the quality of Navy diesel fuel produced in the Pacific basin and in southern Europe. Forecasting System results are routinely reviewed during on-site visits with refiners to verify important areas for research and development of future Navy fuels.

\subsubsection{Evacuation Planning and Analysis}

The center's staff also provided support to the emergency planning work within the division's Integrated Analysis and Assessment Section, under the Chemical Stockpile Emergency Preparedness Program, which is jointly operated by the U.S. Army and FEMA. Center staff developed evacuation time estimates for a number of chemical stockpile sites around the country. As part of this study, altemative evacuation simulation models are being evaluated, and improved procedures for collecting evacuation planning data have been developed. Application of ORNL's dynamic traffic assignment model $^{4}$ to evacuation planning is being pursued, as is the more effective integration of evacuee departure, destination and route selection models, supported by workstation-based geographical analysis software. The goal is to produce software capable of providing rapid and easy-to-use data manipulation and analysis capabilities for use both prior to and during mass evacuations. In related research for FEMA, the prototype Real-Time Traffic Monitoring and Analysis System (RTMAS) software was delivered. RTMAS can be used to collect traffic counts over the course of a number of hours or days, and to compare, via time-series analysis, the resulting temporal traffic count profiles with expected profiles for that count location, season, and time of day/day of the week. ${ }^{5}$ The work represents the start of center's contribution to real-time traffic analysis and control, an area of activity that appears likely to expand significantly in the near future (see "Toward Real-Time Travel Demand Management" highlights). 


\subsection{ENVIRONMENT}

Transportation often causes negative effects on the environment, so understanding the relationship between the two is crucial. For example, natural resources such as tropical rain forests may be unaffected by man's activities until transportation linkages are established. The center is committed to understanding the interrelationships between transportation and the environment and working to limit negative impacts on the environment.

\subsubsection{Transportation and Global Warming}

As part of a series of reports to the U.S. Congress, the center participated in an investigation of altemative opportunities and constraints associated with reducing greenhouse gas emissions within the transportation sector. Transportation vehicle operations in the United States have been estimated to contribute $32 \%$ of the nation's carbon dioxide emissions and 7\% of the world's emissions from energy use. Recommendations include more extensive research into travel-demand-side management techniques, with possible lessons for the transportation industry to be found within the power industry and other industrial sectors of the economy. As important as new technologies are to emissions reduction. attention was also drawn to the complex and multistep (facility supply, fuel supply, vehicle and parts supply, service supply and end-use consumption) decision-making processes associated with the introduction of such technologies to the marketplace. ${ }^{6}$

\subsubsection{Linking Highway System Development to the Ecological Impacts of Deforestation}

Working with staff in the Environmental Sciences Division under the ORNL Director's R\&D Fund, the center developed the first stage of the Dynamic Ecological-Land Tenure Analysis (DELTA) modeling system. DELTA integrates land development and ecological impact sub-models to estimate patterns and rates of deforestation under different immigration policies, land-tenure practices, and road-development scenarios. While impacts are measured and compared at a regional scale, the dynamics of land-use pattern formation and change are simulated within DELTA at the micro-spatial, land lot, and tenant-specific level. This micro-spatial approach to simulation allows DELTA to examine a wide variety of different spatial manifestations of the land-clearing process associated with a particular settlement diffusion process. Of particular concern are the potentially quite different long-term ecological impacts of alternative spatial as well as temporal manifestations of land development patterns, for otherwise secmingly identical aggregate levels of forest clearing. DELTA is currently being used to model the carbon released by the rapid deforestation in the state of Rondonia, Brazil. Located in the south central portion of the Amazon Basin, Rondonia covers approximately $243,000 \mathrm{~km}^{2}$ of what was primarily tropical rain forest. Much of this forest cover is now gone, an example of the magnitude of rain forest conversion in the tropics.

\subsubsection{Transportation and Clean-Up of Hazardous Waste}

The center's staff has also provided some support to DOE's Office of Civilian Radioactive Waste Management Transportation Program, providing technical input to the planning and design of management support systems for the shipment of spent nuclear fuel from commercial nuclear reactors in the United States to a monitored retrievable storage facility and a repository.

During 1990, the center also became involved in a joint ORNL-University of Tennessee project to estimate the costs of cleaning up all the hazardous waste sites in the United States. The center was responsible for estimating the costs of the provision in the Resource Conservation and Recovery Act that all facilities that treat, store, or dispose of hazardous wastes must remediate solid waste management units (SWMUs) that have released hazardous wastes into the environment. Remediation activities include soil capping, incineration, and the pumping and treating of groundwater. Research Triangle Institute (RTI) was also awarded a subcontract to assist in the project. RTI has two databases on SWMUs that include several hundred thousand records each. A scheme was developed to classify each of the more than 70,000 SWMUs in the databases by the kinds of technologies needed to remediate them. The cost of remediation was estimated using a PC-based model called CORA (Cost of Remedial Action). CORA supplies cost estimates for over 40 different technologies. Cost estimates are being prepared with respect to several scenarios and will be ready during 1991. 


\section{National Transportation Data Collection and Distribution}

Several projects are underway for the Federal Highway Administration and the U.S. Department of Transportation (DOT) as a result of DOT's Statement of National Transportation Policy (NTP). The NTP identified a wide range of issues and policies related to the collection, processing, and distribution of transportation data. Further, the NTP stated that it is government policy to identify national needs for information on transportation. During 1990, the center played a significant role in a number of major national transportation database collection, analysis, and distribution efforts including participating in the publication of the following: (1) The 1987 Truck Inventory and Use Survey (TIUS), (2) The 1989 Nationwide Truck Activities and Commodity Survey (NTACS), and (3) The 1990 National Personal Transportation Study.

The center also undertook a project to estimate the extent of the private sector's involvement in constructing and maintaining the nation's highway infrastructure. The center was invited to participate in the planning of several national surveys that will be published as 1992 TIUS, 1993 NTACS, Commodity Flow Survey, and an Intercity Passenger Travel Survey.

\subsection{METHODS AND DATA}

The center places considerable emphasis on the appropriate development of databases and analytical tools to enable better transportation analysis and systems development. Center staff members regularly consult with govemment data collectors to assist in the development of realistic plans to obtain high quality data. Center staff also assist DOE and other agencies with the supervision and conduct of data audits to assure data quality.

\subsubsection{National Transportation and Energy Related Databases}

\subsubsection{Transportation Energy Data Book}

The center continued to analyze and report transportation energy data in an annual publication for the DOE Office of Transportation Technologies. Recognized internationally as the source for transportation data, the external distribution of the Transportation Energy Data Book reached almost 1000 copies this year. ${ }^{7}$ Readers of this publication include the U.S. Congress, the automobile industry (e.g.. General Motors Company), numerous federal and state government agencies, regulatory boards, foreign governments, and research institutes. This publication not only helps to address questions in transportation, but also provides a valuable information link between transportation, energy, and the environment. Data contained within this publication were invaluable to the development of DOE's National Energy Strategy.

\subsubsection{National Multimodal Network Databases and Their Applications}

Building on the success of the ORNL National Highway Planning Network, progress was made toward integrating the nation's highway, rail, and barge networks within a single database. Different data structures and levels of network representation are used both in analytic studies of traffic flow. and for manipulation and display purposes using workstation-based Geographic Information System tools. These data and tools will be of use to a variety of federal agencies, including DOE, DOT, DOD, and FEMA, for use in long-distance commodity and passenger-flow analyses, deployment planning, and hazardous materials and emergency cvacuation routing. 


\section{Toward Real-Time Travel Demand Management}

Of considerable and growing interest to many parties in both the private and public sectors are the opportunities for real-time traffic information gathering, vehicle guidance, and eventually, automated vehicle control. Intelligent Vehicle/Highway Systems research within the United States is now expanding into many different areas. Support from the ORNL Director's R\&D Fund led to ground-breaking basic research and to the development of a prototype "dynamic" traffic routing procedure that better reflects congestion levels on complex urban highway networks than does the static approach currently employed by many of the nation's transportation planning agencies. In both a mathematical sense, and in empirical tests, the current static method of assigning traffic to routes was shown to be a special case of the more general dynamic procedure. ${ }^{4,9}$ FY 1991 work in this area will benefit from related center work in mass evacuation modeling (see Sect. 4.2.4), in which the opportunities for better traffic control during emergencies through telemetric, microwave, infrared, optical, and other emerging technologies for near real-time data acquisition have blossomed into an area requiring considerable behavioral as well as technological research (Fig. 4.3).

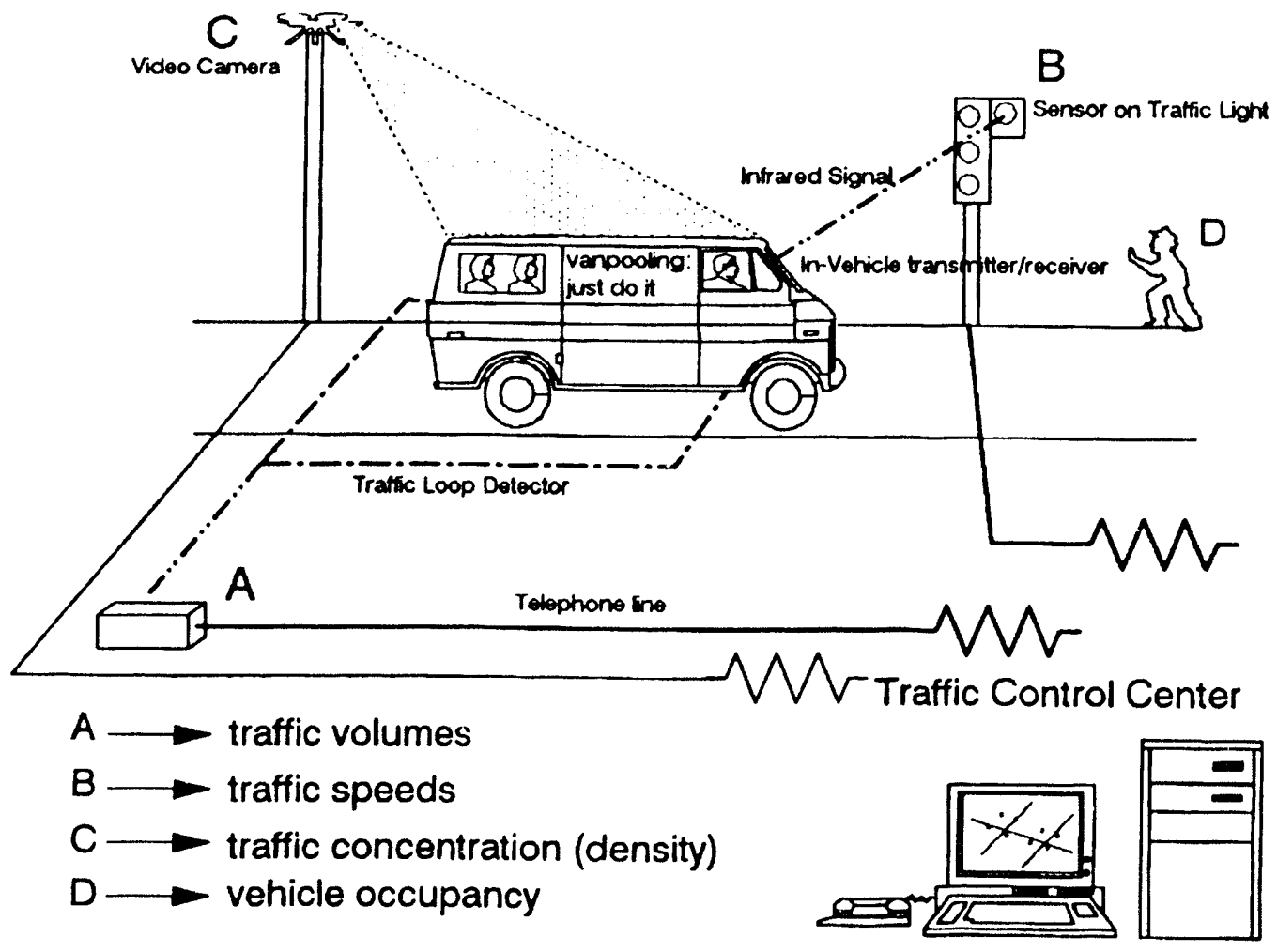

Fig. 4.3. Traffic data acquisition and vehicle guidance systems. 


\subsubsection{Traffic and Transportation Operations Research}

\subsubsection{Intra-Urban and Corridor Traffic Analyses}

Continuing work for FHWA produced workstation-based simulation models to replicate and depict complex traffic-stream management strategies for congested urban street layouts. ${ }^{8}$ In a separate project, estimates and spreadsheets were developed to allow FHW A staff to assess the merits and drawbacks of alternative truck and automobile traffic lane separation schemes.

\subsubsection{Planning and Scheduling Algorithms}

Real progress has been made in developing better methods for the interactive development of complex transportation schedules. Complex delivery schedules involving large vehicle fleets and multiple pick-up and delivery sites have required excessive computer time and could not be quickly or interactively developed. However, new approaches developed at the center, including the use of dynamic programming, advanced database technology, and other advanced mathematical techniques have made transportation planning and scheduling a much more rapid, interactive process. The details of this work are discussed in Sect. 4.5.

\subsubsection{Artificial Intelligence}

Despite significant advancements in computer processing speeds and data management capability, there are still many technical problems that are not successfully solved by traditional computer or database methods. AI research at the center is primarily focused on those AI technologies that may have applications in policy analysis and decision making.

Theoretical research during the year focused upon uncertainty representation and management. The fundamental goal of this research is to develop methods of representing and manipulating uncertainties that are flexible enough for policy applications yet rigorous enough for quantitative policy analysis. This research focuses on ways of generalizing the axioms of probability that have these features. In FY 1990, several advances were made. First, a method was developed to conditionalize lower probability functions and belief functions with classical probability functions. ${ }^{10}$ For example, one could conditionalize a lower probability function output from a diagnostic expert system with statistics on past diagnoses. Second, progress was made on defining the level of uncertainty inherent in various problems. 11 Progress was also made in understanding the difference between the following various methods of synthesizing uncertainties: combination, conditionalization, consensus, upgrading, and updating. In FY 1991, this work will continue under a project funded by the Electric Power Research Institute.

\subsubsection{Communications Alarm Processor (CAP)}

Practical application of the center's AI research efforts is also represented in the Communications Alarm Processor (CAP) project. CAP is an expert system application that has performed well at a task that has resisted solution by conventional software methods: real-time diagnosis of control center alarms.

In general, computer technology has been successfully applied to the identification and reporting of control center alarms data, but it has been less successful in supporting alarm data interpretation. Typical problems include the large volume of alarm data, high input rates, complexity of interpretation, and the presence of useless or misleading information. CAP's on-line diagnosis integrates data from two of Bonneville Power Administration's microwave alarm systems and identifies the probable locations and causes of degradations in microwave equipment performance. The prototype CAP supports one of the 7 microwave networks consisting of about 40 microwave stations.

In addition to on-line diagnosis, CAP saves the system's alarm histories and performs statistical analysis of long-term performance characteristics. In particular, CAP supports a Reliability Centered Maintenance program which attempts to shift maintenance resources from a scheduled organization to an as-needed basis. Knowledge base development has focused on improved identification and discemment of possible diagnoses and augmentation of the expert system's model of the components and topology of microwave systems.

CAP has been in continuous operation for over 2 years in Bonneville's Dittmer Control Center. The CAP prototype is now bcing expanded to handle more networks and additional functions. 


\section{Airlift Deployment Analysis System (ADANS)}

The Military Airlift Command (MAC) of the United States Air Force provides air transportation for military operations in both peacetime and during crises. During Operation Desert Shield, MAC had to achieve the largest airlift movement in history. The first 75 days required the movement of over 100,000 passengers and 100,000 tons of cargo. On many days, more than 100 aircraft unloaded their cargo and passengers in the Middle East.

The airlift system responded to the task, but MAC needed advanced automated scheduling support to provide the flexibility and response time required to manage the quickly changing priorities and operational constraints. MAC asked ORNL to accelerate the development of a new scheduling system still in the prototype stage. ORNL had been working on an innovative airlift scheduling system for several years and had just released a system for managing much of the daily peacetime airlift. The contingency scheduling algorithm and support software was not planned to be delivered until the summer of 1991. Working as team members with the airlift flow planners at MAC, ORNL researchers completed the implementation of a dynamic programming-based scheduling system, developed new functionality to manage the constraints imposed by the airlift concept of operations, and created a collection of tools for allocating resources to the airlift flow, analyzing the schedules generated, and communicating with MAC's command and control system. On October 19, 1990, General H. T. Johnson, Commander-in-Chief of MAC declared that ADANS would be the only scheduling system used for all Desert Shield missions. The airlift planners used the system successfully and are continuing to use it in planning airlift missions for the operation and analyzing options for future movements. The same system will be used for the scheduling of joint training exercises for U.S. forces during peacetine.

The airlift probiem involves scheduling aircraft, crew, and ground support resources to transport cargo and passengers from on-load stations to off-load stations in a specific time. Considerations such as multiple on-loads and off-loads, restricted operating hours, and specified takeoff times for congested stations add complex constraints to the problem. An innovative dynamic programming algorithm embedded within a rule-based heuristic was developed to solve the problem. By exploiting the form of the objective function and limiting the number of possible states using heuristics and airlift planner knowledge, several hundred missions can be scheduled within a few minutes, a task which previously required hours using MAC's traditional approaches.

The power of the scheduling system is enhanced because planners can easily modify the constraints and objectives, analyze the schedule generated, modify individual missions to account for constraints outside the scope of the system, and communicate with other systems. This was accomplished by developing a set of software tools integrated with a database management system which allows multiple users to interact over a local area network to develop and analyze plans. A workstation environment incorporating geographical and time-based interactive graphics allows the user to efficiently analyze a particular problem (see Fig. 4.4). The user remains the absolute authority on airlift, and, although the system will provide checks and warnings if the stated concept of operations is violated, the user can easily modify all aspects of the schedule. The system provided links to world-wide communications networks by importing cargo and passenger data from military planning systems and exporting missions to MAC's command and control system.

While the system is still in the early stages of operation, it has already provided several benefits to MAC. The repetitive tasks of scheduling have been cut from hours to minutes, and schedule conflicts are automatically avoided, eliminating much of the manual "bookkeeping" previously required. The analysis displays and the speed of the scheduler provide the tools and time necessary to analyze schedules before they must be exported to the command and control system. While the major objective of the military airlift system is to deliver cargo on time, the ADANS system also attempts to increase the efficiency of the airlift system. The elimination of a single flying hour for a C-5A aircraft saves $\$ 7630$. 
Already during Operation Desert Shield, MAC has flown more than 75,000 flying hours. In addition, through ADANS, MAC airlift planners are more responsive and have more time to analyze options for addressing changing priorities during crises. ADANS allows MAC to plan ahead when possible and to reacl with flexibility when necessary.

The ADANS scheduling software developed and used in Operation Desert Shield has reached the finals of the prestigious Franz Edelman Competition for Management Science Achievement. Through ADANS, the Flow and Analysis System for Transportation Command (TRANSCOM) (FAST), the Scheduling Algorithm to Improve Lift, and related software development efforts, the center is pushing forward the state-of-the-art in vehicle routing and scheduling on both the theoretical and application frontiers. The interdisciplinary research required to achieve the theoretical and operational breakthroughs achieved on ADANS and FAST, after many previous years of effort involving the military, private, and academic sectors, stands as significant testimony to the power and value of a national laboratory where expertise from each of these sectors can be marshaled for the good of the nation.

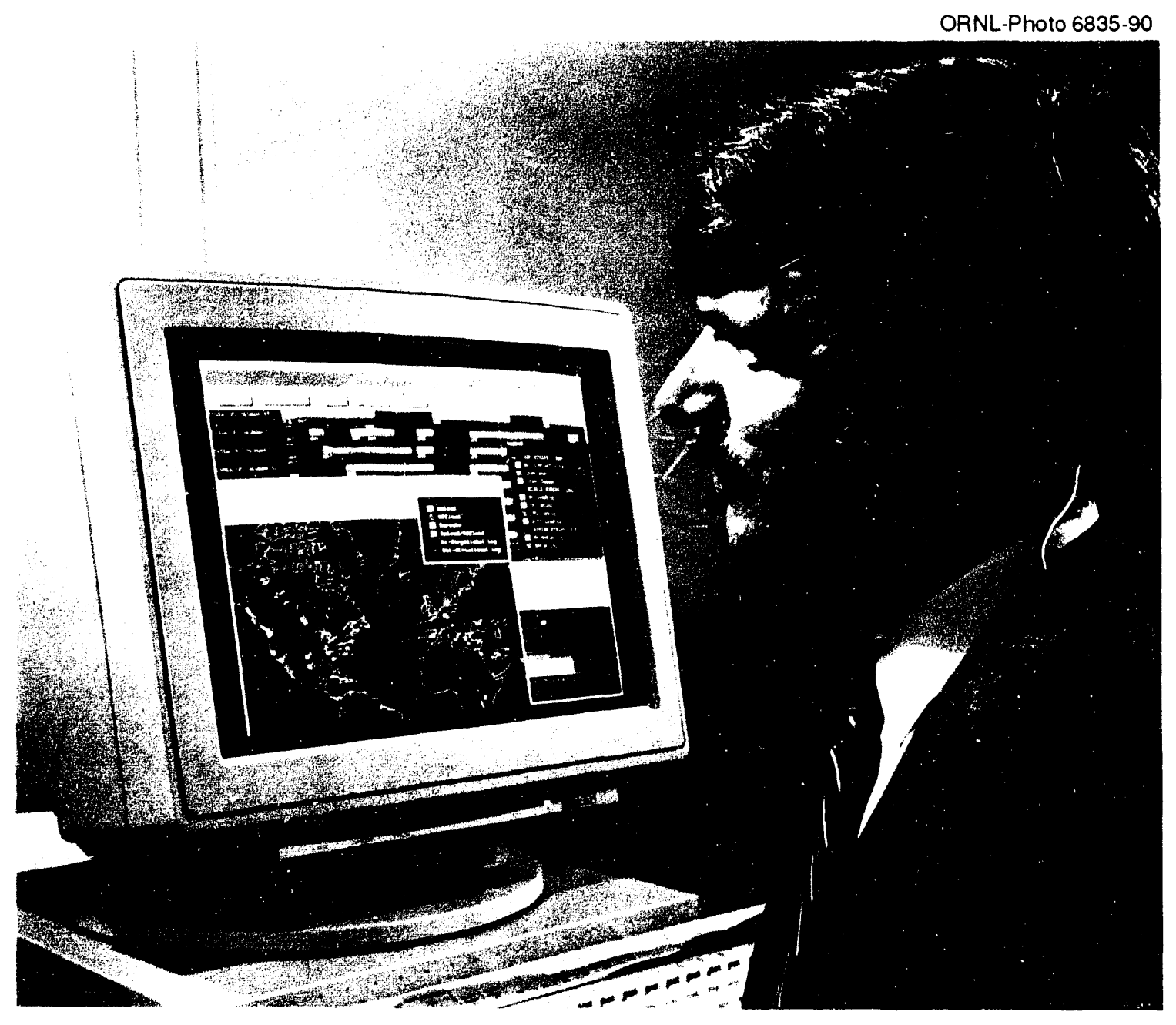

Fig. 4.4. An Airlift Deployment Analysis System workstation. 


\subsection{PLANNING AND SCHEDULING SYSTEMS}

During 1990, the American military conducted the largest and most concentrated movement of personnel and materiel in our nation's history. Planning and managing such an operation requires sophisticated personnel, knowledge, and information technology. Over the past 6 years, the center has assumed a national leadership role in providing military transportation specialists with technical assistance in the fields of operations research, planning methods, and information technology. During that time, ORNL staff has become extremely knowledgeablc about military transportation planning. That expertise was utilized throughout Operation Desert Shield as ORNL staff worked round the clock with their transportation colleagues at the U.S. Transportation Command and the Military Airlift Command (MAC) to facilitate the use of the latest information technology during the deployment.

\subsubsection{Flow and Analysis System for Transcom (FAST)}

To meet DOD needs for analysis of deployments during deliberate planning, exercises, and real-world contingencies, the center has been developing a prototype set of analysis tools. The effort, the Flow and Analysis System for Transportation Command (TRANSCOM) (FAST) employs incremental development and rapid prototyping methods to tailor and extend work with which ORNL has been involved for a number of years. Deployment transportation models addressing land, air, and sealift are being analyzed and integrated by center staff.

The greatest challenges occur during time-sensitive planning and execution of an overseas military operation. DOD deployment managers must be able to provide accurate answers to many strategic transportation questions within the limited time frames associated with course-of-action analysis. Rapid and easy to interpret response tools are key to effective decision making. Answers to questions concerning lift capability, lift required, and time expected to complete or "close" a series of missions must be generated. Recent experience during both exercises and real-world operations showed that deployment managers were often not able to complete such studies of strategic lift alternatives in the amount of time allotted.

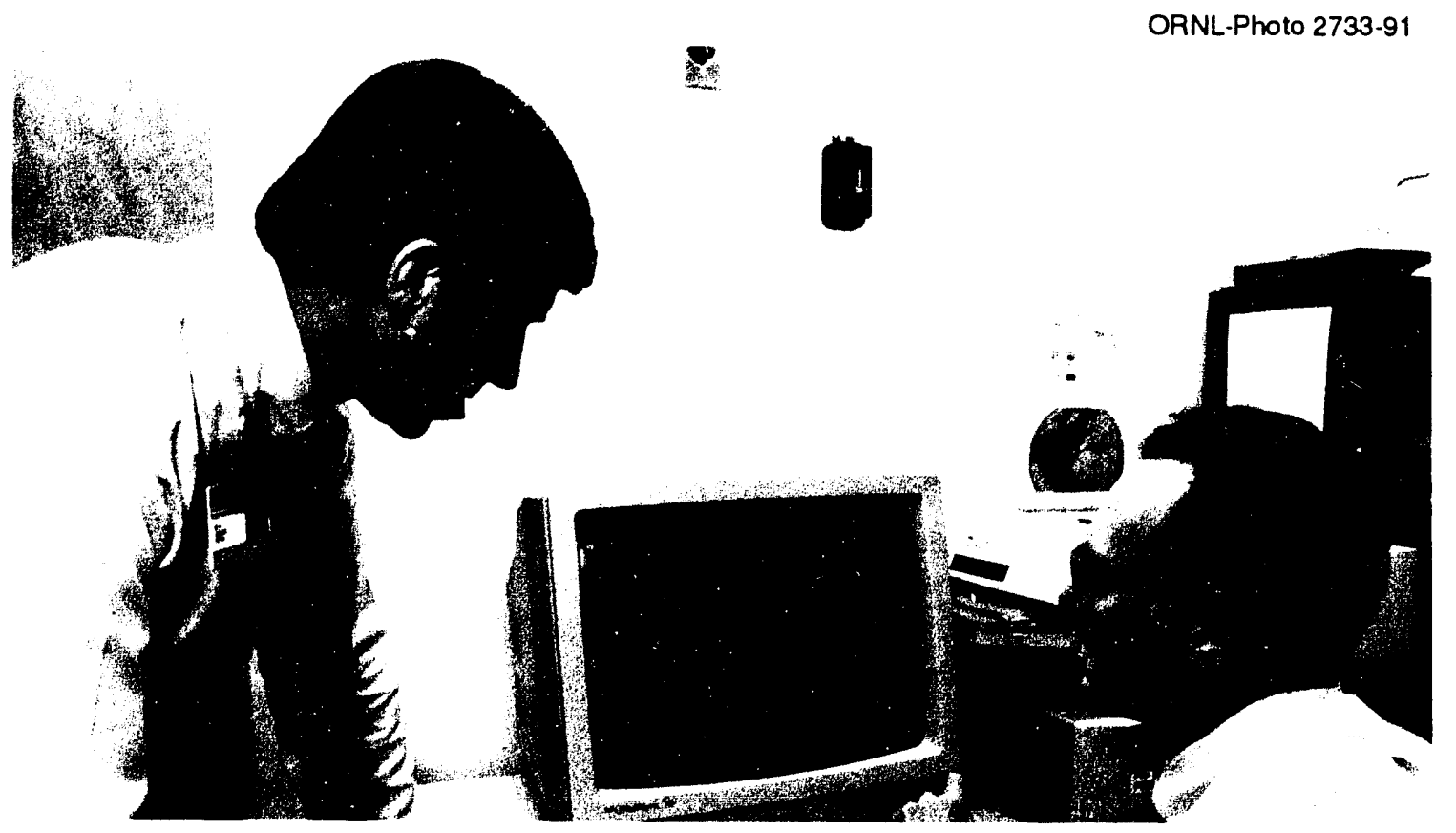

Members of the center's staff work for the U.S. Department of Defense on the Flow and Analysis System for Transportation Command (FAST).

The initial FAST prototype was delivered in July 1990. Although the original intent was to use the prototype in an August 1990 exercise, the prototype was pressed into use for analysis of the transportation required for Operation Desert Shield. FAST presently has modules for the continental United States (CONUS) origin to point-of-embarkation moves and strategic air/sea (CONUS-to-theater) moves. The sealift and CONUS estimators are both based on the

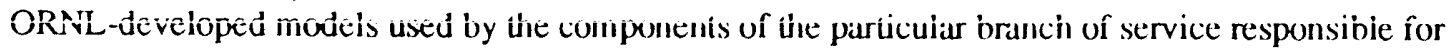


managing these two areas. The CONUS module is based on the Military Traffic Management Command's Strategic Deployment System model, and the sealift module uses the Military Sealift Command's Scheduling Algorithm to Improve Lift model. The current FAST airlift closure estimator will ultimately be replaced by an ADANS airlift estimator (see "Airlift Deployment Analysis System" highlights). Future work is focusing on adding execution support and replanning capability and developing a module for estimating cargo characteristics and requirements when full details are not immediately available.

\subsubsection{World-Wide Household Goods Shipment Information System for Transportation Modernization (WHIST-MOD)}

World-Wide Household Goods Shipment Information System for Transportation Modemization (WHIST-MOD) is a decision support system that will help the MTMC Personal Property Directorate monitor the Personal Property Shipment Program and assist in the projection of probable effects of changes to regulations and policy on the program. In addition the system will allow MTMC management at distributed locations to view and track the personal property business in an accurate and timely manner. ORNL is providing analysis and design expertise for the system hardware, communications, and software architecture and is prototyping the database, data acquisition, and user applications for the headquarters module.

\subsection{INTERACTIONS WITH THE WIDER SCIENTIFIC COMMUNITY}

7 he center staff attended numerous scientific meetings and conferences during the year, making over 22 professional presentations and publishing some 47 journal articles and research reports. Two particularly noteworthy activities are described in Sects. 4.6.1 and 4.6.2.

\subsubsection{Advanced Computing for the Social Sciences Conference}

In April 1990 the center, along with the U.S. Bureau of the Census, cohosted the first conference or advanced computing for the social sciences. Held at Williamsburg, Virginia, the conference attracted over 150 attendees. Over 30 refereed papers were presented and distributed in proceedings. Approximately 20 system demonstrations were given. The conference achieved its goal of identifying new and exciting research in the area of social science computing. Applications ranged from using neural nets for time series analysis to using the Cray supercomputer to process census data from the 1800 s.

\subsubsection{ADANS-Generated Activities on Improved Vehicle Routing and Scheduling Techniques}

The ADANS project has already helped several students acquire the Ph.D. at a number of the nation's leading universities. ADANS is also helping to advance the field of transportation operations research through its focus for and sponsorship of professional sessions at such conferences as the Operations Research Society of America. A number of leading researchers in the field, including faculty and students at the Camegie Mellon University, Case Western University, Georgia Institute of Technology, Johns Hopkins University, and the University of Maryland, have been involved in earlier stages of the ADANS work. A variety of innovative routing and scheduling methods have resulted from these and other collaborations. ${ }^{12}$

\subsection{REFERENCES}

1. D. L. Greene, "CAFE or Price? An Analysis of the Effects of Federal Fuel Economy Regulations on Gasoline Price on New Car MPG, 1978-89," Energy Journal 11(3), 37-57, 1990.

2. D. L. Greene, "Technology and Fuel Efficiency," Forum for Applied Research and Public Policy 5(1), 23-30 (Spring 1990).

3. D. L. Greene, "Fuel Choice for Multi-Fuel Vehicles," Contemporary Policy Issues 7, 118-137 (1990).

4. B. N. Janson, "Dynamic Traffic Assignment for Urban Road Networks," forthcoming in Transportation Research Part B: Methodological.

5. F. Southworth, S-M. Chin, and P. D. Cheng, "An Expert System Approach to Real Time Monitoring and Analysis of Traffic During Evacuations," Chap. 6 in Expert Systems in Urban Planning, T. J. Kim and L. Wiggins, eds., Springer-Verlag. New York. 1989. 
6. E. L. Hillsman and F. Southworth, "Factors That May Influence Responses of the U.S. Transportation Sector to Policies for Reducing Greenhouse Gas Emissions," Transportation Research Record 1267, 1-11 (1990).

7. S. C. Davis, D. B. Shonka, G. L. Anderson-Batiste, and P. S. Hu, Transportation Energy Data Book: Edition 10, Oak Ridge National Laboratory, ORNL-6565, 1989.

8. A. K. Rathi and A. J. Santiago, "The New NETSIM Simulation Program," Traffic Engineering and Control 31(5), 317-20 (1990).

9. B. N. Janson and F. Southworth, "Estimating Departure Times from Traffic Counts Using Dynamic Assignment," forthcoming in Transportation Research Part A: General.

10. Wagner, C. and B. Tonn, "Diagnostic Conditionalization," Mathematical Social Sciences 19. $159-65(1990)$.

11. B. Tonn and A. Schaffhauser, 1990, "Shades of Probability," submitted for publication in Theory and Discussion.

12. R. S. Solanki and F. Southworth, "An Execution Planning Algorithm for Military Airlift," forthcoming in Interfaces. 
ORNL-Photo 2727-91
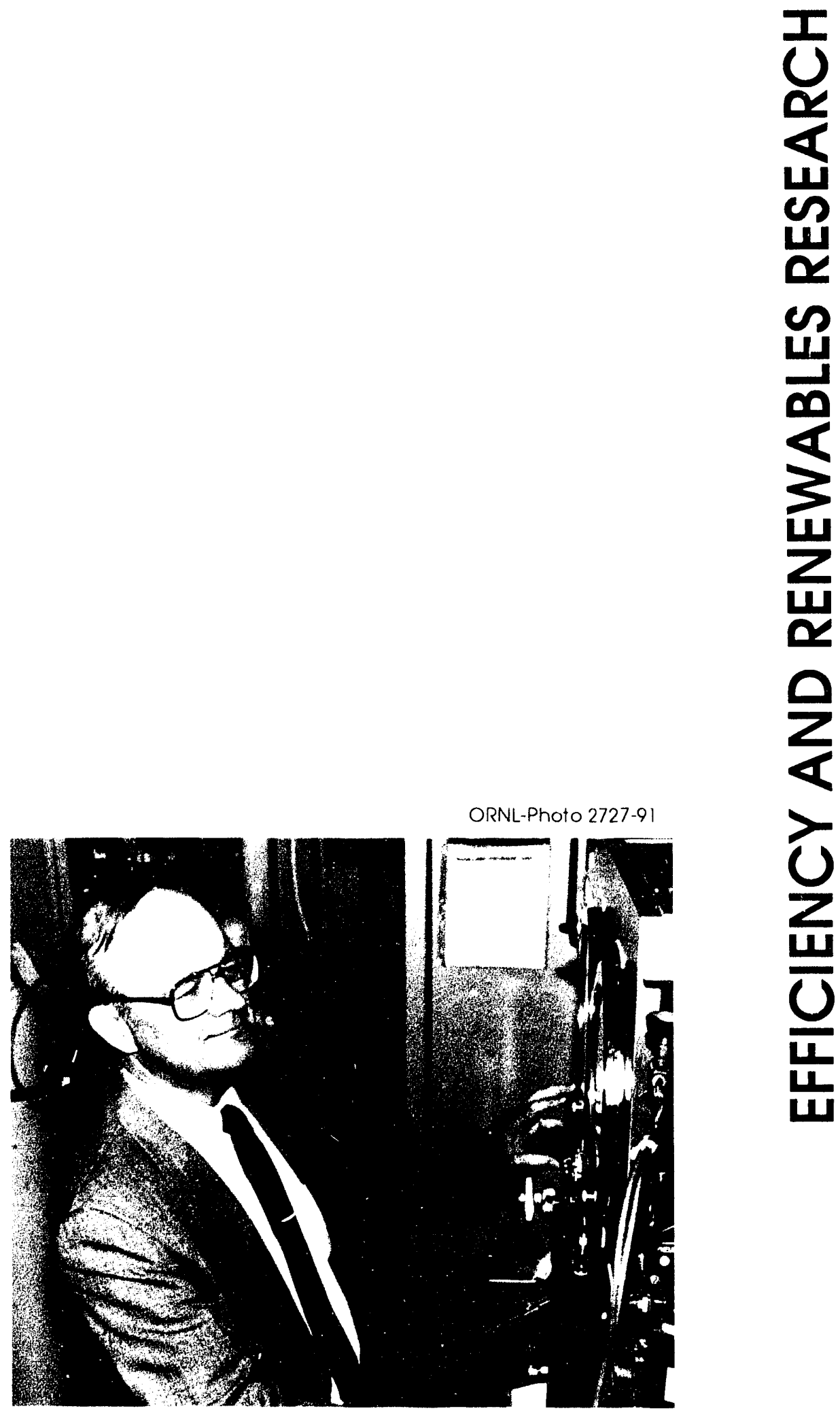

G. E. Courville, Head 


\section{EFFICIENCY AND RENEWABLES RESEARCH SECTION OVERVIEW}

\subsection{INTRODUCTION}

The Efficiency and Renewables Research Section conducts research to improve the efficiency of energy end-use and delivery technologies. The major research areas within the section are related to energy use in buildings, to transmission and distribution of electric energy, and to the development and assessment of implementation strategies for dissemination of energy efficiency measures. Buildings research includes studies of equipment such as heating, ventilation, and air conditioning systems; building envelopes and materials; and monitoring and retrofitting of existing buildings. Electricity delivery systems research analyzes power systems transients caused by, for example, high strength electromagnetic pulses (EMPs) or geomagnetic storm disturbances and assesses novel transmission and distribution materials and components. Implementation strategies research includes demand-side management systems and weatherization assistance programs. Additional areas of research within the section include environmental control systems, chemical heat pumps for selected industrial applications, performance audits for existing buildings, energy systems in developing countries, and research on technology transfer processes. In the past year several significant new activities regarding the characteristics of replacement materials for foam insulations and refrigerant fluids that use chlorofluorocarbon (CFC) compounds have been initiated.

\subsection{BUILDING EQUIPMENT RESEARCH PROGRAM}

The Building Equipment Research (BER) program at Oak Ridge National Laboratory (ORNL), sponsored principally by the U.S. Department of Energy (DOE) Office of Buildings Technology, has as its primary focus the development of technology for more efficient space heating and cooling. refrigeration, and water heating equipment used in residential and commercial buildings. Gloibal environmental issues such as ozone depletion and greenhouse warming are also increasingly important as a driving force in energy research and development. To facilitate the U.S. industry's transition from CFC refrigerants to acceptable, atmospherically safe alternatives that provide equal or better energy efficiency, the BER program has strengthened its ties with industry and is actively working with individual companies and through the major trade associations to plan and structure cooperation between government and industry cooperative $R \& D$ programs. Research sponsorship has also been broadened to include other federal agencies, technical societies, and the national utility research institutes. The research pursued in the BER program falls under three areas of activity: thermally activated heat pumps, novel cycles, and advanced refrigeration systems.

\subsubsection{Thermally Activated Heat Pumps}

System development, component development, and supporting research activities were continued on an absorption cycle heat pump and on Stirling engine-driven and internal combustion (IC) engine-driven vapor compression heat pumps. New initiatives undertaken included a project on a high-efficiency absorption chiller for commercial building cooling and two scoping studies of novel high-durability IC engine concepts for heat pump drive.

The residential generator-absorber heat exchange absorption heat pump under development at Phillips Engineering Company remains a highly promising technology in spite of some difficulties encouniered with absorber performance. Component development efforts at both Phillips Engineering and ORNL on a novel compact absorber configuration were concluded, and work on a more conventional falling-film absorber was initiated. Progress was made at Phillips Engineering on solution pump development, bumer development, and corrosion inhibition. Several possibilities for improved secondary-loop heat transfer fluids were identified by ORNL and subcontractor Ahlgren Associates.

Work was initiated at ORNL on a new concept for an advanced high-efficiency absorption chiller that uses the conventional lithium bromide/water working fluid pair. An assessment study concluded that this system could save energy and reduce costs compared to currently available double-effect chillers; moreover, its use could defer the need for additional electric generating capacity 
and would lead to load leveling for both gas and electric utilities. ORNL conducted static-pool tests, minisorber tests, and thermal stability tests on alternative performance additives that could survive the higher generator temperatures required of this new cycle. A request for proposal (RFP) for a subcontract to conduct pilot plant experiments was issued in August.

Sunpower, Inc., made progress on the development of a magnetically coupled free-piston Stirling engine driven refrigeration compressor (see Fig. 5 1) for use in gas-fired residential and light commercial heat pump systems. The engine section hardware met performance objectives after a short debugging period. After the compressor section performed well in component tests, preparations to test the assembled system at Sunpower were initiated. Mechanical Technology, Inc. (MTI), completed a design and performance analysis of a similar system that employs an alternative Stirling engine design concept. Manufacturing cost analyses of both the Sunpower and MTI designs were conducted to evaluate potential economic feasibility. Supporting research at Massachusetts Institute of Technology on heat transfer in oscillating flow was continued, cofunded by the National Aeronautics and Space Administration-Lewis Research Center.

Development at Tectonics Research, Inc., of a linear, free-piston IC engine compressor for light commercial heat pump service focused on fundamental analytical and experimental studies of the dynamics of the segmented, articulated bellows refrigerant seal. Subcontracts for scoping studies of novel IC engine concepts were awarded to Adiabatics. Inc., and Southwest Research Institute. Both of these projects involved two-stroke cycle engines, without conventional cooling systems or ignition systems, that showed potential for reduced maintenance requirements and exceptional durability.

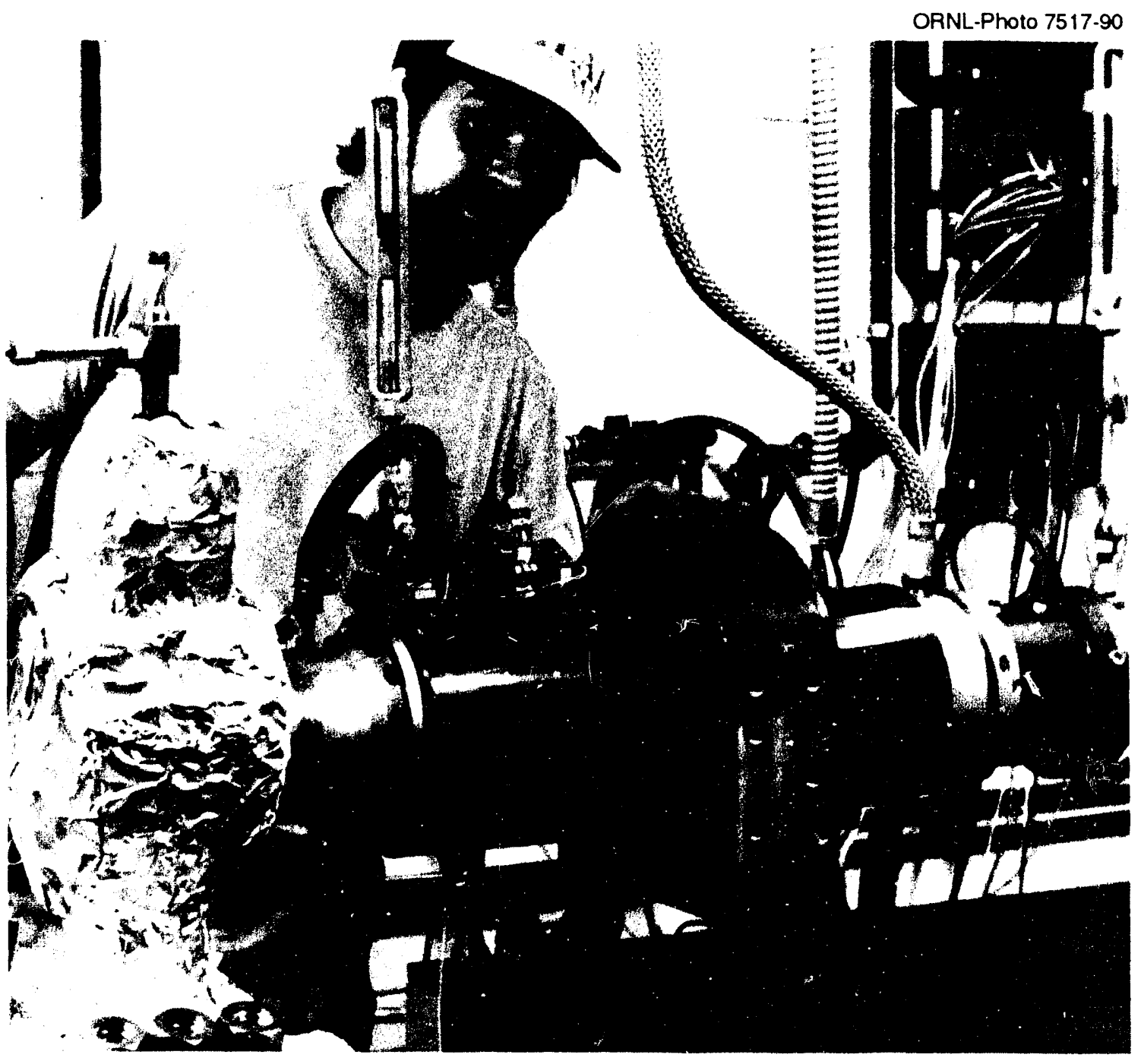

Fig. 5.1. Magnetically coupled free-piston Stirling engine driven refrigerator compressor. 


\subsubsection{Novel Cycles}

Novel cycles research this year focused on the non-CFC Stirling refrigeration cycle (SRC), self-powered appliance technology, and assessment of desiccant dehumidification and cooling technology.

The initial purpose of the SRC work is to assess Stirling cycle technology and its application potential in building equipment. Two companies were selected for this work under a competitive RFP. Applications being investigated include electric space conditioning and food refrigeration systems that would avoid the use of fluorocarbon [CFC. hydrochlorofluorocarbon (HCFC), or hydrofluorocarbon] refrigerants (SRC uses helium). or gas-fired duplex itirling systems (a Stirling engine driving a Stirling refrigeration cycle). The work is on schedulc. Based on promising phase one results, technology development activities are expected to follow in FY 1991.

A second project is to develop self $\tau_{-}$- wered appliances using the thermophotovoltaic concept. This novel concept can make high-efficiency gas-fired water heaters completely self-contained, without being connected to a domestic electric power grid. A ceramic iber is heated to an elevated temperature that will then radiate on to an array of solar cells. The first phiase of this project is more than half completed. An evaluation unit has been tested and delivered to ORNL (see Fig. 5.2). An assessment of applying this concept to thermally activated heai pumps is also underway. The subrontriact woik is being done at Quantum Group.

The third project involves an assessment $c$. current desiccant technology by ORNL. With the advances made recently, this CFC-free

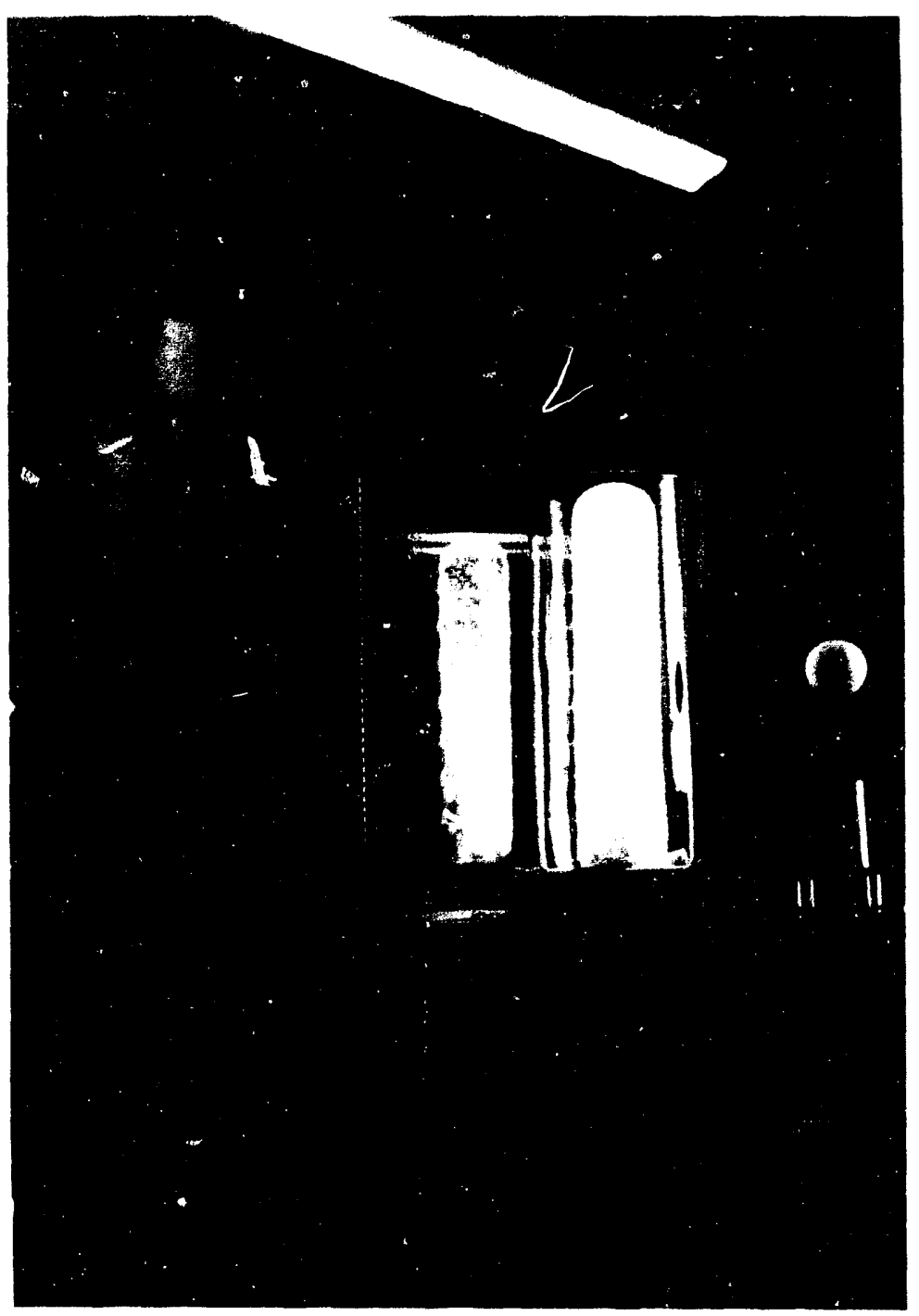

Fig. 5.2. Development of self-powered appliances throu ${ }_{r}$, h the use of a thermophotovoltaic system.

technology has become one of the most promising alternatives to vapor compression cooling technology. It can be used in stand-alone applications or can be integrated into conventional building heating and cooling systems. Currently. the prime energy coefficient of performance of the desiccant part of an integrated cooling system is about 1.5 at the design point, with the potential for further improvement.

\subsubsection{Refrigeration Systems}

The BER Program 's research into CFC alternatives continued to grow this year. Two major

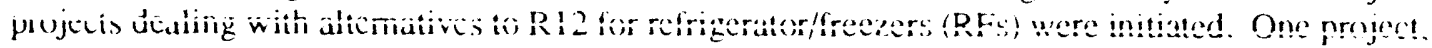
cosponsored by the U.S. Environmental Protection Agency (EPA), focuses on evaluation of advanced refrigeration cycles for RFs. One such cycle features the use of separate evaporators for the fresh food 


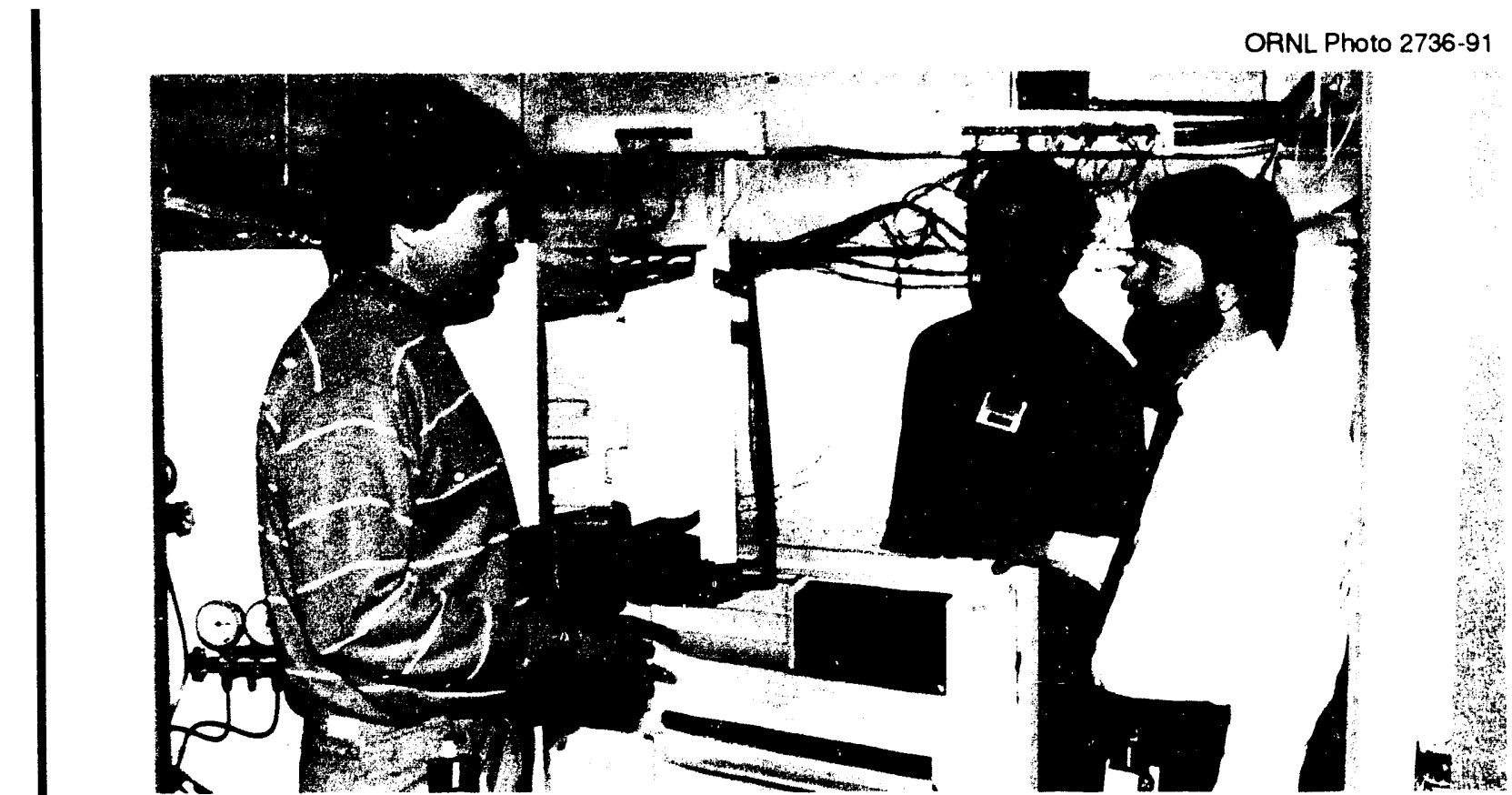

Testing CFC alternatives in a refrigerator freezer.

and freezer sections with a nonazeotropic refrigerant

mixture (NARM) (see

Fig. 5.3). Standard RF designs rely on a single evaporator to cool both sections. Analytical screening of candidate NARMs in this cycle showed that over $20 \%$ performance improvement may be possible (see Table 5.1). A modified $\mathrm{RF}$ incorporating this cycle has been built and will be tested next year. The other project, cosponsored by the Amierican Society of Heating, Refrigerating, and Air Conditioning Engineers (ASHRAE), involves evaluating $R 12$ alternatives for standard RF designs. Six altematives including $R 134$, R134a, R152a, and three mixtures of these compounds are being tested in an RF that is customized for the specific characteristics of each. Americold Compressor Company has provided compressors tailored for each altemative refrigerant for use in this project.

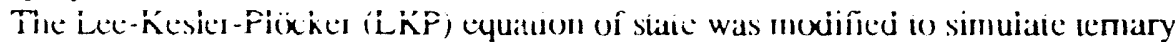
(three-component) and higher order mix'ures of altemative refrigerants. ${ }^{1}$ A major feature of the LKP 
Table 5.1. Coefficients of performance (COP) and capacity: Analytical estimates of the two-evaporator refrigerator-freezer cycle with nonazeotropic refrigerant mixtures (NARMs)

\begin{tabular}{|c|c|c|c|c|c|c|}
\hline Refrigerant & $\mathrm{COP}$ & $\begin{array}{c}\mathrm{COP}^{a} \\
\text { increase over } \\
\mathrm{R} 12(\%)\end{array}$ & $\begin{array}{c}\text { Mass fraction } \\
\text { (maximum } \\
\text { COP) }\end{array}$ & $\begin{array}{c}\text { Relative } \\
\text { volumetric } \\
\text { capacity } \\
(\mathrm{R} 12=1.0)\end{array}$ & $\begin{array}{c}\text { Relative } \\
\text { suction } \\
\text { pressure } \\
(\mathrm{R} 12=1.0)\end{array}$ & $\begin{array}{l}\text { Compressor } \\
\text { pressure ratio }\end{array}$ \\
\hline $\begin{array}{l}\text { R12 (single } \\
\text { evaporator) }\end{array}$ & 1.353 & - & 1.0 & 1.0 & 1.0 & 9.2 \\
\hline $\begin{array}{l}\text { R12 (dual } \\
\text { evaporator }\end{array}$ & 1.379 & 1.9 & 1.0 & 1.0 & 1.0 & 8.9 \\
\hline R23/R152a & 1.529 & 13.0 & 0.1 & 1.4 & 1.2 & 9.7 \\
\hline $\mathrm{R} 23 / \mathrm{R} 124$ & 1.430 & 5.7 & 0.1 & 1.0 & 0.9 & 11.5 \\
\hline $\mathrm{R} 32 / \mathrm{R} 152 \mathrm{a}$ & 1.525 & 12.7 & 0.3 & 1.6 & 1.4 & 8.8 \\
\hline $\mathrm{R} 32 / \mathrm{R} 123$ & 1.516 & 12.0 & 0.8 & 2.5 & 2.3 & 7.5 \\
\hline $\mathrm{R} 32 / \mathrm{R} 142 \mathrm{~b}$ & 1.600 & 18.3 & 0.3 & 1.5 & 1.3 & 8.7 \\
\hline $\mathrm{R} 32 / \mathrm{R} 124$ & 1.575 & 16.4 & 0.3 & 1.7 & 1.6 & 8.0 \\
\hline R125/R152a & 1.485 & 9.8 & 0.3 & 1.2 & 1.1 & 9.5 \\
\hline R125/R142b & 1.548 & 14.4 & 0.4 & 1.0 & 0.9 & 9.4 \\
\hline R125/R124 & 1.469 & 8.6 & 0.4 & 1.2 & 1.1 & 9.2 \\
\hline $\mathrm{R} 143 \mathrm{a} / \mathrm{R} 152 \mathrm{a}$ & 1.481 & 9.5 & 0.2 & 1.2 & 1.1 & 9.6 \\
\hline $\mathrm{R} 143 \mathrm{a} / \mathrm{R} 124$ & 1.468 & 8.5 & 0.3 & 1.1 & 1.0 & 8.6 \\
\hline $\mathrm{R} 143 \mathrm{a} / \mathrm{R} 142 \mathrm{~b}$ & 1.546 & 14.3 & 0.4 & 1.1 & 1.0 & 8.8 \\
\hline $\mathrm{R} 143 \mathrm{a} / \mathrm{R} 123$ & 1.604 & 18.6 & 0.8 & 1.6 & 1.6 & 7.4 \\
\hline R22/R152a & 1.473 & 8.9 & 0.2 & 1.1 & 0.9 & 10.2 \\
\hline $\mathrm{R} 22 / \mathrm{R} 124$ & 1.496 & 10.6 & 0.4 & 1.1 & 0.9 & 3.0 \\
\hline $\mathrm{R} 22 / \mathrm{R} 142 \mathrm{~b}$ & 1.547 & 14.3 & 0.4 & 1.0 & 0.8 & 9.6 \\
\hline $\mathrm{R} 22 / \mathrm{R} 123$ & 1.651 & 22.0 & 0.7 & 1.3 & 1.1 & 8.5 \\
\hline R152a/R123 & 1.712 & 26.5 & 0.5 & 0.7 & 0.5 & 10.4 \\
\hline $\mathrm{R} 134 \mathrm{a} / \mathrm{R} 123$ & 1.671 & 23.5 & 0.6 & 0.7 & 0.5 & 11.1 \\
\hline
\end{tabular}

${ }^{a}$ Lnprovement over $\mathrm{R} 12$ in a single-evaporator configuration.

${ }^{b}$ Of lower boiling point component, listed furst in refrigerant column.

Source: C. K. Rice and J. R. Sand, "Initial Parametric Results Using CYCLEZ-An LMTD-Specified, Lorenz-Meutzner Cycle Refrigerator-Freezer Model," pp. 448-58 in Proceedings of the 1990 ASHRAE-Purdue CFC Conference, West Lafayette. Ind., July 1990.

model is that it requires very little data to generate reasonably accurate estimates of thermodynamic properties-an important advantage in screening mixtures of fluids for which little data are available. A screening analysis was initiated using the LKP model to evaluate alternatives for replacement of R502 in commercial refrigeration applications.

Cooperation and interaction with industry groups on CFC alternatives research has grown tremendously this year. We participated in a round-robin compressor test project sponsored by the Association of Home Appliance Manufacturers (AHAM). The project goal was to perform a standard calorimeter test on a specially instrumented RF compressor to establish a baseline of comparison among the various industry and government laboratories involved in this area. Our results for capacity and energy efficiency ratio were within $1 \%$ of those obtained by the compressor manufacturers involved. AHAM has also indicated an interest in cosponsoring a project at ORNL to investigate advanced concepts for future (post-1998) RF designs. In addition, the Alternative Fluorocarbon Environmental Acceptability Study (a consortium of chemical manufacturers) expressed a desire to have ORNL conduct an assessment of the global warming impacts of CFC alternatives.

Research continued on improving heat exchanger (HX) effectiveness $(\varepsilon)$ with NARMs. Tests of several enhanced surface HXs compared with smooth surface HXs showed definite evidence that NARMs take better advantage of surface enhancement than pure refrigerants (see Fig. 5.4). A theory for HX performance with NARMs incorporating variable specific heat analysis into the classical

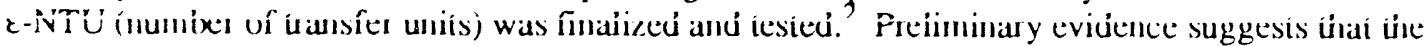
variable specific heat $\varepsilon$-NTU analysis simulates our lab test data more realistically than the classical $\varepsilon-N T U$ analysis with constant specific heat. 


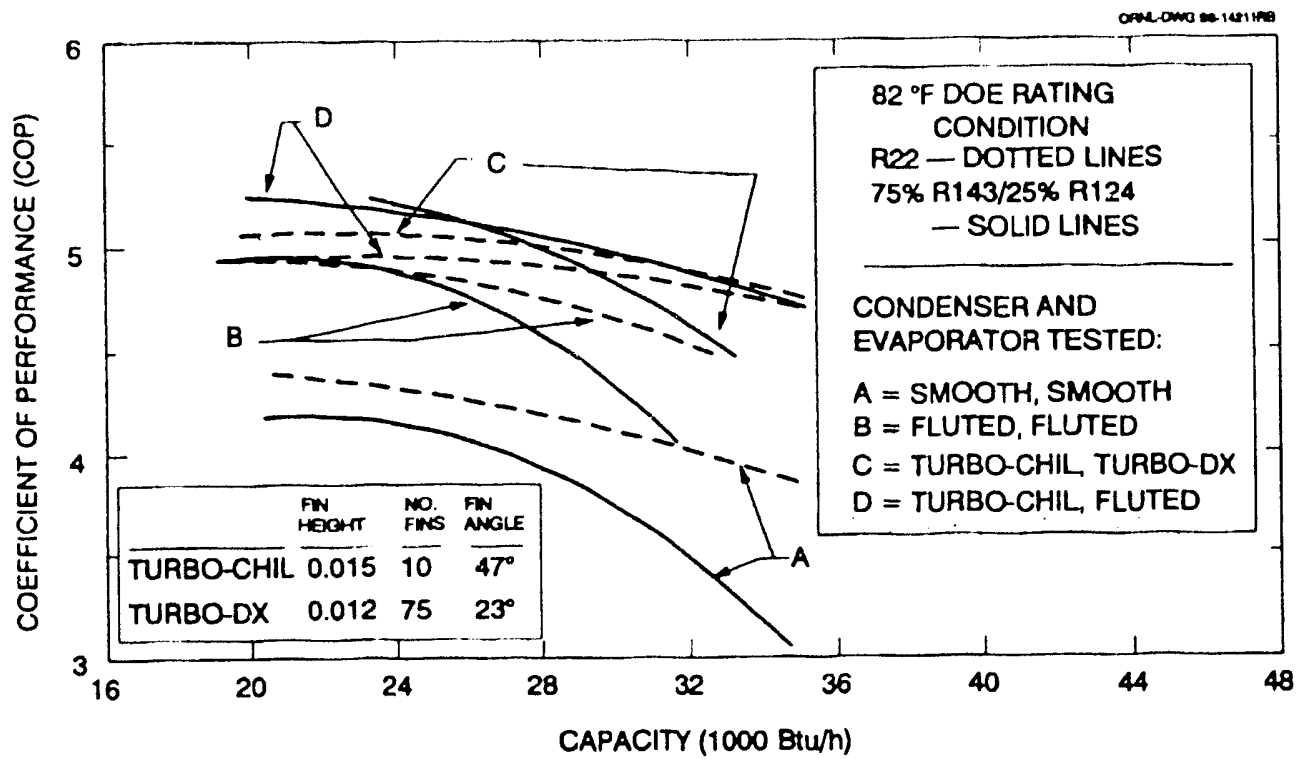

Fig 5.4. Results of performance testing of smooth-tube evaporator and condenser relative to enhanced surface heat exchangers in Oak Ridge National Laboratory's Building Equipment Laboratory.

A limited effort continued on capacity modulation technology. An optimization analysis of variable-speed (VS) heat pumps using state-of-the-art technology (reciprocating compressors and permanent magnet motor drives) was completed (see Fig. 5.5). Calorimeter testing of VS rotary compressors was also completed. Results of these projects together with documentation of the VS heat pu:np design model will be published in FY 1991. Results of this program gamered significant favorable outside publicity this year. According to articles in the Electric Power Research Institute Heat Pump News Exchange, companies using the ORNL heat pump model report reductions in engineering design time of up to $70 \%{ }^{3,4}$

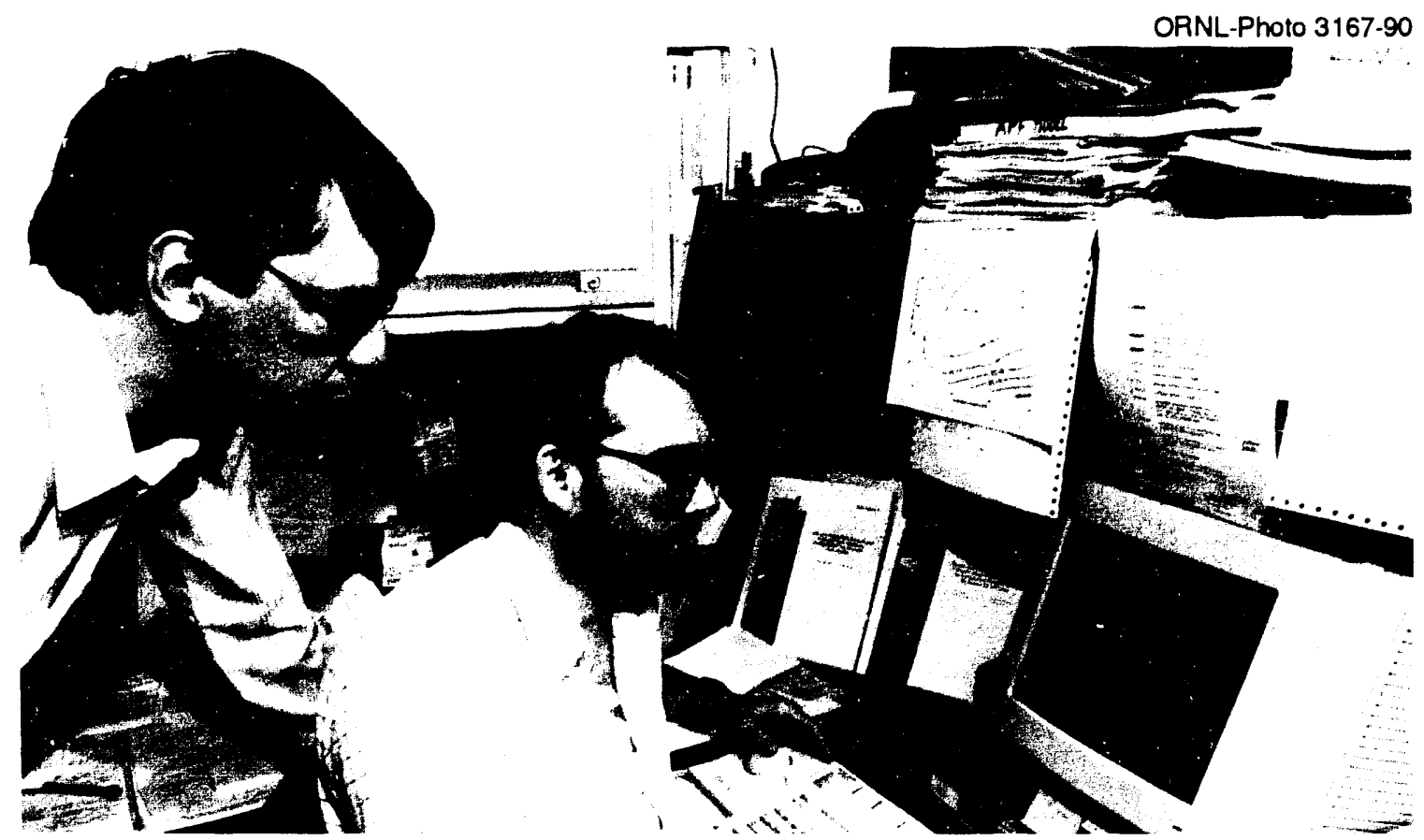

Fig. 5.5. Oak Ridge National Laboratory researchers review a computer-generated plot typical of those created for the variable-speed heat pump optimization analysis. 


\section{Industrial Chemical Heat Pumps}

The chemical heat pump (CHP) program made significant progress in thermodynamic modeling of aqueous based salt solutions for heating and cooling applications and in bringing solid-vapor and liquid-vapor heat pump technologies up to field testing stage. The heat pump group successfully developed a two parameter model that predicts the thermodynamic properties such as water activities, vapor pressure, densities, differential (or integral) enthalpies of solutions of single or mixed salt solutions and the crystalline phases in single salt solutions using sparse data. With this model, researchers will have a powerful tool at their disposal to tailor new fluids for specific applications. The inventors of the analytic technique (see Fig. 5.6) have filed three reports of inventions with ORNL's patent office. The Office of Technology Transfer has determined that all three patent applications have significant commercial potential and are now actively engaged in licensing the technology to industry. In other in-house work, the CHP test facility at ORNL evaluated a total of seven additives for enhancing heat and mass transfer rates in aqueous $\mathrm{LiBr}$ and $(\mathrm{Li}, \mathrm{K}, \mathrm{Na}) \mathrm{NO}_{3}$ solutions. The group also assisted The Trane Company, La Crosse, Wisconsin, in evaluating their proprietary fluids and additives for the triple-effect cycle. Ongoing laboratory experiments include corrosion testing of various metal alloys in ammoniated salt complexes (see Fig. 5.7). This work is expected to conclude in May 1991.

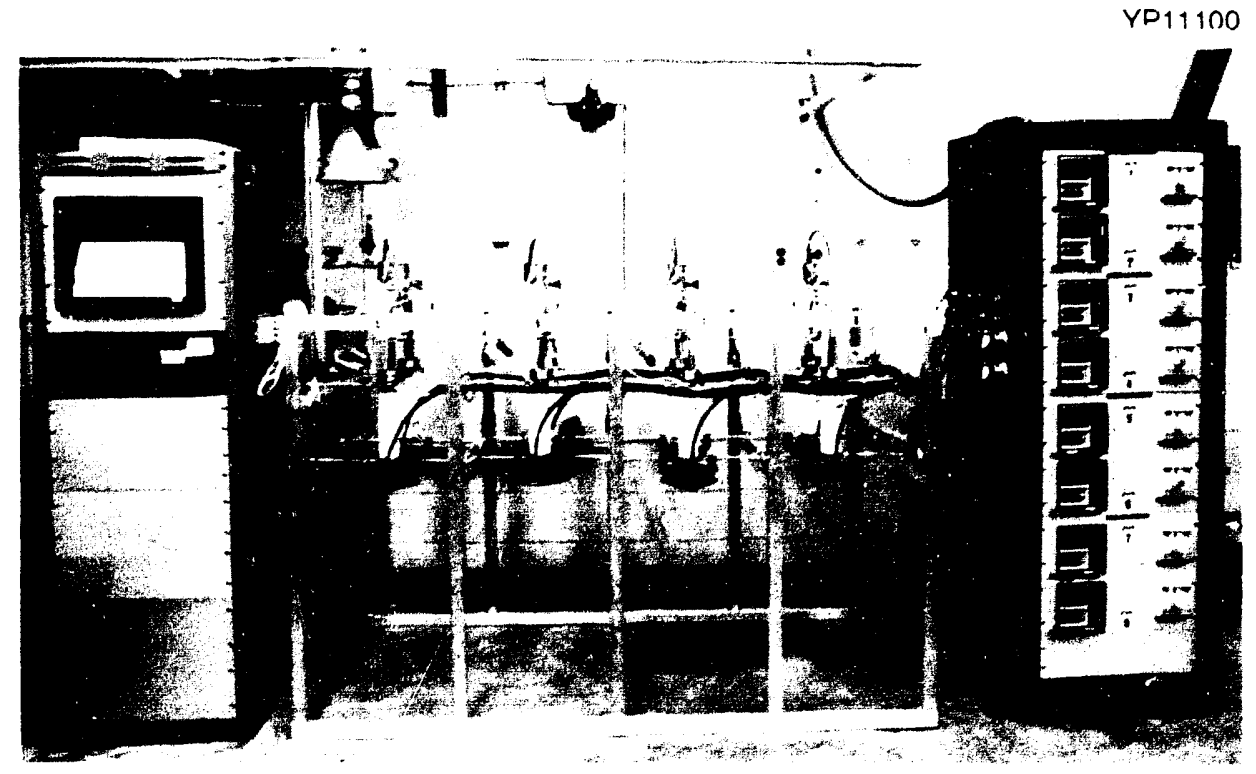

Fig. 5.7. Corrosion testing of various metal alloys in ammoniated salt complexes. 


\subsubsection{Work for Others for the BER Program}

\subsubsection{Advanced Surfaces for Vertical-Tube Absorbers}

A new 2-year absorber research project funded by the Gas Research Institute (GRI) was initiated to develop information on vertical-tube absorbers for use with lithium bromide and water solutions. This work supports system development projects sponsored elsewhere by GRI. Design modifications were made to an existing ORNL test loop to accommodate the vertical-tube test section. Supporting analytical studies to develop data reduction procedures and design correlations were initiated. Tests are to begin in 1991 .

\subsubsection{EPRI CFC Alternatives for Centrifugal Chillers}

An Electric Power Research Institute- (EPRI-) sponsored project was initiated this year within the BER program to investigate zero-ozone-depletion alternatives to R11 and R123 for centrifugal chiller applications. EPRI requested this work to explore long-term alternatives in response to United Nations Environment Programme and U.S. Clean Air Act initiatives to phase out HCFC refrigerants like R123, as well as CFCs, by early next century.

\subsection{ENVIRONMENTAL CONTROL TECHNOLOGY}

The main research objective of the group is to develop innovative environmental control technologies for efficient and effective energy utilization for a variety of end-use applications. During the year, several hardware development and analysis projects, including non-CFC mobile air conditioning, subcompact air conditioners, self-powered space heaters, and thermal sciences, were carried out.

ORNL is leading the transportation CFC reduction effort for DOE. A major activity is an assessment of non-CFC automotive air conditioning technology and evaluation criteria. In collaboration with the Health and Safety Research Division at ORNL, significant progress has been made on leak detectors for new non-CFC working fluids. This work, supported by the Exploratory Research Program and the Office of Technology Applications, has resulted in several invention disclosures.

During the fiscal year, a high-efficiency subcompact air conditioner (sce Fig. 5.8) and an innovative space heater, self-powered by thermoelectrics, were developed and tested. The subcompact unit developed is smaller, lighter, and nearly $10 \%$ more energy efficient (at Air-Conditioning and Refrigeration Institute's test conditions) than originally specified. Testing of the self-powered space heater was done by the Engineering Technology Division.

The concept of magnetic refrigeration is also being studied. In the first phase of this work an analysis of cycle losses was completed. This involved the study of four thermodynamic cycles using five different solid thermomagnetic working media over extended temperature ranges. The results

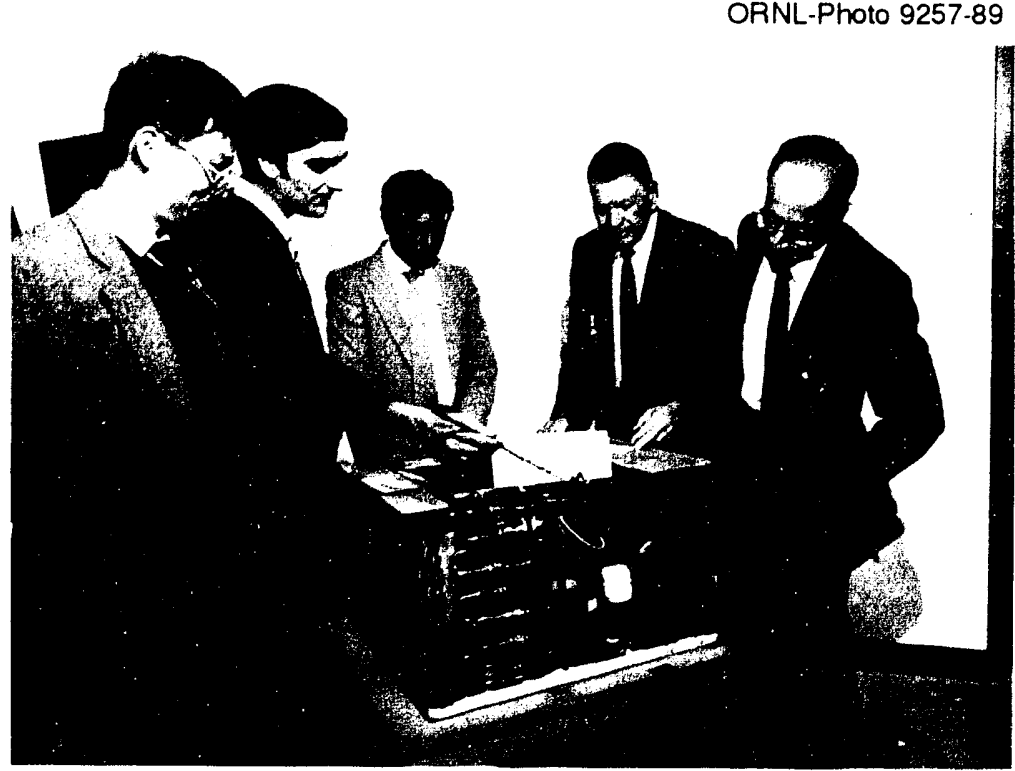

Fig. 5.8. Test unit of a subcompact air conditioner. have been presented in two conferences and published in the open literature. ${ }^{5}$ With the cooperation of the Fusion Energy Division, a iaboratory test faciiity is being deveioped for contınumg research in magnetuc refrigeration. 


\subsubsection{Work for Others for Environmental Control Technology}

During the year. ORNL provided research, design, and engineering support to the U.S. Army in environmental control technology. Two sets of hardware were delivered. In addition, an innovative safety-critical $\mathrm{HX}$ concept is being developed as part of the design analysis of auxiliary power and air cycles.

Under subcontract, Rocky Research Corporation of Boulder City, Nevada, is building a prototype solid-vapor heat pump to deliver $4 \mathrm{~kW}$ of refrigeration at $-9^{\circ} \mathrm{C}$ and produce about $10 \mathrm{~kW}$ of process hot water at $54^{\circ} \mathrm{C}$. The operating conditions focus on one specific application that is representative of a generic industry. The project completion date is May 1991.

Encrgy Concepts Company of Annapolis, Maryland, built and tested a 10-kW dual function (heat and temperature amplifier) heat pump that produces process heat up to $260^{\circ} \mathrm{C}$ in a single stage. The heat pump uses a strong solution of (Li, $\mathrm{K}, \mathrm{Na}$ ) $\mathrm{NO}_{3}$ solution that appears to have very low stress corrosion cracking rates.

\subsection{BUILDING THERMAL ENVELOPE SYSTEMS AND MATERIALS}

The Building Thermal Envelope Systems and Materials (BTESM) Program receives most of its funding from the Building Systems and Materials Division of the Office of Building Energy Research of the U.S. Department of Energy (DOE). The research covers walls, foundations, roofs, attics, and building materials.

The overall mission of this program is to lead private industry to substantially improve the energy efficiency and environmental acceptability of new and existing building envelope components: foundations, walls, attics, and roofs. To accelerate the development and acceptance of advanced envelope systems, this program manages five unique experimental test facilities:

- The Large Scale Climate Simulator is a 20 - by 20 -ft horizontal indoor/outdoor environmental (x)x for testing flat roofs and attics. The outdoor box (climate chamber) can simulate any climate in the United States; air temperatures in the climate chamber can be controlled from 66 to $-25^{\circ} \mathrm{C}\left(150\right.$ to $\left.-40^{\circ} \mathrm{F}\right)$. Roof surface temperatures can be controlled with infrared healing up to $93^{\circ} \mathrm{C}\left(200^{\circ} \mathrm{F}\right)$.

- The Roof Thermal Research Apparatus is composed of four 4- by 8-ft panels on an outdoor facility for testing flat roof sections, four insulated masonry walls, and two slab-on-grade test sections exposed to the East Tennessee climate.

- The Envelope Systems Research Apparatus is a new 30- by 70-ft facility, shown in Fig. 5.9, built this year for field testing large flat roof areas (currently testing 40 different roof systems, each $64 \mathrm{ft}^{2}$ ) and 8 different basement wall insulation systems. Also, this facility could be easily modified to test residential frame walls.

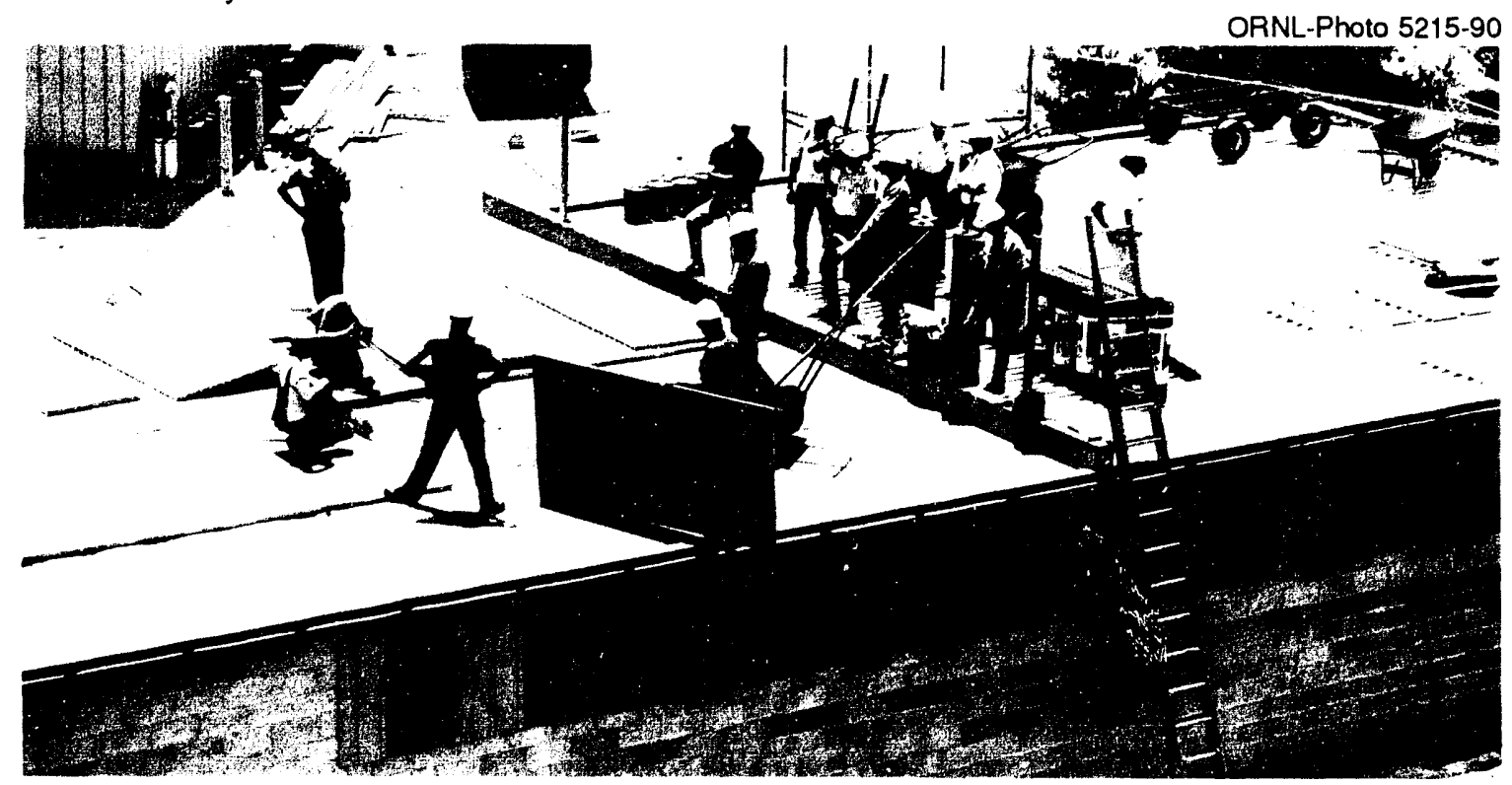

Fig. 5.9. Envelope Systems Research Apparatus tests roof and basement insulation systems at Oak Ridge National Laboratory. 
- The ORNL Heat Flow Meter Apparatus is a 2- by 2-ft comparative heat flow meter designed to meet standard C 518 published by the American Society for Testing and Materials (ASTM); it is equipped with a dedicated computer for unmanned test control, data acquisition, and data analysis. This apparatus automatically calibrates heat flux transducers in-situ used in the field exposure tests of roof, wall, and foundation systems.

- The ORNL Unguarded Thin-Heater Apparatus is a 3-by 5-ft absolute, longitudinal heat flow meter with less than $2 \%$ uncertainty for steady-state thermal resistance measurements. This device has also been used to make transient measurements to determine specific heat and thermal diffusivity of building materials at different mean specimen temperatures.

All of the major experimental facilities owned by this group have been heavily used to make careful thermal measurements of polyisocyanurate foams with non-CFC blowing agents. This cooperative research project with the Polyisocyanurate Insulation Manufacturers Association, Society for Plastics Industry, National Roofing Contractors Association, DOE, and EPA is determining the technical feasibility of using HCFC blowing agents to manufacture more environmentally acceptable roof insulation boards. HCFCs are CFCs with an extra hydrogen atom added to the chlorine, fluorine, and carbon, making the compound less stable, and thereby reducing its ability to deplete the ozone. Laminated polyisocyanurate roof insulation board stock was chosen because it is a major insulation used in commercial and residential construction. Test boards were blown with conventional CFC-11 and with replacements HCFC-123, HCFC-141b, a

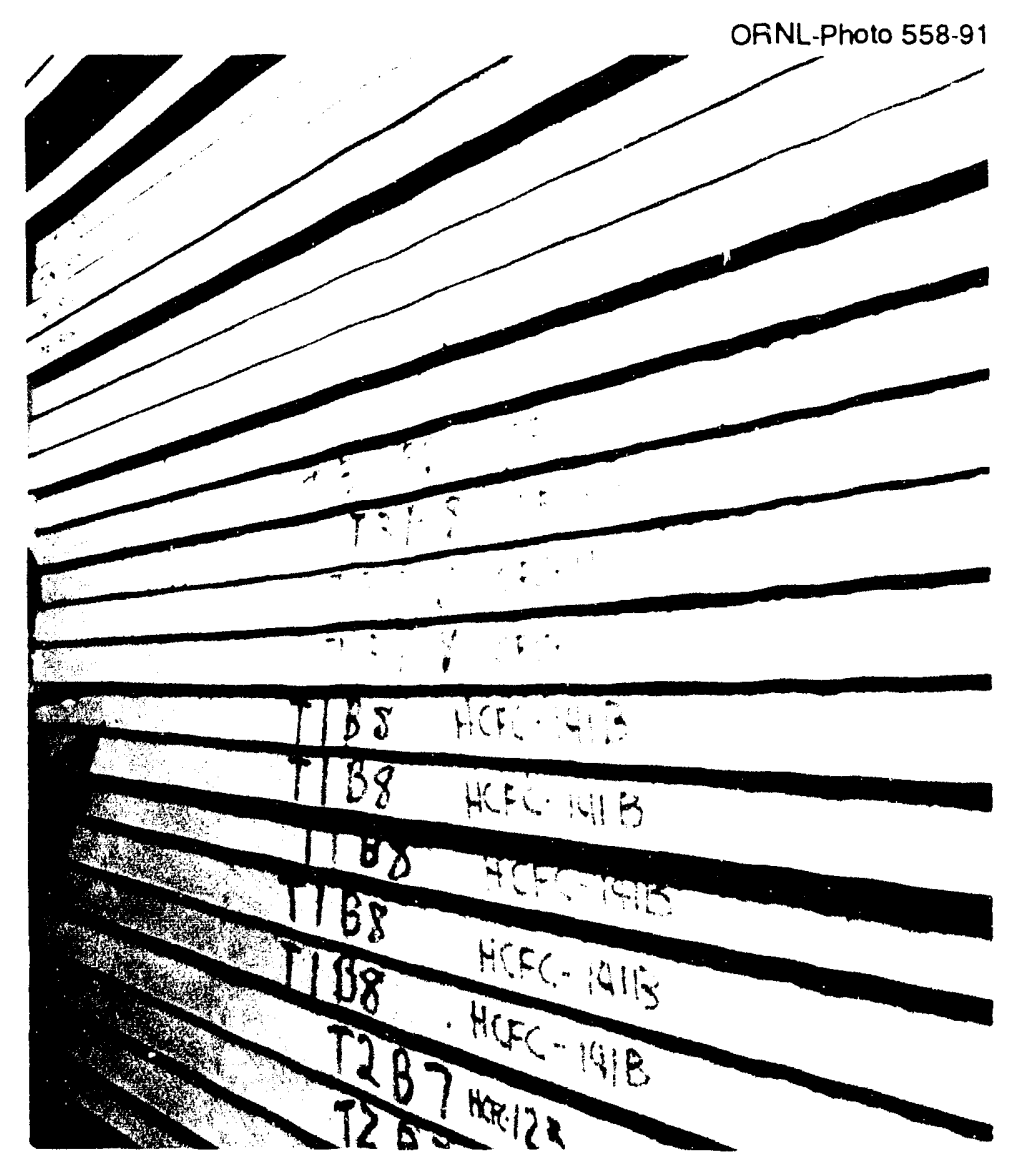

Roof insulation boards blown with conventional CFC-11 and nor-CFC agents.

$50 \%-50 \%$ blend, and a

$65 \%-35 \%$ blend of HCFC- 123 and HCFC- $141 \mathrm{~b}$.

The major determinant of success for these HCFC blown foam insulation boards is whether they produce the same outstanding thermal properties now obtained with CFC-11. The aging phenomena of roof insulation made with CFC-11 and the different alternates are compared for field exposures and accelerated aging laboratory tests. The in-situ thermal performance of the boards is periodically checked against steady-state thermal measurements to validate the "dynamic" method and its results.

Weekly k-values collected from field exposed boards for a 67-week period from September 1989 until December 1990 are shown in Fig. 5.10 for the CFC-11. HCFC-123, and HCFC-141b boards. After $538 \mathrm{~d}$ from production the relative ordering of performance of all three boards remains the same. These data along with accelerated aging data obtained in the laboratory are providing insights into the thermal performance of newly developed foam insulation over the entire in-service life. After the first year of the 3-year study, there has been no indication that therm?' performance differences are serious enough to suggest that any or all of the HCFC alternative blowing agents would not be technically viable in polyisocyanurate roof insulation. 


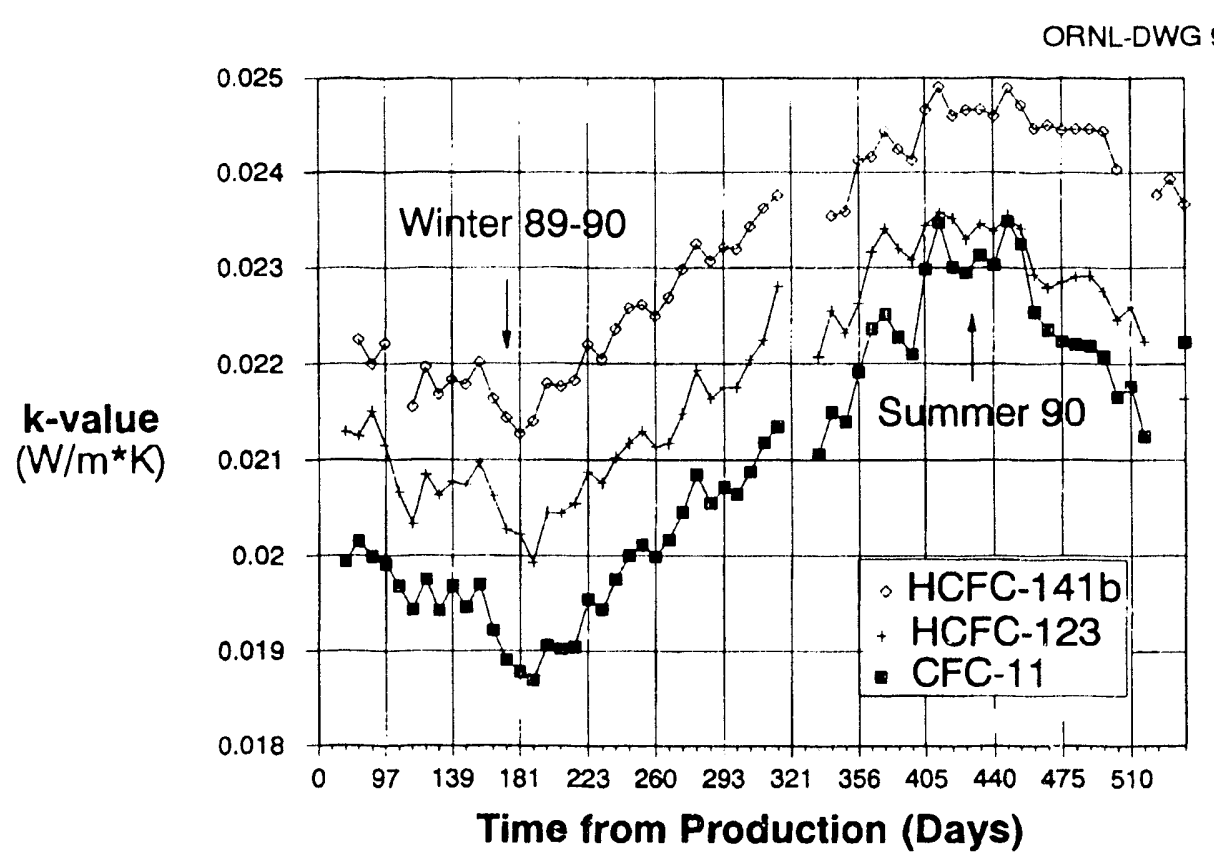

Fig. 5.10. Field k-values at weekly mean insulation temperatures.

Other activities within the BTESM program included two builders handbooks, one on moisture control in residential buildings ana another on building foundations. Several national codes and standards groups adopted foundation insulation levels based on both the modeling and experimental measurements conducted by ORNL on foundation insulation systems.

\subsection{EXISTING BUILDINGS RESEARCH}

Research focusing on technical and implementation issues for improving the energy efficiency of existing buildings is included in two programs for DOE: the Existing Buildings Efficiency Research Program for the Office of Building Energy Research and the Weatherization Assistance Program (WAP) for the Office of Grants Management.

A consumer-oriented fact sheet on the use of radiant barriers in residential attics is near completion. This fact sheet, explaining what radiant barriers are and how they work, also provides information on the range of installed costs and estimates of dollar savings for heating and cooling for a wide range of climates. Energy savings estimates rely heavily upon the modeling work. The fact sheet also provides sources for further information on installation procedures and a work sheet to account for conditions of a specific house.

Nationa! Fuel Gas Distribution Corporation and ORNL staff field tested the cost effectiveness of a refined audit sy: $\mathrm{cm}$ for a single-family, low-income weatherization program. The audit ranked space- and water-heating system measures against envelope measures, considered the interaction of savings between certain measures, selected all cost-effective measures for each house (benefit-to-cost ratio $>1.0$ ), and used air-leakage measurement procedures to determine the amount of air tightening that was cost-effective.

The avcrage savings of 257 therms/year measured for 32 owner-occupied, gas-heated houses was $17 \%$ of the average preweatherization house gas consumption and $78 \%$ of that predicted by the audit. Average space-heating energy savings was 252 therms/year (25\% of preweatherization space-heating energy consumption and $85 \%$ of predicted) and average water-heating savings was 5 therms/year. The overall benefit-to-cost ratio for the measures was 1:24 using the same assumptions followed in the audit: no administrative cost, residential fuel costs, real discount rate of 0.05 , and no fucl escalation. A weatherization program would be cost effective at an administration cost less than \$335/house. On average, the indoor temperature increased in the weatherized houses by $0.5^{\circ} \mathrm{F}$ following weatherization and decreased in the control houses by $0.1^{\circ} \mathrm{F}$.

The following conclusions regarding the audit were drawn from the study: (1) a significant cost-effective level of energy savings resulted; (2) space-heating energy savings and total installation 


\section{Assessing Convective Heat Loss in Attics}

A series of tests was performed on residential attics using an attic test module built to permit research on a number of issues related to attics. This test module was used in the Large Scale Climate Simulator (LSCS). The research included the evaluation of the thermal performance of an attic with one brand of loose-fill fiberglass insulation and the identification of heat loss because of convective air movement through the loose-fill insulation under simulated winter conditions. The thermal performance of the loose-fill fiberglass insulation tested under winter conditions declined by as much as a factor of two as the temperature difference across the insulation increased (see Fig. 5.11). This decline in thermal performance is attributed to the initiation of convection through the insulation as the temperature difference increases. These findings were documented by both energy flow analysis using the LSCS and infrared scans of the insulation surface in the attic. Additional tests were conducted on methods of minimizing this convective heat loss. Several products were tested that successfully block this energy loss. Some of this work was done with funds provided by Attic Seal Inc., the first private industry user of this National User Facility.

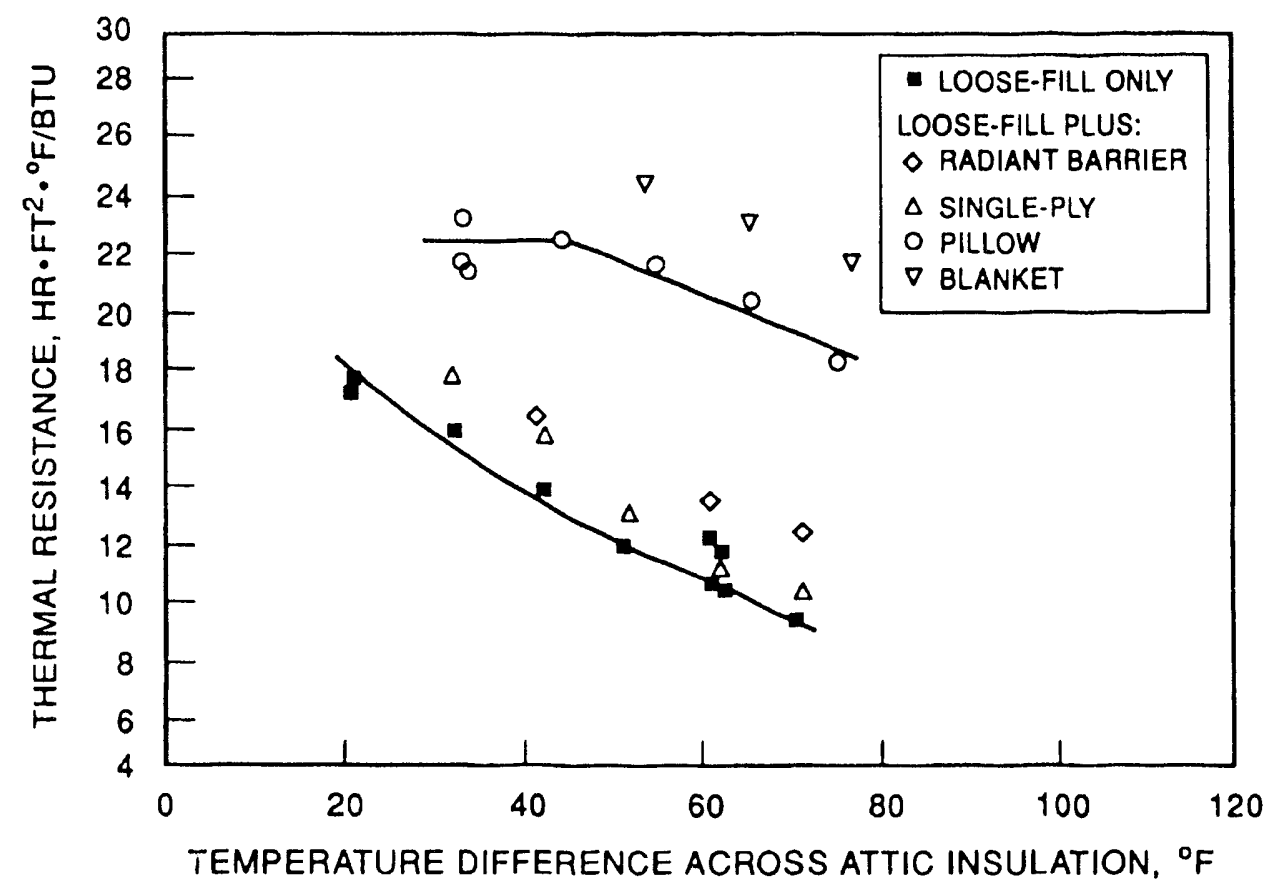

Fig. 5.11. Thermal performance of loose-fill fibrous glass insulation in winter conditions. 
costs were predicted with reasonable accuracy, indicating that the audit's recommendations were justified; (3) effectiveness improved from earlier versions and can continue to be improved; and (4) a wider variety of measures was installed compared to most weatherization programs. An additional conclusion of the study was that a significant indoor temperature take-back effect had not occurred.

The state of Oklahoma and ORNL staff evaluated the effectiveness of installing conservation measures to reduce electric cooling costs in single-family, low-income houses equipped with window air conditioners. The measures tested were replacing existing window air conditioners with high-efficiency units, adding radiant barriers in the attics, and the typical measures installed under Oklahoma's Low-Income Weatherization Assistance Program (justified on the basis of their ability to reduce space-heating energy consumption).

Normalized preweatherization air-conditioning electricity consumption measured in 81 owner-occupied houses averaged $1664 \mathrm{kWh} /$ year $(\$ 119 /$ year), with about 30\% of the houses using less than $1000 \mathrm{kWh} /$ year and only $10 \%$ using more than $3000 \mathrm{kWh} / \mathrm{year}$. Reductions in air-conditioning electricity consumption produced by measures installed under Oklahoma's weatherization program ( $31 \mathrm{kWh} /$ year) or by combining a truss-mounted attic radiant barrier with them $(52 \mathrm{kWh} /$ year) did not produce savings that were significantly different from that measured in a control group of houses ( $107 \mathrm{kWh} /$ year). The gross savings of $535 \mathrm{kWh} /$ year measured in the group of houses that received measures installed under Oklahoma's weatherization program as well as high-efficiency air conditioners was statistically different from the control group. The units were installed at an average cost of $\$ 947$. The average savings was $1068 \mathrm{kWh} /$ year for houses with preweatherization air-conditioning electricity consumption greater than $2500 \mathrm{kWh} /$ year that received a replacement air conditioner.

The following were concluded for Tulsa, Oklahoma, low-income houses cooled by one or two window air conditioners: (1) programs directed at reducing space-cooling electricity consumption are limited by current consumption and thus should be targeted at high-electricity consumers or be inexpensive to achieve cost effectiveness, (2) significant reductions in air-conditioning electricity consumption were not produced by measures installed under Oklahoma's weatherization program or by combining a radiant barrier with them, (3) replacing low-efficiency window air-conditioners with high-efficiency units in all units is likely not to be cost effective, and (4) targeting users with high air-conditioning electricity consumption to receive replacement air conditioners increases savings and cost effectiveness.

A project was initiated to modify the audit for use in hot and humid climates, and the advanced audit was field tested in the North Carolina Weatherization Assistance Program. Preweatherization data were collected for each house in the test. The test includes monitoring of heating and cooling energy use and indoor temperature for a full year before and after weatherization in 3 groups of 40 houses: a group weatherized by the current North Carolina program, a group weatherized as recommended by the audit, and a control group that received no weatherization. At the end of this period, the state weatherization subgrantees had inspected all houses and recorded audit input data and were running audits for the audit group.

The work on commercial buildings continues to focus on procedures for energy studies. A standard guide to help people plan energy monitoring projects for commercial and institutional buildings or facilities through use of project "protocols" has been drafted under ASTM committee E06 on building constructions. Initial balloting for approval of this guide should begin next year.

\subsection{ENERGY PROGRAM PLANNING AND EVALUATION}

The major thrust of the research of the Energy Program Planning and Evaluation (EPPE) group continues to be detailed quantitative assessments of energy-efficiency programs operated by utilities and government agencies. During FY 1990, several evaluation projects were completed, and a major new evaluation was initiated.

An assessment of the commercial progress of participants in DOE's Energy-Related Inventions Program (ERIP) was completed. ${ }^{6}$ Multiple indicators of progress were used, including the rate of commercialization of ERIP-supported technologies, the time required to move a technology from the laboratory bench to the marketplace, the number of years ERIP technologies experienced sales, the number of jobs generated, and the amount of funding raised. The positive impact of participation in ERIP is indicated hy comparing these indicators to statistics generated by private-sector new-product development efforts.

The EPPE group continued to contribute to the energy program evaluation field by conducting several literature reviews and secondary data analyses during FY 1990. Predictors and formal models 


\section{Advanced Single-Family Energy Audit}

Field tests of the advanced single-family energy audit in Wisconsin and in Buffalo, New York (with National Fuel Gas), have shown dramatic improvements in heating energy savings and program cost effectiveness. The new audit includes heating system retrofits ranked against envelope measures, use of methods (such as blower doors) to determine the amount of infiltration control work that is cost effective, consideration of interaction of savings for certain measures, and methods to rank measures for each eligible house. In Table 5.2, the 1985 Wisconsin field test of the audit is compared to a 1983 Wisconsin evaluation study in which weatherization measures were selected from a priority list that did not include furnace retrofit measures or use of blower doors. The priority list approach (in 1983) achieved 10\% heating energy savings at an average cost of $\$ 2250$ per house. Use of the audit (in 1985) with furnace retrofit measures resulted in almost twice the energy savings with less cost per house, with an increase in the savings/cost ratio by 2.5 times. In the Buffalo field test, average savings reached $25 \%$ at about the same cost. The demonstrated improvement from use of the audit in cold climates led to initiation of a project to further develop the audit for use in hot and humid climates and to field test the audit in the North Carolina Weatherization Assistance Program. The audit was completely reprogrammed to run faster on less advanced personal computers, and measures used in North Carolina to save cooling energy were added. The audit was delivered for field testing by training North Carolina subgrantees to use the audit to select cost effective measures for weatherization for each house.

Table 5.2. Field tests of the improved audit show dramatic improvements in the cost effectiveness of programs

\begin{tabular}{lccc}
\hline & $\begin{array}{c}\text { Average cost per } \\
\text { house }(\$)\end{array}$ & $\begin{array}{c}\text { Heating energy } \\
\text { savings }(\%)\end{array}$ & $\begin{array}{c}\text { Annual energy savings } \\
\text { per } \\
\text { hundred program dollars } \\
\text { (MBTU/(year } \$ 100)\end{array}$ \\
\hline 1983 Wisconsin study & 2,250 & 10 & 0.5 \\
1985 Wisconsin ficld test & 1,603 & 19 & 1.3 \\
1988 New York field test & 1,690 & 25 & 1.5 \\
\hline
\end{tabular}

Notes: Cost includes $\$ 300$ house for ADM and audit. Savings based on gas cost of 57.9 cents/therm. 
of the market penetration of energy technologies were reviewed, and an agenda for future research was developed. ${ }^{7}$ The potential for energy savings in the nonprofit sector was estimated, and twelve successful programs to promote energy-efficient nonprofit buildings were reviewed to identify effective program features. ${ }^{8}$

Over the past several years, the group has completed a series of evaluations of Bonneville Power Administration's Residential Weatherization Program, examining the energy saved by participants since the program was first launched in 1981, and assessing the durability of savings 1,2, and 3 years after weatherization. During FY 1990 the latest assessment of the program was completed. ${ }^{9}$ Altogether, these studies constitute an unprecedented analysis of the persistence of energy saved by residential energy retrofits and provide statistics that are critical to effective demand-side management planning. They suggest that energy savings are fairly duratic, decreasing by only $8-10 \%$ each of the first 3 years following weatherization.

During FY 1990 the EPPE group initiated a 3-year, multimillion-dollar evaluation of the impact and potential of DOE's low-income WAP. The evaluation plan calls for assessing the energy savings, cost effectiveness, and nonenergy impacts of WAP. Analyses of factors that cause savings and cost effectiveness to vary, of the WAP network's capabilities, and of the eligible client population remaining to be served also will be studied. Much of FY 1990 was spent designing the evaluation. Data will be collected and analyzed on a nationally representative sample of program participants, a sample of fuel oil participants from nine northeastern states, and matched control groups. Data on numerous aspects of the program, its participants, and its unserved eligible clients will be gathered from a variety of sources including local and state agencies, houschold surveying, on-site building inspections, fuel and indoor temperature monitoring, electric and gas utility billing histories, and DOE's 1990 Residential Energy Consumption Survey. When completed, this evaluation will be the most comprehensive, rigorous evaluation of a national energy conservation program ever conducted.

\subsection{INTEGRATED RESOURCE PLAN ì FOR ELECTRIC UTILITIES}

Integrated resource planning (IRP) helps utilities and state regulatory commissions consistently assess a variety of demand and supply resources to cost-effectively meet customer energy-service needs. Key characteristics of this planning paradigm include (1) explicit consideration of energy-efficiency, load-management, and renewable-energy programs as alternatives to some power plants: (2) consideration of environmental factors as well as direct economic costs; (3) public participation; and (4) analysis of the uncertainties and risks posed by different resource portfolios and by external factors. IRP differs from traditional utility planning in several ways, including the types of resources acquired, the owners of the resources, the organizations involved in planning, and the criteria for resource selection.

IRP will be especially important during the 1990s because of the growing need for additional utility capacity. Because of load growth and retirement of existing plants, the amount of excess capacity is rapidly diminishing. The 1990 s will differ from the 1980 s in more than just the number of new resources needed. Utilities will increasingly rely on competition to define the types and costs of power plants that are constructed. Provision of power by nonutility companies raises important issues about transmission access. In addition, energy-efficiency and load-management programs are increasingly seen as ways to defer the need for new generating capacity.

ORNL's work on integrated resource planning during FY 1990 continued to build a foundation for growth in this nationally important concept. We focused on three topics this year: (1) identifying and defining the key terms that characterize utility demand-side management (DSM) programs, ${ }^{1,10,11}$ (2) reviewing the IRP processes and plans of about 30 utilities throughout the United States, ${ }^{12,13}$ and (3) examining the methods used by electric utilities to analyze DSM programs. ${ }^{14,15}$

As the number, scope, and cost of utility DSM programs increase, the need for accurate data grows. Such data are required to document the performance of these programs to be sure that they deliver the cost effective energy and capacity resources expected of them. Unfortunately, lack of explicit, widely used definitions of DSM terms is a key deficiency that limits utility applications of DSM programs. Variables that describe program participation, energy and load-shape changes, and costs must be carefully defined, and these definitions should then be used throughout the electric-utility industry. We prepared two reports, sponsored by the Bonneville Power Administration, that discuss issues related to program participation and program costs. ${ }^{7.10}$ Building on these two projects, we reviewed DSM-program data needs, sponsored by DOE's Office of Conservation and 
Renewable Energy and EPRI." Finally, we organized a committee, consisting of about 15 people from utilities and public utility commissions, to develop consistent definitions for these key DSM-program terms. The committee's first meeting took place in November 1990, and we hope to complete a handbook on DSM-program terms by the end of 1991.

In FY 1989, we examined the methods that utilities use to treat uncertainty in utility planning. Building on that study, we collected and reviewed long-term resource plans from about 30 utilities throughout the country. We also interviewed staff from 11 of these utilities (and connlucted site visits at an additional 6 utilitics) to learn about the planning processes used by these organizations. ${ }^{12}$ These plan reviews and interviews revealed six key issues that affect a utility's planning process and its plan:

1. the relative emphasis placed on supply-and demand-side resources throughout the planning process,

2. the breadth of inputs considered during plan preparation from in-house departments and from nonutility interests,

3. the criteria used to select resource options for the plan,

4. the use of uncertainty-analysis techniques to ensure that the resources chosen will be appropriate for alternative futures,

5. the relationship between the long-term plan and the short-term action plan,

6. the balance between short- and long-term interests as reflected by the chosen resource mix.

Guidelines in the form of a checklist for the preparation and review of plans were developed on the basis of these reviews. ${ }^{13}$ This checklist, summarized in Table 5.3, should offer guidance to staff in public utility commissions who review utility plans and utility staff who prepare such planning reports.

Table 5.3 Checklist for a good integrated resource plan ${ }^{a}$

\begin{tabular}{|c|c|c|}
\hline Goal & Definition & Means of achieving goal \\
\hline Clarity of plan & $\begin{array}{l}\text { Adequately inform various groups } \\
\text { about future electricity resource } \\
\text { needs, resource alternatives, and the } \\
\text { utility's preferred strategy }\end{array}$ & $\begin{array}{l}\text { Clear writing style } \\
\text { Comprehensible to different groups } \\
\text { Presentation of critical issues facing } \\
\text { utility, its preferred plan, the basis } \\
\text { for its selection, and key decisions } \\
\text { to be made } \\
\text { Logical report structure }\end{array}$ \\
\hline Technical competence of plan & $\begin{array}{l}\text { Positively affect utility decisions on } \\
\text { resource acqusitions and regulatory } \\
\text { approval thereof }\end{array}$ & $\begin{array}{l}\text { Comprehensive and multiple } \\
\text { load forecasts } \\
\text { Thorough consideration of } \\
\text { demand-side options and } \\
\text { programs } \\
\text { Thorough consideration of } \\
\text { supply options } \\
\text { Consistent integration of } \\
\text { demand and supply options } \\
\text { Thoughtful uncertainty } \\
\text { analysis } \\
\text { Full explanation of preferred } \\
\text { plan and its close competitors } \\
\text { Use of appropriate time } \\
\text { horizons }\end{array}$ \\
\hline $\begin{array}{l}\text { Adequacy of short-term } \\
\text { action plan }\end{array}$ & $\begin{array}{l}\text { Provide enough information to } \\
\text { document utility's commitment to } \\
\text { acquire resources in long-term plan, } \\
\text { and to collect and analyze additional } \\
\text { data to improve planning process }\end{array}$ & \\
\hline Fairness of plan & $\begin{array}{l}\text { Provide information so that different } \\
\text { interests can assess the plan from } \\
\text { their own perspectives }\end{array}$ & $\begin{array}{l}\text { Adequate participation in plan } \\
\text { development and review by } \\
\text { various stakeholders } \\
\text { Sufficient detail in report on } \\
\text { effects of different plans }\end{array}$ \\
\hline
\end{tabular}

"Adapted from E. Hirst, M. Schweitzer, E. Yourstone, and J. Eto, Assessing Integrated Resource Plans Prepared by Electric Utilities, ORNL/CON-298, February 1990. 
These ORNL guidelines formed the basis of testimony presented before regulatory commissions in North Carolina and Washington, D.C. Utilities in Maine, Massachuselts, and Oregon used these guic lines in the preparation of their resource plans. Mat rial from this project was published in Public Utilits ss Fortnightly (March 1990) and was presented at several national and regional conferences sponsored by DOE and the National Association of R gulatory Utility Commissioners.

During the latter half of FY 1990, we began work on a new project building on the development of guidelines. By consulting the si'ne utilities, we examined the process used to plan DSM programs and how such programs are integrated with supply options in utilities' long-term resource plans. Although each utility has a unique approach to its resourcc planning, we synthesized a DSM-program analysis approach that includes technology identification and screening, program identification and screening, and integration of DSM and supply options (Fig. 5.12). Final reports from this project will be issued in mid-FY 1991. ${ }^{14.15}$

We anticipate continued growth in our work on integrated resource planning during FY 1991 and beyond. This expansion will involve additional in-house research projects as well as greater assistance to DOE in managing the DOE IRP program.

\section{S.7.1 Work for "jiners fol Integrated Resource Planning for Electric Utilities}

Work on integrated resource planming is sponsored by EPRI and the New York State Energy R\&D authority, as well as by DOE. In addition, we work closely with the National Association of Regulatory Utility Commissioners and other organizations interested in utility planning.

\subsection{TECHNOLOGY TRANSFER AND COMMUNITY SYSTEMS}

During this past year ORNL's support of the DOE Office of Building Technologies (OBT) technology transfer program resulted in the completion of an evaluation of the various DOE OBT biblingraphic databases. This evaluation included the development of criteria for an integrated Buildings Energy Technology Dorument Database and associated computerized database management systems. This endeavor also resulted in the development of individual computerized document database management systems for the Building Systems, Building Services, and Building Eanipment divisions.

The 1990 Institute on Energy and Engineering Education. conducted by the American Consulting Engineers Council Research and Management Foundation, was held at the Radisson Hotel North in Columbus, Ohio, during May 22-25, 1990. This DOE OBT-sponsored technology transfer project was attended by over 25 university engineering faculty and provided a forum for the transference of current tuilding energy technologies that can be integrated into U.S. collcge and university engineering curricula. ORNL aiso completed two separate investigations to determine the potential for collaborative government and private sector joint ventures concerned with factory-made housing and advanced district cooling.

ORNL continued to provide support to DOE in its role as the United States member of the International Energy Agency's Center for the Analysis and Dissemination of Demonstrated Energy Technologies (CADDET). Major activities during FY 1990 included (i) contribution of over 200 records of demonstrated energy technologies in the United States to the CADDET database; (2) convening of the first U.S. CADDET National Team meeting in Washington, D.C.; (3) publication of three major articles in the CADDET New'sletter: and (4) preparation and dissemination of information on exemplary de. Ionstrated energy technologies in the Unit:d States.

\subsection{POWER SYSTEMS TECHNOLOGY}

The objectives of the power systems technology program are to manage and perform research to improve the reliability, efficiency, and security of the nation's electric-power delivery system. Program activities are directed toward providing a fundamental understanding of phonomena and developing technology options for integration and operation of the future electric pow'er system. Management responsibilities include the Electric and Magnetic Fields Effects and Transmission and Distribution program areas funded by the DOE Office of Energy Managemicrit. The p. ogram staff also manages projects on energy development and efficiency in developing countries for DOE and the Ágency for internationai Leveiopment. conducts research on the develupment of a novel superconducting motor funded by the Director'S R\&D f for High Temperature Supercenductivity. 
DEMAND-SIDE MANAGEMENT (DSM) ANALYSIS

INVOLVES IDENTIFICATION, SCREENING, PROGRAM DEVELOPMENT, AND INTEGRATION TECHNOLOGY
IDENTIFICATION
AND SCREENING

\section{PROGRAM} IDENTIFICATION AND SCREENING

DSM AND SUPPLY INTEGRATION

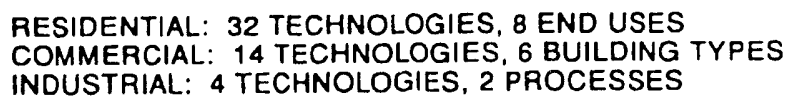

RESIDENTIAL: 32 TECHNOLOGIES, 8 END USES COMMERCIAL: 14 TECHNOLOGIES, 6 BUILDING TYPES INDUSTRIAL: 4 TECHNOLOGIES, 2 PROCESSES

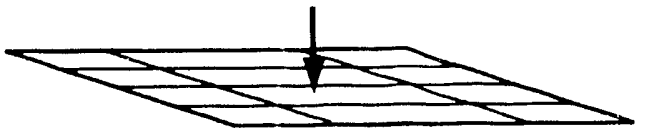

RESIDENTIAL: 21 TECHNOLOGIES COMMERCIAL: 10 TECHNOLOGIES

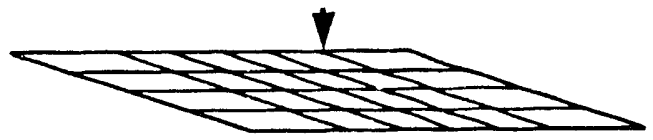

RESIDENTIAL: 8 PROGRAMS COMMERCIAL: 4 PROGRAMS

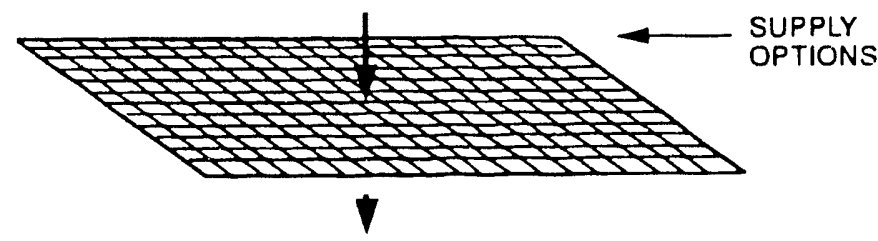

DSM PROGRAMS TO IMPLEMENT

Fig 5.12. Schematic showing the process used by electric utilities to identify and screen Demand-Side Management (DSM) technologies and programs and to integrate DSM programs with power sipply options.

During the year, an agreement was concluded whereby in FY 1991 ORNL will b.gin management responsibility for a significant part of the DOE research on health effects associated with electric and magnetic fields.

\subsubsection{Power Systems Transients}

Since 1983, ORNL has been the principal research laboratory for the DOE EMP program. This program has now been broadened in scope to include the effects on the power system of phenomena such as geomagnetic storms and other natural and system-generated transients such as lightning and fast front surges.

Assessments of EMP effects of electric power systems were completed during this period. ${ }^{16} \mathrm{~A}$ nominal EMP environment with a peak electric field of $39 \mathrm{kV} / \mathrm{m}$ was used to calculate the induced transients on transmission and distribution lines and control cables. The induced transients were co: ipared with experimental data on the iailure of components to assess the failure probability at the co nponent level This process was then extended to the equipment, subsystem, and system levels of the electric power system. It was found that a single high-altitude burst, which significantly disturbs the geomagnetic field, co'ld cause significant load and generation loss, but permanent damage would be isolated. Multiple bursts would increase the disturbance. Late-time EMP effects are similar to geomagnetic storms but have shorter duration and higher intensity. Voltage problems because of insupportable reactive power demand can be severe.

Steep-front transient tests were conducted on surge arresters. ${ }^{17}$ It was found that the voltage response of the arresters consists of a sharp overshoot voltage on the order of $80 \mathrm{kV}$ followed by a relatively level residual voltage, which is a function of current magnitude. The overshoot voltage is a result of the inductance of the arrester. A simple empirical model for the arrester was deternined to be an inducior in series with a current-controlled voltage source. 
A study on the economic consequences of solar geomagnetic storm impacts on electric power systems was performed. ${ }^{18}$ It was found that a severe geomagnetic storm could cause a major blackout with an economic impact of several billion dollars. The vulnerability of electric power systems in the northeast : Inited States will likely increase during the 1990s because of the trend of transmitting large amounts oi power over long distances to meet the electricity demands of this region. A comprehensive research program and a warning satellite to monitor the solar wind are needed to enhance the reliability of electric power systems under the influence of geomagnetic storms. ${ }^{19}$

To determine the effect of solar geomagnetic storms and the similar phenomenon caused by a magnetohydrodynamic- (MHD-) EMP event, an experiment to measure the effects of dc currents on distribution transformers was conducted. ${ }^{20}$ It was found that relatively small dc current levels of a few amperes can cause $75 \mathrm{kVA}$ transformers to be driven into saturation and cause significant harmonic distortion of the ac waveform. The transformer response time to the de injection was found to be much shorter than seen in power transformer tests with lower de injection levels. High levels of de injections for a short duration, such as is the case with MHD-EMP. could produce very high reactive power demand and harmonic distortions in a few tenths of a second.

\subsubsection{Materials and Components}

A Cooperative Research and Development Agreement (CRADA) was prepared for a research program on detection and mitigation of $\mathrm{S}_{2} \mathrm{~F}_{10}$, a toxic by-product of $\mathrm{SF}_{6}$, a gas used in gas-insulated equipment and substations for insulation and arc extinction. Three laboratories will perform the research: ORNL Health \& Safety Research Division, National Institute of Standards and Technology, and Ontario Hydro. The work will be funded by DOE, EPRI, Bonneville Power Administration, Tennessee Valley Authority. Empire State Electric Energy Research Corporation, Ontario Hydro, and the Canadian Electrical Association. A Joint Woth Statement for this CRADA was submitted to DOE for approval.

Transmission and distribution R\&D focused upon measuring and modeling harmonic losses in transformers, measuring and modeling lightning on distribution systems, development of adaptive transmission protection methods, and applications of remote measurement calibration for power system operations.

Remote measurement calibration can improve the evaluation and reduction of uncertainties in analog measurements used in power system control room computer applications to a level that allows satisfactory controt. Power system steady-state estimation provides a real-time database for the on-line-security-rchited functions in a modern power system control center. The reliability of the database and, therefore. the security analysis of the power system operation to a large extent depend upon the accuracy of analog measurements. Typically, several thousand analog measurements are used by a utility company to monitor the power system. At present, instruments are calibrated on-site every 2 to 3 years, a procedure that is unsatisfactory, untimely, and labor intensive. The errors in the analog measurements produce exceedingly large measurements residuals, demanding considerable engineering time and effort to install state estimators. The remote measurement calibration methodology was developed to eliminate installation errors and minimize systematic errors by frequent and remote analysis of measurements and instruments. The method provides the state estimator with unbiased measurements and actual standard deviations, both of which are necessary for a reliable real-time dat? thase. 22

The application $c^{f}$ superconducting materials to rotating electromagnetic machinery has been dominated by reports that substitute the new high $T_{C}$ materials into existing low $T_{c}$ designs. In 1987-88. the Energy Division and the Applied Technology Division evaluated various superconducting motors in a joint DOE- EPRI-funded study of the application of the new ceramic supereonductors to end-use technologies. Motors were found to be a very probable near term bulk application of high $T_{6}$ superconductors with a very favorable cost/benefit ratio.

\subsubsection{Energy for Developing Countries}

Wori on power systems technology applications in developing countries continued to demonstrate the economi:- environmental, and social benefits of power sector efficiency in Central America. A major integrated electric power system efficiency project was initiated in Costa Rica to demonstrate the benefits of integrated resource planning in a developing country selting. I oard 


\section{Systems Research}

A report for the DOE National Energy Strategy (NES) was prepared on the Electricity Policy Option for Transmission, Distribution, and Storage R\&D. Six areas were outlined in which federal support would be beneficial in maintaining the reliable delivery of power over the next 40 years: 1) real-time power systems controls, (2) higher capacity transmission options, (3) high-capacity power electronics, (4) system disturbance and mitigation analysis, (5) resolution of uncertainties regarding health effects from exposure to electric and magnetic fields, and (6) energy storage benefits and options. The report concludes that federal support for precompetitive R\&D $\quad . \quad$ transmission and distribution of electric power can produce significant national benefits. A forecast was made of the growth in transmission capacity needed to meet the NES growth projections in demand. As the estimated consumption grows from 2.8 trillion $\mathrm{kWh}$ in 1990 to 6.6 trillion $\mathrm{kWh}$ in 2030 , the transmission lines in service will nearly double, from 335,700 circuit miles in 1990 to 607,100 circuit miles by 2030 (see Fig. 5.13). The major areas for research outlined in the NES option report were developed in a workshop conducted by the program for DOE in March 1990 in Denver, Colorado, with executives and representatives from five private utilities, five public utilities, and nine organizations from various segments of the electric utility industry. ${ }^{21}$

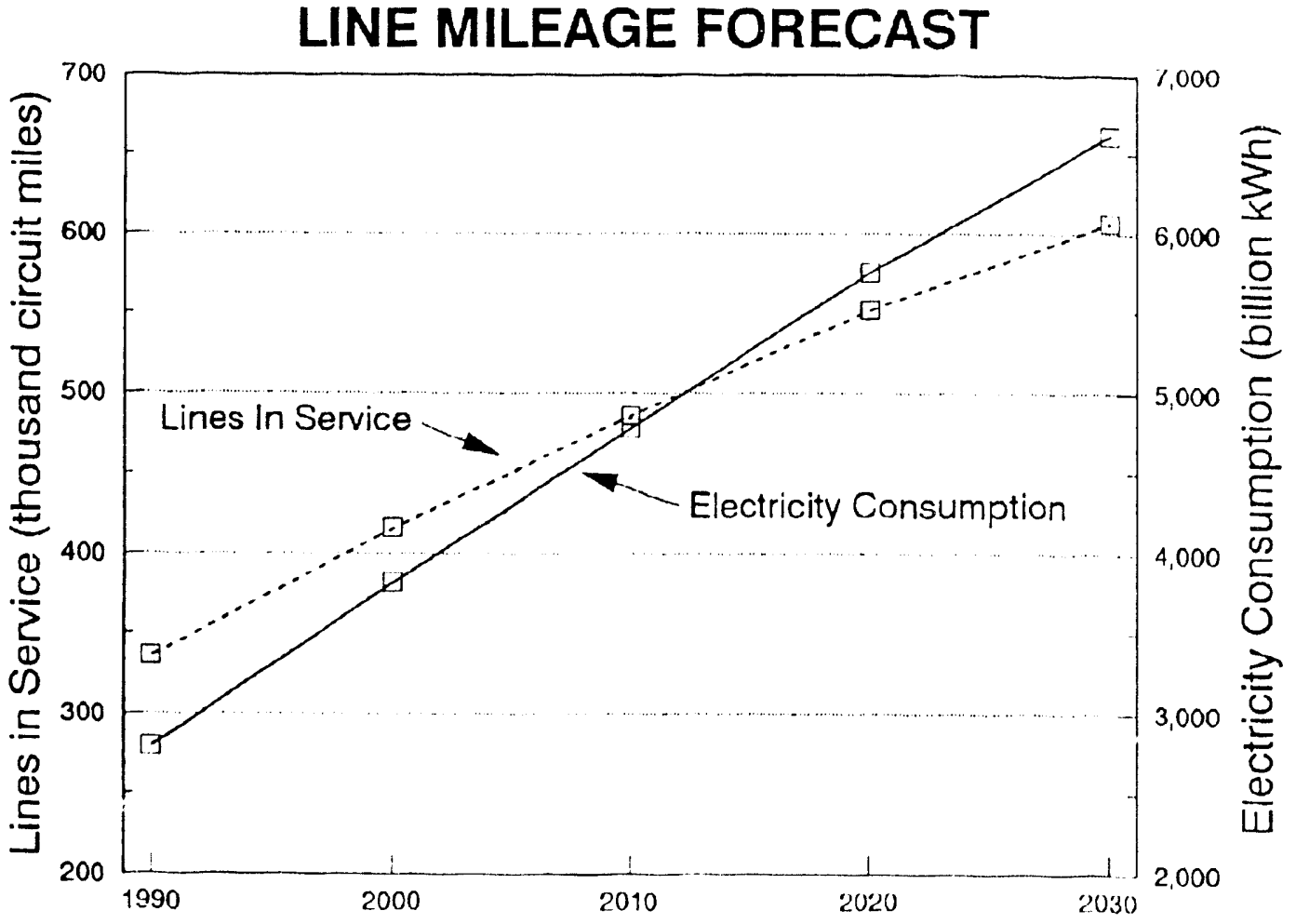

Fig. 5.13. Line mileage forecast. 
management, end-use energy conservation, and pewer plant transmission and distribution loss reduction opportunities were assessed to determine cost-effective investment alternatives. Renewable energy, decentralized power options were explored further, including hydroelectric and photovoltaic electric systems for small and micro-power applications.

\subsubsection{Work for Others for Power Systems Technology}

A study was sponsored by the Defense Nuclear Agency to review, analyze, and document the experience of the electric utility industry with geomagnetic disturbances. Severe geomagnetic storms have caused problems for electric power systems. The vulnerability of electric power systems to such events is increasing as transmission lines increase in length and because power systems are operated closer to their limits than in the past. In this study, we examined and analyzed the experience of electric utilities during geomagnetic storms. Measured data, effects on power system components, and power system impacts were considered. We found that electric power systems are susceptible to geomagnetically induced carth-surface potential gradients as small as about $10 \mathrm{~V} / \mathrm{km}$.

\section{References}

1. S. K. Fischer and J. R. Sand, "Thermodynamic Calculations for Mixtures of Environmentally Safe Refrigerants Using the Lee-Kesler-Plöcker Equation of State," pp. 373-82 in Proceedings of the 1990 ASHRAE-Purdue CFC Conference. West Lafayette, Ind.

2. E. Granryd and J. C. Conklin, "Thermal Performance Analysis for Heat Exchangers Using Nonazeotropic Refrigerant Mixtures." Heat Transfer in Advanced Energy Systems (submitted to ASME for publication at 1990 Winter Annual Meeting, draft completed July 1990).

3. EPRI 1990, "Expert System Allows Heat Pump Equipment Maker to Increase Engineers' Productivity, Cut Costs," Heat Pump News Exchange 2(2), 2.

4. EPRI 1990. "Profile: Oak Ridge National Laboratory, Prominent in Electric Heat Pump Research, Currently Focuses on Variable-Speed and CFC Projects," Heat Pump New's Exchange 2(3), 3-4.

5. F. C. Chen. et al., "Performances of Four Magnetic Heat Pump Cycles," ASME Symposium AES-Vol. 16, 103-116, November 1990.

6. M.A. Brown and C. R. Wilson, The Energy-Related Inventions Program, ORNL/CON-301, May 1990.

7. L. G. Berry, The Market Penetration of Energy-Efficiency Programs, ORNL/CON-299, April 1990.

8. M. A. Brown, B. Prindle, M. I. Scherr, and D. L. White, Energy Efficiency in Nonprofit Agencies: Creating Effective Program Models, ORNL/TM-1 1602, Oak Ridge National Laboratory, August 1990.

9. D. L. White and M. A. Brown, Electricity Savings Among Participants Three Years after Weatherization in Bonneville's 1986 Residential Weatherization Program, ORNL/CON-305, Oak Ridge National Laboratory, September 1990.

10. L. Berry, The Administrative Costs of Energy Conservation Programs, ORNL/CON-294, November 1989.

11. E. Hirst, Balancing the Scales: Data on Electricity Supply and Demand Resources, ORNL/CON-306. September 1990.

12. M. Schweitzer, E. Yourstone, and E. Hirst, Key Issues in Electric-Utility Integrated Resource Planning: Findings from a Nationwide Study, ORNL/CON-300, April 1990.

13. E. Hirst, M. Schweitzer, E. Yourstone, and J. Eto, 4ssessing Integrated Resource Plans Prepared by Electric Utilities, ORNL/CON-298, February 1990.

14. L. Hill, E. Hirst, and M. Schweitzer, Integrating Demand-Side Management Programs into the Resource Plans of U.S. Electric Utilities, ORNL/CON-311, January 1991.

15. M. Schweitzer. E. Hirst, and L. Hill, Integrated Resource Plans and Processes: Findings from a Survey of 24 Elertric Utilities, ORNL/CON-314, forthcoming 1991.

16. V. J. Kruse, et al., Impacts of a Nominal Nuclear Electromagnetic Pulse cen Electric Pow'er Svistems, GRNL/Sub/83-43374/2, to be published.

17. D. B. Miller, et al.. "The Response of MOV and SIX Arresters to Steep-Front Longer Duration Pulses." to be published in IEEE Transactions on Power Delivery.

18. P. R. Bames and J. W. VanDyke, "Potential Economic Costs from Geomagnetic Storms," IEEE Power Engineering Review 10(11), 3-4 (November 1990). 
19. J. G. Kappenman, V. D. Albenson, B. L. Damsky, and S. J. Dale, "Solar Wind Monitor Satellite: Crucial for Geomagnetic Storm Warmings," IEEE Power Engineering Review' 10(5) 4-8 (May 1990).

20. B. W. McConnell, P. R. Barnes, and F. M. Tesche, Results of an Experiment to Determine the Impact of Quasi-DC Currents :3: Three-Phase Distribution Transformer Installations, to be published as an ORNL/TM.

21. J. P. Stovall and S. J. Dale, Maimaining Electric Pow'er Systems Performance: Preparing for Year 2020, to be published as an ORNL report.

22. M. M. Adibi and J. P. Stovall, "On Estimation of Uncertainties in Analog Measurements," IEEE Transactions on Power Systems 5(4), 1222-30 (November 1990). 


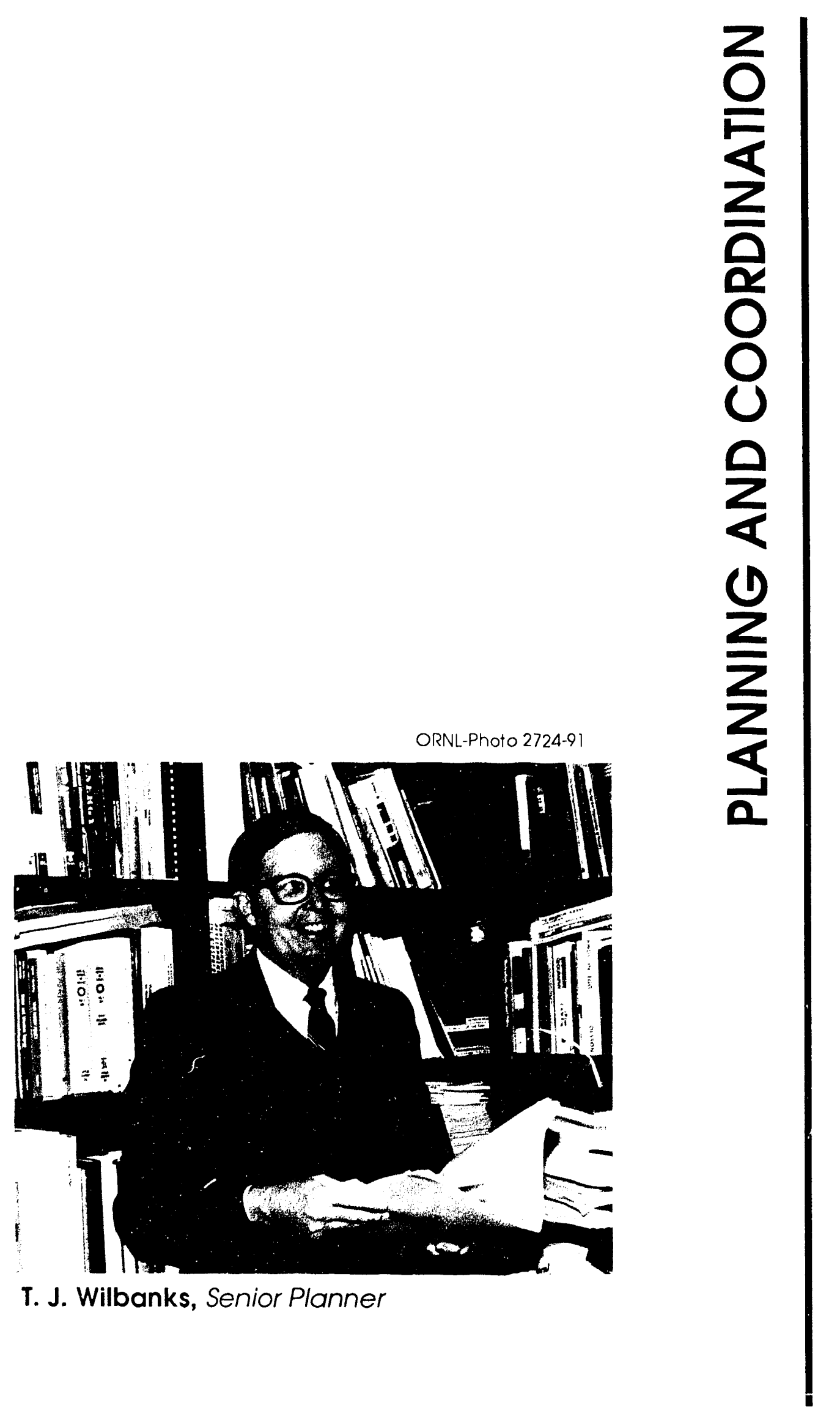




\section{PLANNING AND COORDINATION OVERVIEW}

\subsection{INTRODUCTION}

In FY 1989, the programmatic activities of Planning and Coordination cuntinued to focus on Oak Ridge National Laboratory's (ORNL's) developing country programs. In addition, Planning and Coordination provided its customary support for the Energy Division's long-range planning and program development related to the division's missions and objectives.

\subsection{DEVELOPING COUNTRY PROGRAMS}

During FY 1989, the developing country programs of the Energy Division expanded considerably in their scope and diversity, as national and international concerns about environmental change, economic competitiveness, and energy security continued to grow. The division's major areas of activity were in energy strategy development, energy efficiency improvement, environmental management, renewable energy options and rural area energy systems, energy research and development (R\&D) applications, and energy technology transfer.

\subsubsection{Energy Strategy Development}

More than 8 years of ORNL attention to energy choices for developing countries, especially given the impact on these countries of severe capital supply constraints and global environmental concerns, led to the selection of the program to represent the United States in the Advisory Group on Energy and Electricity Supply and Demand for the 1991 Senior Expert Symposium on Electricity and the Environment, being organized by 11 international agencies as the principal energy-oriented stepping-stone to the 1992 United Nations Conference on the Environment and Development. The program was also selected to participate in the Montebello Workshop on Developing Country Perspectives on Policy Implications of Global Warming, organnized by the International Federation of Institutes for Advanced Study, as another contribution to preparations for the United Nations Conference.

In addition, a report on issues for western hemisphere energy cooperation ${ }^{1,2}$ was completed for DOE's Office of International Affairs as the primary technical basis for a report to the U.S. Congress and was reviewed extensively by interested parties throughout the hemisphere.

\subsubsection{Energy Efficiency Improvement}

The major change in the program during FY 1989 was an increased focus on energy efficiency improvement, in line with ise views of the program about energy strategy directions for developing countries, the strengths of ORNL in this regard, and growing sponsor interests.

In addition to work on the Global Energy Efficiency Initiative (see highlights) and the power sector efficiency improvements in Costa Rica (see highlights), other activities related to efficiency improvement included the following: (1) L. Hill's growing body of research on energy brice reform; (2) important contributions to the multiagency Electric Power Utility Efficiency Improvement Study, which assesses ways that the performance of utilities in developing countries might be improved (including, during FY 1989, assistance in coordinating the entire study-working with the Oak Ridge Associated Universities-and developing a case study of utility performance in Guatemala): and (3) appointment of T. Wilbanks to the Energy Efficiency Committee of the United States Energy Association, the U.S. member of the World Energy Council.

Finally, following up on the Energy Division workshop organized by M. Katzman in 1988, program staff collaborated with Lawrence Berkeley Laboratory (LBL) on a paper ${ }^{3}$ examining the prospects of actually implementing the technological potentials described by Goldemberg et al. in their well-known series of reports. The paper indicates that a number of behavioral and institutional obstacles stand in the way of realizing efficiency improvement potentials that seem to make economic sense. Some efficiency improvements will certainly take place, because the technological and economic fores are already in motion: but realizing the full potentials of available technologies will require major changes in the policy environment in both industrialized and developing countries. 


\section{Global Energy Efficiency Initiative}

Supported by the U.S. Agency for International Development (A.I.D.), the developing country program was heavily involved in efforts to organize a Global Energy Efficiency Initiative (GEEI). T. Wilbanks, L. Hill, and C. Petrich contributed to (1) an assessment of what a GEEI might accomplish in energy savings, capital savings, and reductions in environmental impacts ${ }^{4}$ and (2) a shorter "brochure" on GEEI. Additionally, Wilbanks was elected to the Executive Committee for the U.S. Working Group for GEEI.

As a resilt of a collaboration between ORNL, Lawrence Berkeley Laboratory (LBL), RCG/Hagler-Bailly, Inc., and A.I.D. Office of Energy staff, the GEEI analysis indicated that a realistic, implementable program to promote efficiency improvement globally could be expected to reduce global energy consumption (without reducing economic development) by $25 \%$, equivalent to more than half of current total world energy consumption (Fig. 6.1). This would reduce capital requirements for the energy sector in developing countries and Eastern Europe by several trillion dollars, at a cost of perhaps one one-hundredth as much, and would also reduce global $\mathrm{CO}_{2}$ emissions from fossil fuels by about $25 \%$.

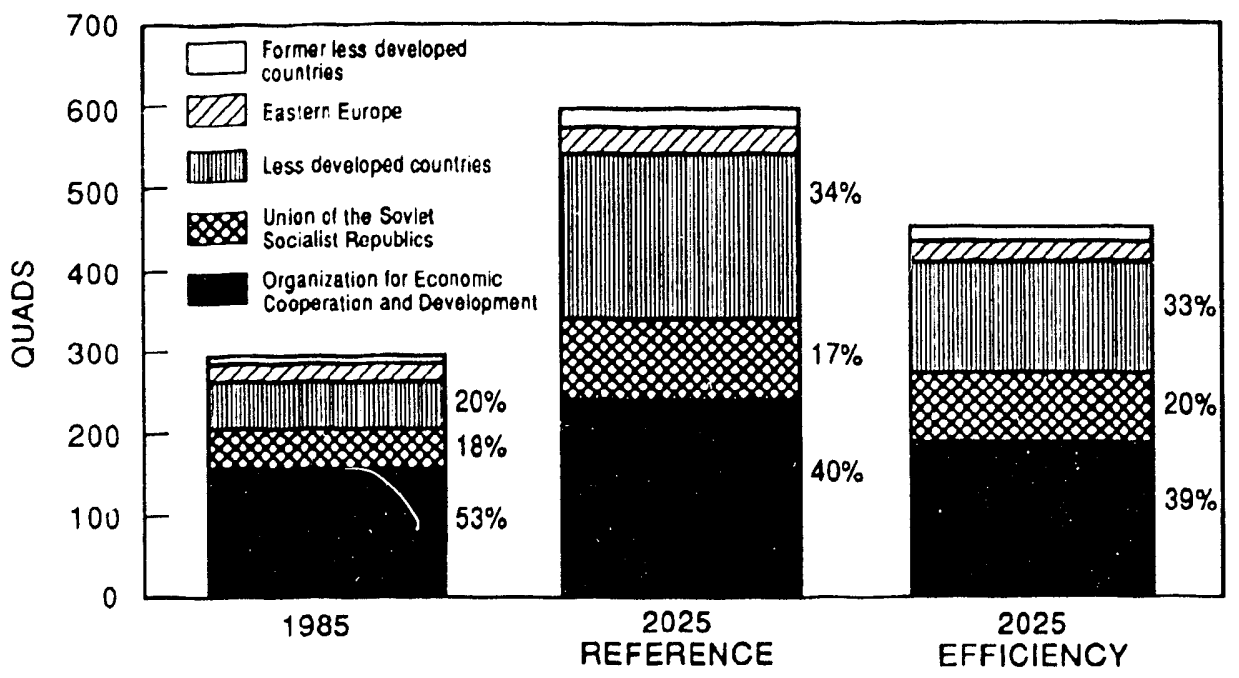

BIOMASS IS NOT INCLUDED.

Fig. 6.1. World primary energy consumption by regions. 


\section{Power Sector Efficiency Improvements in Costa Rica}

Related to the Global Energy Efficiency Initiative and also supported by the U.S. Agency for International Development, Oak Ridge National Laboratory and RCG/Hagler-Bailly, Inc., together with IDEA, Inc., have been analyzing potentials for power sector efficiency improvements in Costa Rica, considering the entire spectrum of possibilities from power generation through transmission, distribution, and load management to end use. This pioneering analysis, intended both to investigate the possibilities outlined by Goldemberg et al. ${ }^{5}$ and to document a record of significant efficiency improvements in a developing country, suggests that Costa Rica is approaching the efficiency standards of industrialized countries in some parts of its power sector-a remarkable accomplishment, testifying to what a developing country can actually accomplish through a combination of local determination and extemal assistance. It also identifies ways to increase the efficiency sector by $10 \%$ or so through economically attractive investments in efficiency improvements in power generation alternatives and electricity end uses.

\subsubsection{Environmental Management}

Programmatic activities related to environmental management in developing countries also expanded substantially. Overall perspectives were provided in a paper, "Implementing Environmentally Sound Power Sector Strategies in Developing Countries," published in the Annual Review of Energy" and in "Potentials to Transfer the U.S. NEPA Experience to Developing Countries," in The Scientific Challenges of NEPA. ${ }^{7}$ But the main features of the year were three projects, descriptions of which follow.

\subsubsection{A.I.D. Climate Change Study}

This effort assessed relationships between the programs of the U.S. Agency for International Development (A.I.D.), both agency-wide and worldwide, and the global climate change issue. ${ }^{8}$ The study concluded that any program promoting a higher level of economic and social development is related to global environmental change, not only because development adds to resource requirements but also because development is the most important of all enablers of an effective response from developing countries. More specifically, of course, areas of interest to A.I.D. relate to the global environment in a wide variety of ways (see Table 6.1). The agency : programs in the fields of population, energy, and forestry are especially relevant, although connections with the climate change issue are only beginning to be i'ormulated by A.I.D. staff. A.I.D., the report suggests, might be able to help involve developing countrie: more effectively in the international policy dialogue and to promote such promising options as energy eificiency improvement.

The results were presented to various officials and advisory groups of A.I.D., as well as the National Academy of Sciences-National Research Council Committee on Global Change, and contributed to a July 1990 report by A.I.D. to the U.S. Congress, Greenhouse Gas Emissions and the De'veloping Countries: Strategic Options and the USAID Response." 
Table 6.1 Impact on global resources as cited by the U.S. Agency for International Development

\begin{tabular}{|c|c|c|}
\hline \multirow[b]{2}{*}{ Resource } & \multicolumn{2}{|c|}{ Impacts } \\
\hline & Long-term change & Emergencies \\
\hline Agriculture & $\begin{array}{l}\text { Crop productivity } \\
\text { (increasc/decrease) } \\
\text { Locations of crop regions } \\
\text { Salinization }\end{array}$ & $\begin{array}{l}\text { Increased crop failures and } \\
\text { losses } \\
\text { Famine }\end{array}$ \\
\hline Water resources & $\begin{array}{l}\text { Salinization } \\
\text { Management and timing of run-off } \\
\text { Water supply } \\
\text { Flood management }\end{array}$ & $\begin{array}{l}\text { Drought } \\
\text { Flood } \\
\text { Salinization }\end{array}$ \\
\hline Population and health & $\begin{array}{l}\text { Infectious and parasitic diseases } \\
\quad \text { (incidence, range) } \\
\text { Nutrition and sanitation } \\
\text { Air pollution }\end{array}$ & $\begin{array}{l}\text { Epidemics } \\
\text { Respiratory and cardiac } \\
\quad \text { Stress } \\
\text { Refugees }\end{array}$ \\
\hline Energy & $\begin{array}{l}\text { Hydropower resource changes } \\
\text { Changes in electricity demand }\end{array}$ & $\begin{array}{l}\text { Supply system failure (e.g., } \\
\text { loss of hydropower } \\
\text { services, storm damage } \\
\text { to supply system) }\end{array}$ \\
\hline $\begin{array}{l}\text { Forestry, fisheries, } \\
\text { ecosystems }\end{array}$ & $\begin{array}{l}\text { Shift in ecological zones } \\
\text { Species composition } \\
\text { Salinization } \\
\text { Productivity change }\end{array}$ & $\begin{array}{l}\text { Fires } \\
\text { Pests and diseases } \\
\text { Flooding }\end{array}$ \\
\hline
\end{tabular}

\subsubsection{Africa $\mathrm{CO}_{2}$}

Because of the general tendency to focus on deforestation in Amazonia and Southeast Asia and fossil fucl use in the industrialized world and China, India, and Eastern Europe, uncertainties persist about the role of Africa in the overall picture of global environmental change. This particular study (see also Sect. 3.3.2), supported by the Africa Bureau of A.I.D. and conducted by ORNL's Environmental Sciences and Energy divisions, tried to reduce these uncertainties through remote sensing and sther readily available data sources before more expensive field survey strategies are employed.

The siudy provided a broad qualitative picture of processes under way in Africa, suggesting considerable diversity from country to country; but it also indicated that available data sources are quite limited as a basis for understanding vegetation cover and land-use trends in Africa. ${ }^{10}$

\subsubsection{Initiatives in Developing Countries}

The division also initiated a relationship with A.I.D./Guatemala to provide technical assistance with environmental projects and to help preserve biosphere resources in the Peten region in northern Guatemala. Working with the local A.I.D. mission and the Guatemalan environmental protection agency, K. Kline of the Energy Division developed a project to provide technical and management support during the establishment of the Maya Biosphere Reserve. Kline's proiect focused particulariy on promoting participation of 'ocal citizens and nongovernmental organizations.

In addition, a project was initiated to analyze emissions from the combustion of coal briyuettes from Pakistan and to compare those emissions with a variety of other household tuel alternatives in 
that country. Also, an agreement was reached with Lahmeyer International GmbH, a German engineering firm, for ORNL staff members (working as individuals) to play key roles in a major World Bank-sponsored project to improve environmental management practices of the national electric utility in Indonesia.

\subsubsection{Renewable Energy Options and Rural Area Energy Systems}

During FY 1989, ORNL continued to assist the Renewable Energy Applications and Training (REAT) Project of A.I.D. 's Office of Energy and to participate in a rural electrification project in Central America: ORNL also began a new biomass en rrgy project in China.

ORNL's technical assistance to REAT has emplaasized the identification and development of renewable energy projects in developing countries, through tests and demonstrations of the feasibility of renewable energy technology options under local conditions. One part of this activity has concerned technical and financial analyses of small hydroelectric technology applications in Costa Rica (see also Sect. 5.9.3), along with geothermal applications in Kenya and photovoltaic energy applications in Southeast Asia and Latin America. A second part has been directed at identifying innovative ways to provide financing to small (and often lower-income) technology users; lack of financing is frequently a major constraint on the market penetration of renewable energy technologies in developing countries. A model approach to address this need that was developed by D. Waddle and others is now being employed in a photovoltaic energy project in the Dominican Republic, and it is included in a new project that will start soon in the Philippines. The financing model will be discussed by several international development lending institutions at an international conference in 1991.

Supported by A.I.D.'s Regional Office for Central American Programs, the Energy Division continued to monitor and evaluate the Central American Rural Electrification Support (CARES) Project, which is managed by the U.S. National Rural Electric Cooperative Association. This project promotes more effective rural electrification strategies in Central America. Besides general project monitoring, during FY 1989, ORNL conducted a mid-term evaluation of the CARES project. Several changes in project direction were recommended and subsequently adopted.

Supported by DOE, the Energy and Environmental Sciences divisions of ORNL conducted a preliminary feasibility study of biomass production for electric power generation in Yunnan Province, China (sce also Sect. 3.3.2). In this region, electricity supply is complicated by the seasonality of the hydroelectric power resource, and the environment has suffered from widespread removal of vegetation cover from the hilly landscape. The study suggested that reforestation via biomass energy plantations is quite feasible, although further research and field tests are needed before large-scale deployment. A demonstration project to fine-tune the concept and improve the information base required for scale-up was proposed.

\subsubsection{Energy R\&D Applications}

In line with its earlier assistance to DOE in preparing the National Energy Strategy, ${ }^{1}$ ORNL continued its discussions with DOE and others about energy R\&D for developing countries, including presentations to and discussions with DOE's Offices of Conservation; Policy, Planning, and Analysis; Fossil Energy; and International Affairs. As part of this process, ORNL developed a proposal for a "one-stop shopping center" for developing countries secking information about energy technologies in general and U.S. technologies in particular, to simplify access to reliable information and facilitate effective linkages. The Energy Division also began preparations for a major workshop on energy R\&D for developing countries, scheduled for November 1990.

\subsubsection{Energy Technology Transfer}

The program built upon its earlier work on patterns of energy technology trade ${ }^{1}$ to examine potentials for transferring to developing countries two technologies related to ORNL R\&D programs: gas separation technologies, as they might be applied in thermal electric power generation and other development sectors, and advanced refrigeration technologies. This research suggests an enormous potential for applications of gas separation technologies in coal and biomass conversion and the food industry. For example, if gas separation technology were to become competitive on a life-cycle cost basis with current coal emission cleanup technologies, the market for gas separation technology could 
be as high as $\$ 41$ billion. In the case of refrigeration technologies, the market for refrigeration equipment is also large (especially for nonhouschold applications). Markets for heat pump technologies appear attractive on a country-specific basis in such countries as Mexico, Indonesia, India, and China.

The program also (1) contributed a paper on the roles of R\&D institutions in iechnology transfer to an international conference in India associated with A.I.D./Government of India's Program for Acceleration of Commercial Energy Research, an innovative attempt to build institutional frameworks for technology transfer, and (2) continued a collaboration with the Center for Mesoamerican Studies on Appropriate Technology to assess urban markets for improved cookstoves in Central America.

\subsection{OTHER ACTIVITIES}

Besides the work in developing countries, the Planning and Coordination office of the Energy Division also supported two committees that explored long-range program development initiatives as part of the division's long-range planning. One committee, chaired by M. Brown, addressed needs and opportunities in relatively basic social science research. The other, chaired by $\mathrm{R}$. Curlee, considered waste management as a subject area that might integrate the expertise of various parts of the division in focusing on a critical national need. The latter effort generated a number of guidelines for program development, an agenda for action, and several promising ideas for specific R\&D proposals.

\subsection{REFERENCES}

1. T. J. Wilbanks, "Planning and Coordination," p. 6-1-6-4 in Energy Division Annual Progress Report for the Period Ending September 1989, Oak Ridge National Laboratory, Oak Ridge, Tennessee, 1990.

2. T. J. Wilbanks and D. W. Jones, The Energy Challenge Facing the Americas: Issues for Western Hemisphere Energy Cooperation, ORNL report, in press.

3. M. T. Katzman et al., "The Prospects for Encrgy Efficiency Improvements in Developing Countries," The Energy Journal, 1991, in press.

4. M. D. Levine et al., Energy Efficiency, Developing Nations and Eastern Europe: An Analysis of Key Issues, draft final Icport. U.S. Working Gruup, Global Energy F ficiency Initiative, February 1991.

5. J. Goldemberg et al., Energy for a Sustainable World, Wiley Eastern Ltd., New Delhi, 1988.

6. T. J. Wilbanks, "Implementing Environmentally Sound Power Sector Strategies in Developing Countries," Annual Review of Energy, 255-76 (1990).

7. T. J. Wilbanks et al. "Potentials to Transfer the U.S. NEPA Experience to Developing Countries," in J. Cannon and S. Hildebrand, eds., The Scientific Challenges of NEPA, in press.

8. T. J. Wilbanks et al., Sustained Development and the Global Climate Change Issue, ORNL report, in press.

9. U.S. Agency for Intemational Development, Greenhouse Gas Emissions and the Developing Countries: Strategic Options and the USAID Response, a report to Congress, Washington, D.C., July 1990.

i0. R. L. Graham et al., Greenhouse Gas Emissions in Sub-Saharan Africa, ORNL-6640, Oak Ridge National Laboratory, Oak Ridge, Tennessec, November 1990. 


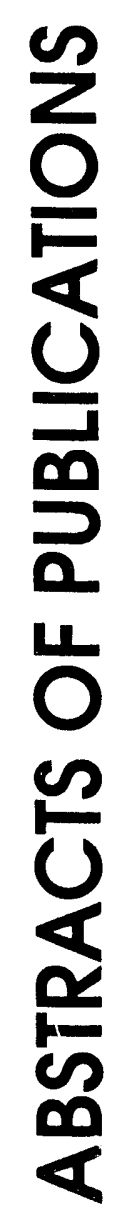




\section{ABSTRACTS OF PUBLICATIONS}

\subsection{ABSTRACTS OF INTEGRATED ANALYSIS AND ASSESSMENT SECTION}

\section{ENVIRONMENTAL PROTECTION FOR HAZARDOUS MATERIALS INCIDENTS}
B. D. Barkenbus
J. E. Dobson ${ }^{b}$
P.S. Ogle ${ }^{d}$
R. J. Carter ${ }^{a}$
C. E. Easterly
A. K. Van Cleave ${ }^{e}$

(Abstract of ORNL/TM-11421, Oak Ridge National L aboratory, February 1990)

This document was prepared to provide the U.S. Air Force fire protection community with an integrated program for handling hazardous materials (HAZMATs) and hazardous materials incidents. The goal of the project was to define and identify a computer system for the base fire departments that would facilitate hazard assessment and response during HAZMAT emergencies, provide HAZMAT incident management guidelines, and provide a training tool to simulate emergency response during normal times. To reach this goal, site visits to Air Furce bases were made to observe existing HAZMAT-related organizations, their methods and procedures used in HAZMAT management, and to collect personnel input for the development of the computerized Hazardous Materials Incident Management System (HMIMS). In a following phase, the study concentrated on defining strategic areas of concern to emergency response personnel. Particular cmphasis was given to such areas as responsibilities and roles for response agencies, personnel requirements for handling HAZMAT incidents, procedures to follow during HAZMAT incidents and decontamination, personnel evacuation, postincident evaluation and feedback, emergency response personnel participation in installation restoration program, personal protective clothing, mutual aid requirements, and training. In light of federal regulations and good HAZMAT management practices, recommendations were made for future purchase, use, storage, disposal, and management of HAZMATs during their life cycle on bases and during incidents. This detailed technical report and HMIMS are expected to meet the integrated HAZMAT program needs primarily of Air Force fire departments and secondarily of other response agencies.

Research sponsored by U.S. Department of the Air Force.

\footnotetext{
${ }^{a}$ Engineering Physics and Mathematics Division

${ }^{b}$ Computing and Telecommunicating Division.

'Health and Safety Research Division.

${ }^{d}$ Information Division.

'Engineering Physics and Mathematics Division.
} 


\section{EMERGENCY RESPONSE CONCEPT PLAN FOR LEXINGTON-BLUE GRASS ARMY DEPOT AND VICINITY PUEBLO DEPOT ACTIVITY AND VICINITY ANNISTON ARMY DEPOT AND VICINITY UMATILLA DEPOT ACTIVITY AND VICINITY ABERDEEN PROVING GROUND AND VICINITY PINE BLUFF ARSENAL AND VICINITY NEWPORT ARMY AMMUNITION PLANT AND VICINITY TOOELE ARMY DEPOT AND VICINITY}
S. A. Carnes
J. H. Sorensen
G. O. Rogers
B. L. Shumpert ${ }^{a}$
R. L. Miller
A. P. Watson

C. V. Chester

\begin{abstract}
(Abstract of ORNL/TM-11099, ORNL/TM-11098, ORNL/TM-11093, ORNL/TM-1 1097, ORNL/TM-1 1096, ORNL/TM-1 1092, ORNL/TM-1 1095, ORNL/TM-1 1094, respectively, Oak Ridge National Laboratory, October 1989)
\end{abstract}

In the continued storage and disposal of the United States' unitary chemical stockpile, there is a potential for accidental releases that could escape installation boundaries and pose a threat to civilian populations. The U.S. Army, in conjunction with the Federal Emergency Management Agency and other federal agencies, is committed to implementing an emergency preparedness program that will significantly reduce the probability of adverse effects from such releases. This concept plan. which is only a part of a comprehensive ongoing effort, provides a framework for initiating such a program for the stockpile. We develop information and methodologies for determining emergency planning zones and selecting protective action strategies. Decisions regarding such choices are based on the nature of the hazards posed by the stockpile and its disposal. These hazards, in tum, are based largely on the distribution of potential accidental releases associated with interim storage and disposal activities and associated external events (e.g., earthquakes and airplane crashes), the distribution of natural features that can affect an agent release (topographical features and meteorological characteristics), and the distribution of people and resources (e.g., homes, schools, and hospitals) potentially affected by an accidental release. These reports identify the advantages and disadvantages of six categories of protective actions (i.e., evacuation, in-place sheltering, respiratory protection, protective clothing, prophylactic drugs, and antidotes) and various options among these categories.

Research sponsored by the U.S. Department of the Army.

${ }^{a}$ The University of Tennessee.

bHealth and Safety Research Division.

\title{
SITE-SPECIFIC EMERGENCY RESPONSE CONCEPT PLANS FOR THE CHEMICAL STOCKPILE DISPOSAL PROGRAM: A COMPARATIVE SUMMARY
}

\author{
S. A. Carnes \\ (Abstract of ORNL/TM-11357, Oak Ridge National Laboratory, November 1989)
}

Site-specific emergency response concept plans were developed to help initiate enhanced emergency preparedness for continued storage of the stockpile and the Chemical Stockpile Disposal Program at the eight Army installations storing the unitary chemical stockpile-Aberdeen Proving Ground. Anniston Army Depot, Lexington-Blue Grass Army Depot, Newport Army Ammunition Plant. Pine Bluff Arsenal. Pueblo Depot Activity, Tooele Army Depot, and Umatilla Depot
Activity. This document summarizes the emergency response plans for all the sites and highlights similarities and differences among them. Section 2 summarizes site-specific differences in stockpile hazard and risk by showing differences in planning-basis accident categories and distributions of topographical features. mieteorological conditions, and populations at risk. Section 3 presents a summary of the methodology used to identify the emergency planning zones for each site 
and the actual recommended boundaries of those zones for the eight sites. Section 4 identifies feasible and recommended protective actions for the sites and explains reasons for differences in them. Finally, Sect. 5 notes the dependence of protective action effectiveness on the development and implementation of command and control and warning systems that can be implemented in a timely manner; it also identifies the differences in recommended lead times (i.e., from the onset of an accidental release) needed at the sites for effective implementation of protective actions.

Research sponsored by the U.S. Department of the Amy

\title{
ARSENAL OF DEMOCRACY IN THE FACE OF CHANGE: PRECISION GUIDED MUNITIONS (PGMS), THEIR EVOLUTION AND SOME ECONOMIC CONSIDERATIONS
}

\author{
C. V. Chester \\ (Abstract of ORNL/TM-1 1275, Oak Ridge National Laboratory, August 1990)
}

A brief study was made of some of the forces driving the move to precision guided munitions (PGMs), including the quest for military effectiveness, combat experience, and logistic compression. PGMs cost from a few hundred to a few thousand dollars per $\mathrm{Kg}$ but are tens to hundreds of times more effective than conventional munitions. The annual peacetime plateau production of each U.S. PGM can be carried by a few C -5 aircraft. Surge quantities of PGMs are within U.S. airlift capabilities, taking some of the risk out of off-shore procurement. The improving capability of antiaircraft PGMs and the escalating cost of combat aircraft (50- to 100-fold in constant dollars) since World War II may bring into question the economic viability of manned attack aircraft. The same may be true to a slightly lesser degree for heavy armored vehicles.

Research sponsored by the Federal Emergency Management Agency.

\section{[7.1.5]}

\section{CHEMICAL STOCKPILE DISPOSAL PROGRAM: RAPID ACCIDENT ASSESSMENT}

\author{
C. V. Chester
}

(Abstract of ORNL/IM-1 1354, Oak Ridge National Laboratory, Au`ust 1990)

This report develops a scheme for the rapid assessment of a release of toxic chemicals resulting from an accident in one of the chemical weapon demilitarization plants or storage areas. The system uses such inputs as chemical and pressure sensors monitoring the plant and reports of accidents radioed to the Emergency Operations Center by work parties or monitoring personnel. The size of release can be estimated from previous calculations done in the risk analysis, from back calculation from an open-air chemical sensor measurement, or from an estimated percentage of the inventory of agent at the location of the release. Potential consequences of the estimated release are calculated from real-lime metcorological data, surrounding population data, and properties of the agent. In addition to the estimated casualties, area coverage and no-death contours vs time would be calculated. Accidents are assigned to one of four categories: community emergencies, which involve a threat to off-site personnel; on-post emergencies, which involve a threat only to on-site personnel; advisory emergencies, which involve a potential for threat to on-site personnel: and chemical occurrences, which can produce abnormal operating conditions for the plant but no immediate threat to on-site personnel.

Research sponsored by the U.S. Department of the Army. 


\title{
INTERGOVERNMENTAL CONSULTATION AND COORDINATION: CONTINUED PROTECTION OF PUBLIC HEALTH AND SAFETY THRO' $\mathrm{*}$ (.H PUBLIC ACCOUNTABILITY
}

\author{
D. L. Feldman \\ S. A. Carnes \\ G. O. Rogers
}

[Abstract of The Environmental Professional 11(4), 409-21 (December 1989)]

\begin{abstract}
Intergovernmental consultation and coordination are means of incorporating the concerns of state and local governments, tribal nations, and the general public in the implementation of programs characterized by real or perceived high risk and public opposition. Although incorporation of public concerns is required by law and regulation before programs having significant environmental impact may begin, agencies are given few guidelines as to how such concerns may be addressed, particularly during program implementation. The theory and practice of intergovernmental consultation and coordination in the Chemical Stockpile Disposal Program (CSDP) is examined in terms of four goals: (1) conformance to federal law, (2) obtaining and maintaining citizen concurrence and gaining public
\end{abstract}

support, (3) increasing program legitimacy, and (4) promoting democratic values of public trust. The potential for success of a proposed Intergovemmental Consultation and Coordination Board, and its possible overlap with public participation components of Superfund Amendments and Reauthorization Act of 1986 Title III, are assessed in light of these goals. Single agency management, early public involvement, and means for small-group advising and sharing of information, as well as consideration of issues through mediation and negotiation, are likely to optimize incorporation of public concerns and acceptance of the CSDP.

\section{SARA TITLE III AND STATE RESPONSE TO CHEMICAL HAZARDS: GAUGING THE EFFECTIVENESS OF PUBLIC PARTICIPATION FOR EMERGENCY PLANNING}

\author{
D. L. Feldman
}

[Abstract of The Environmental Professional 12(1), 67-76 (April 1990)]

The purposes of Title III of the Superfund Amendments and Reauthorization Act of 1986 are to (1) significantly decentralize the dissemination of emergency planning information for chemical hazards; (2) obtain proactive state and local participation in emergency planning: and (3) encourage federal, state. and local cooperation in the design, development, and implementation of databases for monitoring and oversight of chemical emergencies. This article explores the implementation of Title III in eight states and local communities selected for study because of their central role in the U.S. Army's Chemical Stockpile Disposal Program. This disposal program requires consultation with local communities for enactment of emergency preparedness measures related to the incineration of several toxic, carcinogenic, and mutagenic agents slated for destruction by congressional mandate. Problems in Title III implementation included (1) inadequate local emergency planning committee (LEPC) staffing and funding, (2) unclear lines of authority and responsibility in some LEPCs and state emergency response commissions, (3) varying formats for chemical hazards reporting and recordkeeping, and (4) difficulties in recruiting some groups to serve on LEPCs. Resolution of these problems is necessary in order for Title III to accomplish its major goal of establishing an effective system of risk communication for chemical hazards in the United States.

Research sponsored by the U.S. Department of Energy. 


\title{
D. L. Feldman
}

(Abstract of paper in Societal Aspects of Climate Change, proceedings of the Third Symposium on Social Science in Resource Management. College Station, Tex., May 1990)

\section{MANAGING GLOBAL CLIMATE CHANGE THROUGH INTERNATIONAL COOPERATION: LESSONS FROM PRIOR RESOURCE MANAGEMENT EFFORTS}

\author{
D. L. Feldman \\ (Abstract of ORNL/TM-10914, Oak Ridge National Laboratory, July 1990)
}

International cooperation aimed at furthering awareness of anthropogenic climate change has been relative!y rapid, but the task of developing strategies for prevention or mitigation has taken more iime. This is because anthropogenic climate change poses several rarticularly difficult obstacles to an integrated global strategy. These include (1) conceiving of the atmosphere as a shared. sustainable resource: (2) agreeing upon the causes and rates of induced change and the responsibilities apportioned to various national actors;

(3) minimizing collateral effects of economic development while optimizing growth, particularly in less-developed countries; and (4) encompassing the complexity of the problem's various ramifications in a multitateral policy. International cooperation in such other areas as nuclear materials and technology, water pollution, and protecting the ozone layer reveals that effective strategies for managing global climate change are available but require institutional modification and patience. Efforts aimed at controlling pollution in regional seas, minimizing ozone depletion, and regulating the use and transport of nuclear materials were, at one time, viewed as similarly complex problems. One lesson of these cases is that effective international cooperation in environmental and energy issues is the result of an incremental and iterative learning process among scientists, environmental groups, and political leaders who hold divergent perceptions, interests, and stakes in resource controversies. A gradual process of consensus building is most effective when consultation with all affected parties takes place. This would come about after a scientific, technical, economic, and political evaluation of alternative actions by all parties. Once an initial assessment of alternative actions has been carried out, a process of both conflict and cooperation is likely to commence, with greater cooperation likely once agreement upon the scope of the problem is reached. Once common action to assess the impact of $\mathrm{CO}_{2}$ commences, further cooperation is likely to require regulatory agreements based upon acknowledgement of the sovereignty of all nation-states. and the importance of nonstate actors in decision making. An effective strategy will hinge on accommodating the multiple uses of a common resource while obtaining consensus over rights, responsibilities, and the capabilities of individual nations to establish 
compliance targets. Nation-states will continue to be the basic vehicles for implementing decisions, but nonstate actors will often play a vital role in formulating compliance targets and in prodding states to meet them.
Research sponsored by the U.S. Department of Energy Office of Environmental Analysis.

\title{
DECISION MAKING TECHNICAL SUPPORT STUDY FOR THE U.S. ARMY'S \\ CHEMICAL STOCKPILE DISPOSAL PROGRAM: ENHANCING COMMAND, CONTROL, AND COMPUTER OPERATIONS AT ABERDEEN PROVING GROUND AND PINE BLUFF ARSENAL
}

\author{
D. L. Feldman \\ J. E. Dobson ${ }^{a}$ \\ (Abstract of ORNL/TM-11412, Oak Ridge National Laboratory, August 1990)
}

This report examines the adequacy of current command and control systems designed to make timely decisions that would enable sufficient waming and protective response to an accident at the Edgewood area of Aberdeen Proving Ground (APG), Maryland, and at Pine Bluff Arsenal (PBA), Arkansas. We examine institutional procedures designed to facilitate rapid accident assessment, characterization, warning, notification, and response after the onset of an emergency. We also consider computer-assisted. decision-making aids designed to provide salient information to on- and off-post emergency responders. The character of emergency decision making at APG and PBA, as well as potential needs for improvements to decision-making practices, procedures, and automated decision-support systems (ADSSs), are described, and recommendations are offered to guide equipment acquisition and improve on- and off-post command and control relationships. We recommend that (1) a continued effort be made to integrate on- and off-post command, control, and procedures to permit rapid decision making; (2) the pathways for alert and notification among on- and off-post officials be improved and that responsibilities and chain of command among off-post agencies be clarified; (3) greater attention be given to organizational and social context factors that affect the adequacy of response and the likelihood that decision-making systems will work as intended; and (4) faster improvements he made to the on-post ADSSs being developed at APG and PBA, which hold considerable promise for depicting vast amounts of information. Phased development and procurement of computer-assisted decision-making tools should be undertaken to balance immediate needs against available resources and to ensure flexibility, equity among sites, and compatibility among on- and off-post systems.

Research sponsored by the U.S. Department of the Army.

${ }^{a}$ Computing and Telecommunications Division.

\section{THE DEVELOPMENT AND REVISION OF THE FEDERAL RADIOLOGICAL EMERGENCY PLAN}

\author{
K. S. Gant \\ M. V. Adler \\ W. F. Wolff ${ }^{a}$ \\ (.tbstract of pp. $37-40$ in Changing Expectations and Performance, proceedings from the 13th Annual \\ TRADE Conference, Baltimore, Oct. 23-25, 1989, ORAU 90/C-84, \\ Oak Ridge Associated Universities, July 1990)
}

Since 1985, federal agencies have been using the Federal Radiological Emergency Response Plan (FRERP) in exercises and real events. This experience with FRERP and the development of other emergency response guidance systems (e.g., National System for
Emergency Coordination) are fueling current efforts to review and revise FRERP to reflect what the agencies have leamed since FRERP was published. Revision efforts are concentrating on clarifying the plan and addressing deficiencies. No major chianges are expected 
in the general structure of the federal response, nor

U.S. Department of Energy.

should states need to revise their plans because of these

modifications.

\title{
INTEGRATING DEMOGRAPHIC, ATMOSPHERIC, AND DOSE INFORMATION TO ESTIMATE EFFECTS FROM ACCIDENTAL RELEASE OF CHEMICAL AGENTS
}

\author{
E. L. Hillsman \\ P. R. Coleman ${ }^{a}$ \\ [Abstract of The Environmental Professional 11(4), 354-66 (December 1989)]
}

Estimating the population at risk from a release of chemical agent or other hazardous material is conceptually straightforward, given information about the distribution of population, the location of the release. and the area that the release could affect. A computer-based method was used to make these estimates for eight chemical storage sites and along transportation routes between pairs of sites in the programmatic environmental impact statement. The method, its strengths, and its limitations are described. The process of developing and applying the method and communicating its results highlighted a number of issues to be considered in the design and presentation of r'sults for large numbers of locations and alternatives. These include a need to provide local information for reviewers, a need for better coordination between the design of an analysis and the design of the presentation of results, and a need during these design periods to anticipate likely misinterpretation of concepts or results.

Research sponsored by the U.S. Department of the Army.

${ }^{a}$ Computing and Telecommunications Division.

\section{ASSESSING THE POTENTIAL ENVIRONMENTAL IMPACTS OF PROPOSED RULES AFFECTING FUTURE ELECTRIC POWER GENERATION IN THE UNITED STATES}

\author{
D. B. Hunsaker, Jr. \\ W. M. Willis ${ }^{a}$ \\ E. J. Liebsch \\ C. T. Garten ${ }^{b}$ \\ A. W. Campbell
}

R. B. McLean
G. F. Cada
R. L. Graham
C. T. Hunsaker
C.
G. Marland

R. L. Miller

(Abstract of ORNL/IM-11301, Oak Ridge National Laboratory, February 1990)

In 1988, the Federal Energy Regulatory Commission (FERC) began development of two rules with the potential to affect future electric power generation in the United States. One would prescribe minimum conditions under which competitive bidding may be used to establish rates for purchasing electrical power, and the other would reduce FERC regulations that interfere with the ability of independent power producers to produce and sell power. These rules, which would be issued simultaneously, could alter the fuel mix that supplies future electrical generating capacity projected by the utilities, which in turn could affect the environmental impacts of producing electric power. The rules must be issued in accordance with the National Environmental Policy Act (NEPA). This report has been prepared to evaluate the potential for environmental effects from future changes in fuel mix that could result from issuing the rules, and thus, in accordance with NEPA, to help FERC determine if the rules would result in significant impacts on the human environment. Based on the results of this work, FERC prepared and issued draft and final environmental impact statements in 1988 while formally proposing the rules. As of December 1989, the rules had not yet been finalized. We calculated estimates of generating capacities (in megawatts) that could be affected by the rules on a state-by-state basis by deleting 
from the generating capacity projections the types of generating capacity not likely to undergo a change in fucl mix: nuclear, geothermal, planned peak or intermediate operation modes, units currently under construction, or units with a scheduled in-service date before 1993. Because the actual fuel mix that would supply the capacity affected by the rules cannot be predicted at present, it was assumed that coal use, which has the greatest potential for adverse environmental effects, would be encouraged by the rules, thus providing an upper limit of potential environmental impacts. Consequently, coal was also deleted because it is not a fuel type available to be shifted by the rules.

Research sponsored by the Federal Energy Regulatory Ccmmission.

${ }^{a}$ Science Applications, Inc.

${ }^{b}$ Environmental Sciences Division.

SOILS AND GEOMORPHOLOGY OF THE EAST CHESTNUT RIDGE SITE

\author{
D. A. Lietzke ${ }^{a}$ \\ R. H. Ketelle \\ R. R. Lee
}

(Abstract of ORNL/TM-1 1364, Oak Ridge National Laboratory, October 1989)

Intensive soil mapping of the East Chestnut Ridge site in conjunction with subsurface soil and rock coring provides an in-depth evaluation of the site and its suitability for disposal of wastes. Regardless of engineering modifications that can be made to the soils, landforms, and surface and subsurface hydrology, the natural, undisturbed, soil-saprolite-geohydrology system beneath the zone of engineering modifications provides for the ultimate containment of wastes and a means for the filtration and purification of any leachate before it reaches the aquifer. The surface location and extent of each geologic formation on the site were mapped. These locations correlated well with projections of subsurface contacts to the surface even though the criteria used by the pedologist and geologist to identify soil and rock from the same formation may be different. The presence of colluvium. is important in a potential landfill site because (1) it has great ability to transmit water laterally and (2) it is less stable than residuum because of its susceptibility to downslope creep. Colluvium thickness on the site ranges from about one meter or less on upper sideslopes to several meters at the base of high hills. Colluvium has a high hydraulic conductivity compared to the clayey residual soils on the site, so water commonly perches at the colluvium-residuum contact during the winter and during periods of heavy rainfall. Water that perches or flows laterally in the upper soils must be diverted around any landfill trenches. The ancient alluvial soils on the site can be used for trench lining or for other uses where a compactible soil is required. Locally, the saprolite beneath the upper 6 to $10 \mathrm{ft}$ of residual soils has a very high silt content, which may result in poor permeability and compaction characteristics. Colluvial soil and ancient alluvial soil can be mixed with residual saprolite to modify its properties.

Research sponsored by the U.S. Department of Energy.

\title{
$[7.1 .15]$
}

\section{SUPPLEMENTAL HYDROLOGIC DATA COLLECTED AT CENTRAL WASTE MANAGEMENT DIVISION SITES, 9/1/89-3/31/90}

\author{
R. H. Ketelle \\ M. W. Yambert ${ }^{a}$ \\ R. R. Lee \\ H. K. Hardee ${ }^{b}$
}

(Abstract of K/WM-3, Oak Ridge National Laboratory, June 1990)

Site characterization and facility design for future low-level radioactive waste disposal at the Department of Energy Oak Ridge Reservation is being managed by the Central Waste Management Division. Site characterization of four sites has been in progress for several years and this report provides supplemental data collected during the period between September 1, 1989 and March 31, 1990. The sites monitored include the SWSA 7, West Bear Creek Valley, West Chestnut Ridge, and East Chestnut Ridge sites. Data reported 
include water table elevations measured monthly at selected wells, daily precipitation data recorded at three locations, mean daily stream discharge measured at eight stream gaging stations (flumes), and water quality data collected at the East Chestnut Ridge site. Data are organized by site, data type, and measurement location.
Research sponsored by the U.S. Department of Energy.

${ }^{a}$ Computing and Telecommunications Division.

${ }^{b}$ The University of Tennessee.

\title{
PERFORMANCE ASSESSMENT FOR FUTURE LOW-LEVEL WASTE DISPOSAL FACILITIES AT ORNL
}

\author{
D. W. Lee \\ D. C. Kocher ${ }^{a}$ \\ (Abstract of paper in Proceedings of 11 th Annual Department of Energy Low-Level Waste Management Conference, \\ CONF-890854, December 1989)
}

Until recently, low-level radioactive waste disposal performance assessments within the U.S. Department of Energy have focused primarily on shallow-land burial with lesser consideration of site characteristics and alternative disposal technologies. The concept of waste disposal by shallow-land burial was based on the notion that a suitable site could be defined and analyzed using methodologies that were predominantly generic. This approach was difficult to apply at Oak Ridge National Laboratory (ORNL) because the potential sites for disposal are in complex geohydrologic settings and a generic methodology does not address many of the relevant site and waste characteristics. An approach to waste management, emphasizing site and waste characteristics, has evolved at ORNL, requiring the development of a site-specific performance assessment for ensuring the appropriate protection of public heal and the environment. This paper discusses the strategy for waste management on the Oak Ridge Reservation
(ORR) and the approach to preparing future performance assessments that has evolved from previous performance assessment studies of low-level radioactive waste disposal on ORR. The strategy for waste management is based on the concept that waste classification should be determined by performance assessment rather than the sources of waste. This dose-based strategy for waste classification and management places special importance on the preparation and interpretation of waste disposal performance assessments for selecting appropriate disposal technologies and developing waste acceptance criteria. Additionally, the challenges to be overcome in the preparation of performance assessments are discussed.

Research sponsored by the U.S. Department of Energy.

${ }^{a}$ Health and Safety Research Division.

\section{DOWNWIND DOSES FROM POTENTIAL RELEASES ASSOCIATED WITH THE CHEMICAL STOCKPILE DISPOSAL PKOGRAM}

\author{
R. L. Miller \\ F. C. Kornegay ${ }^{a}$
}

[Abstract of The Environmental Professional 11(4), 315-23 (December 1989)]

A crucial component of the Final Programmatic Environmental Impact Statement (FPEIS) for the U.S. Army`s Chemical Stockpile Disposal Program (CSDP) was the development of a methodology to assess potential impacts resulti 'rom an accidental release of chemical agent. Because an accidental release could result in off-site fatalities, the analysis necessarily measured impacts in terms of human fatalities from lethal doses of agent and included the fatality estimates in the comparison of alternatives for disposal of chemical agents and munitions in the CSDP. Because impacts of releases are highly dependent on meteorological conditions, the methodology incorporated impacts for two meteorological scenarios: conservative most likely 
and worst case. As a prerequisite for obtaining fatality estimates, downwind doses of agent from accidental releases via atmospheric transport and diffusion were estimated using the D2PC air dispersion model developed by the U.S. Army's Chemical Research, Development and Engineering Center. The D2PC model assumes a Gaussian distribution of agent in the vertical and crosswind directions as the agent disperses downwind. Although more sophisticated dispersion models could be selected for other purposes such as emergency response, they were not needed within the framework of the FPEIS, in which results from the D2PC model formed an upper bound of the effects of releases to assist the decision maker in selecting an alternative.

Research sponsored by the U.S. Department of the Army.

${ }^{a}$ Environmental Compliance Division.

\title{
ATMOSPHERIC DISPERSION MODELING AND METEOROLOGICAL MONITORING IN SUPPORT OF EMERGENCY PLANNING AND RESPONSE FOR THE ARMY'S CHEMICAL STOCKPILE DISPOSAL PROGRAM
}

\author{
R. L. Miller
}

(Abstract of ORNL/TM-11508, Oak Ridge National Laboratory, August 1990)

ORNL-DWG 90M-7999

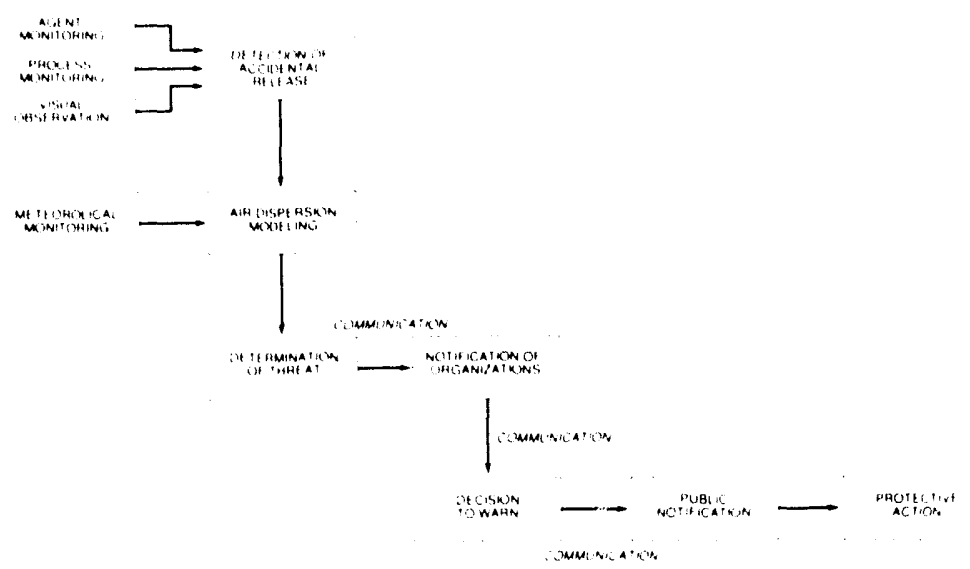

Relationships among components of the integrated accident assessment and warning system.

This technical memorandum examines the roie of atmospheric dispersion modeling and meteorological monitoring in support of emergency planning and response for the U.S. Army's Chemical Stockpile Disposal Program (CSDP). Air dispersion modeling and meteorological monitoring are expected to form key components in integrated accident assessment and warning systems at each of the eight CSDP installa ions.
This report assesses the capabilities of operating state-of-the-art systems in order to establish a baseline for developing the requirements of the CSDP systems. A general tutorial on the types of atmospheric dispersion models currently available is provided, and the criteria for selection of emergency response models are developed. The requirements for meteorological monitoring are also described. In addition, the basic limitations and the current state of modeling and monitoring are discussed, and the importance of model verification is emphasized. The current state of staffing requirements for operating an integrated modeling and monitoring system are characterized. Specific requirements appropriate to emergency planning and response at each of the eight sites are described. Recommendations are made for both the integrated system and the individual components of air dispersion modeling and meteorological monitoring. rinally, future work required to prepare for eniergency response is discussed.

Research sponsored by the U.S. Department of the Army. 


\title{
TWO CITIZEN TASK FORCES AND THE CHALLENGE OF THE EVOLVING NUCLEAR WASTE SITING PROCESS
}

\author{
E. B. Peelle \\ (Abstract of paper in Proceedings of High-Level Radiouctive Waste Managememt C'onference', \\ Las Vegas, Apr. 9-12, 1990)
}

Siting any nuclear waste facility is problematic in today's climatc of distrust toward nuclear agencies and fear of nuclear waste. This study compares and contrasts the siting and public participation processes as two citizen task forces dealt with their difficult responsibilities. Thıugh one dealt with a high-level waste (Monitored Retricvable Storage) proposal in Tennessee in 1985-86 and the other with a proposed low-level waste facility in Illinois (1988 to the present), the needs of citizen decision makers were very similar.
Key differences were found in the communities themselves as well as in the siting and public participation processes. 's a result, the two tash firces performed different func.tons in their different contexts. Conclusions and recommendations for working with site stakeholders are outlined after comparison and analysis of the two cases.

Research sponsored by the U.S. Department of Energy.

\section{HELPING WITH THE CLEANUP: A TWO-STATE CITIZEN TASK FORCE RESPONDS TO DEPARTMENT OF ENERGY ON DEFENSE WASTE}

\author{
E. B. Peelle \\ (Abstract of pp. 7-11 in Procededings of Spectrum 90. Nuclear and Hazardous Waste Managenent International Topical \\ Mecting, Knoxville, Tenn., Sept. 30-Oct. 4, 1990)
}

Successes in public involvement efforts for nuclear waste management are so few that they deserve careful documentation and analysis. This paper chronicles the goals, process, problems and outcomes of one such success, the Northwest Defense Waste Citizens Forum (CF), created by the U.S. Department of Energy (DOE)-Richland manager in 1986 to advise DOE on its plans for nuclear waste disposal and cleanup of the Hanford site in eastern Washington state. The creation of the CF occurred in a context of intensely negative criticism and concern about Hanford operations and rustory. DOE undertook an extensive multifaceted public involvement program to gain advice,

understanding, and support on heretofore neglected defense waste (DW) cleanup problems. DOE sought broad public input for a draft environmental impact statement at an early stage before all characterization data were complete and hefore a recommended altemative was formulated. In the evolving, often controversial, highly visible area of agency-public interactions, citizen task fores have been show'n to be useful in developing public policy at the local level. Making them work at the state level is more problematic.
This case shows that a divorse, two-state citizen group can make significant contributions to complex environmental impact statement evaluations with heavy technical components. The CF's principal contribution to public policy was communication of its tindings to business and professional groups, $t o$ area political representatives, and to state agencies, thereby laying the ground work for refocusing the Northwest upon the need for action on DW cleanup at Hanford. In going well beyond National Environmental Policy Act requirements for public involvement in agency decision making, DOE-Richland demonstrated innovative "ays of dealing with the difficult issues of public confidence and public trust by means of agency openness, responsiveness to citizen needs for information, and good faith two-way communication. The success of this proactive DOE initiative was a result of many factors, including selecting the right issue (existing wastes), structuring the $\mathrm{CF}$ at a broad, regional level, and intensive implementation of trust-building strategies.

Research sponsored by the U.S. Departunent of Energy. 


\title{
MANAGING THE GLOBAL COMMONS: DECISION MAKING AND CONFLICT RESOLUTION IN RESPONSE TO CLIMATE CHANGE
}

\author{
S. Rayner \\ W. Naegeli ${ }^{a}$ \\ P. Lund ${ }^{a}$
}

(Abstract of ORNL/TM-11619, Oak Ridge National Laboratory, July 1990)

This publication is a report of the research workshop "Managing the Global Commons: Decision Making and Conflict Resolution in Response to Climate Change" that was held August 1-4, 1989 in Knoxville, Tennessee. Today, a significant issue is the management of the global commons, especially the earth's surface, oceans, and atmosphere. All of these management problems are beset by extreme scientific and technical uncertainties. The workshop, however, did not attempt to resolve the uncertainties for anthropogenic climate change. Instead, the workshop papers and discussions focused on the varied responses of governmental and nongovernmental organizations and other constituencies concerned with global environmental management.

Research sponsored by the U.S. Department of Energy.

${ }^{a}$ The University of Tennessee.

\section{[7.1.22] PREDICTING AIR CONDITIONER LOAD CURVES FROM ENERGY AUDIT DATA: A COMPARISON OF PREDICTED AND ACTUAL AIR CONDITION DATA FROM ATHENS LOAD CONTROL EXPERIMENT}

\author{
J. H. Reed \\ R. P. Broadwater ${ }^{a}$ \\ A. Chandrasekarn ${ }^{a}$ \\ A. $\mathrm{Oka}^{a}$ \\ [Abstract of IEEE Transactions on Power Delivery 5(2), 259-66 (May 1990)]
}

To evaluate effectively the benefits of direct load control, utilities need an economical planning tool for estimating the potential effects of load control actions. Previous attempts to model the impacts of load control have met with mixed success because the models often could not be adjusted for local variations in appliance and housing stocks. This paper presents an approach for estimating air conditioning load curves based on household duty cycles. The duty cycles are calculated from heat transfer rates using household audit data. thermostat settings, and outdoor temperatures. The fit between the load curves estimated from the duty cycle model and the load curves calculated from measured data for households where customers "set and forget" their air conditioners is presented.

Research sponsored by the U.S. Department of Energy.

aTennessee Technological University.

\author{
G. O. Rogers \\ J. H. Sorensen \\ S. A. Carnes \\ A. P. Watson ${ }^{a}$ \\ R. D. Sharp ${ }^{b}$ \\ (Abstract of ORNI,-6615, Oak Ridge National Laboratory, April 1990)
}

In the process of completing the congressionally mandated destruction of the U.S. stockpile of unitary chemical weapons, the U.S. Army decided that enhanced emergency planning was needed to reduce the consequences of an accidental release of agent. In cooperation with the Federal Emergency Management
Agency, other federal agencies, and affected state and local governments, the U.S. Army is in the process of implementing an enhanced emergency preparedness capability. This research supports that effort by developing a method of evaluation for the principle protective action alternatives - evacuation, in-place 
sheltering, and respiratory protection. In addition, this research examines these alternatives for a limited set of scenarios to "validate" the method's utility and to make sone preliminary program recommendations regarding protective action strategies. A model was developed to examine the effect various protective actions have on expected exposure under a variety of release and neteorological conditions. The model compares the expected exposure without protection with the expected exposure given a specified emergency response system. as well as the capacity of the selected protective action to protect (assuming that ali people to be protected have implemented the protective measure: These exposure estimates are graphically displayed over time from the beginning of the event in the context of their anticipated acute human health effects. This report analyzed a total of 1134 seenarios-5(4) evacuation. 378 in-place sheltering. and 252 respiratory protection scemarios. This proliminary analysis focused on 14 classes of accidents (i.e. $5 \mathrm{~GB}, 5 \mathrm{VX}$. and $4 \mathrm{H} / \mathrm{HD}$ ). for a range or melcorologkal conditions onvolving winds averaging 1,3 , and $6 \mathrm{~m} / \mathrm{s})$. and for a series of downwirid distances $(3,10$, and $20 \mathrm{~km}$ ). These 126 accident scenarios were examined for emergency responses involving evacuation (clearing the area in 1.5 .

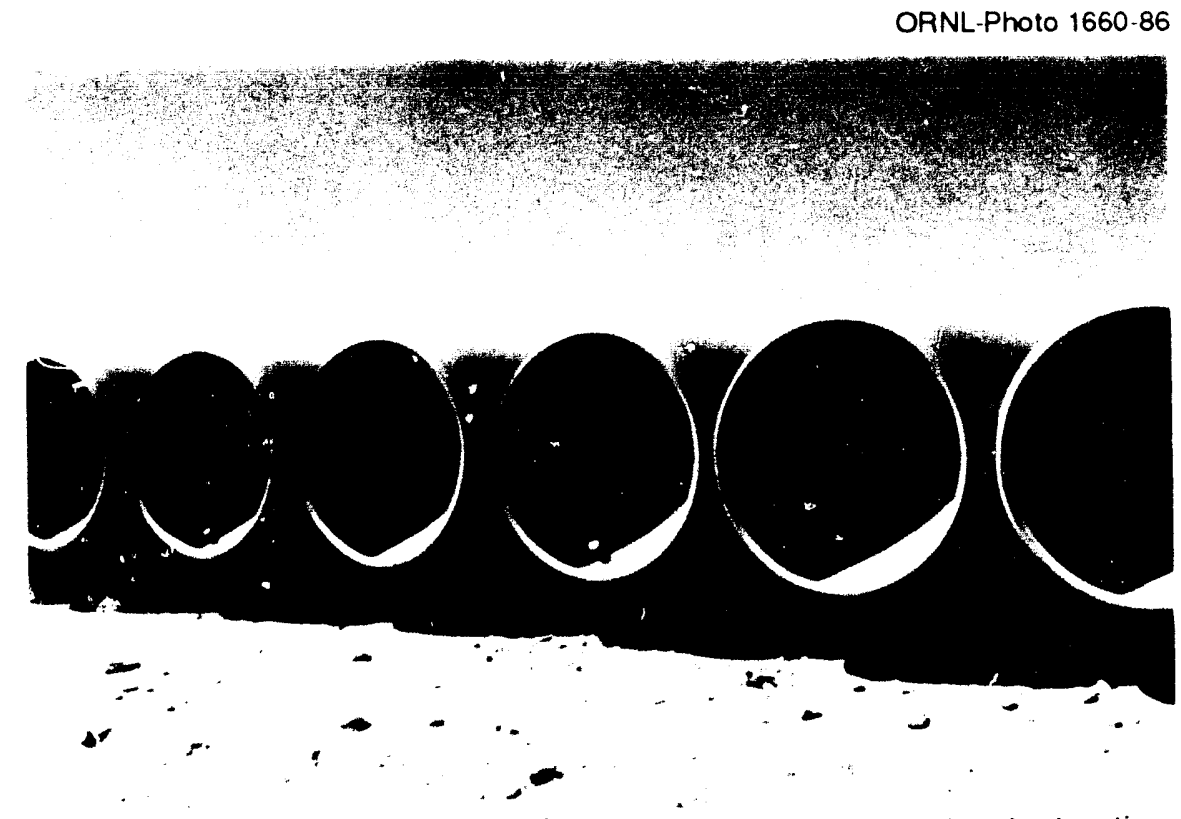

Bar: els or chemical weapon agent slated tor destruction.

10 , and $20 \mathrm{~min}$ ), in-place sheltering (expedient. enhanced. and pressurized shelters), and respiratory protection (North Allantic Treaty Organization civilian and stindard U.S. military masks). All of the scenarios examined assumed that the protective actions would be implemented in the context of a state-of-the-art emergency response system.

Research sponsored by tine U.S. Department of the Amy and the Federal Emergency Management Agency.

"Health and Safety Research Division.

homputing and Telecommunications Division.

\title{
KEY ISSUES IN ELECTRIC UTILITY INTEGRATED RESOURCE PLANNING:
} FINDINGS FROM A NATIONWIDE STUDY

\author{
M. Schweitzer \\ E Yourstone ${ }^{a}$ \\ E. Hirst
}

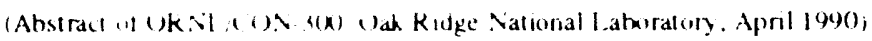

This report describes the findings form an Oak Rudge National Laburatory (ORNL.) study of the integrated resource plans and planning processes of 29 utilitie's and S nonutulity gerenement agencies throughout the

I'rited Stalcs. Risource plans and related decumcits is cre obtamed from all 34 organizatmen and revieued $n$

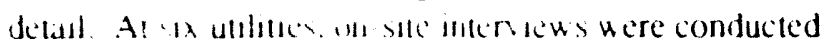

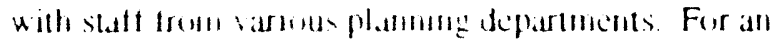

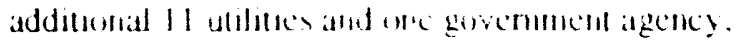

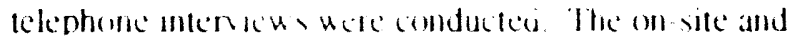

telephone mterviews were designed to elicit additional information on the planning process. Six key issues were identified as likely to influence a plan's societal value. They are (1) the relative emphasis placed on supply-and demand side management resources throughout the planming process: (2) the breadth of inputs considered during plan preparation from varous in-house departments and from nonutility interests: (3) the criteriat used to select resource options for the plan: (t) the use of uncertainty analysis lechniques to 
ensure that the options chosen will be appropriate for alternative futures: (5) the relationship between the long-term plan and action plan, or other short-term documents, that specify utility acquisitions: and (6) the balance between short- and long-term interests as shown by the resource mix specified in the resource plan.
Research sponsored by the U.S. Department of Energy Office of Buildings and Community Systems.

${ }^{¿}$ Consultant, Albuquerque, New Mexico.

\title{
[7.1.25] THE PROCESS OF INTEGRATED RESOURCE PLANNING FOR ELECTRIC UTILITIES
}

\author{
M. Srhweitzer \\ E. Hirst \\ E. Yourstone ${ }^{a}$ \\ (Abstract of pp. 5.177-5.186 in Proceedings of the ACEEE 1990 Summer Study on Energy Efficiency \\ in Buildings, Vol. S. American Council for an Energy Efficient Economy. \\ Washington, D.C., Aug. 26-Sept. 1, 1990)
}

This paper identifies four key issues in utility integrated resource planning that are expected to influence a plan's societal value and discusses the aspects that are related to the planning process. They are (1) the relative emphasis placed on supply-and demand-side resources throughout the planning process. (2) the breadth of inputs considered during plan preparation from various in-house departments and nonu'ility interests. (3) the criteria used to select options for resource plans, and (4) the uncertainty analyses used and their application to the resource selection process. Several opportunities exist for utilities and their regulators to improve the planning process to increase the value of the resource plans that are produced. Specifically, utilities and their state regulatory agencies can (1) conduct comprehensive assessments of demand-side management (DSM) resources, avoid unduly restrictive screening methods. and expand data collection efforts conceming current energy-use patterns and existing DSM program performance; (2) increase the involvement of regulators and other interested nonutility parties in the resource planning process through mechanisms such as public meetings and the establishment of technical advisory boards; (3) when evaluating the cost-effectiveness of potential demand-side resources, use the Total Resource Cost Test or Societal Test instead of thi more restrictive Ratepayer Impact Test, consider the environmental effects of the resources considered, and examine the effects of the entire mix of resource selection criteria used; and (4) focus uncertainty analysis on key uncertainties over the short term and make sure that the results of this analysis are used in resource selection.

Research sponsored by the U.S. Department of Energy Office of Buildings and Community Systems.

${ }^{a}$ Consultant, Albuquerque, New Mexico.

\section{WARNING SYSTEMS FOR NUCLEAR POWER PLANT EMERGENCIES}

\author{
J. H. Sorensen \\ D. Mileti ${ }^{a}$
}

[Abstract of Nuclear Safety, 30(3), 358-70 (July-September 1989)]

Over 200 studies of waming systems and warning response were reviewed. The major findings are as follows. First, variations in the nature and content of warnings have a large impact on whether or not the warning is heeded by the public. Relevant factors include the warning source; the waming channel; the consistency. credibility. accuracy, and understandability of the message; and the warning frequency. Second. characteristics of the population receiving the waming affect their response. These include social characteristics such as gender, ethnicity and age; social setting characteristics such as stage of life or family context: psychological characteristics such as fatalism or risk perception: and knowledge characteristics such as experience or training. Third, many myths about public response to emergency warning currently exist and are at 
odds with knowledge derived from field investigations. Some of these myths include the "keep it simple notion." the "cry wolf syndrome." and notions about public panic. hysteria. and willingness 10 respond to wamings.

Finally, different methods of waming the public are not equally effective at providing an alert and notification in different physical and social settings. Most systems can provide a warning given 3 or more hours of available warning time. Special systems such as tone-alen radios are needed to provide rapid warning.

Researcti sponsored by the Federal Emergency Manazement Agency.

"The liniversity of Colorado.

\title{
COMMUNICATION OF EMERGENCY PUBLIC WARNINGS: A SOCIAL SCIFNCE PERSPECTIVE AND STATE-OF-THE-ART ASSESSMENT
}

\author{
J. H. Sorensen \\ D. Mileti ${ }^{a}$
}

(Abstract of OR.NL-6609, Oak Ridge National Laboratory, August 1990)

More than 200 studies of warning systems and waming response were reviewed for this social science perspective and state-of-the-ant assessment of communication of emergency public warnings. The major findings are as follow's: First. variations in the nature and content of warnings have a large impact on whether or not the public heeds the warning. Relevant factors include the warning source: warning channel: the consistency, credibility. accuracy, and understandability of the message: and the warning frequency. Second. characteristics of the population receiving the warning affect warning response. These include social characteristics such as gender, ethnicity and age: social selting characteristics such as stage of life or family contexl: psychological characteristics such as fatalism or risk perception: and knowledge characteristics such as experience or training. Third. many current myths about public response to cmergency warning are at odds with knowledge derived from field investigations. Some of these myths include the "kecp it simple" notion: the "cry wolle" syndrome: and monons about public pank hysleria, and willingtiess (1) respond to wamings. Finally, difterent meilheds of narmeng the public are hot cyually cllecure al providng

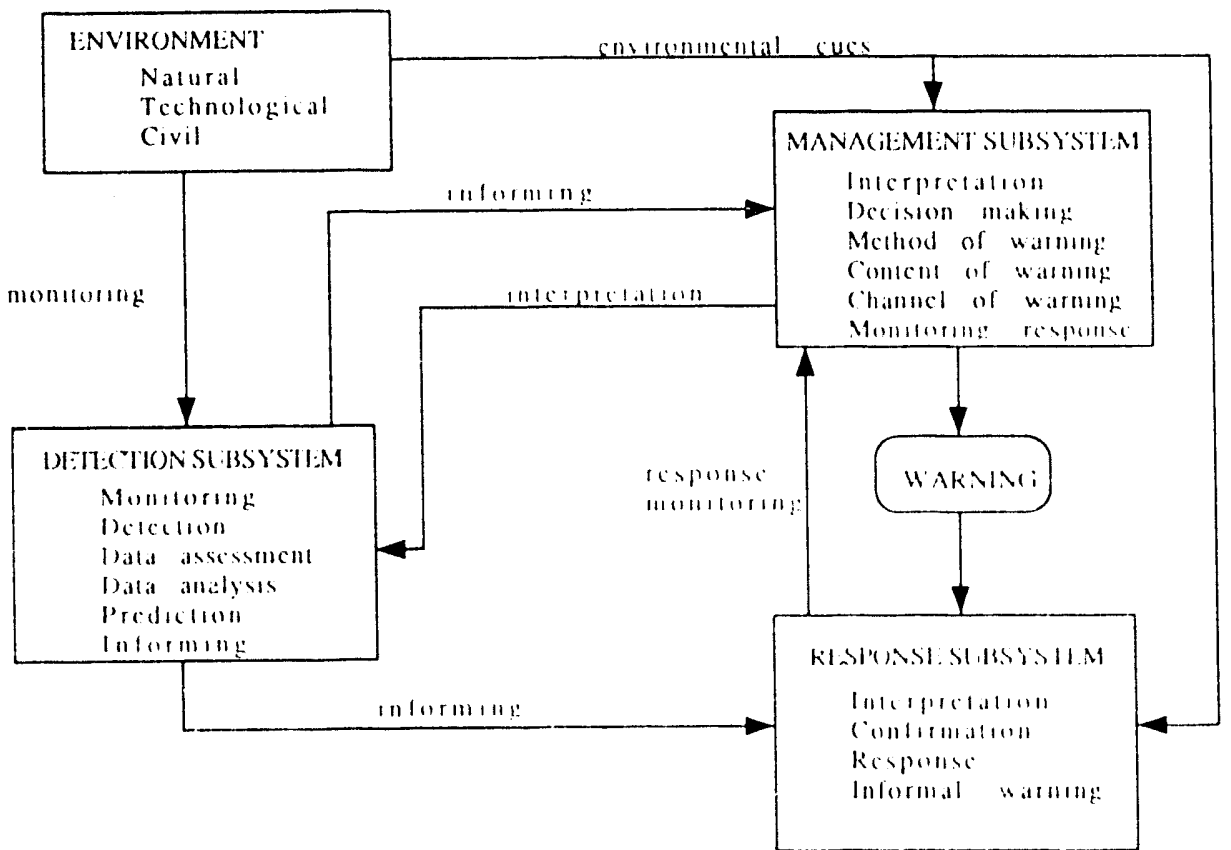

The general components of an integrated warning system.

an aler and notification in different physical and social setlings. Most systems can provide a warning given 3 or more hours of available wamir. ame. Special systems such as tone alert radios are needed to provide rapid winnili:

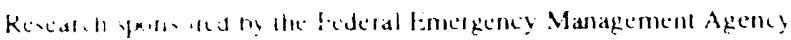

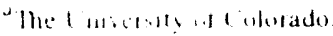




\title{
OVERSIZING RIPRAP FOR PROTECTION OF URANIUM MILL-TAIINGS
}

\author{
W. P. Staub \\ [Abstract of Association of Engineering Geologists 27(1), 85-92 (1990)]
}

This paper presents a methodology for determining the magnitude of oversizing required for marginal quality riprap. Riprap is often used to protect earth cut and fill structures from erosion. Erosion protection of uranium mill tailing emban:'ments, caps, and drainage diversion channels presents a unique challenge. These structures require long-term, maintenance-frec protection in locations where good quality riprap is seldom available. Appropriate oversizing of marginal quality rock will allow mill licensees to meet Nuclear Regulatory Commission (NRC) requirements by using locally available rock at many sites where the use of more durable rock would lead to unreasonable transportation costs. NRC regulations require that riprap used for erosion protection meet design size specifications without periodic maintenance for performance periods ranging from 200 to 1000 years in accordance with Environmental Protection Agency standards. Weathering processes that reduce the size of marginal quality rock over long periods of time can be mitigated by appropriate oversizing.

\section{CONCEPTUAL MODEL FOR RADIOLOGICAL PERFORMANCE ASSESSMENT OF LOW-LEVEL RADIOACTIVE WASTE DISPOSAL FACILITIES}

\author{
M. M. Stevens \\ (Abstract of ORNL/TM-11495, Oak Ridge National Laboratory, May 1990)
}

This document describes components of a conceptual model for performance assessment of the low-level-radioactive-waste disposal facilities operated by Martin Marietta Energy Systems, Inc., for the U.S. Department of Energy (DOE)/Oak Ridge Operations. Radiological performance assessments must be conducted for the low-level waste facilities to demonstrate compliance with the performance objectives established in DOE Order 5820.2A, "Radioactive Waste Management." This report describes the components that must be considered in developing a conceptual model for the assessment of any low-level waste facility and will serve as a standard and guide in the development of models for specific waste facilities.

Research sponsored by the U.S. Department of Energy.

\section{DETERMINANTS OF VARIATION IN CALCULATING A DISCOUNT RATE}

\author{
J. W. Van Dyke \\ P. S. Hu \\ [Ahstract of Energy 14(10), 661-66 (October 1989)]
}

This paper analyzes discount rate calculations from data for the period 1957 to 1982 . The analysis focuses on the methods used in calculating discount rates for project analysis. The approach was to make 864 calculations of the real discount rate by varying the following four factors: the interest rate series, the length of the calculation period, the ending year of the calculation period, and the method of adjusting for inflation. A statistical procedure, analysis of variance, was then utilized to determine the relative contribution of variance from the four factors under consideration. The results indicate that the discount rates calculated from data within this period were not particularly stable and that periods of 5 to 15 years may be too short for the purposes of calculating a long-term real discount rate.

Research sponsored by the U.S. Department of Energy. 


\title{
[7.1.31] GEOPHYSICAL. DIFFRACTION TOMOGRAPHY: VALIDITY AND IMPLEMENTATION
}

\author{
A. J. Witten \\ J. E. Molyneux ${ }^{a}$
}

(Abstatat of Frentiers in Applied Mathenutics, volume on geophysical mversion, ed. B. Bednar)

Geophysical diffaction tomography (GDT) is a technique for subsurface imaging that differs from the more conventional techniques of geophysical tomography in that it maps spatial variations in the physical properties of the subsurtace by backpropagation rather than backprojection. For this reason GDT can provide superior image quality; however, the necessary weak scatter approximation invoked in GDT may restrict its validity, and the need to characterize the full waveform presents practical difficulties in its implementation. An examination of both the Born and Rytov approximations suggests that these weak scatter approximations do not significantly limit the range of validity of GDT, at least for applications involving isolated inclusions. It is shown that for backpropagation within the Rytov approximation, little loss of image quality results from the use of only the real part of the complex phase. This approach eliminates the need to consider signal amplitude and, thereby, avoids the problems associated with the quantification of source/formation coupling.

Research sponsored by the U.S. Department of Encrgy.

${ }^{a}$ Widener University, Chester, Pennsylvania.

\section{CONFIDENCE IN TECHNOLOGIES: INTERACTIONS BETWEEN PUBLICS AND INDUSTRIES}

\author{
A. K. Wolfe \\ (Abstract of pp. 251-57 in Ne'w Risks: Issue's ard Management, eds. L. A. Cox, Jr., and P. F. Ricci, Plenum, New York, 1990)
}

Confidence in the safety of industrial or technological activities is examined in three communities hosting industrial facilities, as well as in a series of communities affected by low-flying jet aircraft. The case studies produced a number of findings that have significant implications for risk communication, including (1) the existence of several audiences for risk communicators. even within a single community: (2) the appropriateness of different risk messages: and (3) the effect of historical and continuing interactions between industries and communities on the types of situations that escalate to crises as well as on the types of risk messages that are appropriate and trusted within industrial communities.

Research sponsored by the U.S. Department of the Air Force Strategic Air Command.

\section{CONCEPTUAL, DESIGN FOR A LAND DECONTAMINATION ROBOT}

\author{
G. P. Zimmerman
}

(Abstract of (ORNI./TM-10416, Oak Ridge National Laboratory. November 1989)

This study is directed loward the conceptual development of a machine that could be used in the cleanup or treatment of land areas contaminated by a nuclear accident. Specifically, a system of hardware components that could remove radioactive, fallout-type contamination from rolling ferrain, such as agricultural farmland, has been identilied. This concept is a remotely operable mobile system which would not expose personnel to the hazard presented hy gamma-enitling radjoactive materials. This system could therefore be referred to as a "land decontamination robot." A survey of vendors has identified a set of hardware components which are commercially available and not special development items. These components include a large vacuum loader unit, a vehicle for moving the unit around the contaminated area, an industrial robot arm for moving the vacuum nozzle over the contaminated surface, an electronic remote control system, and a position determination system to assist with steering the vehicte on subsequent passes around the contaminated 


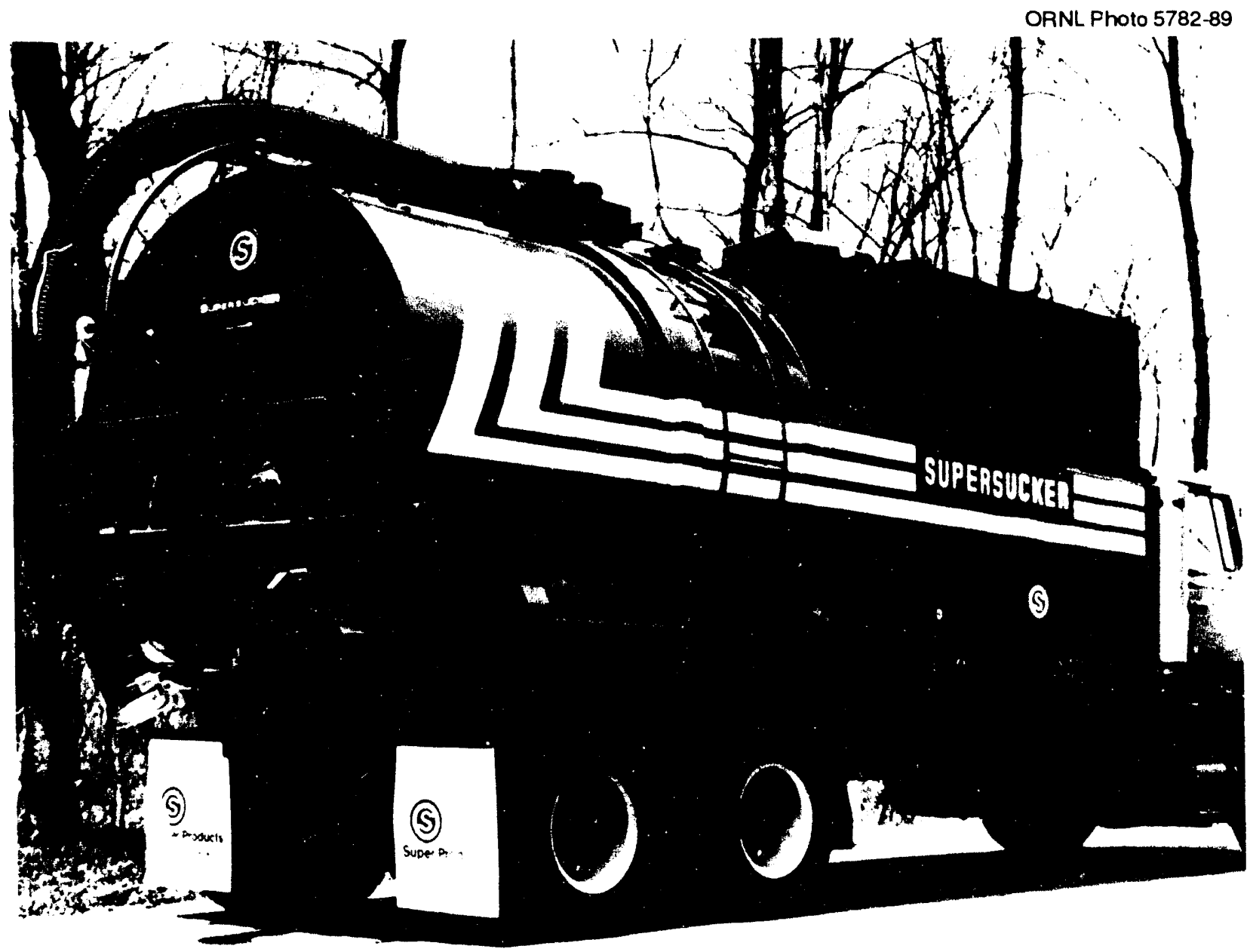

Example of the type of commercially available vacuum systems that could be used to decontaminate radioactively contaminated land areas. (Courtesy of SUPER PRODUCTS, Inc.)

area. Cost estimates were developed for each component. Two versions of the decontamination robot were considered: (1) a truck-mounted vacuum loader unit and (2) a trailer-mounted unit pulled by $a$ bulldozer-type crawler. The costs of the hardware components for the truck-mounted unit are about $\$ 450,000$; the trailer-mounted unit is about $10 \%$ more expensive. These costs are only the hardware costs; the costs associated with integrating this hardware into an operating decontamination system have not been included. Also not included are the costs of programming the sweeping motion of the robot arm and of any computer equipment or software necessary to process and display information relating to the vehicle's position within the contaminated area. It is assumed that these costs will at least equal the cost of the hardware and will thus move the total cost for the complete land decontamination robot system to a minimum of $\$ 1,000,000$.

Research sponsored by the U.S. Department of Energy Office of Nuclear Safety. 


\title{
ENVIRONMENTAL ASSESSMENTS AND IMPACT STATEMENTS
}

\author{
ENVIRONMENTAL ASSESSMENT DEMONSTRATION OF COAL REBURNING

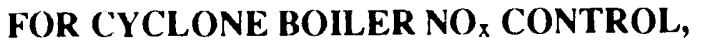 \\ NELSON DEWEY GENERATING STATION, \\ WISCONSIN POWER AND LIGHT COMPANY, \\ CASSVILLE, WISCONSIN
}

\author{
R. L. Kroodsma ${ }^{a}$ \\ R. O. Johnson \\ T. J. Blasing \\ A. W. Campbell \\ R. L. Miller \\ G. K. Eddlemon ${ }^{a}$ \\ V. R. Tolbert ${ }^{a}$ \\ J. W. Van Dyke \\ (Summary of DOE/EA-0440, August 1990)
}

This environmental assessment (EA) evaluates environmental issues associated with a proposed demonstration project that would be cofunded by U.S. Department of Energy (DOE) and private industry under DOE's Innovative Clean Coal Technology Program. The proposed action is the installation and operation of coal reburning equipment on the existing Unit No. 2 boiler at the Nelson Dewey Generating Station, which is located on the Mississippi River at Cassville in southwestern Wisconsin's Grant County. A portion of the crushed coal as currently burned at the plant will be pulverized and then burned by coal rebuming burners to be installed above the boiler's main combustion zone. The purpose of the project is to demonstrate the commercial feasibility of a technology for reducing the amount of nitrogen oxides $\left(\mathrm{NO}_{\mathrm{x}}\right)$ emitted from the stacks of coal-fired power plants having cyclone boilers. Alternatives that are discussed include no action, delayed action, using altemative sites, and employing alternative technologies. This EA concludes that no significant environmental impacts would result from the proposed action, for the following reasons: the reburning equipment would be installed and operated in an existing industrial facility in a previously disturbed location: the amount and type of coal stored and burned at the power plant would not change: the only changes in atmospheric emissions would be a decrease of $25 \%$ or more in $\mathrm{NO}_{\mathrm{x}}$ emissions for the two-unit power plant and an increase of $42 \%$ or less in fly ash emissions (which contribute to particulate matter concentrations); the total amount of effluent released from the fly ash and bottom ash dewatering basins to the Mississippi River or to the groundwater would remain the same as for current operations; the proposed project does not require any land acquisition, change in land use, or loss of wildlife habitat on or off the site: the proposed project does not involve an increase in the area of Mississippi River floodplain occupied by generating station facilities or used by activities associated with the station (e.g., coal storage, fly ash dewatering and disposal); the proposed action would not affect any threatened or endangered species; the proposed project would require only a small construction work force ( 30 workers at peak activity) and no increase in the operational work force; no sites on or eligible for the National Register of Historic Places would be affected: noise levels from construction of the pulverizer building and pulverizer operation would have no impact on off-site areas.

Research sponsored by the U.S. Department of Energy.

anvironmental Sciences Division. 


\title{
FINAL ENVIRONMENTAL ASSESSMENT STARLAB PROGRAM
}

\author{
R. M. Reed ${ }^{a}$ \\ C. E. Easterly ${ }^{b}$ \\ D. M. Evans \\ R. L. Kroodsma ${ }^{a}$ \\ E. J. Liebsch \\ R. B. McLean \\ L. D. Voorhees ${ }^{a}$ \\ (Summary of report, August 1990)
}

This environmental assessment (EA) has been prepared by the U.S. Air Force (USAF) in compliance with the National Environmental Policy Act of 1969 and Executive Order 12114 to determine if significant environmental impacts would result from the STARLAB Program. The proposed action is to conduct a set of engagements and experiments using electro-optical and laser systems to be installed aboard a space shuttle flight. The purpose of these engagements and experiments is to advance the research program of the Strategic Defense Initiative Organization, particularly that involving the acquisition, tracking, and pointing capabilities of the electro-optical and laser systems. A major issue addressed in this EA is the potential exposure of people and wildlife to laser beams. The USAF has prepared extensive analyses of potential laser effects, which are reviewed and evaluated in this EA. Other issues that are discussed and evaluated in the EA include potential impacts of STARLAB activities at Cape Canaveral. Wake Island (Starbird launch sites), and Maui (site of the
Short Wave Adaptive Technology engagement) on land use, ecological resources, endangered and threatened species, and socioeconomic resources. Detailed safety analyses of the effects of laser systems prepared by the USAF and independent calculations and analyses made in preparing the EA indicate that no significant impact to humans or wildlife would occur from exposure to lasers because of the low probability $\left(1 \times 19^{-9}\right)$ of people or wildlife seeing a pulse of 25 nanoseconds.

Environmental impacts of construction and operation of the ground calibration sites on Antigua and Ascension Island will be considered in separate environmental review documents prepared in compliance with Air Force Regulation 19-3.

Research sponsored by the U.S. Department of the Air Force.

${ }^{a}$ Environmental Sciences Division.

${ }^{b}$ Health and Safety Research Division.

\section{FINAL ENVIRONMENTAL IMPACT STATEMENT FOR THE CLOSURE OF MATHER AIR FORCE BASE}

\author{
D. B. Hunsaker, Jr. \\ C. R. Boston \\ L. N. McCold \\ M. A. Mitckes ${ }^{a}$ \\ L. L. Sigal ${ }^{b}$
}

(Summary of report, March 1990)

This environmental impact statement (EIS) assesses the potential environmental impacts from closure of Mather Air Force Base (AFB), located near Sacramento. California. Mather AFB is one of the military installations selected for closure by the Defense Secretary's Commission on Base Realignment and Closure. Mather, an Air Training Command (ATC) installation, has as its host unit the 323rd Flying Training Wing (FTW). The primary mission of the 323rd FTW is the qualification of officers as navigators capable of operating the advanced navigation, bombing, missile, and electronic warfare systems currently in use by the Armed Forces. Major tenant organizations include the 320 th Bombardment Wing (BMW) of the Strategic Air
Command (deactivated as of October 1, 1989), the 940th Air Refucling Group (AREFG) of the Air Force Reserve, and Mather Hospital. The purpose of this EIS is to help the U.S. Air Force (USAF) intelligently cease operations at Mather AFB. It analyzes the local environmental effects caused by the closure and the measures necessary to implement the closure. It also develops appropriate mitigation measures related to closure. The action addressed in this EIS begins with packing and dismantling supplies and equipment at Mather AFB and ends with arrival of equipment, supplies, and personnel at Beale AFB. Only those personnel and equipment associated with the 323rd FTW would be moved to Beale AFB. The 940th AREFG will 
remain at Mather $A F B$ aller closure. All other units at Mather AFB would be deactivated as appropriate. The 320th BMW was withdraw'n from Mather AFB on

October 1, 1989 (independent of base closure activities) to achieve a congressionally mandated reduction in the USAF's conventional B-52 force. Closure would significantly reduce on-base activity and associated environmental impacts. Generation of air emissions. wastewater effluents, and solid wastes would be substantially reduced from current levels and would result in beneficial impacts to the environment. Because Mather AFB's contribution to Sacramento County totals for these parameters is minor, the beneficial effects are also expected to be minor. Effects on ecological resources are expected to be minimal with mitigation as planned. The most significant impact from closure would be a reduction of about $90 \%$ in the area within the 65-decibel noise contour reflecting full operation of Mather AFB, which could result in land-use changes.

Kesearch sponsored by the U.S. Department of the Air fiorce

${ }^{a}$ EBASCO Services, Inc

"Environmental Sciences Division.

\section{FINAL PHASE I ENVIRONMENTAL REPORT, DISPOSAL OF CHEMICAL AGENTS AND MUNITIONS STORED AT ANNISTON ARMY DEPOT, ANNISTON, ALABAMA}

\author{
D. B. Hunsaker, Jr. \\ G. P. Zimmerman \\ E. L. Hillsman \\ R. L. Miller \\ G. M. Schoepfle
}

R. O. Julinson

(Summan of (ORNI./IM-11206/V1, September i990)

The Auntiston Army Depol (ANAD) is une of eight continental United States (CONUS) Army insiallations where lethal unitary chemical agents and munitions are stored, and where destruction of agents and munitions is proposed under the Chemical Stockpile Disposal Program (CSDP). In 1988 the U.S. Army issued a Final Programmatic Environmental Impact Statement (FPEIS) for CSDP that identified on-site disposal of agents and munitions as the environmentally preferred altemative (i.e., the alternative with the least potential to cause significant adverse impacts). In some instances, the FPEIS included generic data and assumptions that were developed to allow a consistent comparison of potential impacts among programmatic alternatives and did not include detailed conditions at each of the eight installations. The environmentally preferred alternative was identified using a method based on five measures of risk directed at potential human health and ecosystem/environmental effects; the adequacy of emergency response also played a key role in the method. In the Record of Decision following the FPEIS. on-site disposal was selected for implementation of the program. The purpose of this Phase I report is to examine the proposed implementation of on-site disposal at ANAD in light of more detailed and more recent data than those included in the FPEIS. Two principal issues are addressed: (1) whether or not the new data would result in identification of on-site disposal at ANAD as the environmentally preferred alternative (using the same selection method and data analysis tools as in the FPEIS) and (2) whether or not the new data indicate the presence of significant environmental resources that could be affected by on-site disposal at ANAD. In addition, a status report is presented on the maturity of the disposal technology and its potential effect on-site disposal at ANAD. Inclusion of these more recent data into the FPEIS decision methodology resulted in confirmation of on-site disposal for ANAD. No unique resources with the potential to prevent or delay implementation of on-site disposal al ANAD have been identified.

Resedrh sponsored by the U.S. Department of the Army.

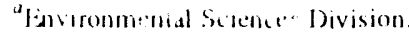


[7.1.38]

\section{ENVIRONMENTAL ASSESSMENT \\ INNOVATIVE CLEAN COAL TECHNOLOGY PROGRAM ADVANCED FLUE GAS DESULFURIZATION DEMONSTRATION PROJECT PORTER COUNTY, INDIANA}

\author{
L. N. McCold \\ D. G. Jernigan \\ R. L. Miller
}

M. A. Mitckes ${ }^{a}$

S. F. Railsback ${ }^{a}$

M. S. Salk ${ }^{b}$

J. W. Van Dyke

(Summary of DOE/EA-0420, May 1990)

This environmental assessment (EA) was prepared for the U.S. Department of Energy to evaluate the environmental effects of a Clean Coal Technology Demonstration Program project that is being partially funded by the federal government. The proposed demonstration project entails the installation and operation of an advanced flue gas desulfurization (AFGD) system at the Northern Indiana Public Service Company`s Bailly Generating Station, Porter County. Indiana. The proposed project is intended to demonstrate the capability of the proposed AFGD technology to reduce Bailly Generating Station sulfur dioxide $\left(\mathrm{SO}_{2}\right)$ emissions by $90 \%$, and to produce a salable gypsum by-product. The principal effect of operating the AFGD system would be to reduce the current $5.2 \mathrm{lb}$ of $\mathrm{SO}_{2}$ per million Btu (of coal heating value) emission rate to between 0.52 and $1.2 \mathrm{lb}$ of $\mathrm{SO}_{2}$ per million Btu. Annual $\mathrm{SO}_{2}$ emissions would be reduced from the current 70,000 tons to between 7,000 and 16,000 tons. Because operation of the AFGD system would decrease the plant's net efficiency and require consumption of about $2 \%$ more coal to produce the same net amount of electricity, emissions of oxides of nitrogen $\left(\mathrm{NO}_{\mathrm{x}}\right)$ and particulate matter could increase by as much as $2 \%$. Annual carbon dioxide $\left(\mathrm{CO}_{2}\right)$ emissions would show an increase of about $5 \%$ because of the combined effect of increased coal consumptic 7 and the generation of $\mathrm{CO}_{2}$ when limestone reacts with ihe flue gas to remove $\mathrm{SO}_{2}$. Emissions of trace metals may decrease slightly because of particulate removal by the AFGD system. The AFGD system would result in changes in local ground-level concentrations of pollutants. Maximum local concentrations of $\mathrm{NO}_{\mathbf{x}}, \mathrm{SO}_{2}$, and particulate matter are expected to be below National Ambient Air Quality Standards for all averaging periods. Minor beneficial ecological effects would be expected to result from the proposed demonstration project to the extent that emissions of $\mathrm{SO}_{2}$ and trace metals are reduced. At the nearest boundary of the Indiana Dunes National Lakeshore (a unit of the national park system), the current noise level has been found to be between 58 and 61 decibels on an A-weighted scale (dBA). The proposed AFGD system is expected to increase the noise level at the national lakeshore's western boundary to between 59.1 and $61.6 \mathrm{dBA}$. To minimize any potential for noise impact to this area, a sound-level survey to verify actual operational noise levels will be performed, and mitigation to reduce noise levels will be initiated if they exceed the predicted levels. Operation would have very little effect on land use unless the gypsum produced by the AFGD system cannot be sold and must be landfilled. Adequate off-site landfill capacity is available within 50 miles of Bailly Generating Station.

Research sponsored by the U.S. Department of Energy.

EBASCO Services, Inc.

${ }^{b}$ Environmental Sciences Division. 


\section{ENVIRONMENTAL ASSESSMENT PINE CREEK HYDROELECTRIC PROJECT ROVANA, CALIFORNIA}

\author{
L. N. McCold \\ G. F. Cada ${ }^{a}$ \\ D. M. Evans
}

\author{
C. H. Petrich \\ B. L. Shumpert \\ J. W. Webb ${ }^{a}$
}

(Summary of report, May 1990)

This environmental assessment (EA) was prepared for the Federal Energy Regulatory Commission to assess the potential impacts of issuing a license to build and operate a small-scale hydroelectric power project on Pine Creek. a tributary of the Owens River in California. The EA provides an analysis of the potential environmental effects of the proposed Pine Creek project on target and other resources. Target resources are resident trout. riparian vegetation, riparian-associated wildlife, aesthetics, recreation, and the local economy. Other resources that are addressed are geoiogy and soils, stream flow and water quality, sensitive species, cultural resources, land use, terrestrial biota, and aquatic biota. The proposed project consists of two developments operating in tandem located along Pine Creek in the Inyo National Forest and adjacent Bureau of Land Management lands. The project site is in Inyo County, approximately 13 miles north of Bishop, Califomia. The nearest town is Rovana. located about one-half mile from the proposed lower powerhouse. The proposed facilities include a diversion structure, a forebay with a working volume of 30 acre- $\mathrm{ft}^{4}$ ( 1 acre- $\left.\mathrm{ft}=43,500 \mathrm{ft}^{3}\right)$, two penstocks in tandem, each followed by a powerhouse, and two afterbays with a combined working volume of 30 acre-ft following the lower powerhouse. In addition to the applicant's proposed project. four alternatives are considered in detail. The first of these is the same as the applicant's proposal except that diversions to the hydroelectric facility are limited to those allowed by the U.S. Forest Service's 4(c) conditions. These 4(e) conditions would permit diversions only during the high-flow months of May through August. The second alternative is the alternative developed by the staff for the Environmental Impact Statement. This alternative minimizes adverse impacts to Pine Creek's resources by allowing the upper diversion only. The third aiternative is the staff alternative but with the minimum flows permitted by the $4(\mathrm{e})$ conditions. Like the second alternative, it avoids impacts to the lower part of Pine Creek by allowing no diversions, then goes on to reduce impacts to the part of the stream affected by the upper diversion. The fourth alternative is the no-action altermative (i.e., not licensing the Pine Creek project). The effects of the other alternatives are compared with the no-action alternative. The pivotal difference between the staff alternatives [with and without 4(e) minimum flows] and the other development alternatives is the development of the lower reach. The lower reach is the most valuable part of the proposed diversion area for all the target resources except for the local economy. Consequently, project effects on target resources in the lower reach more heavily influence the overall impact assessment.

\footnotetext{
Research sponsored by the Federal Energy Regulatory Commission.

${ }^{a}$ Environmental Sciences Division.
} 


\title{
FINAL PROGRAMMATIC ENVIRONMENTAL IMPACT STATEM.ENT CLEAN COAL TECHNOLOGY DEMONSTRATION PROGRAM
}

\author{
R. M. Reed $^{a}$ \\ R. L. Miller \\ D. B. Hunsaker, Jr. \\ C. R. Boston \\ C. C. Coutant ${ }^{a}$ \\ G. Marland ${ }^{a}$ \\ N. B. Munro ${ }^{b}$ \\ R. D. Roop \\ M. S. Salk ${ }^{a}$ \\ J. A. Watts ${ }^{a}$ \\ A. K. Wolfe \\ R. M. Monsour ${ }^{c}$ \\ J. T. Stone ${ }^{c}$ \\ N. E. Hinkle \\ L. N. McCold \\ S. F. Railsback ${ }^{a}$ \\ L. W. Rickert \\ M. Uziel ${ }^{b}$ \\ J. W. Webb ${ }^{a}$ \\ M. Andrews ${ }^{c}$ \\ J. Soni ${ }^{c}$ \\ S. Zukor ${ }^{c}$ \\ (Summary of DOE/EIS-0146, November 1989)
}

The proposed action evaluated in this programmatic environmental impac: statement (PEIS) is to continue the Clean Coal Technology Demonstration Program (CCTDP) involving the selection for cost-shared federal funding of one or more clean coal projects proposed by the private sector. The PEIS addresses the potential environmental consequences of the widespread commercialization of the successfully demonstrated clean coal technologies by the private sector in the year 2010. This analysis of programmatic issues, along with additional environmental information and analysis containing business confidential or proprietary information. will be used by the U.S. Department of Energy (DOE) in making decisions on specific proposals during the selection process. The PEIS evaluates a no-action alternative, which assumes CCTDP is not continued and conventional coal-fired technologies with conventional flue gas desulfurization controls would continue to be used, and a proposed action alternative, which assumes that CCTDP projects are selected for funding and that successfully demonstrated technologies undergo widespread commercialization by the year 2010 . The analysis of environmental consequences focuses on changes to four parameters of concern, namely, sulfur dioxide $\left(\mathrm{SO}_{2}\right)$, oxides of nitrogen $\left(\mathrm{NO}_{\mathrm{x}}\right)$, carbon dioxide $\left(\mathrm{CO}_{2}\right)$, and solid wastes. An upper bound of change to each of these 4 parameters was estimated for each of 22 clean coal technologies, separately, assuming full penetration of potential markets. Using results from the Regional Emission Database and Evaluation System, the
PEIS shows that repowering and retrofit-New Source Performance Standards for capable clean coal technologies - could lead to a significant reduction in $\mathrm{SO}_{2}$ and $\mathrm{NO}_{x}$ relative to the no-action alternative in 2010. Repowering technologies are the only category in which all technologies could lead to a measurable reduction in $\mathrm{CO}_{2}$. The amount of solid waste generated under the proposed altemative varies with each technology, ranging from a maximum increase of $23 \%$ to an equivalent decrease relative to that of the no-action altemative. Commercialization of the clean coal technologies would have a beneficial effect on air quality and could contribute to amelioration of current impacts of acidic deposition. Impacts on $\mathrm{CO}_{2}$ emissions from clean coal technologies would be a direct function of the quantity of coal burned; thus, if commercialization of clean coal technologies results in changed use of coal resources, the technologies would contribute to a change in $\mathrm{CO}_{2}$ emissions. Potential effects of the CCTDP on land use, water resources, ecological systems, endangered and threatened species, socioeconomic resources, and human health and safety are also evaluated in the PEIS.

\footnotetext{
Research sponsored by the U.S. Department of Energy.

${ }^{a}$ Environmental Sciences Division.

${ }^{b}$ Health and Safety Research Division.

'Technology and Management Services, Inc.
} 


\section{JOHNSTON ATOLL CHEMICAL AGENT DISPOSAL SYSTEM (JACADS) \\ FINAL SECOND SUPPLEMENTAL ENVIKONMENTAL IMPACT STATEMENT FOR THE STORAGE AND ULTIMATE DISPOSAL OF THE EUROPEAN CHEMICAL MUNITION STOCKPILE}
R. E. Saylor
C. R. Boston
J. D. Harris
P. Kanciruk ${ }^{a}$
E. J. Licbsch
N. B. Munro ${ }^{b}$
T. G. Patton

\author{
G. P. Zimnicrman \\ C. W. hagan \\ R. O. Johnson \\ R. L. Kroodsma ${ }^{a}$ \\ L. N. McCold \\ B. A. Owens ${ }^{b}$ \\ W. P. Staub
}

G. W. Suter

(Summary of report, June 1990)

This final second supplemental environmental impact statement (SSEIS) to the Johnston Atoll Chemical Agent Disposal System (JACADS) Environmental Impact Statement (EIS) assesses the effects of receiving, storing. and ultimately destroying the United States' stockpile of lethal unitary chemical munitions currently stored in the Federal Republic of Germany (European stockpile) at the Army's JACADS facility located on Johnston Atoll in the Pacific Ocean. The U.S. Army prepared an EIS in 1983 to assess process technology, construction, and operation of the JACADS facility and prepared the first supplemental EIS (SEIS) in 1988 to examine the disposal of solid and liquid waste produced by the JACADS facility. This final SSEIS addresses the effects of the following proposed European stockpile activities: (1) the transport of the European stockpile from the territorial limit [ $19 \mathrm{~km}$ (12 miles)] to Johnston Island. (2) the unloading of munitions from transportation ships, (3) the on-island munitions transport and handling, (4) on-island muritions storage, (5) the disposal of munitions in the JACADS facility, (6) the disposal of incineration wastes, and (7) altematives to the r roposed action. This document also updates information in the 1983 EIS and the 1988 SEIS, as appropriate. The original purpose of JACADS was to destroy chemical agents and munitions currently stored on Johnston
Island. JACADS will also demonstrate the Army's preferred demilitarization process for disposing of the stockpile of unitary chemical agents and munitions. In general, the effects from destruction of the European stockpile relative to destruction of the existing Johnston Island stockpile are expected to be of the same type as those assessed in the 1983 EIS. However, the period of JACADS operation will be extended for $31 / 2$ months, and a larger stockpile will temporarily exist on the island. Thus, impacts will occur over a somewhat longer period of time. No significant incremental impacts are expected during normal operations; however, because of the increased handling, storage, and disposal operations, there will be an increased potential for accidents. Standard operating procedures will be implemented to ensure safety and to minimize overall risks. It is concluded that the European stockpile activities can be conducted in a safe and environmentally acceptable manner. The environmental impacts of routine handling and disposal operations would be minimal.

\footnotetext{
Research sponsored by the U.S. Department of the Amy.

"Environmental Sciences Division.

${ }^{h}$ Health and Safety Research Division.
} 


\title{
7.2 ABSTRACTS OF ENERGY AND ECONOMIC ANALYSIS SECTION
}

\author{
ARSENAL OF DEMOCRACY IN THE FACE OF CHANGE: \\ ECONOMIC POLICY FOR INDUSTRIAL MOBILIZATION IN THE 1990s
}

\author{
D. J. Bjomstad \\ C. V. Chester \\ B. H. Hardy ${ }^{c}$ \\ P. J. Sullivan
}

\author{
J. R. Brinkerhoff ${ }^{a}$ \\ I. Gutmanis ${ }^{b}$ \\ G. Horwich \\ D. A. Trumble
}

(Abstract of ORNL//IM-11271, Oak Ridge National Laboratory, December 1989)

The increasing perception of a Soviet-U.S. nuclear deterrence stalemate, costly improvements in high-tech conventional weapons, and the changing role of the United States in the world economy have focused new attention on the capability to produce defense material. The nation now relies on the ability to mobilize production to meet the needs of a prolonged military buildup. This study addresses seven issues raised by past studies: (1) How should the federal government organize information and plan for a military buildup? (2) What plans and procedures should support mobilizing selected weapons production? (3) What plans and procedures should support total mobilization? (4) What fundamental national economic planning should support the defense effort? (5) How should the nation face offshore sourcing? (6) How can the acquisition system be improved? (7) How should defense technologies be supported and produced? The study provides not simple answers to these questions, but guidelines to their solutions. A surge or mobilization framework should focus attention on the proper cconomic units: firms, economic sectors, or the economy as a whole. The ability to mobilize requires only the political will to make the necessary modest investments in analysis and material. There is little current effort in mobilization planning, especially in how to make civilian economic capability and products meet defense needs. Offshore sourcing is a potential source of vulnerability, but should be addressed on a case-by-case basis rather than by seeking subsidies for domestic industries that may not be critical to the next generation of weapons. The opportunities presented by opening world markets should be exploited. Revision of the acquisition system should include incentives for economic efficiency, cost effectiveness, innovative attitudes and performance-based profits. Calls to restructure the economy to resist forces of international economic change should be ignored.

Research sponsored by the Federal Emergency Management A.gency.

\footnotetext{
${ }^{a}$ Brinkerhoff Associates.

${ }^{h}$ Sterling Hobe Corporation.

'Indiana University.
}

\section{ARSENAL OF DEMOCRACY IN THE FACE OF CHANGE: ISSUES AND POLICY OPTIONS IN INDUSTRIAL PREPAREDNESS PLANNING}

\author{
D. J. Bjornstad \\ B. H. Hardy ${ }^{a}$ \\ (Abstract of ORNL/TM-11273, Oak Ridge National Laboratory, March 1990)
}

This paper is onc of a set of working papers that serve as background for a Federal Emergency Management Agency-(FEMA-) sponsored study of industrial mobilization planning. It identifies issues that will lead to policy alternatives that support industrial preparedness. To do this, a simple framework is used to cross-classify types of economic interaction between the U.S. Department of Defense (DOD) and the private sector given peacetime, surge, and mobilization requirements. Next, policy recommendations from ten recent studies are examined. These come from a variety of different groups and focus on potential actions by DOD, FEMA, the Congress, the Navy, and others. They are summarized and restated to match the crossclassification framework. The planning framework is then used to organize a set of recommendations around 
three themes: acquisition and relationships between the public and private sectoss, technology and factor-inputenhancing activities, and offshore sourcing and intemational competitiveness. DOD has already addressed the acquisition issue at great length and has implemented the bulk of its findings. These will undoubtedly increase the effectiveness and efficiency of its operations. DOD cannot by itself fully rationalize the acquisition process so that incentives to achieve greater efficiency are fully passed on to contractors. It can, however, revise its acquisition process so that surge provisions are a deliberate step in the contract of each sensitive procurement; it could also require a surge analysis for each action, Loth steps that would highlight preparations for surge. DOD should consider the creation of a new institution to handle those activities that directly enhance the defense industrial base. It should also support the creation of an entity to identify nonneutralities in govermment policy. DOD should recognize that generic technologies supporting the defense effort are virtually indistinguishable from those supporting the civilian economy. It should focus its technology efforts on supporting specific concepts that include both performance and producibility, as well as the technical skills needed to support them. DOD should continue to enjoy the economies gained from offshore sourcing, but should seek to document savings so that realistic tradeoffs can be evaluated. While supporting free trade, the govemment shculd seek to overcome instances of market failure by means of such strategies as R\&D support and technology transfer. It should also be attentive to trade barriers created by other nations. Finally, DOD should seek to integrate matters of producibility and resource cost more fully into decisions to develop, purchase, and deploy weapons systems.

Research sponsored by the Federal Emergency Management Agency.

${ }^{a}$ Indiana University.

\title{
TARGETS OF OPPORTUNITY FOR PLASTICS RECYCLING
} AND SOURCE REDUCTION

\author{
T. R. Curlee \\ (Abstract of pp. $21-45$ in Plastics Recycling us a Future Business Opportunity. Technomic \\ Put::ishing, Lancaster, Pa., 1990)
}

This chapter summarizes the results of two recent studies to identify and assess "targets of opportuinty" for additional recycling and source reduction of plastic wastes. The targets of opportunity are discussed in terms of the quantities of plastic wastes that might be affected. the relevant supply-side and demand-sive constraints that must be overcome before these targets can be met. and the degree to which meeting these targets inight be facilitated by government sponsored incentive programs or other regulatory measures. Hypothetica' scenarios depict various supply-side and demand-side conditions. In some cases, the supply-side and demand-side assurnptions reflect present technical, economic, institutional, and regulatory conditions. In other cases, particularly with respect to supply-side constrai!ts, the assumptions represent significant changes in the ways plastics are now collected and processed in the United States. The quantities and types of plastics that could be recycled or source-reduced, given the hypothetical conditions, are estimated.

Research sponsored by the U.S. Department of Energy and the Environmental Protection Agency.

\section{BIOMASS-DERIVED PLASTICS: VIA BLE ECONOMIC ALTERNATIVES} TO PETROCHEMICAL PLASTICS?

\author{
T. R. C irlee
}

[Ahstract of Materials and Sirciety 13(4), 381-409(198.)]

This paper discusses the economic feasibility. at several levels of production and use. of replacing conventionai peurochemicai-derived trastics with piastics manufactured from hir. nass raw materials. In the case of raw materials production, oil and natural gas prices are expected to increase, but not at the rate experienced during the past one and a haif decades. Biomass prices are currently high in relation to oil and natural gas. That 
gap is, however, expected to decrease as selected agricultural operations are dedicated to chemicals production and as genetic engineering produces more appropidtc species. The availability of raw materials does not appear to be a significant problem in either the case of petroleum or biomass. At the intermediate products level, biomass-derived intermediate products, which could substitute for petrochemical feedstocks in the production of conventional plastics, are currently more costly and more contaminated than the same intermediates produced from petroleum and natural gas. Recent studies suggest that real oii and natural gas prices would have to increase by more than $100 \%$ before biomass materials would displace any significant percentage of oil and natural gas. In addition, most agree that if oil and natural gas prices increase sharply, coal-not biomass - is the logical altemative raw material. Revolutionary technologies such as those based on microorganisms may, however, greatly reduce the cost of biomass conversion. At the resin production level, it is generally accepted that without major lechnological advances. the prices of biomass-derived plastics will be significantly higher than the current or forecasted prices of petrochemical-derived plastics. Prices of the few biomass-derived resin` currently being marketed are about double the prices of conventional resins. An added problem for biomass-derived plastics is market entry. The production of some of the main resin feedstocks, e.g. ethylene, is essentially a by-product of the refining industry, so the prices of resin feedstocks could easily decline sharply in response to threatened competition. Further, the arguments for biomass-derived plastics as less damaging to the environment are at this time somewhat tenuous. And the arguments for the development and use of these new resins on the basis of saving petroleum and natural gas have generally been overstated. If inorganic and biomass-derived plastics are to become competitive with conventional plastics, the cost differences between the resin types will have to narrow. Alternatively, the special properties of the new resins will have to r rove to be quite valuable.

Research sponsored by the U.S. Department of Energy.

\title{
ADV ANCED MATERIALS: INFORMATION AND ANALYSIS NEEDS
}

\author{
T. R. Curlec \\ S. Das \\ R. M. Lee \\ D. A. Trumble
}

(Abstract of ORNL./IM-11593, Oak Ridge National Laboratory, September 1990)

This study undertook to identify types of information and analysis needed for advanced materials. The project was sponsored hy the U.S. Bureau of Mines (BOM) and includes a conceptual description of information needs for advanced materials and the development and implementation of a questionnate on the same subject. We review th: $:$ information that has been provided historically by BOM oi traditional materials, and note difficuities in defining and classifying advanced materials. These difticulties complicate any general assessment of advat:ced materials. Twelve fundamental differences exist between advanced and traditional materials; we discuss the implications of these differences for data and analysis needs. Advanced and traditional materials differ significantly in terms of physical and chemical properties. Such fundamental differences indicate a need for "road maps" to help interested individuals find sources of technical and market data. There is also a need to establish meanimgtul houndaries for advance omaterals in terms of input materials and prexducts. i.e. $u$ ken in the processing than does a material become "advanced," and when does an "advanced" material become a "product"? As more data and other information are collected, BOM can assist domestic industries and policy makers by analyzing important issues, including (1) forecasting the potential substitution and market penetration of advanced materials; (2) assessing the impacts of different organizational structures on research, development, and production of advanced materials; (3) estimating life-cycle costs and benefits of advanced materials and the discount rates used by adopters of these new materials; and (4) examining the potential for recycling advanced materials and the potential environmental consequences of producing and using advanced materials. Identifying information needs and analyses for advanced materials requires a fundamental rethinking of why information of various types is important, and to whom and for what purposes that information may be usciful.

Kesearch sperisored by the L.S. Hutedu of Mure. 


\title{
PLASTICS RECYCLING IN THE INDUSTRIAL SECTOR: AN ASSESSMENT OF THE OPPORTUNITIES AND CONSTRAINTS
}

\author{
T. R. Curlce \\ S. Das \\ (Abstract of ORNL./TM-11258, Oak Ridge National Laboratory, December 1989)
}

This report assesses the viability of recycling industrial and postconsumer plastic wastes, which have typically been disposed of by landfill or incineration. A broad range of economic and regulatory issues is addressed. We begin by projecting the quantities and qualities of manufacturing and postconsumer plastic wastes through the year 2000 . We then present the expecied costs and revenues of different recycling approaches. We also report recent legislative, regulatory, and institutional changes that have promoted, and in some cases hindered, additional recycling. Several scenarios depicting probable future technical, economic, institutional. and regulatory conditions are discussed, and the quantitics and qualities of plastics available for recycling under the conditions of such scenarios are estimated. We also estimate the potential energy value of plastic wastes. Postconsumer wastes are projected to increase from 35.8 billion pounds in 1990 to 48.7 billion pounds in 2000 . Plastic packaging is expected to account for about $46 \%$ of all postconsumer plastics during the coming decade and will remain by far the largest single contributor to the waste stream. The largest projected percentage increase will occur in the building and construction sector, which is projected to increase from $2.0 \%$ of the total in 1990 to $8.0 \%$ in 2000 . Manufacturing-nuisance plastics are pmjected to account for about $4 \%$ of total plastic wastes. Our assessment suggests that there will be significant opportunities for the industrial sector to recycle plastic wastes during the coming decade. There are, however, potential barriers. Technologies that can accommodate dirty mixed plastics require further development, especially tertiary technologies that could produce high-valued prepolymers. Separation technologies also require further development if some of the larger waste streams are to be recycled in a secondary or tertiary stage. Market constraints may limit significantly the potential for secondary products, especially those products that compete with wood or concrete. Finally, regulatory programs that will affect the collection of plastics and the economic viability of recycling operations are currently being developed at the federal, state, and local levels.

Research sponsored by the U.S. Department of Energy Office of Industrial Programs.

\section{OIL MARKETS UNDER POLITICAL AND MILITARY STRESS}

\author{
S. Das \\ G. R. Hadder \\ R. M. Davis ${ }^{a}$ \\ R. Lee \\ P. N. Lciby \\ [Abstract of Energy Economics 12(3), 204-10 (July 1990)]
}

Econometric and linear programming models were used to evaluate petroleum markets in two hypothetical sc narios: a politically based disruption and. alternatively, a military confrontation in 1995. The market scenarios were characterized by a substantial loss of exporis from the Persion Gulf region. The hypothetical disruptions resulted in substantially higher prices and reduced supply and demand of refined products, especially fuels for transportation. Oil from the Strategic Petroleum Reserve mitigated the impacts, though the International Energy Agency's oil-sharing agreement was not a factor.

Research sponsored by the U.S. Department of the Navy Office of Naval Research, Navy Energy and Natural Resources R\&D Division.

${ }^{a}$ Central Management Uffice. 
ORNL-DWG. $91-10857$

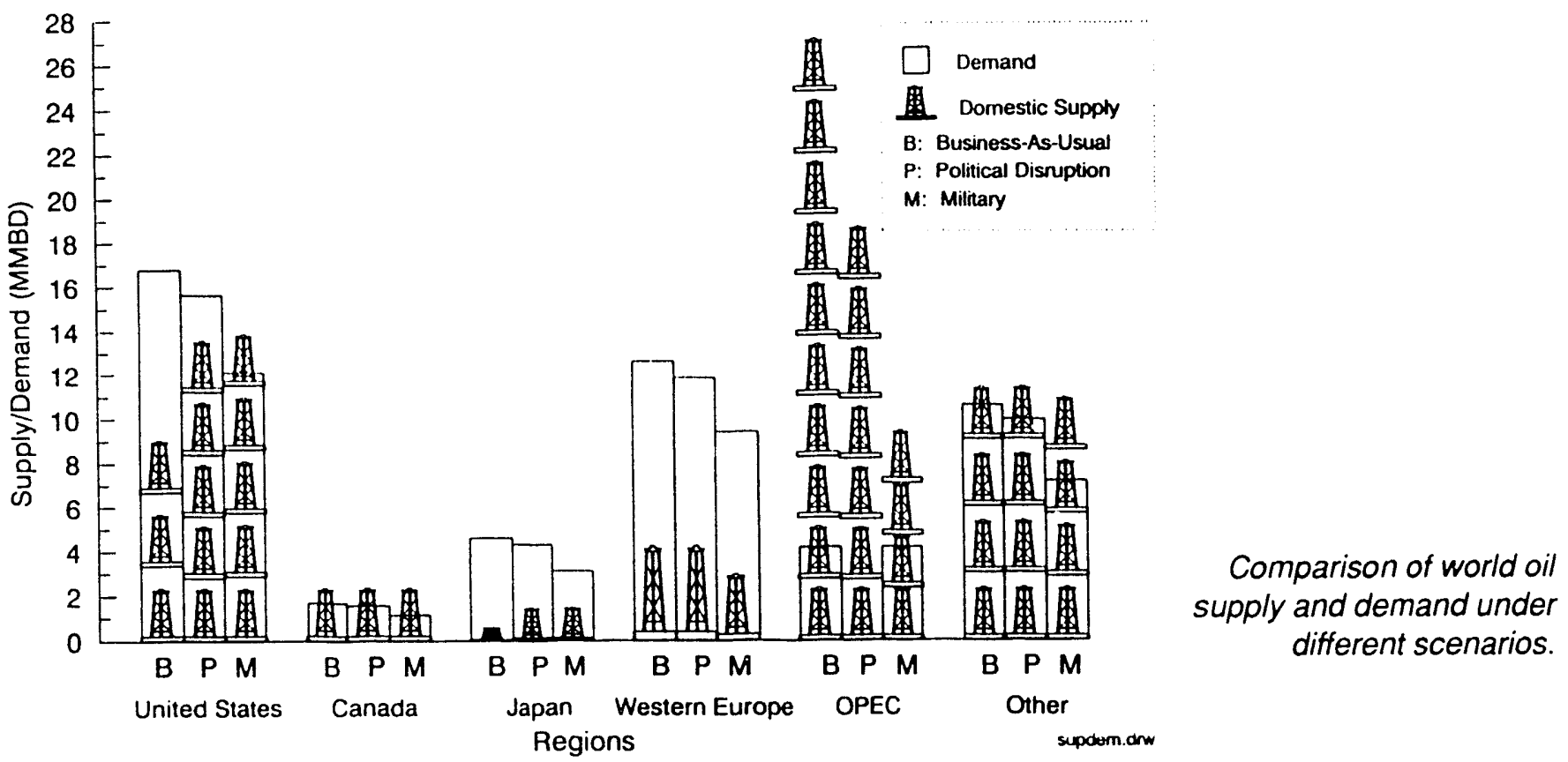

\title{
[7.2.8] ARSENAL OF DEMOCRACY IN THE FACE OF CHANGE: FOUR U.S. MOBILIZATIONS: A MACROECONOMIC PERSPECTIVE
}

\section{G. Horwich}

(Abstract of ORNL/TM.11276, Oak Ridge National Laburatory, April 1990)

Opinions on the magnitude of previous U.S. military mobilizations vary. This study attempts to resolve these differences by examining U.S. government expenditures as a fraction of the gross national product as well as examining the magnitude and sources of manpower during wartime. The level of government national defense expenditures and the simultaneous deployment of manpower, both military and civilian, is taken to be the measure of mobilization. The paper examines the total magnitude of expenditures and manpower in each mobilization, the timing of its implementation and wind-down, and the ease with which the macroeconomy appeared to adapt to the wartime conversion. The bottom-line measure of the magnitude of each war was taken to be the increment between the premobilization percentage of government expenditures on defense and the average percentage sustained during the mobilization years. World War II was the largest mobilization at $36.3 \%$. World War I was next at $9.6 \%$, the Korean War almost a third less at $6.6 \%$, and Vietnam a minuscule 1.2\%. Premobulization military strength was low in both world wars, while for Korea and Vietnam, it was already relatively high. The additional manpower in each of the four mobilizations came from a reduction in prevailing levels of employment, an increase in the working-age population, and an increase in the rate of labor force participation.

Research spensored by the Federal Emergency Management Agency.

\section{DISASTERS AND MARKET RESP(ONSE}

\author{
G. Horwich
}

[Abulade of Cato Journal 9,3), 531-55 (W inter 1940)]

This study exammes the actual and potcutial role of markets in disaster anticipation and response. Disasters are defined as any declince in the value of economic resources le yond some socially determiried threshold that varies direclly with space and time. In this sense the oil shocks of the 1970)s and 1980, which imposed a new 
regime of relative prices and hence significant losses in the value of the pre-existing allocation of resources, qualify as a disaster. In the United States, government-imposed price ceilings and mandatory allocations delayed the necessary adjustment and added to the total costs of the shock; they did not increase social equity in terms of commonly accepted criteria. Free markets have played a major role in the demobilization and recovery following wars, which are disasters of massive proportions. Sociological evidence indicates that people rarely panic in the aftermath of disasters and usually respond effectively at a grassroots level; centrally dictated responses and external donations tend not to be sensitive to local conditions or desires. Markets are seen as an institutional supplement and magnifier of spontaneous individual and community adaptive behavior. Govenment can facilitate the contribution of markets by limiting its own role to coordination and procurement, rather than production, of goods and services obtainable from contestable markets. In the context of disasters, government should (1) seek the services of private-sector disaster consultants and specialists, (2) act as a wholesaler by selling all in-kind gifts to local retailers and by distributing the proceeds to low-income houscholds, (3) avoid arbitrary property seizures, and (4) enable insurance companies to set performance standards for their clients. Government should avoid subsidizing insurance premiums and providing other benefits that reward hazardous behavior, avoid imposing price controls, and share promptly all information with the public while encouraging others to do the same.

Research sponsored by the U.S. Department of Energy.

\section{URHANIZATION AND ENERGY USE IN ECONOMIC DEVELOPMENT}

D. W. Jones

[Abstract of Energy Journal 10(1), 29-44 (October 1989)]

Urbanization and industrialization are the most prominent features of economic development. The encrgy-use changes brought by industrialization are well known, but urbanization also imposes major, if subtle, changes in energy use. Urbanization shifts production activities formerly undertaken in the home with little or no energy to energy-using outside producers. One of the largest changes is in the daily travel of urban residentsprimarily but not exclusively-to work. Personal transportation in rural areas generally entails little or no fuel use, while urban transportation does, particularly as incomes increase. Higher density living also induces substitutions of modern for traditional energy forms. Finally, food must be transported longer distances to urban consumers than to rural agricultural consumers. An aggregate, cross-sectional regression analysis is conducted for 59 developing countries for 1981 .
Aggregate energy use per capita and per dollar of gross domestic product (GDP) is regressed on per capita income (adjusted for purchasing power parity), the percent of GDP coming from industry, the percent of the population urbanized, arable population density, and several product-specific fuel prices. Holding constant per capita income, industrialization, population density, and fuel prices, the elasticity of energy consumption in a $1 \%$ increase in urbanization is between 0.35 and 0.48 . The implication is that, although increasing per capita income and industrialization are important sources of increases in energy consumption, urbanization alone is also an important source of increased consumption and could be a major factor in world energy demand over the next generation.

Research sponsored hy the U.S. Agency for Intemational Development. 


\title{
THE SURVIVABLE OPTICS MODIL: GUIDELINES FOR FORMING R\&D CONSORTIA FROM THE THEORY OF CLUBS
}

\author{
M. T. Katzman \\ D. W. Jones
}

(Abstract of ORNL/OMIS-90/1, Oak Ridge National Laboratory, March 1990)

\begin{abstract}
A Survivable Optics Manufacturing Operations Development and Integration Laboratory (MODIL) has been established at Oak Ridge National Laboratory (ORNL). The purposes of MODIL are to achieve order-of-magnitude cost reductions in the manufacture of optical components and to contribute to the revitalization of the American optics industry. MODIL is a federal laboratory-university-industry consortium that sponsors manufacturing R\&D and aims to transfer this technology to the domestic optics industry by utilizing a manufacturing test bed at ORNL. The purposes of this analysis are (1) to identify the types of firms that would make the best members of MODIL, (2) to identify the conditions under which private firms would be willing to participate in the consortium's research and development efforts, and (3) to indicate conditions under which firms could supplant the federal government as the source of funding. The conceptual approach is derived from the economic theory of clubs. A review of the literature on $R \& D$ consortia in the United States and Japan and informal interviews with 18 industrial participants in MODIL provide the empirical basis for conclusions and recommendations. The analysis concludes that the success of MODIL is favored by three characteristics of its organization and activities. First, it focuses on process R\&D, not product R\&D. Second, briefings have attracted industrial personnel, including a healthy mix between technology-push and market-pull concerns. Third, manufacturability is placed in the midst of the process of establishing product performance
\end{abstract}

specifications. Factors affecting the receptivi, of firms to the MODIL approach are size, stage of the production process, and orientation toward commercial tnarkets. Smaller firms perceive the benefits of collaborative R\&D more than larger firms do. As the MODIL is currently constituted, the major direct gainers from technological advances are likely to be raw materials suppliers and then, through production contracts, Strategic Defense Initiative (SDI) systems. Fabricators, polishers, and systems integration firms also may benefit, depending upon the transferability of manufacturing processes to non-SDI government markets and to commercial applications, which some private firms see as a good possibility. Several recommendations for overcoming industrial hesitancy to participation are suggested. First. MODIL might allow operation in a User Center mode, which would permit access to the optics industry on a fee basis. Second, MODIL should continue to assure industry that procedures have been implemented to protect competition-sensitive information, trade secrets, and proprietary data. Third, MODIL might consider developing technologies with more immediate commercial application in order to assist the Office of SDI in reaching its primary objective of order-of-magnitude cost reductions in SDI optics and its secondary objective of industry revitalization.

Research sponsored by the U.S. Department of Defense Initiative Organization.

\section{STRATEGIC PETROLEUM RESERVE EXPANSION}

\author{
R. Lee \\ P. N. Leiby \\ (Abstract of paper in Procedings of the 1989 North American Conference of the International Association \\ for Energy Economists, Oct. 16-18, 1989)
}

The Teisberg and Hogan-Leiby Oil Market Risk Analysis (OMRA) models are used to support the planning of Strategic Petroleum Reserve (SPR) size, oil acquisition, and withdrawal policies. Teisherg is a stochastic dynamic programming model which computes the pptimal SPR crude oil acquisition and drawdown rates. The Hogan-Leiby app roach uses a model of the world oil market within a risk analysis framework to provide guidance on related issues of optir al SPR size and management. Both models may be viewed as addressing SPR "staged decision making tinder uncertainty" in which decisions are made, events occur. 
and uncertaintics are resolved in stages over time. As such, they represent two contrasting methods of analyzing a wide class of public decision problems. The two general approaches are presented, and the prerequisites for placing them on a comparable footing are discussed. Numerical experiments with the Teisberg and Hogan-Leiby models have provided insight into SPR modeling and planning. With appropriate assumptions and constraints, the models hehaved very similarly in both base and disrupted market scenarios and they recommended similar size SPRs. However. there are key differences between the models. The OMRA model allows dynamic pricing and demand pattems, important energy market phenomena omitted from the Teisbery model. Also, the OMRA model is more helpful for assessing the risk of an SPR plan and can either buttress or undermine conclusions based solely on expected value analysis, which is used in the Teisherg model. On the other hand, the Teisberg dynamic programming approach provides information on optimal acquisition and drawdown rates. whereas the OMRA model takes the acyuisition rule as an input. As a result of their similarities and their differences, well structured. complementary use of the models is feasible and worthwhile. The numerical experiments also suggested some broad, preliminary conclusions regarding SPR planning.

\title{
$|7.2 .13|$
}

\section{MID-TFRM EVALUATION OF USAII)/ROCAP AND NRECA CENTRAL AMERICA RURAL ELECTRIFICATION SUPPORT PROGRESS}

\author{
R. D. Perlack \\ A. Garcia ${ }^{b}$ \\ H. G. Jones ${ }^{a}$ \\ E. Flores' \\ (Abstract of ORN1./IM-11567. Oak Ridge National Lahoratory, September 1990)
}

The Regional Office for Central America and Panama asked Oak Ridge National Laboratories to conduct a mid-term evaluation of the Cares Project, which is being implemented by the National Rural Electric Cooperative Association. This evaluation was conducted over a 3-weck period by a four-person team. Overall, the project has had numerous successes and is highly valued by local counterpart utilities and U.S. Agency for International Development missions. Notwithstanding the significant results of the project, changes in certain operating procedures and in the direction of some programmatic activities could lead to an even more effective project.

Research sponsored by the U.S. Agency for International Development.

“Oak Ridge Associated Iniversities.

"Texas A\&M Liniversity.

'Consultant, (ivatemalat.

\author{
G. G. Stevenson
}

(Abstract of paper in P'rocededings of an Internationel Workshop on Bumuss Fuel Briquetting in Developing Countries, Khartoum, Sudan, Oct. 23-26, 1988, COWlconsult, Virum, Denmark. April 1990)

As 63 of 95 developing countries struggle with fuelwood shortages. biomass briquelting may provide an important opportunity to alleviate the problem. Yet that opportunity has not been grasped adequately o date. The Agency for Interiational Development (AID)/Washington has embarged on a program to identify places where coal and hiomass briquelling may be commercially feasible. The approach of this program and some of the lessons leamed to date are summarized in this paper. With private sector hacking as an essential element to the approach outlined. preinvestment analysis is described in detail. The components of such an analysis include a resource assessment, a technological assessment, a financial competitiveness analysis, a market size estimate, consumer acceptance studies, a government policy assessment, and an assessment of private sector capabilities. The financial competitiveness analysis is the heart of this study, and a technique to determine which hiomass sources and markets can compete is described using a simple spreadsheet. The author has applied this type of analysis under AID funding in Haiti and Pakistam. Lessons learned from this 
experience are also documented. Most importantly, private sector participation. while difficult to muster, is crucial at the beginning stages of the preinvestment analysis. Where this is not possible due to private sector caution, the donor agency must commit itself to adequate information dissemination on the analysis results and to working closely with the private sector beyond the preinvestment analysis in product development, plant design, and market definition.

Research sponsored by the U.S. Agency for International Development.

\title{
[7.2.15] THE PRODUCTION, DISTRIBUTION, AND CONSUMPTION OF FUELWOOD IN HAITI
}

\author{
G. G. Stevenson
}

[Abstract of Journal of Developing Areas 24(1), 59-76 (October 1989)]

One contributor to the

deforestation that has

devastated Haiti is fuelwood

use, whose production,

distribution, and

consumption systems this

paper discusses.

Overexploitation in

fuelwood production results

both from open access land

use and landholders' high

discount rates. Charcoal

making in a given area

undergoes a boom-and-bust

cycle, resulting in a shifting

pattern of charcoal

production and

deforestation. Haiti's most desperately poor charcoal producers were able to carn only $\$ 6$ to $\$ 12$ (U.S.) for 23 days' labor in 1985. Besides producers, the charcoal distribution system involves collectors, transporters, wholesalers, and several types of retailers. These actors convey the charcoal to Pon-au-Prince wholesale markets, the neighborhood markets, and directly to households. Prices and gross margins for the various actors range widely, with retail selling prices for a gros sac $(38 \mathrm{~kg})$ of charcoal varying between $\$ 105$ and $\$ 158$ (U.S.) per metric ton in Port-au-Prince in 1985. The simpler commercial firewood distribution system services mainly urban commercial establishments. Regressions indicate that price, household income, family size, use of other fuels, and small-scale commercial aclivities practiced by houscholds determine residential chareoal use rates. Charcoal is shown to be a normal good; as income rises, charcoal use increases. Estimated price elasticities

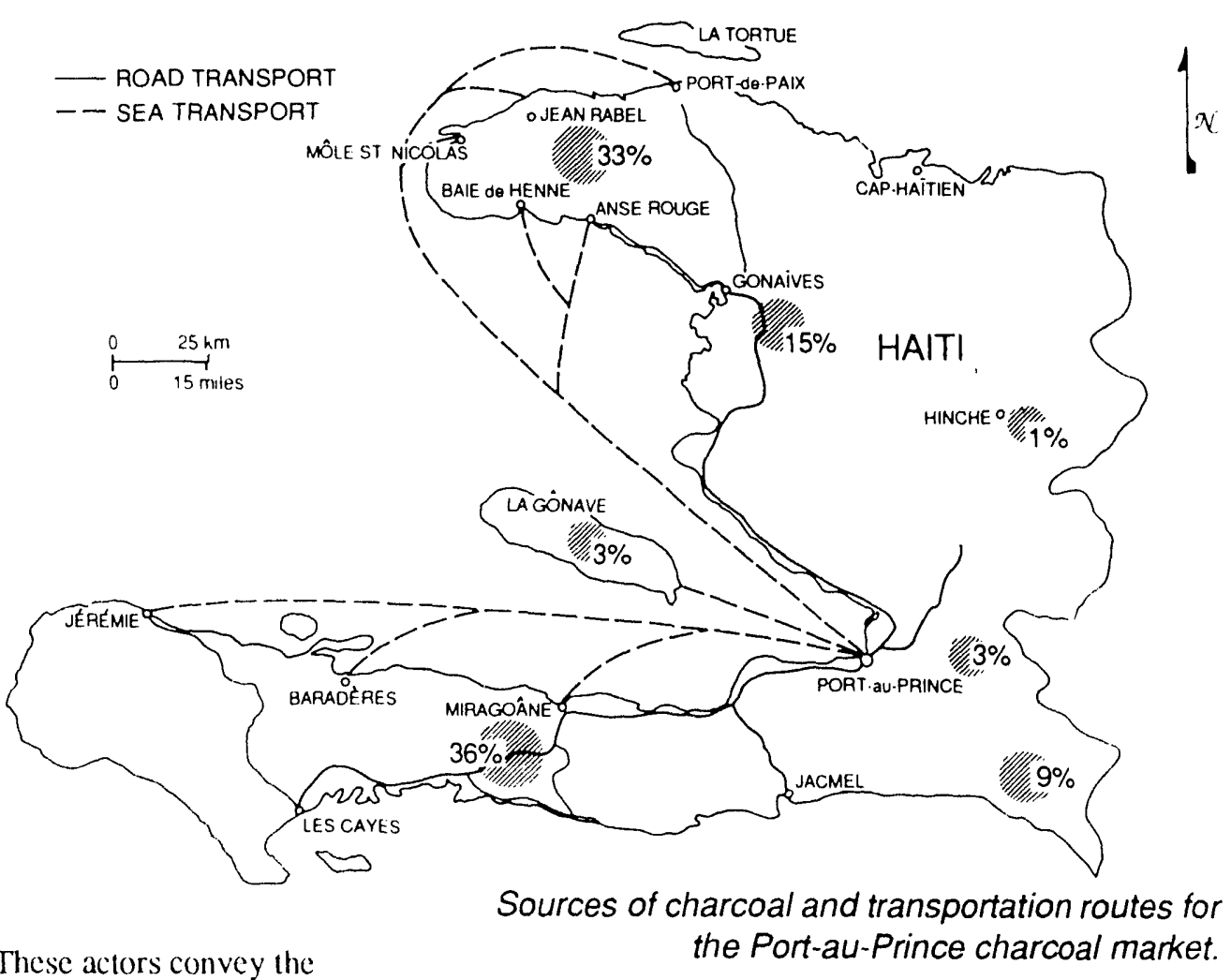

indicate inclastic demand for charcoal, except the highest priced charcoal (bought by the poor), which has elastic demand. Port-au-Prince firewood and charcoal market sizes and charcoal stove types and replacement rates are also discussed. The author concludes that fundamental solutions to Haiti's deforestation lic in changing property rights and reducing poverty, but that more accessible solutions involve the conventional means of charcoal taxation, the introduction of altemative fuels, improved appliances, and reforestation.

Research sponsored by the U.S. Agency for Intemational Development. 


\title{
7.3 ABSTRACTS OF CENTER FOR TRANSPORTATION ANAL YSIS
}

\section{PERSONAL COMPUTER BASED DECISION SUPPORT SYSTEM FOR ROUTING NUCLEAR SPENT FUEL}

\author{
S.-M. Chin \\ D. S. Joy ${ }^{a}$ \\ P. E. Johnson ${ }^{b}$ \\ S. M. Bobic ${ }^{c}$ \\ S.-P. Miaouc \\ (Abstract of pp. 90-100 in Proceedings of the TIMS 10th International DSS Conference: Information Technology \\ for Executives and Managers, Boston, May 1990)
}

A way to route nuclear spent fuel over the U.S. interstate highway nelwork has been formulated. This approach involves generating alternative routes so that any potential damage will not be concentrated along the shortest path between the nuclear power plant and repository. Extensive literature research on the shortest path-finding algorithms has been carried out.

Consequently, an extremely efficient shortest path algorithm has been implemented and significantly increases the overall system performance.

State-of-the-art interactive computer graphics are used.
In addition to casy-to-use pop-up menus, full color mapping and display capabilities are also incorporated. All of these features have been implemented on commonly available personal computers.

Research sponsored by the U.S. Department of Energy.

${ }^{4}$ Chemical Technology Division.

${ }^{b}$ Computing and Telecommunications Division.

'Transportation Research Center, the University of Tennessee, Knoxville.

\section{OB.JECT-ORIENTED PRUCGRAMMING IN TRAFFIC SIMULATION}

$$
\begin{aligned}
& \text { J. Rodriguez-Moscoso }{ }^{a} \\
& \text { S.-M. Chin } \\
& \text { A. J. Santiago }{ }^{b} \\
& \text { R. Roland }{ }^{c}
\end{aligned}
$$

(Abstrat of pp. 171 ..90 in Procedings of the 1989 Engine ering Foundation Conference, Santa Barbara, (alif, January 1990)

Object-oriented programming is a new style of computer programming that differs from conventionai structured programming in that solutions to problems are obtained as a more "natural" activity. Current implementations of traffic simulation models lack explicit representations of the assumptions made about the real world. Thus, they have become increasingly difficult to understand as new changes are added or new' modifications are made. An object-oriented approach to Iraffic simulation modeling will overcome some of these problems and promises to offer a new solution. This paper introduces, by means of examples, the concept of object-oriented programming and provides some starting considerations necessary to develop a general framework for building a traffic simulation tool based on the object-oriented paradigm of computer problem solving.

Reseasch sponsored by the U.S. Department of Transportation Federal llighway Administration.

\footnotetext{
“Vanderhill Lniversity, Nashville. Tennessee

tFederal Highway Administration

'The Lniversity of 'Tennessee.
} 


\title{
SQTTEXT: A TOOL FOR EDITING STRUCTURED QUERY LANGUAGE (SQL) TEXT WITHIN ORACLE SQL*FORMS APPLICATION
}

\author{
P. F. Daugherty \\ P. T. Singley
}

(Abstract of ORNL/IM-11639, Oak Ridge National Laboratory. August 1990)

SQTTEXT is an ORACLE SQL*Forms application that allows a programmer to view and edit all the Structured Query Language (SQL) text for a given application on one screen. This application is an outgrowth of a prototype on-line system dictionary for the Worldwide Household Goods Information System for the Transportation Modernization decision support system being prototyped by the Oak Ridge National Laboratory, but it can be applied to all SQL*Forms softw: e development, debugging, and maintenance. The system dictionary and SQTTEXT were written in version 2.3 of ORACLE's application generator. SQL*Forms. SQL*Forms greatly simplifies users' access to ORACLE databases, but the design of the tool should be friendlier to those programming, debugging, and maintaining SQL*Forms applications. Because SQL*Forms version 2.3 forces the programmer to view cach component of a program through a window specific to that component, it is impossible to get an overview of the whole application at one time. The SQTTEXT application allows expcrienced ORACLE programmers to increase their productivity by allowing access to all SQL text within an SQL*Forms application on one screen. The SQTTEXT application is based on the eight ORACLE Integrated Application Processor (IAP) tables that store information about SQL*Forms applications. The SQTTEXT application displays the trigger level, trigger name, SQL text associated with triggers, block names, base table names, and the SQI, text for WHERE/ORDER BY clauses. This report provides a step-by-step explanation of how to use SQTTEXT, descriptions of the IAP tables, and a listing of the SQTTEXT code. SQTTEXT is a very powerful tool for experienced ORACLE programmers who have at least a rudimentary understanding of the IAP tables. However, it should not be used by inexperienced users because it is possible to destroy inadvertently the relationships among the eight IAP tables.

Rescarch sponsored by the U.S. Department of Defense Military Traffic Management Command.

\section{[7.3.4] STRATEGIC MOBILITY MODELING AT OAK RIDGE NATIONAL LABORATORY}

\author{
R. G. Edwards \\ T. G. Yow \\ (Abstract of pp. 297-328 in Proceedings of RAND Corporation's Conference on Strategic Mobility Modeling: Status, Needs, and \\ Prospects, Santa Monica, Calif., January 1990)
}

This paper on strategic mobility modeling at Oak Ridge National Laboratory (ORNL) focuses on four ORNL projects: the Airlift Deployment Analysis System being developed for the Military Airlift Command; the Scheduling Algorithm for Improving Lift being developed for the Military Sealift Command; the Strategic Deployment System being developed for the Military Traffic Management Command; and the Flow and Analysis System for TRANSCOM. The topics to be covered for each of these projects include the initiatives that led to the development of the models, differences between new models and old models, new techniques being utilized, and problems that can be addressed now that could not be adequately addressed before.

Research sponsored by the U.S. Department of Defense. 


\title{
17.3.5] BONNEVILLE POWER ADMINISTRATION COMMIUNICATION ALARM PROCESSOR EXPERT SYSTEM: DESIGN ANI) IMPLEMENTATION
}

\author{
R. T. Goell \\ B. E. Tonn \\ S. L. Purucher \\ D. MacGregor \\ T. Wiggen ${ }^{a}$ \\ (Abstracl of UKN1 /1M-11323. Odk Ridge Nallomall dinialory. June 1990)
}

This report describes the Communications

Alarm processor, a prototype expen system developed for the Bonneville Power Administration by Oak Ridge National Laboratory. The system is designed to receive and diagnose alarms from Bonneville's Microwave Communications System. The prototype encompasses one of seven branches of the communications network and a subset of alarm systems and alarm types from each system. The expert system employs a backward chaining approach to diagnosing alarms. Alarms are fed into the expert system directly from the communication system via RS232 ports and sophisticated alarm filtering and mailbox software. Alarm diagnoses are presented to operators for their review and concurrence before the diagnoses are archived. Statistical software is incorporated to allow analysis of archived data for report generation and maintenance studies. The delivered system resides on a Digital Equipment Corporation VAX 3200 workstation and utilizes Nexpert Object and Statistical Analysis System for the expert system and statistical analysis, respectively.

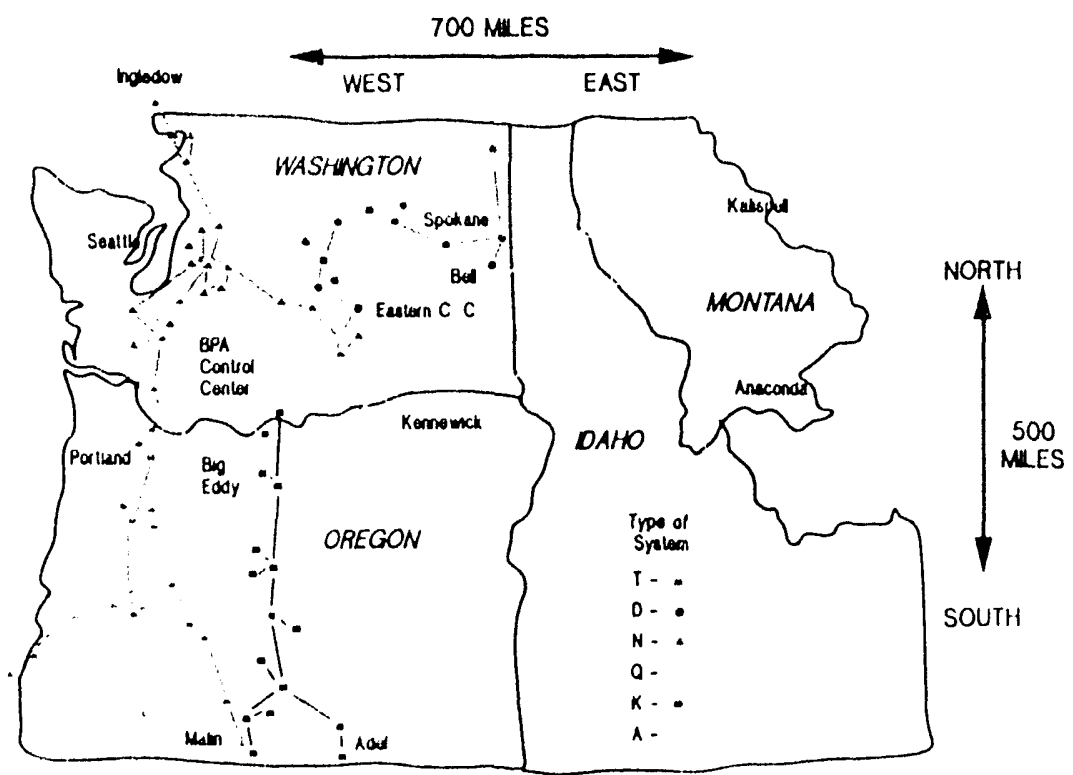

Bonneville Power Administration Microwave Communication System.

Research sponsored by Bonneville Power Administration.

"Oak Ridge Assoctated Linversities.

${ }^{b}$ Macciregor-Bates, Inc

\section{ENERGY EFFICIENCY IMPROVEMENT POTENTIAL. (SF COMMERCIAL.} AIRCRAFT TO 2010

\author{
D. L. Greene \\ (Abstract of ORNI.6622. Oak Ridge National laboratory, June ly90)
}

Aircraft are second only to motor vehicles in the use of motor fuels. Furthermore, air travel is growing twice as fast as highway travel. Clearly, the importance of energy use by commercial aircraft will continue to increase. Since 1970, air travel has more than tripled. but the growth of fuel use has been restrained by a near doubling of efficiency, from 26.2 seat miles per gallon (SMPG) in 1970 to aboul 49 SMPG in 1989. This paper explores the potential for future efficiency improvements via the replacement of existing aircraft with "1990s generation" and "post-20(0)" aircraft that incorporate advances til engine and airframe technology. Today, new conimercial passenger aircraft deliver from 50 to 70 SMPG. New aircraft types scheduled for delivery in the early 1990) are expected to achicve from 65 to 80 SMPG. Industry and government researchers have identified technologies capable of boosting aircraft efficiencies to the $1(x)-150$ SMPG range. Under current 
industry plans, which do not include a post-2000 generation of new aircraft, the total aircraft fleet should reach the vicinity of 65 SMPG by 2010 . If a new generation of 100-150 SMPG aircraft were introduced in 2005, the fleet average efficiency could rise to 75 to
$80 \mathrm{SMPG}$ in 2010 . In any case, fuel use will likely continue to grow at from $0.8 \%$ per year to $1.8 \%$ per year through 2010.

\title{
SHORT TERM OPTIONS FOR CONTROLLING $\mathrm{CO}_{2}$ EMISSIONS OF LIGHT DUTY VEHICLES
}

\author{
D. L. Greene \\ [Abstract of paper in Society of Automotive Engineers, Inc., Ser. 901111, 1-15 (May 1990)]
}

Automobiles and light trucks are important sources of greenhouse gases, particularly carbon dioxide $\left(\mathrm{CO}_{2}\right)$. Continued fuel economy improvements for these vehicles, using available, cost-effective, marketable fuel economy technology, can hold $\mathrm{CO}_{2}$ emissions constant through the year 2000 . An aggressive effort to improve fuel economy through 2001 could hold $\mathrm{CO}_{2}$ emissions in 2015 near present levels. $\mathrm{CO}_{2}$ emissions can be reduced by controlling the growth of vehicle travel, but this is likely to be a very costly strategy. Recent trends, such as declining new car mpg, increasing market share of light trucks, and a growing gap between federal test mpg levels and on-road performance, indicate that a $50 \%$ increase in light duty vehicle $\mathrm{CO}_{2}$ emissions by 2015 is not out of the question.

Research sponsored by the U.S. Department of Energy Office of Policy, Planning and Analysis, Office of Policy Integration.

\section{ALTERNATIVE MOTOR FUEL USE MODEL}

\author{
D. L. Greenc \\ A. Rathi ${ }^{a}$ \\ (Abstract of ORNL/IM-11448, Oak Ridge National Laboratory, April 1990)
}

The Alternative Motor Fuel Use model (AMFU) is a tool for the analysis and prediction of highway vehicle motor fuel use. The model advances the art of vehicle stock modeling by including a representation of the choice of motor fuel for flexible and dual fuel vehicles. Part one of the report is a user's guide to the operation of the model. Part two describes the model's structure and the theory of vehicle stock modeling of energy use on which it is based. The model is designed for IBM PCs, $\mathrm{PC} / \mathrm{XTs}, \mathrm{PC} / \mathrm{ATs}, \mathrm{PS} / 2 \mathrm{~s}$, and compatibles. It is written in compiled BASIC, and data are entered via automated, menu driven spreadsheets. From within the spreadsheets users can define the dimensions of a forecast, the types of vehicle technologies, and the fuels used. The AMFU model can be run for one or many vehicle types (e.g., automobiles, light trucks, heavy trucks) simultaneously. The effort involved in creating the data tables required for a model run is substantial.

Research sponsored by the U.S. Department of Energy Office of Policy, Planning and Analysis, Office of Policy Integration.

${ }^{a}$ The University of Tennessee. 


\title{
CAFE OR PRICE? AN ANALYSIS OF THE EFFECTS OF FEDERAL FUEL ECONOMY REGULATIONS AND GASOLINE PRICE ON NEW CAR MPG, 1978-89
}

\author{
D. L. Greene \\ |Abstract of Energy Journal 11(3), 37-57 (Septenther 1990)|
}

Following a trip'ing of world oil prices in 1973-74. the U.S. Congress passed the Energy Policy and Conservation Act of 1975, which established mandatory fuel economy standards for automobiles and light trucks. Beginning at $18 \mathrm{mpg}$ in 1978, the passenger car standards increased to $27.5 \mathrm{mpg}$ by 1985 . There has been considerable debate about the influence of the standards, as opposed to the gasoline price increases in 1973-74 and 1979-80, on new car fuel economy. Twelve years of average 1 , ' economy data are now available for every manufacturer's domestic and imported car fleets, making possible a statistical estimation of the relative importance of standards versus fuel prices in determining new car mpg. In this paper a penalty function is for nulated in which deviations from either the standard or from the market equilibrium demand for fuel economy create costs for manufacturers. An equation for new car mpg is derived by minimizing the surn of quadratic penalty functions. Estimation of the model using 15 sets of manufacturer Corporate Average Fuel Economy (CAFE) data for 1978-89 clearly indicates that the CAFE standards were a significant constraint for many manufacturers, and were perhaps twice as important an influence as gasoline prices. A test for structural change in the model does not reject the hypothesis that the CAFE constraint had the same effect on carmakers before and after 1983.

Research sponsored by the U.S. Department of Energy Office of Policy. Planning and Analysts, Office of Policy Integration.

\section{COMMERCIAL AIRCRAFT FUEL EFFICIENCY POTENTIAL THROUGH 2010}

\author{
D. L. Greene
}

(Abstract of a paper in Procedings of the 1990) Intersoctety Energ. Converston Engineering Conference'. American Institute of Chemical Engineers, Reno. Nev., August 1990)

Aircraft are second only to motor vehicles in the use of motor fuels, and air travel is growing twice as fast. Since 1970 air travel has more than tripled, but the growth of fuel use has been restrained by a near doubling of efficiency, from 26.2 seat miles per gallon (SMPG) in 1970 to about 49 SMPG in 1989. This paper explores the potential for future efficiency improvements via the replacement of existing aircraft with "1990s generation" and "post-2(v0)" aircraft that incorporate advances in engine and airframe technology. Today, new commercial passenger aircraft deliver 50 to 70 SMPG. New aircrati lypes scheduled for delivery in the early 1990s are expected to achieve 65 to 80 SMPG. Industry and government researchers have identified technologies capable of boosting aircraft efficiencies to the 100-150 SMPG range. Under current industry plans, which do not include a post-2000 generation of new aircraft, the total aircraft fleet should reach the vicinity of 65 SMPG by 2010. A new generation of 100-150 SMPG aircraft introduced in 2005 could raise the fleet average efficiency to 75-80 SMPG in 2010. In any case, fuel use will likely continue to grow at from $1102 \%$ per year through 2010 .

Research sponsored by the U.S. Department of Energy Office of Policy. Planning. and Analysis, Office of Policy Integration. 


\title{
[7.3.11] NAVY MOBILITY FUELS FORECASTING SYSTEM PHASE VI REPORT: IMPACTS OF A MILITARY DISRUP'TION ON NAVY FUEL AVAILABILITY AND QUALITY
}

\author{
G. R. Hadder \\ R. M. Davis
}

(Abstract of ORNL-6637, Oak Ridge National Laboratory, September 1990)

The Refinery Yield Model of the Navy Mobility

Fuels Forecasting System has been used to study the impacts of a severe military disruption on the production of Navy JP-5 jet fuel and F-76 marine diesel fuel in the year 1995. The global petroleum supply reduction caused by the disruption would be about $40 \%$ of the normal supply. Regional production cost increases for JP- 5 would be between $\$ 3$ and $\$ 11 /$ gal during the disruption. For F-76, the production cost increases would be between $\$ 3$ and $\$ 5 / \mathrm{gal}$. The disruption would cause substantial degradations for certain fuel quality properties of F-76 produced in the Pacific basin and in southern Europe. During both normal and disrupted production times, the most prevalent Navy fuel quality problem would be F-76 instability caused by high levels of light cycle oils.

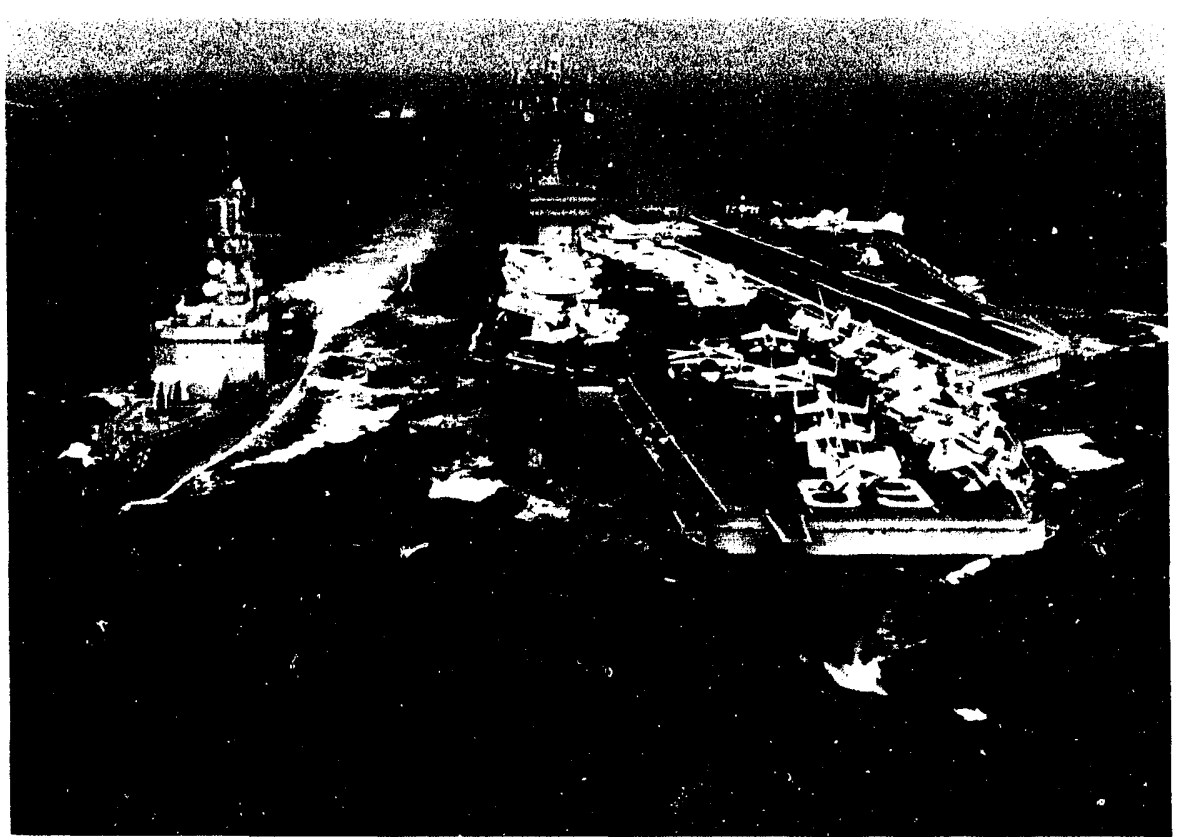

Researchers examined the effects of several economic-political scenarios on the availability of Navy mobility fuels, which power strategic assets like this aircraft carrier and its support ships.

Research sponsored by the U.S. Department of the Navy Office of Naval Research, Navy Energy and Natural Resources R\&D Division.

\section{NAVY FUEL PRODUCTION DURING A MIDDLE EAST POLITICAL DISRUPTION}

\author{
G. R. Hadder \\ S. Das \\ P. N. Leiby \\ R. Lee
}

R. M. Davis ${ }^{a}$

|Abstract of Energy 14(12), 965-66 (December 1989)]

Given the uncertainties of oil markets, military planners have recognized the need for a methodology to analyze mobility fuel production. This note summarizes the results of using such a methodology to estimate the production of Navy mobility fucls in a politically motivated oil supply disruption scenario. The methodology, which is called the Navy Mobility Fuels Forecasting System, consists of three models: (1) the econometric Oil Market Simulation Model, which estimates the price at which global supply and demand for oil are in balance; (2) the Petroleum Allocation (PAL) Model, a linear program used to estimate global petroleum movements for different market scenarios; and (3) the Refinery Yield Model, a linear program employed to represent regional refining operations. The Navy Mobility Fucls Forecasting System was used to estimate the production of Navy jet fuel JP-5 and marine diesel fuel F-76 during a politically based disruption scenario in the year 1995. Persian Gulf, Libyan, and Algerian exports of crude oil and refined products would 
decrease by 50\% (a loss of $8.9 \mathrm{MBD}$ ) and output from other Organization of Petroleum Exporting Countries members would surge to maximum capacity (a gain of (0.4 MBD) during the disruption. Strategic petroleum reserves would be reduced in both the United States and Japan, at 4.5 MBD and 0.9 MBD, respectively. There would be no net changes in privately held petroleum inventories. The net total supply loss would be 3.1 MBD. Several issues with potentially important policy and research implications emerged in this study. A steep decline in JP-5 preduction is projected for the political disruption, with stable jet-fuel price differentials (the jet-fuel price differential is defined as the refiners" price of JP-5 minus the refiners' price of ute civilian kerosene jet fuel). At constant regional jet-fuel price differentials the production of JP-5 in the study regions during the disruption would fall by almost $90 \%$. With adjustments of the jet-fuel price differential, refiners would probably be able to satisfy the demand for JP-5 in the disruption. The monetary outlays for JP-5 purchases during the disruption are estimated to be about twice the normal outlays, with the bulk of the expense attributable to increased crude oil feedstock prices. The sulfur content of JP-5 is predicted to rise substantially, relative to today's fuel. The sulfur increase could be caused by a combination of factors including refinery feedstocks, process utilization, and product slate constraints, such as the ultra-low-sulfur levels in U.S. civilian diesel fuel in 1995. Large increases in jet fuel sulfur might adversely affect fuel storage stabilit $v$, combustion, and corrosivity. Production of F-76 is limi ed in a majority of cases by sulfur content. Large incri ases in diesel fuel sulfur might adversely affect engi ie performance and fuel storage stability. Navy fuel availability can be increas'd through either the price mechanism or property modifications. During the projected disruption, the production of JP-5 was most frequently limited by flash point. F-76 production was limited most frequently by sulfur content and flash point.

Research sponsored by the U.S. Department of the Navy Office of Naval Research, Navy Energy and Natural Resources R\&D Division.

${ }^{a}$ Central Management Office.

\title{
[7.3.13] U:JDERSTANDING THE COMPUTING SYSTEM DOMAIN OF ADVANCED COMPUTING WTI II MICROCOMPUTERS
}

\author{
K. A. Hake \\ (Ahstract of Sect. 13 in Proceedings of the Advanced Computing for the Social Sciences Conference, Williamsburg, Va., April 1990)
}

This paper provides social scientists with a general hackground in the area of advanced microcomputers. The concept of systems integration serves as a framework for understanding the various elements of advanced microcomputing. The systems integration framework is viewed as a series of interrelated building blocks composed of the processor platform, operating system, display technology, mass storage, application software, and $\mathrm{h}$ sman-computer interface. References from recent articles in popular magazines and journals help emphasize the easy access of this information, its appropriate technical leyel for the social scientist, and its currency.

Research sponsored by the U.S. Department of the Army.

\section{[7.3.14] INCORPORATING GISs INTO DECISION SI,PPORT SYSTEMS: WHERE HAVE WE COME RROM AND WHERE DO WE NEED TO GO?}

R. B. Honea
K. A. Hake
R. C. Durfee

(Abstract of pp. 215-19 in Preceedings of the GIS ' C) Meetings, Vancouver, Canada, March 1990)

Based on 20 years of university, government, and private industry experience with the design, use, and tallure of geographic intormation systems (Gilss), we have some observations and advice concerning the future dir stions of GIS development. This paper reviews some of the problems in the design and use of GISs that we have encountered with both iarge and smaii projects for a variety of sponsors. Our lineage can be traced back 
to the precomputer GIS era, when mylar overlays on maps constituted the principle means for conducting evaluation, through the 1960s and 1970s, when the principle analysis engine was the IBM 360 and 3090, to today when the "mini" and the "micro" are viewed as all one really needs to "do Gis work." We have had our eye-opening and horrifying experiences with all of these and believe the future value of GISs lies not in the realm of the technology itself but rather in the role that they play as one significant part of much larger decision support systems. This paper, therefore, may be viewed in part as a statement of beliefs or convictions that may be contrary to others' opinions regarding the role of GISs in the decision-making process. The stand-alone, self-sufficient GIS prevalent today does not adequately meet the needs of decision support systems. Developers of these systems are left with the difficult task of software system integration, which generally produces less than adequate results. Modularization of GIS concepts is critical to the solution, which involves the establishment of a GIS toolkit. More functionality and flexibility are introduced through this approach so that GISs may be truly "applied" in system development projects.

Research sponsored by the U.S. Department of Energy.

${ }^{a}$ Central Management Office.

${ }^{b}$ Computing and Telecommunications Division.

\title{
A COMPARATIVE STUDY OF SIX DATA SOURCES' ABILITY FOR ESTIMATING INTERSTATE MOTOR CARRIER VMT
}

\author{
P. S. Hu \\ T. Wright ${ }^{a}$ \\ S.-P. Miaou ${ }^{b}$
}

(Abstract of pp. 29-34 in Proceen 7gs of the 1989 American Statistical Association's Annual Meeting. Washington, D.C., May 1990)

Several federal government agencies require estimates of vehicle miles of travel (VMT) by interstate commercial trucks. These estimates are essential in determining accident exposure and accident rates for these trucks and in determining highway investment needs and the allocation of highway costs. VMT estimate; are currently based on various nationwide transportation surveys and data sources and on various estimation procedures. Unfortunately, these data sources and es imation procedures do not provide consistent estimates. A summary of evaluation results of these data sources and estimation procedures is presented in this paper.

Research sponsored by the U.S. Department of Transportation, Federal Highway Administration.

${ }^{a}$ Engineering Physics and Mathematics Division.

${ }^{b}$ The University of Tennessee.

\section{[7.3.16] ESTIMATING COMMERCIAL TRUCK VMT OF INTERSTATE MOTOR CARRIERS:} DATA EVALUATION

\author{
P. S. Hu \\ S.-P. Miaou ${ }^{b}$ \\ T. Wright ${ }^{a}$ \\ S. C. Davis ${ }^{b}$ \\ D. J. Beal ${ }^{b}$ \\ (Abstract of ORNL/IM-i1278, Oak Ridge National Laboratory, November 1989)
}

Several federal government agencies require estimates of vehicle miles traveled (VMT) by interstate comm " $"$ al vehicles. These estimates are essential in determining accident exposure and accident rates for these vehicles and in determining highway investment needs and the allocation of highway costs. VMT estimates are currently based on various nationwide transportation surveys and data sources and on various estimation procedures. Unfortunately, these data sources and estimation procedures do not provide consistent estimates. The evaluation results of six data sources are summarized in terms of their abilities to estimate the number of commercial trucks operating in interstate commerce and their VMT by carrier type and by state. Although several attempts were made in this study to combine the strengths of different data sources so that all 
indicators could be synthesized and reliable estimates might be generated, none was successful. Currently. there are three main obstacles in the attempt to synthesize different data sources: (1) at present, information at the state level is either incomplete or insufficient: (2) the data sources are incompatible in many areas, which limits the efforts to bring together the strengths from different sources; (3) complete results from the 1987 Truck Inventory and Use Survey (TIUS) are not available. The Nationwide Truck Activities and Commodity Survey has not been implemented, and state fuel tax (or IFTA) and the Installation Restoration Program (IRP) are not readily obtainable. The outlook of these six data sources in terms of their developments in the future are that (1) TIUS will be conducted every
5 years; (2) the Highway Performance Monitoring System will be available every year, (3) it is likely to be a long process before all states become members of IRP/IFTA; (4) the Nationwide Truck Activities and Commodity Survey's future is likely to depend on the extent of users' support; and (5) the National Truck Trip Information Survey's future is subject to funding availability.

Research sponsored by the U.S. Department of 'Transportation, Federal Highway Administration.

${ }^{a}$ Engineering Physics and Mathematics Division.

${ }^{b}$ The University of Tennessee.

TRANSPORTATION ENERGY DATA BOOK: EDITION 10
S. C. Davis ${ }^{a}$
D. B. Shonka ${ }^{b}$
G. Anderson-Batiste
P. S. Hu

(Abstract of ORNL-6565, Oak Ridge National Laboratory, October 1989)

The Transportation Energy Data Book: Edition 10 is a statistical compendium prepared and published by Oak Ridge National Laboratory under contract with the Office of Transportation Systems in the U.S. Department of Energy. Designed for use as a desk-top reference, the data book represents an assembly of statistics and information that characterize transportation activity and presents data on other factors that influence transportation energy use. The purpose of this document is to present relevant statistical data in the form of tables and graphs. Each of the major transportation modes-highway, air, water, rail, pipeline-is discussed in separate chapters or sections. Chapter 1 compares U.S. transportation data with data from seven other countries. Aggregate energy use and energy supply data for all modes are presented in Chap. 2. The highway mode, which accounts for more than three-fourths of total transportation energy consumption, is dealt with in Chap. 3. Topics in this chapter include automobiles. trucks, buses, fleet automobiles, federal standards, fuel economies, and household data. The last chapter, Chap. 4, covers each of the nonhighway modes: air, water, pipeline, and rail, respectively.

\footnotetext{
Research sponsored by the U.S. Department of Energy Office of Transportation Systems.

${ }^{a}$ The University of Tennessee.

${ }^{b}$ Shonka Research Associates, Inc., Marietta, Creorgia.
}

\title{
[7.3.18] LIGHT-DUTY VEHICLE MPG AND MARKET SHARES REPORT: MODEL YEAR 1989
}

\author{
L. S. Williams ${ }^{a}$ \\ P. S. Hu \\ (Abstract of ORNL,-6626, Oak Ridge National laboratory, April 1990)
}

This issue of Light-Duty Venicle MPG and Market Shares Report: Model Year 1989 reports the estimated sales-weighted fuel economies, sales. market shares, and other vehicle characteristics of automobiles and light trucks. The estimates are made on a make and model basis (e.g., Chevrolet is a make and (orsica is a model). from model year 1976 to model year 1989 . Vehicie sales data are used as weighing factors in the sales-weighted estimation procedure. Thus, the estimates represent averages of the overall new vehicle flect, reflecting the composition of the fleet. Highlights are provided on the trends in the venicie characteristics from one moxiti year 
to the next. Analyses are also made on fuel economy changes to determine what caused the changes. Both new automobile and new light truck fleets experienced fuel economy losses of $0.5 \mathrm{mpg}$ from the previous model year, dropping to $28.0 \mathrm{mpg}$ for automobiles and $20.2 \mathrm{mpg}$ for light trucks. This is the first observed decline in fuel economy in new automobiles since model year 1983 and the largest decline since model year 1976. Every automobile size class showed either losses or no change in their fuel economies. Two popular size classes of light trucks, the large pickup and the small utility vehicle, both experienced losses in their fuel economies. Overall, the sales-weighted fuel economy of the entire light-duty vehicle fleet (automobiles and light trucks) dropped to $25.0 \mathrm{mpg}$, a reduction of $0.5 \mathrm{mpg}$ from model year 1988. For the first time since model year 1985 , total sales of light-duty vehicles fell below 15 million units. Despite record high light truck sales, automobile sales opped for the third consecutive year. Corsuently, the trend of light trucks gaining a larger portion of the entire new light-duty vehicle market continued, reaching a record high of $31.9 \%$ in model year 1989.

Research sponsored by the U.S. Department of Energy Office of Transportation Systems.

${ }^{a}$ The University of Tennessee.

\title{
LIGHT-DUTY VEHICLE SUMMARY: FIRST SIX MONTHS OF MODEL YEAR 1990
}

\author{
L. S. Williams ${ }^{a}$ \\ P. S. Hu
}

(Abstract of ORNL-6626/S1, Oak Ridge National Laborâtory, July 1990)

This summary includes the most recent fuel economy and market share data for the new light-duty vehicle fleet. Model year 1990 fuel economies are weighted based on the sales of the first 6 months of model year 1990 (from September 1989 to March 1990).

Sales-weighted fuel economy of all new automobiles decreased in the first 6 months of model year 1990, from $28.0 \mathrm{mpg}$ in model year 1989 to $27.7 \mathrm{mpg}$. The compact, midsize, and large size classes, which together claimed $75 \%$ of the new automobile market, each showed fuel economy declines of $0.4 \mathrm{mpg}$ or more. Unlike automobiles, new 1990 light trucks showed an overall $0.4 \mathrm{mpg}$ gain from model year 1989. This increase was primarily caused by the increased fuel economy of the small van size class. In the first half of model year 1990, small vans replaced small pickups as the second most popular light trucks. Although the fuel economy of light trucks improved, the larger market share of automobiles in the light-duty vehicle market (automobiles and light trucks combined) and the decreased fuel economy in automobiles resulted in an overall reduction of $0.2 \mathrm{mpg}$ for the entire light-duty vehicle fleet in the first half of model year 1990. Also, in the first half of model year 1990, light trucks claimed more than $33 \%$ of the light-duty vehicle market-a considerable increase from their $19.8 \%$ share in 1976.

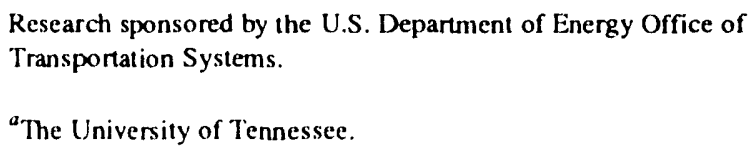

${ }^{a}$ The University of Tennessee.

\section{IIAA: A PROTOTYPE CAI SYSTEM IN MILITARY TRANSPORTATION}

\author{
H.-L. Hwang \\ C. Trammell ${ }^{a}$ \\ D. Valentine ${ }^{a}$
}

(Ahstract of pp. 80-88 in Procedings of the Third International Conference on Microcomputers in Transportation, American Society of (ivil Engineers, San Francisco, June 1990)

A microcomputer-based database management system, the Installation Transportation Offices-Military Traffic Management Command (ITO/MTMC) Interface Module. was developed hy researchers at Oak Ridge National Laboratory. The oystem helps staff at the
United States Army ITOs prepare cargo-related movement requirements under the MTMC. Release 1 of the Interface Module was sent out to 24 Army installations from May to October 1987. On-site, perwon to persen consultation sessions were conducted 
to teach each ITO user how to use this new automated system. Follow-up evaluations on this deployment procedure revealed two important issues. First, the deployment process was too costly and time consuming. Second, many users retained their knowledge for only a very short time, so frequent reviews and retraining seem unavoidable. To reduce the cost and time associated with on-site training, but to retain the advantage of a one-to-one learning environment, a computer-aided-instruction (CAI) approach was proposed. This CAI system is designed for the deployment ? Release 2, a major system upgrade of the ITO/MTMC Interface Module. Using a commercially available authoring software, the ITO Deployment Assistant (IDA) was developed on the IBM/PC and compatibles. This paper describes characteristics of the IDA system. Examples are shown to demonstrate the actual use of the system. The design concept for CAI systems in the military environment is presented, and experiences and lessons learned from the IDA prototyping effort are discussed.

Research sponsored by the Military Traffic Management Command.

${ }^{a}$ The University of Tennessee.

\title{
MODIFIED SEASONAL FACTORS IN EXPONENTLAL SMOOTHING
}

\author{
J. S. Armstrong ${ }^{a}$ \\ H.-L. Hwang \\ J. Bandy ${ }^{b}$
}

(Abstract of ORNL/M-1262, Oak Ridge National Laboratory, September 1990)

Current practice uses statistical tests to determirie whether seasonal factors should be applied in a given forecasting situation. Research suggests that an optimal policy might lie somewhere between using full seasonal factors and using no seasonal factors on series. This research proposes and tests a modified seasonal factor. Modified seasonal factors reduce the emphasis on the seasonal adjustments when forecasts are made. The adjustments account for errors in the estimation of the factors and for possible changes in the factors over the forecast horizon. Data from U.S. Navy personnel inventories were analyzed to test the use of a modified seasonal factor. Modificd seasonal factors led to improved accuracy for predictions of inventories by paygrade using quarterly data from the Navy Personnel Research and Development Center. Under certain selections of factors, the mean absolute percent error was reduced by $4.4 \%$. No gain was obtained, however, for the inventories by length of service. It is expected, but not shown here, that the modified seasonal factors will only be of value for series where the estimated seasonal factors show a substantial variation across the year.

Research sponsored by the U.S. Department of the Navy, Navy Personnel Research and Development Center.

"The Wharton School, University of Pennsylvania.

${ }^{b}$ The University of Tennessee.

\section{QUALITY ASSURANCE (QA) PLAN FOR THE AIRLIFT DEPLOYMENT ANALYSIS SYSTEM (ADANS)}

\author{
R. S. Loffman \\ L. F. Truett \\ (Abstract of ORNL.M-1250, Oak Ridge National Laboratory, September 1990)
}

Development of the Airlift Deployment Analysis System (ADANS) at Oak Ridge National Laboratory (ORNL) began in 1986. When fully implemented in 1992, ADANS will provide Headquarters, Military Airlift Command with an automated airlift planning and scheduling system. ADANS will be operational through at least the year 2000. This Quality Assurance (QA) plan will be used by the ADANS team at ORNL to ensure that the ADANS software development project results in a high-quality product completed on time and within budget. The plan defines the program elements to be considered under QA management, the responsibilities of each individual concerned, the 
acceptance criteria, and a schedule for QA program element reviews. Forms for maintaining appropriate QA records are also included.
Research sponsored by the U.S. Deparument of Defense Military Airlift Command.

\title{
[7.3.23] A TECHNICAL DESCRIPTION OF ENHANCEMENTS TO THE FRONT-END INTERFACE FOR THE WHIST-MOD
}

\author{
J. P. Loftis \\ T. L. James ${ }^{a}$ \\ M. P. Spears
}

(Abstract of ORNL/TM-1 1595. Oak Ridge National Laboratory, August 1990)

The Directorate of Personal Property of the Military

Traffic Management Command (MTMC) asked Oak Ridge National Laboratory (ORNL) to design a decision support system, the Worldwide Household Goods Information System for Transportation Modernization (WHIST-MOD). This decision support system will automate tasks and provide analytical tools for evaluating the Personal Property Program, predicting impacts to the program, and planning modifications to meet the evolving needs of military service members and the transportation industry. The system consists of three modules: system dictionary applications, data acquisition and administration applications, and user applications. The user applications module is dividad into two phases, the data selection front-end interface and the postprocessing back-end interface. This paper describes the prototyped front-end interface using ORACLE SQL*Forms, part of the ORACLE Relational Database Management System toolset. We discuss the need for enhancements to the initial interface design and the coding techniques used to prototype the enhancements. These enhancements make the front-end interface more flexible and easier to use by giving users options for identifying data to be used by the back-end interface. Our report is based on in-depth interviews of MTMC staff, prototype mectings with the users, and the research and design work conducted at ORNL.

Research sponsored by the U.S. Department of Defense Military Traffic Management Command.

${ }^{a_{a}}$ The University of Tennessee.

\section{A CONCEPTUAL DESIGN FOR A GRAPHICS OUTPUT INTERFACE FOR THE WHIST-MOD}

\author{
J. P. Loftis \\ T. L. James ${ }^{a}$ \\ (Abstract of ORNL/TM-1 1627, Oak Ridge National Laboratory, August 1990)
}

The Directorate of Personal Property of the Military Traffic Management Command (MTMC) requested that Oak Ridge National Laboratory (ORNL) design and prototype a decision support system, the Worldwide Household Goods Information System for Transportation Modemization (WHIST-MOD). This decision support system will automate current tasks and provide analytical tools for evaluating the Personal Property Program, predicting impacts to the program, and planning modifications to meet the evolving needs of military service members and the transportation industry. The system consists of three modules: system dictionary applications, data acquisition and administration applications, and user applications. The development of the user applications module is divided into two phases. Round 1 is the data selection front-end interface, and Round 2 is the output or back-end interface. This report describes the conceptual design for the back-end output interface of the user applications module, which will be prototyped using SAS, a data management and statistical analysis toolset. This report discusses our goals for the back-end interface and describes how we plan to meet 
these goals. Our design fulfills the users' needs for a flexible interface that can be used to produce a variety of tabular and graphical outputs.
Research sponsored by the U.S. Department of Defense Military

Traffic Management Command.

a' The University of Tennessee.

\title{
PROVIDING DYNAMIC SORTING AND SEARCHING; CAPABILITIES USING SQL*FORMS
}

\author{
J. P. Loftis \\ (Abstract of pp. 303-09 in Proceedings of the International ORACLE Users Group Mecting, Anaheim, Calif., September 1990)
}

One of the goals of software system developers is to build a front-end that can retrieve and display data in different ways, depending on the current needs of the user. This paper describes two techniques that are being used for a design prototype system under development at Oak Ridge National Laboratory that provide casy interactive capability between the user and the database using ORACLE's SQL*Forms. The first technique explains how to build an ORACLE application that allows users to decide whether they would like a subset of data retrieved to a multi-record display form, and if so, to define the boundaries for the subset. The second technique allows users to choose how these displayed data will be sorted. Neither of the techniques requires the user to understand Structured Query Language (SQL) or the underlying database structure of table and column names.

Research sponsored by the U.S. Department of Defense Military Traffic Management Command.

BUILDING A USER-FRIENDLY DATA DICTIONARY SYSTEM IN ORACLE

\author{
J. P. Loftis \\ W. E. Friggle ${ }^{a}$ \\ (Abstract of pp. 439-44 in Proceedings of the International ORACLE Users Group Meeting, Dallas, October 1989)
}

Oak Ridge National Laboratory is designing and prototyping a decision support system for the Military Traffic Management Command using ORACLE and SQL*NET. This system will support up to 50 users on microcomputers connected via an ethemet local area network to a central database on a workstation. We have emphasized data administration to maintain high quality data. At the heart of this system is a set of ORACLE-based data dictionary tools. This paper discusses the current theory for developing an active data dictionary that is an integral part of the entire life cycle of a system. This includes a discussion of what data are of interest to the developers, users, and system administrators and how this information can be presented in a useful form to both novice and educated users. The data dictionary is a powerful end-user $t(x)$ l that provides decision makers who may not understand the data structure with information about the database and its contents. The data dictionary prototype will provide end users with descriptive text about the data elements, entities, and their relationships; indicators of data quality, consistency, and accuracy; and information about where data are being used (i.c., reported). This information will be available through a menu-driven toolset that requires no previous knowledge of data dictionary components or database file structures. For database administrator and system managers, the data dictionary will provide information about data and table usage (through ORACLE audit functions); data source documents, files, formats, and source systems; and system activity profiles. The data dictionary is currently in the design phase and some prototyping has already begun, using a UNISYS port of ORACLE to supplement the design process. The final version will be prototyped in ORACLE 6.0 on the UNIX-based SUN workstation.

\footnotetext{
Research sponsored hy the Li.S. Department of Defense Military Traffic Management Command.

The University of Tennessee.
} 


\title{
USER INTERFACE IN ORACLE FOR THE WORLDWIDE HOUSEHOLD GOODS INFORMATION SYSTEM FOR TRANSPORTATION MODERNIZATION (WHIST-MOD)
}

\author{
T. L. James ${ }^{a}$ \\ J. P. Loftis \\ (Abstract of ORNL/IM-11596, Oak Ridge National Laboratory, July 1990)
}

The Directorate of Personal Property of the Military

Traffic Management Command (MTMC) requested that Oak Ridge National Laboratory (ORNL) design a prototype decision support system, the Worldwide Household Goods Information System for Transportation Modernization. This decision support system will automate current tasks and provide analytical tools for evaluating the Personal Property Program, predicting impacts to the program, and planning modifications to the program to meet the evolving needs of military service members and the transportation industry. The system consists of three modules: system dictionary applications, data acquisition and administration applications, and user applications. The development of the user applications module is divided into two phases. Round 1 is the data selection front-end interface, and Round 2 is the output or back-end interface. This report describes the prototyped front-end interface for the user application module. It discusses user requirements and the prototype design. The information contained in this report is the product of in-depth interviews with MTMC staff, prototype mectings with the users, and the research and design work conducted at ORNL.

Research sponsored by the U.S. Department of Defense Militan' Traffic Management Command.

${ }^{a}$ The University of Tennessee.

\author{
A. K. Rathi \\ A. J. Santiago ${ }^{a}$
}

[Abstract of Traffic Engineering and Control 31(6), 351-55 (June 1990)]

This paper describes an enhancement to the TRAF-NETSIM simulation model. The enhancement allows users to simulate with identical traffic streams through a series of runs. Thus, the user can make a series of simulation runs by retaining the traffic stream of an initial run while simulating under different traffic control or operational conditions in subsequent runs. The representation of stochastic behavior in the TRAF-NETSIM simulation model is described and the need for the generation of identical traffic streams is discussed. The two approaches considered in implementing this feature and the program modifications necessary to implement the selected approach are described. Some representative simulation results are presented and the applications and limitations of the identical traffic streams feature are discussed.

Research sponsored by the U.S. Department of Transportation Federal Highway Administration.

${ }^{a}$ Federal Highway Administration.

\section{THE NEW NETSIM SIMULATION PROGRAM}

\author{
A. K. Rathi \\ A. J. Santiago ${ }^{a}$ \\ [Abstract of Traffic Engineering and Control 31(5), 317-20 (May 1990)]
}

NETSIM, now a component model of the TRAF simulation system, has been extensively modified over the past 4 years as part of a project to maintain and support the TRAF simulation software. Four new features have been added to the NETSIM simulation program: actuated controller logic, identical traffic 
streams, conditional tuming movements, and signal transition. Several major modifications have also been made to the simulation logic to resolve the problems encountered during the testing of the simulation program. These modifications include enhancement of the logic to represent complex decision processes and the enhancement and extension of the input-output capabilities, user-interaction, and computational efficiency of the program. These new features and the modifications to the TRAF-NETSIM simulation model are described in this paper.

Research sponsored by the U.S. Department of Transportation Federal Highway Administration.

${ }^{a}$ Federal Highway Administration.

\title{
A FORMULATION OF EXTERNAL METERING CONTROL FOR CONGESTED URBAN NETWORKS
}

\author{
A. K. Rathi \\ (Abstract of p. 10 in Proceedings of the TIMS, JRSA National Meeting, Las Vegas, May 1990, \\ and in the ORSA/TIMS Bulletin, Md., May 1990)
}

External metering is a control policy which limits the inflow of traffic entering an urban network (control area). The overriding function of external metering is to disperse entering traffic demand over time, and possibly space, so as to eliminate severe congestion within the control area. This paper describes a mathematical formulation of external metering control that relates metering rates to the density within the control area.

Research sponsored by the U.S. Department of Transportation Federal Highway Administration.

\section{DEPLOYMENT ANALYSIS PROTOTYPE OF U.S. TRANSCOM}

\author{
R. L. Church ${ }^{a}$ \\ A. K. Rathi \\ R. S. Solanki \\ (Abstract of p. 64 in Proceedings of the ORSA/TIMS National Meeting. New York, October 1989)
}

This paper presents the basic structure of two optimization models employed in the Deployment Analysis Prototype of U.S. TRANSCOM. The prototype involves the analysis of air, sea, and land transport capabilities for specific courses of action. Special emphasis is given to modeling airlifts.
Research sponsored by the U.S. Department of Transportation.

${ }^{\circ}$ University of Califomia.

\section{AUTOMATED SUPPORT FOR PROCESSING SPECIAL ASSIGNMENT AIRLLFT MISSIONS (SAAMs)-A CONCEPT PAPER}

\author{
A. K. Sexton \\ H.-L. Hwang \\ (Abstract of ORNL/IM-1 1024, Oak Ridge National Laboratcry, October 1989)
}

The Airlift Deployment Analysis System (ADANS) is a research and development effort sponsored by the Headquarters of Military Airlift Command (HQ MAC) and conducted by researchers at Oak Ridge National
Laboratory (ORNL). The purpose of this effort is to upgrade HQ MAC's automated capabilities for scheduling peacetime or wartime missions, for deliberate and execution planning, and for analysis of the airlift 
system. HQ MAC is also integrating its airlift scheduling processes to provide an easicr transition from peacetime to wartime duties. The goal of this research and development effort is to provide an integrated system that allows HQ MAC to better maintain its forces in a constant state of readiness. The development for ADANS is scheduled in three increments and is to be completed in September 1992. The Special Assignment Airlift Missions (SAAMs) at HQ MAC are to be supported at the end of Increment II of ADANS development. Increment II development began in October 1988 and will be completed in June 1991. To develop a useful decision support system for the HQ MAC staff to process SAAMs, it is essential that both HQ MAC and ORNL understand and agree, in advance, what should be done in ADANS for SAAMs and how it should be accomplished. This report intends to provide a baseline for future discussions and communications on this subject. This paper documents the procedures for processing SAAMs at HQ MAC as of May 1989 and presents functions that will be provided by ADANS to support SAAMs. In general, ADANS will provide HQ MAC Current Operations, Airlift Management Division, Special Airlift Branch and Air Transportation, the Director of Cargo and Requirements, and Special Assignment Airlift Division with the ability to automate SAAM information management and data processing tasks, along with systematic checking for errors and consistency. Reports will be generated automatically by the system for analysis of SAAM requirements and airlift allocation. Consequently, better data integrity among various forms and reports can be expected.

Research sponsored by the U.S. Department of Defense Military Airlift Command.

\title{
ARCHITECTURAL ANALYSIS FOR THE WORLDWIDE HOUSEHOLD GOODS INFORMATION SYSTEM FOR TRANSPORTATION MODERNIZATION (WHIST-MOD)
}

\author{
P. M. Spears \\ P. F. Daugherty \\ P. T. Singley \\ A. H. Voelker
}

(Abstract of ORNL/M-936, Oak Ridge National Laboratory, October 1989)

The present Worldwide Household Goods Information System for Transportation (WHIST) provides limited support for the management information needs of Department of Defense (DOD) personal property moving and storage activities. The purpose of the WHIST Modernization (WHIST-MOD) project is to provide rescarch and development support for the modernization of the current WHIST system, portions of which are more than 20 years old. The analysis and design phase of this project is being performed for the Directorate of Personal Property, Military Traffic Management Command by the Oak Ridge National Laboratory's Transportation and Systems Research Section. This report is an analysis of the hardware and software architecture of the proposed WHIST-MOD system.

Research sponsored by the U.S. Department of Defense Military Traffic Management Command.

\section{REQUIREMENTS ANALYSIS FOR WHIST-MOD PROJECT AT FIELD OFFICE}

T. L. James ${ }^{a}$

P. T. Singley

(Abstract of ORNL/M-894, Oak Ridge National Laboratory, October 1989)

Oak Ridge National Laboratory (ORNL) was asked th design a decision support system for the Military Traffic Management Command's Personal Property Directorate. The project is the Worldwide Household Goods Information System Modernization (WHIST-MOD). This requirements-analysis paper describes those requirements of the Personal Property Directorate's Field Offices (FOs) that could benefit from automation with WHIST-MOD. It is an analysis of user requirements based on interviews with FO personnel and documentation provided to ORNL by the FO and the Headquarters office. This paper contains detailed 
descriptions of the FO work processes, current automation, the impacts of the Transportation Operational Personal Property Standard System on the work processes, and automation possibilities for WHIST-MOD. Information from this document will be used in the design and prototyping of WHIST-MOD.
Research sponsored by the U.S. Department of Defense Military Traffic Management Command.

${ }^{a}$ The University of Tennessee.

\title{
[7.3.35]
}

\section{TECHNOLOGY INNOVATION AND MANAGEMENT IN THE U.S. BUREAU OF THE CENSUS: DISCUSSION AND RECOMMENDATIONS}
B. E. Tonn
R. T. Goeltz
R. G. Edwards
K. A. Hake

(Abstract of ORNL-6600, Oak Ridge National Laboratory, August 1990)

This report contains a set of recommendations prepared by Oak Ridge National Laboratory (ORNL) for the 21 st-century staff of the U.S. Bureau of the Census; the recommendations pertain to technology innovation and management in the Census Bureau. The topic is important because technology has the potential to improve the bureau's data collection, capture, processing, and analysis activities. However, these benefits will be realized only if new technologies are well conceived and managed. Given the bureau's recent history of innovative successes, our recommendations are designed to complement and fine-tune existing bureau processes and to combat problems that work against technology change and innovation. No recommendation depends on the bureau changing government procurement recommendations or personnel systems. Recommendations fall into five independent but mutually beneficial categories: (1) It is recommended that the Automated Data Processing Steering Committee be disbanded and replaced with a technology forum with the responsibility of debaung and discussing a broad range of technologies. (2) A Technology Review Committee (TRC) should be established, to be composed of technology experts from outside the bureau. The TRC will encourage the bureau to continue to adopt new technologies and will provide a regular flow of critical comments on technology innovation and management to the bureau's executive staff. (3) The bureau should designate technological "gurus." These individuals will be the bureau's experts in new and innovative technologies. (4) It is recommended that the bureau adopt a technology innovation process. (5) The Census Bureau should establish an Advanced Technology Studies Staff to promote technology transfer, obtain funding for technological innovation, manage innovation projects unable to find a home in other divisions, evaluate innovations that cut across bureau organizational boundaries, and provide input into bureau technology analyses. In summary, these recommendations are designed to enhance the bureau's current successful innovation processes. The recommendations can be adopted and implemented separately or together. None represents a radical departure from the present state of affairs, and none depends on the bureau changing its external environment.

\section{KNOWLEDGE-BASED REPRESENTATIONS OF RISK BELIEFS}

\author{
B. E. Tonn \\ C. Travis ${ }^{a}$ \\ R. T. Goeltz \\ R. Phillippi ${ }^{a}$ \\ [Abstract of Risk Analysis 10(1), 169-84 (March 1990)]
}

Beliefs about risks associated with AIDS and toxic waste are modeled using knowledge-based methods; beliefs are elicited from subjects via interactive computer technology. A concept net organizes subject responses conceming the consequences of the risk agents. Death and adverse personal emotional and sociological consequences are found to be most associated with AIDS. Toxic waste is most associated with 
environmental problems. These consequence profiles are quite dissimilar, although past work in risk perception would have judged the risk agents as being quite similar. Subjects frequently used causal statements to represent their beliefs and "percent of time" instead of "probability" to represent likelihoods. The news media are the most prevalent source of risk information, but experiences of acquaintances appear more credible. The results suggest that "broadly based risk" communication may be ineffective because people differ in their conceptual representation of risk beliefs. In general, the knowledge-based approach to risk perception representation has great potential to increase our understanding of important risk topics.

Research sponsored by NAVSEA.

${ }^{a}$ The University of Tennessee.

\title{
ARTIFICIAL INTELLIGENCE FOR SUBJECT INTERVIEWING
}

\author{
B. E. Tonn \\ R. T. Goeltz \\ L. Arrowood ${ }^{a}$ \\ K. A. Hake
}

(Abstract of Sect. 17 in Proceedings of the Advanced Computing for the Social Sciences Conference, Williamsburg, Va., April 1990)

This paper has two goals: to discuss, in general terms, issues related to applying artificial intelligence (AI) techniques to computerized interviewing; and to describe two AI-based interviewing systems developed at Oak Ridge National Laboratory. Al techniques can be used effectively to collect data of complex representation, provide flexibility in collecting data, and improve data validity through real-time reviews. One AI system, ARK, elicits subjects' beliefs on an open-ended range of issues and topics through menu-driven, dialogue-based interactions. The other system, LES, elicits uncertainty assessments related to events, statements, and propositions, and tailors questions for subjects to explore their uncertainty-processing heuristics.

Research sponsored by the U.S. Bureau of the Census.

${ }^{a}$ Computing and Telecommunications Division.

\section{DIAGNOSIS, PARSIMONY, AND GENETIC ALGORITHMS}

\author{
W. D. Potter ${ }^{a}$ \\ B. E. Tonn \\ M. R. Hilliard \\ G. E. Liepins \\ S. L. Purucker \\ R. T. Goeltz \\ (Abstract of pp. 1-8 in Proceedings of the Third International Conference on Industrial and Engineering Applications of \\ Artificial Intelligence and Expert Systems, Charleston. S.C., July 1990)
}

The Communication Alarm Processor Expert System (CAP), developed at Oak Ridge National Laboratory (ORNL) for the Bonneville Power Administration, is a near real-time system that helps microwave communication system operators with interpreting the causes of large communication system problems. Problems in the communications network arc indicated by the real-time arrival of alarms at the central control site. CAP receives and processes these alarms, then presents the operator with a sorted list indicating the most probable cause (and location) of the alarms. One of the future goals for the CAP system is to be able to identify and diagnose multiple problems in the entire network based on the timely interpretation of incoming alarms. This goal includes knowledge-base migration from a purely compiled (also known as "experiential" or "shallow") approach to a combined compiled and functional knowledge base such as the integrated database management system. To achieve the goal of multiple problem diagnosis, a strategy is needed that (1) satisfies the previously defined near real-time processing constraints, (2) "scales up" easily to handle large (more than 50 components) real-world applications, and (3) gives the operator highly reliable information on the current status of the communications network. This paper describes the recent results of our efforts to develop a general multiple problem (fault) diagnostic strategy that meets those requirements.

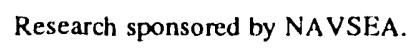

${ }^{a}$ The University of Georgia. 


\author{
C. Travis ${ }^{a}$ \\ R. Phillippi ${ }^{a}$ \\ B. E. Tonn
}

[Abstract of Patient Education and Counselling 13, 211-20 (1989)]

The literature of social psychology and cognitive science is reviewed to examine the possible effects of common judgment heuristics, or intuitive decision rules and biases, on medical decisions. Prior expectations, the availability bias, false consensus, and illusory correlations are reviewed for their effect on the recognition and reporting of signs and symptoms. Physicians' desire to avoid risk, representativeness, and adjustment or anchoring heuristics are reviewed for possible effects on diagnostic strategy. The perception of risk, regret, framing effects, and illusions of control are examined for effects on the selection of treatment options. The implications of these heuristics and biases for medical education, provider-patient communications, and informed consent are also discussed.

Research sponsored by NAVSEA.

${ }^{a}$ The University of Tennessee.

\title{
[7.3.40] AIRLIFT DEPLOYMENT ANALYSIS SYSTEM (ADANS) DEVELOPMENT GUIDELINES: USER INTERFACE
}

\author{
L. F. Truett \\ R. S. Loffman \\ S. S. Stevens \\ (Abstract of ORNL/TM-11391, Oak Ridge National Laboratory, January 1990)
}

This report presents guidelines for the development of the Airlift Deployment Analysis System (ADANS) user interface. The purpose of this report is to provide guidelines for the interface developers and to inform the U.S. Air Force of the design. The guidelines include the design of specific applications and the general "look and feel" of the user interface. The ADANS data are complicated and extensive, and the ADANS user interface must provide an effective, efficient means for the user to interact with those data. The guidelines conform, as much as possible, to established standards for developing computer systems.

Research sponsored by the U.S. Air Force Military Airlift Command.

\author{
L. F. Truett \\ S. Das \\ J. C. Worthington ${ }^{a}$ \\ (Abstract of ORNL/M-1198, Oak Ridge National Laboratory, August 1990)
}

The Airlift Deployment Analysis System (ADANS) is an automated system that will provide Headquarters, Military Airlift Command (HQ MAC) with planning, scheduling, and analysis tools for peacetime and contingency airlift operations. This Life Cycle Cost (LCC) analysis identifies cost factors affecting ADANS during its life cycle. The analysis lists exact costs when known and reasonable estimates of other costs. The report states costs in fiscal year (FY) dollars for costs already expended (FY 1986-89) and in FY 1990 dollars for projected costs. Factors that could have a substantial impact on the ADANS life cycle development and maintenance costs are noted. The development effort will conclude in FY 1992. This LCC analysis covers a 15-year period from FY 1986 to FY 2000. The total cost of ADANS is projected to be approximately $\$ 60$ million. Of this total, about $20 \%$ is for development of functional capability, about $9 \%$ for development of the 
cross-cutting subsystems, and about $71 \%$ for program and system support. The total Oak Ridge National Laboratory development cost for FY 1986-92 is about \$27.5 million: the total cost for HQ MAC is about $\$ 3.2 .5$ million.
Research sponsored by the U.S. Department of Defense Military Airlift Command.

${ }^{a}$ Sybase, Inc., Rockville, Maryland.

\title{
A STUDY OF AUDITING METHODOLOGIES FOR THE ENERGY INFORMATION ADMINISTRATION DATA COLLECTION AND PROCESSING SYSTEM QUALITY ASSESSMENT PROGRAM
}

\author{
L. F. Tructt \\ T. G. Yow \\ (Abstract of ORNL/TM-11327, Oak Ridge National Laboratory, November 1989)
}

Since FY 1983, Oak Ridge National Laboratory (ORNL) has assisted the Department of Energy's (DOE's) Energy Information Administration (EIA) Quality Assurance Division, Office of Statistical Standards (OSS), with assessments of the quality of EIA's automated data collection and processing systems. These assessments have had three objectives: (1) to determine whether the survey systems collect, process, and publish accurate and reliable information; (2) to ensure that the system documentation is current and adequate; and (3) to evaluate the systems' compliance with applicable EIA standards. By the end of 1989, over 40 different EIA data survey systems will have been audited. This will complete the first round of EIA auditing. As part of this EIA OSS quality audit tasking, ORNL was asked to review some current auditing methodologies and to develop recommendations for alternative techniques that might be used in the second round of EIA quality audits. Based on a survey of current quality assurance literature, interviews with personnel involved in auditing, and personal experiences with the auditing process, ORNL (1) presents a brief overview of the world of quality auditing; (2) briefly discusses some standard, proven audit methodologies; (3) identifies some new approaches to the auditing of data collection systems, with an emphasis on the area of software metrics; (4) identifies areas of EIA survey operations that were not thoroughly examined in the first audit cycle and that may deserve additional attention during the second round of auditing; and (5) makes specific recommendations for improvements to techniques used in the first audit cycle that will be retained for the second round. ORNL also presents an audit matrix to be used as a tool for evaluating which audit method(s) would provide the best results for each area to be covered in an audit.

Research sponsored by the U.S. Department of Energy, Energy Information Administration. \\ SUPPLEMENTAL DATA PACKAGE FOR THE LOW-LEVEL WASTE DISPOSAL DEVELOPMENT AND DEMONSTRATION PROGRAM-DATA COLLECTION PERIOD: APRIL 1988-SEPTEMBER 1989}

\author{
L. F. Truett \\ R. H. Ketelle \\ (Abstract of ORNL/TM-11416, Oak Ridge National Laboratory, December 1989)
}

This data package is the final report of data that were collected between April 1988 and September 1989 at each of four Oak Ridge Reservation sites: Solid Waste Storage Area 7, West Bear Creek Valley, West Chestnut
Ridge, and East Chestnut Ridge. This report contains water table elevation data, precipitation data, surface water discharge data, and results of water quality analyses. Specific dates for each data type collected are given in the appropriate sections, which are organized by 
site. This report will support an environmental impact statement whose purpose is to evaluate the effects of future low-level waste disposal at these four sites.
Research sponsored by the U.S. Department of Energy.

\title{
[7.3.44] ELECTRONIC COMMUNICATION AND DATA TRANSFER: PRODUCTIVITY ENHANCEMENTS
}

\author{
L. F. Truett \\ S. S. Stevens \\ (Abstract of pp. 57-65 in Proceedings of the Third International Conference on Microcom:puters in Transportation, American Society of Civil \\ Engineers, San Francisco, June 1990)
}

Transportation projects can be small local efforts or large, multi-sited ventures. For large projects, electronic mail and data transfer are not merely productivity aids; they are indispensable components of success. Electronic communication via microcomputers is quick and convenient and provides documented evidence of the communication. The rapid exchange of cost data, routing data, plans and schedules, and information on the availability of transportation equipment and personnel ensures maximum use of transportation assets and provides responsiveness to customer requests for transportation services. Large ventures operating at widely separated sites cannot depend on local area networks for their communication requirements, as can small, single-sited projects. Not all projects have access to established communication networks such as BITNET (used widely by universities) or DDN (the Defense Data Network). In additior, transportation efforts that involve several diverse agencies such as the federal government, local afficials, public utilities, industry, or the private sector have special communication requirements. This paper focuses on criteria for choosing an appropriate microcomputer-based communication mechanism. Emphasis is placed on determining communication requirements and ranking the importance of system characteristics. Advantages and limitations of three different system configurations are discussed in nontechnical terms.

\section{[7.3.45] WORLDWIDE HOUSEHOLD GOODS INFORMATION SYSTEM FOR TRANSPORTATION MODERNIZATION (WHIST-MOD) CONCEPTIONAL DESIGN}

\author{
A. H. Voelker \\ P. F. Daugherty \\ W. E. Friggl ${ }^{a}$ \\ M. Hughes
}

\author{
P. T. Singley \\ T. L. James ${ }^{a}$ \\ T. Shelton ${ }^{a}$
}

'Abstract of ORNL/TM-11298, Oak Ridge National Laboratory, August 1989)

The Directorate of Personal Property of the Military Traffic Management Command asked Oak Ridge National Laboratory to design a decision support system. This report describes the proposed Worldwide Household Goods Information System for Transportation Modemization (WHIST-MOD). It is the result of an analysis of user requirements and the constraints imposed by the available hardware and software. Tw'n hardware/software options and two data source option: äs prescritcud. This repont aúvocates a uscr-driver. system that will require several organizational adjustments. These include creating additional tasks. such as data administration and maintenance and modification of the system, as well as requiring additional training for present and proposed staff. User needs will be translated into a finished design via prototyping. A recommendation is made on how to proceed. WHIST-MOD will be an evolving system designed to meet the dynamic needs of the personal property organization.

Research sponsored by the U.S. Department of Detense Military Traffic Management Command.

\footnotetext{
${ }^{a}$ The University of Tennessec
} 


\title{
[7.3.46]
}

\section{QUALITY ASSURANCE REVIEW OF MANUAL AND AUTOMATED DATA-HANDLING PROCEDURES: ANNUAL SURVEY OF DOMESTIC OIL AND GAS RESERVES, FORM EIA-23}

\author{
T. G. Yow \\ L. F. Truett \\ P. X. Armendarez ${ }^{a}$ \\ T. Wright ${ }^{b}$
}

(Abstract of ORNL/M-1000, Oak Ridge National Laboratory, November 1989)

\begin{abstract}
A post-implementation review of Form ELA-23, "Annual Survey of Domestic Oil and Gas Reserves," was conducted for the following purposes: (1) to determine whether the system's manual and automated procedures collect and process data in a manner that ensures data reliability and produces accurate and timely information, (2) to ensure that the system's documentation accurately describes the data collection and processing procedures, and (3) to evaluate the survey system's compliance with current applicable Energy Information Administration (EIA) standards. To accomplish these objectives, the audit team reviewed the system documentation, compared the system's operations and procedures with EIA standards, and examined the flow of data through the system. Both manual and automated procedures were analyzed. The system documentation that was provided was found to be complete; only minor
\end{abstract}

deficiencies were identified. Evaluation of the Form EIA-23 system in terms of the EIA standards revealed that in most major respects the system complied with the relevant standards. The audit team also found that system operations produced accurate and reliable results. The flow of data through the system is modular and appropriate. Both manual and automated edit procedures and quality assurance procedures are in place and functioning properly. Thus, the audit team judged the Form EIA-23 survey system to be operating efficiently and effectively.

Research sponsored by the U.S. Department of Energy, Energy Information Administration.

${ }^{a}$ Analysas Corporation.

${ }^{b}$ Engineering Physics and Mathematics Division.
The Transportation Operational Personal Property Standard System (TOPS) is an automated information management system to help administer the personal property transportation program for the Department of Defense (DOD). TOPS was fielded at four prototype sites in the late summer of 1988. Prototype testing is currently underway, with system deployment scheduled for 1989. When fully deployed, TOPS will save DOD time and money and will help ensure that all shipments made by armed services personnel are handled quickly and efficiently. The success of the TOPS system depends on several key factors. Of course. TOPS must give transportation clerks at military personal property shipping of fices a tool for performing their jobs with greater ease, speed, and correctness. However, the system must first be accepted by the clerks themselves. To ensure acceptance of the system by end users, TOPS system analysts and programmers at Oak Ridge National Laboratory made the design of an effective, consistent user interface one of their primary goals. As the front end of TOPS, the counseling module presented unique opportunities and challenges in the design of human/machine interface. This interface design effort has produced a module that should afford transportation clerks throughout the United States and overseas a user-friendly, effective introduction to the TOPS system. The purpose of this document is to examine the user interface techniques used in the counseling module of TOPS to ensure user acceptance and database integrity, both key elements in the ultimate success of TOPS.

Restarch sponsored by the U.S. Department of Defense Military Traffic Management Command. 


\title{
7.4 ABSTRACTS OF EFFICIENCY AND RENEWABLES RESEARCH
}

\author{
TRANSIENT RESPONSE OF A DISTRIBUTION CIRCUIT RECLOSER AND \\ CONTROL UNIT TO A HIGH-ALTITUDE ELECTROMAGNETIC PULSE \\ (HEMP) AND LIGHTNING
}

\author{
P. R. Barnes \\ F. M. Tesche ${ }^{a}$ \\ [Abstract of IEEE Transactions on Electromagnetic Compatibility 32(2), 113-24 (May 1990)]
}

This paper presents an analysis of the response of a power system distribution line recloser unit to a high altitude electromagnetic puise (HEMP) and a lightning direct-strike excitation. From details of the configuration of the system, physical and mathematical models are developed, and a study of possible HEMP responses is conducted. Two voltage and two current responses at selected points within the system are studied for both the
HEMP and lightning stresses. The possibility of simulating the HEMP responses is also discussed, with predicted and measured responses being provided for the Advanced Research Electromagnetic Pulse Simulator.

Research sponsored by the U.S. Department of Energy Office of Energy Storage and Distribution.

${ }^{a}$ E-Systems, Inc., Greenville. Texas.

\section{THE U.S. DEPARTMENT OF ENERGY LEAST-COST UTILITY PLANNING PROGRAM}

\author{
L. G. Berry \\ E. Hirst \\ [Abstract of Energy 15(12), 1107-17 (December 1990)]
}

The Least-Cost Utility Planning Program (LCUP) of the U.S. Department of Energy (DOE) was created at the direction of Congress in 1986. The purpose of the program is to provide utility planners and regulators with data, analysis, and evaluation tools that can assist with the selection of supply and demand options that deliver high-quality, low-cost energy services to customers. In 1987. DOE selected 14 grantees to develop least-cost planning data and tools. Oak Ridge National Laboratory (ORNL) is conducting an ongoing assessment of the 14 DOE/LCUP projects which includes technical oversight and reviews of draft and final reports. ORNL is also preparing a report that synthesizes the individual projects to assess the accomplishments of LCUP as a whole. This paper summarizes the types of data, models, and planning tools being developed by each of the 14 grantees and suggests who could best use them for what purposes. The grantecs are addressing a wide range of issues, including (1) database development for demand-side planning; (2) the review, critique, selection. application, and development of models for a variety of least-cost planning problems: (3) consensus building processes to support the development of organizational structures that will institutionalize economical planning; (4) the development of tools for incorporating renewable resources and cogeneration into utility planning; and (5) the analysis of legal issues related to the incorporation of least-cost planning objectives into bulk power transactions. The purpose of this paper is to familiarize readers with the resources available from the DOE/LCUP program and to summarize the program's primary accomplishments to date.

Research sponsored by the U.S. Department of Energy Office of Conservation and Renewable Fnergy. 


\title{
THE MARKET PENETRATION OF ENERGY-EFFICIENCY PROGRAMS
}

L. G. Berry

(Abstract of ORNI/CON-299, Oak Ridge National Laboratory, April 1990)

The focus of this report is on one source of resource planning uncertainty: the expected market penetration of demand-side management (DSM) programs. Its purpose is to help refine planning assumptions and reduce uncertainty about the market penetration of utility DSM programs by (1) investigating concepts and definitions of market penetration; (2) reviewing data that characterize patterns of variation (including ranges, averages, and maximum levels) in program participation rates;

(3) identifying the factors that affect participation: and (4) reviewing the structure and data requirements of models that forecast market penetration.

Research sponsored by the Bonneville Power Administration Office of Energy Resources.

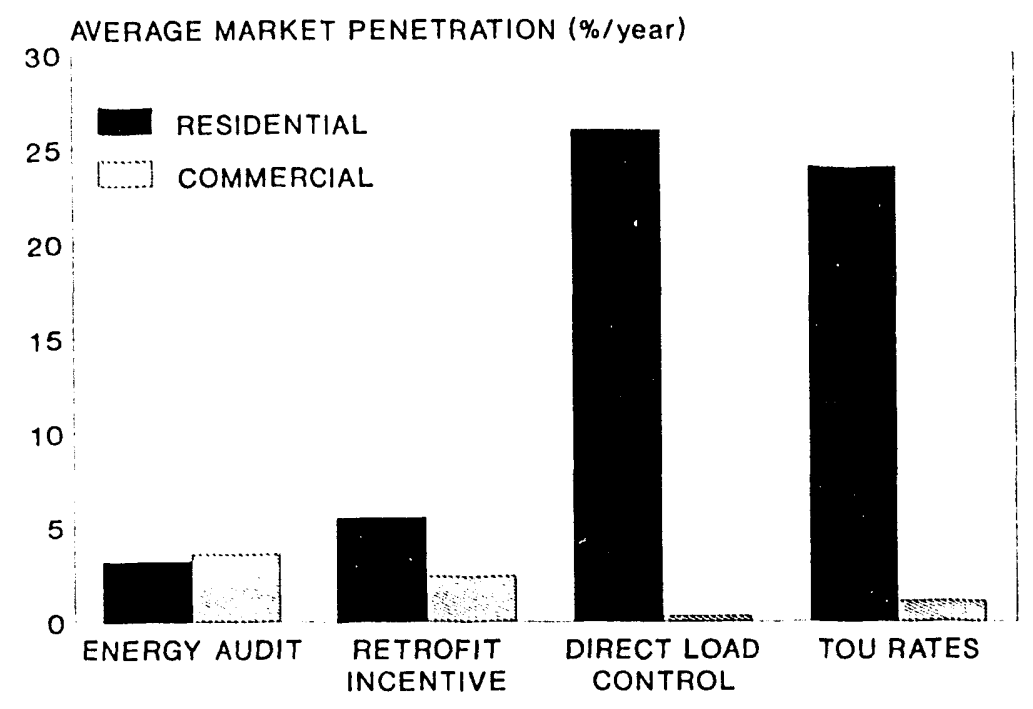

A comparison of the market penetration of different energy-efficiency incentive programs.

THE ADMINISTRATIVE COSTS OF ENERGY CONSERVATION PROGRAMS

\author{
L. G. Berry
}

(Abstract of ORNL/CON-294, Oak Ridge National Laboratory, November 1989)

The administrative costs of conservation programs can be substantial. Administrative costs may support a variety of functions, including (1) program planning, design, analysis, and evaluation; (2) activities designed to reach customers, bring them into the program, and deliver services such as marketing, audits, application processing, and bid reviews; (3) inspections and quality control: (4) staff recruitment, placement, compensation, development, training. and transportation; (5) data collection, reporting, recordkeeping. and accounting; and (6) overhead costs such as office space and equipment, vehicles, and legal fees. In this report, data on the administrative costs of conservation programs were assembled to explore the factors that contribute to cost variations and to make recommendations about planning assumptions. Current planning approaches assume that administrative costs add a fixed ratio of expenses to the direct costs for energy conservation measures. In reality, administrative costs are a function of many factors. They vary by the stage of program development, the type of technology being promoted, the extent of program marketing and financial incentives being offered, the desired level of market penetration, and the market segment at which the program is aimed.

Research sponsored by the Bonneville Power Administration Office of Energy Resources. 


\title{
EVALUATING THE IMPACTS OF MODEL CONSERVATION STANDARDS ON SINGLE-FAMILY CONSTRUCTION PRACTICES IN THE NORTHWEST
}

\author{
P. Brandis ${ }^{a}$ \\ M. A. Brown \\ B. Cody ${ }^{a}$ \\ M. H. Haeri ${ }^{b}$ \\ (Abstract of pp. 6.15-6.24 in Proceedings of the ACEEE 1990 Summer Study on Energy Efficiency in \\ Buildings, Vol. 2, Pacific Grove, Calif., Aug. 26-Sept. 1, 1990)
}

The Bonneville Power Administration (BPA) in conjunction with the Northwest Power Planning Council has implemented a wide range of activities to improve building practices in the Pacific Northwest. These activities include offering technical assistance, the use of financial incentives, the Super Good Cents marketing program, the Early Adopter Code Program, and even a threatened surcharge. The purpose of this study is to assess the impacts of these activities on single-family home construction. This is accomplished by comparing the energy efficiency of 1983 preprogram homes with 1987 homes, and by comparing 1987 homes built under BPA programs with other homes constructed in the same year. The evaluation is composed of four interrelated components: an occupant survey; billing history analysis; energy simulation modeling; and construction characteristics data from site visits, including blower door tests. This paper describes the research plan, discusses several methodological issues, and presents preliminary results of this evaluation.

Research sponsored by the Bonneville Power Administration Office of Energy Resources.

${ }^{a}$ Bonneville Power Administration, Portland, Oregon.

${ }^{b}$ ERC Environmental and Energy Service Company, Portland, Oregon.

\section{IMPLEMENTATION AND ENFORCEMENT OF BONNEVILLE'S MODEL CONSERVATION STANDARDS WITHIN EARLY ADOPTING JURISDICTIONS}

\author{
M. A. Brown \\ S. M. Cohn \\ J. O. Kolb
}

(Abstract of ORNL/CON-296, Oak Ridge National Laboratory, February 1990)

This report evaluates the enforcement methods and costs of eight jurisdictions participating in Bonneville Power Administration's Early Adopter Program. This program was begun in 1986 to help jurisdictions within the Pacific Nonhwest adopt energy-efficient, Model Conservation Standards (MCS) for new residential construction. The objectives of this evaluation are to (1) document the strategies used by Early Adopters to implement the MCS in their jurisdictions, (2) estimate the incremental time and cost associated with enforcing the MCS, and (3) identify changes in enforcement in enforcement activities and costs that occurred between 1987 and 1989. Each of the eight jurisdictions used either an "interactive" or "code-enforcement" strategy to implement the MCS. All three of the jurisdictions selecting interactive strategies were located in Idaho. The fourth Idaho jurisdiction used a code-enforcement strategy, as did the four Washington jurisdictions. The total incremental time spent on MCS enforcement efforts for interactive jurisdictions in our sample was almost twice that of code-enforcement jurisdictions. On average, interactive jurisdictions devoted approximately 9 hours on MCS-related activities for single-family homes, excluding travel time; code-enforcement jurisdictions spent 5 hours. For both strategies, approximately $40 \%$ of time is spent on inspections, another $40 \%$ on plan review, and the remaining $20 \%$ is spent providing technical assistance. Bonneville's reimbursements for MCS implementation and enforcement (\$125 for single-family and \$225 for multiple-family buildings) exceeds the average incremental costs only in jurisdictions that employ code-enforcement strategies. The costs in the interactive jurisdictions greatly exceed the reimbursement levels when travel costs are included. Total incremental time did not change significantly between 1987 and 1989. demonstrating that the overall magnitude of any learning effects was relatively small. However, approximately 
one-half of the phase I jurisdictions had reductions in each of the three enforcement activities. The document concludes with a series of recommendations.
Research sponsored by the Bonneville Power Administration Office of Energy Resources.

\title{
THE ENERGY-RELATED INVENTIONS PROGRAM: COMMERCIAL PROGRESS OF PARTICIPANTS THROUGH 1988
}

\author{
M. A. Brown \\ C. R. Wilson ${ }^{a}$ \\ (Abstract of ORNL/CON-301, Oak Ridge National Laboratory, May 1990)
}

This report provides information on the recent commercial progress of inventions supported by the Energy-Related Inventions Program (ERIP). It describes the results of the latest in a series of ERIP evaluation projects that have been completed since 1980 . It focuses on the economic impacts of the program, notably sales and employment benefits, from 1980 through 1988. By the end of 1988, at least 88 ERIP inventions had entered the market, generating total cumulative sales of more than $\$ 400$ million. With $\$ 21.4$ million in grants awarded from 1975 through 1988 , and $\$ 53.8$ million in program appropriations over the same period, ERIP has generated a 19:1 return in terms of sales values to grants, and a 7:1 return in sales versus program appropriations. It is estimated that $24 \%$ of all ERIP inventions had achieved sales by the end of 1988. Employment benefits, tax revenues, sources of funding, and spin-off technologies are also discussed.

Research sponsored by the U.S. Department of Energy Office of Conservation and Renewable Energy.

${ }^{a}$ The University of Tennessee.

\section{ENERGY EFFICIENCY IN NONPROFIT AGENCIES: CREATING EFFECTIVE PROGRAM MODELS}

\author{
M. A. Brown \\ B. Prindle ${ }^{a}$ \\ M. I. Scherr ${ }^{b}$ \\ D. L. White
}

(Abstract of ORNL/TM-1 1602, Oak Ridge National Laboratory, August 1990)

Nonprofit health and human service agencies have a significant potential for cost-effective energy efficiency improvements which are often unrealized because of competing financial priorities. Because nonprofit agencies play such a vital role in our communities, the Department of Energy conceived a project to help states develop energy efficiency programs for nonprofit agencies. The purpose of the project was two-fold: (1) to analyze existing programs to determine which design and delivery mechanisms are particularly effective and (2) to create model programs for states to follow in tailoring their own plans for helping nonprofit agencies with energy efficiency programs. Twelve existing programs were reviewed, and three model programs were devised and put into operation. The model programs provide various forms of financial assistance to nonprofit agencies and serve as a source of information on energy efficiency as well. After examining the results from the model programs (which are still ongoing) and from the existing programs, several "replicability factors" were developed for use in the implementation of programs by other states. These factors-some concrete and practical, others more generalized-serve as guidelines for states devising programs based on their own particular needs and resources.

Research sponsored by the Department of Energy Office of Conservation and Renewable Energy.

\footnotetext{
${ }^{a}$ Alliance to Save Energy, Washington, D.C.

${ }^{b}$ United Way of America, Alexandria, Virginia.
} 


\author{
M. A. Brown \\ W. C. Koehler, Jr. ${ }^{a}$ \\ D. L. White \\ J. Hayes ${ }^{a}$ \\ (Abstract of pp. 2.7-2.16 in Proceedings of the ACEEE 1990 Summer Study on Energy Efficiency in Buildings, Vol. 2. \\ Pacific (irove, Calif., Aug. 26-Sept. 1, 1990)
}

This paper explores the roles of organizations that are innovators and opinion leaders in demand-side management (DSM). Opinion leaders are highly influential organizations in the process by which DSM programs and concepts are evaluated and replicated by others. Channeling information through these organizations is an effective way to accelerate the technology transfer process and improve the effectiveness of DSM. Innovators are those organizations that are most receptive to early experimentation with new DSM programs or concepts and are consistently among the first to adopt DSM innovations. They provide the initial base of experience for evaluating DSM innovations. Opinion leaders are identified through an analysis of the organizations that have delivered papers at 11 DSM conferences held between 1983 and 1989. Innovators are identified through a content analysis of the same database of 1020 papers. The database is also used (1) to identify geographic, temporal, and organizational patterns of opinion leadership and innuvation; and (2) to characterize the role of innovators and opinion leaders in directing attention towards unconventional DSM opportunities. The results indicate that a small number of innovative and influential organizations have been particularly active in the DSM field. Approximately $10 \%$ of the organizations participating in the 11 DSM conferences presented more than $50 \%$ of the papers. Similarly, less than $10 \%$ of the organizations studied here account for a majority of the papers earmarked as innovative. These players represent various types of organizations, underscoring the complexity of the process of initiating and adopting innovation.

Research sponsored by the U.S. Department of Energy.

${ }^{a}$ Applied Management Sciences, Inc.

\title{
TECHNOLOGY TRANSFER STRATEGIES OF DOE'S CONSERVATION PROGRAMS
}

\author{
M. A. Brown \\ C. H. Major ${ }^{a}$ \\ [Abstract of Journal of Technology Transfer 15(1), 33-40 (1990)]
}

This paper examines the processes by which $R \& D$ results funded by the conservation program of the U.S. Department of Energy have generated commercial applications. It considers examples of successful technology transfer activities in three offices that correspond to the major energy end-use sectors-transportation, buildings, and industry. Close industry cooperation characterizes the conservation program's technology transfer approach, but the unique context of each office (e.g. . concentrated vs fragmented audiences and basic vs applied research) has necessitated individually tailored approaches. The transportation program has a highly concentrated primary audience and its research is largely exploratory. The result is a reliance on contracting basic $R \& D$ to the major automotive manufacturers, which have the ability to produce derivative commercial products, and licensing to capitalize on nonautomotive spin-off applications. The buildings program serves a highly fragmented audience and conducts a wide array of research ranging from basic to applied. Contracting with small businesses has been a successful technology transfer strategy, and trade and professional organizations are often employed as technology and information brokers. Faced with easily targeted audiences and an R\&D focus on mature technologies, the industrial program relies on cost-shared performance testing by industrial end-users to generate demand. Thus, what might appear at first glance to be a confusing array of technology transfer strategies actually 
represents a logical and effective solution to the technology transfer problems faced by each conservation office.
Research sponsored by the U.S. Department of Energy Office of Conservation and Renewable Energy.

${ }^{a}$ U.S. Department of Energy.
Inadequate financing is a common cause of failure among inventors and entrepreneurs striving to bring new energy technologies onto the market. This paper describes the cost of commercializing energy inventions and sources of funds used by successful entrepreneurs, based on data from the U.S. Department of Energy's Energy-Related Inventions Program (ERIP). On average, it has taken several years of work and $\$ 1.1$ million for an ERIP technology to enter the market.
Personal sources of funding play an important role throughout the development process, while external investors are practically invisible until the technologies are into mature stages of prototype development. The role for pre-venture government programs is clearly indicated from these findings and is discussed.

Research sponsored by the U.S. Department of Energy Office of Conservation and Renewable Energy.

\title{
A HEAT FLUX TRANSDUCER GUARD PLATE FOR EXTERIOR ENVELOPE SURFACE MEASUREMENTS
}

\author{
J. E. Christian \\ (Abstract of paper in Proceedings of the In-Situ Heat Flux Measurements in Buildings Conference, \\ Hanover, N.H., May 22-23, 1990)
}

A calibrated slab-on-grade edge insulation test facility has been collecting hourly heat flux transducer (HFT) measurements at Oak Ridge National Laboratory (ORNL) since February 1989. This facility has been measuring in-service performance of foundation insulations applied to a monolithic poured slab-on-grade foundation. The site contains experimental prototypes of a calibrated HFT plate assembly. These were fastened to the exterior vertical face of the slab edge in two instrument planes cutting perpendicularly to the slab edge and adjacent soil. The HFT guarding and masking technique used could benefit others interested in making heat flux measurements on the exterior face of building envelopes. The guard was constructed of materials that produce a composite with a measured thermal conductivity within $1.5 \%$ of the HFT and the same thickness as the HFT. The guard was designed to minimize the lateral heat transfer at the sensor. The guarded HFTs were sandwiched between two layers of a laminate acting as a mask that provides protection from the harsh conditions found in the adjacent soil. Provisions were made for this application to use the extended guards to help distribute uniformly the horizontal heat flow from the slab edge, yet minimize the potential artificial lateral heat path caused by the presence of the HFT guard. Three HFTs were installed at different vertical levels on both insulated and uninsulated slab locations. The HFTs were calibrated, prior to installation, in the ORNL Thermal Properties Laboratory; field measurements were validated periodically with laboratory checks.

Research sponsored by the U.S. Department of Energy Office of Buildings and Community Systems. 


\section{THE TECHNICAL VIABILITY OF ALTERNATIVE BLOWING AGENTS IN POLYISOCYANURATE ROOF INSULATION: PART 4, IN-SITU THERMAL AGING AND PERFORMANCE IN DIFFERENT ROOF SYSTEMS}
J. E. Christian
G. E. Courville
R. L. Linkous
R. L. Wendt
R. S. Graves ${ }^{a}$
T. L. Smith

(Abstract of paper in Proceedings of the 33rd Annual Polyurethane Conference, Orlando, Fla., Sept. 30-Oct. 3, 1990)

This paper presents a progress report on ficld thermal performance measurements on a set of private-industry-produced. experimental polyisocyanurate laminate board stock foams blown with chlorofluorocarbon (CFC)-11, hydrochlorofluorocarbon (HCFC)-123, HCFC-141b, 50/50, and $65 / 35$ blends of HCFC- 123 and HCFC-141b. These boards have been observed for almost 300 days of roof field exposure in East Tennessee. The field data are used to derive an empirical model that can, in turn, be used to predict effective diffusion coefficients for the air components into the foam cells. These diffusion coefficients are compared with those developed from steady state laboratory measurements of thin-sliced samples from the same batch of experimental boards. The relative performance of test specimens of HCFC-14lb under a black and under a white membrane are reported. Aging of the HCFC-141b blown foam under the white membrane occurred more slowly during cold weather, but accelerated after the winter season, resulting in no significant resistivity difference after 280 days of exposure from September 1989 until May 1990. The field data analysis suggests that the percent increase in $k$ over that of the foam blown with CFC-11 is, after one year of aging, $5.5 \%$ for HCFC-123 and $11.7 \%$ for HCFC-141b. This leads to the same ordering as derived from the laboratory thin-slicing analysis report in Part 3 of this session. Additional plans are described for further thermal and mechanical property measurements to be conducted on two ORNL roof field testers. After the
ORNL Photo 6579-89

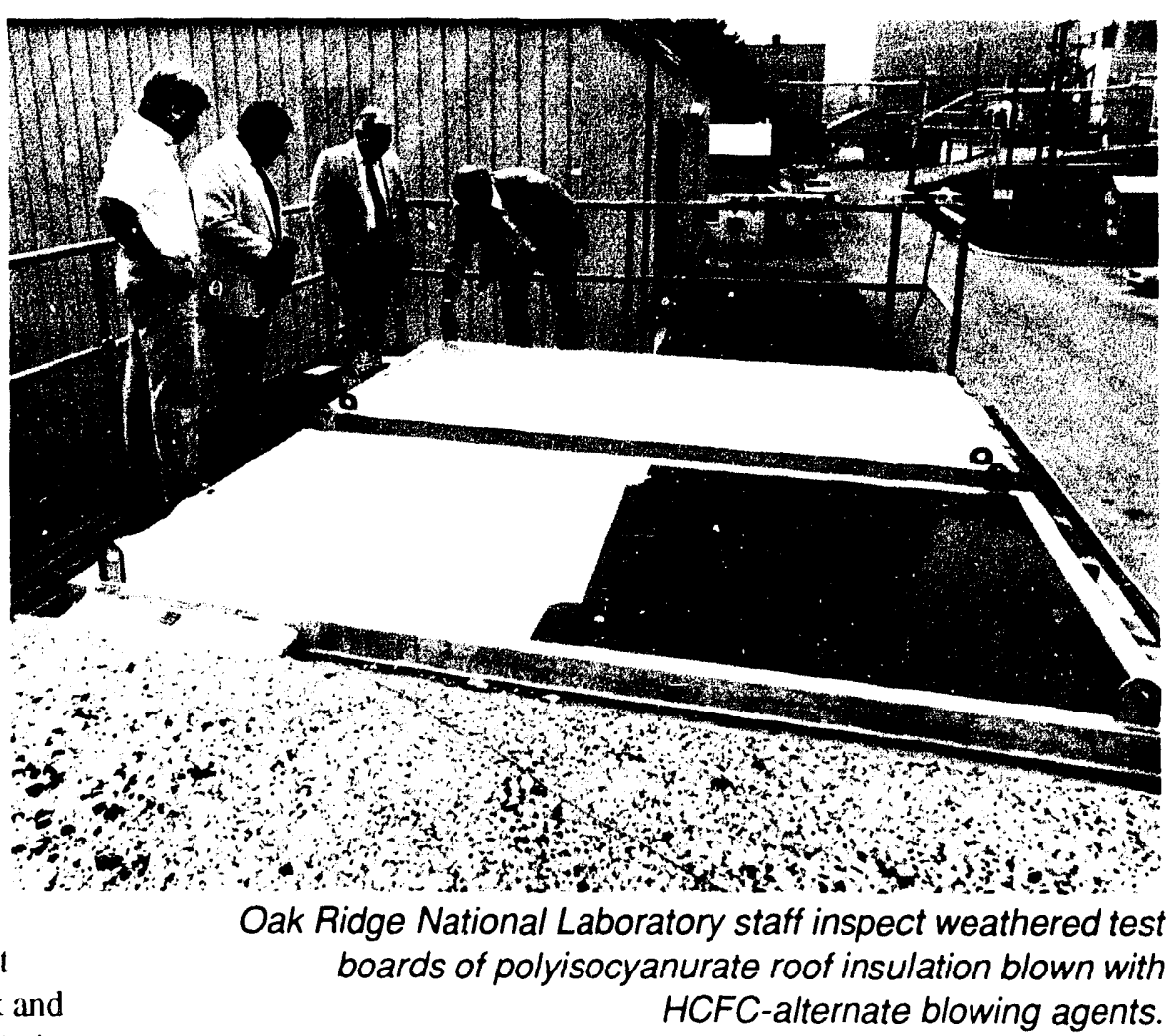

first year of this 3-year study, there has been no indication that thermal performance differences are serious enough to suggest that any or all of the HCFC alternate blowing agents would not be technically viable in polyisocyanurate roof insulations.

Research sponsored by the U.S. Department of Energy Office of Buildings and Community Systems and National Roofing Contractors Association.

Metals and Ceramics Division.

'National Roofing Contractors' Association, Upper Marlboro, Maryland. 


\author{
J. E. Christian
}

(Abstract of pp. 655-62 in Insulation Materials. Testing, and Applications, ASTM STP 1030, eds. D. L. McElroy and J. F. Kimpflen, American Society for Testing and Materials, Philadelphia, 1990)

This paper describes a research program aimed at the potential for significant energy savings from improved residential building foundations design. A recent study at the University of Minnesota estimates that less than $5 \%$ of foundations in the present building stock are optimally insulated. In addition, this study indicates that the potential national savings from upgraded basements, crawl spaces, and slab-on-grade foundation systems in residential and small commercial buildings is about 0.5 quads/year $\left(0.523 \times 10^{18} \mathrm{~J} /\right.$ year $)$. This research program is based upon a research-nceds assessment developed by the Building Foundations Research Review Panel. This panc! was established by the U.S. Department of Energy (DOE) and Oak Ridge National Laboratory to assist in the formulation of DOE foundations research policy and the development of a technology transfer strategy to get this research to the marketplace. Half of the panel members are from private industry. One of the first tasks the panel addressed was to formulate a prioritized list of building foundation research needs, including (1) widescale dissemination of existing information on good practices for energy-efficient construction and retrofit, (2) accurate characterization of the thermal properties of soils, (3) validated foundation heat and mass transfer algorithms coupled into whole-building simulation models, (4) an experimental database from one or more well-characterized test sites, and (5) design tools to effectively transfer the results of research into practice.

Research sponsored by the U.S. Department of Energy Office of Buildings and Community Systems.

\title{
WILL CFC RESTRICTIONS JEOPARDIZE ANTICIPATED FOUNDATION THERMAL EFFICIENCY GAINS?
}

\author{
J. E. Christian
}

[Abstract of paper in ASHRAE Transactions 96(1) (February 1990)]

A significant increase in the use of foundation insulation had been expected because of the near completion of ASHRAE 90.2P, the publication of the 1989 edition of the Council of American Building Officials Model Energy Code, and increasing sophistication of foundation design resulting from concerns about moisture damage, indoor air quality, and radon. Restrictions on the future availability and price of chlorofluorocarbon (CFC)-12 and

hydrochlorofluorocarbon (HCFC) alternatives will affect the goal of improving the efficiency of building foundations. One of the better ways to insulate foundations is to insulate on the exterior in contact with the earth, and one of the better insulating products for this application is extruded polystyrene. Because the predominant blowing agent used in extruded polystyrene has been CFC-12 and since CFC production limitations are at hand and further restrictions on HCFCs are possible. changes in this product's cost and performance are imminent. Current understanding of the thermal performance of building foundations and moisture movement in and around foundations is such that deciding how to best insulate is not always an easy decision for designers and builders. The absence of reasonably priced extruded polystyrene would make the decision even harder. This paper quantitatively addresses the energy-saving impacts using a state-level analysis of foundation insulation current usage and potential growth. This analysis concludes that the total impact could be anywhere from near zero to 0.8 quads/year $\left(0.8 \times 10^{15} \mathrm{Btu} /\right.$ year $)$ in the year 2010 , with the most likely impact being around 0.13 quads/year. The risk of higher impacts can be reduced by an accelerated research effort.

Research sponsored by the U.S. Department of Energy Office of Buildings and Community Systems. 


\author{
S. J. Dale \\ S. M. Wolf ${ }^{a}$ \\ T. R. Schneider ${ }^{b}$
}

[Abstract of ER-6682, Electric Power Research Institute.

Palo Alto, Calif., Vol. 1 (February 1990), Vol. 2 (Septenber 1990)]

In view of the potentially large impact of

the new superconductors on energy

ORNL-DWG. $91-8723$ systems and the need for a comprehensive understanding of this impact, the U.S. Department of Energy (DOE) Office of Conservation and Renewable Energy, Energy Conservation and Utilization Technologies Program, the DOE Office of Fossil Energy, and the Electric Power Research Institute (EPRI) Office of Exploratory Research cosponsored a major assessment of the technological opportunities for cost-effective and energy-efficient applications of the new superconductors. This paper gives the background for the study, the assessment approach, and the findings and conclusions. This study was undertaken to (1) assess the potential technical and economic benefits of applying the high-critical-temperature superconductors to a number of energy technologies,

(2) determine system characteristics and superconductor material parameters required for the application of the high-temperature superconductors, and (3) provide DOE and EPRI with a basis for future directions in research on superconductivity. The assessment convened study groups in nine application sectors and was conducted by four national laboratories and their subcontractors. The nine assessments were on electric motors, power electronics, transportation, electromagnetic pumping, magnetic heat pumps, materials fabrication, materials production, separation, and lighting. The study showed that critical current density $\left(J_{c}\right)$ of the superconductors of $10^{5} \mathrm{~A} / \mathrm{cm}^{2}$ or higher was needed for most applications, as well as operating magnetic fields of $2 \mathrm{~T}$ and higher. The successful development of the new higher-temperature superconductors will affect electric energy use in many different ways. Direct substitution in current electrical apparatus will reduce energy use. Ncw applications, typically using magnetic fields, will add further value to the use of electric energy.

Research sponsored by the U.S. Department of Energy Office of Conservation and Renewable Energy and Electric Power Research Institute.

${ }^{a}$ U.S. Department of Energy.

${ }^{b}$ Electric Power Research Institute. 


\title{
ADVANCED ABSORPTION TECHNOLOGY DEVELOPMENT IN THE
} UNITED STATES

\author{
R. C. DeVault \\ (Abstract of pp. 69-80 in Heat Pumps-Solving Energy and Environmental Challenges, \\ proceedings of the 3rd IEA Heat Pump Conference, Tokyo, Mar. 12-15, 1990, Pergamon Press, Elmsford, N.Y.)
}

Advanced technologies for gas-fired absorption heat pumps, air-conditioners, and chillers for building space conditioning are being developed in the United States with support from a number of organizations and manufacturers. Single-effect cycle absorption heat pumps were developed in the 1970s, but proved to be too costly to manufacture. Several advanced cycle heat pump projects were started in 1982 and 1983 and have demonstrated substantially improved efficiency with simultaneously reduced manufacturing cost.

Development of advanced cycle residential heat pumps continues with a goal of product introduction by 1992 or
1993. Because of the importance of air conditioning, projects have also been underway since the mid-1980s to substantially improve the cooling performance of absorption equipment. Air-cooled LiBri/H20 air-conditioning technology is being developed to increase the potential markets for double-effect equipment, and triple-effect cycles are being developed to dramatically improve cooling efficiency compared to existing absorption chillers.

Research sponsored by the U.S. Department of Energy Office of Buildings and Community Systems.

\section{TRIPLE EFFECT ABSORPTION CHILLER CYCLE: A STEP BEYOND DOUBLE-EFFECT CYCLES}

\author{
R. C. DeVault \\ (Abstract of pp. II-27-II-40 in Proceedings of the IEA Annex XVI Workshop, Report No. HPC-WR-6, \\ IEA Heat Pump Centre, Susono City, Japan, March 1990)
}

Many advanced absorption cycles have been proposed during the current century. Of the hundreds of absorption cycles that have been patented throughout the world, all commercially manufactured products for air-conditioning buildings have been variations of only two basic absorption cycles: single-effect and conderiser-coupled, double-effect cycles. The relatively low cooling coefficients of performance (COPs) inherent in single-effect and double-effect cycles limits the economic applicability of absorption air conditioners (chillers) in the United States. A triple-effect absorption chiller cycle is discussed. This cycle uses two condensers and two absorbers to achieve the triple effect. Depending on the absorption fluids selected, this triple-effect cycle is predicted to improve cooling COPs by $18 \%$ to $60 \%$ compared with the equivalent double-effect cycle. This performance improvement is obtained without increasing the total amount of heat-transfer surface area needed for the heat exchangers. A comparison between the calculated performances of a double-effect cycle and a triple-effect cycle [both using ammonia-water $\left(\mathrm{NH}_{3} / \mathrm{H}_{2} \mathrm{O}\right)$ as the absorption fluid pair] is presented. The triple-effect cycle is predicted to have an $18 \%$ higher cooling COP ( 1.41 compared with 1.2 for a double-effect), lower pressure [ $47.70 \mathrm{~atm}(701 \mathrm{psi})$ instead of $68.05 \mathrm{~atm}$ (1000 psi)], significantly reduced pumping power (less than one-half that of the double-effect cycle), and potentially lower construction cost (33\% less total heat exchange needed). Practical implications for this triple-effect cycle are discussed.

Research sponsored by the U.S. Department of Energy Office of Buildings and Community Systems. 


\author{
R. C. DeVault \\ J. Marsala ${ }^{a}$
}

[Abstract of paper in ASHRAE Transactions 96(1) (February 1990)]

There are a number of known absorption cycles capable of triple-effect refrigeration. Among the basic triple-effect cycles, only one particular cycle is able to use ammonia-water $\left(\mathrm{NH}^{3} / \mathrm{H}_{2} \mathrm{O}\right)$ as the absorption fluid pair. This cycle uses two condensers and two absorbers to achieve the triple effect. This paper presents several basic triple-effect cycles superimposed on $\mathrm{NH}^{3} / \mathrm{H}_{2} \mathrm{O}$ pressure-temperature-concentration equilibrium diagrams (PTX) showing that only one particular cycle can use $\mathrm{NH}^{3} / \mathrm{H}_{2}$. Calculations are presented comparing the performance of a conventional double-effect cycle using $\mathrm{NH}^{3} / \mathrm{H}_{2} \mathrm{O}$ and the performance of this triple-effect cycle using $\mathrm{NH}^{3} / \mathrm{H}_{2} \mathrm{O}$. The triple-effect cycle is predicted to have $18 \%$ higher cooling efficiency [coefficient of performance $(\mathrm{COP})=1.41$ compared to COP $=1.2$ for a double-effect $]$, lower pressure (701 psi instead of $1000 \mathrm{psi}$ ), significantly reduced pumping power (less than one-half that of the double-effect cycle), and potentially lower construction cost (33\% less total heat exchange needed). Practical implications for this triple-effect cycle are discussed.

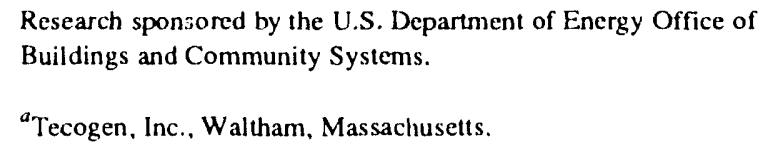

\title{
ENERGY TECHNOLOGY R\&D AND THE GREENHOUSE EFFECT
}

\author{
P. D. Fairchild \\ W. Fulkerson ${ }^{a}$ \\ (Abstract of pp. 231-41 in Heat Pumps-Solving Energy and Environmental Challenges, \\ proceedings of the 3rd IEA Heat Pump Conference, Tokyo, March 12-15, 1990, Pergamon Press, Elmsford, N.Y.)
}

Global warming from rising atmospheric $\mathrm{CO}_{2}$ concentrations is linked to fossil fuel use, which, in turn, is directly linked to energy end-use needs and the technologies we employ to meet those needs. None of the nonfossil options are ready yet to displace fossil fuels on the scale necessary to stop this rise. What do heat pumps have to do with the greenhouse warming effect? First, heat pumps represent one technology that can be used to increase the efficiency of energy use, which is the best near- to mid-term strategy for reducing the rate of greenhouse warming. Also, chlorofluorocarbons (CFCs) used in heat pump, air conditioning, and refrigeration equipment have emerged as potential "greenhouse gases." Future heat pump technology development therefore faces a complex set of trade-offs between direct atmospheric effects from CFC substitutes, indirect effects associated with energy efficiency and $\mathrm{CO}_{2}$ emissions, and the availability of options that can be used in the developing nations. Industrialized nations must recognize that solutions to these global environmental problems require international cooperation and worldwide participation.

\footnotetext{
Research sponsored by the U.S. Department of Energy Office of Buildings and Community Systems.

${ }^{a}$ Central Management Office.
} 
[7.4.21]

\title{
NATIONAL ENERGY IMPACTS OF CFC ALTERNATIVES IN HEATING, AIR-CONDITIONING, AND REFRIGERATION EQUIPMENT AND FOAM INSULATION
}

\author{
S. K. Fischer \\ [Abstract of paper in ASHRAE Transactions 96(1) (February 1990)]
}

Chlorofluorocarbons (CFCs) are used extensively as the working fluids in high-efficiency refrigeration equipment and as blowing agents in manufacturing high $\mathrm{R}$-value foam insulations. CFCs contribute to the destruction of stratospheric ozone and are a significant threat to the global environment. Future production and emissions of CFCs will be controlled under the

provisions of the Montreal Protocol, and the use of these compounds will be phased out. The U.S. Department of Energy is concerned about the energy efficiency impacts of alternative chemical compounds and technologies that may be used as substitutes for CFC-11 and CFC- 12 as refrigerants and blowing agents. This paper discusses the possible increase in national energy use resulting from the replacement of CFCs with alternative compounds. Significant increases in energy use could occur, particularly in refrigerator/freezers, freezers, water heaters, and commercial buildings.

Research sponsored by the U.S. Department of Energy Office of Buildings and Community Systems.

\section{[7.4.22]}

\section{THERMODYNAMIC CALCULATIONS FOR MIXTURES OF ENVIRONMENTALLY SAFE REFRIGERANTS USING THE LEE-KESLER-PLÖCKER EQUATION OF STATE}

\author{
S. K. Fischer \\ J. R. Sand \\ (Abstract of pp. 373-82 in Proceedings of the ASHRAE/Purdue CFC Conference, W. Lafayette, Ind., July 1990)
}

The imminent phaseout of R-11, R-12, and R-115 because of their high ozone depletion potentials has prompted many independent investigations of alternative or substitute refrigerants, either as pure compounds or as mixtures of two or more environmentally acceptable fluids. There are very few pure compounds which can be used to produce refrigerants that are nontoxic, nonflammable, and also have very low ozone depleting potentials and greenhouse warming potentials. Mixtures composed of three or more components offer a distinct advantage in that careful selection of the components could permit a flammable refrigerant to be used in a blend that remains nonflammable under all conditions. Also, component concentrations in ternary or higher order mixtures can be adjusted to linearize the temperature-enthalpy profile of a mixture, making it more suitable for applications where secondary fluids are heated or cooled through large temperature glides (i.e., refrigeration and air conditioning). The computer model LKPSIM was constructed from subroutines written by Ulf Plöcker and incorporated into a Lorenz cycle refrigerator/freezer simulation model for binary refrigerant mixtures developed at the University of Hannover. Modifications were made to the Hannover routines to compute thermodynamic properties for mixtures of 3 or more components, the list of available refrigerants was expanded from 11 to 17 possible choices, and a new correlation was developed for computing the interaction coefficients for mixtures of halocarbon refrigerants. Tables of refrigerant molecular weights, critical temperatures and pressures, normal boiling points, acentric factors, and coefficients for fits to the ideal gas heat capacity for each refrigerant are built into the model. Results of calculations of saturated and superheated vapor properties from the LKPSIM program were compared with experimental data and with computations using the Camahan-Starling-DeSantis (CSD) equation of state (EOS) for pure refrigerants and for binary and ternary mixtures of refrigerants. There is excellent agreement between the calculations and the published data for pure refrigerants that are well characterized (c.g., R-12, R-22) with greater discrepancies between LKPSIM and data from other sources for newer compounds (e.g., R-143a, R-124). Calculations were also performed to validate the program for mixtures. LKPSIM calculations agreed more closely with observed saturation properties for mixtures of $R-143 a$ and $R-124$ over a range of operating 
conditions and mixture compositions than did those of the CSD EOS. They also gave very close agreement with data from a manufacturer of a temary blend of refrigerants.
Research sponsored by the U.S. Department of Energy Office of Buildings and Community Systems.

\title{
CLOSING THE EFFICIENCY GAP: BARRIERS TO IN!PROVING ENERGY EFHTCIENCY
}

\author{
E. Hirst \\ M. A. Brown
}

[Abstract of Resources, Conservation and Recycling 3(4), 267-81 (June 1990)]

For a variety of reasons, households, businesses, menufacturers, and government agencies fail to fully exploit cost-effective energy-conserving opportunities. The result is a significant gap between the current and optimal levels of energy efficiency. This paper discusses various structt:al and behavioral bar .ers that inhibit adoption of energy-efficient practices and measures. Closing the energy-efficiency gap is important for many reasons. The most obvious benefit is the economic savings experienced by those who adopt energyefficiency improvements. At least $\$ 150$ billion is being saved annually as a result of the energy-effici ncy gains that have taken place over the past 15 years. beyond these airect benefits, there are also several $w a_{3} 3$ that society gains. Improved energy efficiency can help U.S. industrial competitiveness in both domestic and international markets. It contributes to nationai security by offering an altemative to imported fueis, which are vulnerable to price shocks and suppiy shortages. Improved energy efficiency can also reduce the foreign trade deficit by reducing the $\$ 40$ billion a year that the country pays for imported oil. Finally, energy-efficiency improvements offer an cnvironmentally benign way to fuel the economy and satisfy end-user needs.

Research sponsored by the U.S. Department of Energy Office of Conservation and Renewable Energy.

\section{BALANCING THE SCALES: DATA ON ELECTRICITY SUPPLY AND DEMAND RESOURCES}

\author{
E. Hirst
}

(Abstract of ORNL/CON-306, Oak Ridge National Laboratory. September 1990)

As the number, scope, and cost of utility demand-side management (DSM) programs increas:, the need for accurate data grows. Such data are required in order to be sure that such programs deliver the cost-effective energy and capacity resources expected of them. Unfortunately, the amount and quality of data availabie on DSM programs fall far short of what is needed. Lack of explicit, widely used definitions of DSM terms is a key deficiency. Variables that tescribe program participation, electricity saving,s, and costs must be carefully defined, and these definitions should then be used throughout the electric-utility industry. Reports on program cricrgy savings should distinguish between total and net savings. (Total energy savings refer to the reductions in electricity use that program participants experience.) Such reports should also indicate the basis for these estimates. Energy saving: can be computed with simple rules of thumb, engineering models, periodic measurements of electricity use, monthly electricity bills, or end-use load monitoring. These approaches differ in th. ir accuracy, relevance to different types of DSM programs, and cost. Data on program costs should distinguish between utility and customer costs. It is also useful to separate the utility costs for installation of equipment from administrative costs.

Reseas 2 sponsored by the U.S. Department of Energy Office of

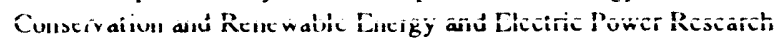
Instriute 


\title{
INTEGRATED RESOURCE PLANNING FOR ELECTRIC AND GAS UTILITIES
}

\author{
E. Hirst \\ C. Goldman ${ }^{a}$ \\ M. E. Hopkins ${ }^{b}$
}

(Abstract of pp. 5.95-5.114 in Proceedings of the ACEEE 1990 Sunmer Study on Energy Efficiency in Buildings, Vol. 5, Pacific Grove, Calif., Aug. 26-Sept. 1, 1990)

During the past few years, the scope and nature of resource planning at electric utilities have changed dramatically. The scope of planning has expanded to consider energy-efficiency and load-management programs as resources, the environmental costs of electricity production, and a variety of resource-selection criteria beyond electricity price. The nature of planning has expanded to include regulatory commissions, nonutility energy experts, and customers, as well as utilities themselves. Similar changes are beginning to occur at gas utilitie. This paper discusses a few of the key issues related to resource planning: provision of financial incentives to utilities for successful implementation of integrated resource plans, incorporation of environmental factors in resource planning, bidding for demand and supply resources, development of guidelines for preparation and review of utility integrated resource plans, resource planning for gas utilities, and greater efforts by the U.S. Department of Energy to encourage integrated resource planning.

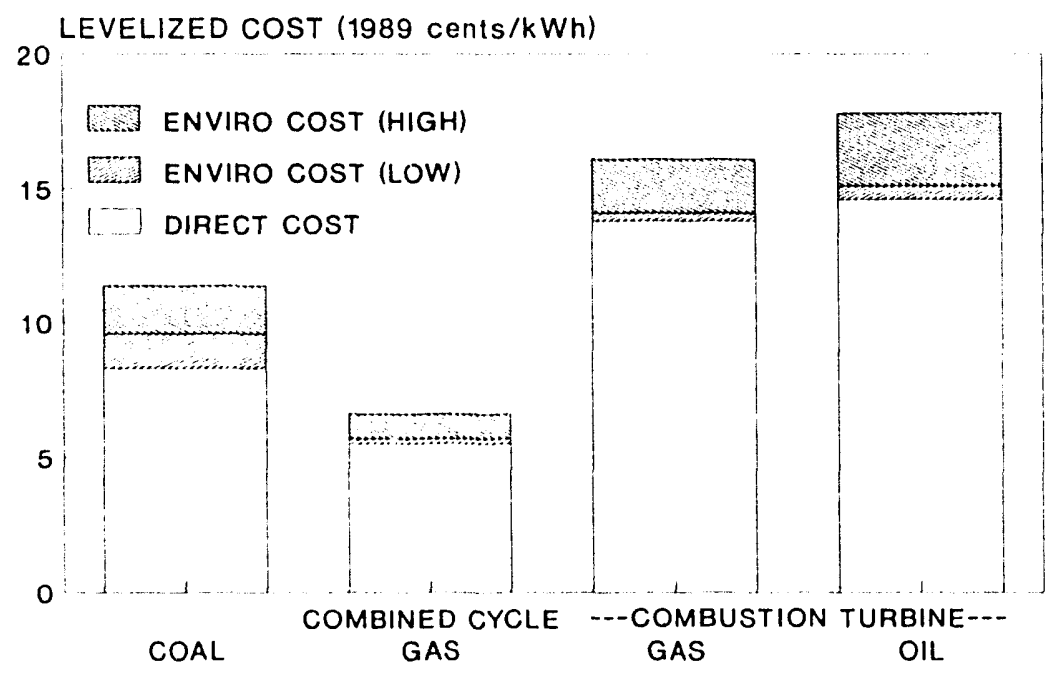

The environmental costs of electricity production are not reflected in the price of electricity. Such pollution adds $5 \%$ to $40 \%$ to the direct cost of building and operating power plants.

Research sponsored by the U.S. Department of Energy Office of Conservation and Renewable Energy.

${ }^{a}$ Lawrence Berkeley Laboratory, Berkeley, Califomia.

${ }^{b}$ The Fleming Group, Washingion, D.C.

\section{GUIDELINES FOR A "GOOD" INTEGRATED RESOURCE PLAN}

\author{
E. Hirst
}

[Abstract of Public Utilities Fortnightly 125(7), 18-24 (March 1990)]

During the past several years, more and more electric utilities have prepared long-term resource plans that integrate demand-side programs into the utility's mix of energy and capacity resources. Although several organizations have listed the number of states with laws or regulations requiring utilities to prepare such plans, no one has yet reviewed enough plans to assess utility progress in integrated-resource planning or to develop criteria for what constitutes a good plan. This paper offers initial guidelines, an early product of an ongoing project at Oak Ridge National Laboratory.

Research sponsured by the U.S. Department of Energy Office of Conservation and Renewable Energy. 


\title{
ELECTRIC-UTILITY RESOURCE PLANNING AND DECISION MAKING: THE IMPORTANCE OF UNCERTAINTY
}

\author{
E. Hirst \\ M. Schweitzer
}

[Abstract of Risk Analysis 10(1), 137-46 (March 1990)]

Uncertainty is a critical factor that pervades all aspects of electric-utility planning. Uncertainties about future load growth; about the continued performance of existing supply and demand resources; and about the costs, construction times, and operations of new resources greatly complicate utility resource acquisition. This paper discusses the factors that lead to uncertainty, reviews the methods that utilities use in planning and acquiring resources, and suggests future research to help deal with these uncertainties. This review is based on assessments of the long-term resource plans prepared by 10 utilities and one public service commission, telephone interviews with staff at these 11 organizations and with staff at 3 consulting firms, and reviews of many other related publications.

Research sponsored by the U.S. Department of Energy Office of Conservation and Renewable Energy.

\section{[7.4.28] ASSESSING INTEGRATED RESOURCE PLANS PREPARED BY ELECTRIC UTILITIES}

\author{
E. Hirst \\ M. Schweitzer \\ E. Yourstone ${ }^{a}$ \\ J. Eto ${ }^{b}$
}

(Abstract of ORNL/CON-298, Oak Ridge National Laboratory, February 1990)

During the past several years, more and more electric utilities have prepared long-term resource plans that integrate demand-side programs into the utility's mix of energy and capacity resources. Several organizations have enumerated the states with laws or regulations requiring utilities to prepare such plans. But no one has yet reviewed enough plans to assess utility progress in integrated-resource planning or to develop criteria for a good plan. This report suggests guidelines for the preparation and review of utilities' reports on their resource plans. We reviewed more than 30 resource plans and related documents from electric utilities and government agencies. Guidelines in the form of a checklist were developed on the basis of these reviews. This chesklist should help staff in public utility commissions who review the utility reports, as well as utility staff who prepare such planning reports. Four broad topics are covered in the checklist (and in the body of this report): (1) the clarity with which the contents of the plan, the procedures used to produce it, and the expected outcomes are presented; (2) the technical competence (including the computer models and supporting data and analysis) with which the plan was produced; (3) the adequacy and detail of the short-term action plan; and (4) the extent to which the interests of various stakeholders are addressed.

\footnotetext{
Research sponsored by the U.S. Department of Energy Office of Buildings and Community Systems.

${ }^{a}$ Consultant, Albuquerque, New Mexico.

${ }^{b}$ Lawrence Berkeley Laboratory, Berkeley, California.
}

DATA REQUIREMENTS FOR UTILITY INTEGRATED RESOURCE PLANNING

\author{
E. Hirst
}

[Abstract of Energy Systems \& Policy 12(3), 219-31 (December 1989)]

Integrated resource planning requires electric utilities to carefully and comprehensively assess a broad array of demand and supply alternatives. Data and ascumptions on these resources and on a utility's extemal environment are required. both to compare resources and to test diverse resource portfolios against various uncertainties. This review of available data concludes that much more information is availahle on supply resources than on demand-side management programs. This disparity exists because utilities have had 
substantially more experience with the construction and operation of power plants than with the design and administration of conservation and load-management programs. However, demand-side programs have inherent uncertainty-reducing features that make them attractive to utilities.
Research sponsored by the U.S. Department of Energy Office of Policy Integration and the Office of Buildings and Community Systems.

\title{
FLEXIBILITY BENEFITS OF DEMAND-SIDE PROGRAMS IN UTILITY PLANNING
}

\author{
E. Hirst
}

[Abstract of Energy Journal 11(1), 151-65 (November 1989)]

Electric utilities face a variety of uncertainties that complicate their long-term resource planning and acquisition. Many utilities deal with these uncertainties by pursuing flexible strategies that allow changes to be made incrementally with little difficulty and at low cost. Thus, utilities today avoid construction of large, baseload power plants because of their long construction times and high capital costs. On the other hand, utilities view combustion turbines as flexible because they have small unit sizes, take only a few years to build, are inexpensive, and can later be converted to combined-cycle units (to increase capacity and improve performance). Conservation and load-management programs, because of their inherently small unit size and opportunities to adjust participation over time, are more attractive for the same reasons. This paper compares the benefits of flexibility provided by resources with short lead times and small sizes with the costs of these altematives. The focus is on utility demand-side managemci:c programs, primarily because the flexibility benefits of such programs have not been quantified. Utilities can adjust participation in their demand-side programs over time. This flexibility yields substantial economic benefits because these electricity savings can closely match future load growth.

Research sponsored by the U.S. Department of Energy Office of Buildings and Community Systems.

\section{ELECTRIC-UTILITY DEMAND-SIDE PROGRAMS: RESOURCES FOR THE 1990s}

\author{
E. Hirst
}

\author{
(Abstract of pp. 46-56 in Proceedings of the American Power Conference, Vol. 51, Apr. 24, 1989. \\ Illinois Institute of Technology, Chicago, November 1989)
}

The purpose of this paper is to suggest much larger and more active roles for electric utilities in acquiring energy-efficiency and load-management resources. Valuable strategies include (1) increased efforts to assess existing and new demand-side technologies; (2) testing alternative ways to implement demand-side programs; (3) aggressively acquiring energy and capacity resources through efficiency and load-management programs; (4) developing innovative pricing mechanisms to modify load shapes and levels and encouraging participation in utility programs; (5) working with govemments to support efficiency standards for new buildings, appliances. and other energy-using equipment;
(6) integrating planning for demand-side programs with planning for supply resources; and (7) incorporating the risk-reduction benefits of demand-side programs into resource planning. These activities will improve the efficiency with which energy and capital resources are used, rather than suppressing electricity demand per se. In so doing, these utility programs will enhance economic productivity and international competitiveness and will reduce emissions of pollutants from power plants.

Research sponsored by the U.S. Department of Energy Office of Buildings and Community Systems. 


\title{
A NONALGORITHMIC REVIEW OF UNCERTAINTY IN ELECTRIC-UTILITY RESOURCE PLANNING AND DECISION MAKING
}

\author{
E. Hirst \\ (Abstract of pp. 65-80 in Proceedings on Resource Planning Under Uncertainty for Electric Power Systems, Jan. 21-22, 1989. \\ Department of Operations Research, Stanford University, Stanford, Calif., November 1989)
}

Uncertainty is a critical factor that pervades all aspects of electric-utility planning. Uncertainties about future load growth; about the continued performance of existing supply and demand resources; and about the costs, construction times, and operations of new resources greatly complicate utility resource acquisition. This paper discusses the integrated-resource planning process that many utilities now use to address uncertainty, reviews the methods that utilities use in planning and in acquiring resources, and suggests future research to help deal with uncertainties. This review is based on assessments of the long-term resource plans prepared by 10 utilities and one public service commission, telephone interviews with staff at these 11 organizations and with staff at 3 consulting firms, and reviews of other related publications.

Research sponsored by the U.S. Department of Energy Office of Conservation and Renewable Energy.

\section{FEDERAL ROLES TO REALIZE NATIONAL ENERGY-EFFICIENCY OPPORTUNITIES IN THE 1990s}

\author{
E. Hirst \\ (Abstract of ORNL/CON-290, Oak Ridge National Laboratory, October 1989)
}

The purpose of this report is to suggest an expanded role for the U.S. Department of Energy (DOE) in improving energy efficiency during the $1990 \mathrm{~s}$. In an ideal world, the normal workings of the market place would yield optimal energy-efficiency purchase and operating decisions. Unfortunately, distortions in fuel prices, limited access to capital, misplaced incentives, lack of information, and difficulty in processing information complicate energy-related decision making. Thus, consumers in all sectors of the economy underinvest in energy-efficient systems. These market barriers, coupled with growing concern about environmental quality, justify a larger federal role. DOE's ongoing National Energy Strategy may develop an energy policy for the 1990s with a strong role for energy

efficiency. As part of that energy

policy, the President could direct all federal agencies to make improved energy efficiency a priority. This directive plus increased funding and responsibility for the Fodcral Encrgy Management Program could greatly reduce the federal government's fuel bill, currently

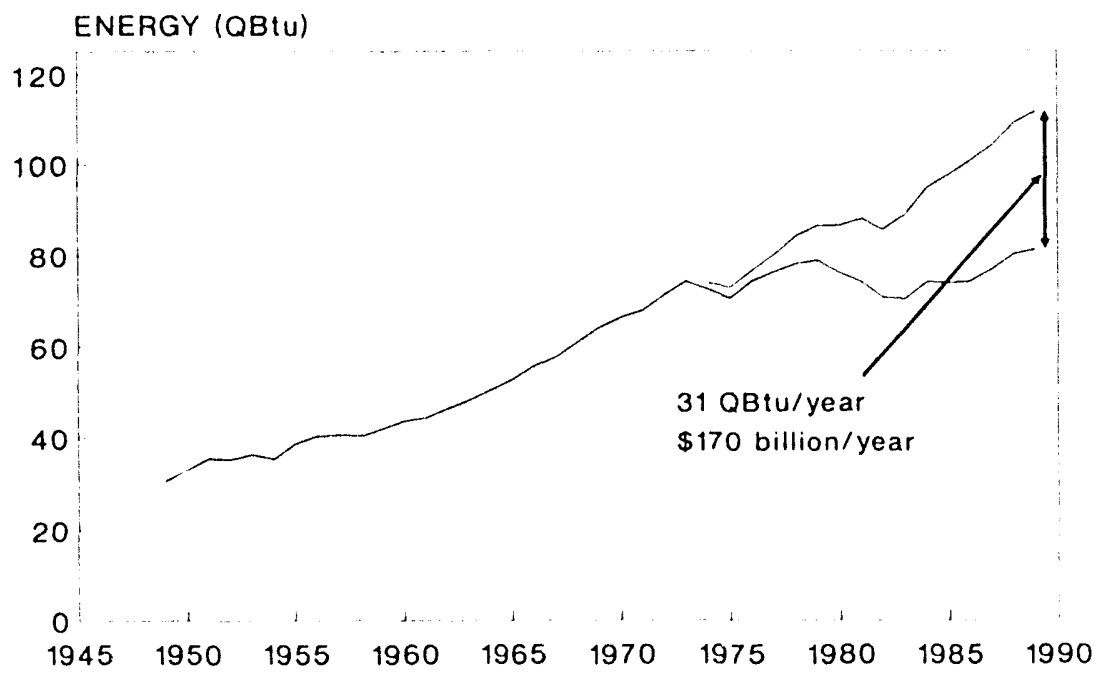

U.S. primary energy consumption from 1947 through 1989. The upper line shows what energy use would have been had the energy use/gross national product ratio remained at its 1973 level.
$\$ 8$ billion a year. In addition, federal facilities could demonstrate new technologies, which would be a valuable technology-transfer mechanism.

Research sponsored by the U.S. Department of Energy Office of Conservation and Renewable Energy. 


\title{
RADIANT BARRIER FIELD TESTS IN ARMY HOUSING UNITS AT FORT BENNING, GEORGIA
}

\author{
W. P. Levins \\ D. Herron ${ }^{a}$
}

[Abstract of paper in ASHRAE Transactions 96(2) (June 1990)]

The U.S. Army initiated a project to make

measurements of heating and cooling energy in occupied Army housing units to determine the effect of radiant barriers (RBs) on energy consumption at Fort Benning in Columbus, Georgia. One side $\left(1700 \mathrm{ft}^{2}\right)$ of each of five duplexes was used as a control (no RB was installed in it), while the other side had a perforated RB laid on top of the existing estimated R-11 fiberglass loose-fill attic insulation in the middle of July. The RBs were removed in the middle of January. All houses were instrumented with data logging equipment which measured air conditioner and gas furnace energy usages. Cooling season measurements showed that submetered air conditioner KWh-meter data, read on a weekly basis, did not describe the performance of the RBs. Occupant lifestyle in general, and a dirty air filter at one site, nullified direct meter reading comparisons. Attic heat flow and temperature measurements revealed that the RBs were effective at all sites. Extensive regression analyses showed that savings were indeed obtained. Using the regression results with published temperature-bin data for Fort Benning gave estimated annual cooling savings from horizontal radiant barrier (HRB) use ranging from 253 to $1354 \mathrm{KWh}$, or from 3 to $17 \%$. Heating energy usage did not appear to be affected by lifestyle as much as was cooling energy usage. HRBs gave an annual space heating savings of about 42 to 70 hundred cubic feet of gas ( 11 to $19 \%$ ) using averaged daily data to generate regression models. Measured emissivity values for samples of the horizontally mointed radiant barrier material showed essentially no change for the 6-month period during which they were installed in the 5 test units. Although RBs were effective at Fort Benning, it is recommended that more testing be done, especially in colder climates and in drier desert climates, before any general conclusions regarding the use of RBs in Army housing are formulated.

Research sponsored by the U.S. Department of Energy Office of Buildings and Community Systems.

${ }^{\circ}$ Construction Engineering Research Laboratory, Champaign, Illinois.

\section{MEASURED EFFECTS OF DUST ON THE PERFORM 6 NCE OF RADIANT BARRIERS INSTALLED ON TOP OF ATTIC INSULATION}

\author{
W. P. Levins \\ J. A. Hall ${ }^{a}$ \\ [Abstract of paper in ASHRAE Transactions 96(2) (June 1990)]
}

The rate of dust accumulation and the effect of this accumulation on a horizontal radiant barrier (HRB) are of special interest because HRB may perform better in both summer and winter than a truss radiant barrier (TRB). An HRB is much easier to retrofit in existing homes and requires less radiant barrier (RB) material than a TRB. However, an HRB has two important potential disadvantages - condensation during winter which might cause structural damage, and dust accumulation that could significantly degrade thermal performance. TVA tested dusted HRB performance in small $48-\mathrm{ft}^{2}$ test cells in the summer of 1987 . The results indicated that dust accumulation may not be a prohibitive problem for HRB installations. However, TVA researchers believed further study of this subject was needed. Oak Ridge National Laboratory conducted tests on dusted HRBs at the Karns research houses near Oak Ridge, Tennessee, during the summer of 1988. Results showed that the lighter dust loading $\left(0.34 \mathrm{mg} / \mathrm{cm}^{2}\right)$ increased total house cooling loads, compared to a clean $\mathrm{HRB}$, by $2.3 \%$. The heavier dust loading $\left(0.74 \mathrm{mg} / \mathrm{cm}^{2}\right)$ increased house cooling loads by $8.4 \%$, again compared to a clean HRB. However, HRBs with these dust loadings still decreased house cooling loads by $7 \%$ when compared to the same house with no HRB.

\footnotetext{
Research sponsored by the U.S. Department of Energy Office of Buildings and Community Systems.

${ }^{a}$ Tennessee Valley Authority.
} 


\title{
COOLING SEASON ENERGY MEASUREMENTS OF DUST AND VENTILATION EFFECTS ON RADIANT BARRIERS
}

\author{
W. P. Levins \\ J. A. Hall ${ }^{a}$ \\ M. A. Kamitz
}

(Abstract of ORNL/CON-271, Oak Ridge National Laboratory, March 1990)

Cooling season tests were conducted in three unoccupied ranch-style houses in Karns, Tennessee, to determine the effects on attic radiant barrier performance incurred by changes in attic ventilation area ratio, attic ventilation type, and the buildup of dust on horizontal radiant barriers (HRB). All three houses had R-19 fiberglass batt insulation in their attics. HRBs were artificially dusted and the dusted barriers showed measurable performance degradations, although the dusted barriers were still superior to no radiant barriers (RB). Dust loadings of 0.34 and $0.74 \mathrm{mg} / \mathrm{cm}^{2}$ reduced a clean RB surface emissivity of 0.055 to 0.125 and 0.185 , respectively. Total house cooling load increases amounted to 2.3 and $8.4 \%$ compared to house loads with clean HRBs, respectively. When compared to R-19 with no HRB conditions, the dusted HRs reduced cooling loads by about $7 \%$.

Research sponsored by the U.S. Department of Energy Office of Buildings and Community Systems, Tennessee Valley Authority, Electric Power Research Institute, and Reflective Insulation Manufacturers Association.

${ }^{\lrcorner}$Tennessee Valley Authority.

\section{[7.4.37]}

\section{MEASURED EFFECTS OF ZONING IN SINGLE-FAMILY HOUSES}

\author{
W. P. Levins \\ (Abstract oi Thermal Per,ormance of the Exterior Envelopes of Buildings $W$, proceedings of the \\ ASHRALiIOE/BTECC/CIBSE Conference, Orlando, Fla., December 1989)
}

The zoning of sections of a house by closing doors and air supply and return registers in certain rooms is a practice usually thought to conserve energy in households. Previously reported measurements of energy required for resistance heating and heat pump heating in three unoccupied, well-instrumented, single-family, ranch-style houses in Knoxville, Tennessee, showed that heat pump heating savings were somewhat lower than resistance heating savings. Measurements of heat pump cooling energy usage as well as actual, sensible, and latent loads were made in the same houses. Temperatures in closed-off rooms floated with the outdoor temperature variations, but no savings were observed in the overall heat pump electrical usage or in the house cooling load. Measurements made on the heat pump operating parameters showed minor effects on airflows and refrigerant operating pressures until about $40 \%$ of the house area was zoned off. Formaldehyde measurements in zoned-off rooms were also made during cooling season operation, and they did not differ appreciably from the levels in the nonzoned portion of the house.

Research sponsored by the U.S. Department of Energy Office of Buildings and Community Systems. 


\title{
EXPLORATORY INVESTIGATION OF A NEW MODELING APPROACH AND AN ENERGY INDEX FOR MULTIFAMILY BUILDINGS IN THE PACIFIC NORTHWEST
}

\author{
J. M. MacDonald \\ D. L. White \\ (Abstract of Ip. 10.145-10.152 in Proceedings of the ACEEE 1990 Summer Study in Energy Efficiency in Buildings, Pacific Grove, Calif., Aug. \\ 26-Sept. 1, 1990)
}

In this study, a sinusoidal model of empirical energy data for all-electric multifamily (MF) buildings in the Pacific Northwest was developed. The sinusoidal model uses short-term submetered heating energy data to model seasonal heating energy use for MF buildings. The model gives reasonable estimates of annual heating energy use for three older buildings for the preretrofit and postretrofit cases and less reasonable answers for heating energy savings. The estimates of heating energy and heating energy savings for the three buildings were based on starting values for three free parameters of the model developed for one building. After the starting parameters are determined, only one parameter is modified for other buildings and conditions, based on the monthly fraction of energy used for heating in January.
The heating fraction in January is determined from submetered heating energy for that month. Thus, metering studies would need to monitor heating energy use for January and collect monthly data from the utility billing meters for a particular building, to obtain the data needed for this model to provide an annual heating energy estimate. Further research is needed to verify the potential benefits of this model. A two-parameter index for representation of MF energy use is also presented. This index helps keep space heating energy in perspective relative to other energy use in MF buildings and should aid in comparing the energy performance of MF buildings.

Research sponsored by Bonneville Power Administration.

\section{MOTORS}

\section{B. W. McConnell}

(Abstract of Energy Applications of High-Temperature Superconductivity, Vol. 2, Chap. 3, eds. S. J. Dale, S. M. Wolf, and T. R. Schneider, ER-6682, Electric Power Research Institute, Palo Alto, Calif., September 1990)

Previous experience i $r_{i}$ applying superconductors to electri: motors and the difficulties encountered are reviewed. Although motors and generators have a common basis, several differences that have significant impacts on motor design exist. The application of high-temperature superconductors to the major electric motor types is discussed; expected difficultics are presented. A set of desired performance features is developed and the known types of superconducting motors are evaluated subjectively against these features. The five most promising motor types are further evaluated both technically and ORNL-DWG. 89-6605 economically. The limitations imposed by various motor designs are reflected in a statement of the desired

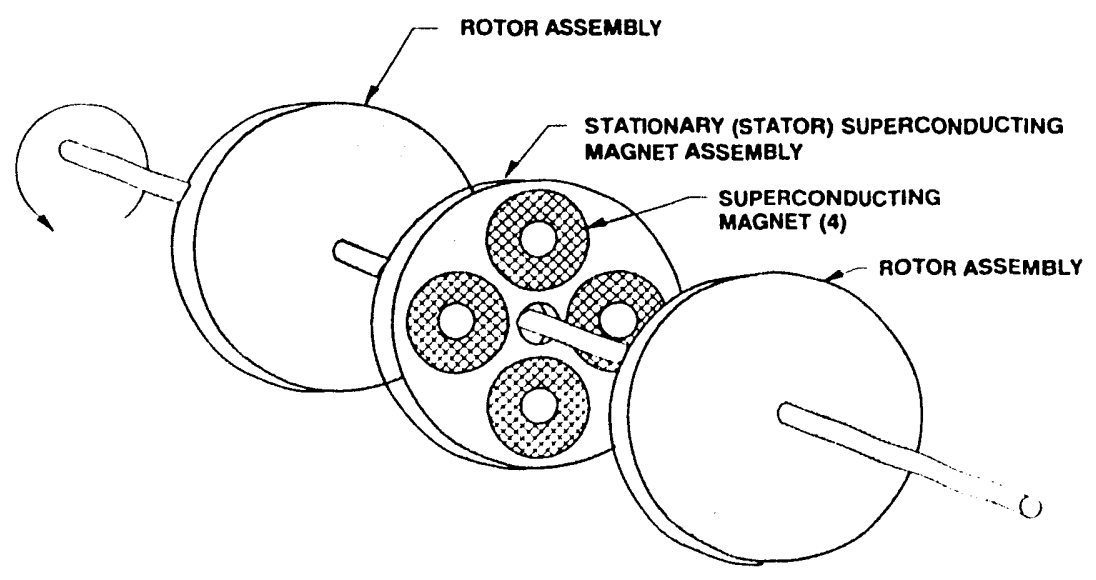

An ax:al-gap superconducting motor. 
material propertics for high-temperature superconductor electric-motor applications. The economics of superconducting motors is then examined based on the time required for break-even costs and for the break-even size for different motor types with both openand closed-cycle cooling.
Research sponsored by the U.S. Department of Energy Office of Conservation and Renewable Energy and Electric Power Research Institute.

\title{
HEAT TRANSFER OF BURIED PIPE FOR HEAT PUMP APPLICATION
}

\author{
V. C. Mei \\ (Abstract of pp. 23-29 in Advances in Heat Pumps 1989, ASME Symposium Volume AES-Vol. 7. Dec. 10-15, 1989)
}

Ground coil heat pump systems are well known for their potential for energy conservation. The inajority of the ground coil designs were based on the application of the line source theory. A modified line source method was later derived to calculate the ground temperature distribution by dividing the ground around the coil into "blocks." However. the line source approach has some major drawbacks, a fact that often leads to the over design of the ground coil. It was anticipated that in order for the ground coil heat pump systems to be economically competitive with other residential heating and cooling systems, grouild coil over design had to be kept at a minimum. A new ground coil model was derived, based on energy balance rather than the line source theory. It was intended to accurately predict the operation of ground coils. It is, therefore, interesting to compare different ground coil models by using them to simulate the same field test data. The results indicated that the new model predicted the experimental data better than the other two models. In this paper, the above-mentioned ground coil models were selected for this study. The results indicated that the model based on energy balance predicted the test data best.

Research sponsored by the U.S. Department of Energy Buildings and Community Systems.

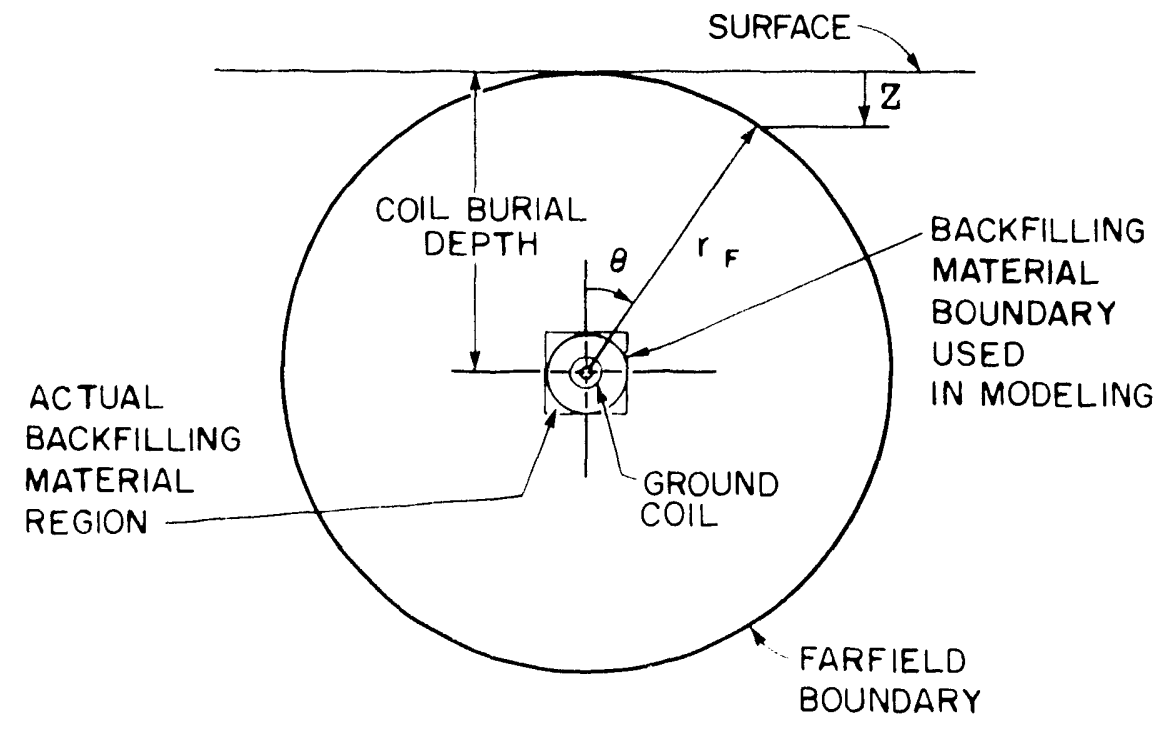

Schematic of ground coil for Mei's mor'el. 


\title{
LABORATORY SIMULATION OF DIRECT EXPANSION GROUND COIL HEAT EXCHANGER
}

\author{
V. C. Mci \\ V. D. Baxter \\ [Abstract of paper in ASHRAE Tre nsactions 96(1) (February 1990)]
}

Direction expansion ground coil (DXGC) ground coupled heat pump (GCHP) systems have certain energy efficiency advantages over conventional GCHPs. Principal among them is the elimination of the secondary heat transfer fluid heat exchanger and circulating pump. While the DXGC concept can have higher efficiencies, it also has more system design and environmental problems (e.g., compressor starting and oil return problems). General design guidelines for DXGC systems are not well documented. This study aimed to examine experimentally some of the advantages and disadvantages of DXGC designs. A laboratory study of a DXGC heat pump system was performed. The results of the laboratory tests indicated that a DXGC can absorb from or dissipate to the ground at least twice as much heat as can conventional plastic tube ground coil heat exchangers. Some of the previously mentioned concerns were also studied during the tests. A set of general design guidelines was derived from the test results and observations; it is presented in this report.

\section{PERFORMANCE TESTING OF A COMMERCIALLY PRODUCED CRYOGENIC REFRIGERATOR}

\author{
E. G. Keshock ${ }^{a}$ \\ R. W. Murphy \\ (Abstract of ORNL/TM-10809, Oak Ridge National Laboratory, September 1990)
}

A commercially available cryogenic refrigeration unit, model M-20 (3-phase, 60-Hz, 230-V), manufactured by Cryodynamics, Inc., was subjected to laboratory testing to measure some of its performance characteristics. Comparisons were made with those performance characteristics given in manufacturer literature for the M-20 unit (3-phase, 400-Hz, 208-V). At $77 \mathrm{~K}$, the measured cooling capacity of the $60-\mathrm{Hz} / 230-\mathrm{V}$ unit was very nearly the same ( $<2 \%$ difference) as the specified capacity $(110 \mathrm{~W})$ of the $400-\mathrm{Hz} / 208-\mathrm{V}$ unit. At temperature levels higher than $77 \mathrm{~K}$, measured cooling capacities exceeded the manufacturer product data sheet values. Coefficients of performance (COPs) based on the experimental measurements ranged from about 0.37 at $250 \mathrm{~K}$ to 0.03 at $70 \mathrm{~K}$. Comparison of measured to ideal (Carnot cycle) COPs yielded values ranging from about 8 to $18 \%$, with a broad maximum occurring between approximately 100 and $150 \mathrm{~K}$. Finally, the measured cool-down time from room temperature to $77 \mathrm{~K}$ was about $10 \mathrm{~min}$ compared with a specification sheet value of $7.4 \mathrm{~min}$. This difference may be attributed to lower thermal mass (without heater block) and higher operating frequency conditions associated with the specification.

\footnotetext{
Research sponsored by the U.S Department of Energy Office of Buildings and Community Systems.

${ }^{a}$ University of Tennessee.
} 

AQUEOUS LITHIUM BROMIDE SOLUTIONS

\author{
M. R. Patterson ${ }^{a}$ \\ R. N. Crosswhite ${ }^{b}$ \\ H. Perez-Blanco
}

(Abstract of ORNL/TM-11331, Oak Ridge National Laboratory, January 1990)

This report is a user's guide with a floppy disk containing a PC program to calculate and plot the properties of lithium bromide-water solutions. The properties of aqueous lithium bromide solutions are employed for cycle calculations and for sizing components of absorption machines. In the past, those calculations were done employing diagrams extracted from handbooks or property routines available in mainframe computers. However, the routines needed updating, and the widespread use of PCs seemed to call for a program that combined the convenience of a menu to select properties with the ability to draw cycles and processes on the screen. A menu-driven computer program was developed for use in IBM-compatible PCs with math coprocessors. The program calculates the thermodynamic and transport properties of lithium bromide-water solutions as reported in the open literature. The program includes plotting capabilities that allow the user to draw cycles and processes in property charts and to save the relevant state points for further calculations.

Research sponsored by the U.S. Department of Energy Office of Buildings and Community Systems.

${ }^{a}$ Computing and Telecommunications Division.

${ }^{b}$ Oak Ridge Associated Universities.

\title{
[7.4.44]
}

\section{INITIAL PARAMETRIC RESULTS USING CYCLEZ-AN LMTD-SPECIFIED LORENZ CYCLE REFRIGERATION-FREEZER MODEL}

\author{
C. K. Rice \\ J. R. Sand
}

(Abstract of pp. 448-58 in Proceedings of the ASHRAE/Purdue CFC Conference, W. Lafayette, Ind., July 1990)

A computer model representing a

ORNL-DWG. 90-6063

two-evaporator, two-intercooler

refrigerator-freezer operating at steady state

with nonazeotropic refrigerant mixtures

(CYCLEZ) has been developed at Oak Ridge

National Laboratory. This model is being used

to assess the effects of system design and

operating parameters on the cycle performance

of a refrigerator-freezer designed around the

Lorenz-Meutzner circuit. Separate evaporators

for the freezer and fresh-food compartments

are modeled, as well as two intercoolers that

subcool liquid refrigerant from the condenser

by heat transfer with low-pressure refrigerant.

The CYCLEZ refrigerator/freezer model is derived from the CYCLE7 heat-pump model developed originally by the National Institute

Schematic diagram of the Lorenz-Meutzner refrigerator-freezel

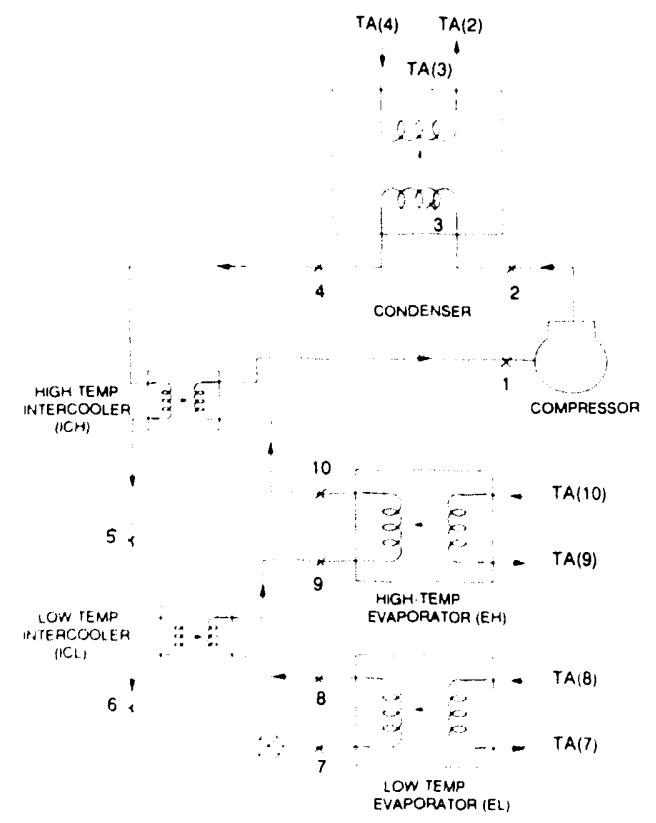


of Standards and Technology. CYCLEZ currently uses the Carnahan-Starling-DeSantis equation of statc to compute refrigerant thermodynamic properties, so that new refrigerants can easily be added. Condenser and evaporator heat-exchanger performance are defined by user-specificd overall logarithmic mean temperature differences (LMTDs) that allow equivalent heat-exchanger sizing per unit refrigeration load to be maintained for different refrigerant mixtures. A more consistent formulation of overall heat-exchanger LMTD is applied across the condenser superheated and two-phase regions as well as over the two evaporators. Source and sink conditions are specified in terms of inlet and outlet temperatures of the external fluid streams. Intercooler high-side (subcooling) $\Delta T$ s and relative fresh-food-to-freezer load ratio are also user-specified. These features make this model well suited for evaluating the optimal thermodynamic cycle requirements of the five heat exchangers used in the L-M refrigerator/freezer circuit. Parametric investigations involved 19 ozone-safe refrigerant combinations being considered for this application. Effects of the distribution of heat-exchanger area, extent and distribution of intercooler subcooling/superheat, refrigerant mixture composition, and relative refrigerator/freezer loading were investigated. The model indicates that improvements of 10 to $20 \%$ in coefficients of performance are possible using mixed refrigerants in this cycle configuration compared with the standard refrigerator/freezer circuit using R12. Most of this improvement is due to closer matching between the air and refrigerant temperature profiles across the evaporators. However, intercooler subcooling also results in a decreased pressure ratio across the compressor.

Research sponsored by the U.S. Department of Energy Office of Buildings and Community Systems.

\title{
[7.4.45] EXPERIMENTAL PERFORMANCE OF OZONE-SAFE ALTERNATIVE REFRIGERANTS
}

\author{
J. R. Sand \\ E. A. Vineyard \\ J. R. Nowak ${ }^{a}$ \\ [Abstract of paper in ASHRAE Transactions 96(2) (June 1990)]
}

Several compuunds proposed as near-term or longer range substitutes for the regulated chlorofluorocarbon (CFC) refrigerants were tested in a breadboard vapor-compression circuit, and their performance was compared to that of more commonly used refrigerants. The limited physical property information available in the literature for these alternative compounds was used to fit an equation of state so that coefficients of performance and capacities calculated from refrigerant property subroutines could be compared to those obtained experimentally. Comparisons of measured and modeled performance are given for 11 alternatives and for R22, R12, and R114. Estimates of compressor efficiency with each refrigerant are provided. Several of the alternatives exhibited better performance than the more widely used refrigerants at some or all of the conditions tested. Ozone-safe, altemative refrigerants that performed better than CFC counterparts at selected conditions are R152a, R143a, R134a, R134, and R142b.
ORNL-DWG. 91Z-7905

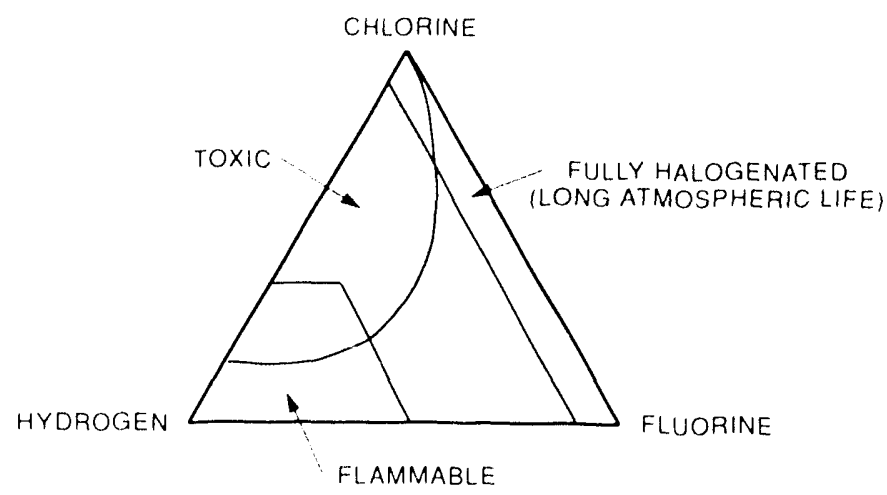

Trade-offs among the properties of CFC refrigerants.

Research sponsored by the U.S. Department of Energy Office of Buildings and Community Systems.

a'urdue Lniversity, West Lafayette, Indiana. 


\title{
[7.4.46] EFFECTIVE LOW-COST HVAC CONTROLS UPGRADE IN A SMALL BANK BUILDING
}

\author{
T. R. Sharp \\ J. M. MacDonald
}

[Abstract of paper in ASHRAE Transactions, 96(1) (February 1990)]

This report summarizes the measured results from a field study of the performance of a low-cost controls retrofit in a small bank building in Knoxville, Tennessee. The retrofit consisted of a simple upgrade of heating and cooling system controls and new operating strategies. The project was undertaken to better understand how commercial energy-use measurement studies should be performed and to demonstrate the effectiveness of a low-cost controls retrofit in a small commercial building. This report describes the details of the project, including building and building system characteristics, the heating, ventilating, and air conditioning (HVAC) control changes made, energy end-use patterns, and the heating and cooling energy savings achieved. An improved control strategy involving thermostat setback/setup and on/off control was devised around a single replacement programmable thermostat. The strategy allowed thermostat setback/setup control of the primary HVAC system in the building and provided on/off (time-of-day) control for the two secondary systems. The energy efficiency improvements provided a $33 \%$ reduction in heating and a $21 \%$ reduction in cooling energy consumptions. Simple payback for the retrofit, including installation cost, was achieved in under 1 year. In addition to reducing the energy needs of the building, the replacement electronic thermostat provided improved interior comfort.

Research sponsored by the U.S. Department of Energy Office of Buildings and Community Systems.

IANCE IN A SMALL BANK BUILDING

\author{
T. R. Sharp \\ J. M. MacDonald
}

(Abstract of ORNL/CON-297, Oak Ridge National Laboratory, May 1990)

As part of the U.S. Department of Energy's program on Existing Buildings Efficiency Research, we monitored the energy use in a small commercial building before and after a low-cost HVAC controls upgrade. The results were used to demonstrate the effectiveness of an attractive retrofit option for small commercial buildings. The energy improvement consisted of replacing the mechanical thermostat on the primary heating and cooling system with a programmable thermostat and interfacing it to control two secondary systems. Thus, limited changes to existing controls were made. The new operating strategy consisted of setback/setup control on the primary systern and on/off control elsewhere. The weekly operational times were changed from $100 \%$ normal operation for all systems to $30 \%$ normal, $70 \%$ setback/setup for the primary system and 30\% normal, $70 \%$ off for the two secondary systems. The 1988-89 winter heating energy use was reduced by $33 \%$,

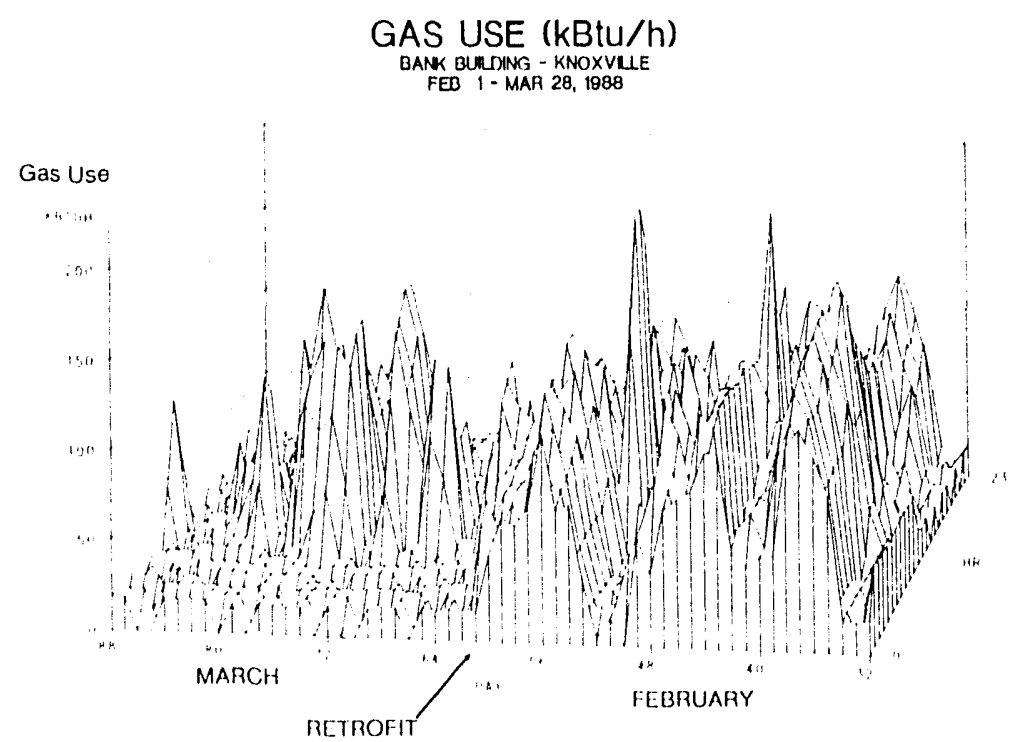

Hourly gas consumption profile 1 month before and after retrofit, 1988. saving approximately $\$ 500\left(\$ 0.12 / \mathrm{ft}^{2}\right)$. The new strategy 
practically eliminated space-heating energy use at moderate wintertime temperatures above $40^{\circ} \mathrm{F}$. The heating energy savings were approximately equally split between weekday and weekends. Air conditioning energy use for 1988 was reduced by $21 \%$, saving approximately $\$ 300\left(0.07 / \mathrm{ft}^{2}\right)$. Most of the cooling energy savings occurred on weekends. Thermostat setup turned the HVAC systems on over the weekends at an average daily outdoor temperature approximately $10^{\circ} \mathrm{F}$ higher than the preretrofit average. Payback from the retrofit was achieved in well under 1 year because its cost was $\$ 600$ including installation. The new operating strategy produced a slight shift in electric demand profiles. Typical building loads were well below the point at which electric demand charges are assessed $(50 \mathrm{~kW})$. In addition to energy and expense savings, occupants noted an improvement in comfort in the area under digital temperature control.

Research sponsored by the U.S. Department of Energy Office of Buildings and Community Systems.

\title{
[7.4.48]
}

\section{DEVELOPING OPERATIONAL STRATEGIES FOR THE FORT BENNING SHALLOW SOLAR POND DOMESTIC WATER HEATING SYSTEMS: PERFORMANCE TESTING AND RESULTS}

\author{
T. R. Sharp \\ (Abstract of ORNL/IM-11519, Oak Ridge National Laboratory, June 1990)
}

Performance tests were conducted on 6 of the 80 individual solar ponds that make up the Fort Benning Shallow Solar Pond Domestic Water Heating System. The system was originally designed to operate at a 3-in. pond Fili and provide 500,000 gal of heated water daily to a laundry and barracks buildings. Since construction, hot water needs from the system have decreased approximately $50 \%$, so the original operating strategy was no longer appropriate for current conditions. New operating strategies were tested that could potentially improve system performance. Specifically, these involved varying pond fill levels from 2 to 4 in. and exposure periods from 1 to 3 days. Lower pond fills were found to increase final water temperatures for all exposures. At a 1-day exposure, lowering pond fill from 3 to 2 in. increased pond performance (Btu/gal) by $30 \%$. A larger reduction, from 4 to 2 in., produced an approximate $62 \%$ increase. With hot water demand on the Fort Benning system well below capacity, lowering pond fill is an excellent option for an immediate and significant performance improvement. Although increasing exposure increased final water temperatures in all but one test case, lowering pond fill was more productive. An individual pond operating at a 3-in. fill and a 1-day exposure collects around $488 \mathrm{MBtu}$ annually, equivalent to around $\$ 4500$ in avoided fuel costs. With excess capacity, only the water utilized is saving energy. Therefore, the key operating objective for Fort Benning is to add the most energy possible to the water that is used. Pond fills at Fort Benning should be reduced to $2 \mathrm{in}$. and exposures should remain at 1 day (unless more ponds are activated). This should provide an immediate increase in pond perforınance of approximately $30 \%$. Other measures that can be taken to improve system performance include changing from an evening to a morning fill, reducing the storage tank fill level, minimizing the impact of unheated water on the storage tank water, and identifying additional loads that can be added to the system. Some of these changes can be implemented easily and at low cost. As demand on the system changes, information provided can be used to determine appropriate adjustments to the system operating strategy. By making the recommended changes and adapting to operational changes that occur, system benefits can be improved immediately and sustained in the future.

Research sponsored by the U.S. Army Engineering and Housing Support Center, Fort Belvoir, Virginia. 


\author{
T. R. Sharp \\ M. P. Ternes
}

(Abstract of ORNL/IM-11339. Oak Ridge National Laboratory, August 1990)

The North Carolina Field Test will test the effectiveness of t\%o weatherization approaches: the current North C: rolina Low-Income Weatherization Assistance Program and the North Carolina Field Test Audit. Tive Field Test Audit will differ from North Carolina's current weatherization ?rograin in that it will incorporate new weatherization $i$ easures and techniques, a procedure for basing measure selection on the characteristics of the individual house and the cost-effectiveness of the measure, and will also emphasize cooling energy savings. The field test will determine the' aif 'erences of the two weatherization approaches in the viewpoints of energy savings, cost effectiveness, and implementation ease. This Experimental Plan details the steps in performing the field test. The field test will be a group effort by several participating organizations. Pre-and postweatherization data will be collected over a 2-year period (Novernber 1989 through August 1991). The 120 houses included in the test will be divided into a control group and 2 treatment groups (cne for each weatherization procedure) of 40 houses each. Weekly energy-use data will be collected for each house representing whole-house electric, space heating and cooling, and water heating energy uses. Corresponding outdoor weather and house indoor temperature data will also be collected. The energy savings of each house will be determined using linear-regression based models. To account for variations between the pre- and postweatherization periods, house energy savings will be normalized for differences in outdoor weather conditions and indoor temperatures. Differences between the average energy savings of treatment groups will be identified using analysis of variance. Differences between energy savings will be quantified using muitiple comparisnn techniques. The control group will be used to normalize for occupancy variations between the preand postweatherization periods.

Researci sponsored by the U.S. Department of Energy Office of Statc and Local Assistance Prugrams.

\title{
PLANNING BUILDING ENERGY MONITORING FIELD TESTS
}

M. P. Ternes

(Abstract of paper in Field Monitoring for a Purpose, an Intemational Energy
Agency (IEA) Workshop. University of Technology, Gothenburg, Sweden, Apr. 2-5, 1990]

One detailed planning step is vital to the development of a successful building energy monitoring field test, bur that step is often overlooked. An eight-part planning process, starting with the identification on research questions and using those questions to identify fielu data and coliection hardware. is outlined in this paper. Knowledge of individual aspects of project des:gn is used through the process. An experimental plan. which documents this planning work, should be developed for all field projects. The author has successfully used this process to design several experiments and finds that $i$ : helps ensure that a project meets clearly defined objectives within available project resources.

Research sponsored by the U.S. Department of Energy Office of Buildings and Community Systems. 


\section{ENERGY SA VINGS AND PERFORMANCE OF AN IMPROVED ENERGY EFFICIENCY MEASURE SELECTION TECHNIQUE}

\author{
M. P. Ternes
}

[Abstract of paper in ASHRAE Transactions 96(2) (June 1990)]

\begin{abstract}
which is $25 \%$ of preweatherization space heating energy consumption and $85 \%$ of predicted. Comparisons of the predicted space heating energy savings to measured savings were scattered just around a line of equivalency rather than appearing as a shotgun pattern, indicating that the selection technique was reasonably accurate in predicting savings for individual houses. A direct analysis of the indoor temperature data indicated that indoor temperatures changed about $0.5^{\circ} \mathrm{F}\left(0.3^{\circ} \mathrm{C}\right)$ after weatherization, although this small change may not be significant.
\end{abstract}

Research sponsored by the U.S. Department of Energy Otfice of Buildings and Community Systems.

\section{MEASURED SPACE-COOLING ELECTRICITY SAVINGS FROM STANDARD ENERGY CONSERVATION MEASURES, RADIANT BARRIERS, AND HIGH-EFFICIENCY WINDOW AIR CONDITIONERS}

\author{
M.P. Ternes \\ W. P. Levins
}

(Abstract of pp. 9.299-9.308 in Proceedings of the ACEEE 1990 Summer Study on Energy Efficiency in Buildings, Vol. 9, Pacific Grove, Calif., Aug. 26-Sept. 1, 1990)

A cooperative field test was pe:- med in Tulsa, Oklahoma, to determine the space-cooling electricity consumption of lo.v-income homes equipped with window air conditioners, the reduction in consumntion due to energy conservation measures (ECMs) installed under Oklahoma's Weatherization Assistance Program (W AP), and the additional reduction due to two ECMs designed to reduce space-cooling electricity co' isumption: attic radiant barriers and replacement of low-efficiency window air condiuoners with high efficiency units. Eighty-one single-family, owner-occupied houses were divided into a control group and three treatment groups: ECMr merformed under Oklahoma's WAP, WAP ECMs plus a truss-mounted attic radiant barrier, and WAP ECMs plus a high-tfficiency window air conditioner to replace a less efficient unit. Preweatherization data were collected during the summer of 1988 and postweatherization data were collected the following summer. Air-conditioning electricity consumptions and indoor
ORNL-DWG. 91-10853

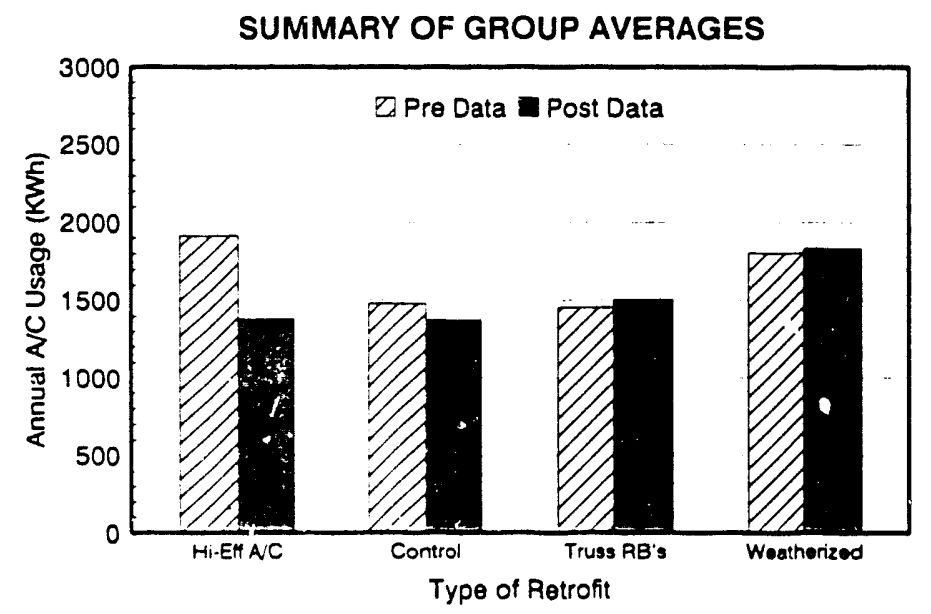

Significant energy savings are achieved by replacing low-efficiency window air conditioners with high-efficiency units. 
temperatures were monitored weekly. Air-conditioring energy use models and regression analyses were employed to normalize annual space-cooling electricity consumptions and savings to average outdoor temperatures and preweatherization indoor temperatures. Normalized preweatherization air-conditioning electricity consumption averaged $1664 \mathrm{kWh} /$ year (\$119/year). Significant reductions in air-conditioning electricity consumption were not produced by WAP ECMs or by combining a truss-mounted attic radiant barrier with them. Replacing low-efficiency air conditioners with high-efficiency units in all houses was not cost-effective. An average normalized reduction in air-conditioning electricity consumption of $535 \mathrm{kWh} /$ year (\$38/year) resulted from replacing one low-efficiency air conditioner per house with a high-efficiency unit at a cost of $\$ 947 /$ house. These savings and cost-effectiveness are improved by targeting houses for replacement based on higher than average consumption: average normalized savings of $1069 \mathrm{kWh} /$ year (\$76/year) were obtained at a cost of $\$ 999 /$ house in houses with air-conditioning electricity consumption greater than $2500 \mathrm{kWh} /$ year.

Research sponsored by the U.S. Department of Energy Office of Buildings and Community Systems.

\title{
RENEWABLE ENERGY PROJECTS: LESSONS FROM THE PAST AND DIRECTIONS FOR THE FUTURE
}

\author{
D. B. Waddle \\ R. D. Perlack \\ H. M. Jones ${ }^{a}$ \\ [Abstract of Natural Resources Forum 13(4), 303-09 (November 1989)]
}

The promotion of renewable energy during the last decade did not result in widescale application of the technology. In many cases, technologies were promoted before they were commercially viable or were inappropriately seleited for the particular end-use application. In other cases, local technical expertise and support infrastructure were not present to sustain the technology once it had been placed in the field. There was also a loss of donor interest and funding for renewables corresponding with the decline in oil prices. This paper attempts to summarize lessons learned from this decade of experience with renewable energy and to offer criteria and suggestions for future activities in transferring renewable energy technology.

Research sponsored by the U.S. Agency for Intemational Development.

${ }^{a}$ Oak Ridge Associated Universities.

\section{FUTURE ROLE OF BIOMASS ENERGY USE IN DEVELOPING COUNTRIES}

D. B. Waddle

R. D. Perlack

\begin{abstract}
(Abstract of paper in Proceedings of the 1989 International Winter Meeting of the American Saciety for Agricultural Engineers, Paper No. 89-6548, New Orleans, December 1989)
\end{abstract}

Biomass plays a large and significant role in energy use in developing countries; however, these resources are used very inefficiently. Currently, there are some efforts directed at introducing higher efficiency technology for power generation, especially in the wake of recent changes that are taking place in private power generation. Efforts are also being directed at developing biomass conversion technologies that can compete with internal combustion engines. This paper reviews the technological status of biomass conversion technology appropriate for commercial, industrial, and small utility applications in developing countries. Market opportunities, constraints, and technology developments are also discussed.

Research sponsored by the U.S. Agency for International Development. 


\title{
INTEGRATED POWER SECTOR EFFICIENCY ANALYSIS: A CASE STUDY OF COSTA RICA
}

\author{
D. B. Waddle \\ J. M. MacDonald \\ (Abstract of paper in Proceedings of the Energy Conservation Symposium 1990, Karachi, Pakistan, May 1990)
}

\begin{abstract}
In an effort to analyze and document the potential for power sector efficiency improvements from generation to end-use. the Agency for International Development and the government of Costa Rica are jointly conducting an integrated power sector efficiency analysis. The potential for energy and cost savings in power plants, transmission and distribution, and demand-side management programs is being evaluated. The product
\end{abstract}

of this study will be an integrated investment plan for the Instituto Costarricense de Electricidad, incorporating both supply- and demand-side investment options. This paper presents the methodology employed in the study, as well as preliminary estimates of the results of the study.

Research sponsored by the U.S. Agency for Intemational Development.

\section{A SUMMARY OF THE STATUS OF BIOMASS CONVERSION TECHNOLOGIES AND OPPORTUNITIES FOR THEIR USE IN LATIN AMERICA}

\author{
D. B. Waddle \\ R. D. Perlack \\ [Abstract of paper in Conference Proceedings of the 1990 Union Americana de \\ Asociaciones de Ingeneiros (UPADI) Annual Convention, \\ Washington, D.C., August 1990]
}

Biomass plays a significant role in energy use in developing countries; however, these resources are often used very inefficiently. Recent technology developments have made possible improved conversion efficiencies for utility scale technologies. These developments may be of interest in the wake of recent policy changes occurring in Central America with respect to independent power production. Efforts are also being directed at developing biomass conversion technologies that can interface or compete with internal combustion engines for small, isolated loads. This paper reviews the technological status of biomass conversion technologies appropriate for commercial, industrial, and small utility applications in developing countries, and in Latin America in particular. Market opportunities, constraints, and technology developments are also discussed.

Research sponsored by the U.S. Agency for Intemational Development.

\section{ANALYSIS OF POWER SECTOR EFFICIENCY IMPROVEMENTS FOR AN INTEGRATED PLANNING PROCESS IN COSTA RICA}

\author{
D. B. Waddle \\ J. M. MacDonald \\ (Abstract of paper in Proceedings of the IECEC Conference, Reno, Nev., August 1990)
}

In an effort to analyze and document the potential for power sector efficiency improvements from generation to end-use, the Agency for International Development and the government of Costa Rica are jointly conducting an iniegraíed power secior ef́ficiency anaiysis. The potential for energy and cost savings in power plants, transmission and distribution, and demand-side management programs is being evaluated. The product of this study will be an integrated investment plan for the Instituto Costarricense de Electricidad, incorporating both supply-and demand-side investment options. This 
paper presents the methodology employed in the study, as well as preliminary estimates of the results of the study.

\title{
ELECTRICITY SAVINGS AMONG PARTICIPANTS THREE YEARS AFTER WEATHERIZATION IN BONNEVILLE'S 1986 RESIDENTIAL WEATHERIZATION PROGRAM
}

\author{
D. L. White \\ M. A. Brown \\ (Abstract of ORNL/CON-305, Oak Ridge National Laboratory, September 1990)
}

This study continues the series of evaluations of the Bonneville Power Administration's Long-Term Residential Weatherization Program (Long-Term RWP). Data were collected from households weatherized in 1986 under Bonneville's Data Gathering Project and from a control group of nonparticipants. This study is an update of the original 1989 analysis by Schweitzer. Brown, and White, which examined retrofit activities, costs, and electricity savings 1 and 2 years after participation in the 1986 Long-Term RWP. Specifically, this update examines electricity savings 3 years after weatherization. The houscholds selected come from seven of the eight utilities examined in the original analysis. It was shown in the original analysis that in the 1986 Long-Term RWP. 83\% of audit-recommended measures were installed, approximately the same installation rate attained by participants in the Residential Weatherization Pilot Program (1980-82), the Interim RWP (1982-83), and the 1985 Long-Term RWP. Also, as in previous program years, the installation rate was higher for recommended measures with greater estimated energy savings. Although Bonneville's retrofit costs have remained fairly constant over time, total retrofit costs have increased from $\$ 1700$ per house in $198210 \$ 2400$ in 1986 (in $1986 \$$ ); the additional costs have been absorbed by participating houscholds and utilities. Similarly, Bonneville's cost per estimated kWh of first-year electricity savings has stayed at about 27 cents $/ \mathrm{k}$ Wh while the average total cost has risen from 28 cents/kWh in 1982 10 44 cents/kWh in 1986 (in 1986 \$). The characteristic difference in preprogram electricity consumption between participant and control group households is becoming less distinct. In the Bonneville Residential Weatherization Pilot Program conducted during 1980 through 1982, participating households included in the evaluation used $30,280 \mathrm{kWh} /$ year in the preweatherization year while nonparticipants used $25,780 \mathrm{kWh} /$ year. Thus, participants used nearly $18 \%$ more electricity than nonparticipants. In the 1986 Long-Term RWP, participants used $24,310 \mathrm{kWh}$ (weighted) in the preretrofit year, while the control group households used an average of $22,270 \mathrm{kWh}$ (weighted). Participants used only $9 \%$ more electricity than nonparticipants. From the Pilot Program to the 1986 Long-Term DGP, the difference in preprogram electricity consumption between participants and control group households declined by almost 50\%. For the 1986 Long-Term RWP overall, savings experienced by participants were substantial. During the first year after weatherization, weighted net savings averaged $3060 \mathrm{kWh}$, or almost $13 \%$ of the previous year's energy consumption for the updated sample. In the second postweatherization year, a weighted average of $2112 \mathrm{kWh}$ was saved, amounting $109 \%$ of preweatherization energy use. In the third postweatherization year, a net weighted average of $2140 \mathrm{kWh}$ was saved, $9 \%$ of preweatherization electricity use.

Research sponsored by Bonneville Power Administration. 


\title{
LIFE AFTER RCS
}

\author{
R. Vories ${ }^{a}$ \\ D. L. White
}

[Abstract oi /fome Energy 7(3), 24-28 (May/June 1990)]

The short answer is "yes." The expiration of the Residential Conservation Service (RCS) in June 1989 did not by itself signal significant changes in the planning, implementation, and evaluation of residential conservation programs. This article will discuss the changes that are expected to occur, as determined by discussions with 60 representatives of state energy offices, public service commissions, and utilities. Those discussions indicate that state needs for information and technical assistance have not diminished. State and utility programs will continue to vary widely in terms of staffing, funding, emphasis (goals and objectives), needs for information and technical assistance, and the corresponding sources for obtaining information. Interactions among state energy of fices, public utility commissions, and utilities have typically been informal. Some states have already undertaken measures to assure periodic and substantive interstate communications. The focus of residential conservation programs themselves will more directly emphasize new buildings. Efficiency rating systems, enhanced building codes, reguiatory and incentive approaches to encourage utilities to develop programs, and the reduction of arrearages will be the most prominent strategies used for elevating interest in residential energy conservation. Planning,

implementation, and evaluation of these programs can be improved through more synthesis and consolidation of lessons already learned. Additional improvement can be secured through innovative marketing, especially more effective market segmentation, and through the development of measuring tools that best enable public service commissions and utilities to identify the best mix of energy conservation programs.

Research sponsored by the U.S. Department of Energy Office of State and Local Assistance Programs.

${ }^{a}$ Infinite Energy, Denver, Colorado.

\section{MODEL FOR THE THERMAL PERFORMANCE OF LOW-SLOPED ROOFS}

\author{
K. E. Wilkes
}

\begin{abstract}
[Abstract of pp. 184-97 in Thermal Performance of the Exterior Envelopes of Buildings IV, proceedings of the ASHRAE/DOE/BTECC/CIBSE Conference, Orlando, Fla., Dec. 4-7, 1989]
\end{abstract}

This paper gives a detailed description of the Simplified Transient Analysis of Roofs model (STAR) that has been developed at Oak Ridge National Laboratory (ORNL) for predicting the heat flows and temperatures within roof systems. STAR is a one-dimensional, finite-difference, transient heat conduction model that can be used on a personal computer. It has full coupling to the ambient weather conditions, but can also be used with specified temperature boundary conditions. The paper also gives results of a validation study in which predictions of the model were compared with temperatures and heat flows measured on roof sections at ORNL's outdoor Roof Thermal Research Apparatus. Finally, the paper gives several examples of the application of the model in performing parametric analyses of the thermal performance of roofs. The model is used to predict membrane temperatures and roof heat flows as influenced by variations in parameters such as level of insulation, amount of surface mass, and solar absorptance of the roof surface.

Research sponsored by the U.S. Department of Energy Office of Buildings and Community Systems. 


\title{
THERMAL MODELING OF RESIDENTIAL ATTICS WITH RADIANT BARRIERS: COMPARISON WITH LABORATORY AND FIELD DATA
}

\author{
K. E. Wilkes
}

\begin{abstract}
[Abstract of pp. 294-311 in Thermal Performance of the Exterior Envelopes of Buildings IV, proceedings of the ASIIRAE/DOE/BTISCC/CIBSE Conference, Orlando, Fla., Dec. 4-7, 1989]
\end{abstract}

Radiant barriers $(\mathrm{RBs})$ are receiving increasing attention as an energy conservation measure. A number of experiments, performed by several organizations, have demonstrated the energy savings potential for RBs. The experiments have utilized a number of different attic and RB configurations and have been conducted under differing weather conditions. Because of this, it is difficult to compare the experimental results. Models are needed to gain a better understanding of the performance of RBs, to extrapolate experimental data to seasonal and annual performances, and to estimate the performance under other climatic conditions. This paper describes models that have been developed at ORNL for residential attics, with or without radiant barriers.
Models based on systems of heat balances have been devcloped for both horizontal RBs that are laid on top of the attic insulation, and for radiant barriers attached to the bottom of the top chords of attic trusses. The models include features such as radiation interchanges within the attic space, convection to ventilation air, and sorption/desorption of moisture at surfaces facing the attic space. The paper gives comparisons of model predictions with data from steady-state laboratory experiments and from field experiments with full-size houses.

Research sponsored by the U.S. Department of Energy Office of Buildings and Community Systems.
Comparison of predicted and measured ceiling heat flows for Karns, Tennessee, house test with R-19 insulation and truss radiant barrier. Positive values are heat flows into the house.

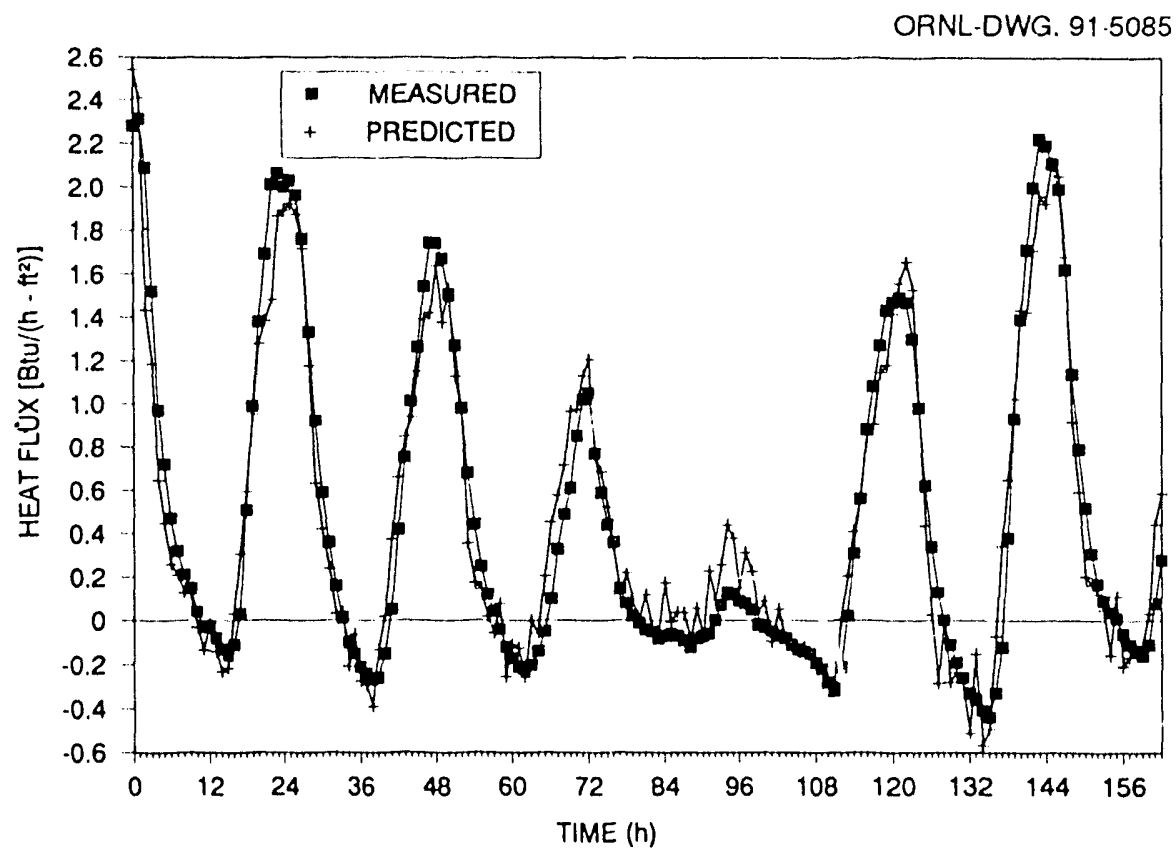




\title{
ANALYSIS OF ANNUAL ENERGY SAVINGS DUE TO RADIANT BARRIERS
}

\author{
K. E. Wilkes
}

(Abstract of pp. 235-45 in Proceedings of the ACEEE 1990 Summer Study on Energy Efficiency in Buildings, Vol. 1, Pacific Grove, Calif., Aug. 26-Sept. 1, 1990)

Radiant barriers (RBs) are receiving increasing attention as an energy conservation measure for residential buildings, especially for warmer climates. They are being actively promoted for use in residential attics, sometimes with exaggerated claims about savings in utility bills that will result from their installation. To provide consumers with factual information to assist them in deciding to invest in an RB, the U.S. Department of Energy, along with an industry advisory panel, has developed a Radiant Barrier Fact Sheet. A major part of this fact sheet is estimates of energy savings that might be expected from RBs in various climates. This paper presents the details of the methodology underlying the energy savings estimates, and gives a summary of values listed in the fact sheet. The energy savings estimates were obtained from calculations using a detailed attic thermal model coupled with DOE-2.1C. A life cycle cost analysis was performed to estimate the present value savings on utility fuel costs. The results show that the fuel cost savings vary significantly with the level of conventional insulation already in the attic and from one climate to another.

Research sponsored by the U.S. Department of Energy Office of Buildings and Community Systems, Electric Power Research Institute, and Tennessee Valley Authority.

\author{
A. Zaltash \\ M. R. Ally \\ [Abstract of paper in ASHRAE Transoc:ions 96(2) (June 1990)]
}

Viscosity plays an important role in quantifying heat and mass transfer rates as depicted in theoretical and semi-empirical correlations. In practical problems where extreme temperatures and solute concentrations are encountered, viscosity data are usually unavailable. At these conditions, no dependable correlation appears to exist in the literature. This paper uses the hole type model to predict the viscosity of aqueous electrolytes containing single and mixed salts up to the molten salt regime. This model needs two parameters which can be evaluated from sparse data. For $\mathrm{LiBr} /$ water and $\mathrm{Li}$, $\mathrm{K}, \mathrm{Na}$ ) $\mathrm{NO}_{3} /$ water mixtures, it is shown that the agreement between predicted and experimental values is

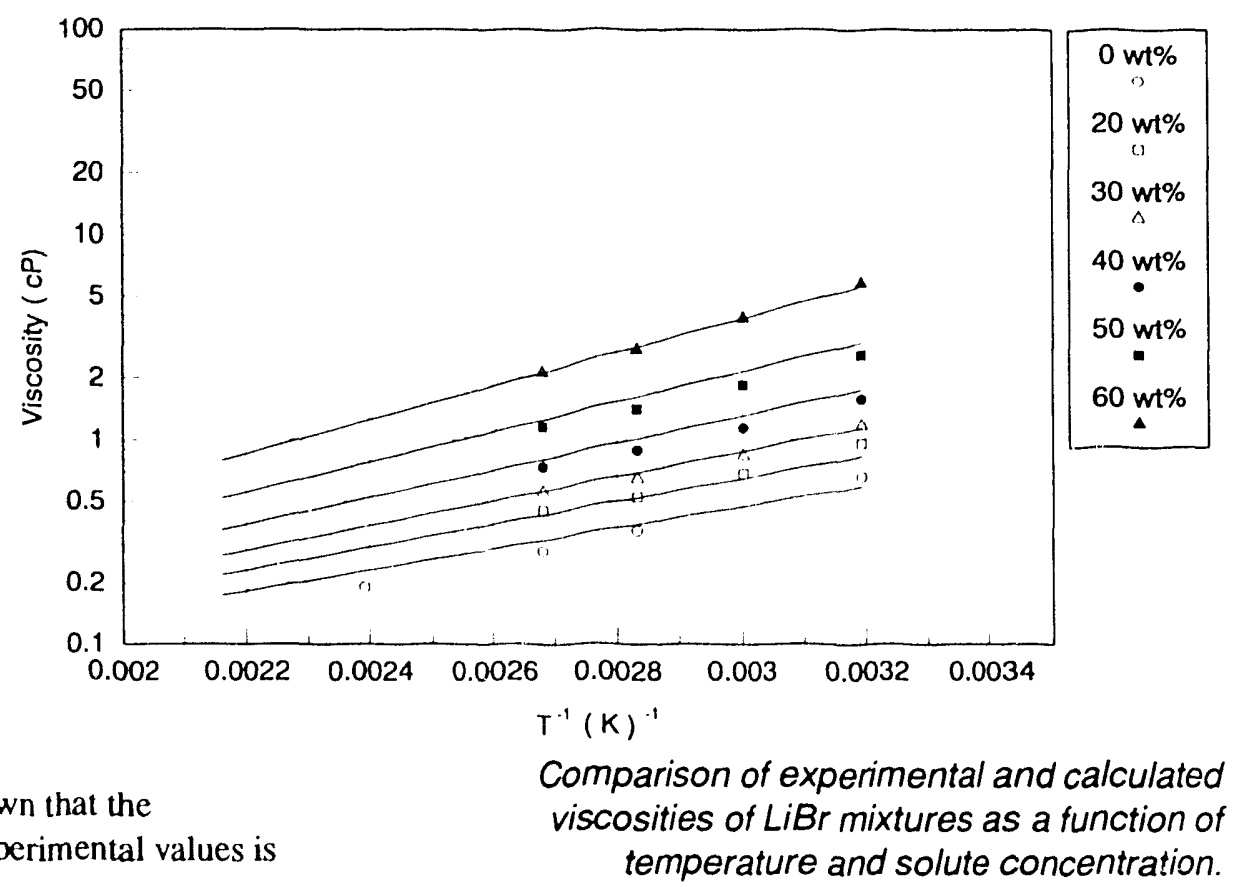


very good over wide temperature and concentration ranges. The deviation between these two values was found to be less than $9 \%$.
Research sponsored by the U.S. Department of Energy Office of Indust rial Programs.

[7.4.64]

\section{MEASUREMENTS OF HEAT AND MASS TRANSFER COEFFICIENTS DURING ABSORPTION OF WATER VAPOR BY LITHIUM BROMIDE AND ( $\mathrm{Li}, \mathrm{K}, \mathrm{Na}) \mathrm{NO}_{3}$ MIXTURES}
A. Zaltash
M. R. Ally
R. L. Linkous
L. N. Klatt

[Abstract of paper in ASHRAE Transactions 96(2) (June 1990)]

A knowledge of heat and mass transfer coefficients in heat pump fluids plays an important role in the design of absorption machines. Heat and mass transfer coefficients as well as subcooiing are measured for absorption of water vapor in $(\mathrm{Li}$, $\mathrm{K}, \mathrm{Na}) \mathrm{NO}_{3}$ (alkitrate) and lithium bromide ( $\mathrm{LiBr}$ ) mixtures. The amount of mass transfer of water vapor is obtained from the difference in concentration of mixtures between inlet and outlet streams across the absorber. In-situ concentrations of aqueous salt mixtures over temperature ranges between 80 and $135^{\circ} \mathrm{C}$ were calculated from the density measurements. This technique of measurement is reliable and convenient, but not a very accurate ( $=0.8 \mathrm{wt} \%$ salt) method of measuring the in-situ salt concentration. Results show that the subcooling at the

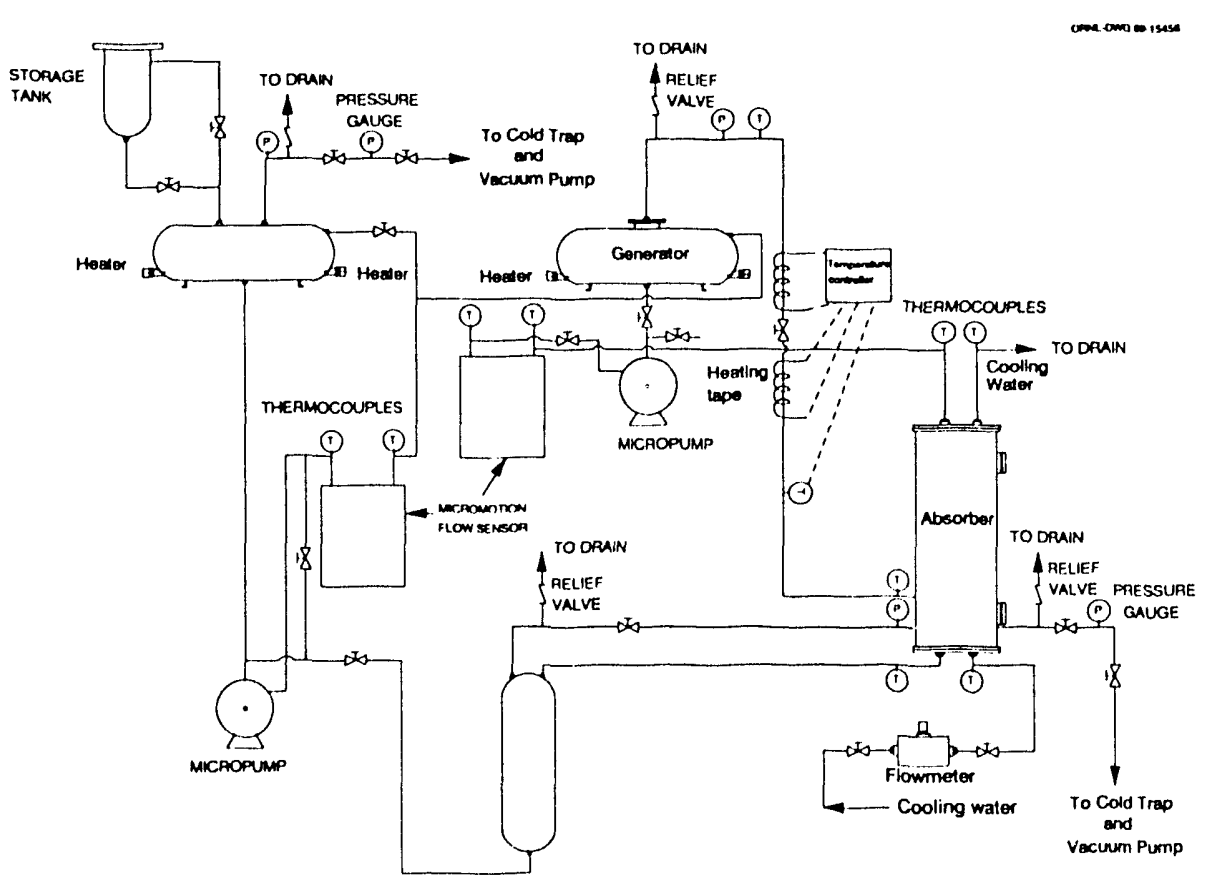
absorber exit is not only a property of the fluid, but depends strongly on the process conditions. The subcooling in $\mathrm{LiBr}$ mixtures without additive is shown to vary betweet 2.2 and $24.3^{\circ} \mathrm{C}$ and the film heat transfer coefficient between 1365.2 and $801.1 \mathrm{~W} / \mathrm{m}^{2} \mathrm{~K}$, respectively, depending upon process conditions. These empirical results will prove to be of value to heat pump manufacturers because they have a strong bearing on

Schematic of the apparatus used for heat and mass transfer experiments.

costs and performance. He:: tand mass transfer coefficients in aqueous salt solutions are presented as a function of dimensionless numbers.

Research sponsored by the U.S. Danartment of Energy Office of Industrial Programs. 


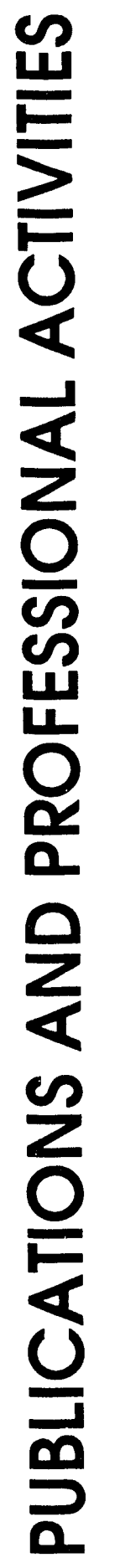




\section{PUBLICATIONS AND PROFESSIONAL ACTIVITIES}

\subsection{ENERGY DIVISION ADVISORY COMMITTEE 1990}

Dr. Bruce G. Buchanan

Mr. John J. Cuttica

Dr. Allan Hirsch

Dr. Denton E. Morrison

Dr. Martin Williams
Computer Science Department

University of Pittsburgh

206 Mineral Industries Building

Pittsburgh, Pennsylvania 15260

Phone: (412) 624-9183

Vice President, End Use

Research and Development

Gas Research Institute

8600 W. Bryn Mawr Avenue

Chicago, Illinois 60631

Phone: (312) 399-8241

Vice President, Environmental Sciences

Director, Washington Operations

Midwest Research Institute

5109 Leesburg Pike

suite 414

Falls Church, Virginia 22041

Phone: (703) 671-0400

333 Oxford Road

East Lansing, Michigan 48823

Phone: (517) 351-4044

Professor, Department of Economics

Northern Illinois University

DeKalb, Illinois 60115

Phone: (815) 753-6960 


\subsection{ENERGY DIVISION PERSONNEL BY DISCIPLINE}

[Full-time equivalents (FTEs)]

September 1990

\begin{tabular}{|c|c|c|c|c|c|c|c|}
\hline Discipline & $\mathrm{IAAS}^{a}$ & EEAS & CTA & ERRS & $\mathrm{P} \& \mathrm{C}$ & $\begin{array}{c}\text { Division } \\
\text { Administration }\end{array}$ & $\begin{array}{l}\text { Total } \\
\text { (FTEs) }\end{array}$ \\
\hline \multicolumn{8}{|l|}{ Social sciences } \\
\hline Anthropologists & 2.0 & & & & & & 2.0 \\
\hline Architects & & & & 1.0 & & & 1.0 \\
\hline Economists & 2.0 & 11.5 & & & & 1.0 & 14.5 \\
\hline Geographers & 2.0 & 2.0 & 6.0 & 1.0 & 1.0 & & 12.0 \\
\hline Planners & 3.0 & & & 1.0 & 1.0 & & 5.0 \\
\hline Political scientists & 3.0 & & & & & & 3.0 \\
\hline Sociologists & 2.5 & & & 0.5 & & & 3.0 \\
\hline Other & 1.0 & & & & & & 1.0 \\
\hline Total social sciences & 15.5 & 13.5 & 6.0 & 3.5 & 2.0 & 1.0 & 41.5 \\
\hline \multicolumn{8}{|l|}{ Physical and lifi sciences } \\
\hline Biologists & 4.5 & & 1.0 & & & & 5.5 \\
\hline Chemists & 2.0 & & 1.0 & 2.0 & & & 5.0 \\
\hline Geologists & 4.0 & & 2.0 & & & & 6.0 \\
\hline Meteorologists & 3.0 & & & & & & 3.0 \\
\hline Physicists & 2.0 & & & 4.0 & & & 6.0 \\
\hline $\begin{array}{l}\text { Total physical and life } \\
\text { sciences }\end{array}$ & 15.5 & & 4.0 & 6.0 & & & 25.5 \\
\hline \multicolumn{8}{|l|}{ Engineering Sciences } \\
\hline Agricultural engineers & & & & 1.0 & & & 1.0 \\
\hline Chemical enginecrs & 1.0 & & 1.0 & 5.0 & & & 7.0 \\
\hline Civil enginecers & & & 2.0 & & & & 2.0 \\
\hline Electrical engineers & 1.0 & & 2.0 & 4.0 & & & 7.0 \\
\hline Engineering physicists & & & & 1.0 & & & 1.0 \\
\hline Engineering scientists & 1.0 & & & 2.0 & & & 3.0 \\
\hline Environmental engineers & 1.0 & & & & & & 1.0 \\
\hline Mechanical engineers & 5.0 & & & 15.0 & & 0.5 & 20.5 \\
\hline Nuclear engincers & & & & & & 1.0 & 1.0 \\
\hline Oher & & & & 2.0 & & & 2.0 \\
\hline $\begin{array}{l}\text { Total engincering } \\
\text { sciences }\end{array}$ & 9.0 & & 5.0 & 30.0 & & 1.5 & 45.5 \\
\hline \multicolumn{8}{|l|}{ Data Systems. } \\
\hline Computer sciences & & 1.0 & 2.5 & & & & 3.5 \\
\hline $\begin{array}{l}\text { Mathematicians/ } \\
\text { statisticians }\end{array}$ & 2.0 & & 6.0 & 1.0 & & & 9.0 \\
\hline Operations restarch & & & 1.0 & & & & 1.0 \\
\hline Systems analyysts & & & 1.0 & & & & 1.0 \\
\hline Other & & & 2.0 & & & & 2.0 \\
\hline Total data sy'stems & 2.0 & 1.0 & 12.5 & 1.0 & & & 16.5 \\
\hline $\begin{array}{l}\text { Total techunical } \\
\text { professionals }\end{array}$ & 42.0 & 14.5 & 27.5 & 40.5 & 2.0 & 2.5 & 129.0 \\
\hline Accountants & & & & & & 2.0 & 2.0 \\
\hline Administrative assistants & & & & & & 1.0 & 1.0 \\
\hline Administrative support & 9.0 & 5.5 & 7.0 & 10.0 & 1.0 & 6.0 & 38.5 \\
\hline Technical suppour & 5.0 & 1.0 & 3.0 & 7.0 & 1.0 & & 17.0 \\
\hline $\begin{array}{l}\text { Total administrative and } \\
\text { technical support }\end{array}$ & 14.0 & 6.5 & 10.0 & 17.0 & 2.0 & 9.0 & 58.5 \\
\hline Total & 56.0 & 21.0 & 37.5 & 57.5 & 4.0 & 11.5 & 187.5 \\
\hline
\end{tabular}




\subsection{ENERGY DIVISION PROFESSIONAL HONORS AND AWARDS FY 1990}

Broders, M. A., ASME Committee Nuclear Assurance, Certificate of Award for meritorious service.

Dale, S. J., Fellow, Institute of Electrical Electronics Engineers.

Greene, D. L., Transportation Research Board, Distinguished Service Certificate.

Harrison, I. G., Martin Marietta Energy Systems, Inc., Significant Event Award.

Hillsman, E. L., Fulbright nominee.

Huskey, M. G., Martin Marietta Energy Systems, Inc., Administration and Office Support Award.

Lasley, B. D., Scientific Research Society Sigma Xi Support of Research Award.

Peelle, E. B., Society for Applying Sociology, Award for Applying Sociology.

Peelle, E. B., honorary Doctor of Law degree from Miami University of Ohio.

Rayner, S., Martin Marietta Energy Systems, Inc., Significant Event Award.

Rizy, D. T., et al., 1990 Power Engineering Society Prize Paper Award.

Sharp, T. R., East Tennessee Chapter, Society for Technical Communication Award, Merit in Technical Reports.

Shelton, R. B., et al., East Tennessee Chapter, Society for Technical Communication Award, Achievement in Periodic Activity Reports.

Solanki, R. S., Martin Marietta Energy Systems, Inc., Technical Achievement Publication Award.

Vineyard, E. A., and J. R. Sand, ASHRAE 1989 Best Paper Award.

Wilbanks, T. J., 12th Annual Applied Geography Conference, Special Recognition Award.

Zimmrman, G. P., Martin Marietta Energy Systems, Inc., Significant Event Award. 


\subsection{ENERGY DIVISION PROFESSIONAL ACTIVITIES FY 1990}

Berry, L. G., Associate Editor, Evaluation Review: A Journal of Applied Social Research, 1989 to present.

Blasing, T. J., Referec, Ecology, 1989.

Blasing, T. J., Adjunct Associate Professor of Geography, University of Tennessee, Knoxville, 1981 to present.

Blasing, T. J., Referec, Proposals to the National Science Foundation, 1989-1990.

Boston, C. R., Nominating Committee, Sigma Xi, 1990.

Bownds, J. M., Reviewer, Mathematical Reviews, 1968 to present.

Bownds, J. M., Instructor, ORNL Saturday Academy of Computing and Mathematics.

Bownds, J. M., Referee, Journal of Hydraulics, 1990 to present.

Bownds, J. M., Ph.D. Dissertation Committee, N.C. State University, 1990.

Bownds, J. M., Adjunct Professor of Mechanical/Aeronautical Engineers, N.C. State University, 1990.

Braid, R. B., Releree, Journal of the American Medical Association, 1989 to present.

Braid, R. B., Referee, The Environmental Professional, 1988 to present.

Brown, M. A., National Councillor, Association of American Geographers, 1988-1991.

Brown, M. A., Editorial Boards, The Professional Geographer, 1989-1992, and Home Energy, 1990 to present.

Brown, M. A., Adjunct Associate Professor, Department of Geography, University of Tennessec, 1989 to present.

Carnes, S. A., Manuscript Reviewer, The Environmental Professional, 1987 to present.

Carnes, S. A., Guest Editor, The Environmental Professional, 11:4, 1989.

Cames, S. A., Manuscript Reviewer, Risk Analysis, 1983 to present.

Chen, F. C., Vice Chaiman, ASHRAE TC 9.5 on Cogeneration Systems, 1989-1991.

Chen, F. C., ASHRAE RC 4.7 on Transportation Space Conditioning.

Chen, F. C., ASME Heat Pump Technical Committee.

Christian, J. E., Board of Directors, Building Thermal Envelope Coordinating Council.

Christian, J. E., ASHRAE SPC 90.2, Energy Standard for Residential Buildings.

Christian, J. E., Testimony at Building Officials and Code Adminstrators International, Inc. (BOCA), Energy Code hearings, Louisville, Kentucky, January 1990, and Ontario, Canada, June 1990.

Christian, J. E., ASHRAE TC 4.4, Technical Committee on Insulation and Vapor Retarder Periomance.

Christian, J. E., ASHRAE TC 4.7, Technical Committee on Energy Calculations.

Curiee, T. R., Formal Contributor, National Advisory Council for Environmental Policy and Technology (NACEP7), Technology Innovation and Economics Committee, U.S. Environmental Protection Agency, 1990 to present.

Curlee, T. R., Municipal Solid Waste Advisory Panel, Congress of the United States, Office of Technology Assessment, 1989-90.

Curlec, T. R., Committec on Plastics and Composite Materials, Massachusetts Institute of Technology, Materials Systems Laboratory, 1989-90.

Curlec, T. R., presented a Congressional testimony, August 2, 1990, Hearing on the Energy Production and Conservation Act of 1990, Subcommittec on Energy Regulation and Conservation, Committec on Energy and Natural Resources, U. S. Senatc. 
Curlee, T. R., RecyclingPlas Advisory Committee, Plastics Institute of America, 1988 to present.

Curlee. T. R., Referee, Review' of Regional Studies.

Curlee, T. R., Referee, Optimal Control Applications and Methods.

Curlee, T. R., Mayor's Solid Waste Task Force, City of Knoxville. Tennessee, 1990 to present.

Dale, S. J., Chairman, IEEE Insulated Conductors Committee Task Force 5.12 Insulation Systems for Gas Cables.

Dale, S. J., Reviewer, IEEE Transaction on Electrical Insulation.

Dale, S. J., IEEE-USA Congressional Fellows Committee, 1991 to present.

Dale, S. J., IEEE-USA Engineering R\&D Policy Committee, 1987 to present.

Dale. S. J., Expert Advisor, U.S. National Committee of CIGRE, Study Committee 15, Insulation.

Dale. S. J., Reviewer, IEEE Transaction on Power Delivery.

Dale, S. J., U.S. Representative CIGRE Study Committee 15, Working Group 15.03, Gas Insulation, and 15.06-01, Cryogenic Insulation.

Dale, S. J., Administrative Committee. IEEE Dielectrics and Electrical Insulation Society, 1984-1990.

Dale, S. J., Chairman, IEEE Dielectrics and Electrical Insulation Society Meetings Committee, 1988 to present.

Dale, S. J., Division II Representative IEEE Technical Meetings Council, 1989-1990.

Feldman, D. L., Referee, Policy Sciences, 1984 to present.

Feldman. D. L., Referee, Western Political Quarterly, 1990 to present.

Feldman, D. L., Referee, Choice, The Association of College and Research Libraries, 1983 to present.

Feldman, D. L., Referee. The Environmental Professional, 1988 to present.

Feldman, D. L., Referee, Forum for Applied Research and Public Policy, 1989 to present.

Gant, K. S.. NCRP Task Group on Radiological Protection for Different Groups in the Popuiation, 1986 to present.

Greene, D. L., Reviews for Transportation Research Board, Transportation Research, Energy Information Administration, Office of Technology Assessment, and Contemporary Policy Issues.

Greene, D. L., Board of Directors, Association of American Geographers, Transportation Specialty Group, 1989-1991.

Greene, D. L., Special Committee, Transportation Research Board, National Research Council, Organizing Committee Workshop on Transportation, Urban Structure and Environment, 1990.

Greene, D. L., Special Committee, Committee on High Speed Ground Transportation, Transportation Research Board, National Research Council, 1990.

Greene, D. L., Special Committee. Committee on Strategic Freight Issues, Transportation Research Board, National Research Council, 1990.

Greene, D. L., Section Chair, Energy and Environmental Concerns, Transportation Research Board, National Research Council, 1990 to present.

Greene, D. L., Freight Data Task Force, Transportation Research Board, National Research Council, 1989-1992.

Hillsman, E. L., Board of Directors, AAG Energy and Environment Specialty Group, 1988-1991. 
Hirst, E., Demand-Side Planning and Information Group, Electric Power Research Institute. Hirst, E., Advisory Committee, Energy Conservation Coalition.

Hirst, E., Associate Editor, Energy.

Hirst, E. Editorial Boards, Energy Journal, International Journal of Energy Systems, Energy Systems and Policy, and Energy Policy.

Hirst, E., presented a Congressional testimony, October 4, 1989, Federal Roles to Encourage Electric-Utility Energy-Efficiency and Load-Management Programs, Energy Security: Energy Efficiency and National Security, to the Subcommittee on Economic Stabilization, Committce on Banking, Finance, and Urban Affairs, U.S. House of Representatives.

Hirst, E., presented a Congressional testimony, June 6, 1990, The Federal Govemment Should Do More to Improve U.S. Energy Efficiency, Fiscal Year 1991 Department of Energy Authorization, before the Subcommittee on Energy Research and Development, Committee on Science, Space, and Technology, U.S. House of Representatives.

Hirst, E., presented testimony, January 11, 1990, Least-Cost Integrated Resource Planning in North Carolina: Review of Utility Plans and Planning Processes, before the North Carolina Utilities Commission.

Hirst, E., presented testimony, October 30, 1989, before the Washington Utilities and Transportation Commission on behalf of Puget Sound Power and Light Company.

Hirst, E., presented testimony, September 10, 1990, review of the 1990 Energy Plan prepared by Potomac Electric Power Company, before the Public Service Commission of the District of Columbia, Washington, D.C.

Hunsaker, D. B., Jr., Vice President, National Association of Environmental Professionals, 1990-1991.

Hunsaker, D. B., Jr., Board of Directors, National Association of Environmental Professionals, elected to 3-year term, 1990.

Hunsaker, D. B., Jr.. Policy and Regulations Committee (EP-1), Air and Waste Management Association, 1983 to present.

Hunsaker, D. B., Jr., Secret:iy, National Association of Environmental Professionals, 1989-1990.

Hunsaker, D. B., Jr., Chairman, Publications Committee, National Association of Environmental Professionals, 1988 to present.

Hwang, H.L., Vice President, American Statistical Association, East Tennessee Chapter, 1990-1991.

James, D. R., Board Member, Conference on Electrical Insulation and Dielectric Phenomena, 1990-1992.

Lee, D. W., Reviewer, ASCE Journal of Hydraulics, 1982 to present.

Lee, D. W., Mixed Waste Task Committee, Air and Radiation Management Committee, Environmental Engineering Division, American Society of Civil Engineers, 1988 to present.

Lee, D. W., Reviewer, Waste Management Journal, 1988 to present.

Lee, D. W., Adjunct Associate Professor, North Carolina State University, Department of Mechanical and Aerospace Engineering, 1987 to present.

Lee, D. W., Secretary, Control Member, Air and Radiation Management Committee, Environmental Engineering Division, American Society of Civil Engineers, 1989 to present.

Loftis, J. P., Officer, Meeting Coordinator for the Tennessee ORACLE User Group, 1990 to present. 
MacDonald, J. M., Chairman, ASTM E06.25.21, Task Group on Energy Monitoring Protocols, 1989 to present.

MacDonald, J. M., ASHRAE SPC 100P on Energy Conservation in Existing Buildings, 1990 to present.

MacDonald, J. M., ASHRAE TC 9.6 Subcommittee on Building Energy Monitoring, 1987 to present.

MacDonald, J. M., ASHRAE TC 9.6 on Systems Energy Utilization, 1987 to present.

MacDonald, J. M, ASHRAE SPC 100.5-1981R on Energy Conservation in Institutional Buildings, 1986 to present.

McLean, R. B., NEPA Working Group, National Association of Environmental Professionals.

Mei, V. C., ASHRAE TC 1.3 on Heat Transfer and Fluid Flow.

Mei, V. C., Coordinator, ASME Advanced Energy Division Heat Pump Committee, 1989-1990.

Mixon, W. R., Building Energy Symposium Advisory Committee, Texas A\&M, College Station, Texas.

Mixon, W. R., ASHRAE TC 9.6 on Systems Energy Utilization.

Mixon, W. R., Chairman, ASHRAE TC 9.6 Subcommittee on Building Monitoring.

Peelle, E. B., Reviewer, Forum for Applied Research and Public Policy, 1989 to present.

Peelle, E. B., Reviewer, International Association for Impact Assessment, 1989 to present.

Rathi, A.K., Appointed Member, Committee on Traffic Flow Theory and Characteristics,

Transportation Research Board, National Research Council, February 1, 1990-January 31, 1993.

Rathi, A.K., Appointed Member, Committee on Expert Systems, Transportation Research

Board, National Research Council, February 1, 1990-January 31, 1993.

Rayner, S., Referee, Risk Analysis, 1984 to present.

Rayner, S., Social Science Research Council working group on Land Use and Global Envirorımental Change.

Rayner, S., Visiting Associate Professor Program in Science, Technology, and Society, Cornell University, 1990.

Rayner, S., Adjunct Faculty, U.S. Government Executive Seminar Center, Oak Ridge, Tennessee, 1988 to present.

Rickert. L. W., Techlib OPAC Screen Design Committee for Central Research Library On-Line System (user community representative), 1990-1991.

Rizy, D. T., IEEE Standards Coordinating Committee on DSG.

Rizy, D. T., IEEE Power Engineering Society T\&D Committee Working Group on Distribution System Design.

Russell, M., Committee on Risk Perception and Communication, National Research Council, 1987-1989.

Russell, M., National Council of Association for Environmental and Resource Economics, 1986-1989.

Russell, M., Consultant, National Environmental Protection Agency of China, and lecturer (July-August) under auspices of the United Nations Development Program and the Rockefeller Foundation, 1989.

Russell, M., Board of Editors, Journal of Cultural Economics, 1978 to present.

Russell, M., Advisory Committee, Wharton Risk and Decision Processes Center, 1986 to present. 
Russell, M., National Academy of Sciences (U.S.)- Polish Academy of Sciences Workshop on Ecological Research and Environmental Protection, 1987-1989.

Russell, M., President, Southern Appalachian Man and the Biosphere Foundation, 1990 to present.

Russell, M., International Advisory Council on the Economic Development of Hainan in Harmony with the Natural Environment, Haikou, People's Republic of China.

Russell, M., Environmental Advisory Committee, Westinghouse Savannah River Corporation.

Russell, M., Chairman, Oversight Review Board, National Acid Precipitation Assessment

Program, 1989 to present.

Russell, M., Advisory Panel on Environmental Risk Communication, Center for

Environmental Information, Inc., 1989 to present.

Russell, M., Mitigation Panel, Global Climate Change Committee, National Academy of

Sciences/National Academy cf Engineering, 1989 to present.

Russell, M., Advisory Panel to the U.S. Congress Office of Technology Assessment, Panel on

Technological Risks and Opportunities for Future U.S. Energy Supply and Demand, 1987 to present.

Russell, M., National Research Council, Board on Environmental Studies and Toxicology, 1988 to present.

Russell, M., Editorial Board, The Annals of Regional Science, 1988 to present.

Russell, M., Science Advisory Board, U.S. EPA, Committees on Global Climate, 1988-1989.

Sorensen, J. H., Manuscript Reviewer, Journal of Hazardous Materials, 1990.

Sorensen, J. H., International Research Group on Risk Communica ions, 1987 to present.

Sorensen, J. H., Manuscript Reviewer, International Journal of Mass Emergencies and Disasters, 1990.

Sorensen, J. H., National Research Council Commission on Physical Sciences, Mathematics, and Resources, Earth Sciences Board, Subcommittee on Earthquake Research, 1989-1991.

Sorensen, J. H., Manuscript Reviewer, Environmental Management, 1990.

Sorensen, J. H., Proposal Reviews for Critical Engineering Systems, Earthquake Hazards Mitigation Program, National Science Foundation, 1990.

Southworth. F., Committee on Travel Behavior and Values, Transportation Research Board, National Research Council, 1991-1994.

Tonn, B. E., EPRI Decision Methods Advisory Board, 1990-1991.

Tonn, B. E., DARPA Research Proposal Evaluation Team, 1990-1991.

Tonn, B. E., Reviewer, Energy Systems and Policy Risk Analysis, 1990.

Wilbanks, T. J., Executive Committee, U.S. Working Group for the Global Energy Efficiency Initiative, 1990 to present.

Wilbanks, T. J., Joint Steering Committee for association between the Oak Ridge National Laboratory and the Universidad Nacional Autonoma de Mexico, 1990 to present.

Wilbanks, T. J., Vice Chairman, U.S. National Committee for the International Geographical Union, National Academy of Sciences/National Research Council, 1989 to present.

Wilbanks, T. J., Committee on Energy Efficiency, United States Energy Association, 1990 to present.

Wilbanks, T. J., Treasurer and Member of the Board of Directors, 27th International Geographical Congress (1992), 1986 to present.

Wilbanks, T. J., Editorial Board, Annals of the Association of American Geographers, 1987 to present.

Wilbanks, T. J., Councillor, American Geographical Socicty, 1985 to present. 
Wilbanks, T. J., Expert Group on Energy and Electricity Supply and Demand for the 1991 Senior Expert Symposium on Electricity and the Environment (Helsinki), 1990-91.

Wilkes, K. E., ASHRAE TC 4.9 on Building Envelope Systems, Research Project Monitoring Subcommittee Chairman, 1989 to present.

Wilkes, K. E., ASHRAE TC 4.4 on Thermal Insulation and Moisture Retarders, Research Subcommittee Chairman, 1990 to present.

Witten, A. J., Reviewer, ASCE Journal of the Hydraulics Divisions.

Witten, A. J., Reviewer, IEEE Transactions Biomedical Engineering.

Witten, A. J., Reviewer, Geophysics.

Witten, A. J., Reviewer, IEEE Transactions on Geoscience and Remote Sensing.

Wolfe, A. K., Chairman, Committee of Anthropologists in Environmental Planning, 1988 to present.

Wolfe, A. K., Referee, National Sea Grant College Program, National Oceanic and Atmospheric Administration, 1989 to present. 


\subsection{ENERGY DIVISION PUBLICATIONS FY 1990}

Adams, H. S., S. B. McLaughlin, T. J. Blasing, and D. N. Duvick, A Survey of Radial Growth Trends in the Great Smoky Mountains National Park as Influenced by Topography, Age, and Stand Development, ORNL/TM-1 1424, Oak Ridge National Laboratory, February 1990.

Armstrong, J. S., H.-L. Hwang, and J. Bandy, Modified Seasonal Factors in Exponential Smoothing, ORNL/M-1262, Oak Ridge National Laboratory, September 1990. [See Abstract 7.3.21.]

Barkenbus, B. D., R. J. Carter, J. E. Dobson, C. E. Easterly, P. S. Ogle, and A. K. Van Cleave, Environmental Protection for Hazardous Materials Incidents, ORNL/TM-11421, Oak Ridge National Laboratory, February 1990. [See Abstract 7.1.1.]

Bames, P. R., and F. M. Tesche, "Transient Response of a Distribution Circuit Recloser and Control Unit to a High-Altitude Electromagnetic Pulse (HEMP) and Lightning," IEEE Transactions on Electromagnetic Compatibility 32(2), 113-24 (May 1990). [See Abstract 7.4.1.]

Berry, L. G., The Market Penetration of Energy-Efficiency Programs, ORNL/CON-299, Oak Ridge National Laboratory, April 1990. [See Abstract 7.4.3.]

Berry, L. G., and E. Hirst, "The U. S. Department of Energy Least-Cost Utility' Planning Program," Energy, 15(12), 1107-17 (December 1990). [See Abstract 7.4.2.]

Berry, L. G., The Administrative Costs of Energy Conservation Programs, ORNL/CON-294, Oak Ridge National Laboratory, November 1989. [See Abstract 7.4.4.]

Berry, L. G., "The Role of Incentives in the Market Penetration of Energy-Efficiency Programs," Proceedings of the NORDAX Incentives Roundtable, Ontario Hydro, Toronto, July 1990.

Bjornstad, D. J., and B. H. Hardy, Arsenal of Democracy in the Face of Change: Issues and Policy Options in Industrial Preparedness Planning, ORNL/TM-11273, Oak Ridge National Laboratory, March 1990. [See Abstract 7.2.2.]

Bjomstad, D. J.. J. R. Brinkerhoff, C. V. Chester, I. Gutmanis, B. H. Hardy, G. Horwich, P. J. Sullivan, and D. A. Trumble, Arsenal of Democracy in the Face of Change: Economic Policy for Industrial Mobilization in the 1990s, ORNL/TM-11271, Oak Ridge National Laboratory, December 1989. [See Abstract 7.2.1.]

Bradley, R. A., and E. R. Williams, eds., A Compendium of Options for Government Policy to Encourage Private Sector Responses to Potential Climate Change, Vol. 1: Methodological Justification and Generic Policy Instruments, Report to the U.S. Congress [R. B. Braid, M. A. Brown, D. L. Feldman, E. L. Hillsman, E. Hirst, D. W. Jones, P. N. Leiby, S. Rayner, J. H. Reed, G. G. Stevenson] DOE/EH-0103, U.S. DOE, Washington, D.C., October 1989.

Bradley, R. A., and E. R. Williams, eds., A Compendium of Options for Government Policy to Encourage Private Sector Responses to Potential Climate Change, Vol. 2: Policy Options by Sector and Considerations for Assembling a Policy Package, Report to the U.S. Congress, [R. B. Braid, M. A. Brown, D. L. Feldman, E. L. Hillsman, E. Hirst, D. W. Jones, P. N. Leiby, S. Rayner, J. H. Reed, G. G. Stevenson] DOE/EH-0103, U.S. DOE, Washington, D.C., October 1989.

Bradley, R. A., and E. R. Williams, eds., A Compendium of Options for Government Policy to Encourage Private Sector Responses to Potential Climate Change, Executive Summary, Report to the U.S. Congress [R. B. Braid, M. A. Brown, D. L. Feldman, E. L. Hillsman, E. Hirst, D. W. Jones, P. N. Leiby, S. Rayner, J. H. Reed, G. G. Stevenson] DOE/EH-0102, U.S. DOE, Washington, D.C., October 1989.

Braid, R. B., review of Effective Risk Communication: The Role and Responsibility of Government and Nongovernment Organizations, eds. V. T. Covello, D. B. McCallum, P. T. Pavlova, The Environmental Professional 12(2), 179-81 (1990). 
Brandis, P., B. Cody, M. A. Brown, and M. H. Haeri, "Evaluating the Impacts of Model Conservation Standards on Single-Fanily Construction Practices in the Northwest," pp. 6.15-6.24 in Proceedings of the ACEEE 1990 Summer Study on Energy Efficiency in Buildings, Vol. 2, Pacific Grove, Calif., Aug. 26-Sept. 1, 1990. [See Abstract 7.4.5.]

Brock, W. R., and D. W. Lee, Proceedings of the Information Exchange Workshop-Design Basis Floods, Oak Ridge, Tenn., Mar. 20, 1990, K/GDP/SAR-2, September 1990.

Bronfman, B. H., M. Warwick, and E. Hirst, Least Cosi Integrated Resource Planning in North Carolina: Review of Utility Plans and Planning Processes, ERCE/PO-43, ERC Environment and Energy Services Co., prepared for Public Staff-North Carolina Utilities Commission, Raleigh, N.C., October 1989.

Brown, M. A., and C. H. Major, "Technology Transfer Strategies of DOE's Conservation Programs," Journal of Technology Transfer, 15(1), 33-40 (1990). [See Abstract 7.4.10.]

Brown, M!. A., "The Cost of Commercializing Energy Inventions," Research Policy 19(2), 147-55 (April 1990). [See Abstract 7.4.11.]

Brown, M. A., L. L. White, W. C. Kochler, Jr., and J. Hayes, "Innovators and Opinion Leaders in Demand-Side Management," pp. 2.7-2.16 in Proceedings of the ACEEE 1990 Summer Study on Energy Efficiency in Buildings, Vol. 2, Pacific Grove, Calif., Aug. 26-Sept. 1, 1990. [See Abstract 7.4.9.]

Brown, M. A., B. Prindle, M. I. Scherr, and D. L. White, Energy Efficiency in Nonprofit Agencies: Creating Effective Program Models, ORNL/TM-11602, Oak Ridge National Laboratory, August 1990. [See Abstract 7.4.8.]

Brown, M. A., S. M. Cohn, and J. O. Kolb, Implementation and Enforcement of Bonneville's Model Conservation Standards Within Early Adopting Jurisdictions, ORNL/CON-296, Oak Ridge National Laboratory, February 1990. [See Abstract 7.4.6.]

Brown, M A., and C. R. Wilson, The Energy-Related Inventions Program: Commercial Progress of Participants Through 1988, ORNL/CON-301, Oak Ridge National Laboratory, May 1990. [See Abstract 7.4.7.]

Burrage, L. M., J. H. Shaw, and B. W. McConnell, "Distribution Transformer Performance When Subjected to Steep-Front Impulses," IEEE Transactions On Power Delivery, 5(2), 984-90 (April 1990).

Campbell, A. W., and E. J. Liebsch, Biological Assessment of Potential Impacts to Federally Listed Threatened Species: Florida Scrub Jay and Southeastern Beach Mouse, U.S. Air Force, Patrick Air Force Base, Fla., December 1989.

Cantor, R. A.. D. W. Jones, P. N. Leiby, and S. Rayner, "Policies to Encourage Private Sector Responses to Potential Climate Changes," pp. 318-28 in Energy Markets in the 1990's and Beyond, ed. A. B. Baker and H. G. Huntington, Proceedings of the Eleventh Annual North American Conference of the International Association for Energy Economics, New York, November 1989.

Cames, S. A., Site-Specific Emergency Response Concept Plans for the Chemical Stockpile Disposal Program: A Comparative Summary, ORNL/TM-11357, Oak Ridge National Laboratory, November 1989. [See Abstract 7.1.3.]

Cames, S. A., "Disposing of Chemical Weapons: A Desired End in Search of an Acceptable Means," The Environmental Professional 11(4), 279-90 (December 1989).

Carnes. S. A., "Decisionmaking for the CSDP Health and Environmental Assessment," The Environmental Professional 11(4), 422-33 (December 1989).

Cames, S. A., "NEPA Compliance for the Chemical Stockpile Disposal Program," The Environmental Professional 11(4), 434-46 (December 1989).

Carnes, S. A. J. H. Sorensen, G. O. Rogers, B. L. Shumpert, R. L. Miller, and A. P. Watson, Emergency Response Concept Plan for Anniston Army Depot and Vicinity, ORNL/TM-1 1093, Oak Ridge National Laboratory, October 1989. [Sce Abstract 7.1.2.] 
Cames, S. A., J. H. Sorensen, G. O. Rogers, B. L. Shumpert, R. L. Miller, and A. P. Watson, Emergency Response Plan for Umatilla Depot Activity and Vicinity, ORNL/TM-11097, Oak Ridge National Laboratory, October 1989. [See Abstract 7.1.2.]

Cames, S. A., J. H. Sorensen, G. O. Rogers, B. L. Shumpert, R. L. Miller, and A. P. Watson, Emergency Response Concept for Pine Bluff Arsenal and Vicinity, ORNL/TM-11092, Oak Ridge National Laboratory, October 1989. [See Abstract 7.1.2.]

Cames, S. A., J. H. Sorensen, G. O. Rogers, B. L. Shumpert, R. L. Miller, and A. P. Watson, Emergency Response Concept Plan for Tooele Army Depot and Vicinity, ORNL/TM-11094, Oak Ridge National Laboratory, October 1989. [See Abstract 7.1.2.]

Cames, S. A.. J. H. Sorensen, G. O. Rogers, B. L. Shumpert, R. L. Miller, and A. P. Watson, Emergency Response Concept Plan for Newport Army Ammunition Plant and Vicinity, ORNL/TM-1 1095, Oak Ridge National Laboratory, October 1989. [See Abstract 7.1.2.]

Carnes, S. A., J. H. Sorensen, G. O. Rogers, B. L. Shumpert, R. L. Miller, and A. P. Watson, Emergency Response Concept for Aberdeen Proving Ground and Vicinity, ORNL/TM-11096, Oak Ridge National Laboratory, October 1989. [See Abstract 7.1.2.]

Carnes, S. A., J. H. Sorensen, G. O. Rogers, B. L. Shumpert, R. L. Miller, and A. P. Watson, Emergency Response Concept Plan for Pueblo Depot Activity and Vicinity, ORNL/TM-1 1098, Oak Ridge National Laboratory, October 1989. [See Abstract 7.1.2.]

Carnes, S. A., J. H. Sorensen, G. O. Rogers, B. L. Shumpert, R. L. Miller, and A. P. Watson, Emergency Response Concept Plan for Lexington-Blue Grass Army Depot and Vicinity, ORNL/TM-1 1099, Oak Ridge National Laboratory, October 1989. [See Abstract 7.1.2.]

Cames. S. A., and R. L. Perrine, "Introduction to a Highlighted Topic: The Integrated Assessment Process for a Major Activity Leading to a Programmatic Environmental Impact Statement," The Environmental Professional 11(4), 277-78 (December 1989).

Chester, C. V.. Chemical Stockpile Disposal Program: Rapid Accident Assessment, ORNL/TM-11354, Oak Ridge National Laboratory, August 1990. [See Abstract 7.1.5.]

Chester, C. V., Ar ienal of Democracy in the Face of Change: Precision Guided Munitions (PGMs), Their Evolution and Some Economic Considerations, ORNL/TM-11275, Oak Ridge National Laboratory, August 1990. [See Abstract 7.1.4.]

Chin, S.-M., D. S. Joy, P. E. Johnson. S.-P. Miaou, and S. M. Bobic, "Personal Computer Based Decision Support System for Routing Nuclear Spent Fucl," pp. 90-100 in Proceedings of the TIMS 10th International DSS Conference: Information Technology for Executives and Managers, Boston, May 1990. [See Abstract 7.3.1.]

Christian, J. E.. W. R. Strzepek, P. H. Billing, M. F. McBride, and K. D. Mentzer, "Would Code Change B 171-90 Be Cost Effective?" BOCA, The Building Official and Code Administrator Magazine 24(3) (May/June 1990).

Christian, J. E., "The Most Needed Building Foundation Rescarch Products," pp. 655-62 in Insulation Materials, Testing, and Applications, ASTM STP 1030, eds. D. L. McElroy and J. F. Kimptlen, American Society for Testing and Matcrials, Philadelphia, 1990. [Sce Abstract 7.4.14.1

Christian. J. E., "ORNL's Search for Roof Insulation CFC Alternatives," The Construction Specifier 43(11) (November 1990).

Christian. J. E., G. E. Courville, R. L. Linkous, R. L. Wendt, R. S. Graves, and T. L. Smith, "The Technical Viability of Altemative Blowing Agents in Polyisocyanurate Roof Insulation: Part 4. In-Situ Thermal Aging and Performance in Different Roof Systems," in Proceedings of the 33rd Annual Polyurethane Conference, Orlando, Fla., Sept. 30-Oct. 3, 1990. ISec Abstract 7.4.13.1

Christian, J. E., "A Heal Flux Transducer Guard Plate for Exterior Envelope Surface Measurements," in Proceedings of the In-Situ Heat Flux Measurements in Buildings Conference. Hanover, N.H., May 22-23, 1990). (See Abstract 7.4.12.) 
Christian, J. E., "Will CFC Restrictions Jeopardize Anticipated Foundation Thermal Efficiency Gains?" ASHRAE Transactions 96(1) (February 1990). [See Abstract 7.4.15.]

Church, R. L., A. K. Rathi, and R. S. Solanki, "Deployment Analysis Prototype of U.S. TRANSCOM," p. 64 in Proceedings of the ORSA/TIMS National Meeting, New York, October 1989. [See Abstract 7.3.31.]

Curlee, T. R., "Biomass-Derived Plastics: Viable Economic Altematives to Petrochemical Plastics?" Materials and Society 13(4), 381-409 (1989). [See Abstract 7.2.4.]

Curlee, T. R., S. Das, R. M. Lee, and D. A. Trumble, Advanced Materials: Information and Analysis Needs, ORNL/TM-11593, Oak Ridge National Laboratory, September 1990. [See Abstract 7.2.5.]

Curlee, T. R., "Targets of Opportunity for Plastics Recycling and Source Reduction," pp. 21-45 in Plastics Recycling as a Future Business Opportunity, Technomic Publishing, Lancaster, Pa., 1990. [See Abstract 7.2.3.]

Curlee, T. R., and S. Das, Plastics Recycling in the Industrial Sector: An Assessment of the Opportunities and Constraints, ORNL/TM-11258, Oak Ridge National Laboratory, December 1989. [See Abstract 7.2.6.]

Curlee, T. R., "Production and Conservation Act of 1990," pp. 74-77 in Testimony for Subcommittee on Energy Regulation and Conservation, Committee on Energy and Natural Resources, U.S. Senate, Bill S.2923, S. Hrg. 101-928, Aug. 2, 1990.

Curlee, T. R., Congressional Testimony, Hearing on Waste Minimization, Testimony for Subcommittee on Environment and Labor, Committee on Small Business, U.S. House of Representatives, Aug. 1, 1989, U.S. Govemment Printing Office, Washington, D.C., pp. 36-38; 143-147, 1990.

Dale, S. J., S. M. Wolf, and T. R. Schneider, eds., Energy Applications of High-Temperature Superconductivity, ER-6682, Electric Power Research Institute, Palo Alto, Calif., Vol. 1, February 1990. [Sce Abstract 7.4.16.]

Dale, S. J., S. M. Wolf, and T. R. Schneider, eds., Energy Applications of High-Temperature Superconductivity, ER-6682, Electric Power Research Institute, Palo Alto, Calif., Vol. 2, September 1990. [See Abstract 7.4.16.]

Das, S., R. M. Davis, G. R. Hadder, R. Lee, and P. N. Leiby, "Oil Markets Under Political and Military Stress," Energy Economics 12(3), 204-10 (July 1990). [See Abstract 7.2.7.]

Daugherty, P. F., and P. T. Singley, SQTTEXT: A Tool for Editing Structured Query Language (SQL) Text Within ORACLE SQL*Forms Application, ORNL/TM-11639, Oak Ridge National Laboratory, Augist 1990. [See Abstract 7.3.3.]

Davis, S. C., D. B. Shonka, G. Anderson-Batiste, and P. S. Hu, Transportation Energy Data Book: Edition 10, ORNL-6565, Oak Ridge National Laboratory, October 1989. ISee Abstract 7.3.17.]

Deonigi, D., N. Moore, S. Smith, R. Watts, M. A. Brown, and B. Noun, The Technology Transfer Process: Background for the U.S. National Energy Strategy, PNL-SA-17482, Pacific Northwest Laboratory, January 1990.

DeVault, R. C., and J. Marsala, "Ammonia-Water Triple-Effect Absorption Cycle," ASHRAE Transactions 96(1) (February 1990). [See Abstract 7.4.19.]

DeVault, R. C., "Triple Effect Absorption Chiller Cycle: A Step Beyond Double-Effect Cycles," pp. II-27-II-40 in Proceedings of the IEA Annex XVI Workshop, Report No. HPC-WR-6, IEA Heat Pump Centre, Susono City, Japan, March 1990. [See Abstract 7.4.18.]

DeVault, R. C., "Advanced Absorption Technology Development in the United States," pp. 69-80 in Heat Pumps-Solving Energy and Environmental Challenges, procecdings of the 3rd IEA Heat Pump Conference, Tokyo, Mar. 12-15, 1990, Pergamon Press, Elmsford, N.Y. [See Abstra 4.17.]

Difiglio, C., K. G. Duleep, and D. L. Greene, "Cost Effectiveness of Future Fuel Economy Improvements," Energy Journal 11(1), 65-86 (January 1990). 
Edwards, R. G., and T. G. Yow, "Strategic Mobility Modeling at Oak Ridge National Laboratory," pp. 297--328 in Proceedings of RAND Corporation's Conference on Strategic Mobility Modeling: Status, Needs, and Prospects, Santa Monica, Calif., January 1990. [Sec Abstract 7.3.4.1

Fairchild, P. D., and W. Fulkerson, "Energy Technology R\&D and the Greenhouse Effect," pp. 231-41 in Heat Pumps-Solving Energy and Environmental Challenges, proceedings of the 3rd IEA Heat Pump Conference, Tokyo, Mar. 12-15, 1990, Pergamon Press, Elmsford, N.Y. [Sec Abstract 7.4.20.]

Feldman, D. L., Managing Global Climate Change Through International Cooperation: Lessons from Prior Resource Management Efforts, ORNL/TM-10914, Oak Ridge National La'joratory, July 1990. [See Abstract 7.1.9.]

Feldman, D. L., S. A. Carnes, and G. O. Rogers, "Intergovernmental Consultation and Coordination: Continued Protection of Public Health and Safety Through Public Accountability," The Environmental Professional 11(4), 409-21 (December 1989). [See Abstract 7.1.6.1

Feldman, D. L., review of Natural Gas and Electrical Power: Partners for the 1990s, ed. J. Newcomb and T. Robinson, in Forum for Applied Research and Public Policy 5(3), 105-6 (Fall 1990).

Feldman, D. L., "Global Change and International Cooperation," in Societal Aspects of Climate Change, proceedings of the Third Symposium on Social Science in Resource Management, College Station, Tex., May 1990. [See Abstract 7.1.8.]

Feldman, D. L., and J. E. Dobson, Decision Making Technical Support Study for the U.S. Army's Chemical Stockpile Disposal Program: Enhancing Command, Control, and Computer Operations at Aberdeen Proving Ground and Pine Bluff Arsenal, ORNL/TM-11412, Oak Ridge National Laboratory, August 1990. [Sec Abstract 7.1.10.]

Feldman, D. L., "SARA Title III and State Response to Chemical Hazards: Gauging the Effectiveness of Public Participation for Emergency Planning," The Environmental Professional 12(1), 67-76 (April 1990). [See Abstract 7.1.7.]

Fischer, S. K., "Energy Use Impact of CFC Altematives," Proceedings of the 5th Cogeneration and Independent Power Congress, Association of Energy Engineers, June 6-7, 1990.

Fischer, S. K., "National Energy Impacts of CFC Alternatives in Heating, Air-Conditioning, and Refrigeration Equipment and Foam Insulation," ASHRAE Transactions 96(1) (February 1990). [See Abstract 7.4.21.]

Fischer, S. K., and J. R. Sand, "Thermodynamic Calculations for Mixtures of Environmentally Safe Refrigerants Using the Lee-Kesler-Plöcker Equation of State." pp. 373-82 in Proceedings of the ASHRAE/Purdue CFC Conference, W. Lafayctte, Ind., July 1990. [See Abstract 7.4.22.]

Gant, K. S., and M. V. Adler, "The Continuing Evolution of the Federal Radiological Emergency Response Plan," p. 78 in Transactions of the A, nerican Nuclear Society, 60. (1-792), 1989 Winter Meeting, San Francisco, California, Ncv. 26-30, 1989.

Gant, K. S., M. V. Adler, and W. F. Wolff, "The Development and Revision of the Federal Radiological Emergency Plan," pp. 37-40 in Changing Expectations and Performance, proceedings from the 13th Annual TRADE Conference, Baltimore, Oct. 23-25, 1989. ORAU 90/C-84, Oak Ridge Associated Universities, July 1990. [See Abstract 7.1.11.]

Gerry, P., J. H. Reed, E. R. Williams, "Respecting the Environment," pp. 125-84 in Interim Report National Energy Strate $y$. A Compilation of Public Comments, DOE/S-0066, U.S. Department of Energy, Washingion, D.C., April 1990.

Gettings, M. B., and J. M. MacDonald, "Direct Installation of Lighting Measures in Nonresidential Buildings," in Proceedings of the ACEEE 1990 Summer Study on Energy Efficiency in Buildings, Pacific Grove, Calif., Aug. 26-Sept. 1, 1990. 
Gettings, M. B. "New Weatherization Assistance Program Audit," in Proceedings of the 1989 U.S. DOE National Weatherization State Managers' Conference, Buffalo, N.Y., Oct. 30-Nov. 3, 1989.

Gnadt, P. A., and J. S. Lawler, eds., Automating Electric Utility Distribution Systems: The Athens Automation and Control Experiment, Prentice-Hall, Englewood Cliffs, N.J., March 1990.

Goeltz, R. T., S. L. Purucker, B. E. Tonn, T. Wiggen, and D. MacGregor, Bonneville Power Administration Communication Alarm Processor Expert System: Design and Implementation, ORNL/TM-11323, Oak Ridge National Laboratory, June 1990. [See Abstract 7.3.5.]

Goldman, C., and E. Hirst, "Key Issues in Developing Demand-Side Bidding Programs," LBL-27748, Lawrence Berkeley Laboratory, Berkeley, Calif., Noven xr 1989.

Goldman, C., and E. Hirst. "Key Issues in Developing Demand-Side Bidding Programs," Chapter 23 in Demand-Side Management: Partnerships in Planning for the Next Decade, Proceedings of the ECNE National Conference on Utility DSM Programs, CU-6598, Electric Power Research Institute, Palo Alto, Calif., November 1989.

Graves, R. S., D. W. Yarbrough, and J. E. Christian, "Thermal Performance of a Closed-Cell Foamboard Insulation Containing HCFC-22," Proceedings of the Sixth International Conference on Thermal Insulation, Millbrae, Calif., February 12-14, 1990.

Greene, D. L., and C. Difiglio, "First Interim Report of the Interagency Commission on Alternative Motor Fuels," Office of Energy Demand Policy, Office of Policy, Planning, and Analysis, U.S. Department of Energy, 'Washington, D.C., September 1990.

Greene, D. L., "Commercial Aircraft Fuel Efficiency Potential Through 2010," in Proceedings of the 1990 Intersociety Energy Conversion Engineering Conference, American Institute of Chemical Engineers, Reno, Nev., August 1990. [See Abstract 7.3.10.]

Greene, D. L., Energy Efficiency Improvement Potential of Commercial Aircraft to 2010, ORNL-6622, Oak Ridge National Laboratory, June 1990. [See Abstract 7.3.6.]

Greene, D. L., "CAFE or Price? An Analysis of the Effects of Federal Fuel Economy Regulations and Gasoline Price on New Car MPG, 1978-89," Energy Journal 11(3), 37-57 (September 1990). [See Abstract 7.3.9.]

Greene, D. L., "Technology and Fuel Efficiency," Forum for Applied Research and Public Policy 5(1), 23-30 (Spring 1990).

Greene, D. L., "Short Tem Options for Controlling $\mathrm{CO}_{2}$ Emissions of Light Duty Vehicles," Society of Automotive Engineers, Inc., Ser. 901111, 1-15 (May 1990). [Sce Abstract 7.3.7.]

Greene, D. L., and A. K. Rathi, Alternative Motor Fuel Use Model, ORNL/TM-11448, Oak Ridge National Laboratory, April 1990. [See Abstract 7.3.8.]

Groeger, J. H., M. S. Mashikian, and S. J. Dale, "Laboratory Tests On The Role Of Impurities In Semiconducting Shield Materials On The Degradation of XLPE Insulation," in Mimutes of the 56th Annual Conference of Doeble Clients, Doeble Engineering Company, 1989.

Groeger, J. H., M. S. Mashikian, S. J. Dale, B. S. Bernstein, and E. P. Barry, "Surmounting Pitfalls In The Application Of Diagnostics For Characterization Of Aged Polymeric Cable Insulation," CIGRE 1990 Session. Paper No. 15/33-1.J9, Aug. 26-Sept. 1, 1990.

Hadder, G. R., and R. M. Davis, Navy Mobility Fuels Forecasting System Phase VI Report: Impacts of a Military Disruption on Navy Fuel Availability and Quality, ORNL-6637, Oak Ridge National Laboratory, September 1990. [See Abstract 7.3.11.]

Hadder, G. R., M. N. Burnett, L. E. Creech, C. K. Johnson, J. W. Terry, and R. W. Tucker, Jr., Security and Accountability Procedures for Protection of Bureau of Engraving and Printing Security Items at Oak Ridge National Laboratory, ORNL/TM-11444, Oak Ridge National Laboratory, September 1990.

Hadder, G. R., S. Das, P. N. Leiby, R. Lee, and R. M. Davis, "Navy Fuel Production During a Middle East Political Disruption," Energy 14(12), 965-66 (December 1989). ISec Abstract 7.3.12.] 
Hake, K. A.. "Understanding the Computing System Domain of Advanced Computing with Microcomputers," Sect. 13 in Proceedings of the Advanced Computing for the Social Sciences Conference, Williamsburg, Va.. April 1990. [See Abstract 7.3.13.]

Hamblin, D. M. G. D. Pine, R. Maddigan, J. M. MacDonald, H. A. McLain, and J. Y. Rimpo, "Commercial Sector Gas Cooling Technology Frontier and Market Share Analysis," pp. 239-50 in International Association for Energy Economics Twelfth Annual North American Conference Proceedings, October 1990.

Hawsey, R. A., W. K. Kahl, S. W. Schwenterly, J. N. Luton, B. W. McConnell, V. W. Campbell, C. W. Sohns, and J. M. Bailey, Performance Test Plan For A Variable-Speed AC Superconducting Motor, ORNL/ATD-39, Oak Ridge National Laboratory, May 1990.

Hill, L. J., and C. H. Petrich, "Potential Use of Oil Shale for Direct Production of Power in Jordan," Natural Resources Forum 13(4), 310-18 (November 1989).

Hillsman, E. L., G. Marland, and S. Rayner, "Options for Technological Response to Climate Change," in Energy and Climate Change: Report of the DOE Multi-Laboratory Climate Change Committee, ed. M. MacCracken, Lewis Publishers, Chelsea, Mich., 1990.

Hillsman, E. L., and P. R. Coleman, "Integrating Demographic, Atmospheric, and Dose Information to Estimate Effects from Accidental Release of Chemical Agents," The Environmental Professional 11(4), 354-66 (December 1989). [Sec Abstract 7.1.12.]

Hillsman, E. L., and F. Southworth, "Factors That May Influence Responses of the U.S. Transportation Scctor to Policies for Reducing Greenhouse Gas Emissions," Transportation Research 1267, 1-11 (January 1990).

Hirst, E., and C. Goldman, "Review of Demand-Side Data Needs for Least-Cost Utility Planning," Energy 15(5), 403-12 (May 1990).

Hirst, E. "The Many Benefits of Utility Demand-Side Management Programs," Communications \& Meterings, 20-21 (Summer 1990).

Hirst. E. "Balancing the Scales: Toward Parity in Electricity Supply and Demand Data," Electricity Journal 3(4), 28-33 (May 1990).

Hirst, E., and R. S. Carlsmith, "The Federal Government Should Do More to Improve U.S. Energy Efficiency." Fiscal Year 1991 Department of Ene:gy Authorization, Testimony for Subcommittee on Energy Research and Development, Committee on Science, Space, and Technology, U.S. House of Representatives, Volume III, 51-64, June 6, 1990.

Hirst, E. "Federal Roles to Encourage Electric-Utility Energy-Efficiency and Load-Management Programs," in Energy Security: Energy Efficiency and National Security, Testimony for Subcommittee on Economic Stabilization Committee on Banking, Finance and Urhan Affairs, U.S. House of Representatives, Serial No. 105-58, Oct. 4, 1989, pp. 129-143.

Hirst, E., C. Goldman, and M. E. Hopkins, "Integrated Resource Planning for Electric and Gas Utilities," pp. 5.95-5.114 in Proceedings of the ACEEE 1990 Summer Study on Energy Efficiency in Buildings, Vol. 5. Pacific Grove, Calif., Aug. 26-Sept. 1, 199(). ISee Abstract 7.4.25.]

Hirst. E., "A Nonalgorithmic Review of Uncertainty in Electric-Utility Resource Planning and Decision Making." pp. 65-80 in Proceedings on Resource Planning Under Uncertainty for Electric Pow'er Systems, Jan. 21-22, 1989, Department of Operations Research, Stanford University, Stanford, Calif., November 1989. [See Abstract 7.4.32.]

Hirst, E. "Electric-Utility Demand-Side Programs: Resources for the 1990s," pp. 46-56 in Proceedings of the American Power Conference, Vol. 51, Apr. 24, 1989, Illinois Institute of Technology. Chicago, November 1989. [See Abstract 7.4.31.]

Hirst, E. "Flexibility Benefits of Demand-Side Programs in Utility Planning." Energy Journal 11(1), 151-65 (November 1989). [See Abstract 7.4.30).]

Hirst. E.. Testimony hefore the Washington Utilities and Transportation Commission on behalf of Puget Sound Power \& Light Company, Docket No. U-89-2688-T, Exhibit Y-791, October 1989. 
Hirst, E., Federal Roles to Realize National Energy-Efficiency Opportunities in the 1990s, ORNL/CON-290, Oak Ridge National Laboratory, October 1989. [See Abstract 7.4.33.]

Hirst, E., "Conservation Programs Can Cut Load-Growth Uncertainty for Electric Utilities," Technological Forecasting and Social Change 36(4), 415-24 (December 1989).

Hirst. E., "Data Requirements for Utility Integrated Resource Planning," Energy Systems \& Policy 12(3), 219-31 (December 1989). [See Abstract 7.4.29.]

Hirst, E., and M. Schweitzer, "Electric-Utility Resource Planning and Decision Making: The Importance of Uncertainty," Risk Analysis 10(1), 137-46 (March 1990). [See Abstract 7.4.27.]

hiirst, E., "Guidelines for a 'Good' Integrated Resource Plan," Public Utilities Fortnightly 125(7), 18-24 (March 1990). [See Abstract 7.4.26.]

Hirst, E., "Progress and Potential in Evaluating Energy-Efficiency Programs," Evaluation Review 14(2), 192-205 (April 1990).

Hirst, E., M. Schweitzer. E. Yourstone, and J. Eto, Assessing Integrated Resource Plans Prepared by Electric Utilities, ORNL/CON-298, Oak Ridge National Laboratory, February 1990. [See Abstract 7.4.28.]

Hirst, E., "Integrated Resource Planning at Electric Utilities: The Planning Proce.ss," Evaluation and Program Planning 12(3), 213-23 (1989).

Hirst, E., and M. A. Brown, "Ciosing the Efficiency Gap: Barriers to Improving Energy

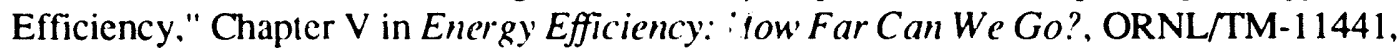
Oak Ridge National Laboratory, January 1990.

Hirst, E., "Demand-Side Management, An Underused Tool for Conserving Electricity," Environment 21(1), 4-9; 27-31 (Jan/Feb 1990).

Hirst, E., "The Benefits of Utility Demand-Side Management Programs," Energy User New's 15(4), 56 (April 1990).

Hirst, E., "Why the Federal Government Should Help Improve U.S. Energy Efficiency," Ambio, A Journal of the Human Environment 19(2), 96-98 (April 1990).

Hirst, E., and M. A. Brown, "Closing the Efficiency Gap: Barriers to Improving Energy Efficiency," Resources, Conservation and Recycling 3(4), 267-81 (June 1990). [See Abstract 7.4.23.]

Hirst, E., "Electricity, Getting More with Less," Technology Review' 93(5), 32-40 (July 1990).

Hirst, E., Balancing the Scales: Data on Electricity Supply and Demand Resources, ORNL/CON-306, Oak Ridge National Laboratory, September 1990. [See Abstract 7.4.24.]

Honea, R. B., K. A. Hake, and R. C. Durfee, "Incorporating GISs Into Decision Support Systems: Where Have We Come Prom and Where Do We Need to Go?," pp. 215-19 in Proceedings of the GIS ' 90 Meetings, Vancouver, Canada, March 1990. [See Abstract 7.3.14.]

Horwich, G., Arsenal of Democracy in the Face of Change: Four U.S. Mobilizations: A Macroeconomic Perspective, ORNL/TM-11276, Oak Ridge National Laboratory, April 1990. [See Abstract 7.2.8.]

Horwich, G., "Disasters and Market Response," Cato Journal 9(3), 531-55 (Winter 1990). [See Abstract 7.2.9.]

Hu, F'. S., T. Wright, and S.-P. Miaou, "A Comparative Study of Six Data Sources' Ability for Estimating Interstate Motor Carrier VMT." pp. 29-34 in Proceedings of the 1989 American Statistical Association's Annual Meeting, Washington, D.C., May 1990. [See Abstract 7.3.15.]

Hu. P. S., T. Wright. S.-P. Miaou. D. J. Beal, and S. C. Davis, Estimating Commercial Truck VMT of Interstate Motor Carriers: Data Evaluation, ORNL/TM-11278, Oak Ridge National Laboratory, November 1989. [See Abstract 7.3.16.]

Hunsaker, D. B., Jr., R. B. McLean, W. M. Willis, G. F. Cada, E. J. Liebsch, R. L. Graham, C. T. Garten, C. T. Hunsaker, A. W. Campbell, G. Marland, and R. L. Miller, Assessing the Potential Environmental Impacts of Proposed Rules Affecting Future Electric Power Generation in the United States, ORNL/TM-11301, Oak Ridge National Laboratory, February 1990. [See Abstract 7.1.13.] 
Hwang, H.-L.. C. Trammell, and D. Valentine, "IDA: A Prototype CAI System in Military Transportation." pp. 80-88 in Proceedings of the Third International Conference on Microcomputers in Transportation. American Society of Civil Engineers, San Francisco. June 1990. [See Abstract 7.3.20.]

James. T. L.. and P. T. Singley, Requirements Analysis for WHIST-MOD Project at Field Office, ORNL/M-894, Oak Ridge National Laboratory, October 1989. [See Abstract 7.3.34.]

James. T. L., and J. P. Loftis, User Interface in ORACLE for the Worldwide Household Goods Information System for Transportation Modernization (WHIST-MOD), ORNL/TM-11596. Oak Ridge National Laboratory. July 1990. [See Abstract 7.3.27.]

Jones, D. W.. "Urbanization and Energy Use in Economic Development," Energy Journal 10(1), 29-44 (October 1989). [Sec Abstract 7.2.10.]

Kappenman, J. G., V. D. Albertson, B. L. Damsky, and S. J. Dale, "Solar Wind Monitoring Satcllite. Crucial For Geomagnetic Storm Waming," IEEE Power Engineering Review 10(5), 4-8 (May 1990).

Katzman, M. T., "Scrap Metal Industry Faces Environmental Dilemma," Risk Management, 38-45 (December 1989).

Katzman. M. T., and D. W. Jones, The Survivable Optics MODIL: Guidelines for Forming $R \& D$ Consortia from the Theory of Clubs, ORNL/OMIS-90/1, Oak Ridge National Laboratory, March 1990. [See Abstract 7.2.11.]

Katzman, M. T., L. Hill, M. Levine, and T. J. Wilbanks, "The Prospects for Energy Efficiency Improvements in Developing Countries," in special issue on the Global Warming Symposium, Energy Journal, 1990.

Keshock, E. G., and R. W. Murphy, Performance Testing of a Commercially Produced Cryogenir Refrigerator. ORNL/TM-10809, Oak Ridge National Laboratory, September 1990. [See Abstract 7.4.42.]

Ketelle. R. H., R. R. Lee, M. W. Yambert, and H. K. Hardee, Supplemental Hydrologic Data Collected at Central Waste Management Division Sites, 9:1/89-3/31/90, K/WM-3, Oak Ridge National Laboratory, June 1990. [See Abstract 7.1.15.]

Kocher, D. C., and D. W. Lee. "A Preliminary Performance Assessment for Near-Surface Land Disposal of Low-Level Radioactive Wastes," in Proceedings of 11th Anmual Department of Energy Low'Level Waste Management Conference, CONF-890854, December 1989.

Kruse. V. J., P. R. Bames, and G. B. Rackcliffe, "Load Flow Studies in the Presence of Magnetohydrodynamic Electromagnetic Pulse," IEEE Transactions on Power Delivery 5(2), 1158-63 (April 1990).

Kruse, V. J., P. R. Barnes, and F. M. Tesche, "Flashover Vulnerability of Transmission and Distribution Lines to High-Altitude Electromagnetic Pulse (HEMP)," IEEE Transactions on Pon'er Delivery 5(2), $1164-69$ (April 1990).

Kolb, J. O.. and K. E. Wilkes, "Power Generation from Waste Incineration," Energy Engineering 87(3), 49-62 (1990).

Lawler. J. S.. D. T. Rizy, J. P. Stovall, J. B. Patton, and N. H. Fortson, "Impact of Automated Feeder Reconfiguration on Capacity Utilization at the Athens Utilities Board," Proceedings of the Twenty-First Annual Pittshurgh Conference on Modeling and Simulation, May 1990.

Lee, D. W.. and D. C. Kocher, "Performance Assessment for Future Low-Level Waste Disposal Facilitics at ORNL." Proceedings of 11th Annual Department of Energy Low-Level Waste Management Conference. CONF-890854, December 1989. [See Abstract 7.1.16.]

Lee, R., and P. N. Leiby. "Strategic Petroleum Reserve Expansion," Proceedings of the 1989 North American Conference of the International Association for Energy Economists. Oct. 16-18, 1989. [Sec Abstract 7.2.12.] 
Levins, W. P., J. A. Hall, and M. A. Kamitz, Cooling Season Energy Measurements of Dust and Ventilation Effects on Radiant Barriers, ORNL/CON-271, Oak Ridge National Laboratory, March 1990. [See Abstract 7.4.36.]

Levins, W. P., "Measured Effects of Zoning in Single-Family Houses," in Thermal Performance of the Exterior Envelopes of Buildings $I V$, proceedings of the ASHRAE/DOE/BTECC/CIBSE Conference, Orlando, Fla., December 1989. [Sec Abstract 7.4.37.]

Levins, W. P., and M. P. Ternes, "Measured Space Cooling Electricity Savings from Standard Energy Conservation Measures, Radiant Barriers, and High-Efficiency Window Air Conditicners," Proceedings of the ACEEE 1990 Summer Study on Energy Efficiency in Buildings, Pacific Grove, Calif., Aug. 26-Sept. 1, 1990.

Levins, W. P., M. A. Karnitz, and J. A. Hall, "Dust and Ventilation Effects on Radiant Barriers: Cooling Season Energy Measurements," in EPRI Vol. CU-6817, May 1990.

Levins, W. P., and D. Herron, "Radiant Barrier Field Tests in Army Housing Units at Fort Benning, Georgia," ASHRAE Transactions 96(2) (June 1990). [See Abstract 7.4.34.]

Levins, W. P., and J. A. Hall, "Measured Effects of Dust on the Performance of Radiant Barriers Installed on Top of Attic Insulation," ASHRAE Transactions 96(2) (June 1990). [See Abstract 7.4.35.]

Liepins, G. E., A Framework for Studying Genetic Optimization of Complex Systems, ORNL/TM-11140, Oak Ridge National Laboratory, September 1989.

Lietzke, D. A., R. H. Ketelle, and R. R. Lee, Soils and Geomorphology of the East Chestnut Ridge Site, ORNL/TM-1 1364, Oak Ridge National Laboratory, October 1989. [See Abstract 7.1.14.]

Loffman, R. S., and R. M. Rush, "Formulating Data Element Rules to Improve Data Quality," Database Programming \& Design.

Loffman, R. S., and L. F. Truett, Quality Assurance (QA) Plan for the Airlift Deployment Analysis System (ADANS), ORNL/M-1250, Oak Ridge National Laboratory, September 1990. [See Abstract 7.3.22.]

Loftis, J. P., and T. L. James, A Conceptual Design for a Graphics Output Interface for the WHIST-MOD, ORNL/TM-1 1627, Oak Ridge National Laboratory, August 1990. [See Abstract 7.3.24.]

Loftis, J. P., T. L. James, and M. P. Spears, A Technical Description of Enhancements to the Front-End Interface for the WHIST-MOD, ORNL/TM-11595, Oak Ridge National Laboratory, August 1990. [See Abstract 7.3.23.]

Loftis, J. P., "Providing Dynamic Sorting and Searching Capabilities Using SQL*Forms," pp. 303-09 in Proceedings of the International ORACLE Users Group Meeting, Anaheim, Calif., September 1990. [See Abstract 7.3.25.]

Lofi:s, J. P., and W. E. Friggle, "Building a User-Friendly Data Dictionary System in ORACLE," pp. 439-44 in Proceedings of the International ORACLE Users Group Meeting, Dallas, October 1989. [Sce Abstract 7.3.26.]

MacDonald, J. M., and D. L. White, "Exploratory Investigation of a New Modeling Approach and an Energy Index for Multifamily Buildings in the Pacific Northwest," pp. 10.145-10.152 in Proceedings of the 1990 ACEEE Summer Study in Energy Efficiency in Buildings, Pacific Grove, Calif., Aug. 26-Sept. 1, 1990. [See Abstract 7.4.38.]

MacDonald, J. M., G. E. Courville, E. I. Griggs, and T. R. Sharp, "A Guide for Estimating Potential Energy Savings from Increased Solar Reflectance of a Low-Sloped Roof," pp. 348-57 in Thermal Performance of the Exterior Envelopes of Buildings $I V$, proceedings of the ASHRAE/DOE/BTECC/CIBSE Conference, Orlando, Fla., Dec. 4-7, 1989.

Macey, S. M., and M. A. Brown, "Demonstrations as a Policy Instrument with Energy Technology Examples," Knowledge: Creation, Diffusion, and Utilization 11(3), 219-36 (March 1990). 
Marland, G., and A. F. Turhollow, $\mathrm{CO}_{2}$ Emissions from Production and Combustion of Fuel Ethanol from Corn, ORNL/TM-11180, Oak Ridge National Laboratory, May 1990.

McConnell, B. W., "Motors," in Energy Applications of High-Temperature Superconductivity, Vol. 2. Chap. 3. cds. S. J. Dalc, S. M. Wolf, and T. R. Schneider, ER-6682, Electric Power Research Institute, Palo Alto. Calif., September 1990. [See Abstract 7.4.39.]

Mei, V. C., "Heat Transfer of Buried Pipe for Heat Pump Application," pp. 23-29 in Advances in Heat Pumps 1989. ASME Symposium Volume AES-Vol. 7, Dec. 10-15, 1989. [See Abstract 7.4.40.]

Mei. V. C., and V. D. Baxter, Design Guidelines for Direct Expansion Ground Coils, EPRI Repon CU-6828, Research Project 2892-4, Electric Power Research Institute, Palo Alto, Calif., May 1990.

Mei, V. C., F. C. Chen, and W. A. Miller, Development of Army Two-Ton Subcompact Air Conditioner, report to Belvoir Research, Development and Engineering Center, Ft. Belvoir, U.S. Army, August 1990.

Mei, V. C., and V. D. Baxter, "Laboratory Simulation of Direct Expansion Ground Coil Heat Exchanger," ASHRAE Transactions 96(1) (February 1990). [See Abstract 7.4.41]

Mileti, D. S.. and J. H. Sorensen, "La Eficacia de los Sistemas de Alarma en America Latina," in Consecuencias Psicosociales de los Desastres, ed. B. Lima, John Hopkins University, 1989.

Miller, D. B.. A. E. Lux, S. Grzybowski, and P. R. Barnes, "The Effects Of Steep-Front Short-Duration Impulses On Power Distribution Component," IEEE Transactions on Power Delivery, 5(2), 708-15 (April 1990).

Miller, R. L., and F. C. Kornegay, "Downwind Doses from Potential Releases Associated with the Chemical Stockpile Disposal Program," The Environmental Professional 11(4), 315-23 (December 1989). [See Abstract 7.1.17.]

Miller, R. L., Atrnospheric Dispersion Modeling and Meteorological Monitoring in Support of Emergency Planning and Response for the Army's Chemical Stockpile Disposal Program. ORNL/TM-1 1508, Oak Ridge National Laboratory, August 1990. [See Abstract 7.1.18.]

Mixon. W. R., and A. Meier, "Monitoring Made Easier," Home Energy 7(5), 36-37 (September/October 1990).

Mixon, W. R., "Existing Single-Family Efficiency Research," pp. 18-19 in Making Housing More Affordable Through Energy Efficiency, summary of proceedings of the ASE Conference, Washington, D.C., Oct. 5-6, 1989.

Ng, V. W., A Case Study in Specifying Data Requirements for a Decision Support System Database, ORNL/TM-11583, Oak Ridge National Laboratory, August 1990.

$\mathrm{Ng}, \mathrm{V}$. W.. On the Implementation of Cumplex Many-to-Many Relations in Focus, ORNL-6572, Oak Ridge National Laboratory, April 1990.

O'Riordan. T., and S. Rayner, "Chasing a Spectre: Risk Management for Global Environmental Change." The Council for Science and Socicty, Occasional Paper No. 2, London, 1990.

Patterson. M. R., R. N. Crosswhite, and H. Perez-Blanco, A Menu-Driven Program for Determining Properties of Aqueous Lithium Bromide Solutions, ORNL/TM-11331, Oak Ridge National Laboratory, January 1990. [See Abstract 7.4.43.]

Patton. J. B.. D. T. Rizy, and J. S. Lawler, "Applications Software for Modeling Distribution Automation Operations on the Athens Utilities Board," IEEE Transactions on Power Delivery, 5(2), 1019-25 (April 1990).

Patton, J. B.. D. T. Rizy, and J. S. Lawler. "Applications Software for Modeling Distribution Automation Operations on the Athens Utilities Board," paper summary, IEEE Power Enginecring Review 10(4), 85 (April 1990).

Peelle, E. B., "Two Citizen Task Forces and the Challenge of the Evolving Nuclear Waste Siting Process." in Proceedings of High-Level Radioactive Waste Management Conference, Las Vegas. Apr. 9-12, 1990). [Sec Abstract 7.1.19.] 
Peelle. E. B., "Understanding Risk in a Dangerous World," book review of Perceptions of Technological Risks and Benefits, by L. Gould, G. Gardner, D. DeLuca, A. Tiemann, L. Doob, and J. Stolwijk, in Forum for Applied Research and Public Policy, 5(2), 102 (Summer 1990).

Peelle. E. B., "Helping with the Cleanup: A Two-State Citizen Task Force Responds to Department of Energy on Defense Waste," pp. 7-11 in Proceedings of Spectrum 90, Nuclear and Hazardous Waste Management International Topical Meeting, Knoxville, Tenn., Sept. 30-Oct. 4, 1990. [Sce Abstract 7.1.20.]

Perlack, R. D., H. G. Jones, A. Garcia, and E. Flores, Mid-Term Evaluation of USAIDIROCAP and NRECA Ceritral America Rural Electrification Support Progress, ORNL/TM-1 1567, Oak Ridge National Laboratory, September 1990. [See Abstract 7.2.13.]

Petrich, C. H., book review of Bordering on Trouble: Resources and Politics in Latin America, eds. A. Maguire and J. W. Brown, Environmental Management 13(5), 649-51 (September/October 1989).

Potter, W. D., B. E. Tonn, M. R. Hilliard, G. E. Liepins, S. L. Purucker, and R. T. Goeltz, "Diagnosis, Parsimony, and Genetic Algorithms," pp. 1-8 in Proceedings of the Third International Conference on Industrial and Engineering Applications of Artificial Intelligence and Expert Systems, Charleston, S.C., July 1990. [See Abstract 7.3.38.]

Railsback, S. F., J. M. Bownds, M. J. Sale, M. M. Stevens, and G. H. Taylor, "Aeration at Navigational Dams in the Upper Ohio River Basin," Journal of Environmental Engineering 116(2), 361-75 (April 1990).

Rathi, A. K., and A. J. Santiago, "Identical Traffic Streams in the TRAF-NETSIM Simulation Program," Traffic Engineering and Control 31(6), 351-55 (June 1990). [See Abstract 7.3.28.]

Rathi, A. K., and A. J. Santiago, "The New NETSIM Simulation Program," Traffic Engineering and Control 31(5), 317-20 (May 1990). [See Abstract 7.3.29.]

Rathi, A. K., "A Formulation of External Metering Control for Congested Urban Networks," p. 10 in Proceedings of the TIMS/ORSA National Meeting, Las Vegas, May 1990, and in the ORSA /TIMS Bulletin, Md., May 1990. [See Abstract 7.3.30.]

Rayner, S., "Fiddling While the Globe Warms," Anthropology Today 5(6), 1-2 (December 1989).

Rayner, S., book review of Searching for Safety, A. Wildavsky, American Anthropology 92(3), 807-8 (September 1990).

Rayner, S., W. Naegeli, and P. Lund, Managing the Global Commons: Decision Making and Conflict Resolution in Response to ${ }^{\circ}$ Climate Change, ORNL/TM-11619, Oak Ridge National Laboratory, July 1990. [See Abstract 7.1.21.]

Reddoch, T. W., and J. H. Reed, "Innovative Transmission and Distribution Technologies," prepared for the Program for the Acceleration of Commercial Energy Research (PACER) Conference, New Delhi, India, April 1990.

Reed, R. M., C. E. Easterly, D. M. Evans, R. L. Kroodsma, E. J. Liebsch, R. B. McLean, L. D. Voorhees, and A. K. Wolfe, Environmental Review STARLAB Site on Antigua, U.S. Air Force, Space Systems Division, September 7, 1990.

Reed, J. H., R. P. Broadwater, A. Chandrasekarn, and A. Oka, "Predicting Air Conditioner Load Curves from Energy Audit Data: A Comparison of Predicted and Actual Air Condition Data from Athens Load Control Experiment," IEEE Transactions on Power Delivery 5(2), 259-66 (May 1990). [See Abstract 7.1.22.]

Rice, C. K., and J. R. Sand, "Initial Parametric Results Using CycleZ-An LMTD-Specified Lorenz Cycle Refrigeration-Freezer Model," pp. 448-58 in Proceedings of the ASHRAE/Purdue CFC Conference, W. Lafayette, Ind., July 1990. [See Abstract 7.4.44.]

Rizy, D. T., et. al., The Potential of Renewable Energy: An Irterlaboratory White Paper, SERI/TP-260-3674. Solar Energy Research Institute, March 1990. 
Rizy, D. T., E. R. Broadaway, J. S. Lawler. J. H. Reed, and G. R. Wetherington, "Monitoring," in Electric Utility Distribution System: Athens Automation and Control Experiment, ed. P. A. Gnadt, pp. 3-1-3-12, Prentice Hall, Englewood Cliffs, N.J., March 1990.

Rodriguez-Moscoso. J., S.-M. Chin, A. J. Santiago, and R. Roland, "Object-Oriented Programming in Traffic Simulation." pp. 177-190 in Proceedings of the 1989 Engineering Foundation Conference, Santa Barbara. Calif.. January 1990. [See Abstract 7.3.2.]

Rogers, G. O., J. H. Sorensen. J. F. Long, and D. Fisher, "Emergency Planning for Chemical Agent Releases," The Environmental Professional 11(4), 396-408 (December 1989).

Rogers, G. O., A. P. Watson, J. H. Sorensen, R. D. Sharp, and S. A. Carnes, Evaluating Protective Actions for Chemical Agent Emergencies, ORNL-6615, Oak Ridge National Laboratory, April 1990. [See Abstract 7.1.23.]

Rovero, C., and D. B. Waddle, Vaccine Refrigeration Technologies and Power Sources, ORNL-6558, Oak Ridge National Laboratory, October 1989.

Russell, M., "The Making of Cruel Choices," in Valuing Health Risks, Costs, and Benefits for Environmental Decision Making: Report of a Conference, eds. P. B. Hammond and R. Coppock, National Academy Press, Washington, D.C., 1990.

Russell, M., "Evaluating Ecological Impacts: A Conceptual Framework," in Ecological Risks: Perspectives from Poland and the United States, eds. W. Grodzinski, E. B. Cowling, and A. I. Breymeyer, National Academy Press, Washington, D.C., 1990.

Russell, M., "Keeping Promises: EPA and the Protection of Wetlands," in Freshwater Wetlands and Wildlife, eds. R. R. Sharitz and J. W. Gibbons, DOE Symposium Series, No. 61, U.S. DOE Office of Scientific and Technical Information, Oak Ridge, Tenn., 1990.

Russell, M., "Ozone Puzzle Offers Few Easy Choices," Forum for Applied Research and Public Policy, 5(3), 31-37 (Fall 1990).

Russell, M., with Committee on Risk Perception, Improving Risk Communication, National Academy of Sciences, National Academy Press, Washington, D.C., 1989.

Russell, M., Clean Air Act Amendments of 1989, Testimony before the Subcommittee on Environmental Protection, Committee on Environment and Public Works, U.S. Senate, Washington, D.C., U.S. Government Printing Office, October 1989.

Russell, M., "Environmental Protection in China," Oak Ridge National Laboratory Review 23(1), 44-53 (1990).

Russell, M., "Population, Poverty, and Prosperity: China's Environmental Woes," Survey of Business 24(2) (Fall 1989).

Sand, J. R., E. A. Vineyard, and J. R. Nowak, "Experimental Performance of Ozone-Safe Altemative Refrigerants." ASHRAE Transactions 96(2) (June 1990). [See Abstract 7.4.45.]

Schweitzer, M., E. Hirst, and E. Yourstone, "The Process of Integrated Resource Planning for Electric Utilities," pp. 5.177-5.186 in Proceedings of the ACEEE 1990 Summer Study on Energy Efficiency in Buildings, Vol. 5, American Council for an Energy Efficient Economy, Washington, D.C., Aug. 26-Sept. 1, 1990. [See Abstract 7.1.25.]

Schweitzer, M., E. Yourstone, and E. Hirst, Key Issues in Electric Utility Integrated Resource Planning: Findings from a Nationwide Study, ORNL/CON-300, Oak Ridge National Laboratory, April 1990. [Sec Abstract 7.1.24.]

Sexton, A. K., and H.-L. Hwang, Automated Support for Processing Special Assignment Airlift Missions (SAAMs) A Concept Paper, ORNL/TM-11024, Oak Ridge National Laboratory, October 1989. [See Abstract 7.3.32.]

Sharp, T. R., Developing Operational Strategies for the Fort Benning Shallow Solar Pond Domestic Water Heating Systems: Performance Testing and Results, ORNL/TM-11519, Oak Ridge National Laboratory, June 1990. [See Abstract 7.4.48.]

Sharp, T. R., and J. M. MacDonald, "Effective Low-Cost HVAC Controls Upgrade in a Small Bank Building," ASHRAE Transactions 96(1), Atlanta, Feb. 11-14, 1990. [See Abstract 7.4.46.] 
Sharp, T. R., and M. P. Ternes, The North Carolina Field Test: Experimental Plan, ORNL/TM-1 1339, Oak Ridge National Laboratory, August 1990. [Sce Abstract 7.4.49.]

Sharp, T. R. and J. M. MacDonald, Measurement of Energy Performance in a Small Bank Building, ORNL/CON-297, Oak Ridge National Laboratory, May 1990. [See Abstract 7.4.47.]

Sorensen, J. H., and D. Mileti, Communication of Emergency Public Warnings: A Social Science Perspective and State-of-the-Art Assessment, ORNL-6609, Oak Ridge National Laboratory, August 1990. [See Abstract 7.1.27.]

Sorensen, J. H., "The Cheyenne Flash Flood: Were the Warnings Effective," Oak Ridge National Laboratory Review' 23(1), 39-41 (1990).

Sorensen, J. H., and D. Mileti, "Warning Systems for Nuclear Power Plant Emergencies," Nuclear Safety 30(3), 358-70 (July-September 1989). [See Abstract 7.1.26.]

Sorensen, J. H., "Psychosocial Effects of Restarting a TMI Reactor," Oak Ridge National Laboratory Review 23(1), 41-42 (1990).

Sorensen, J. H., "Human Behavior in Emergencies," Oak Ridge National Laboratory Review 23(1), 30-38 (1990).

Sorensen, J. H., and G. O. Rogers, "Chemical Fears: The Social Effects of the Disposal Program," The Environmental Professional 11(4), 385-95 (December 1989).

Spears, P. M., P. T. Singley, P. F. Daugherty, and A. H. Voelker, Architectural Analysis for the Worldwide Household Goods Information System for Transportation Modernization (WHIST-MOD), ORNL/M-936, Oak Ridge National Laboratory, October 1989. [See Abstract 7.3.33.]

Staub, W. P., "Oversizing Riprap for Protection of Uranium Mill-Tailings," Association of Engineering Geologists 27(1), 85-92 (1990). [See Abstract 7.1.28.]

Stevens, M. M., Conceptual Model for Radiological Performance Assessment of Low-Level Radioactive Waste Disposal Facilities, ORNL/TM-11495, Oak Ridge National Laboratory, May 1990. [See Abstract 7.1.29.]

Stevenson, G. G., "The Production, Distribution, and Consumption of Fuelwood in Haiti," Journal of Developing Areas 24(1), 59-76 (October 1989). [See Abstract 7.2.15.]

Stevenson, G. G. "Preinvestment Analysis for Biomass Briquettes," Proceedings of an International Workshop on Biomass Fuel Briquetting in Developing Countries, Khartoum, Sudan, Oct. 23-26, 1988, COWIconsult, Virum, Denmark, April 1990. [See Abstract 7.2.14.]

Ternes, M. P., "Energy Savings and Performance of an Improved Energy Efficiency Measure Selection Technique." ASHRAE Transactions 96(2) (June 1990). [Sce Abstract 7.4.51.]

Ternes, M. P., "Planning Building Energy Monitoring Field Tests," in Field Monitoring For a Purpose, Intemational Energy Agency (IEA) Workshop, University of Technology, Gothenburg, Sweden, April 2-5, 1990. [See Abstract 7.4.50.]

Ternes, M. P., "Single-Channel Temperature Recorder," Field Monitoring For a Purpose, International Energy Agency Workshop, University of Technology, Gothenburg, Sweden, March 1990.

Ternes, M. P., and W. P. Levins, "Measured Space-Cooling Electricity Savings from Standard Energy Conservation Measures, Radiant Barriers, and High-Efficiency Window Air Conditioners," pp. 9.299-9.308 in Proceedings of the ACEEE 1990 Summer Study on Energy Efficiency in Buildings Vol. 9, Pacific Grove, Calif., Aug. 26-Sept. 1, 1990. [See Abstract 7.4.52.]

Tonn, B. E., R. G. Edwards, R. T. Goeltz, and K. A. Hake, Technology Innovation and Management in the U.S. Bureau of the Census: Discussion and Recommendations, ORNL-6600, Oak Ridge National Laboratory, August 1990. [See Abstract 7.3.35.]

Tonn, B. E., R. T. Goeltz, C. Travis, and R. Phillippi, "Knowledge-Based Representations of Risk Beliefs," Risk Analysis 10(1), 169-84 (March 1990). [See Abstract 7.3.36.] 
Tonn, B. E., R. T. Gocltz, L. Arrowood, and K. A. Hake, "Artificial Intelligence for Subject Interviewing." Sect. 17 in Proceedings of the Advanced Computing for the Social Sciences Conference. Williamsburg, Va., April 1990.

Torn, B. E., and D. L. White, "Residential Wood Combustion for Space Heating in the Pacific Northwest: Difficulties for Electric Utilitics," Energy Policy, 283--92 (April 1990). [Sec Abstract 7.3.37.]

Travis, C., R. Phillippi, and B. E. Tonn, "Judgement Heuristics and Medical Decisions," Patient Education and Counselling 13, 211-20 (1989). [Sce Abstract 7.3.39.]

Truett, L. F., R. S. Loffman, and S. S. Stevens, Airlift Deployment Analysis System (ADANS) Development Guidelines: User Interface, ORNL/TM-11391, Oak Ridge National Laboratory, January 1990. [See Abstract 7.3.40.]

Truett, L. F., S. Das, and J. C. Worthington, Airlift Deployment Analysis System Life Cycle Cost Analysis, ORNL/M-1198, Oak Ridge National Laboratory, August 1990. [See Abstract 7.3.41.]

Truett, L. F., and T. G. Yow, A Study of Auditing Methodologies for the Energy Information Administration Data Collection and Processing System Quality Assessment Program, ORNL/TM-11327, Oak Ridge National Laboratory, November 1989. [See Abstract 7.3.42.]

Truet1, L. F., and S. S. Stevens, "Electronic Communication and Data Transfer: Productivity Enhancements," pp. 57-65 in Proceedings of the Third International Conference on Microcomputers in Transportation, American Society of Civil Engineers, San Francisco, June 1990. [See Abstract 7.3.44.]

Truett, L. F., and R. H. Ketelle, Supplemental Data Package for the Low-Level Waste Disposal Development and Demonstration Program Data Collection Period: April 1988-September 1989, ORNL/TM-11416, Oak Ridge National Laboratory, December 1989. [Sec Abstract 7.3.43.]

Van Dyke. J. W., and P. S. Hu., "Determinants of Variation in Calculating a Discount Rate," Energy 14(10), 661-66 (October 1989). [See Abstract 7.1.30.]

Voclker, A. H., P. T. Singley, P. F. Daugherty, T. L. James, W. E. Friggle, T. Shelton, and M. Hughes, Worldwide Household Goods Information System for Transportation Modernization (WHIST-MOD) Conceptional Design, ORNL/TM-11298, Oak Ridge National Laboratory, August 1989. [See Abstract 7.3.45.]

Vories, R., and D. L. White, "Life after RCS," Home Energy 7 (3), 24-28 (May/June 1990). [Sce Abstract 7.4.59.]

Waddle, D. B., R. D. Perlack, and H. G. Jones, "Renewable Energy Projects: Lessons from the Past and Directions for the Future," Natural Resources Forum 13(4), 303-09 (November 1989). [Sce Abstract 7.4.53.]

Waddle, D. B., and R. D. Perlack," A Summary of the Status of Biomass Conversion Technologies and Opportunities for Their Use in Latin America," in Conference Proceedings of the 1990) Union Americana de Asociaciones de Ingeneiros (UPADI) Annual Convention. Washington, D.C., August 1990. [See Abstract 7.4.56.]

Waddle, D. B. and R. D. Perlack, "Future Role of Biomass Energy Use in Developing Countries," in Proceedings of the 1989 Winter Meeting of the American Society of Agricultural Engineers, Paper No. 89-6548, New Orleans, December 1989. [Sec Abstract 7.4.54.J

Waddle, D. B. and J. M. MacDonald, "Analysis Of Power Sector Efficiency Improvements for an Integrated Planning Process in Costa Rica," in Proceedings of the IECEC Conference, Reno, Nev., August 1990. [Sec Abstract 7.4.57.]

Waddle. D. B., and J. M. MacDonald, "Integrated Power Sector Efficiency Analysis: A Case Study Of Cosla Rica." in Proceedings of the Energy Conservation Symposium 1990, Karachi, Pakistan. May 199). [Sec Abstract 7.4.55.] 
White, D. L., and M. A. Brown, Electricity Savings Among Participants Three Years After Weatherization in Bonneville's 1986 Residential Weatherization Program, ORNL/CON-305, Oak Ridge National Laboratory, September 1990. [Sec Abstract 7.4.58.]

Wilbanks, T. J., C. H. Petrich, D. B. Hunsaker, Jr., B. E. Tonn, Phase I: Framework for Tool Development and Survey of Available Software, U.S. Agency for International Development, October 1989.

Wilbanks, T. J., "Implementing Environmentally Sound Power Sector Strategies in Developing Countries," Annual Review of Energy, 255-76 (1990).

Wilkes, K. E., "Model for the Thermal Performance of Low-Sloped Roofs," pp. 184-97 in Thermal Performance of the Exterior Envelopes of Buildings $I V$, proceedings of the ASHRAE/DOE/BTECC/CIBSE Conference, Orlando, Fla., Dec. 4-7, 1989. [See Abstract 7.4.60.]

Wilkes, K. E., "Analysis of Arnual Energy Savings Due to Radiant Barriers," pp. 235-45 in Proceedings of the ACEEE 1990 Summer Study on Energy Efficiency in Buildings, Vol. 1, Pacific Grove, Calif., Aug. 26-Sept. 1, 1990. [See Abstract 7.4.62.]

Wilkes, K. E., "Thermal Modeling of Residential Attics with Radiant Barriers: Comparison with Laboratory and Field Data," pp. 294-311 in Thermal Performance of the Exterior Envelopes of Buildings $I V$, proceedings of the ASHRAE/DOE/BTECC/CIBSE Conference, Orlando, Fla., Dec. 4-7, 1989. [See Abstract 7.4.61.]

Williams, L. S., and P. S. Hu, Light-Duty Vehicle Summary: First Six Months of Model Year 1990, ORNL-6626/S1, Oak Ridge National Laboratory, July 1990. [See Abstract 7.3.19.]

Williams, L. S., and P. S. Hu, Light-Duty Vehicle MPG and Market Shares Report: Model Year 1989, ORNL-6626, Oak Ridge National Laboratory, April 1990. [See Abstract 7.3.18.]

Witten, A. J., and J. E. Molyneux, "Geophysical Diffraction Tomography: Validity and Implementation," in Frontiers in Applied Mathematics, volume on geophysical inversion, ed. B. Bednar. [See Abstract 7.1.31.]

Wolfe, A. K., "Confidence in Technologies: Interactions Between Publics and Industries," pp. 251-57 in New Risks: Issues and Management, eds. L. A. Cox and P. F. Ricci, Plenum, New York, 1990. [See Abstract 7.1.32.]

Yow, T. G., L. F. Truett, P. X. Armendarez, and T. Wright, Quality Assurance Review of Manual and Automated Data-Handling Procedures: Annual Survey of Domestic Oil and Gas Reserves, Form EIA-23, ORNL/M-1000, Oak Ridge National Laboratory, November 1989. [See Abstract 7.3.46.]

Yow, T. G., User Interface Techniques in the Counseling Module of TOPS, ORNL/TM-11336, Oak Ridge National Laboratory, October 1989. [See Abstract 7.3.47.]

Zaltash, A., M. R. Ally, R. L. Linkous, and L. N. Klatt, "Measurements of Heat and Mass Transfer Coefficients During Absorption of Water Vapor by Lithium Bromide and ( $\mathrm{Li}, \mathrm{K}$, $\mathrm{Na} \mathrm{NO}_{3}$ Mixtures," ASHRAE Transactions 96(2) (June 1990). [See Abstract 7.4.64.]

Zaltash, A., and M. R. Ally, "Predicting Viscosities of Aqueous Salt Mixtures," ASHRAE Transactions 96(2) (June 1990). [See Abstract 7.4.63.]

Zimmerman, G. P., Conceptual Design for a Land Decontamination Robot, ORNL/TM-10416, Oak Ridge National Laboratory, November 1989. [See Abstract 7.1.33.]

\subsection{ENVIRUNMENTAL ASSESSMENTS AND ENVIRONMENTAL IMPACT STATEMENTS}

Department of the Air Force, Environmental Assessment, Withdrawal of the 320th Bombardment Wing from Mather AFB, Headquarters, Air Training Command, Randolph AFB Texas, November 1989. [D. B. Hunsaker, Jr., J. T. Ensminger, J. Morrissey] 
Department of the Air Force, Environmental Assessment, Recharting Tyndall Military Operations Areas. Tactical Air Command, Tyndall Air Force Base, Florida, January 1990. [L. N. McCold, J. T. Ensminger, J. Morrisscy]

Department of the Air Force, Environmental Assessment, Deactivation of the SR-7I Program at Beale Air Force Base, California, Headquarters, Strategic Air Command, Offutt Air Force Base, Nebraska, January 1990. [J. T. Ensminger, C. R. Boston, G. W. Hayward, K. M. Brasted]

Department of the Air Force, Final Environmental Assessment, U.S. Air Force Titan IV/Solid Rocket Motor Upgrade Program, Cape Canaveral Air Force Station, Florida and Vandenberg Air Force Base, California, February 1990. [A. W. Campbell, R. L. Graham, E. J. Licbsch, R. D. Roop, W. P. Staub, V. R. Tolbert]

Department of the Air Force, Final Environmental Impact Statement for the Closure of Mather AFB, Texas, Headquarters, Air Training Command, Randolph AFB, Texas, March 1990. [D. B. Hunsaker, Jr., C. R. Boston, L. N. McCold, L. L. Sigal, M. A. Mitckes] [Sec Abstract 7.1.36.1

Department of the Air Force, Final Environmental Impact Statement, Realignment of Beale Air Force Base, Headquarters, Strategic Air Command, Offutt Air Force Base, Nebraska, July 1990. [J. T. Ensminger, C. R. Boston, G. W. Hayward, K. M. Brasted]

Department of the Air Force, Final Environmental Assessment, STARLAB Program, Space Systems Division, A'.gust 17, 1990. [R. M. Reed, C. E. Easterly, D. M. Evans, R. L. Kroodsma, E. J. Liebsch, R. B. McLean, L. D. Voorhees] [See Abstract 7.1.35.] Department of the Army, Final Phase I Ervironmental Report, Disposal of Chemical Agents and Munitions Stored at Umatilla Depot Activity, Hermiston, Oregon, Program Manager for Chemical Demilitarization, Aberdeen Proving Ground, Maryland, February 1990. IG. P. Zimmerman, D. L. Feldman, E. L. Hillsman, D. B. Hunsaker, Jr., R. O. Johnson, R. L. Kroodsma, R. L. Miller, J. Morrissey, T. G. Patton, L. W. Rickert, G. M. Schoepfle, W. P. Staub, V. R. Tolbert, D. C. West]

Department of the Army, Final Phase I Environmental Report, Disposal of Chemical Agents and Munitions Stored at Pine Bluff Arsenal, Pine Bluff, Arkansas, May 1990.

[J. T. Ensminger, D. B. Hunsaker, Jr., G. P. Zimmerman, C. R. Boston, D. L. Feldman, E. L. Hillsman, R. O. Johnson, R. L. Kroodsma, R. L. Miller, J. Morrissey, L. W. Ricken, G. M. Schoepfle, W. P. Staub, V. R. Tolbert, D. C. West]

Department of the Amiy, Johnston Atoll Chemical Agent Disposal System (JACADS): Final Second Supplemental Environmental Impact Statement for the Storage and Ultimate Disposal of the European Chemical Munition Stockpile, Program Manager for Chemical Demilitarization, Aberdeen Proving Ground, Maryland, June 1990. [R. E. Saylor, G. P. Zimmerman, C. R. Boston, C. W. Hagan, J. D. Harris, R. O. Johnson, P. Kanciruk, R. L. Kroodsma, E. J. Licbsch, L. N McCold, N. B. Munro, B. A. Owens, T. G. Patton, W. P. Staub, G. W. Suter] [See Abstract 7.1.41.]

Department of the Army, Final Phase I Environmental Report, Disposal of Chemical Agents and Munitions Stored at Anniston Army Depot, Anniston, Alabama, ORNL/TM-11206/V1, Oak Ridge National Labos atory, September 1990. [D. B. Hunsaker, Jr., G. P. Zimmerman, E. L. Hillsman, R. L. Miller, G. M. Schoepfle, R. O. Johnson, V. R. Tolbert, R. L. Kroodsma, L. W. Rickert, G. O. Rogers, W. P. Staub] [See Abstract 7.1.37.]

Department of the Army, Addendum, Final Phase I Environmental Report, Disposal of Chemical Agents and Munitions Stored at Anniston Army Depot, Anniston, Alabama, ORNL/TM-112()6/V2, Oak Ridge National Laboratory, September 1990. (D. B. Hunsaker, Jr., W. P. Staub, G. P. Zimmerman, E. L. Hillsman]

Federal Energy Regulatory Commission, Environmental Assessment, Pine Creek Hydroelectric Project, Rovana, California, May 1990. [L. N. McCold, G. F. Cada, D. M. Evans, C. H. Petrich, B. L. Shumpert, J. W. Webb] [See Abstract 7.1.39.] 
U. S. Department of Energy, Final Environmental Assessment, Innovative Clean Coal Technology Program, Circulating Fluidized Bed Boiler Repowering Demonstration Project, Southwestern Public Service Company, Nichols Station, Potter County, Texas, DOE/EA-0415, Pittsburgh Energy Technology Center, October 1989. [A. W. Campbell, G. F. Cada, R. L. Miller, M. S. Salk, W. P. Staub, J. W. Van Dyke, J. W. Webb]

U. S. Department of Energy, Final Programmatic Environmental Impact Statement, Clean Coal Technology Demonstration Program, DOE/EIS-0146, November 1989. [R. M. Reed, R. L. Miller, D. B. Hunsaker, Jr., C. R. Boston, C. C. Coutant, N. E. Hinkle, G. Marland, L. N. McCold, N. B. Munro, S. F. Railsback, R. D. Roop, L. W. Rickert, M. S. Salk, M. Uziel, J. A. Watts, J. W. Webb, A. K. Wolfe, M. Andrews, R. M. Monsour, J. Soni, J. T. Stone, S. Zukor] [See Abstract 7.1.40.]

U. S. Department of Energy, Final Environmental Assessment, Coke Oven Gas Cleaning Demonstration Project, Bethlehem Steel Corporation, Sparrows Point Plant, Baltimore County, Maryland, DOE/EA-0404, December 1989. [A. W. Campbell, G. F. Cada, R. L. Miller, R. O. Roop, M. S. Salk, W. P. Staub, J. W. Van Dyke]

U. S. Department of Energy, Environmental Assessment, Strategic Petroleum Reserve, Sulphur Mines Decommissioning and Big Hill Expansion, U.S. Department of Energy, Washington, D.C., DOE/EA-0401, U.S. Department of Energy, January 1990.

[D. B. Hunsaker, Jr., W. P. Staub, J. L. Van Dyke, J. W. Webb, G. F. Cada]

U. S. Department of Energy, Environnmental Assessment, Proposed 7-GeV Advanced Photon Source, DOE/EA-0389, February 1990. [R. B. McLean, E. Ricci, R. L. Kroodsma, R. L. Miller, W. P. Staub, J. P. Witherspoon, M. Swihart]

U. S. Department of Energy, Environmental Assessment, Innovative Clean Coal Technology Program Advanced Flue Gas Desulfurization Demonstration Project, Porter County, Indiana, DOE/EA-0420, Pittsburgh Energy Technology Center, May 1990. [L. N. McCold, D. G. Jemigan, R. L. Miller, S. F. Railsback, M. S. Salk, J. W. Van Dyke, M. A. Mitckes] [See Abstract 7.1 38.]

U. S. Department of Energy, Environmental Assessment, Shipment of Oak Ridge National Laboratory's Contact-Handled Transuranic Waste to the Waste Isolation Pilot Plant, DOE/EA-0349, May 1990. [L. N. McCold, R. E. Saylor, R. B. McLean, E. Ricci]

U. S. Department of Energy, Draft Environmental Assessment, Advanced Coal Conversion Process Demonstration Project, Rosebud County, Montana, Clean Coal Technology Program, Pittsburgh Energy Technology Center, August 1990. [A. W. Campbell]

U. S. Department of Energy, Environmental Assessment, Demonstration of Uranium-Atomic Vapor Laser Isotope Separation (U-AVLIS) at Oak Ridge, Tennessee (Predecisional Draft), Office of Nuclear Energy, August 1990. [A. W. Campbell, E. J. Licbsch, J. P. Witherspoon].

U. S. Department of Energy, Final Environmental Assessment, Demonstration of Coal Reburning for Cyclone Boiler NOx Control, Nelson Dewey Generating Station, Wisconsin Power and Light Company, Cassville, Wisconsin, DOE/EA-0440, Pittsburgh Energy Technology Center, August 1990. [R. L. Kroodsma, T. J. Blasing, A. W. Campbell, G. K. Eddlemon, R. O. Johnson, R.L. Miller, V. R. Tolbert, J. W. Van Dyke] [See Abstract 7.1.34.]

\subsection{PUBLICATIONS BY SUBCONTRACTORS}

Chen, G., and J. McEntee, "Hardware Development and Initial Subassembly Test of a Gas-Fired Stirling-Rankine Residential Heat Pump," pp. 258-61 in Proceedings of the 25th IECEC, Vol. 5, American Society of Chemical Engincers, 199(). 
Chen, G., and W. Beale, "Magnetically Linked Free-Piston Stirling-P_.. Igerant Compressor Heat Pump," pp. 57- 60 in Analysis and Applications of Heat F umps, AES-Vol. ¿, SED-Vol. 6, American Society of Mechanical Engineers, 1989.

Chen, G., and W. Bealc, "System Design and Performance Prediction of a Frec-Piston Stirling Engine/Magnetic Coupling/Compressor Assembly in a Gas Residential Heat Pump," pp. 81-86, Advances in Heat Pumps 1989, AES-Vo!. 7, HTD-Vol. 125, American Society of Mechanical Engineers, 1989.

Diendorfer, G., and M. A. Uman, "An Improved Return Stroke Model with Specified Channel-Base Current," Journal of Geophysical Research 95(D9), 13,621-44 (August 1990).

Diendorfer, G., "Induced Voltage on an Overhead Line Due to Nearby Lightning," IEEE Transactions on Electromagnetic Compatibility, 32(4), 292-99 (November 1990).

Griffin, G. D., M. G. Nolan, C. E. Easterly, I. Sauers, and P. C. Votaw, "Conceming Biological Effects of Spark-Decomposed SF6," IEE Proceedings 137A(4); also in Science, 221-227 (July 1990).

James, T. L., "Building a User Interface Using SQL*Forms and an Intermediate Table," pp. 311-16 in Proceedings of the International ORACLE Users Group Meetings, Anaheim, Calif., September 1990.

Kauffeld, M., W. Mulroy, M. McLinden, and D. Didion, An Experimental Evaluation of Two Nonazeotropic Refrigerant Mixtures in a Water-to-Water Breadboard Heat Pump, ORNL/M-1117 (NISTIR 90-4290), Oak Ridge National Laboratory, April 1990.

Kelley, E. F., M. Nehmadi, R. E. Hebner, M. O. Pace, A. L. Wintenberg, T. V. Blalock, and J. V. Foust, "Measurement of Partial Discharges in Hexane Under DC Voltage," IEEE Transactions on Electrical Insulation 24(6), 1109-19 (December 1989).

Kirol, L., "Complex Salt Technology Application to Irdustrial Chemical Heat Pumps," Phase I-A Final Report by Rocky Research Corporation, Boulder City, Nev., October 1989.

Macriss, R. A., and T. S. Zawacki, Absorption Fluids Data Survey 1989 Update, ORNL/Sub/84-47989/4, Oak Ridge National Laboratory, November 1989.

McCoy, H. E., Jr., Updated Evaluation of Polymer Films for Electrical Insulation, ORNL-6603, Oak Ridge National Laboratory, August 1990.

Modine, F. A., and R. B. Wheeler, "Pulse Response Characteristics of ZnO Varistors," Journal of Applied Physics 67(10), 6560-66 (May 1990).

Modine, F. A., R. W. Major, S. I. Choi, L. B. Bergman, and M. N. Silver, "Polarization Currents in Varistors," Jounal of Applied Physics 68(1), 339-45 (July 1990).

Olthoff, J. K., R. J. Van Brunt, I. Sauers, and G. Harman, "Catalytic Decomposition of $\mathrm{S}_{2} \mathrm{~F}_{10}$ and Its Implications of Sampling and Detection From SF6-Insulated Equipment," p. 248 in Conference Record of the 1990 IEEE International Symposium on Electrical Insulation, Toronto, June 3-6, 1990.

Pace, M. O., I. Alexeff, A. L. Wintenberg, and T. V. Blalock, "Evaluation of a Model For Prebreakdown at the Cathode in DC-Stressed Liquid," pp. 47-51 in Conference Record of the 1990 IEEE International Symposium on Electrical Insulation, Report No. 90-CH 2727-6, Toronto, June 3-6, 1990.

Pace, M. O., A. L. Wintenberg, T. V. Blalock, E. F. Kelley, G. J. FitzPatrick, D. Fenimore, and H. Yamashita, "Pressure Effects on Partial Discharges In Hexane Under DC Voltage," pp. 87-92 in IEEE Transactions on Electrical Insulation, 1989 Annual Report of Conference on Electrical Insulation and Dielectric Phenomena, Report No. 89-CH2773-0, Oct. 29-Nov. 1, 1989.

Rubinstein, M., and M. A. Uman, "On the Radiation Field Turn-On Term Associated with Traveling Current Discontinuities in Lightning," Journal of Geophysical Research 95(D4), 3711-13 (March 1990). 
Rubinstein, M., A. Y. Tzeng, M. A. Uman, P. J. Medelius, and E. M. Thomson, "An

Experimental Test of a Theory of Lightning-Induced Voltages on an Overhead Wire," IEEE Transactions on Electromagnetic Compatibility 31(4), 376-83 (November 1989).

Uman, M. A., and E. P. Krider, "Natural and Artificially Initiated Lightning," Science 246 (4929), 457-64, October 1989.

Voght, B., Evacuation of Institutional and Special Populations, ORNL/Sub-7685/1\&T23, Oak Ridge National Laboratory, April 1990.

Vincent, R. J., and W. Waldron, "A Magnetically Coupled Stirling Engine Driven Heat Pump: Design Optimization and Operating Cost Analysis," pp. 204-210 in Proceedings of the 25th IECEC, Vol.2, American Society of Chemical Engineers, 1990.

Wintenberg, A.L., T.V. Blalock, and M.O. Pace, "High-Bandwidth Measurement of Low-Level Prebreakdown Currents in Liquid Dielectrics," pp. 422-26 in Conference Record of the 1990 IEEE International Symposium on Electrical Insulation, Report No. 90-CH2727-6, Toronto, June 3-6, 1990. 


\subsection{ENERGY DIVISION CONSULTANTS AND SUBCONTRACTORS}

\subsubsection{Consultants}

P. R. Achenbach

M. M. Adibi

M. K. Anderson

J. S. Armstrong

W. F. Barron

J. V. Beck

W. J. Biermann

R. Bohman

S. C. Borgelt

J. Brunon

J. Carmody

D. Chapman

L. L. Christianson

R. A. Chronowski

R. L. Church

G. W. Clark

K. Clements

R. K. Collier

T. J. Considine

M. A. Deluchi

W. F. Eddy

D. M. Evans

G. J. Foster

C. A. Franchuk

A. A. Frank

P. C. Gailey

A. Garcia III

P. A. Gnadt

E. I. Griggs

G. C. Groff

G. Grossman

J. W. Grubb

B. Hardy

D. T. Harrje

O. Holzapfel

W. R. Huntley

M. Katz

W. C. King

R. Kitamura

C. D. Kolstad

H. Kuff
Z. Lavan

M. K. Mason

A. S. Mann

J. McCorkle

J. L. Medford

J. E. Molyneux

T. D. Mount

M. L. Nicholls

F. M. O'Hara

R. K. Pachauri

J. A. Patterson

J. B. Patton

R. W. Peplies

A. M. Perry

F. J. Powell

G. T. Privon

J. P. Quirk

W. A. Radasky

A. Z. Rose

G. Rothwell

A. J. Schaffhauser

E. E. Sherrod

J. L. Solow

S. W. Spurrier

W. F. Stoecker

J. Sypnieuwski

F. M. Tesche

R. R. Tardiff

E. F. Vance

C. Wagner

Q. Wang

D. Wasserman

R. L. Webb

R. Wehrmann

J. M. Weingart

L. White

R. D. White

C. R. Wilson

N. E. Yourstone

H. E. Zittel 


\subsubsection{Subcontractors by Company}

ABB Power Systems, Inc.

Adiabatics, Inc.

Ahlgren Associates

Alliance To Save Energy

Allied Technology Group

American Consulting Engineers Council

Analysas Corp.

Anstech, Inc.

Applied Management Sciences, Inc.

Arthur D. Little, Inc.

Association of Collegiate Schools

Athens Uility Board

Authorization Systems, Inc.

Automated Sciences Group

B D M Corp.

Battelle

Bethel Valley Resources, Inc.

Biomass Energy Reserch Association

Building Thermal Envelope Coordination

Camden Corp.

Carlton Enterprises

Carrier Corp.

Cemat

Center for Planning \& Rescarch. Inc.

Charles River Associates

Collier Engineering Services

Computer Aided Planning

Cooper Power Systems, Inc.

Dames \& Moore

Dan Hamblin \& Associates, Inc.

Decision Focus, Inc.

Distinct Management Consultants, Inc.

E R C Environmental \& Energy

E-Systems, Inc.

East-West Center

Ebasco Services, Inc.

Ecotope, Inc.

Electric Power Research Institute.

Electrotek Concepts

Energy \& Environmental Analysis, Inc.

Energy Concepts Co.

Enersol Associates. Inc.

Enginecring Science, Inc.

Environmental Solutions, Inc.

Flow Research Co.

Geo-Compu-Graph. Inc.

Home Energy

Hone; well, Inc.
I R G Systems, Inc.

Integraied Computer Systems, Inc.

International Energy Agency

J B F Associates, Inc.

Jaycor

King Research, Inc.

Knoxville College

Lambert Enginecring, Inc.

Lawrence Berkeley Laboratory

Logicon, Inc.

Los Alamos Technical Associates, Inc.

M S B D F A \& Buhler \& Abraham, Inc.

MacGregor-Bates, Inc.

Market Facts

Marquette University

Massachusetts Institute of Mechanical

Technology, Inc.

Midviest Research Institute

Minnegasco

Mississippi State Unniversity

Mitre Corp.

Mohawk Research Corp.

N A H B National Research Center

National Association for State Community

National Association of Home Builders

National Bureau of Standards

New Jersey Institute of Technology

North Carolina Alternative Energy Co.

North Carolina State University

Norwegian Building Research Institute

Nuclear Assurance Corp.

Nuclear Resources Intcrnational, Inc.

Oak Ridge Associated Universities

P A I Corp.

P E 1 Associates, Inc.

Parnell, Pearson \& Wucsthoff

Pel North Amcrica, Lid.

Pennsylvania State University

Petrolcum Finance, Lid.

Phillips Enginecring Co.

PIMA

Purdue University

QED Research, Inc.

Quantum Group, Inc.

R. A. Technoloiry

R O H Inc.

RE/SPEC Inc

Resources for the Future 
RJO Enterprises, Inc.

Robinson Technical Services

Rocky Research Corp.

Schneider Engineers

Science \& Technology, Inc.

Science Applications International

Simpact Associates, Inc.

Southwest Research Institute

Sparta, Inc.

Sterling Hobe Corp.

Sumner-Rider \& Associates

Sunpower, Inc.

Synertech Systems Corp.

Systems Reszarch Applications, Inc.

T. J. Murphy \& Associates PA

Techmatics, Inc.

Tectonics Research, Inc.

Telesoft, Inc.

Tennessee State University

Tennessee Technological University

Tennessee Valley Authority

The Trane Co.

The University of Florida
The University of Wisconsin Regents

L!S. Export Council for Renewable Energy Unisys Corp.

United Way of America

University of Arizona

University of California

University of Colorado

University of Connecticut

University of Minnesota

University of Pennsylvania

University of South Carolina

University of Tennessec

University of Texas

URS Corp.

U.S. Department of Interior

V S E Corp.

Virginia Polytechnic Institute

W. S. Flemming \& Associates

Washington Consulting Group

Wayne State Unviersity

Westinghouse Electric Corp.

Widener University 


\subsection{INVITED SPEAKERS}

Datc Subject Speaker

1989

October 20 New Developments in Decision Support Systems

November 3 Flow-Augmentation and Facility Location

November 10 Risk Perception and Energy Policy: A Swedish Case Study

November 28 Markets for Advanced Materials

December 14 An Insider's View of How Environmental Legislation Is Made and the Role of Federal Research Institutions

December 15 Advanced Housing Technology Program Overvicw

December 15 Advanced Construction Technology

1990

February 5 Practical pH Seminar

February 12 Common-Value Oral Auctions with Independent Information: A Framing Effect Observed in a Market Game

February 15 Building Energy Research at Tohoku University

February 21 An Integrated and Geographically Based Solution to Utility Data Problems

March 1 Protection of Small Computer Systems from Power Line Transients
Andrew B. Whinston University of Texas Austin, Texas

Julian Ray University of Tennessee Knoxville, Tennessee

Ragnar Lofstedt Clark University Worchester, Massachusetts Joel Clark

Director of the Materials System Laboratory Massachusetts Institute of Technology

J. Patrick Adcock AAAS Congressional Fellow, Legislative Assistant to Sen. Albert Gore, Jr.

Lisa Frantzis Arthur D. Little, Inc.

Fred Moavenzadeh Massachusetts Institute of Technology

Ned Morgan Beckman Instruments, Inc. Houston, Texas

Ronald M. Harstad Virginia Commonwealth University Richmond, Virginia

Hiroshi Yoshino and Shin Matsumoto Tohoku University Japan

Robert P. Broadwater Virginia Polytechnic Institute Blacksburg, Virginia

Ronald B. Standler Pennsylvania State University 


\begin{tabular}{|c|c|c|}
\hline Date & Subject & Speaker \\
\hline March 2 & $\begin{array}{l}\text { Development of a Residential } \\
\text { Gas-Fired, Double Effect Air } \\
\text { Conditioner-Heater, Using } \\
\text { Lithium-Bromide-Water }\end{array}$ & $\begin{array}{l}\text { Tony DeBuono } \\
\text { Battelle Memorial Institute }\end{array}$ \\
\hline March 2 & Energy Policy in Taiwan & $\begin{array}{l}\text { Gwo-Hshiung Tzeng } \\
\text { University of Maryland } \\
\text { Hong-Neng Wu } \\
\text { Taiwan Power Company }\end{array}$ \\
\hline March 6 & $\begin{array}{l}\text { The Bangladesh Transportation } \\
\text { Modeling System }\end{array}$ & $\begin{array}{l}\text { Bruce Ralston } \\
\text { University of Tennessee }\end{array}$ \\
\hline March 16 & $\begin{array}{l}\text { The "Most Value" Criterion: Screening } \\
\text { Demand-Side } \\
\text { Management Programs Using } \\
\text { a Value-Based Test }\end{array}$ & $\begin{array}{l}\text { Benjamin F. Hobbs } \\
\text { Case Western Reserve University } \\
\text { Cleveland, Ohio }\end{array}$ \\
\hline March 20 & Problems in Karst & $\begin{array}{l}\text { George F. Sowers } \\
\text { Law Companies Group, Inc. } \\
\text { Kennesaw, Gcorgia }\end{array}$ \\
\hline April 9 & $\begin{array}{l}\text { Convective Heat Transfer in Porous } \\
\text { Media }\end{array}$ & $\begin{array}{l}\text { Ping Cheng } \\
\text { University of Hawaii } \\
\text { Honolulu, Hawaii }\end{array}$ \\
\hline April 18 & $\begin{array}{l}\text { Ice Centre Environment Canada: } \\
\text { A Unique Application for GIS } \\
\text { and Digital Image Analysis } \\
\text { Technology }\end{array}$ & $\begin{array}{l}\text { Bruce Ramsay } \\
\text { Ice Centre Environment Canada } \\
\text { Ottawa, Ontario, Canada }\end{array}$ \\
\hline May 4 & $\begin{array}{l}\text { Global Warming and International } \\
\text { Interactions: The Problem of } \\
\text { an International Public Good }\end{array}$ & $\begin{array}{l}\text { Eystein Gjelsvik } \\
\text { Center for Energy Policy Research } \\
\text { Massachusetts Institute of } \\
\text { Technology }\end{array}$ \\
\hline May 7 & $\begin{array}{l}\text { Cognitive Components of Operator } \\
\text { Decision-Making Performance } \\
\text { and Implications for the Design } \\
\text { of Control Systems }\end{array}$ & $\begin{array}{l}\text { Bruce G. Coury } \\
\text { University of Massachusetts } \\
\text { Amherst, Massachusetts }\end{array}$ \\
\hline May 23 & $\begin{array}{l}\text { An Informal Seminar on Shipment } \\
\text { Consolidation }\end{array}$ & $\begin{array}{l}\text { Richard Church } \\
\text { University of California at } \\
\text { Santa Barbara }\end{array}$ \\
\hline July 11 & $\begin{array}{l}\text { The Navy Encrgy R\&D Agenda: } \\
\text { Past Achievements, Current and } \\
\text { Future Priorities }\end{array}$ & $\begin{array}{l}\text { Paul Petzrick } \\
\text { Energy Market Consultant for the } \\
\text { Washington Consulting Group }\end{array}$ \\
\hline July 19 & $\begin{array}{l}\text { From Sin to Social Peace: The } \\
\text { Origins of Modern Day Treatment } \\
\text { of Industrial Accidents }\end{array}$ & $\begin{array}{l}\text { Tom Dwyer } \\
\text { Cornell University } \\
\text { Ithaca, New York }\end{array}$ \\
\hline July 30 & $\begin{array}{l}\text { Altemative Refrigerants Research } \\
\text { in the People's Republic of } \\
\text { China and Refrigerator Testing } \\
\text { with R-152a }\end{array}$ & $\begin{array}{l}\text { Tan Liancheng } \\
\text { Xi'an Jiaotong University } \\
\text { People's Republic of China }\end{array}$ \\
\hline August 7 & $\begin{array}{l}\text { Environmental Management in } \\
\text { Hong Kong: Playing Catch Up }\end{array}$ & $\begin{array}{l}\text { William F. Barron } \\
\text { University of Hong Kong }\end{array}$ \\
\hline
\end{tabular}


8.9 INVITED SPEAKERS (continued)

\begin{tabular}{ccc}
\hline Date & \multicolumn{1}{c}{ Subject } & \multicolumn{1}{c}{ Speaker } \\
\hline August 10 & Research on Refrigerant Mixtures in & Masaru Nakaiwa \\
& NCL & National Chemical Laboratory \\
& & for Industry \\
September 6 6 & Tsukuba, Japan \\
& Environmental Concems with & Anatoly A. Afanasiev \\
& Energy Technologies in the & Academy of Sciences \\
& Soviet Union & Moscow, USSR \\
\hline
\end{tabular}




\subsection{WORKSHOPS AND SYMPOSIA ORGANIZED BY ENERGY DIVISION STAFF}

Advanced Computing for the Social Sciences, Williamsburg, Virginia, April 10-12, 1990, organized by B. E. Tonn and Robert Hammond (Bureau of the Census).

Air Force Review Meeting, Oak Ridge, Tennessec, January 16-18, 1990, orga nized by C. R. Kerley.

ARI Research and Technology Committee, Energy Conservation Subcommitlee Mectings, Oak Ridge, Tennessee, February 27, 1990 and September 18, 1990, organiz ed by P. D. Fairchild.

Chemical Stockpile Emergency Preparedness Program National Conference, Bend, Oregon, May 9-11, 1990, organized by J. H. Sorensen.

Committee Meeting, Roof Industry on Wind Issues, Washington, D.C., April 24, 1990, organized by G. E. Courville.

CSDP Emergency Planning Meeting, Washington, D.C., February 22-23, 1990, organized by J. H. Sorensen.

CSDP/FEMA Meeting, Emergency Planning for the Army's Chemical Stockpile Disposal Program, Park City, Utah, November 7-8, 1989, organized by S. A. Carnes.

EMP Program Review Meeting, Washington, D.C., November 3, 1989, organized by P. R. Barnes.

IEA Annex 19 on Low Slope Roofing Meeting, Orlando, Florida, November 30December 1, 1989, organized by G. E. Courville.

JACADS RCRA Permit Modification Public Meeting, Honolulu, Hawaii, August 20-21, 1990, organized by T. G. Patton.

Johnston Atoll Chemical Agent Disposal System (JACADS) Public Meeting, Honolulu, Hawaii, March 19-22, 1990, organized by T. G. Patton.

National Intergovernmental Consultation and Coordination Board (ICCB) Meeting, Salt Lake City, Utah, April 10, 1990, organized by T. G. Patton.

Ninth Oak Ridge National Laboratory Life Sciences Symposium, Knoxville, Tennessec, Oct. 24-27, 1989, organized by J. B. Cannon and S. G. Hildebrand.

Roof Research Center Industry Advisory Panel Meeting, Oak Ridge, Tennessee, April 5-6, 1990, organized by G. E. Courville.

U.S. CADDET National Team Workshop, Washington, D.C., December 6, 1989, organized by M. A. Brown.

Wind Uplift Seminar, Oak Ridge, Tennessee, November 7-9, 1989, organized by

G. E. Courville. 


\subsection{ENERGY DIVISION PATENT INFORMATION}

Patents Granted in FY 1990

\begin{tabular}{|c|c|c|c|}
\hline Title & Inventor & U.S. Patent No. & Date \\
\hline $\begin{array}{l}\text { Automated Appliance and } \\
\text { Energy Distribution } \\
\text { Control System }\end{array}$ & $\begin{array}{l}\text { D. J. MacFadyen } \\
\text { R. G. Edwards } \\
\text { K. P. Wacks } \\
\text { D. J. Foley }\end{array}$ & $4,899.129$ & February 6, 1990 \\
\hline $\begin{array}{l}\text { Communication and } \\
\text { Energy Control System } \\
\text { for Houses }\end{array}$ & $\begin{array}{l}\text { D. J. MacFadyen } \\
\text { R. G. Edwards } \\
\text { K. P. Wacks } \\
\text { D. J. Foley }\end{array}$ & $4,899,217$ & February 6, 1990 \\
\hline $\begin{array}{l}\text { Method for Reducing } \\
\text { Chlorofluorocarbon } \\
\text { Refrigerant Emissions } \\
\text { to the Atmosphere }\end{array}$ & $\begin{array}{l}\text { R. C. DeVault } \\
\text { P. D. Fairchild } \\
\text { W. J. Biermann }\end{array}$ & $4,934,149$ & June 19,1990 \\
\hline
\end{tabular}




\subsection{ENERGY DIVISION SPONSORS, EXPENDITURES, AND COMMITMENTS OF SCIENTIFIC STAFF FOR FY 1990}

\begin{tabular}{|c|c|c|c|c|c|}
\hline \multirow[b]{2}{*}{ Sponsor } & \multirow[b]{2}{*}{$\begin{array}{c}\text { Expenditures }^{a} \\
\left(10^{3}\right)\end{array}$} & \multicolumn{2}{|c|}{$\begin{array}{c}\text { Scientific } \\
\text { (person-years) }\end{array}$} & \multirow{2}{*}{$\begin{array}{l}\text { Direct } \\
\text { person- } \\
\text { year costs } \\
\left(10^{3}\right)\end{array}$} & \multirow{2}{*}{$\begin{array}{l}\text { Subcontract } \\
\text { costs with } \\
\text { overhcad }^{d} \\
\left(10^{3}\right)\end{array}$} \\
\hline & & $\begin{array}{l}\text { Energy } \\
\text { Division }\end{array}$ & $\begin{array}{c}\text { Other } \\
\text { Divisions }\end{array}$ & & \\
\hline \multicolumn{6}{|c|}{ Department of Energy Work } \\
\hline \multicolumn{6}{|l|}{$\begin{array}{l}\text { Conservation and Renewable } \\
\text { Energy }\end{array}$} \\
\hline $\begin{array}{l}\text { Buildings and Community } \\
\text { Systems }\end{array}$ & 9,002 & 24.3 & 1.2 & 3,462 & 4.138 \\
\hline Electric Energy Systems & 1.519 & 3.6 & 0.0 & 551 & 740 \\
\hline Industrial Energy Conservation & 580 & 1.6 & 0.4 & 295 & 239 \\
\hline Multi-sector & 321 & 0.7 & 0.1 & 134 & 111 \\
\hline Solar Energy & 257 & 1.0 & 0.0 & 171 & 70 \\
\hline State/Local Programs & 989 & 3.5 & 0.1 & 522 & 76 \\
\hline Transportation & 308 & 0.4 & 0.0 & 78 & 190 \\
\hline Energy Storage Systems & 60 & 0.2 & 0.0 & 41 & 0 \\
\hline Subrotal & 13,036 & 35.3 & 1.8 & 5,254 & 5,564 \\
\hline $\begin{array}{l}\text { Civilian Radioactive Waste } \\
\text { Management }\end{array}$ & 3 & 0.0 & 0.0 & 0 & (4) \\
\hline \multicolumn{6}{|l|}{ Defense Programs } \\
\hline Materials Production & 7 & 0.0 & 0.0 & 6 & 0 \\
\hline $\begin{array}{l}\text { Defense Waste and } \\
\text { Environmental Restoration }\end{array}$ & 34 & 0.1 & 0.0 & 20 & 2 \\
\hline Subtotal & 41 & 0.1 & 0.0 & 26 & 2 \\
\hline $\begin{array}{l}\text { Naticnal Energy Information } \\
\text { System }\end{array}$ & 1,456 & 1.9 & 0.0 & 315 & 981 \\
\hline \multicolumn{6}{|l|}{ Energy Research } \\
\hline Magnetic Fusion & 3 & 0.0 & 0.0 & 0 & 0 \\
\hline Basic Energy Sciences & 27 & 0.1 & 0.0 & 25 & 0 \\
\hline Energy Research Analysis & 14 & 0.0 & 0.0 & 0 & 12 \\
\hline Subtotal & 44 & 0.1 & 0.0 & 25 & 12 \\
\hline $\begin{array}{l}\text { Environmental Safety and } \\
\text { Health }\end{array}$ & 86 & 0.4 & 0.0 & 60 & 0 \\
\hline $\begin{array}{l}\text { Federal Energy Regulatory } \\
\text { Commission }\end{array}$ & 52 & 0.1 & 0.1 & 1 & 4 \\
\hline \multicolumn{6}{|l|}{ Fossil Energy } \\
\hline $\begin{array}{l}\text { Innovative Clean Coal } \\
\text { Technology }\end{array}$ & 478 & 1.9 & 0.7 & 389 & 14 \\
\hline Strategic Petroleum Reserve & 330 & 1.5 & 0.0 & 227 & 74 \\
\hline Subtotal & 808 & 3.4 & 0.7 & 616 & 88 \\
\hline
\end{tabular}




\begin{tabular}{|c|c|c|c|c|c|}
\hline \multirow[b]{2}{*}{ Sponsor } & \multirow[b]{2}{*}{$\begin{array}{c}\text { Expenditures }^{a} \\
\left(10^{3}\right)\end{array}$} & \multicolumn{2}{|c|}{$\begin{array}{c}\text { Scientific } \\
\text { (person-years) }\end{array}$} & \multirow{2}{*}{$\begin{array}{c}\text { Direct } \\
\text { person- } \\
\text { year costs } \\
\left(10^{3}\right)\end{array}$} & \multirow{2}{*}{$\begin{array}{l}\text { Subcontract } \\
\text { costs with } \\
\text { overhead }^{d} \\
\left(10^{3}\right)\end{array}$} \\
\hline & & $\begin{array}{l}\text { Energy } \\
\text { Division }\end{array}$ & $\begin{array}{c}\text { Other } \\
\text { Divisions }^{b}\end{array}$ & & \\
\hline \multicolumn{6}{|l|}{$\begin{array}{l}\text { International Affairs and } \\
\text { Energy Emergencies }\end{array}$} \\
\hline Intemational Affairs & 115 & 0.2 & 0.0 & 41 & 50 \\
\hline Emergency Preparedness & 60 & 0.1 & 0.0 & 22 & 28 \\
\hline Subtotal & 175 & 0.3 & 0.0 & 63 & 78 \\
\hline Policy, Planning and Analysis & 699 & 2.1 & 0.0 & 330 & 263 \\
\hline Argonne National Laboratory & 6 & 0.0 & 0.0 & 6 & 0 \\
\hline $\begin{array}{l}\text { Battelle Pacific Northwest } \\
\text { Laboratory }\end{array}$ & 22 & 0.1 & 0.0 & 23 & 0 \\
\hline Bonneville Power Administration & 590 & 2.0 & 0.0 & 275 & 252 \\
\hline Comell University & 19 & 0.2 & 0.0 & 13 & 0 \\
\hline $\mathrm{K}-25$ A VLIS & 184 & 1.0 & 0.2 & 113 & 16 \\
\hline K-25 LLWDDD & 605 & 2.3 & 1.2 & 344 & 96 \\
\hline K-25 Miscellaneous & 220 & 1.9 & 0.0 & 175 & 22 \\
\hline Los Alamos National Laboratory & 19 & 0.1 & 0.0 & 16 & 0 \\
\hline Oak Ridge Operations Office & 439 & 1.7 & 1.0 & 355 & 16 \\
\hline ORAL & 4 & 0.0 & 0.0 & 3 & 0 \\
\hline Portsmouth & 16 & 0.0 & 0.0 & 13 & 0 \\
\hline Paducah & 35 & 0.3 & 0.0 & 34 & 0 \\
\hline Silas Mason Company, Inc. & 76 & 0.4 & 0.0 & 66 & 0 \\
\hline Y-12 Landfill & 25 & 0.0 & 0.1 & 23 & 0 \\
\hline Subtotal & 2,260 & 10.0 & 2.5 & 1.459 & 402 \\
\hline Total DOE Work & 18.660 & 53.7 & 5.1 & 8.189 & 7.390 \\
\hline \multicolumn{6}{|c|}{ Other Federal Agencies Work } \\
\hline \multicolumn{6}{|l|}{ Department of Defense } \\
\hline \multicolumn{6}{|l|}{ Department of the Air Force } \\
\hline Air Training Command & 54 & 0.2 & 0.0 & 29 & 1 \\
\hline $\begin{array}{l}\text { Engineering and Services } \\
\text { Center }\end{array}$ & 835 & 1.9 & 0.8 & 470 & 183 \\
\hline Logistics Command & 138 & 0.3 & 0.4 & 113 & 0 \\
\hline Military Airlift Command & 5.996 & 7.9 & 1.8 & 1.258 & 4,048 \\
\hline Space Division & 136 & 0.2 & 0.2 & 81 & 31 \\
\hline Sirategic Air Command & 174 & 0.2 & 0.0 & 45 & 112 \\
\hline Tactical Air Command & 21 & 0.0 & 0.0 & 6 & 9 \\
\hline U.S. Transcom & 599 & 3.0 & 0.0 & 310 & 152 \\
\hline Subtotal & 7.953 & 13.7 & 3.2 & 2,312 & 4,536 \\
\hline \multicolumn{6}{|l|}{ Department of the Army } \\
\hline $\begin{array}{l}\text { Construction Engineering } \\
\text { Research Laboratory }\end{array}$ & 129 & 0.4 & 0.0 & 48 & 25 \\
\hline
\end{tabular}




\begin{tabular}{|c|c|c|c|c|c|}
\hline \multirow[b]{2}{*}{ Sponsor } & \multirow[b]{2}{*}{$\begin{array}{l}\text { Expenditures }^{a} \\
\qquad\left(10^{3}\right)\end{array}$} & \multicolumn{2}{|c|}{$\begin{array}{c}\text { Scientific } \\
\text { (person-years) }\end{array}$} & \multirow{2}{*}{$\begin{array}{c}\text { Direct } \\
\text { person- } \\
\text { year costs } \\
\left(10^{3}\right)\end{array}$} & \multirow{2}{*}{$\begin{array}{l}\text { Subcontract } \\
\text { costs with } \\
\text { overhead }^{d} \\
\left(10^{3}\right)\end{array}$} \\
\hline & & $\begin{array}{l}\text { Energy } \\
\text { Division }\end{array}$ & $\begin{array}{c}\text { Other } \\
\text { Divisions }^{b}\end{array}$ & & \\
\hline Corps of Engineers & (1) & 0.0 & 0.0 & (1) & 0 \\
\hline $\begin{array}{l}\text { Facilities Engineering Support } \\
\text { Agency }\end{array}$ & 378 & 1.0 & 0.0 & 156 & 130 \\
\hline Forces Command & 15 & 0.0 & 0.0 & 7 & 4 \\
\hline $\begin{array}{l}\text { Natick } R \& D \text { and Engineering } \\
\text { Center }\end{array}$ & 131 & 0.0 & 0.1 & 19 & 0 \\
\hline $\begin{array}{l}\text { Toxic and Hazardous } \\
\text { Materials Agency }\end{array}$ & 4,436 & 11.7 & 1.6 & 1.865 & 1,598 \\
\hline Subtotal & 5,088 & 13.1 & 1.7 & 2,094 & 1,757 \\
\hline \multicolumn{6}{|l|}{ Department of the Navy } \\
\hline Marine Corps & 243 & 0.2 & 0.0 & 31 & 211 \\
\hline Military Sealift Command & 100 & 0.0 & 0.0 & 4 & 0 \\
\hline $\begin{array}{l}\text { Naval Regional Data } \\
\text { Automation }\end{array}$ & 113 & 0.0 & 0.0 & 6 & 0 \\
\hline Naval Rese.urch & 338 & 1.3 & 0.0 & 185 & 69 \\
\hline Naval Sea System Command & 1,107 & 0.3 & 0.0 & 63 & 997 \\
\hline Navy Personnel R\&D Center & 37 & 0.0 & 0.0 & 5 & 33 \\
\hline Pacific Missile Test Center & 73 & 0.0 & 0.0 & 0 & 73 \\
\hline Subtotal & 2.011 & 1.8 & 0.0 & 294 & 1,383 \\
\hline \multicolumn{6}{|l|}{ Joint Agencies } \\
\hline DARPA & 3 & 0.1 & 0.0 & 22 & 8 \\
\hline Defense Nuclear Agency & 150 & 0.6 & 0.0 & 79 & 55 \\
\hline $\begin{array}{l}\text { Military Traffic Management } \\
\text { Command }\end{array}$ & 2,166 & 6.0 & 1.0 & 936 & 739 \\
\hline National Guard Bureau & 632 & 1.8 & 0.0 & 250 & 200 \\
\hline Office Joint Chiefs of Staff & 28 & 0.0 & 0.0 & 0 & 0 \\
\hline Subtotal & 3,011 & 8.5 & 1.0 & 1,287 & 1,002 \\
\hline Total DOD Work & 18,063 & 37.1 & 5.9 & 5.987 & $8,67 \xi$ \\
\hline Bureau of Census & 24 & 0.0 & 0.0 & 9 & 0 \\
\hline Bureau of Land Management & 217 & 1.0 & 0.0 & 140 & 49 \\
\hline $\begin{array}{l}\text { Department of State-Agency for } \\
\text { Intemational Development }\end{array}$ & 1,357 & 4.0 & 0.3 & 656 & 457 \\
\hline Department of Transportation & 707 & 2.7 & 0.0 & 372 & 260 \\
\hline Environmental Protection Agency & 382 & 2.0 & 0.2 & 246 & 6 \\
\hline $\begin{array}{l}\text { Federal Emergency Management } \\
\text { Agency }\end{array}$ & 723 & 1.2 & 0.0 & 198 & 254 \\
\hline General Services Administration & 4 & 0.0 & 0.0 & 3 & 0 \\
\hline $\begin{array}{l}\text { National Center for Toxicological } \\
\text { Research }\end{array}$ & 87 & 0.0 & 0.0 & 0 & 85 \\
\hline National Library of Medicine & 16 & 0.0 & 0.0 & 10 & 0 \\
\hline
\end{tabular}




\begin{tabular}{|c|c|c|c|c|c|}
\hline \multirow[b]{2}{*}{ Sponsor } & \multirow[b]{2}{*}{$\begin{array}{l}\text { Expenditures }^{a} \\
\left(10^{3}\right)\end{array}$} & \multicolumn{2}{|c|}{$\begin{array}{c}\text { Scientific } \\
\text { (person-years) }\end{array}$} & \multirow{2}{*}{$\begin{array}{c}\text { Direct } \\
\text { person- } \\
\text { year costs } \\
\left(10^{3}\right)\end{array}$} & \multirow{2}{*}{$\begin{array}{l}\text { Subcontract } \\
\text { costs with } \\
\text { overhead }^{d} \\
\left(10^{3}\right)\end{array}$} \\
\hline & & $\begin{array}{l}\text { Energy } \\
\text { Division }\end{array}$ & $\begin{array}{c}\text { Other } \\
\text { Divisions }\end{array}$ & & \\
\hline Nuclear Regulatory Commission & 1,705 & 7.3 & 3.3 & 1,402 & 95 \\
\hline National Science Foundation & 159 & 0.8 & 0.2 & 124 & 7 \\
\hline $\begin{array}{l}\text { Total Oher Federal Agencies } \\
\text { Work }\end{array}$ & 23,444 & 56.1 & 9.9 & 9.147 & 9.891 \\
\hline \multicolumn{6}{|c|}{ Private Organizations Work } \\
\hline Alliance to Save Energy & 25 & 0.2 & 0.0 & 25 & 0 \\
\hline ASHRAE & 28 & 0.2 & 0.0 & 29 & 0 \\
\hline Attic Seal Inc. & 20 & 0.1 & 0.0 & 20 & 0 \\
\hline Electric Power Research Institute & 113 & 0.7 & 0.0 & 103 & 0 \\
\hline GRI & 164 & 0.5 & 0.0 & 58 & 0 \\
\hline KLD Associates & 7 & 0.0 & 0.0 & 3 & 4 \\
\hline Intemational Energy Agency & 1 & 0.0 & 0.0 & 0 & 0 \\
\hline Pacific Power \& Light Company & 10 & 0.0 & 0.0 & 10 & 0 \\
\hline $\begin{array}{l}\text { Puget Sound Power \& Light } \\
\text { Company }\end{array}$ & 5 & 0.0 & 0.0 & 4 & 0 \\
\hline $\begin{array}{l}\text { Total Private Organizations } \\
\text { Work }\end{array}$ & 373 & 1.7 & 0.0 & 252 & 4 \\
\hline Total Non-DOE Woik & 23,817 & 57.8 & 9.9 & 9,399 & 9,895 \\
\hline Total DOE Work & 18,660 & 53.7 & 5.1 & 8,189 & 7,390 \\
\hline Total Fnergy Division Work & 42,477 & 111.5 & 15.0 & 17,588 & 17,285 \\
\hline
\end{tabular}

${ }^{a}$ The difference between total expenditures (Column 2) and the sum of Columns 5 and 6 is money spent on computer, programmer, and analyst support from Computer Services; travel; material purchases; technical information services; etc.

${ }^{b}$ Includes the following research divisions: Analytical Chemistry, Central Management, Engineering Physics and Mathematics, Engineering Technology, Environmental Sciences, Fuel Recycle, Health and Safety Research. Metals and Ceramics, Research Reactors, and Solid State.

'Includes technical staff labor costs for Energy Division and other research divisions and Laboratory overhead.

${ }^{d}$ Includes Laboratory overhead for on-site services and the subcontract surcharge for off-site services. The subcontract surcharge is to pay for the costs of accounts payable, auditing, and accounting. 


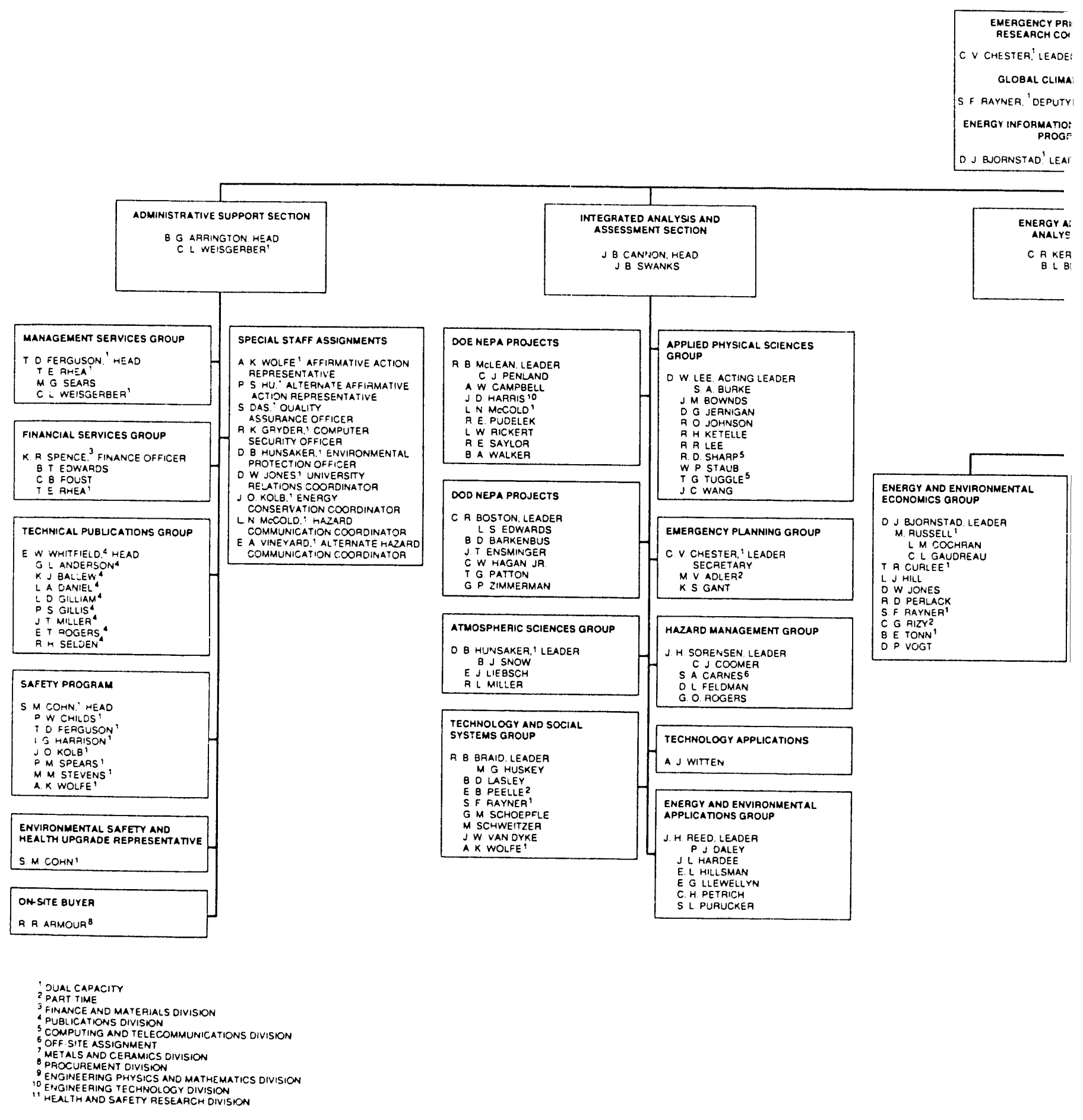




\section{ENERGY DIVISION}

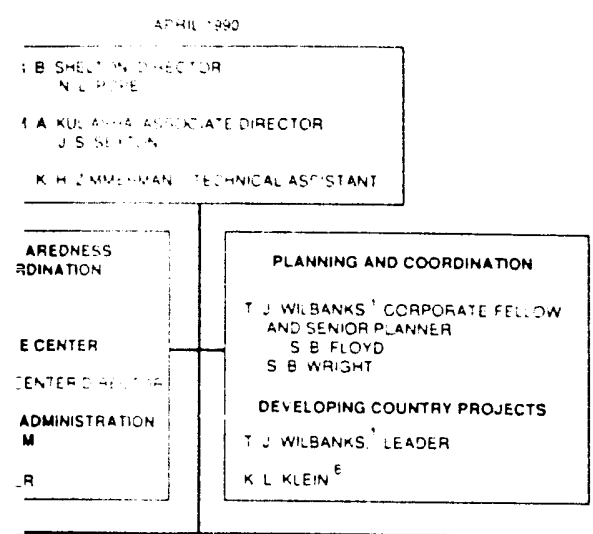

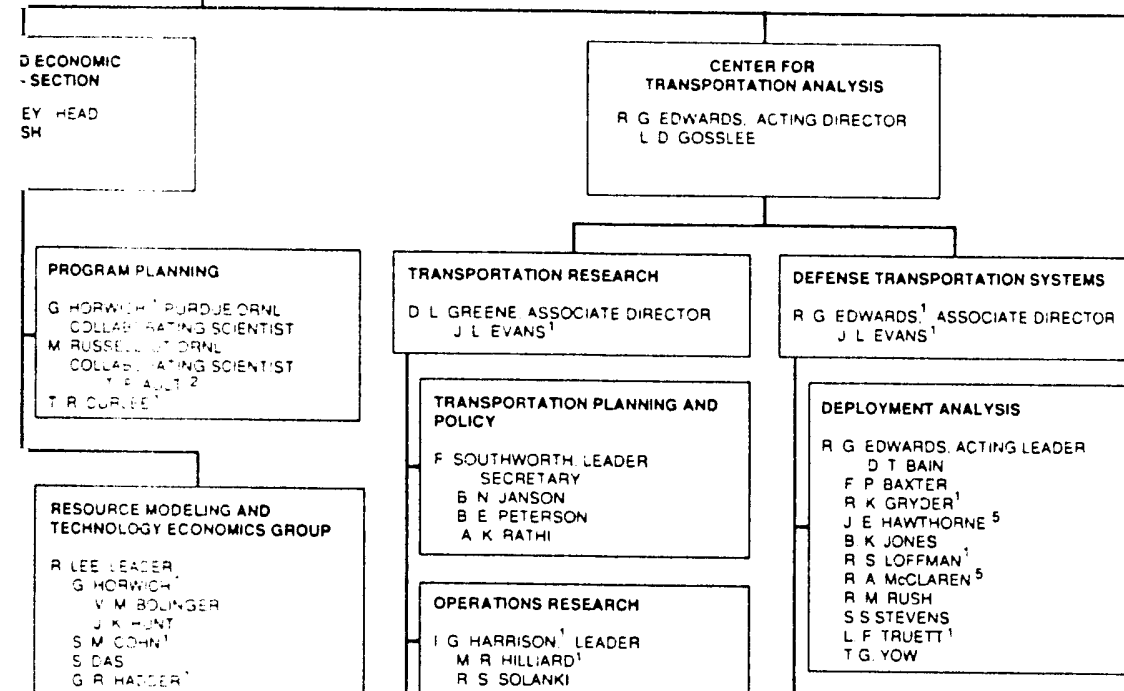

G R MAOTE

a dier

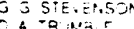

a f r tanjion Ja

\begin{tabular}{l} 
STATISTCS AND DATA ANALYSIS \\
PS HU.' LEADEA \\
J E SORENSEN \\
GR MADDER' \\
T G WRIGHT \\
\hline \\
POLICY RESEARCH \\
S M CHIN
\end{tabular}

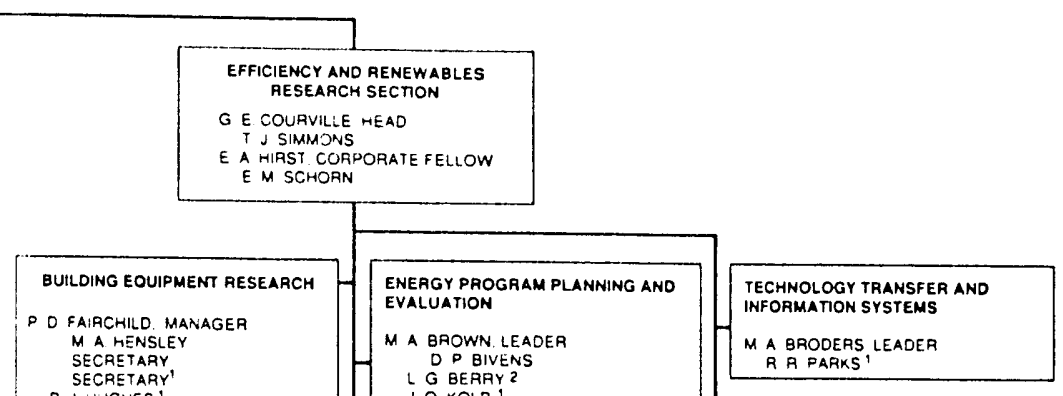

P J LEW:S'

REFRIGERATION SYSTEMS

$\checkmark$ O BAXTEA LEADER

S K F SCHEA
$C \checkmark$ HARDIN

W A MLLLER

C K AICE

E A VINEYAAD

NOVEL CYCLES

F C CHEN.' LEADER

R W MURPHY

\begin{tabular}{|c|}
\hline $\begin{array}{l}\text { AIR TRANSPORTATION } \\
\text { A O KRAEMER LEADEA } \\
\text { KG GGLLEY } \\
\text { J OOBSON } \\
\text { G G HARRISON } \\
\text { M R HLLLIARD 1 } \\
\text { R S LOFFMAN } \\
\text { S M MARGLE } \\
\text { A K SEXTON } \\
\text { L F TRUETT' }\end{array}$ \\
\hline
\end{tabular}

THERMALIY ACTVATEO HEAT

PUMPS (TAHP)

F A CAESWIEK, ' COORDINATOR

STIRUNG.ENGINE TAHP

F C CHEN ${ }^{\prime}$ LEADER

W MULPPHY

\begin{tabular}{l} 
SURFACE TRANSPORTATION \\
P T SINGLEY LEADER \\
R L NOE \\
P DAUGHERTY \\
S N DIEGEL \\
JP LOFIS \\
V NG S \\
P M SPEARS' \\
\hline
\end{tabular}

ABSORPTION ANO IC ENGINE

TAKP

F A CRESWICK! LEADER

R C DEVAJUT
DE HOLT
P J HUSTES

D E HOLT

P J HUGHES
H. PEREZ-BLANCO

T. PEREZ BLANCO

J A SHONDER

INTELLLGENT COGNITVE SYSTEMS

B E TONN.' LEADER

A $A$ M GOELTZ

$X$ A HAKE

M S HUBABAD

\begin{tabular}{|l|l}
\hline CMEMICAL HEAT PUMPS \\
MA ALLY. LEADER \\
A R PAAKS' \\
AALTASH
\end{tabular}

J M MacDONALO
POWER SYSTEMS TECHNOLOGY

S J DALE MANAGER

D J SLAUGHTE

GUILOING THERMAL ENYELOPE SYSTEMS AND MATERIALS

$J$ E CHRISTIAN. LEADER

C L BROWN

SECFETARY'

$P$ W CHILDS
$P M$ LOVE

OL MCELAOY?

A L WENDT
-

EXISTING BUILOINGS RESEARCH

W R MIXON.' MANAGER R N SCOGIN
SECAETAAY

R L LINKOUS

FIELD PERFORMANCE

$M$ P TEFNES
$T$ P SHARP

MODELING ANO ANALYSIS

$X$ E WILKES'

W P LEVINS

H. A MCLAIN
W A NELSON

POWER SYSTEM TRANSIENTS

$P$ P BARNES

B W MCCONNELL'

SYSTEMS RESEARCH

$J$ P STOVALL
D.T RIZY

MATEPIALS AND

COMPONENTS RE

D. R JAMES"

G D GAIFFIN"

ELECTRIC AND MAGNETIC FIELDS

B W. MCCONNELL'

ENERGY FOR DEVEL OPING

COUNTAIES

O B WADDLE

INTEGRATED RESOUACE PLANNING

E A HIRST 


\section{INTERNAL DISTRIBUTION}

1. M. R. Ally

2. B. D. Barkenbus

3. F. P. Baxter

4. V. D. Baxter

5. D. P. Bivens

6. D. J. Bjornstad

7. T. J. Blasing

8. V. M. Bolinger

9. C. R. Boston

10. J. M. Bownds

11. R. B. Braid

12. M. A. Broders

13. M. S. Bronzini

14. C. L. Brown

15. M. A. Brown

16. B. L. Bush

17. A. W. Campbell

18. J. B. Cannon

19. R. S. Carlsmith

20. S. A. Carnes

21. F. C. Chen

22. J. E. Christian

23. S. M. Cohn

24. R. E. Conrad

25. C. J. Coomer

26. G. E. Courville

27. R. B. Craig

28. T. R. Curlee

29. G. A. Dailey

30. S. J. Dale

31. P. J. Daley

32. L. A. Daniel

33. S. Das

34. R. M. Davis

35. R. C. Devault

36. L. D. Duncan

37. L. B. Dunlap

38. B. T. Edwards

39. L. S. Edwards

40. R. G. Edwards

41. A. Ekkebus

42. M. L. Emrich

43. J. T. Ensminger

44. J. L. Evans

45. P. D. Fairchild

46. D. L. Feldman

47. R. Fenstermaker

48. T. D. Ferguson

49. S. K. Fischer

50. S. D. Floyd

51. C. Forsberg

52. W. Fulkerson

53. K. S. Gant

54. R. K. Genung

55. K. G. Gilley
56. L. D. Gilliam

57. P. S. Gillis

58. H. A. Glovier

59. L. D. Gosslee

60. C. A. Grametbauer

61. D. L. Greene

62. G. R. Hadder

63. C. W. Hagan

64. I. G. Harrison

65. M. A. Hensley

66. J. N. Herndon

67. J. R. Hightower, Jr.

68. S. Hildebrand

69. L. J. Hill

70. E. L. Hillsman

71. E. A. Hirst

72. R. B. Honea

73. P. S. Hu

74. M. S. Hubbard

75. P. J. Hughes

76. D. B. Hunsaker

77. D. W. Jared

78. J. E. Johnson

79. R. O. Johnson

80. R. L. Jolley

81. B. K. Jones

82. D. W. Jones

83. J. E. Jones

84. L. Jung

85. S. V. Kaye

86. C. R. Kerley

87. R. H. Ketelle

88. A. Klein

89. J. O. Kolb

90. C. H. Krause

91. E. H. Krieg, Jr.

92. R. Krishnan

93. J. Kuhaida

94. M. A. Kuliasha

95. D. D. Lee

96. D. W. Lee

97. R. M. Lee

98. P. J. Lewis

99. E. G. Llewellyn

100. A. S. Loebl

101. R. S. Loffman

102. P. M. Love

103. P. Y. Lu

104. J. M. MacDonald

105. G. Marland

106. L. N. McCold

107. R. McGill

108. H. A. McLain

109. R. B. McLean

110. S. A. Meacham 
111. V.C. Mei

112. J. R. Merrinan

113. R. L. Miller

114. W. A. Miller

115. W. . Mixon

116. O. B. Morgan

117. W. R. Nelson

118. G. W. Oliphant

119. C. E. Oliver

120. R. R. Parks

121. E. B. Peelle

122. R. D. Perlack

123. C. H. Petrich

124. N. L. Pope

125. M. L. Poutsma

126. C. E. Pugh

127. I W. Ranney

128. A. K. Rathi

12C. S. Rayner

130. D. E. Reichle

131. T. E. Rhea

132. J. B. Richard

133. C. R. Richmond

134. C. G. Rizy

135. D. T. Rizy

136. J. B. Roberto

137. W. L. Roberts

138. T. H. Row

139. D. R. Rupert

140. R. M. Kin:

141. M. Russell

142. J. R. Sand

143. R. E. Saylor

144. A. C. Schaffhauser

145. E. M. Schorn

146. M. Schweitzer

147. R. N. Scogin

148. R. H. Selden
149. A. K. Sexton

150. F. L. Sexton

151. J. S. Sexton

152. T. R. Sharp

153. J. Sheffield

154. R. B. Shelion

155. B. L. Shumpert

156. P. T. Singley

157. J. E. Sorensen

158. J. H. Sorensen

155. F. Southworth

160 S. Stow

161. J. H. Swanks

162. M. P. Temes

163. B. E. Tonn

164. A. W. Trivelpiece

165. L. F. Truett

166. E. A. Vineyard

167. B. A. Walker

168. R. C. Ward

169. D. A. Waters

170. J. S. Watson

171. R. L. Wendt

172. G. E. Whitesides

173. E. W. Whitfield

174. T. J. Wilbanks

175. B. Y. Wilkes

176. K. E. Wilkes

177. S. B. Wright

178. G. P. Zimmerman

179. K. H. Zimmerman

180. A. Zucker

181. ORNL Patent Office

182. Central Research Library

183. Document Reference Section

184-186. Laboratory Records (3)

187. Laboratory Records (Record Copy) 


\section{EXTERNAL DISTRIBUTION}

188. B. G. Buchanan, Computer Science Department, University of Pittsburg, 206 Mineral Building, Pittsburgh, Pennsylvania 15260

189. A. Hirsch, Vice President of Environmental Sciences, Midwest Research Institute, 5109 Leesburg Pike, Suite 414, Falls Church, Virginia 22041

190. M. Williams, Professor, Department of Economics, Northern Illinois University, DeKalb, Illinois 60115

191. MERT Division Library, ORAU

192. Office of Assistant Manager for Energy Research and Development, DOE-ORO, P. O. Box 2001, Oak Ridge. Tennessee 37831-8600

193. Office of Information Services, ORAU

194-203. OSTI, U.S. Department of Energy, P.O. Box 62, Oak Ridge, Tennessee 37831

204-740. Energy Division Extemal Distribution 

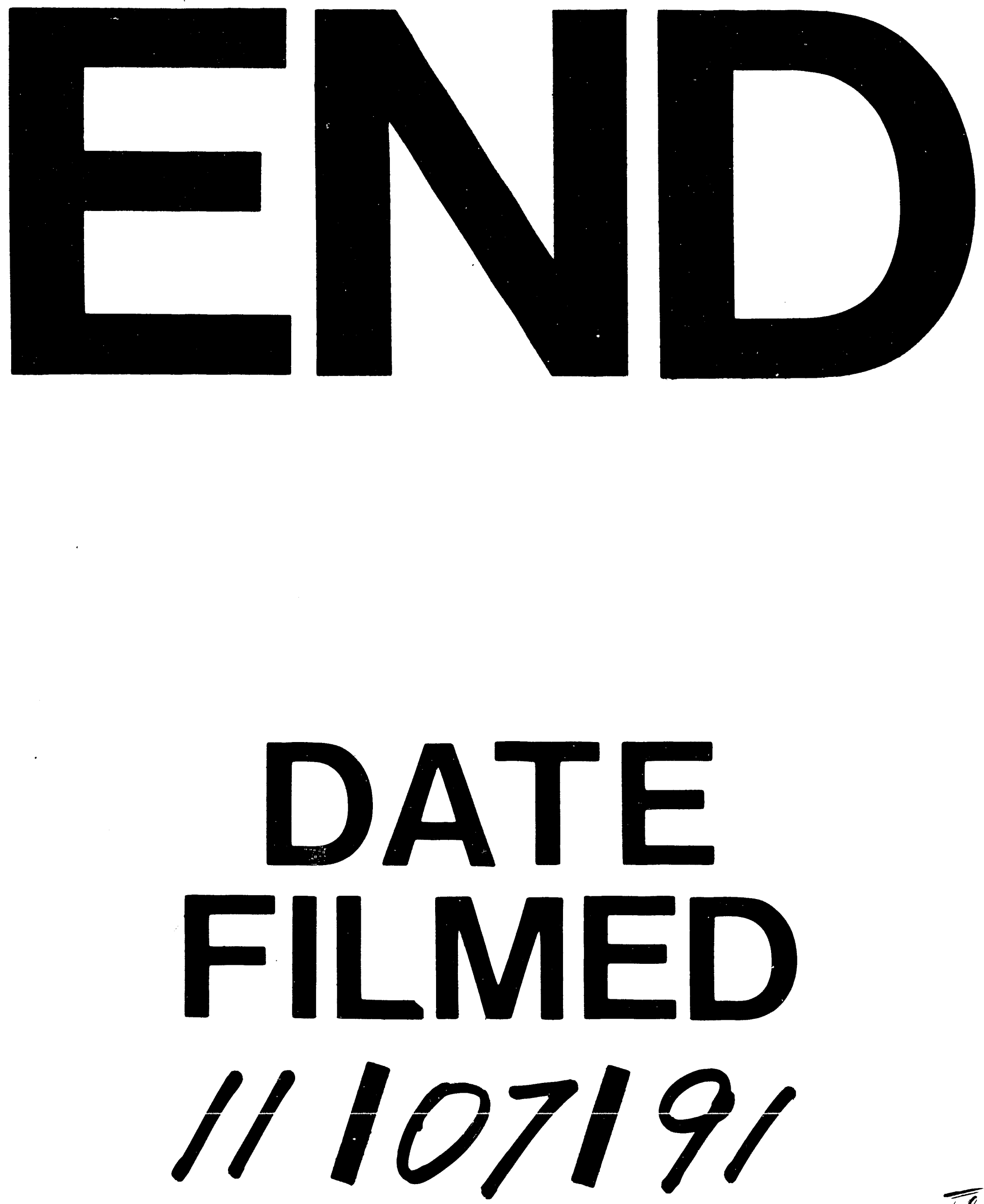

$\bar{T}$ 
